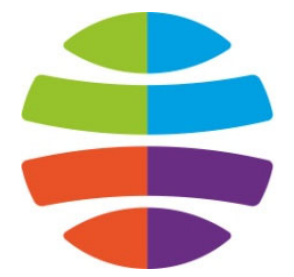

СГУГиТ

СИБИРСКИЙ

ГОСУДАРСТВЕННЫЙ УНИВЕРСИТЕТ

ГЕОСИСТЕМ И ТЕХНОЛОГИЙ
Учредитель федеральное государственное бюджетное образовательное учреждение высшего образования «Сибирский государственный университет геосистем и технологий» (СГУГиТ)

\section{Вестник СГУГиТ}

Научный журнал

Издается с 1996 г.

Выходит 4 раза в год
Том 25, № 3, 2020

DOI: $10.33764 / 2411-1759-2020-25-3$

\section{СОДЕРЖАНИЕ}

\section{ГЕОДЕЗИЯ И МАРКШЕЙДЕРИЯ}

А. Г. Барлиани, Г. А. Нефедова, И. В. Карнетова. Метод псевдонормальной оптимизации и геодезические уравнительные вычисления

Д. т. н., проф. В. С. Айрапетян

Д. б. н. К. С. Байков

К. т. н., проф. Г. Гиенко (США)

Д. т. н., проф. С. Златанова

(Нидерланды)

Д. т. н., доц. А. В. Комиссаров

Д. т. н., проф. М. Конечны (Чехия)

Д. ф.-м. н., проф. С. М. Копейкин

(США)

Д. б. н., проф. Ю. В. Кравцов

К. ф.-м. н., доц. Е. Левин (США)

Д. т. Н., проф. Е. М. Мазурова

Акад. РАН Н. П. Похиленко

Д. ф.-м. н., проф. О. А. Романовский

Д. т. н., проф. А. П. Сизов

Д. г. н., проф. В. С. Тикунов

Д. ф.-м. н., проф. В. Ю. Тимофеев

Д. т. н., проф. А. С. Толстиков

Д. т. н., проф. Л. К. Трубина

Д. т. н., доц. В. С. Хорошилов

Д. т. н., проф. Ю. В. Чугуй

Д. т. н., проф. Д. А. Шаповалов

Акад. РАН М. И. Эпов

Д. т. н., проф. Р. Ягер (Германия)

До 2015 г. журнал выходил под названием «Вестник СГГА»

С 2017 г. нумерация журнала включает номер тома

(порядковый номер года издания) и номер выпуска в текущем году

СГУГиТ, 2020
И. Г. Ганагина, Д. С. Челнокова, Д. Н. Голдобин. Создание модели квазигеоида на локальном участке средствами ГИС

А. В. Елагин, М. В. Зайцев, Д. А. Прохоров, Н. К. Шендрик. Оценка точности определения координат спутниковыми приемниками EFT M3 GNSS и EFT M4 GNSS в режиме RTK

В. В. Калинников, А. В. Устинов, Н. С. Косарев. Влияние атмосферных нагрузок на результаты спутникового мониторинга здания станционного узла Загорской ГАЭС-2 методом РРР

Н. В. Канашин, Д. А. Афонин. Геодезический мониторинг при эксплуатации футбольных стадионов Чемпионата мира 2018

Н. Н. Кобелева, В. С. Хорошилов. Анализ входных воздействующих факторов и выбор типа математической модели на этапах их структурной и параметрической идентификации для изучения деформационного состояния плотины Саяно-Шушенской ГЭС в период 2013-2016 годов.

В. Г. Сальников. Совершенствование методики выполнения высокоточного нивелирования цифровыми нивелирами в условиях недостаточной освещенности штрихкодовых реек....

B. E. Терещенко. Анализ качества спутниковых измерений с помощью программной утилиты Теqс.

В. Е. Терещенко, А. В. Радченко, В. А. Мелкий. Глобальная система отсчета и ее локальная реализация - государственная система координат 2011 года 
Журнал зарегистрирован Федеральной службой по надзору в сфере связи, информационных технологий и массовых коммуникаций свидетельство ПИ № ФС 77-62654 от 10 августа 2015 г.

Журнал входит в Перечень рецензируемых научных изданий, в которых должны быть опубликованы основные научные результаты диссертаций на соискание ученой степени кандидата и доктора наук

Журнал включен в Российский индекс научного цитирования (РИНЦ)

Подписные индексы в каталогах: «Пресса России» - 43809 Электронный каталог «Российская периодика» (www.ideg.ru) - 43809э

Технический редактор журнала А. В. Конева

Адрес редакции:

630108, Новосибирск, ул. Плахотного, 10, к. 436

E-mail: vestnik@ssga.ru

Тел. (383)361-06-55

http://vestnik.ssga.ru

Перевод на английский язык

Д. В. Романова

Редакторы

Е. К. Деханова

Е. Н. Ученова

\section{Компьютерная верстка}

Н. Ю. Леоновой

Дата выхода в свет 10.09.2020.

Формат $60 \times 84$ 1/8.

Усл. печ. л. 29,06.

Тираж 100 экз. Заказ 103.

Редакционно-издательский отдел СГУГиТ

630108, Новосибирск,

ул. Плахотного, 10.

Отпечатано в картопечатной лаборатории СГУГиТ 630108, Новосибирск, ул. Плахотного, 8.
А. И. Уваров, Л. А. Пронина. Исследование технологий геодезического мониторинга деформаций дна в зоне расположения подводных переходов магистральных трубопроводов

А. А. Шоломицкий, Б. Н. Ахмедов. Геодезический мониторинг большепролетных сооружений с пространственной металлической конструкцией

$B$. В. Щербаков. Методика создания цифровых проектов для автоматизированных систем управления строительной железнодорожной техникой

\section{ДИСТАНЦИОННОЕ ЗОНДИРОВАНИЕ ЗЕМЛИ, ФОТОГРАММЕТРИЯ}

A. А. Верхотуров. Анализ изменений состояния экосистем на острове Атласова (Курильские острова).

Д. В. Долгополов. Использование данных дистанционного зондирования Земли при формировании геоинформационного пространства трубопроводного транспорт

A. C. Зарипов. Особенности создания трехмерной цифровой модели центрального планировочного района города Перми по данным аэрофотосъёмки

В. В. Крыленко, М. В. Крыленко. Мониторинг берега Вербяной косы по спутниковым данным

\section{КАРТОГРАФИЯ И ГЕОИНФОРМАТИКА}

А. П. Мохирев, С. Ю. Резинкин, С. О. Медведев, Н. А. Брагина. Использование географических информационных систем при оценке плотности дорог лесозаготовительных районов

О. Н. Николаева, Г. П. Мартынов, А. В. Могильникова. Использование картографического метода исследования при изучении химического состава воздушной среды промышленного центра ....

A. B. Тарасов. Современные методы оперативного картографирования нарушений лесного покрова

\section{ЗЕМЛЕУСТРОЙСТВО, КАДАСТР И МОНИТОРИНГ ЗЕМЕЛЬ}

В. Ф. Ковязин, Данг Тхи Лан Ань, Данг Вьет Хунг. Прогноз состояния растительного покрова лесных угодий заповедника Донг Най Вьетнама

E. В. Коиур, А. В. Дубровский. Информационное обеспечение мероприятий по воспроизводству и повышению эффективности использования агроландшафтов.

Ю. С. Ларионов, В. Б. Жарников, А. А. Стуканов. Формирование системы рационального сельскохозяйственного землепользования на основе теории воспроизводства почвенного плодородия. 
SSUGT

SIBERIAN STATE

UNIVERSITY OF GEOSYSTEMS

AND TECHNOLOGIES
Founder Federal State Budgetary

Educational Institution of Higher Education

"Siberian State University

of Geosystems and Technologies"

\section{Vestnik SSUGT}

Scientific journal

Published since 1996

Issued 4 times a year
Volume 25(3), 2020

DOI: $10.33764 / 2411-1759-2020-25-3$

\section{Editor-in-Chief:}

D. Sc. (Eng.), Prof. Karpik A. P.

\section{Depute Editor-in-Chief:}

D. Sc. (Eng.), Prof. D. V. Lisitsky

D. Sc. (Eng.), Prof. G. A. Ustavich

\section{Editorial team:}

D. Sc. (Eng.), Prof. V. S. Ajrapetyan

D. Sc. (Biol.) K. S. Baikov

Ph. D. (Eng.), Prof. G. Gienko (USA)

D. Sc. (Eng.), Prof. S. Zlatanova (Netherlands)

D. Sc. (Eng.), Assoc. Prof.

A. V. Komissarov

D. Sc. (Eng.), Prof. M. Konečný (Czech

Republic)

D. Sc. (Phys.-Math.), Prof.

S. M. Kopeikin (USA)

D. Sc. (Biol.), Prof. Yu. V. Kravtsov

Ph. D. (Phys.-Math.), Assoc. Prof.

E. Levin (USA)

D. Sc. (Eng.), Prof. E. M. Mazurova

Member of RAS N. P. Pokhilenko

D. Sc. (Phys.-Math.), Prof.

O. A. Romanovskij

D. Sc. (Eng.), Prof. A. P. Sizov

D. Sc. (Geogr.), Prof. V. S. Tikunov

D. Sc. (Phys.-Math.), Prof.

V. Yu. Timofeev

D. Sc. (Eng.), Prof. A. S. Tolstikov

D. Sc. (Eng.), Prof. L. K. Trubina

D. Sc. (Eng.), Assoc. Prof.

V. S. Horoshilov

D. Sc. (Eng.), Prof. Yu. V. Chugui

D. Sc. (Eng.), Prof. D. A. Shapovalov

Member of RAS M. I. Epov

D. Sc. (Eng.), Prof. R. Jäger (Germany)

Before 2015 journal

was published under the name

«Vestnik SSGA»

Starting from 2017 numbering of the volume refers to the number of years the journal has been circulated. The number of the issue refers to how many times the journal was published during the year

(C) SSUGT, 2020

\section{CONTENTS}

\section{GEODESY AND MINE SURVEY}

A. G. Barliani, G. A. Nefedova, I. V. Karnetova. Pseudonormal Optimization Method and Geodesic Equation Calculations

I. G. Ganagina, D. S. Chelnokova, D. N. Goldobin. Creation of a Quasigeoid Model on a Local Section by Gis Means

A. V. Elagin, M. V. Zaitsev, D. A. Prokhorov, N. K. Shendrik. Estimation of Coordinates Accuracy Determination by Eft M3 Gnss And Eft M4 Gnss Satellite Receivers In Rtk Mode.... 26 $V$. V. Kalinnikov, A. V. Ustinov, N. S. Kosarev. Impact of Atmospheric Loadings on the Results of Gnss Monitoring of Main Building Of Zagorskaya Pspp-2 By Ppp Method......... 34 N. V. Kanashin, D. A. Afonin. Geodetic Monitoring During the Operation the Football Stadiums of The World Championship 2018 ....

N. N. Kobeleva, V. S. Khoroshilov. Analysis of Input Influencing Factors And Selection of the Type of a Mathematical Model At the Stages of Their Structural And Parametric Identification for Studying Deformation State of the Sayano-Shushenskaya Hpp Dam in 2013-2016....

V. G. Salnikov. Improvement of High-Precision Levelling Method By Digital Levels in the Condition of NonSufficient Light Intensity of Lined Rod

V. E. Tereshchenko. Quality Analysis of GNSS Observations of Reference Stations Network with the Teqc Utility ....... 72 V. E. Tereshchenko, A. V. Radchenko, V. A. Melkiy. Global Reference System and Its Local Realization - Russian State Coordinate System GSK-2011

A. I. Uvarov, L. A. Pronina. Research of Technologies of Geodesic Monitoring of Bottom Deformations in the Area of Location of Underwater Transitions of Main Pipelines 107

A. A. Sholomitskii, B. N. Akhmedov. Geodesic Monitoring of Large-Span Constructions with Spatial Metal Structure ..... 117 


\section{Registration certificate}

The journal is registered in the Federal Service for Supervision of Communications Information Technology, and Mass Media - Certificate

PI No. 77-62654 of August 10, 2015

The journal is included

in the List of refereed scientific journals, recommended

by HAC for publishing the

scientific results of dissertations

in candidacy for a degree

of Candidate or Doctor

of Science degree

Journal included in Russian Science

Citation Index (RSCI)

Subscription indexes in catalogues:

«Russian press» - 43809

Electronic catalogue

«Russian periodicals»

(www.ideg.ru) - 43809э

Layout editor of journal

A. V. Koneva

Reduction address:

630108, Novosibirsk,

10 Plakhotnogo St., r. 436

E-mail: vestnik@ssga.ru

Phone: (383)361-06-55

http://vestnik.ssga.ru

English translation

D. V. Romanov

Editor

E. K. Dehanova

E. N. Uchenova

\section{Desktop publishing}

N. Yu. Leonova

Issue data 10.09.2020.

Format $60 \times 84$ 1/8.

Conv. pr. sheets 29,06 .

Circulation 100 copies.

Order 103.

Printing and publication department SSUGT

630108, Novosibirsk,

10 Plakhotnogo St.

Printed in map printing laboratory SSUGT

630108, Novosibirsk, 8 Plakhotnogo St.
V. V. Shcherbakov. Method of Creating Digital Projects for Automated Control Systems of Construction Railway Engineering.....

\section{REMOTE SENSING, PHOTOGRAMMETRY}

A. A. Verkhoturov. Analysis of Changes in the State of Ecosystems on Atlasova Island (Kuril Islands)

D. V. Dolgopolov. Use of Earth Remote Sensing Data for for mation of Geodata Space of Pipeline Transport

A. S. Zaripov. Creating A Three-Dimensional Digital Surface Model of the Central Planning District of Perm Based on Aerial Survey Data

V. V. Krylenko, M. V. Krylenko. Coastal Monitoring of the Verbyanaya Spit by Satellite Data

\section{CARTOGRAPHY AND GEOINFORMATICS}

A. P. Mokhirev, S. Yu. Rezinkin, S. O. Medvedev, N. A. Bragina. Use of Geographic Information Systems in the Evaluation of the Density of Roads of for Estry Areas

O. N. Nikolaeva, G. P. Martynov, A. V. Mogil'nikova. The Cartographic Technique for the Study of Chemical Composition of the Urban Air Environment.

A. V. Tarasov. Traditional and Modern Methods of Satellite Images Processing for Operational Mapping of for Est Cover Distubances.

\section{LAND MANAGEMENT, CADASTRE AND LAND MONITORING}

V. F. Kovyazin, Dang Thi Lan Anh, Dang Viet Hung. Predicting for Est Land Cover Changes of Dong Nai Reserve, Vietnam

E. V. Kotsur, A. V. Dubrovsky. Information Support for Measures for Recreation and Improvement of Agricultural Landscapes Usage

Yu. S. Larionov, V. B. Zharnikov, A. A. Stukanov. For mation of Rational Agricultural Land use System on the Basis of Soil Fertility Recreation Theory. 


\section{ГЕОДЕЗИЯ И МАРКШЕЙДЕРИЯ}

УДК 528.1

DOI: $10.33764 / 2411-1759-2020-25-3-5-13$

\section{МЕТОД ПСЕВДОНОРМАЛЬНОЙ ОПТИМИЗАЦИИ И ГЕОДЕЗИЧЕСКИЕ УРАВНИТЕЛЬНЫЕ ВЫЧИСЛЕНИЯ}

\section{Амридон Гемзаевич Барлиани}

Сибирский государственный университет геосистем и технологий, 630108, Россия, г. Новосибирск, ул. Плахотного, 10, кандидат технических наук, доцент кафедры прикладной информатики и информационных систем, тел. (383)343-18-35

\section{Галина Александровна Нефедова}

Сибирский государственный университет геосистем и технологий, 630108, Россия, г. Новосибирск, ул. Плахотного, 10, кандидат технических наук, доцент кафедры прикладной информатики и информационных систем, тел. (383)343-18-35

\section{Ирина Викторовна Карнетова}

Сибирский государственный университет геосистем и технологий, 630108, Россия, г. Новосибирск, ул. Плахотного, 10, старший преподаватель кафедры прикладной информатики и информационных систем, тел. (383)343-18-35

Целью представленной работы является сравнительный анализ методов наименьших квадратов и псевдонормальной оптимизации на примере уравнивания и оценки точности звена триангуляции первого класса. Псевдонормальная оптимизация кардинально отличается от традиционного способа оптимизации по методу наименьших квадратов, так как он приводит к сложным и громоздким процедурам уравнивания и оценки точности результатов обработки геодезических построений из-за сложных формул. Приведена рекуррентная методика последовательного формирования псевдообратной матрицы параметрических уравнений поправок, что позволяет миновать трудоемкий вычислительный процесс составления и решения нормальных уравнений. Рассмотрен математический алгоритм оценки точности уравненных параметров. Анализ уравнительных работ показал, что метод псевдонормальной оптимизации позволяет вычислить значения уравненных координат в 4 раза точнее, чем оптимизация по методу наименьших квадратов.

Ключевые слова: звено триангуляции первого класса, базисная сторона, вырожденная матрица, уравнение поправок, метод наименьших квадратов, метод псевдонормальной оптимизации, начало координат сети, ранговый дефект матрицы, Евклида норма.

\section{Введение}

Долгое время авторам статьи приходилось решать проблемы обработки и анализа различных данных, связанных как с геодезическими, так и с экономическими моделями, методом наименьших квадратов. При анализе результатов обработки часто выяснялось, что выводы, полученные с помо- щью данного метода, резко контрастировали с ожидаемыми практическими результатами. Это относится в основном к оцениваемым параметрам и их среднеквадратическим ошибкам. Для некоторого класса свободной и несвободной геодезической сети поправки к параметрам и среднеквадратические ошибки параметров получались недопустимо большими. 
Следует отметить, что при уравнивании геодезических сетей (особенно больших) коэффициенты уравнений поправок вычисляются приблизительно, что может привести к плохой обусловленности или даже вырождению матрицы коэффициентов нормальных уравнений. Естественно, что в этих и других условиях оценивание параметров геодезических сетей выходит за рамки классического метода наименьших квадратов.

Указанные обстоятельства явились причиной предложить для обработки и анализа геодезических данных теорию, основанную на методе псевдонормальной оптимизации, а также провести на модели звена триангуляции первого класса сравнительный анализ результатов уравнивания и оценки точности для методов наименьших квадратов и псевдонормальной оптимизации.

\section{Методы и материаль}

Прежде чем перейти к сути вопроса, приведем некоторые важные теоретические выкладки, связанные с обработкой геодезических построений. Известно [1-4], что в нивелирных и плановых сетях минимально необходимое число исходных данных $m$, привязывающих сеть к фиксированной системе координат, должно быть равно соответственно 1 и 4.

Например, в плановой геодезической сети этими исходными данными являются координаты одного пункта $(x, y)$, а также дирекционный угол и длина стороны. На основании этих исходных данных можно зафиксировать начало координат сети, ее ориентацию в пространстве и масштаб.

Если же в геодезической сети имеется $t<m$ таких исходных данных, то столбцы матрицы коэффициентов уравнений поправок становятся линейно зависимыми. Этот факт приводит к ранговому дефекту $d$ матрицы $A$. Таким образом, при наличии в геодезической сети $t<m$ таких исходных данных, число $d=m-t$ называется дефектом исходных данных. Следовательно, при наличии рангового дефекта в матрице параметрических уравнений поправок геодезическая сеть считается свободной, и при отсутствии - несвободной.

Теперь требуется перейти к конкретной задаче описания алгоритма уравнивания и оценки точности геодезических сетей методом псевдонормальной оптимизации (МПНО) параметрической версии. Пусть уравнивается геодезическая сеть с матрицей параметрических уравнений поправок:

$$
A \tilde{\Delta}+l=V .
$$

Теорию метода псевдонормальной оптимизации приведем для неравноточно измеренных величин с ковариационной матрицей:

$$
K_{y}=\mu^{2} P^{-1},
$$

где $\mu$ - оценка генеральной средней квадратической ошибки единицы веса; $P$ - диагональная матрица весов результатов измерений.

В этих условиях система параметрических уравнений поправок (1) перепишется следующим образом:

$$
P^{\frac{1}{2}} A \tilde{\Delta}+P^{\frac{1}{2}} l=P^{\frac{1}{2}} V .
$$

Необходимо ввести обозначения:

$$
P^{\frac{1}{2}} A=\bar{A}, P^{\frac{1}{2}} l=\bar{l}, P^{\frac{1}{2}} V=\bar{V} .
$$

С учетом введенных обозначений систему (1) можно переписать в следующей форме:

$$
\bar{A} \tilde{\Delta}+\bar{l}=\bar{V} .
$$

Так как ранг матрицы $\bar{A}$ равен рангу матрицы $A$, псевдонормальное решение системы (4) запишется так:

$$
\tilde{\Delta}=-\bar{A}^{+} \bar{l}=-\bar{A}^{+} P^{\frac{1}{2}} l .
$$

Вектор уравненных значений неизвестных параметров $\tilde{x}$ можно выразить через вектор-столбец приближенных параметров $x^{0}$ и вектор-столбец поправок $\tilde{\Delta}$ следующим образом:

$$
\tilde{x}=x^{0}+\tilde{\Delta} .
$$


Итак, на основании формул (5) и (6) решается задача уравнивания свободных и несвободных геодезических сетей методом псевдонормальной оптимизации. В данном случае основная проблема состоит в вычислении псевдообратных матриц $\bar{A}^{+}$.

Для вычисления псевдообратной матрицы приведем рекурсивный алгоритм, который основан на блочном представлении матрицы параметрических уравнений поправок [5]:

$$
\bar{A}_{j}^{+}=\left(\begin{array}{c}
\bar{A}_{j-1}^{+}-\bar{A}_{j-1}^{+} \bar{a}_{j} \bar{\beta}_{j} \\
\bar{\beta}_{j}
\end{array}\right) .
$$

Здесь вектор $\bar{\beta}_{j}$ для первых $r$ столбцов определяется по формуле:

$$
\bar{\beta}_{j}=\frac{\bar{C}_{j}^{T}}{\left\|\bar{C}_{j}\right\|^{2}},
$$

а для последних $d=m-t$ столбцов матрицы $\bar{A}$ вектор $\bar{\beta}_{j}$ находится по формуле:

$$
\bar{\beta}_{j}=\frac{\bar{d}_{j}^{T} \bar{A}_{j-1}^{+}}{1+\left\|\bar{d}_{j}\right\|^{2}},
$$

где

$$
\begin{gathered}
\bar{d}_{j}=\bar{A}_{j-1}^{+} \bar{a}_{j} ; \\
\bar{C}_{j}=\bar{a}_{j}-\bar{A}_{j-1} \bar{d}_{j} .
\end{gathered}
$$

Второй этап уравнительных вычислений оценка точности результатов уравнивания. Для оценки точности уравненных параметров воспользуемся готовой формулой, которая позволяет вычислить среднеквадратическую ошибку любого параметра. Она имеет вид [1]:

$$
m_{\tilde{x}_{j}}=\mu\left\|a_{j}^{+}\right\|
$$

где $\left\|a_{j}^{+}\right\|$- евклидова норма $j$-го векторастроки псевдообратной матрицы; $\mu$ - среднеквадратическая ошибка единицы веса, вычисляемая по формуле [2]:

$$
\mu=\tilde{\sigma}=\sqrt{\frac{V^{T} P V}{n-k+d} .}
$$

Так осуществляется уравнивание и оценка точности геодезических построений анализируемым методом.

Теперь вкратце приведем алгоритм метода наименьших квадратов (МНК). В этих условиях от параметрических уравнений поправок переходят к системе нормальных уравнений и решают и $[3,4,6-16]$ :

$$
\hat{\Delta}=-R^{-1} b=-\left(A^{T} P A\right)^{-1} A^{T} l,
$$

где $R^{-1}$ - обратная матрица; $b$-вектор столбец свободных членов нормальных уравнений.

Для оценки точности уравненных параметров в данном случае вычисляется полная ковариационная матрица:

$$
K_{\hat{x}}=\mu^{2} R^{-1} .
$$

Здесь среднеквадратическую ошибку единицы веса можно рассчитать, например, по следующей формуле:

$$
\mu=\sqrt{\frac{V^{T} P V}{n-k}} .
$$

Имея ковариационную матрицу вектора уравненных параметров (15), можно определить среднеквадратическую ошибку любого параметра. Для этого стоит воспользоваться следующей формулой:

$$
m_{\hat{x}_{j}}=\sqrt{K_{\hat{x}_{j j}}},
$$

где $K_{\hat{x}_{j j}}$ - диагональные элементы ковариационной матрицы (15).

Таким образом, решается задача уравнивания и оценки точности элементов геодезической сети при параметрическом способе по методу наименьших квадратов.

\section{Результать}

Сравнительный анализ двух алгоритмов уравнивания и оценки точности показывает, что метод псевдонормальной оптимизации значительно сокращает и упрощает процедуру уравнивания и оценку точности геодезических сетей, так как отпадает этап перехода к нормальным уравнениям, а также упрощается оценка точности параметров из-за про- 
стой формулы (12), позволяющей вычислить среднеквадратическую ошибку для любого уравненного параметра.

Другие преимущества предлагаемого метода покажем на практическом примере геодезической сети. Сравнительный анализ из- ложенных методов проведем на модели звена триангуляции первого класса. Модель звена сети триангуляции первого класса представляет собой цепочку равносторонних треугольников с длинами сторон 20 км (рисунок).

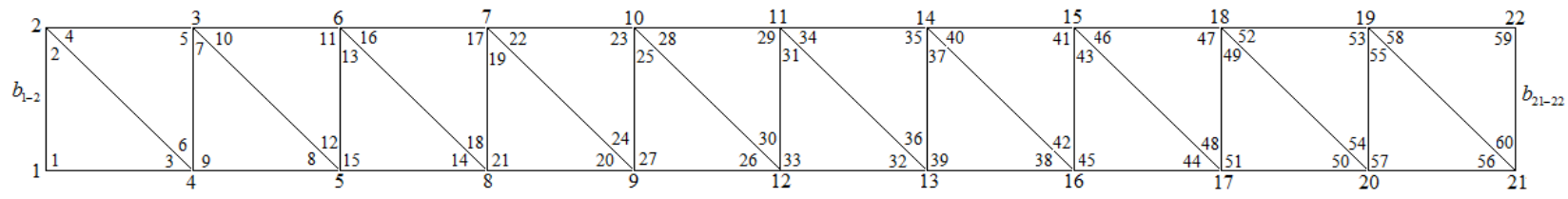

Звено триангуляционной сети первого класса

На концах звена триангуляции измерены два базиса ( $b_{12}$ и $\left.b_{2122}\right)$ и их дирекционные углы $\left(\alpha_{12}\right.$ и $\left.\alpha_{2122}\right)$. Координаты пункта 1 фиксированы.

Моделирование измеренных горизонтальных углов, базисных сторон и дирекционных углов этих сторон выполнялось в предположении, что стандартные ошибки этих элементов составят соответственно: $\sigma_{\beta_{0}}=0,7^{\prime \prime}, \sigma_{b_{0}}=50 \mathrm{mм}, \sigma_{\alpha_{0}}=0,5^{\prime \prime}$. Смоделированные значения элементов звена триангуляции приведены в табл. 1.

С использованием исходных координат пункта 1 , длин измеренных базисных сторон $b_{12}, b_{2122}$ и данных из табл. 1 по ходовой линии были вычислены приближенные значения координат определяемых пунктов. Результаты представлены в табл. 2.

Таблица 1

Смоделированные (измеренные) значения элементов цепи триангуляции первого класса

\begin{tabular}{|c|c|c|c|c|c|}
\hline $\begin{array}{c}\text { Обозначе- } \\
\text { ние }\end{array}$ & $\begin{array}{c}\text { Измеренные } \\
\text { значения }\end{array}$ & $\begin{array}{c}\text { Вес измеренных } \\
\text { величин }\end{array}$ & $\begin{array}{c}\text { Обозначе- } \\
\text { ние }\end{array}$ & $\begin{array}{c}\text { Измеренные } \\
\text { значения }\end{array}$ & $\begin{array}{c}\text { Вес измеренных } \\
\text { величин }\end{array}$ \\
\hline $\mathrm{b}_{12}$ & $19999,9912 \mathrm{м}$ & 0,000196 & $\mathrm{~b}_{2122}$ & $20000,0000 \mathrm{м}$ & 0,000196 \\
$\alpha_{12}$ & $0^{\circ} 00^{\prime} 00,00^{\prime \prime}$ & 1 & $\alpha_{2122}$ & $0^{\circ} 00^{\prime} 00,00^{\prime \prime}$ & 1 \\
\hline$\beta_{1}$ & $89^{\circ} 59^{\prime} 59,91^{\prime \prime}$ & 1 & $\beta_{31}$ & $44^{\circ} 59^{\prime} 59,69^{\prime \prime}$ & 1 \\
$\beta_{2}$ & $44^{\circ} 59^{\prime} 59,71^{\prime \prime}$ & 1 & $\beta_{32}$ & $45^{\circ} 00^{\prime} 00,09^{\prime \prime}$ & 1 \\
$\beta_{3}$ & $45^{\circ} 00^{\prime} 00,07^{\prime \prime}$ & 1 & $\beta_{33}$ & $89^{\circ} 59^{\prime} 59,66^{\prime \prime}$ & 1 \\
\hline$\beta_{4}$ & $44^{\circ} 59^{\prime} 59,81^{\prime \prime}$ & 1 & $\beta_{34}$ & $44^{\circ} 59^{\prime} 59,88^{\prime \prime}$ & 1 \\
$\beta_{5}$ & $90^{\circ} 00^{\prime} 00,66^{\prime \prime}$ & 1 & $\beta_{35}$ & $89^{\circ} 59^{\prime} 59,91^{\prime \prime}$ & 1 \\
$\beta_{6}$ & $44^{\circ} 59^{\prime} 59,95^{\prime \prime}$ & 1 & $\beta_{36}$ & $44^{\circ} 59^{\prime} 59,69^{\prime \prime}$ & 1 \\
\hline$\beta_{7}$ & $45^{\circ} 00^{\prime} 00,27^{\prime \prime}$ & 1 & $\beta_{37}$ & $44^{\circ} 59^{\prime} 59,64^{\prime \prime}$ & 1 \\
$\beta_{8}$ & $44^{\circ} 59^{\prime} 59,31^{\prime \prime}$ & 1 & $\beta_{38}$ & $44^{\circ} 59^{\prime} 59,68^{\prime \prime}$ & 1 \\
$\beta_{9}$ & $90^{\circ} 00^{\prime} 00,03^{\prime \prime}$ & 1 & $\beta_{39}$ & $90^{\circ} 00^{\prime} 00,12^{\prime \prime}$ & 1 \\
\hline$\beta_{10}$ & $44^{\circ} 59^{\prime} 59,93^{\prime \prime}$ & 1 & $\beta_{40}$ & $45^{\circ} 00^{\prime} 00,11^{\prime \prime}$ & 1 \\
$\beta_{11}$ & $89^{\circ} 59^{\prime} 59,97^{\prime \prime}$ & 1 & $\beta_{41}$ & $90^{\circ} 00^{\prime} 00,81^{\prime \prime}$ & 1 \\
$\beta_{12}$ & $45^{\circ} 00^{\prime} 00,45^{\prime \prime}$ & 1 & $\beta_{42}$ & $45^{\circ} 00^{\prime} 00,07^{\prime \prime}$ & 1 \\
\hline$\beta_{13}$ & $44^{\circ} 59^{\prime} 59,81^{\prime \prime}$ & 1 & $\beta_{43}$ & $44^{\circ} 59^{\prime} 59,60^{\prime \prime}$ & 1 \\
$\beta_{14}$ & $44^{\circ} 59^{\prime} 59,22^{\prime \prime}$ & 1 & $\beta_{44}$ & $45^{\circ} 00^{\prime} 00,10^{\prime \prime}$ & 1 \\
$\beta_{15}$ & $89^{\circ} 59^{\prime} 59,67^{\prime \prime}$ & 1 & $\beta_{45}$ & $90^{\circ} 00^{\prime} 00,40^{\prime \prime}$ & 1 \\
\hline
\end{tabular}


Окончание табл. 1

\begin{tabular}{|c|c|c|c|c|c|}
\hline $\begin{array}{c}\text { Обозначе- } \\
\text { ние }\end{array}$ & $\begin{array}{c}\text { Измеренные } \\
\text { значения }\end{array}$ & $\begin{array}{c}\text { Вес измеренных } \\
\text { величин }\end{array}$ & $\begin{array}{c}\text { Обозначе- } \\
\text { ние }\end{array}$ & $\begin{array}{c}\text { Измеренные } \\
\text { значения }\end{array}$ & $\begin{array}{c}\text { Вес измеренных } \\
\text { величин }\end{array}$ \\
\hline$\beta_{16}$ & $44^{\circ} 59^{\prime} 59,65^{\prime \prime}$ & 1 & $\beta_{46}$ & $44^{\circ} 59^{\prime} 59,01^{\prime \prime}$ & 1 \\
$\beta_{17}$ & $90^{\circ} 00^{\prime} 00,14^{\prime \prime}$ & 1 & $\beta_{47}$ & $89^{\circ} 59^{\prime} 59,83^{\prime \prime}$ & 1 \\
$\beta_{18}$ & $45^{\circ} 00^{\prime} 00,28^{\prime \prime}$ & 1 & $\beta_{48}$ & $45^{\circ} 00^{\prime} 00,09^{\prime \prime}$ & 1 \\
\hline$\beta_{19}$ & $45^{\circ} 00^{\prime} 00,12^{\prime \prime}$ & 1 & $\beta_{49}$ & $45^{\circ} 00^{\prime} 01,21^{\prime \prime}$ & 1 \\
$\beta_{20}$ & $44^{\circ} 59^{\prime} 59,13^{\prime \prime}$ & 1 & $\beta_{50}$ & $45^{\circ} 00^{\prime} 00,25^{\prime \prime}$ & 1 \\
$\beta_{21}$ & $90^{\circ} 00^{\prime} 00,44^{\prime \prime}$ & 1 & $\beta_{51}$ & $89^{\circ} 59^{\prime} 59,90^{\prime \prime}$ & 1 \\
\hline$\beta_{22}$ & $44^{\circ} 59^{\prime} 59,99^{\prime \prime}$ & 1 & $\beta_{52}$ & $44^{\circ} 59^{\prime} 59,62^{\prime \prime}$ & 1 \\
$\beta_{23}$ & $90^{\circ} 00^{\prime} 00,27^{\prime \prime}$ & 1 & $\beta_{53}$ & $89^{\circ} 59^{\prime} 59,33^{\prime \prime}$ & 1 \\
$\beta_{24}$ & $44^{\circ} 59^{\prime} 59,65^{\prime \prime}$ & 1 & $\beta_{54}$ & $45^{\circ} 00^{\prime} 00,03^{\prime \prime}$ & 1 \\
\hline$\beta_{25}$ & $45^{\circ} 00^{\prime} 00,52^{\prime \prime}$ & 1 & $\beta_{55}$ & $45^{\circ} 00^{\prime} 00,48^{\prime \prime}$ & 1 \\
$\beta_{26}$ & $45^{\circ} 00^{\prime} 00,22^{\prime \prime}$ & 1 & $\beta_{56}$ & $44^{\circ} 59^{\prime} 59,74^{\prime \prime}$ & 1 \\
$\beta_{27}$ & $90^{\circ} 00^{\prime} 00,94^{\prime \prime}$ & 1 & $\beta_{57}$ & $90^{\circ} 00^{\prime} 00,32^{\prime \prime}$ & 1 \\
\hline$\beta_{28}$ & $44^{\circ} 59^{\prime} 59,77^{\prime \prime}$ & 1 & $\beta_{58}$ & $45^{\circ} 00^{\prime} 00,52^{\prime \prime}$ & 1 \\
$\beta_{29}$ & $90^{\circ} 00^{\prime} 00,15^{\prime \prime}$ & 1 & $\beta_{59}$ & $89^{\circ} 59^{\prime} 59,87^{\prime \prime}$ & 1 \\
$\beta_{30}$ & $45^{\circ} 00^{\prime} 00,46^{\prime \prime}$ & 1 & $\beta_{60}$ & $45^{\circ} 00^{\prime} 00,11^{\prime \prime}$ & 1 \\
\hline
\end{tabular}

Таблица 2

Приближенные значения координат

\begin{tabular}{|c|c|c|c|c|c|}
\hline \multirow{2}{*}{ Пункты сети } & \multicolumn{2}{|c|}{ Координаты } & \multirow{2}{*}{ Пункты сети } & \multicolumn{2}{|c|}{ Координаты } \\
\cline { 2 - 3 } \cline { 5 - 6 } & $X(\mathrm{M})$ & $Y(\mathrm{M})$ & & $X(\mathrm{м})$ & $Y(\mathrm{M})$ \\
\hline 1 & 1000,0000 & 1000,0000 & 12 & 999,5734 & 101000,4428 \\
2 & 20999,9912 & 1000,0000 & 13 & 999,4909 & 121000,5115 \\
3 & 20999,9447 & 20999,9796 & 14 & 20999,5781 & 121000,5726 \\
4 & 999,9787 & 20999,9563 & 15 & 20999,4928 & 141000,6976 \\
5 & 999,9147 & 41000,0154 & 16 & 999,3639 & 141000,5948 \\
6 & 20999,9408 & 41000,0823 & 17 & 999,2321 & 161000,6752 \\
7 & 20999,8215 & 61000,2112 & 18 & 20999,2552 & 161000,8255 \\
8 & 999,7537 & 61000,0987 & 19 & 20999,1854 & 181000,8274 \\
9 & 999,5685 & 81000,2625 & 20 & 999,2233 & 181000,7915 \\
10 & 20999,7197 & 81000,3294 & 21 & 999,2088 & 201000,8254 \\
11 & 20999,6809 & 101000,5038 & 22 & 20999,2465 & 201000,8254 \\
\hline
\end{tabular}

Для выполнения уравнительных работ на основе исходных и данных табл. 1 и 2 были рассчитаны матрица коэффициентов уравнений поправок и вектор-столбец свободных членов. Далее по выше предложенному методу была вычислена псевдообратная матрица $\bar{A}^{+}$. По формулам (5) и (6) были вычислены соответственно вектор поправок к приближенным координатам и вектор уравненных координат пунктов. Для оценки точности уравненных координат звена триангуляции применяется формула (12).

Теперь необходимо перейти к уравниванию и оценке точности цепи триангуляции по методу наименьших квадратов. Для этого предварительно определяют матрицу коэффициентов и вектор-столбец свободных членов нормальных уравнений. Далее по формулам (14) и (6) находят соответственно вектор поправок к приближенным координатам и вектор уравненных координат пунктов. Для оценки точности уравненных координат пунктов сети по формуле (15) определяют ковариационную матрицу уравненного вектора координат и далее по формуле (17) - их среднеквадратические ошибки.

Для сравнения двух методов уравнивания приведем среднеквадратические ошибки положения нескольких удаленных пунктов сети от исходного пункта 1 (табл. 3). 
Таблица 3

Среднеквадратические ошибки положения пунктов сети

\begin{tabular}{|c|c|c|c|c|c|c|c|c|c|}
\hline \multicolumn{2}{|c|}{ Номера пунктов } & 15 & 16 & 17 & 18 & 19 & 20 & 21 & 22 \\
\hline \multirow{2}{*}{$\begin{array}{c}\text { СКО, } \\
\text { см }\end{array}$} & МПНО & 8,1 & 8,1 & 7,5 & 7,5 & 11,0 & 11,0 & 14,8 & 14,8 \\
\cline { 2 - 10 } & MНК & 57,4 & 57,3 & 64,1 & 64,1 & 69,3 & 69,3 & 72,4 & 72,4 \\
\hline
\end{tabular}

Как видно из табл. 3, среднеквадратические ошибки положения пунктов, полученные сравниваемыми методами, сильно разнятся между собой. Например, для метода наименьших квадратов эта ошибка достигает максимума для пунктов 21 и 22 и равна 72,4 см, тогда как для метода псевдонормальной оптимизации она составляет всего 14,8 см, то есть почти в 5 раз меньше.

\section{Обсуждение}

Чтобы оценить корректность, полученных результатов уравнивания по уравненным значениям горизонтальных углов и длин сторон для 20 треугольников звена цепи триангуляции, необходимо проверить выполнение геометрических условий.

Результаты представлены в табл. 4.

Таблица 4

Результаты выполнения геометрических условий для двух методов

\begin{tabular}{|c|c|c|c|c|}
\hline \multirow{2}{*}{$\begin{array}{c}\text { Номера } \\
\text { треугольников }\end{array}$} & \multicolumn{2}{|c|}{ Условия фигур } & \multicolumn{2}{c|}{ Синусные условия } \\
\cline { 2 - 5 } & МПН & МНК & МПНО (мм) & МНК (мм) \\
\hline 1 & $-0,01 "$ & $-0,01 "$ & 0,40 & 0,48 \\
\hline 2 & $-0,01$ & $-0,01$ & $-0,38$ & 0,16 \\
\hline 3 & 0 & 0,01 & 0,13 & $-0,17$ \\
\hline 4 & 0 & 0 & 0,00 & 0,48 \\
\hline 5 & 0 & 0 & 0,29 & 0,49 \\
\hline 6 & 0 & 0 & 0,20 & 0,48 \\
\hline 7 & 0 & $-0,01$ & 0,22 & 0,15 \\
\hline 8 & 0 & 0 & 0,12 & 0,17 \\
\hline 9 & 0 & 0 & $-0,26$ & $-0,17$ \\
\hline 10 & 0 & 0 & $-0,34$ & $-0,16$ \\
\hline 11 & 0 & 0 & 0,06 & $-0,17$ \\
\hline 12 & 0 & 0 & 0,02 & $-0,16$ \\
\hline 13 & 0 & 0 & 0,43 & 0,16 \\
\hline 14 & 0 & 0 & 0,17 & $-0,16$ \\
\hline 15 & 0 & 0,01 & 0,47 & 0,48 \\
\hline 16 & 0 & 0 & $-0,28$ & $-0,17$ \\
\hline 17 & 0 & 0 & 0,07 & 0,16 \\
\hline 18 & 0 & 0 & $-0,08$ & 0,16 \\
\hline 19 & 0 & 0 & 0,44 & $-0,16$ \\
\hline 20 & 00,01 & 0 & 0,41 & \\
\hline
\end{tabular}

Анализ результатов проверки условий (см. табл. 4) показывает, что уравненные элементы сети, полученные по предлагаемым методам, дают практически одинаковые нулевые невязки во всевозможных условных уравнениях, возникающих в данной цепи.

\section{Заключение}

Для окончательного сравнения двух методов уравнивания и оценки точности выполним дополнительные вычисления обобщающих характеристик для сравниваемых 
алгоритмов. Такими характеристиками могут выступать обобщенные среднеквадратические ошибки положения пунктов сети. Для метода наименьших квадратов этот показатель вычислим по известной формуле:

$$
M_{S_{2}}=\sqrt{\frac{\operatorname{tr}(K x)}{k}},
$$

где $\operatorname{tr}(K x)$-след ковариационной матрицы уравненного вектора координат (15).

А для метода псевдонормальной оптимизации авторы предлагают формулу, которая имеет вид:

$$
M_{S_{1}}=\mu \frac{\sum_{j=1}^{k}\left\|\bar{a}_{j}^{+}\right\|}{\sqrt{k}},
$$

где $\left\|a_{j}^{+}\right\|$- евклидова норма $j$-го векторастроки псевдообратной матрицы.

Наконец перейдем к расчету и анализу этих показателей:

$$
M_{S_{1}}=\mu \frac{\sum_{j=1}^{k}\left\|\bar{a}_{j}^{+}\right\|}{\sqrt{k}}=8,34 \mathrm{~cm} ;
$$

$$
M_{S_{2}}=\sqrt{\frac{\operatorname{tr}(K x)}{k}}=33,48 \mathrm{~cm} .
$$

Вычислим отношение этих двух показателей:

$$
\delta=\frac{M_{S_{2}}}{M_{S_{1}}}=4,01 .
$$

Анализируя вычисления, можно заключить, что метод псевдонормальной оптимизации позволяет вычислить значения уравненных координат в 4 раза точней, чем метод наименьших квадратов.

Bсе вышепроделанные экспериментальные вычисления и анализ результатов дают уверенность авторам рекомендовать метод псевдонормальной оптимизации (метод псевдорешения) для уравнивания и оценки точности любых геодезических построений, в том числе обширных государственных геодезических сетей. Он значительно упрощает процедуру уравнивания и оценки точности, а также является универсальным, то есть может решать вырожденные, плохо обусловленные и невырожденные геодезические задачи и, как показывают расчеты в этой и других работах, окончательные результаты получаются значительно точней.

\section{БИБЛИОГРАФИЧЕСКИЙ СПИСОК}

1. Барлиани А. Г. Разработка алгоритмов уравнивания и оценки точности свободных и несвободных геодезических сетей на основе псевдонормального решения : монография. - Новосибирск : СГГА, 2010. - 135 с.

2. Барлиани А. Г. Методы обработки и анализа пространственных и временных данных : монография. - Новосибирск : СГУГиТ, 2016. - 177 с.

3. Герасименко М. Д. Современный метод наименьших квадратов с геодезическими приложениями. - Владивосток : Дальнаука, 1998. - 98 с.

4. Жарников В. Б., Ларионов Ю. С. Мониторинг плодородия земель сельскохозяйственного назначения как механизм их рационального использования // Вестник СГУГиТ. - 2017. - Т. 22, № 1. - C. 203-212.

5. Асташков Г. Г., Барлиани А. Г., Колмогоров В. Г. Коррелатная версия уравнивания и оценки точности геодезических сетей с равноточно измеренными величинами методом псев- дооптимизации // Вестник СГУГиТ. - 2016. Вып. 4 (36). - С. 52-65.

6. Бугакова Т. Ю. Моделирование изменения пространственно-временного состояния инженерных сооружений и природных объектов по геодезическим данным // Вестник СГУГиТ. 2015. - № 1 (29). - С. 34-42.

7. Мазуров Б. Т. Геодинамические системы (кинематические и деформационные модели блоковых движений) // Вестник СГУГиТ. - 2016. Вып. 3 (35). - С. 5-15.

8. Маркузе Ю. И. Уравнивание и оценка точности плановых геодезических сетей. - М. : Недра, 1982. - 191 с.

9. Маркузе Ю. И., Голубев В. В. Теория математической обработки геодезических измерений. - М. : Альма Матер, 2010. - 247 с.

10. Матвеев С. И. Уравнивание повторных измерений с учетом подвижности пунктов геодезической сети // Геодезия и картография. - 1986. № 3. - C. 20-24. 
11. Коугия В. А. Избранные труды. Исследования по теории математической обработки результатов измерений : монография. - СПб. : ПГУПС, 2012. - 447 с.

12. Карпик А. П., Каленицкий А. И., Соловицкий А. Н. Новый этап развития геодезии переход к изучению деформаций блоков земной коры в районах освоения угольных месторождений // Вестник СГГА. - 2013. - Вып. 3 (23). C. 3-9.

13. Карпик А. П. Разработка методики качественной и количественной оценки кадастровой информации // Изв. вузов. Геодезия и аэрофотосъемка. - 2013. - № 4/С. - С. 137-142.

14. Карпик А. П., Мурзинцев П. П., Падве В. А. Прикладная геодезия. Геодезическое обеспечение изысканий, строительства и мониторинга мостовых сооружений : учеб. пособие. - Новосибирск : СГУГиТ, 2015. - 222 с.

15. Карпик А. П., Обиденко В. И. Формирование единого геопространства территорий для повышения качества геодезического обеспечения государственного кадастра недвижимости // Интерэкспо ГЕО-Сибирь-2013. IX Междунар. науч. конгр. : Пленарное заседание : сб. материалов в 2 т. (Новосибирск, 15-26 апреля 2013 г.). - Новосибирск : СГГА, 2013. Т. 1. - С. 3-11.

16. Совершенствование аналитического способа вычисления границ земельных участков / Е. И. Аврунев, В. В. Вылегжанина, И. А. Гиниятов, В. Г. Колмогоров, Х. К. Ямбаев // Вестник СГУГиТ. - 2019. - Т. 24, № 4. - С. 126-135.

Получено 12.03.2020

(C) А. Г. Барлиани, Г. А. Нефедова, И. В. Карнетова, 2020

\section{PSEUDONORMAL OPTIMIZATION METHOD AND GEODESIC EQUATION CALCULATIONS}

\section{Amridon G. Barliani}

Siberian State University of Geosystems and Technologies, 10, Plakhotnogo St., Novosibirsk, 630108, Russia, Ph. D. Associate Professor, Department of Applied Informatics and Information Systems, phone: (383)343-18-35

\section{Galina A. Nefedova}

Siberian State University of Geosystems and Technologies, 10, Plakhotnogo St., Novosibirsk, 630108, Russia, Ph. D. Associate Professor, Department of Applied Informatics and Information Systems, phone: (383)343-18-35

\section{Irina $V$. Karnetova}

Siberian State University of Geosystems and Technologies, 10, Plakhotnogo St., Novosibirsk, 630108, Russia, Senior Lecturer, Department of Applied Informatics and Information Systems, phone: (383)343-18-35

The purpose of this paper is a comparative analysis of the methods of least squares and pseudonormal optimization on the example of equalization and estimation of the accuracy of the first-class triangulation link. Pseudonormal optimization is radically different from the traditional method of least squares optimization, since it leads to complex and cumbersome procedures for equalizing and evaluating the accuracy of the results of processing geodesic constructions due to complex formulas. A recurrent method of sequential formation of a pseudoinverse matrix of parametric correction equations is presented, which allows avoiding the time-consuming computational process of composing and solving normal equations. A mathematical algorithm for estimating the accuracy of the equalized parameters is considered. The analysis of the equation works has shown that the pseudonormal optimization method allows calculating the values of the equalized coordinates 4 times more accurately than the least squares optimization.

Key words: first class triangulation link, basis side, degenerate matrix, correction equation, least squares method, pseudonormal optimization method, origin of the network coordinates, rank defect of the matrix, Euclidean norm. 


\section{REFERENCES}

1. Barliani, A. G. (2010). Razrabotka algoritmov uravnivaniya $i$ otsenki tochnosti svobodnykh $i$ nesvobodnykh geodezicheskikh setey na osnove psevdonormal'nogo resheniya [Development of algorithms for adjustment and estimation of the accuracy of free and non-free geodetic networks based on a pseudonormal solution]. Novosibirsk: SSGA Publ., 135 p. [in Russian].

2. Barliani, A. G. (2016). Metody obrabotki $i$ analiza prostranstvennykh $i$ vremennykh dannykh [Techniques for processing and analyzing spatial and temporal data]. Novosibirsk: SSUGT Publ., 177 p. [in Russian].

3. Gerasimenko, M. D. (1998). Sovremennyy metod naimen'shikh kvadratov $s$ geodezicheskimi prilozheniyami [Modern least squares method with geodesic applications]. Vladivostok: Dal'nauka, 98 p. [in Russian].

4. V. B. Zharnikov, Yu. S. Larionov. (2017). Soil fertility monitoring of agricultural purpose lands as a mechanism of their rational use. Vestnik SGUGiT [Vestnik SSUGT], 22(1), 203-212 [in Russian].

5. Astashenkov, G. G., Barliani, A. G., \& Kolmogorov, V. G. (2016). Correlated version of accuracy assessment equalization of geodetic networks with equal observations by means of pseudooptimisation. Vestnik SGUGiT [Vestnik SSUGT], 4(36), 52-65 [in Russian].

6. Bugakova, T. Yu. (2015). Modelling of spatio-temporal variations for engineering structures and natural objects by geodetic data. Vestnik SGUGiT [Vestnik SSUGT], 1(29), 34-42 [in Russian].

7. Mazurov, B. T. (2016). Geodynamic system (kinematic and deformation model of block movements). Vestnik SGUGiT [Vestnik SSUGT], 3(35), 5-15 [in Russian].

8. Markuze, Yu. I. (1982). Uravnivanie i otsenka tochnosti planovykh geodezicheskikh setey [Adjustment and estimation of the accuracy of the planned geodetic networks]. Moscow: Nedra Publ., 191 p. [in Russian].

9. Markuze, Yu. I., \& Golubev, V. V. (2010). Teoriya matematicheskoy obrabotki geodezicheskikh izmereniy [Theory of mathematical processing of geodetic measurements]. Moscow: Al'ma Mater Publ., 247 p. [in Russian].

10. Matveev, S. I. (1986). Equalization of repeated measurements taking into account the mobility of points of the geodetic network. Geodeziya $i$ kartografiya [Geodesy and Cartography], 3, 20-24 [in Russian].

11. Kougiya, V. A. (2012). Izbrannye trudy. Issledovaniya po teorii matematicheskoy obrabotki rezul'tatov izmereniy [Selected Works. Research on the theory of mathematical processing of measurement results]. Saint Petersburg: PGUPS Publ. 447 p. [in Russian].

12. Karpik, A. P., Kalenitsky, A. I., \& Solovitsky, A. N. (2013). New stage of geodesy development: investigation of earth blocks deformation in regions of coal deposits development. Vestnik $S G G A$ [Vestnik SSGA], 3(23), 3-9 [in Russian].

13. Karpik, A. P. (2013). Development of a methodology for the qualitative and quantitative assessment of cadastral information. Izvestiya vuzov. Geodeziya i aerofotos"emka [Izvestiya Vuzov. Geodesy and Aerophotography], 4/S, 137-142 [in Russian].

14. Karpik, A. P., Murzintsev, P. P., \& Padve, V. A. (2015). Prikladnaya geodeziya. Geodezicheskoe obespechenie izyskaniy, stroitel'stva $i$ monitoringa mostovykh sooruzheniy [Geodetic support of surveys, construction and monitoring of bridge structures]. Novosibirsk: SSUGT Publ., 222 p. [in Russian].

15. Karpik, A. P., \& Obidenko, V. I. (2013). Formation of a single geospace of territories to improve the quality of geodetic support of the state real estate cadastre. In Sbornik materialov Interekspo GEO-Sibir'-2013: Plenarnoe zasedanie: T. 1. [Proceedings of Interexpo GEO-Siberia-2013: Plenary Session: Vol. 1] (pp. 3-11). Novosibirsk: SSUGT Publ. [in Russian].

16. Avrunev, E. I., Vylegzhanina, V. V., Ginijatov, I. A., Kolmogorov, V. G., \& Jambaev, Kh. K. (2019). Improvement of analytical method for land parcel boundaries calculation. Vestnik SGUGiT [Vestnik SSUGT], 24(4), 126-135 [in Russian].

Reseived 12.03.2020 
УДК 528.242: 528.91

DOI: $10.33764 / 2411-1759-2020-25-3-14-25$

\section{СОЗДАНИЕ МОДЕЛИ КВАЗИГЕОИДА НА ЛОКАЛЬНОМ УЧАСТКЕ СРЕДСТВАМИ ГИС}

\section{Ирина Геннадвевна Ганагина}

Сибирский государственный университет геосистем и технологий, 630108, Россия, г. Новосибирск, ул. Плахотного, 10, кандидат технических наук, доцент, зав. кафедрой космической и физической геодезии, e-mail: gam0209@yandex.ru

\section{Дарья Сергеевна Челнокова}

Сибирский государственный университет геосистем и технологий, 630108, Россия, г. Новосибирск, ул. Плахотного, 10, магистрант, тел. (905)956-44-74, e-mail: sergeevna0403@gmail.com

\section{Денис Николаевич Голдобин}

Сибирский государственный университет геосистем и технологий, 630108, Россия, г. Новосибирск, ул. Плахотного, 10, кандидат технических наук, инженер кафедры космической и физической геодезии, e-mail: phis.geo.sgga@gmail.com

Возможности полнофункциональных геоинформационных систем, применяемых в различных областях, позволяют моделировать характеристики гравитационного поля, представляя измерительную информацию в виде непрерывных поверхностей, тем самым расширяя область использования данных о гравитационном поле Земли. Важным этапом визуализации является выбор метода интерполирования данных, обеспечивающих максимально высокую точность создания цифровой модели исследуемой характеристики гравитационного поля. Авторами разработана технология выбора оптимального метода интерполирования характеристик гравитационного поля Земли в среде ГИС для создания моделей с оценкой их точности по исходным данным, представленная в виде технологической схемы. Рассмотрены возможности программного продукта Golden Software Surfer для создания модели высот квазигеоида по неравномерно представленным данным спутникового и геометрического нивелирования на исследуемой территории. Предложен метод интерполяции высот квазигеоида в Golden Software Surfer, создана модель квазигеоида на локальном участке. Выполнена оценка точности созданной модели по исходным данным.

Ключевые слова: аппроксимация исходных данных, геоинформационные системы, геопространственное моделирование, методы интерполирования, характеристики гравитационного поля Земли, высота квазигеоида.

\section{Введение. Анализ вопроса}

Важными факторами, определяющими формирование информационного пространства с учетом потребностей в получении качественных и достоверных данных, создание и применение отечественных цифровых платформ и технологий, обеспечение их конкурентоспособности на международном уровне, являются технологии координатно-временного и навигационного обеспечения (КВНО), включающие в себя получение данных об объекте с высокой точностью и дающие возможность их анализа и интерпретации.

Координатное обеспечение любого объекта поддерживается благодаря активному использованию ГНСС-технологий. Для получения высокоточной гравитационной составляющей КВНО на современном этапе необходимо решить ряд проблем, связанных с наземными определениями и созданием моделей характеристик гравитационного поля планетарного, регионального и локального характера с высокой точностью. Проблемы высокоточного определения основных характеристик гравитационного поля, к которым относятся аномалии силы тяжести, высоты квазигеоида и уклонения отвесной линии, достаточно полно освещены в многочисленных публикациях [1-5].

Ocобое место занимает проблема представления характеристик гравитационного по- 
ля, получения достоверных картографических произведений для целей не только визуализации, но и качественного анализа, интерпретации данных и их дальнейшего использования при решении задач геодезии, геофизики, геодинамики и смежных наук.

Развитие цифровых технологий в сфере картографирования позволили хранить, обрабатывать и анализировать большой объем модельных и измерительных данных, применяя геоинформационные системы (ГИС) [6]. В настоящее время для представления информации о гравитационном поле и его характеристиках глобального и локального характера используют различные полнофункциональные ГИС.

Проблематика, принципы и методы геоинформационного моделирования характеристик гравитационного поля как для целей визуализации, так и для анализа полученной картографической информации представлены в различных публикациях [7-13], авторы которых приводят результаты моделирования аномалий силы тяжести, высот квазигеоида средствами ГИС. Анализ публикаций [14-18] позволил выделить активно применяемые программные продукты и круг решаемых задач в рамках исследования гравитационного поля.

Специализированная программа Golden Software Surfer используется для моделирования, анализа и визуализации поверхностей, построения различных карт как двумерного, так и трехмерного изображения. С помощью программного пакета Surfer создаются карты высот квазигеоида, аномалий силы тяжести, абсолютных значений силы тяжести непосредственно по наблюдениям, абсолютных значений напряженности силы тяжести, модуля полного горизонтального градиента силы тяжести, выполняется анализ структуры поля [19-22].

Для решения задач визуализации гравитационного поля и его характеристик активно используются программные продукты корпорации ERSI. Комплексное применение программных продуктов ERSI: ArcGIS, ArcMap, ArcScene, ArcGlob и ArcCatalog позволяет создавать картографические материалы по гравиметрическим и геофизическим данным на основе широкого спектра возможностей базовой комплектации программы и наличия дополнительных модулей для визуализации, в которых представлены различные методы интерполяции [16, 23- 25]. Особое значение имеют возможности программного продукта, которые позволяют исключить ошибки оператора и сократить время выполнения обработки пространственных данных $[13,18,26]$.

Широкое внедрение в производство работ по изучению характеристик гравитационного поля Земли (ГПЗ) программного комплекса ArcGIS базируется на возможности использования его в качестве платформы для создания новых приложений и модификации стандартных, решающих определенные профессиональные задачи: упрощение процедуры обработки и хранения гравиметрических данных с возможностью восстановления [27, 28], вычисление трансформант геопотенциальных полей в произвольно выбранных точках пространства [21], отображение пространственных векторных полей на плоскости установленной палитрой цветов и восстановление положения векторов в пространстве по созданному цветному изображению $[15,29]$.

Отдельное место при геоинформационном картографировании гравиметрических данных занимают программные продукты, разработанные для решения специализированных задач геологии, геофизики и гравиразведки полезных ископаемых. Исследовательские институты, производственные объединения создают программные комплексы, позволяющие получать карты характеристик ГПЗ с помощью широкого набора инструментов и методов с возможностью визуализации данных в трехмерном пространстве $[17,30-33]$ и проводить интегрированный анализ разнородных и разноуровневых данных [34-38].

В последнее время для решения широкого спектра задач геоинформационного картографирования применяются программные продукты с открытым исходным кодом, который позволяет пользователям самостоятельно создавать и интегрировать необходимые модули и тем самым динамично развивать геоинформационные технологии [10, 39]. 
На рис. 1 представлен перечень задач, для решения которых в настоящее время применяют средства и методы геоинформационного картографирования характеристик гравитационного поля Земли.

Анализ геоинформационного картографирования гравиметрических данных показал широкое применение созданных материалов для решения научных и прикладных задач средствами ГИС.

Создание цифровой информации о гравитационном поле Земли и его характеристиках, ее картографическое представление является одной из актуальных задач геодезии, геофизики и ряда других наук о Земле. Исследования в этой области имеют не только научный, но и производственный интерес. Работы, отражающие создание картографического изображения гравитационного поля Земли и его характеристик в среде ГИС, очень разнообразны по используемым про- граммным продуктам, решаемым задачам и территориальному охвату.

Анализ публикаций результатов геоинформационного моделирования характеристик гравитационного поля показал, что в работах отсутствует оценка точности полученных моделей. Как правило, созданные произведения используются только для визуализации полученных результатов. Для использования результатов геоинформационного картографирования характеристик ГПЗ для анализа и интерпретации результатов необходимо быть уверенным, что методы и средства используемого программного продукта позволяют выполнять моделирование характеристик на исследуемую территорию с необходимой точностью.

Целью данного исследования является создание модели высот квазигеоида на локальном участке в среде ГИС с оценкой их точности по исходным данным.

\begin{tabular}{|c|c|c|c|}
\hline \multicolumn{4}{|c|}{ Отображаемые характеристики гравитационного поля средствами ГИС } \\
\hline $\begin{array}{c}\text { Горизонтальный градиент } \\
\text { поля силы тяжести }\end{array}$ & $\begin{array}{c}\text { Аномалия высоты } \\
\text { (высота квазигеоида) }\end{array}$ & $\begin{array}{c}\text { Аномалия силы } \\
\text { тяжести }\end{array}$ & $\begin{array}{c}\text { Абсолютные } \\
\text { значения силы тяжести }\end{array}$ \\
\hline
\end{tabular}

Задачи:

- получение высот пунктов на земной поверхности высокой точности;

- создание государственных геологических карт разных масштабов;

- визуализация данных, создание демонстрационных материалов;

- моделирование рельефа;

- создание моделей квазигеоида/геоида;

- выполнение специализированных расчетов с учетом гравиметрических данных;

- создание геоинформационных моделей характеристик ГПЗ для решения научных и практических задач геодезии, геофизики, гравиразведки и смежных наук

Рис. 1. Задачи, решаемые с применением средств и методов геоинформационного картографирования характеристик ГПЗ

\section{Методы исследования}

Геоинформационное моделирование высот квазигеоида выполнено средствами программного обеспечения Golden Software Surfer. Программное обеспечение Surfer разработано фирмой Golden Software специально для создания, анализа, моделирования и визуализации поверхностей $[40,41]$.

Для осуществления поставленной цели в работе проанализированы методы интерполирования исходных наземных данных при создании модели высот квазигеоида на территорию Новосибирской области.
Методы интерполяции: Kriging, Minimum Curvature, Modified Shepard's Method, Natural Neighbor, Nearest Neighbor, Radial Basis Function, Triangulation with Linear Interpolation, Inverse Distance to a Power, алгоритмы которых заложены в программном коде Golden Software Surfer позволяют создавать цифровые модели поверхности по неравномерно распределенным в пространстве данным.

Метод Kriging рассчитывает значение концентрации в промежуточных точках с наименьшей возможной ошибкой и решает задачу интерполяции с применением линейных оценок, при этом позволяет вклю- 
чать в создаваемую модель анизотропию и тренды. При том условии, что данные имеют нормальное распределение, Kriging становится наилучшим средством прогнозирования [40, 42, 43].

Использование метода Minimum Curvature предполагает создание двухмерного сплайна с натяжением и основывается на прохождении через все точки с минимальным числом изгибов, генерируя наиболее гладкую поверхность, которая проходит настолько близко к экспериментальным точкам, насколько это возможно [43].

Modified Shepard's Method и Inverse Distance to a Power основаны на принципе распределения весов - значения, измеренные близко от интерполируемого местоположения, оказывают большее влияние на результат оценки, чем удаленные от него на значительное расстояние, т. е. точки выборки, расположенные ближе всего к точке, где выполняется оценка, имеют больший вес, а вес выборочных точек уменьшается с увеличением расстояния от интерполируемого местоположения [42, 43].

В методе Natural Neighbor оценка интерполируемой переменной определяется как среднее взвешенное значений этой переменной в выборочных точках. С помощью данного метода могут быть получены изолинейные карты хорошего качества по наборам данных, в которых содержатся скопления выборочных точек в одних подобластях и разреженные выборочные точки в других подобластях [40, 43].

Метод Nearest Neighbor применяется, если исходные выборочные точки расположены в узлах некоторой регулярной сетки, которая покрывает область исследования, или если точки незначительно смещены относительно узлов сетки [43].

Метод Radial Basis Function представляет оценку переменной в произвольной точке области исследования, которая находится как линейная комбинация значений радиальных базисных функций. Радиальная базисная функция определяет оптимальные веса, применяемые к точкам данных во время интерполяции. С помощью радиальных базисных функций создаются модели слабо изменяющихся поверхностей [40, 42$]$.
Triangulation with Linear Interpolation использует алгоритм построения триангуляции Делоне - разбиение области исследования на совокупность треугольников, где соседние точки выборки являются вершинами треугольников, а точки соединяются так, что ребра треугольников не пересекаются. Метод является эффективным, когда требуется сохранить линии разрывов поверхности, при этом точно могут быть воспроизведены значения в выборочных точках [40, 42, 43].

С использованием всех перечисленных методов интерполяции созданы модели высот квазигеоида по данным исходной информации, неравномерно представленной на исследуемой территории.

\section{Результаты}

Исходной информацией для выполнения исследования являются значения высот квазигеоида, полученные по данным спутникового и геометрического нивелирования для 188 пунктов, расположенных на территории Новосибирской области. На рис. 2 приведена картосхема расположения пунктов, на которых выполнены спутниковые измерения и проведено геометрическое нивелирование.

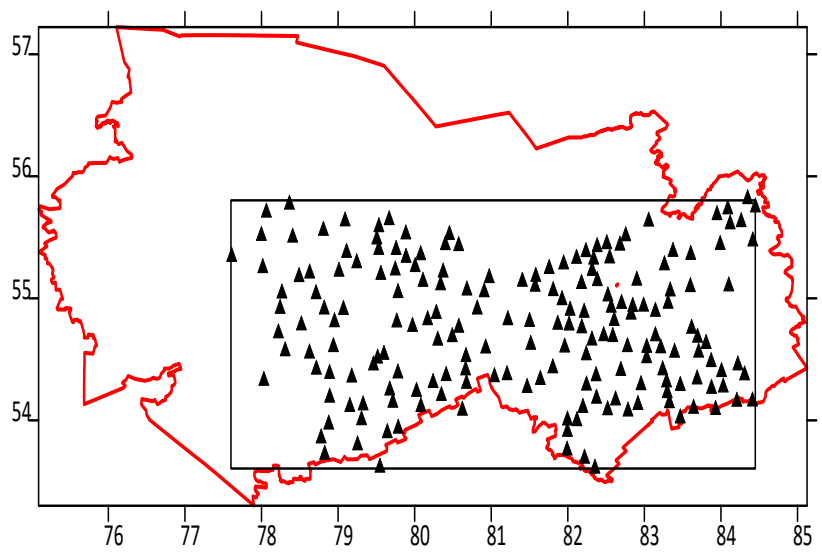

Рис. 2. Картосхема расположения пунктов на территории Новосибирской области:

$\boldsymbol{\Delta}$ - исходные пункты; / - граница НСО

Технология выбора оптимального метода интерполирования высот квазигеоида для создания модели в среде ГИС с оценкой ее точности по исходным данным приведена на схеме, представленной на рис. 3. 
На рис. 4-6 приведены результаты моделирования аномалий высоты на территории Новосибирской области по наземным измерениям данным с помощью методов интерполяции:
Kriging, Minimum Curvature, Modified Shepard's Method, Natural Neighbor, Nearest Neighbor, Radial Basis Function, Triangulation with Linear Interpolation, Inverse Distance to a Power.

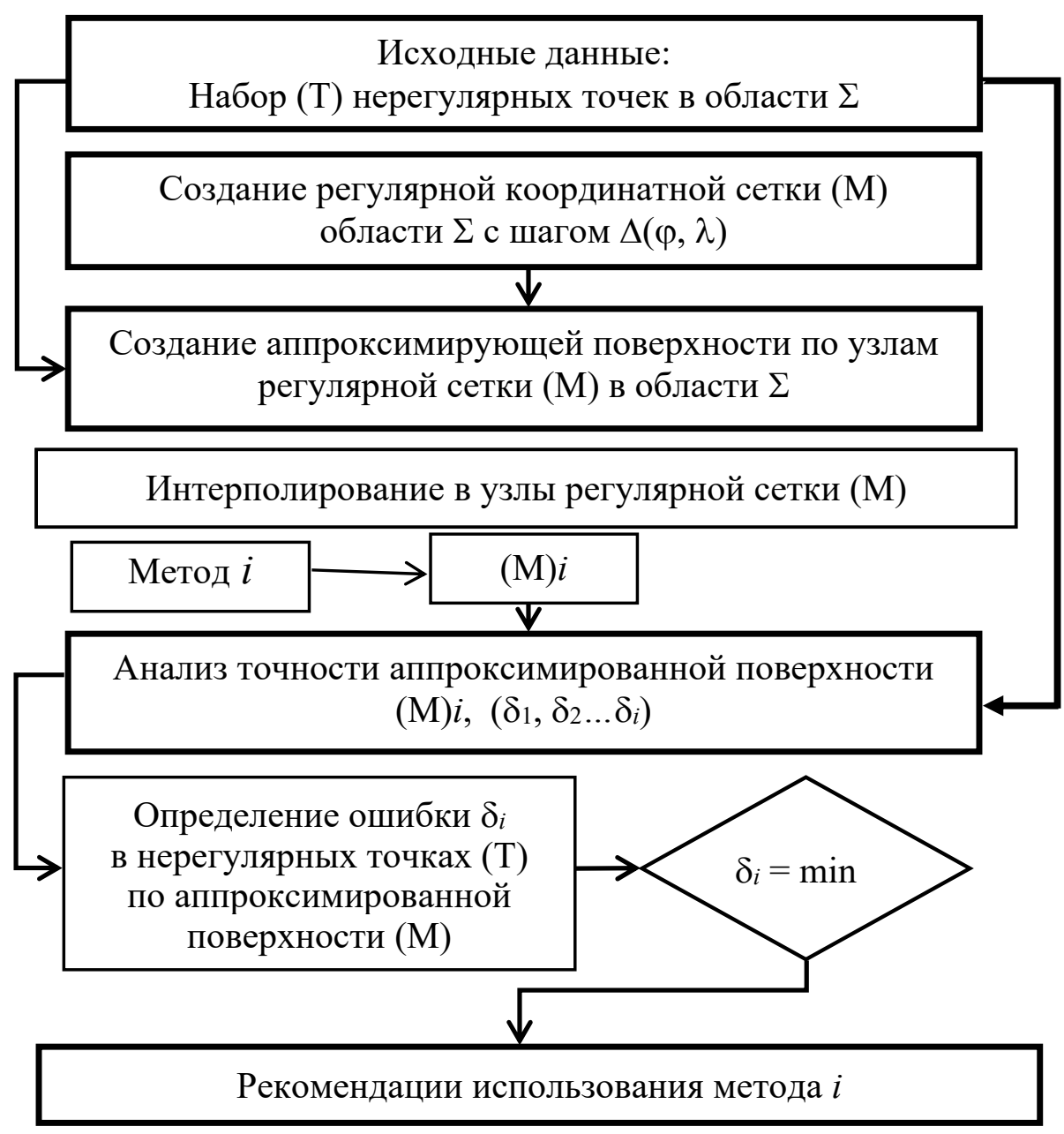

Рис. 3. Технологическая схема выбора оптимального метода интерполирования высот квазигеоида для создания модели в среде ГИС с оценкой ее точности по исходным данным
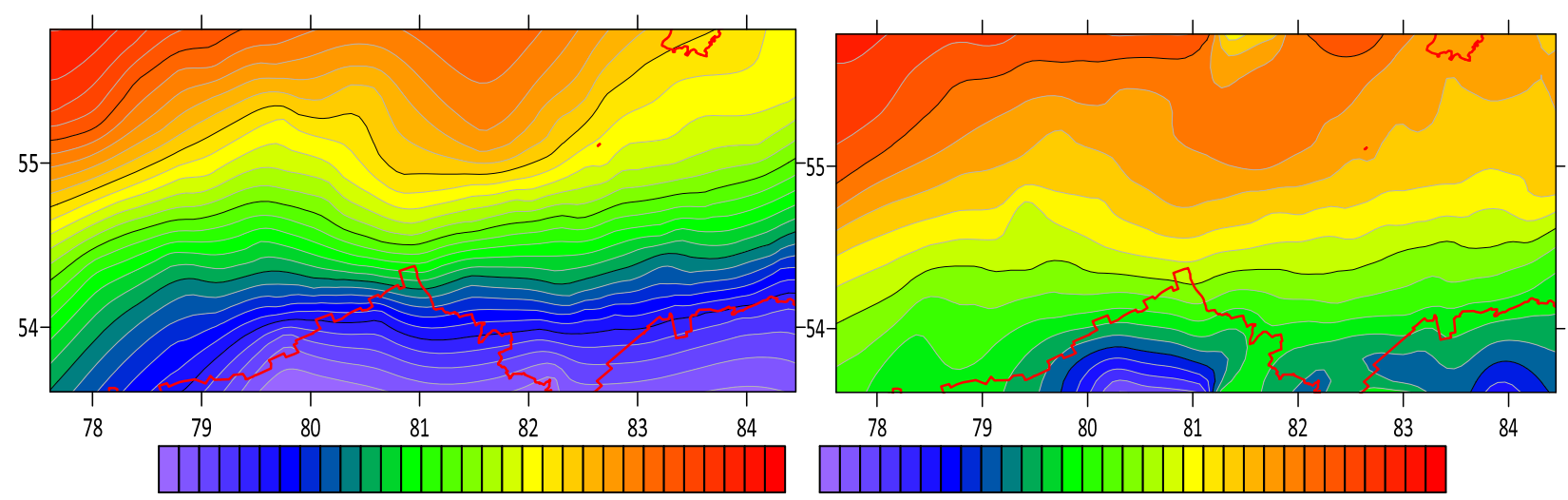

-39.2 -38.6 -38.0 -37.4 -36.8 -36.2 -35.6 -35.0 -34.4 -33.8 -33.2-39.2 -38.6 -38.0 -37.4 -36.8 -36.2 -35.6 -35.0 -34.4 -33.8 -33.2

a)

б)

Рис. 4. Картосхема результатов моделирования аномалий высоты:

a) методом Kriging; б) методом Modified Shepard's Method 


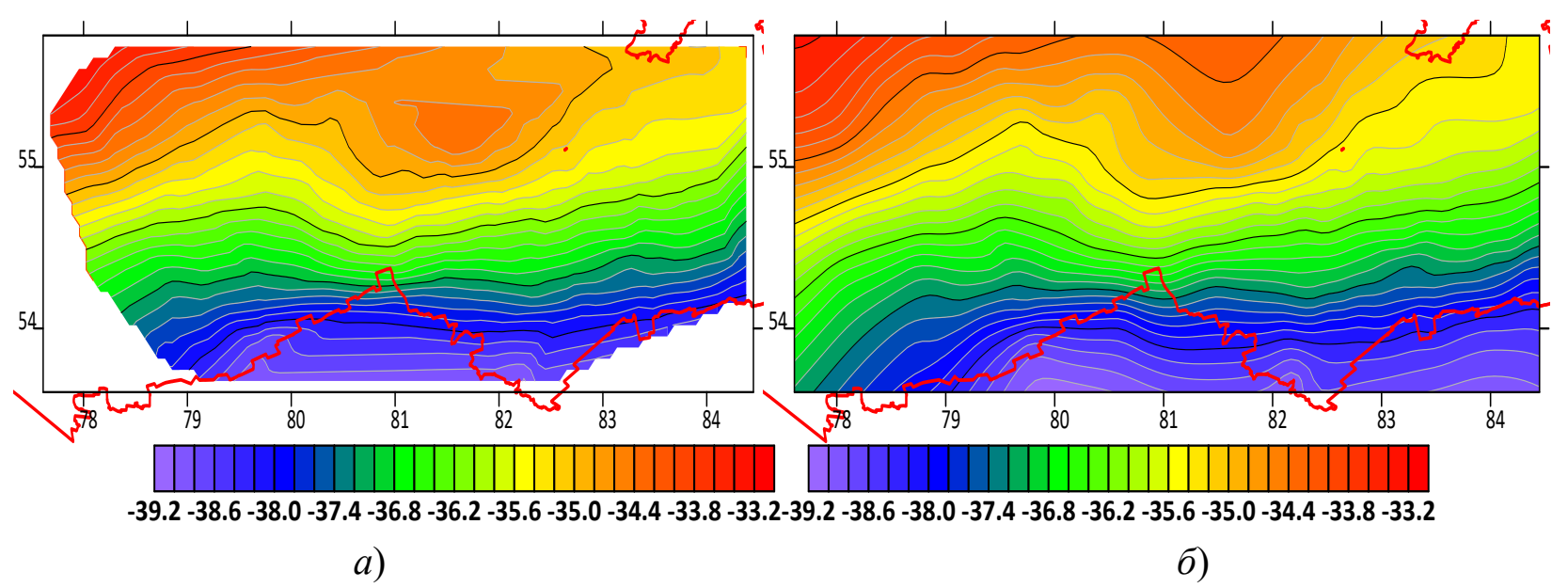

Рис. 5. Картосхема результатов моделирования аномалий высоты:

a) методом Triangulation with Linear Interpolation; б) методом Radial Basis Function

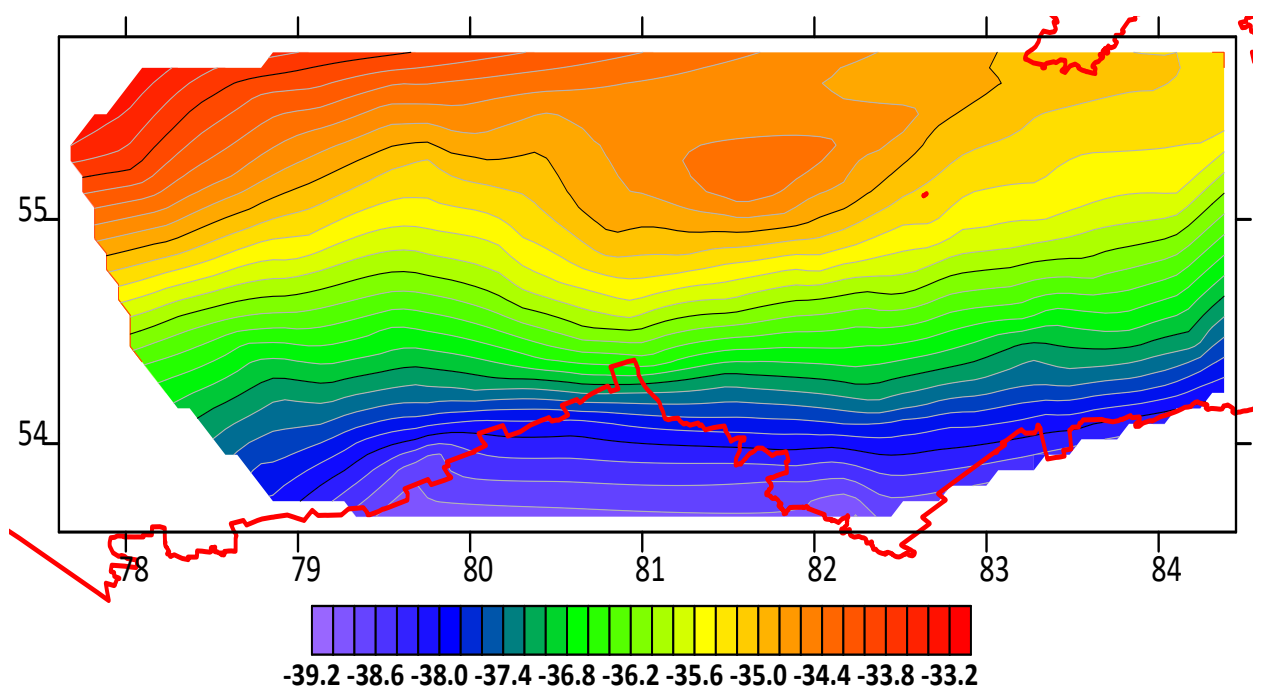

Рис. 6. Картосхема результатов моделирования аномалий высоты при использовании метода Natural Neighbor

В работе выполнено сравнение полученных моделей высот квазигеоида на заданную территорию с исходными данными и выполнен статистический анализ созданных поверхностей. Результаты статистической оценки отклонений исходных точечных значений от модельных данных приведены в таблице.

Анализируя приведенные в таблице статистические параметры распределения разностей между данными, полученными в результате измерений на пунктах исследуемой территории, и значениями, полученными в ре- зультате интерполирования в программном продукте Surfer, можно сделать следующие выводы:

- наименьшее стандартное отклонение получено при использовании методов Modified Shepard's Method (0,005 м при среднем значении $\mathrm{E}=0,0003 \mathrm{м}$ ) и Radial Basis Function $(0,005$ м при среднем значении $\mathrm{E}=0,0000 \mathrm{M})$;

- заслуживают внимания и параметры распределения разностей методом Kriging: стандартное отклонение составило $0,015 \mathrm{~m}$ при среднем значении $\mathrm{E}=-0,0001 \mathrm{M}$. 
Статистическая оценка отклонений исходных точечных значений от результирующей поверхности

\begin{tabular}{|c|c|c|c|c|c|c|c|c|}
\hline $\begin{array}{l}\text { Харак- } \\
\text { теристика }\end{array}$ & 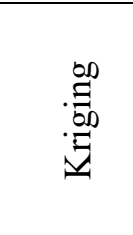 & $\underset{\Xi}{\Xi}$ & 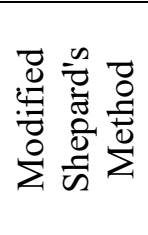 & 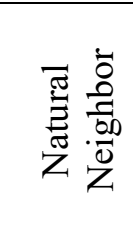 & 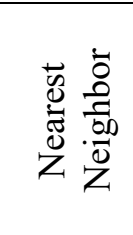 & 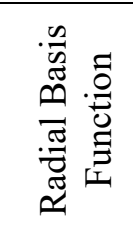 & 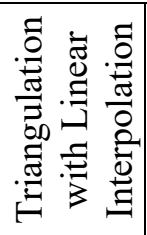 & 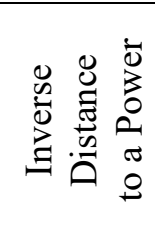 \\
\hline Количество точек & 188 & 188 & 188 & 175 & 188 & 188 & 176 & 188 \\
\hline Минимум, м & $-0,058$ & $-0,061$ & $-0,019$ & $-0,109$ & $-0,037$ & $-0,019$ & $-0,101$ & $-0,329$ \\
\hline Максим & & & & 0,054 & & 0,017 & 0,046 & 0,207 \\
\hline Диапаз & & 0,119 & 0,0 & 0,163 & 0,120 & 0,036 & 0,147 & 0,536 \\
\hline Среднее, м & $-0,0001$ & 0,0018 & 0,0003 & 0,0025 & 0,0002 & 0,0000 & 0,0024 & $-0,0018$ \\
\hline $\begin{array}{l}\text { Стандартное } \\
\text { отклонение, м }\end{array}$ & 0,015 & 0,019 & 0,005 & 0,022 & 0,009 & 0,005 & 0,019 & 0,107 \\
\hline Асимметрия, м & $-0,548$ & 0,136 & $-0,301$ & $-1,071$ & 3,607 & $-0,403$ & $-1,189$ & $-0,675$ \\
\hline Эксцесс, м & 1,255 & 0,509 & 2,763 & 4,438 & 46,733 & 1,403 & 5,203 & 0,111 \\
\hline
\end{tabular}

\section{Выводы. Обсуждения}

Стандартные установки программного продукта Golden Software Surfer предполагают использование метода Kriging, который дает хорошие результаты аппроксимации высот квазигеоида с точностью, позволяющей проводить анализ и интерпретацию полученных результатов для решения геодезических задач.
Для создания картографических произведений характеристик ГПЗ средствами программного продукта Golden Software Surfer методы интерполирования Modified Shepard's Method и Radial Basis Function можно использовать при визуализации аномалии высоты для территорий с преобладанием равнинного рельефа с незначительными перепадами высот.

\section{БИБЛИОГРАФИЧЕСКИЙ СПИСОК}

1. Современные глобальные модели квазигеоида: точностные характеристики и разрешающая способность / В. Ф. Канушин, И. Г. Ганагина, Д. Н. Голдобин, Е. М. Мазурова, Н. С. Косарев, А. М. Косарева // Вестник СГУГиТ. 2017. - T. 22, № 1. - C. 30-46.

2. Сравнение спутниковых моделей проекта GOCE c различными наборами независимых наземных гравиметрических данных / В. Ф. Канушин, И. Г. Ганагина, Д. Н. Голдобин, Е. М. Мазурова, Н. С. Косарев, А. М. Косарева // Вестник СГУГиТ. - 2014. - Вып. 3 (27). - С. 21-34.

3. Исследования спектральных характеристик глобальных моделей гравитационного поля Земли, полученных по космическим миссиям CHAMP, GRACE И GOCE / А. П. Карпик, В. Ф. Канушин, И. Г. Ганагина, Д. Н. Голдобин, Е. М. Мазурова // Гироскопия и навигация. 2014. - № 4 (87). - C. 34-44.

4. Непоклонов В. Б. Об использовании новых моделей гравитационного поля Земли в автоматизированных технологиях изысканий и проектирования [Электронный ресурс] //
Автоматизированные технологии изысканий и проектирования. - 2009. - № 2. - Режим доступа: http://www.credodialogue.com/journal.aspx (дата обращения: 17.03.2020).

5. Непоклонов В. Б., Лидовская Е. А., Спесивцев А. А. Оценка качества моделей гравитационного поля Земли // Изв. вузов. Геодезия и аэрофотосъемка. - 2014. - № 2. - С. 24-32.

6. Виканова А. А. Методы прогнозирования в геоинформационных системах [Электронный ресурс] // Научное сообщество студентов XXI столетия. Технические науки : сб. ст. по мат. IV междунар. студ. науч.-практ. конф. - 2012. - № 4. C. 78-88. - Режим доступа: http://sibac.info/ archive/technic/4.pdf (дата обращения 13.04.2020).

7. Логинов Д. С. Картографическое обеспечение геофизических исследований: современное состояние и перспективы // Геодезия и картография. - 2019. - № 8. - С. 32-44.

8. Логинов Д. С. Отечественный и зарубежный опыт геофизического картографирования // Изв. вузов. Геодезия и аэрофотосъемка. - 2015. № 5. - C. 71-77. 
9. Логинов Д. С. Текущее состояние и перспективы использования ГИС и веб-технологий в геофизическом картографировании : тезисы материалов конференции // Национальная картографическая конференция - 2018. - Москва: Географический факультет Московского государственного университета им. М. В. Ломоносова, 2018. - C. 172-173.

10. Нафикова А. Р., Габбасова Р. И., Рахимова А. Р. Возможности геоинформационной системы QUANTUM GIS // Интеграция наук. 2018. - № 5 (20). - С. 66-67.

11. Черноусова М. В., Ганагина И. Г. Сравнительный анализ создания новых систем координат и инструментов работы с ними в ГИС MapInfo и ArcGIS // Интерэкспо ГЕО-Сибирь2019. XV Междунар. науч. конгр.: сб. материалов в 9 т. (Новосибирск, 24-26 апреля 2019 г.). - Новосибирск : СГУГиТ, 2019. Т. 6, № 1. - С. 101-107.

12. Loginov D. S. Specific features of using GIS atlases in the geophysical mapping // Proceedings of the 6th International Conference on Cartography and GIS (13-17 June 2016). - Albena, Bulgaria, 2016. P. 61-62.

13. Басаргин А. А. Создание цифровых моделей месторождений полезных ископаемых с применением современных технологий // Вестник СГУГиТ. - 2014. - № 1 (25). - С. 34-39.

14. Боярчук М. А., Журкин И. Г., Непоклонов В. Б. Анализ методов визуализации геофизических полей в геоинформационных системах // Изв. вузов. Геодезия и аэрофотосъемка. - 2017. № 1. - С. 108-113.

15. Боярчук М. А., Журкин И. Г., Непоклонов В. Б. Концепция графического метода отображения гравитационного поля Земли на плоскости // Научная визуализация. - 2019. - Т. 1, № 1. C. $70-79$.

16. Васильев В. В., Васильева Е. Г., Теплякова Е. А. Геофизическое картирование арктического шельфа для составления геофизических основ Госгеолкарты-1000 // Разведка и охрана недр. - 2007. - № 9. - С. 64-69.

17. Геоинформационные технологии для природопользования [Электронный ресурс] // ГИС INTEGRO. - Режим доступа: http://www.gisintegro.ru/geophysic/ (дата обращения: 13.03.2020).

18. Логинов Д. С. Применение геоинформационных технологий в геофизическом картографировании // Славянский форум. - 2015. - № 4 (10). C. $192-201$.

19. Годжаманов М. Г. Методика построения детальной карты высот квазигеоида на территории Азербайджана // Baki universitetinin xəbərləri. 2008. - № 1. - C. 169-173.
20. Годжаманов М. Г. Разработка современных технологий реконструкции и развития государственной геодезической сети с учетом особенностей территории Азербайджанской Республики : автореф. дис. ... д-ра техн. наук. - М., 2005. $-48 \mathrm{c}$.

21. Долгаль А. С. Компьютерные технологии обработки и интерпретации данных гравиметрической и магнитной съемок в горной местности. Абакан: ООО Фирма «Март», 2002. - 188 с.

22. Карта абсолютных значений поля силы тяжести территории Украины и некоторые аспекты ее возможной интерполяции / В. А. Ентин, С. И. Гуськов, М. И. Орлюк, О. Б. Гинтов, Р. В. Осьмак // Геофизический журнал. - 2015. T. 37, № 1. - С. 53-63.

23. Васильев В. В. Актуализация гравиметрических данных на Западно-Арктическом шельфе с использованием геоинформационных технологий // Геоинформатика. - 2009. - № 2. C. 41-47.

24. Мазурова Е. М., Огиенко С. А. Отображение геодезических данных в ArcGIS // Изв. вузов. Геодезия и аэрофотосъемка. - 2013. - № 5. С. 34-42.

25. Огородова И. В. Использование ГИСтехнологий для трехмерной визуализации геофизической информации // Геофизика. - 2016. № 5. - C. 32-46.

26. Алексеева М. Л., Кривошеев Д А. Расширенные возможности автоматизации геообработки на примере ESRI ArcGIS // Информационные технологии. Проблемы и решения: мат. междунар. научно-практической конференции. - Уфа : УГНТУ, 2014. - № 1-1 (1). - С. 46-49.

27. Симанов А. А. Информационноаналитическая система обработки материалов гравиметрических съемок // Материалы 33-й сессии Международного семинара им. Д. Г. Успенского. - Екатеринбург : Институт геофизики УрО PAH, 2006. - C. 328-330.

28. Симанов А. А., Пугин А. В. Применение современных геоинформационных технологий при хранении и обработке геолого-геофизических данных // ГЕО-Сибирь-2006. II Междунар. науч. конгр.: сб. материалов в 6 т. (Новосибирск, 13-25 апреля 2006 г.). - Новосибирск : СГГА, 2006. Т. 3, ч. 1. - С. 159-163.

29. Крылов В. И., Яшкин С. Н. Кватернионы и их использование в теории вращений пространств // Изв. вузов. Геодезия и аэрофотосъемка. - 2016. - № 6. - С. 3-6.

30. Программное обеспечение для геофизики [Электронный ресурс] // Азимут геология: геолого-геофизическая компания. - Режим доступа: 
http://azimut-geology.kz/program_geo/ (дата обращения: 17.03.2020).

31. Спиридонов В. А. Экспертное редактирование при автоматизированном создании геологических карт // Геоинформатика. - 2005. - № 1. C. 7-13.

32. Черемисина Е. Н., Финкельштейн М. Я., Любимова А. В. ГИС INTEGRO - импортозамещающий программно-технологический комплекс для решения геолого-геофизических задач // Геоинформатика. - 2018. - № 3. - С. 8-17.

33. Шумихин А. С. Особенности архитектуры ГИС INTEGRO // Геоинформатика. - 2018. № 3. - C. 68-75.

34. Бусыгин Б. С., Никулин С. Л., Бойко В. А. Геоинформационная система РАПИД как средство мониторинга и прогнозирования чрезвычайных ситуаций: сб. трудов 9 Междунар. конф. «Стихия-2006». - Севастополь : СНУЯЕтаП, 2006. - C. 21-33.

35. Бусыгин Б. С., Никулин С. Л., Бойко В. А. ГИС-технология поисков золота в Западном Узбекистане // Геоінформатика. - 2006. - № 1. C. $44-49$.

36. Бусыгин Б. С., Никулин С. Л. Специализированная геоинформационная система РАПИД: структура, технология, задачи // Геоінформатика. - 2016. - № 1 (57). - С. 22-36.

37. Геоинформационная система интегрированного анализа разнородных и разноуровНаціональний ТУ «Дніпровська політехніка». відповідність Часу. - Режим доступа: $\mathrm{http} / / /$ science.nmu.org.ua/ru/ndc/int. невых данных РАПИД [Электронный ресурс] //

scien_projects/horizont20200/14.php. (дата обращения: 18.03.2020).

38. Пивняк Г. Г., Бусыгин Б. С., Никулин С. Л. ГИС-технология интегрированного анализа разнородных и разноуровневых геоданных // Доповіді Національної академії наук України. 2007. - № 7. - С. 121-128.

39. Ермолаев Н. Р. Использование программного обеспечения QGIS при подготовке картографического материала // Ломоносов-2018 : тезисы докладов XXV Междунар. научной конф. студ., аспирантов и молодых ученых. - М. : ООО «МАКС Пресс», 2018. - С. 250-251.

40. Дреева Ф. Р, Реутова Н. В., Реутова Т. В. Решение задач картографирования гидрохимической информации с помощью геоинформационной системы Surfer // Изв. Кабардино-Балкар ского научного Центра РАН. - 2018. - № 5 (85). C. $12-17$.

41. Мыслыва Т. Н., Куцаева О. А., Подлесный А. А. Сравнение эффективности методов интерполяции на основе ГИС для пространственного распределения гумуса в почве // Вестник Белорусской государственной сельскохозяйственной академии. - 2017. - № 4. - С. 146-152.

42. Крюкова С. В., Симакина Т. В. Оценка методов пространственной интерполяции метеорологических данных // Общество. Среда. Развитие (Terra Humana). - 2018. - № 1. - С. 144-151.

43. Мальцев К. А., Мухарамова С. С. Построение моделей пространственных переменных (с применением пакета Surfer) : учеб. пособие. - Казань : Казанский университет, 2014. $103 \mathrm{c}$.

Получено 21.04.2020

(C) И. Г. Ганагина, Д. С. Челнокова, Д. Н. Голдобин, 2020

\section{CREATION OF A QUASIGEOID MODEL ON A LOCAL SECTION BY GIS MEANS}

\section{Irina G. Ganagina}

Siberian State University of Geosystems and Technologies, 10, Plakhotnogo St., Novosibirsk, 630108, Russia, Ph. D., Associate Professor, Head of the Department of Space and Physical Geodesy, e-mail: gam0209@yandex.ru

\section{Darya S. Chelnokova}

Siberian State University of Geosystems and Technologies, 10, Plakhotnogo St., Novosibirsk, 630108, Russia, Master Student, phone: (905)956-44-74, e-mail: sergeevna0403@gmail.com

\section{Denis N. Goldobin}

Siberian State University of Geosystems and Technologies, 10, Plakhotnogo St., Novosibirsk, 630108, Russia, Engineer, Department of Space and Physical Geodesy, e-mail: phis.geo.sggs@gmail.com 
The capabilities of fully functional geographic information systems used in various fields make it possible to simulate the characteristics of the gravitational field, presenting measuring information in the form of continuous surfaces, thereby expanding the area of use of data on the Earth's gravitational field. An important stage of visualization is the choice of a method of interpolating data that provides the highest possible accuracy in creating a digital model of the studied characteristic of the gravitational field. The authors developed a technology for choosing the optimal method for interpolating the characteristics of the Earth's gravitational field in a GIS to create models with an assessment of their accuracy according to the initial data, presented in the form of a technological scheme. The possibilities of the Golden Software Surfer software product for creating a model of quasi-geoid heights from the unevenly presented satellite and geometric leveling data in the study area are considered. A method for interpolating the heights of a quasi-geoid in Golden Software Surfer is proposed, a model of a quasi-geoid in a local area is created. An assessment of the accuracy of the created model according to the initial data is performed.

Key words: approximation of the source data, geographic information systems, geospatial modeling, interpolation methods, Earth's gravitational field, quasigeoid height.

\section{REFERENCES}

1. Kanushin, V. F., Ganagina, I. G., Goldobin, D. N., Mazurova, E. M., Kosarev, N. S., \& Kosareva A. M. (2017). Modern global quasigeoid models: accuracy characteristics and resolving power. Vestnik SGUGiT [Vestnik SSUGT], 22(1), 30-46 [in Russian].

2.Kanushin, V. F., Ganagina, I. G., Goldo bin, D. N., Mazurova, E. M., Kosarev, N. S., \& Kosareva A. M. (2014). Comparison of satellite models of the GOCE project with various sets of independent ground-based gravity data. Vestnik SGUGiT [Vestnik SSUGT], 3(27), 21-34 [in Russian].

3. Karpik, A. P., Kanushin, V. F., Ganagina, I. G., Goldobin, D. N., \& Mazurova,E. M. (2014). Studies of the spectral characteristics of global models of the Earth's gravitational field obtained from the space missions CHAMP, GRACE and GOCE. Giroskopiya i navigatsiya [Gyroscopy and Navigation], 4(87), 34-44 [in Russian].

4. Nepoklonov, V. B. (2009). On the use of new models of the Earth's gravitational field in automated technologies for research and design. Avtomatizirovannye tekhnologii izyskaniy i proektirovaniya [Automated Technologies for Research and Design], 2. Retrieved from: http://www.credodialogue.com/ journal.aspx (accessed 17.03.2020) [in Russian].

5. Nepoklonov, V. B., Lidovskaya, E. A., \& Spesivtsev, A. A. (2014). Estimation of the quality of models of the Earth's gravitational field. Izvestiya vuzov. Geodeziya i aerofotos"emka [Izvestiya Vuzov. Geodesy and Aerophotography], 2, 24-32 [in Russian].

6. Vikanova, A. A. (2012). Methods of forecasting in geographic information systems (n. d.). In Sbornik materialov IV mezhdunarodnoy studencheskoy nauchno-prakticheskoy konferentsii: Vol. 4.
Nauchnoye soobshchestvo studentov XXI stoletiya. Tekhnicheskiye nauki [Proceedings of IV International Student Scientific and Practical Conference: Vol. 4. Scientific Community of Students of the XXI Century. Technical Sciences] (pp. 78-88). Retrieved from http://sibac.info/archive/technic/4.pdf (accessed 13.04.2020) [in Russian].

7. Loginov, D. S. (2019). Cartographic support of geophysical research: current status and prospects. Geodeziya i Kartografiya [Geodesy and Cartography], 8, 32-44 [in Russian].

8. Loginov, D. S. (2015). Domestic and foreign experience of geophysical mapping. Izvestiya vuzov. Geodeziya i aerofotos"emka [Izvestiya Vuzov. Geodesy and Aerophotography], 5, 71-77 [in Russian].

9. Loginov, D. S. (2018). Current status and prospects for the use of GIS and web technologies in geophysical mapping: abstracts of conference materials. In Sbornik tezisov Natsional'noi kartograficheskoi konferentsii - 2018 [Collection abstracts of National Cartographic Conference - 2018] (pp. 172-173). Moscow: Geography Department of Moscow State University named after M.V. Lomonosov Publ. [in Russian].

10. Nafikova, A. R., Gabbasova, R. I., \& Rakhimova, A. R. (2018). Possibilities of the geographic information system QUANTUM GIS. Integraciya nauk [Integration of Sciences], 5(20), 66-67 [in Russian].

11. Chernousova, M. V., \& Ganagina, I. G. (2019). Comparative analysis of the creation of new coordinate systems and tools for working with them in the GIS MapInfo and ArcGIS. In Sbornik materialov Interekspo GEO-Sibir'-2019: Mezhdunarodnoy nauchnoy konferentsii: T. 6, ch. 1. Magisterskaya nauchnaya sessiya "Pervyye shagi v nauke" [Proceedings of Interexpo GEO-Siberia-2019: International 
Scientific Conference: Vol. 6, Part 1. Master's Scientific Session "First Steps in Science"] (pp. 101-107). Novosibirsk: SSUGT Publ. [in Russian].

12. Loginov, D. S. (2016). Specific features of using GIS atlases in the geophysical mapping. Production of the 6th International Conference on Cartography and GIS (pp. 61-62). Albena, Bulgaria.

13. Basargin, A. A. (2014). Creation of digital models of mineral deposits using modern technologies. Vestnik SGUGiT [Vestnik SSUGT], 1(25), 34-39 [in Russian].

14. Boyarchuk, M. A., Zhurkin, I. G., \& Nepoklonov, V. B. (2017). Analysis of visualization methods of geophysical fields in geographic information systems. Izvestiya vuzov. Geodeziya $i$ aerofotos"emka [Izvestiya Vuzov. Geodesy and Aerophotography], 1, 108-113 [in Russian].

15. Boyarchuk, M. A., Zhurkin, I. G., \& Nepoklonov, V. B. (2019). The concept of the graphical method for displaying the Earth's gravitational field on the plane. Nauchnaya vizualizaciya [Scientific Visualization], 1(1), 70-79 [in Russian].

16. Vasiliev, V. V., Vasielieva, E. G., \& Teplyakova, E. A. (2007). Geophysical mapping of the Arctic shelf for the compilation of geophysical foundations of the State Geological Map-1000. Razvedka i ohrana nedr [Exploration and Mineral Protection], 9, 64-69 [in Russian].

17. Geoinformation technologies for nature management (n. d.). Retrieved from http://www.gisintegro.ru/geophysic/ (accessed 13.03.2020) [in Russian].

18. Loginov, D. S. (2015). Application of geographic information technologies in geophysical mapping. Slavyanski forum [Slavic Forum], 4(10), 192-201 [in Russian].

19. Gojamanov, M. G. (2008). Method for constructing a detailed map of the heights of a quasigeoid on the territory of Azerbaijan. Baki universitetinin xabarlari [News of Baku University], 1, 169-173 [in Russian].

20. Godzhamanov, M. G. (2005). Development of modern technologies for reconstruction and development of the state geodetic network, taking into account the characteristics of the territory of the Republic of Azerbaijan. Extended abstract of doctoral thesis. Moscow, 48 p. [in Russian].

21. Dolgal, A. S. (2002). Komp'yuternyye tekhnologii obrabotki $i$ interpretatsii dannykh gravimetricheskoy $i$ mag-nitnoy $s^{\prime \prime y e m o k} v$ gornoy mestnosti [Computer technology for processing and interpreting data of gravimetric and magnetic surveys in mountainous areas]. Abakan: LLC Firm Mart Publ., 188 p. [in Russian].
22. Entin, V. A., Guskov, S. I., Orlyuk, M. I., Gintov, O. B., \& Osmak, R. V. (2015). Map of the absolute values of the gravity field of the territory of Ukraine and some aspects of its possible interpolation. Geofizicheskiy zhurnal [Geophysical Journal], 37(1), 53-63 [in Russian].

23. Vasiliev, V. V. (2009). Actualization of gravimetric data on the West Arctic shelf using geoinformation technologies. Geoinformatika [Geoinformatics], 2, 41-47 [in Russian].

24. Mazurova, E. M., \& Ogienko, S. A. (2013). Mapping of geodetic data in ArcGIS. Izvestiya vuzov. Geodeziya i aerofotos"emka [Izvestiya Vuzov. Geodesy and Aerophotography], 5, 34-42 [in Russian].

25. Ogorodova, I. V. (2016). Use of GIStechnologies for three-dimensional visualization of geophysical information. Geofizika [Geophysics], 5, 32-46 [in Russian].

26. Alekseeva, M. L., \& Krivosheev, D. A. (2014). Advanced capabilities for automating geoprocessing using ESRI ArcGIS as an example. In Sbornik materialov mezhdunarodnoy nauchnoprakticheskoy konferentsii: No 1-1 (1). Informatsionnyye tekhnologii. Problemy $i$ resheniya [Proceedings of International Scientific and Practical Conference: No 1-1 (1). Information Technology. Problems and Solutions] (pp. 46-49). Ufa: UGNTU Publ. [in Russian].

27. Simanov, A. A. (2006). Information-analytical system for processing materials of gravimetric surveys. In Materialy 33-y sessii Mezhdunarodnogo seminara imeni $D$. G. Uspenskogo [Proceedings of the $33 r d$ Session of the International Seminar named after D. G. Uspensky]. (pp. 328-330). Yekaterinburg: Institute of Geophysics, Ural Branch of the Russian Academy of Sciences Publ. [in Russian].

28. Simanov, A. A., \& Pugin, A. V. (2006). The use of modern geoinformation technologies in the storage and processing of geological and geophysical data. In Sbornik materialov GEO-Sibir'-2006: T. 3, ch. 1 [Proceedings of GEO-Siberia-2006: Vol. 3, Part. 1] (pp. 159-163). Novosibirsk: SSGA Publ. [in Russian].

29. Krylov, V. I., \& Yashkin, S. N. (2016). Quaternions and their use in the theory of rotations of spaces. Izvestiya vuzov. Geodeziya i aerofotos"emka [Izvestiya Vuzov. Geodesy and Aerophotography], 6, 3-6 [in Russian].

30. Software for geophysics (n. d.). Retrieved from: http://azimut-geology.kz/program_geo/. (accessed 03/17/2020) [in Russian].

31. Spiridonov, V. A. (2005). Expert editing in automated creation of geological maps. Geoinformatika [Geoinformatics], 1, 7-13 [in Russian]. 
32. Cheremisina, E. N., Finkelshtein, M. Ya., \& Lyubimova, A. V. (2018). GIS INTEGRO - an import-substituting software and technology complex for solving geological and geophysical problems. Geoinformatika [Geoinformatics], 3, 8-17 [in Russian].

33. Shumikhin, A. S. (2018). Features of the GIS architecture INTEGRO. Geoinformatika [Geoinformatics], 3, 68-75 [in Russian].

34. Busygin, B. S., Nikulin, S. L., \& Boyko, V. A. (2006). Geographic information system RAPID as a means of monitoring and forecasting emergencies. In Sbornik trudov 9 Mezhdunarodnoy konferentsii "Stikhiya-2006" [Proceedings of the 9th International Conference "Element 2006"] (pp. 21-33). Sevastopol: SNUYaETAP Publ. [in Russian].

35. Busygin, B. S., Nikulin, S. L., \& Boyko, V. A. (2006). GIS technology for gold prospecting in Western Uzbekistan. Geoinformatika [Geoinformatics], 1, 44-49 [in Russian].

36. Busygin, B. S., \& Nikulin, S. L. (2016). Specialized geographic information system RAPID: structure, technology, tasks. Geoinformatika [Geoinformatics], 1(57), 22-36 [in Russian].

37. Geoinformation system of integrated analysis of heterogeneous and multilevel data RAPID (n. d.). Retrieved from: http://science.nmu.org.ua/en/ndc/ int_scien_projects/horizont 20200/14.php. (accesses 18.03.2020) [in Russian].

38. Pivnyak, G. G., Busygin, B. S., \& Nikulin, S. L. (2007). GIS-technology for integrated analysis of heterogeneous and multilevel geodata. Dopovidi Natsional'noyi akademiyi nauk Ukrayiny [Additional National Academy of Sciences of Ukraine], 7, 121-128 [in Russian].
39. Ermolaev, N. R. (2018). The use of QGIS software in the preparation of cartographic material. In Tezisy dokladov XXV Mezhdunarodnoy nauchnoy konferentsii studentov, aspirantov $i$ molodykh uchenykh: Lomonosov-2018 [Abstracts of XXV International Scientific Conference of Students, Graduate Students and Young Scientists: Lomonosov2018 Reports] (pp. 250-251). Moscow: LLC MAX Press Publ. [in Russian].

40. Dreeva, F. R, Reutova, N. V., \& Reutova, T. V. (2018). Solution of the problems of mapping hydro-chemical information using the Surfer geographic information system. Izvestiya KabardinoBalkarskogo nauchnogo Tsentra RAN [Bulletin of the Kabardino-Balkarian Scientific Center of the Russian Academy of Sciences], 5(85), 12-17 [in Russian].

41. Myslyva, T. N., Kutsaeva, O. A., \& Podlesny, A. A. (2017). Comparison of the efficiency of GIS-based interpolation methods for the spatial distribution of humus in soil. Vestnik Belorusskoy Gosudarstvennoy sel'skokhozyaystvennoy akademii [Bulletin of the Belarusian State Agricultural Academy], 4, 146-152 [in Russian].

42. Kryukova, S. V., \& Simakina, T. V. (2018). Evaluation of spatial interpolation methods for meteorological data. Obshchestvo. Sreda. Razvitiye [Society. Wednesday. Development], 1, 144-151 [in Russian].

43. Maltsev, K. A., \& Mukharamova, S. S. (2014). Postroyeniye modeley prostranstvennykh peremennykh (s primeneniyem paketa Surfer) [Construction of models of spatial variables (using the Surfer package)]. Kazan: Kazan University Publ., 103 p. [in Russian].

Received 21.04.2020 
УДК 528.06.1:629.783

DOI: $10.33764 / 2411-1759-2020-25-3-26-33$

\section{ОЦЕНКА ТОЧНОСТИ ОПРЕДЕЛЕНИЯ КООРДИНАТ СПУТНИКОВЫМИ ПРИЕМНИКАМИ ЕFТ M3 GNSS И EFT M4 GNSS B PЕЖИМЕ RTK}

\section{Александр Викторович Елагин}

Сибирский государственный университет геосистем и технологий, 630108, Россия, г. Новосибирск, ул. Плахотного, 10, кандидат технических наук, доцент кафедры космической и физической геодезии, тел. (383)361-01-59, e-mail: kaf.astronomy@ssga.ru

\section{Михаил Викторович Зайцев}

ООО «Эффективные технологии Центр», 630048, Россия, г. Новосибирск, пл. Маркса, 7, инженер, тел. (383)383-23-71, e-mail: zmv@eftgroup.ru

\section{Дмитрий Анатольевич Прохоров}

ООО «Эффективные технологии Центр», 630048, Россия, г. Новосибирск, пл. Маркса, 7, руководитель регионального представительства, тел. (383)383-23-71, e-mail: nsk@eftgroup.ru

\section{Николай Кириллович Шендрик}

Сибирский государственный университет геосистем и технологий, 630108, Россия, г. Новосибирск, ул. Плахотного, 10, зав. лабораторией кафедры космической и физической геодезии, тел. (383)361-01-59, e-mail: kaf.astronomy@ssga.ru

В работе представлены результаты тестирования спутниковых приемников EFT M3 GNSS и EFT M4 GNSS в режиме «Real Time Kinematic» (RTK). На десяти пунктах вблизи постоянно действующей базовой станции NSKW были выполнены измерения в режиме RTK тестируемыми приемниками и в режиме «статика» приемником Trimble 5700. Кроме этого, определены нормальные высоты пунктов из нивелирования II класса нивелиром Н-05. Пункты удалены от базовой станции на расстояния от 39 до 1227 м. Оценка точности выполнена по разностям двойных неравноточных измерений в режиме RTK и «Статика». Для дополнительного контроля оценки точности определения высот использованы разности нормальных и геодезических высот. В работе показано, что средняя квадратическая погрешность измерений в режиме RTK не превосходит 16 мм в плане и по высоте. В режиме RTK современные ГНСС-приемники EFT M3 GNSS и EFT M4 GNSS позволяют достичь сантиметрового уровня точности определения пространственных координат пунктов. Погрешности тестируемых приемников в режиме RTK сопоставимы.

Ключевые слова: ГНСС, RTK, статика, оценка точности, геометрическое нивелирование.

\section{Введение}

В настоящее время развитая сеть базовых станций и современная спутниковая аппаратура в совокупности позволяют в режиме RTK почти мгновенно получать координаты на сантиметровом уровне точности [1-13]. Группа компаний EFT GROUP предоставила Сибирскому государственному университету геосистем и технологий (СГУГиТ) два ГНССприемника последних моделей ЕFT M3 GNSS (M3) и EFT M4 GNSS (M4) для их тестирования в режиме RTK и оказала непосредственное содействие в проведении изме- рений. Для оценки точности определения координат в мае-июне 2019 г. в режиме RTK были выполнены измерения приемниками M3 и M4, а в режиме «Статика» - приемником Trimble 5700 (Т). Были измерены геодезические широты, долготы, высоты и нормальные высоты на десяти пунктах, удаленных от базовой станции NSKW на расстояния от 39 до 1227 м. Измерения выполнены во время учебных практик обучающимися групп БГ-31 и МГ-11.

Оценка точности произведена по разностям двойных неравноточных измерений $[14,15]$. Для внешнего контроля точности определе- 
ния высот нивелиром Н-05 (N) были определены нормальные высоты с использованием методики геометрического нивелирования II класса. Схема сети представлена на рис. 1.

В табл. 1 показаны априорные значения средних квадратических погрешностей (СКП)
ГНСС-приемников и нивелира.

Средние квадратические погрешности ГНСС-приемников M3, M4 и Т взяты с сайтов производителей аппаратуры (http://www.eftsurvey.ru, http://www.trimble.com), а СКП нивелирования II класса - из работы [14].

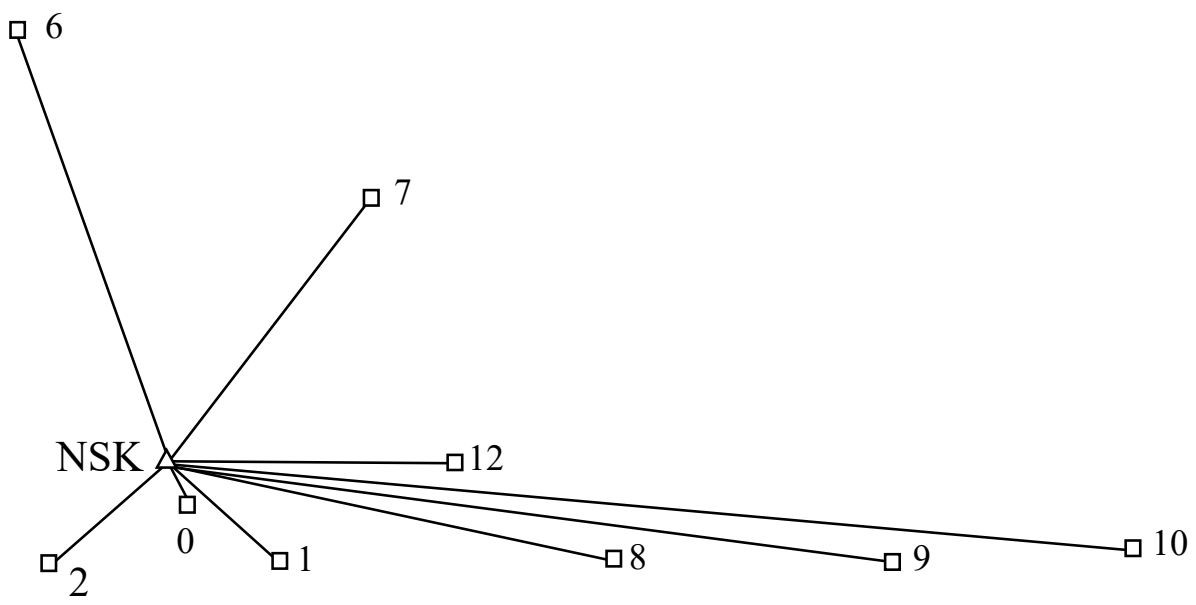

Рис. 1. Схема геодезической сети:

$\Delta-$ базовая станция геодезической сети; $\square$ - пункт геодезической сети

Таблица 1

Априорные значения средних квадратических погрешностей измерений ГНСС-приемников и нивелира

\begin{tabular}{|c|c|c|c|c|}
\hline Инструмент & $\begin{array}{l}\text { Сокращ. } \\
\text { назв. }\end{array}$ & $\begin{array}{l}\text { Режим работы } \\
\text { в эксперименте }\end{array}$ & $\begin{array}{c}\text { Априорная СКП } \\
\text { в плане } m_{p l}=\bar{a}+\bar{b} \cdot S\end{array}$ & $\begin{array}{c}\text { Априорная СКП } \\
\text { по высоте } m_{h}=\bar{a}+\bar{b} \cdot S\end{array}$ \\
\hline $\begin{array}{c}\text { EFT M3 } \\
\text { GNSS }\end{array}$ & M3 & RTK & $\pm 8 \mathrm{мм}+1 \mathrm{Mм} / \mathrm{\kappa м}$ & $\pm 15 \mathrm{мм}+1 \mathrm{мм} / \mathrm{км}$ \\
\hline $\begin{array}{c}\text { EFT M4 } \\
\text { GNSS }\end{array}$ & M4 & RTK & $\pm 5 \mathrm{мм}+0,5 \mathrm{мм} / \mathrm{км}$ & $\pm 10 \mathrm{Mм}+0,8 \mathrm{MM} / \mathrm{Kм}$ \\
\hline $\begin{array}{c}\text { Trimble } \\
5700\end{array}$ & $\mathrm{~T}$ & Статика & $\pm 5 \mathrm{мм}+0,5 \mathrm{мм} / \mathrm{км}$ & $\pm 5 \mathrm{MM}+1 \mathrm{Mм} / \mathrm{KM}$ \\
\hline $\begin{array}{c}\text { Нивелир } \\
\text { Н-05 }\end{array}$ & $\mathrm{N}$ & $\begin{array}{l}\text { Нивелирование } \\
\text { II класса }\end{array}$ & - & $\pm 3,6$ мм/км \\
\hline
\end{tabular}

\section{Методика измерений}

Приемник М3 устанавливался над пунктами по уровню на вешке с биподом. Это позволяло фиксировать его во время измерений и не держать в руках.

Второй приемник M4 устанавливался по уровню на простой вешке и без жесткой фиксации во время измерений. Измерения на каждом пункте длились приблизительно 10 секунд.
При измерении приемником Т в режиме «Статика» антенна приемника устанавливалась на штативе с трегером, который центрировался над пунктами с помощью оптического центрира. Измерения на каждом пункте в режиме «Статика» выполнялись в течение одного часа.

Нивелирование II класса выполнялось нивелиром $\mathrm{N}$ по инварным трехметровым рейкам в прямом и обратном направлениях. Пункт Т0 расположен на земной поверхно- 
сти на расстоянии 39 м в плане от базовой станции NSKW, которая находится на крыше здания СГУГиТ. Для передачи нормальной высоты с пункта T0 на пункт NSKW использовалось геодезическое превышение высот, измеренное в статике спутниковым приемником T.
По априорным данным уклонение отвесной линии на пункте NSKW не превышает 3" [2]. При таком УОЛ предварительные расчеты показали, что погрешность передачи высоты не превысила 1 мм.

Процесс измерений приемниками М3 и Т показан на рис. 2.
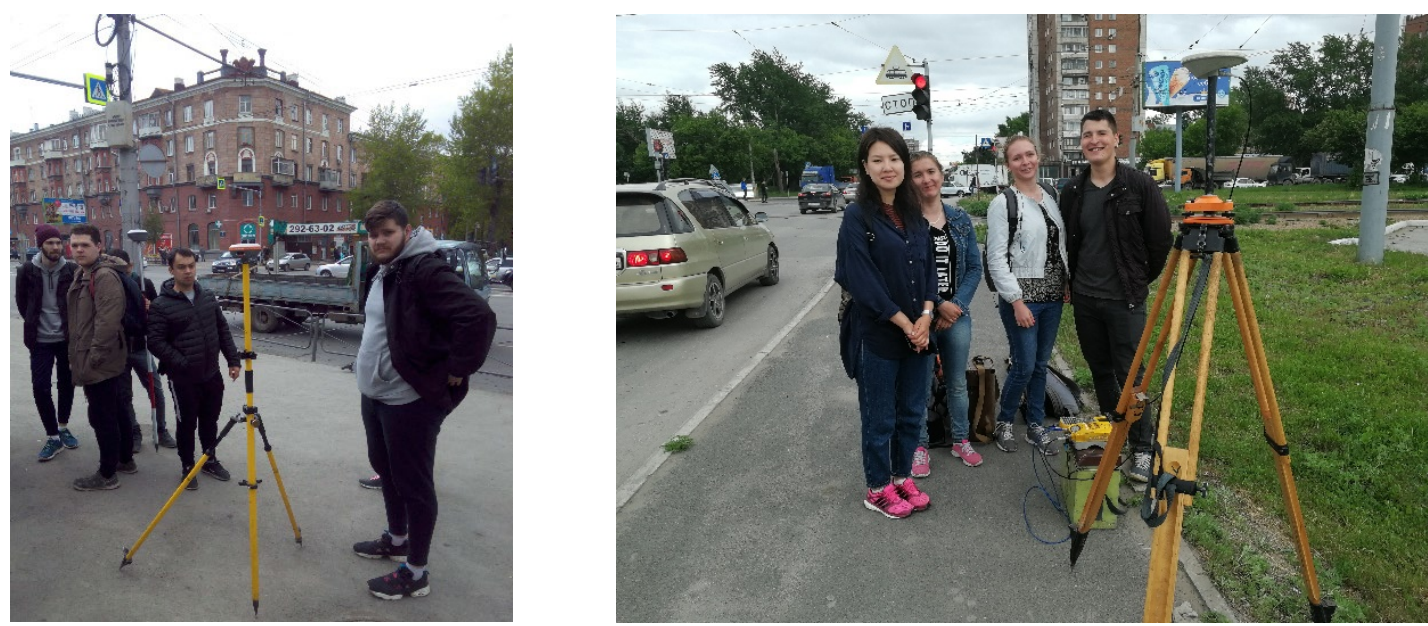

Рис. 2. Измерения приемниками М3 и Т

\section{Оценка точности}

Вычисление СКП единицы веса $\mu$ выполнялось по разностям двойных неравноточных измерений $d_{i}$ на девяти пунктах по формулам [15-26]:

$$
\begin{gathered}
d_{i}=l_{i}^{\prime \prime}-l_{i}^{\prime} ; \\
\omega=\frac{[d]}{[S]} ; \\
\varepsilon_{i}=d_{i}-\omega \cdot S_{i}, \quad i=1,2, \ldots, 9 ; \\
\mu= \pm \sqrt{\frac{\left[P_{d} \cdot \varepsilon^{2}\right]}{n-1}},
\end{gathered}
$$

где $l_{i}^{\prime \prime}, l_{i}^{\prime}-$ неравноточные измерения, выполненные двумя приемниками в каждой точке; $\omega$ - систематическая погрешность на 1 км; $S_{i}$ - расстояние от базовой станции до пунктов сети; $\varepsilon$ - разность с исключенными систематическими погрешностями; $P_{d}-$ веса разностей измерений; $n$ - число разностей.
Веса разностей находились из выражений

$$
P_{d_{i}}=\frac{p_{i}^{\prime} \cdot p_{i}^{\prime \prime}}{p_{i}^{\prime}+p_{i}^{\prime \prime}}, \quad i=1,2, \ldots, 9 .
$$

В формуле (5) на место $p_{i}^{\prime}$ подставлялись веса измерений приемников М3 или M4, а на место $p_{i}^{\prime \prime}$ вес измерения приемником Т либо вес нормальной высоты, полученной из нивелирования II класса. Веса измерений определялись по априорным СКП, представленным в табл. 1. Вес уменьшался в связи с увеличением СКП при удалении от базовой станции и определялся из соотношений

$$
\begin{gathered}
m^{\prime} \text { или } m_{i}^{\prime \prime}=\bar{a}+\bar{b} \cdot S_{i}, \\
p_{i}^{\prime}=\frac{m_{1}^{\prime 2}}{m_{i}^{\prime 2}}, \quad p_{i}^{\prime \prime}=\frac{m_{1}^{\prime 2}}{m_{i}^{\prime 2}}, \quad i=1,2, \ldots, 9,
\end{gathered}
$$

где $\bar{a}$ и $\bar{b}$ - выбирались, в зависимости от используемых приемников, из табл. 1 .

Веса измерений приемников M3 и M4 на пункте 6 , при $i=1$, принимались за единицу. После определения СКП единицы веса из 
выражений (1)-(7), СКП измерения координат пунктов сети приемниками M3 и M4 определялись по формуле

$$
m_{i}^{\prime}=\frac{\mu}{\sqrt{p_{i}^{\prime}}}, i=1,2, \ldots, 9 .
$$

Разностями измерений являлись разности геодезических широт, долгот, высот и разности нормальных высот:

$$
\begin{gathered}
\Delta B_{i}=B_{i}^{\prime \prime}-B_{i}^{\prime} ; \quad \Delta L_{i}=L_{i}^{\prime \prime}-L_{i}^{\prime} ; \\
\Delta h_{i}=H_{i}^{\prime \prime}-H_{i}^{\prime} ; \quad \Delta h n_{i}=H_{i}^{\gamma}-\left(H_{i}^{\prime}-\zeta\right),
\end{gathered}
$$

где $\zeta$ - высота квазигеоида на базовой станции NSKW.

Для наглядности, разности геодезических широт и долгот преобразованы в линейные величины $\Delta x$ и $\Delta y$ с использованием соотношений

$$
\begin{gathered}
M_{i}=\frac{a\left(1-e^{2}\right)}{\left(1-e^{2} \sin ^{2} B_{i}^{\prime \prime}\right)^{\frac{3}{2}}} ; \quad N_{i}=\frac{a}{\sqrt{1-e^{2} \sin ^{2} B_{i}^{\prime \prime}}} ; \\
\Delta x_{i}=M_{i} \Delta B_{i} ; \Delta y_{i}=N_{i} \cos B_{i}^{\prime \prime} \Delta L_{i} ; \\
i=1,2, \ldots, 9,
\end{gathered}
$$

где $a, e^{2}$ - соответственно, большая полуось и квадрат эксцентриситета эллипсоида системы координат WGS-84.

\section{Результаты оценки точности}

Двойные разности неравноточных измерений представлены в табл. 2.

Средние квадратические погрешности определения координат пунктов приемниками М3 и M4 в режиме RTK представлены в табл. 3.

Разности измерений

Таблица 2

\begin{tabular}{|c|c|c|c|c|c|c|c|c|c|}
\hline \multirow{2}{*}{$\begin{array}{c}\text { Номера } \\
\text { пунктов }\end{array}$} & \multirow{2}{*}{$\begin{array}{c}\text { Расстояние } S \text { от } \\
\text { NSKW, м }\end{array}$} & \multicolumn{9}{|c|}{ T-M3 } & \multicolumn{9}{|c|}{ Р-M3ности, мм } \\
\cline { 3 - 9 } & & $\Delta x$ & $\Delta y$ & $\Delta h$ & $\Delta h n$ & $\Delta x$ & $\Delta y$ & $\Delta h$ & $\Delta h n$ \\
\hline 0 & 39 & $-5,2$ & $-5,7$ & $-9,0$ & $-9,0$ & $-5,2$ & $-13,5$ & $-13,0$ & $-13,0$ \\
\hline 2 & 242 & $+10,8$ & $-2,5$ & $+14,0$ & $+3,0$ & $+7,4$ & $-6,6$ & $+5,0$ & $-6,0$ \\
\hline 1 & 244 & $-12,3$ & $-14,0$ & $+11,0$ & $-11,0$ & 0,0 & $-34,0$ & $-8,0$ & $-30,0$ \\
\hline 12 & 431 & $-0,3$ & $+2,8$ & $-7,0$ & $-13,0$ & $-1,8$ & $+4,4$ & $+5,0$ & $-1,0$ \\
\hline 8 & 579 & $-4,6$ & $-11,7$ & $+8,0$ & $+8,0$ & $+22,5$ & $+0,5$ & $+10,0$ & $+10,0$ \\
\hline 7 & 649 & $-1,8$ & $-8,2$ & $+8,0$ & $-2,0$ & $-2,5$ & $-7,3$ & $-9,0$ & $-19,0$ \\
\hline 6 & 831 & $+3,4$ & $+1,1$ & $+2,0$ & $+3,0$ & $+5,8$ & $-9,1$ & $+5,0$ & $+6,0$ \\
\hline 9 & 955 & $+15,7$ & $-0,4$ & $-2,0$ & $-1,0$ & $+6,5$ & $+2,7$ & $-8,0$ & $-7,0$ \\
\hline 10 & 1227 & $-1,5$ & $+10,8$ & $+10,0$ & $+12,0$ & $-5,5$ & $+15,1$ & $+8,0$ & $+10,0$ \\
\hline
\end{tabular}

Таблица 3

Средние квадратические погрешности определения координат пунктов в режиме RTK

\begin{tabular}{|c|c|c|c|c|c|c|c|c|c|c|c|c|c|}
\hline \multirow{2}{*}{$\begin{array}{c}\text { Номера } \\
\text { точек }\end{array}$} & \multirow{2}{*}{$S$, м } & \multicolumn{10}{|c|}{ М } & \multicolumn{10}{|c|}{ Медние квадратические погрешности, мм } \\
\cline { 3 - 16 } & & $m_{x}$ & $m_{y}$ & $m_{h}$ & $m_{p l}$ & $m_{p r}$ & $m_{h n}$ & $m_{x}$ & $m_{y}$ & $m_{h}$ & $m_{p l}$ & $m_{p r}$ & $m_{h n}$ \\
\hline 0 & 39 & 6,7 & 7,2 & 7,6 & 9,8 & 12,4 & 8,7 & 6,0 & 11,0 & 6,1 & 12,5 & 13,9 & 14,9 \\
\hline 2 & 242 & 6,9 & 7,4 & 7,7 & 10,1 & 12,7 & 8,8 & 6,1 & 11,2 & 6,2 & 12,8 & 14,2 & 15,1 \\
\hline 1 & 244 & 6,9 & 7,4 & 7,7 & 10,1 & 12,7 & 8,8 & 6,1 & 11,2 & 6,2 & 12,8 & 14,2 & 15,1 \\
\hline 12 & 431 & 7,1 & 7,5 & 7,8 & 10,3 & 12,9 & 8,9 & 6,2 & 11,4 & 6,3 & 13,0 & 14,4 & 15,3 \\
\hline 8 & 579 & 7,2 & 7,7 & 7,9 & 10,5 & 13,1 & 9,0 & 6,3 & 11,6 & 6,4 & 13,2 & 14,7 & 15,5 \\
\hline 7 & 649 & 7,3 & 7,7 & 7,9 & 10,6 & 13,2 & 9,0 & 6,3 & 11,6 & 6,4 & 13,2 & 14,7 & 15,6 \\
\hline 6 & 831 & 7,4 & 7,9 & 8,0 & 10,8 & 13,4 & 9,1 & 6,5 & 11,8 & 6,5 & 13,5 & 15,0 & 15,8 \\
\hline 9 & 955 & 7,5 & 8,0 & 8,1 & 11,0 & 13,7 & 9,2 & 6,5 & 12,0 & 6,6 & 13,6 & 15,1 & 16,0 \\
\hline 10 & 1227 & 7,7 & 8,2 & 8,2 & 11,2 & 13,9 & 9,3 & 6,7 & 12,3 & 6,7 & 14,0 & 15,5 & 16,3 \\
\hline
\end{tabular}


В табл. 3 используются следующие обозначения СКП:

$m_{x}-$ СКП геодезической широты в линейной мере;

$m_{y}-$ СКП геодезической долготы в линейной мере;

$m_{h}-$ СКП геодезической высоты;

$m_{p l}=\sqrt{m_{x}^{2}+m_{y}^{2}}-$ СКП в плане; $m_{p r}=\sqrt{m_{x}^{2}+m_{y}^{2}+m_{h}^{2}}-$ СКП в пространстве;

$m_{h n}$ - СКП геодезической высоты, полученная с использованием разностей нормальных высот.

Из табл. 2 и 3 выписаны максимальные разности координат и максимальные СКП, полученные для приемников М3 и М4. Они представлены в табл. 4.

Таблица 4

Максимальные разности и СКП, мм

\begin{tabular}{|c|c|c|c|c|c|c|c|}
\hline \multicolumn{4}{|c|}{ M3 } & \multicolumn{4}{c|}{ M4 } \\
\hline$\Delta x$ & $+15,7$ & $m_{x}$ & 7,7 & $\Delta x$ & $+22,5$ & $m_{x}$ & 6,7 \\
\hline$\Delta y$ & $-14,0$ & $m_{y}$ & 8,2 & $\Delta y$ & $-34,0$ & $m_{y}$ & 12,3 \\
\hline$\Delta h$ & $+14,0$ & $m_{h}$ & 8,2 & $\Delta h$ & $-13,0$ & $m_{h}$ & 6,7 \\
\hline$\Delta h n$ & $-13,0$ & $m_{h n}$ & 9,3 & $\Delta h n$ & $-30,0$ & $m_{h n}$ & 16,3 \\
\hline
\end{tabular}

Из табл. 4 видно, что спутниковый приемник М3 практически подтвердил данные табл. 1, показал себя с лучшей стороны при определении плановых координат, по сравнению с приемником М4. И это несмотря на то, что у приемника M4 априорные СКП в режиме RTK в полтора раза меньше, чем у приемника M3 (см. табл. 1). СКП по высоте у приемников М3 и M4 почти совпадают и соответствуют данным табл. 1. По-видимому, большую роль сыграло то, что приемник М3 установливался по уровню на вешке с биподом. Он жестко фиксировался во время измерений и его не нужно было держать в руках. Приемник M4 был закреплен на простой вешке с уровнем и его невозможно было твердо зафиксировать над пунктами. Отклонения центра антенны от вертикали, проходящей через пункт во время измерений приемником M4, практически не повлияли на определение геодезической высоты пункта, но оказали влияние на определение плановых координат. Целесообразно для повышения точности определения координат рекомендовать вместо простой вешки при выполнении работ использовать вешки с биподами.

Что касается большого отклонения $\Delta h n=-30,0$ мм на пункте 1 в разности нормальных высот при измерении приемником
M4, то, возможно, некоторую роль сыграло неучтенное уклонение отвесной линии и особые условия наблюдения на этом пункте (рядом с высоким металлическим забором).

\section{Заключение}

В представленной статье выполнена оценка точности определения координат ГНСС-приемниками M3 и M4 фирмы EFT в режиме RTK. Оценка точности выполнена по разностям двойных неравноточных измерений. Разности получены путем вычитания измеренных приемниками M3 и M4 в режиме RTK геодезических координат $B, L, H$, из геодезических координат, измеренных в режиме «Статика» приемником Т.

Для контроля оценки точности определения геодезических высот на пунктах сети были получены нормальные высоты из геометрического нивелирования II класса. Результаты эксперимента показали, что в режиме RTK приемники M3 и M4 позволяют определять координаты пунктов на сантиметровом уровне точности. Для повышения точности определения координат рекомендуется использовать вешки с уровнем и биподами, которые жестко фиксируют приемники над пунктами. 


\section{БИБЛИОГРАФИЧЕСКИЙ СПИСОК}

1. Антонович К. М. Использование спутниковых радионавигационных систем в геодезии : монография. В 2 т. Т. 2. - М. : Картгеоцентр, 2006. $-360 \mathrm{c}$.

2. Сеть базовых станций ПРИН [Электронный pecypc]. - Режим доступа: http://www.prin.ru/seti_referencnyh_stancij/.

3. SmartNet Russia [Электронный pecypc]. Режим доступа: http://smartnet-ru.com/index.htm.

4. EFT. Базовые станции на территории РФ [Электронный ресурс]. - Режим доступа: http://eft-cors.ru/.

5. Hofmann-Wellenhof B., Lichtenegger H., Wasle E. GNSS-Global Navigation Satellite Systems: GPS, GLONASS, Galileo and more. - Wien, New-York : Springer, 2008. $-516 \mathrm{p}$.

6. Reach High accuracy L1 RTK GNSS [Электронный ресурс] // EMLID. - Режим доступа: http://emlid.com/reach/.

7. Leick A. GPS Satellite Surveying. - New York : A Willey-Interscience Publication, 2004. $464 \mathrm{p}$.

8. Аврунев Е. И. Использование активных базовых станций при выполнении кадастровых работ в отношении объектов недвижимости // Вестник СГУГиТ. - 2019. - Т. 24, № 1. C. $135-145$.

9. Юнес Ж. А., Мустафин М. Г., Морозова В. Д. Создание опорной маркшейдерской сети с использованием технологии спутникового позиционирования // Маркшейдерский вестник. 2017. - № 2 (117). - C. 25-28.

10. Шендрик Н. К. Методика выноса проектных точек на местность в WGS-84 // Геопрофи. 2016. - № 5. - C. 44-46.

11. Xu Guochang. GPS. Theory, algorithms and applications (2nd ed.). - Springer-Verlag Berlin Heidelberg New York, 2007. - 350 p.

12. GPS for geodesy / P. J. G. Teunissen, Y. Bock, G. Beutler [et al.]. Teunissen P. J. G., Kleusberg A. (Eds.). - Berlin : Springer, 1998. - 650 p.

13. Seeber G. Satellite Geodesy. - 2-nd edition. - Berlin, New York : Walter de Gruyter, 2003. -589 p.

14. Яковлев Н. В. Высшая геодезия. - М. : Недра, 1989. - 382 с.

15. Папазов М. Г., Могильный С. Г. Теория ошибок и способ наименьших квадратов. - М. : Недра, 1968. - 302 с.
16. Гиенко Е. Г., Решетов А. П., Струков А. А. Исследование точности получения нормальных высот и уклонений отвесной линии на территории Новосибирской области с помощью глобальной модели геоида ЕGM2008 // ГЕОСибирь-2011. VII Междунар. науч. конгр. : сб. материалов в 6 т. (Новосибирск, 19 - 29 апреля 2011 г.). - Новосибирск: СГГА, 2011. Т. 1. ч. 2. C. $164-168$.

17. Барлиани А. Г. Методы обработки и анализа пространственных и временных данных : монография. - Новосибирск : СГГА, 2016. $188 \mathrm{c}$.

18. Карпик А. П., Варламов А. А., Аврунев Е. И. Совершенствование методики контроля качества спутникового позиционирования при создании геоинформационного пространства территориального образования // Изв. вузов. Геодезия и аэрофотосъемка. - 2014. - № 4/С. - С. 185-188.

19. Маркузе Ю. И., Голубев В. В. Теория математической обработки геодезических измерений : учеб. пособие. - М. : Академический Проект; Альма Матер, 2010. - 247 с.

20. Wells D. E., Krakiwsky E. J. The Method of least squares. - Canada : University of New Brunswick, 1971. - $192 \mathrm{p}$.

21. Teunissen P. J. G. Adjustment theory (an introduction). - Delft University Press, 2000. - 193 p.

22. Kubàček L. Statistical theory of geodetic networks. - Zdiby : Výzkumný ústav geodetický, topografický a kartografický, 2013. - 286 p.

23. Падве В. А. Математическая обработка и анализ результатов геодезических измерений: монография. В 2 ч. Ч. 1. Основы теории погрешностей измерений и фундаментальные алгоритмы точностной МНК-оптимизации результатов измерений. - Новосибирск : СГУГиТ, 2015. $163 \mathrm{c}$.

24. Машимов М. М. Уравнивание геодезических сетей : учеб. пособие для вузов. - М. : Недра, 1979. - 367 с.

25. Шендрик Н. К. Исследование точности геодезической сети активных базовых станций Новосибирской области в государственной системе координат и высот // Геодезия и картография. - 2014. - № 1. - С. 2-7.

26. Телеганов Н. А., Елагин А. В. Высшая геодезия и основы координатно-временных систем. - Новосибирск : СГГА, 2004. - 238 с.

Получено 06.02.2020 


\section{ESTIMATION OF COORDINATES ACCURACY DETERMINATION BY EFT M3 GNSS AND EFT M4 GNSS SATELLITE RECEIVERS IN RTK MODE}

\section{Alexandr V. Elagin}

Siberian State University of Geosystems and Technologies, 10, Plakhotnogo St., Novosibirsk, 630108, Russia, Ph. D., Associate Professor, Department of Space and Physical Geodesy, phone: (383)361-01-59, e-mail: kaf.astronomy@ssga.ru

\section{Mikhail V. Zaitsev}

Effective Technologies Center LLC, 7, Marx Square, Novosibirsk, 630048, Russia, Engineer, phone: (383)383-23-71, e-mail: zmv@eftgroup.ru

\section{Dmitry A. Prokhorov}

Effective Technologies Center LLC, 7, Marx Square, Novosibirsk, 630048, Russia, Head of the Regional Representative Office, phone: (383)383-23-71, e-mail: nsk@eftgroup.ru

\section{Nikolay K. Shendrik}

Siberian State University of Geosystems and Technologies, 10, Plakhotnogo St., Novosibirsk, 630108, Russia, Head of Laboratory, Department of Space and Physical Geodesy, phone: (383)361-01-59, e-mail: kaf.astronomy@ssga.ru

The paper presents the test results of satellite receivers EFT M3 GNSS and EFT M4 GNSS in Real Time Kinematic (RTK) mode. At ten points near the NSKW permanent operating base station, measurements were made in the RTK mode by the tested receivers and in the "static" mode by the Trimble 5700 receiver. In addition, the normal heights of points from leveling of class II with the $\mathrm{N}-05$ level were determined. The points are removed from the base station at distances from $39 \mathrm{~m}$ to $1227 \mathrm{~m}$. The accuracy was estimated by the differences of double non-equal measurements in the RTK and "static" modes. For additional control of the accuracy estimation in determining the heights, differences of normal and geodetic heights are used. The work shows that the mean square error of measurements in the RTK mode does not exceed $16 \mathrm{~mm}$ in plan and height. In RTK mode, modern GNSS receivers EFT M3 GNSS and EFT M4 GNSS can achieve a centimeter level of accuracy in determining the spatial coordinates of points. The errors of the tested receivers in RTK mode are comparable.

Key words: GNSS, RTK, statics, accuracy estimation, geometric leveling.

\section{REFERENCES}

1. Antonovich, K. M. (2006). Ispol'zovanie sputnikovyh radionavigacionnyh system $v$ geodezii: T. 2 [Using satellite radio-navigation systems in geodesy: Vol. 2]. Moscow: Cartgeocentr Publ., 360 p. [in Russian].

2. PRIN network of base stations. (n. d.). Retrieved from http://www.prin.ru/seti referencnyh stancij/ [in Russian].

3. SmartNet Russia. (n. d.). Retrieved from http://smartnet-ru.com/index.htm [in Russian].

4. EFT. Base station on the territory of the Russian Federation. (n. d.). Retrieved from http://eftcors.ru/ [in Russion].

5. Hofmann-Wellenhof, B., Lichtenegger, H., \& Wasle, E. (2008). GNSS-Global Navigation Satellite Systems: GPS, GLONASS, Galileo and more. Wien, New-York: Springer, $516 \mathrm{p}$.
6. Reach High accuracy L1 RTK GNSS. (n. d.). Retrieved from http://emlid.com/reach/.

7. Leick, A. (2004). GPS Satellite Surveying. New York: A Willey-Interscience Publication, $464 \mathrm{p}$.

8. Avrunev, E. I. (2019). Use of active basic stations in the performance of cadastral works with respect to real estate objects. Vestnik SGUGiT [Vesnik SSUGT], 24(1), 135-145 [in Russian].

9. Younes, Z. A., Mustafin, M. G., \& Morozova, V. D. (2017). Creation of a support surveying network using satellite positioning technology. Markshejderskij vestnik [Mine Surveying News], 2(117), 25 - 28 [in Russian].

10. Shendrik, N. K. (2016). Methods of removal of design points on the terrain in the WGS-84. Geoprofi [Geoprofi], 5, 44-46 [in Russian]. 
11. Xu Guochang. (2007). GPS. Theory, algorithms and applications (2nd ed.). Springer-Verlag Berlin Heidelberg New York, $350 \mathrm{p}$.

12. Teunissen, P. J. G., Bock, Y., \& Beutler, G. (1998). GPS for geodesy. Teunissen P. J. G., Kleusberg A. (Eds.). Berlin: Springer, $650 \mathrm{p}$.

13. Seeber, G. (2003). Satellite Geodesy (2nd ed.). Berlin, New York: Walter de Gruyter, 589 p.

14. Yakovlev, N. V. (1989). Vysshaya geodeziya [Higher geodesy]. Moscow: Nedra Publ., 382 p. [in Russian].

15. Papazov, M. G., \& Mogilny, S. G. (1968). Teoriya oshibok $i$ sposob naimenshikh kvadratov [Theory of errors and the method of least squares]. Moscow: Nedra Publ., 302 p. [in Russian].

16. Gienko, E. G., Reshetov, A. P., \& Strukov, A. A. (2011). Research of normal height and vertical deflection determination accyracy on Novosibirsk region territory by the global model of geoid EGM2008. In Sbornik materialov GEO-Sibir-2011: T. 1, ch. 2. [Proceedings of GEO-Siberia-2011: Vol. 1, Part 2] (pp. 164-168). Novosibirsk: SSGA Publ. [in Russian].

17. Barliani, A. G. (2016). Metody obrabotki i analiza prostranstvennykh I vremennykh dannykh [Methods of processing and analysis of spatial and temporal data]. Novosibirsk: SSUGT Publ., 188 p. [in Russian].

18. Karpik, A. P., Varlamov, A. A., \& Avrunev, E. I. (2014). Improving methods for quality control of satellite positioning when creating geo-space territorial education. Izvestiya vuzov. Geodeziya $i$ aehrofotos"emka [Izvestiya Vuzov. Geodesy and Aerophotography], 4/S, 182-186 [in Russian].

19. Markuze, Yu. I., \& Golubev, V. V. (2010). Teoriya matematicheskoy obrabotki geodezicheskikh izmereniy [Theory of mathematical processing of geodetic measurements]. Moscow: Academic Project: Al'ma Mater Publ., 247 p. [in Russian].

20. Wells, D. E., \& Krakiwsky, E. J. (1971). The Method of least squares. Canada: University of New Brunswick Publ., 192 p.

21. Teunissen, P. J. G. (2000). Adjustment theory (an introduction). Delft University Press, $193 \mathrm{p}$.

22. Kubàček, L. (2013). Statistical theory of geodetic networks. Zdiby: Výzkumný ústav geodetický, topografický a kartografický, 286 p.

23. Padve, V. A. (2015). Matematicheskaya obrabotka i analiz rezul'tatov geodezicheskikh izmereniy: Ch. 1, Osnovy teorii pogreshnostej izmerenij $i$ fundamental'nye algoritmy tochnostnoj MNKoptimizacii rezul'tatov izmerenij [Mathematical processing and interpretation of the results of geodetic measurements: Part 1, Fundamentals of the theory of measurement errors and the fundame ntal algorithms of the precision OLS optimization measurements]. Novosibirsk: SSUGT Publ., 163 p. [in Russian].

24. Mashimov, M. M. (1979). Uravnivanie geodezichescikh cetey [Adjustment geodetic networks]. Moscow: Nedra Publ., 367 p. [in Russian].

25. Shendrik, N. K. (2014). The investigation of precision geodetic network of active base stations Novosibirsk region in the state system of coordinates and altitudes. Geodeziya i kartografiya [Geodesy and Cartography], 1, 2-7 [in Russian].

26. Teleganov, N. A., \& Elagin, A. V. (2004). Vysshaya geodeziya $i$ osnovy koordinatnovremennyh system [Higher geodesy and fundamentals of coordinate-time systems]. Novosibirsk: SSGA Publ., 238 p. [in Russian].

Received 06.02.2020

(C) A. V. Elagin, M. V. Zaitsev, D. A. Prokhorov, N. K. Shendrik, 2020 
УДК 629.783:528.236

DOI: $10.33764 / 2411-1759-2020-25-3-34-41$

\section{ВЛИЯНИЕ АТМОСФЕРНЫХ НАГРУЗОК НА РЕЗУЛЬТАТЫ СПУТНИКОВОГО МОНИТОРИНГА ЗДАНИЯ СТАНЦИОННОГО УЗЛА ЗАГОРСКОЙ ГАЭС-2 МЕТОДОМ РРР}

\section{Владислав Валерьевич Калинников}

Университет Иннополис, 420500, Россия, г. Иннополис, ул. Университетская, 1, кандидат физико-математических наук, главный инженер проектов центра геоинформационных систем, e-mail: vlad-kalinnikov@mail.ru

\section{Александр Валерьевич Устинов}

Филиал АО «Институт Гидропроект» - «ЦСГНЭО», 125993, Россия, г. Москва, Волоколамское шосce, 2, начальник отдела, e-mail: a.ustinov@hydroproject.ru; Сибирский государственный университет геосистем и технологий, 630108, Россия, г. Новосибирск, ул. Плахотного, 10, ст. преподаватель кафедры инженерной геодезии и маркшейдерского дела

\section{Николай Сергеевич Косарев}

Сибирский государственный университет геосистем и технологий, 630108, Россия, г. Новосибирск, ул. Плахотного, 10, кандидат технических наук, доцент кафедры инженерной геодезии и маркшейдерского дела, тел. (913)706-91-95, e-mail: kosarevnsk@yandex.ru

На основе опытных измерений, выполненных на Загорской ГАЭС-2, рассмотрена возможность применения метода Precise Point Positioning (PРP) в системе комплексного мониторинга гидротехнических сооружений. Показано, что абсолютные значения координат точек мониторинга, определенные методом РРР, достаточно сильно подвержены влиянию атмосферных нагрузок, возникающих изза изменения атмосферного давления. По теоретическим исследованиям вертикальные смещения, обусловленные этим эффектом, могут составлять до 25 мм, горизонтальные - до 1/3 от этой величины. Авторами на основе сравнительного анализа были получены следующие выводы. Рассчитанные методом РPР в программном продукте TropoGNSS среднесуточные значения координат мониторинговой станции PS34 с высокой вероятностью коррелируют с рядами деформаций земной коры в районе расположения Загорской ГАЭС-2, вычисленные с помощью онлайн-сервиса International Mass Loading Service. Вариации среднесуточных значений координат мониторинговой станции позволяют уверенно идентифицировать деформации земной коры величиной порядка 5 мм. Это говорит, с одной стороны, о сравнительно высокой точности результатов применения метода РPР, а с другой, о необходимости применения внешних моделей атмосферных нагрузок для использования метода РPР в качестве эффективного инструмента для мониторинга сложных динамических объектов, в частности гидротехнических сооружений. Применение внешних моделей атмосферных нагрузок может позволить обеспечить нормативную точность наблюдений за осадками и горизонтальными смещениями бетонных плотин методом РРР.

Ключевые слова: Загорская ГАЭС-2, гидротехнические сооружения, автоматизированный мониторинг, ГНСС, атмосферные нагрузки, PPP, TropoGNSS.

\section{Введение}

С целью обеспечения безопасности гидротехнических сооружений (ГТС) и прилегающей территории необходимо в процессе эксплуатации проводить мониторинг технического состояния ГТС для своевременного принятия необходимых оперативных и инженерных решений при появлении и развитии деформационных процессов [1-4].
В настоящее время для деформационного мониторинга инженерных сооружений широко применяются методы ГНСС-технологий, которые, в отличие от классических методов мониторинга, обладают достаточно высокой точностью, оперативностью, возможностью производить круглосуточный мониторинг в режиме реального времени [5-6]. В основу мониторинга ГТС с использованием ГНССтехнологий положен анализ положения мони- 
торинговых приемников, располагающихся на гребне плотины, относительно базовых станций, установленных на стабильном основании, вне зоны деформаций плотины [7-10]. Для достижения высокой точности определения координат мониторинговых точек используется концепция RTN (Real Time Network), заключающаяся в следующем. Базовые и мониторинговые ГНСС-приемники собирают спутниковые измерения, которые затем по коммуникационным каналам передаются в режиме реального времени на сервер в центр управления. На сервере «разворачивается» специализированное программное обеспечение (СПО) для управления базовыми и мониторинговыми ГНСС-приемниками. СПО объединяет все измерения и выдает сетевое решение по каждой мониторинговой станции.

Однако в связи с рядом ограничений, связанных, в основном, с влиянием различных факторов, понижающих точность координатных определений, применение ГНССтехнологий не позволяет производить мониторинг технического состояния ГТС с требуемыми нормативными допусками.

Одним из таких негативных факторов является многопутность (многолучевость), влияние которой исключается выбором мест расположения опорных и мониторинговых приемников. Другой фактор - сложность учета остаточного влияния тропосферной рефракции, возникающего из-за большой разности высот вектора базовой линии. Существуют и другие факторы, которые накладывают ограничения на использование спутниковых измерений для мониторинга гидротехнических сооружений. Тем не менее, ГНСС-технологии активно применяются в комплексных автоматизированных системах мониторинга ГТС, где они выполняют функцию контроля положения опорных пунктов сети $[5,6]$.

В настоящее время в научной литературе активно обсуждается применение метода Precise Point Positioning (PРP) для мониторинга сложных динамических объектов с получением дециметрового и сантиметрового уровня точности в режиме реального времени [11-13]. Такая высокая точность определения координат одним приемником достигается за счет применения точных апостериорных параметров орбит (эфемерид) и поправок к часам спутников, а также учетом таких основных ошибок, как ионосферная и тропосферная задержки. Дополнительно в методе РРР исключаются ошибки, которые могут вызывать значительные (до нескольких сантиметров) изменения в фазовых наблюдениях. К ним относят смещение фазового центра антенны спутника, эффекты в смещении пункта из-за приливов в твердой Земле, океанические нагрузки и поправка за набег фазы.

Кроме этого, из-за периодических и непериодических изменений давления на земную поверхность оказывают влияние так называемые атмосферные нагрузки, которые приводят к тому, что земная поверхность деформируется. Для оценки вертикального смещения, обусловленного периодическим изменением давления, используется упрощенная формула:

$$
d h=-0,35 \cdot p_{\text {аном }}-0,55 \cdot \bar{p}_{\text {аном }} .
$$

где $p_{\text {аном }}-$ аномалия локального давления относительно стандартного давления, редуцированного на высоту пункта, в мбар;

$\bar{p}_{\text {аном }}$ - аномалия давления в круговой области радиусом 2000 км, в мбар.

По теоретическим исследованиям вертикальные смещения из-за атмосферных нагрузок могут составлять до 25 мм, горизонтальные - до 1/3 от этой величины [14].

Таким образом, атмосферные нагрузки, возникающие из-за изменения атмосферного давления, должны быть учтены в методе РPР, для того, чтобы использовать его в качестве эффективного инструмента для мониторинга сложных динамических объектов, в частности гидротехнических сооружений.

\section{Цель исследования}

Целью исследования является анализ влияния атмосферных нагрузок, возникающих из-за изменения атмосферного давления, на результаты спутникового мониторинга гидротехнических сооружений методом РРР. В качестве тестового объекта для 
исследования было выбрано здание станционного узла Загорской ГАЭС-2.

\section{Исходные данные}

Загорская ГАЭС-2 располагается в 2,4 км от устья реки Куньи в Сергиево-Посадском районе Московской области, недалеко от села Богородское на расстоянии около 900 м к югу от створа основных сооружений Загорской ГАЭС (рис. 1).

В конце сентября 2013 г. специалистами OAO «Институт Гидропроект» на станционном узле Загорской ГАЭС-2 была развернута опытная система спутникового геодезического мониторинга, которая включала в себя восемь ГНСС-приемников: один базовый и семь мониторинговых (рис. 2).

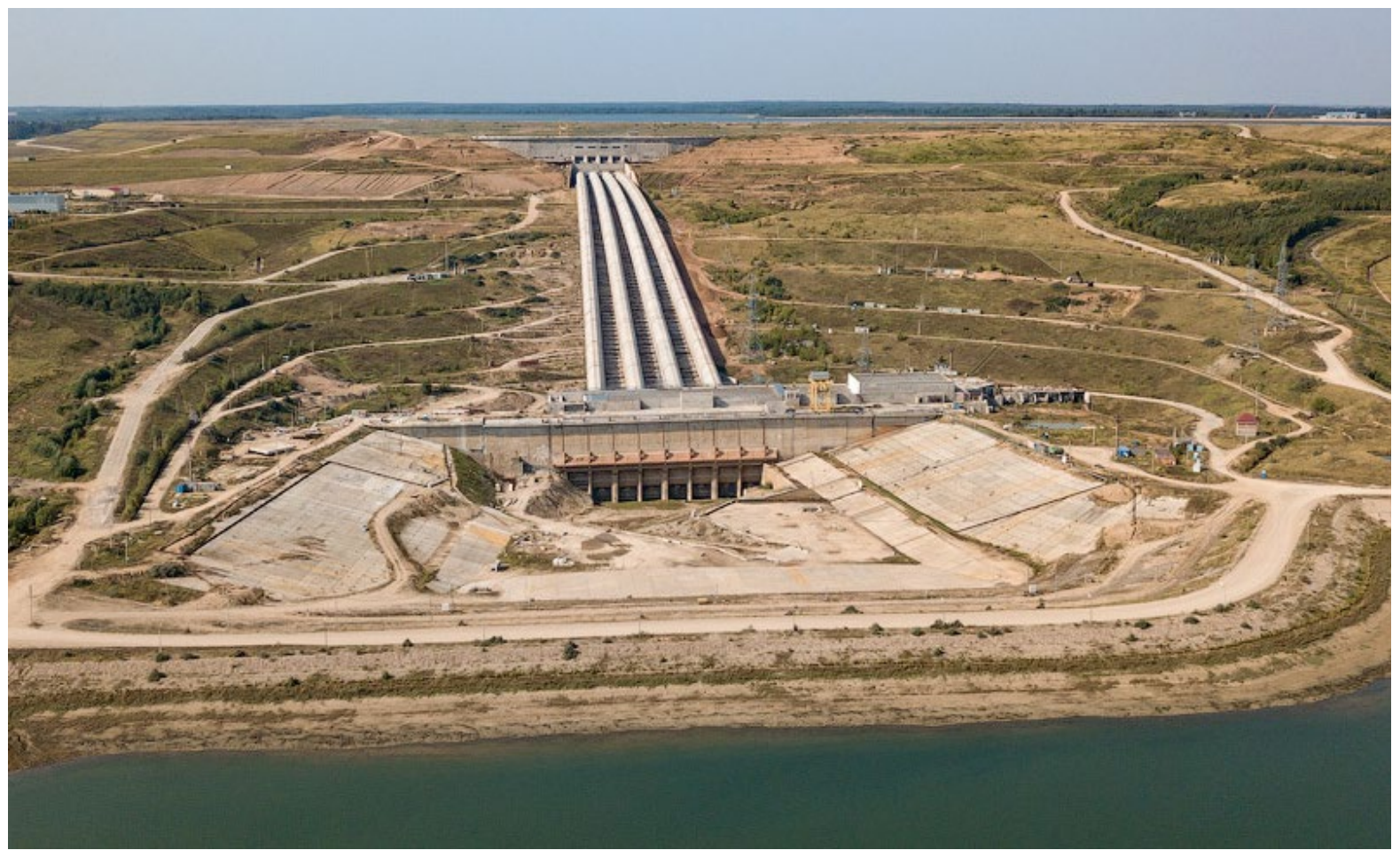

Рис. 1. Общий вид Загорской ГАЭС-2

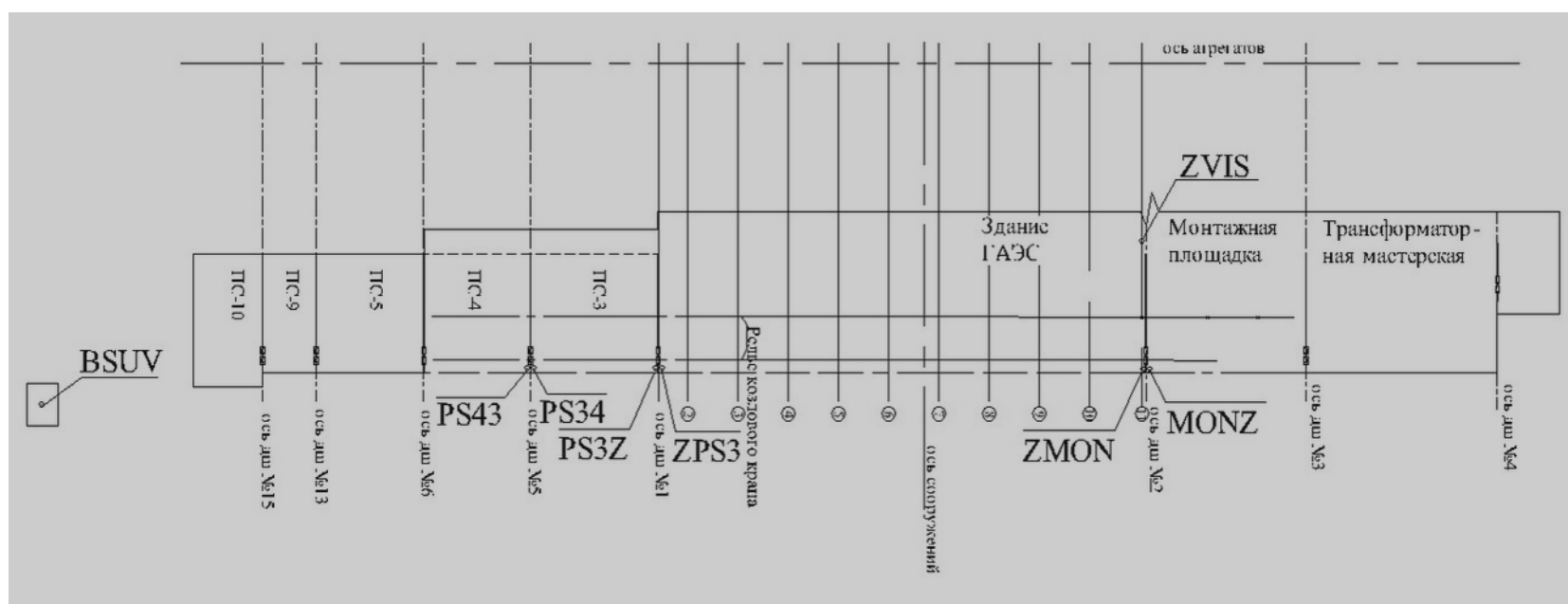

Рис. 2. Схема экспериментальной сети Загорской ГАЭС-2 
На всех пунктах системы спутникового геодезического мониторинга установлены ГНССприемники GM10 фирмы Leica Geosystems (Швейцария) с антеннами типа Choke Ring. Базовый ГНСC-приемник (BSUV) находится вне зоны деформаций здания ГАЭС на расстоянии около 60 м. Контроль стабильности пункта BSUV осуществлялся относительно других пунктов опорной геодезической сети Загорской ГАЭС-2 методом линейно-угловых измерений согласно программе натурных наблюдений.

\section{Методика обработки исходных данных}

Для достижения поставленной цели авторами проанализированы месячные данные мониторинговой станции PS34. Обработка данных проводилась методом РPР в программном продукте TropoGNSS $[15,16]$. Программный продукт TropoGNSS позволяет определять высокоточные координаты ГНССстанций, оценивать ошибки часов приемника, а также выдавать временные ряды зенитной тропосферной задержки и градиентные тропосферные параметры. Точность оценки всех выходных параметров зависит от продолжительности измерений, а также от числа использованных в обработке навигационных систем. При обработке измерений суточной продолжительности точность определения координат составляет 1-3 мм.

При обработке измерений использовались суточные измерения с дискретностью 30 секунд, маска по высоте составляла 7 градусов. По результатам обработки в программном продукте TropoGNSS были получены временные ряды среднесуточных значений координат мониторинговой станции PS34.

\section{Результаты исследования}

Для оценки влияния атмосферных нагрузок на результаты спутникового мониторинга здания станционного узла Загорской ГАЭС-2 авторами был выполнен сравнительный анализ рассчитанных в программном продукте TropoGNSS среднесуточных значений координат мониторинговой станции PS34 с рядами деформаций земной коры в районе расположения Загорской ГАЭС-2, вычисленных с помощью онлайн-сервиса International Mass Loading Service [17]. Нa рис. 3-5 показано сопоставление рядов координат ГНСС-станции, полученных методом PРP, с деформациями земной коры, вычисленными с помощью указанного сервиса.

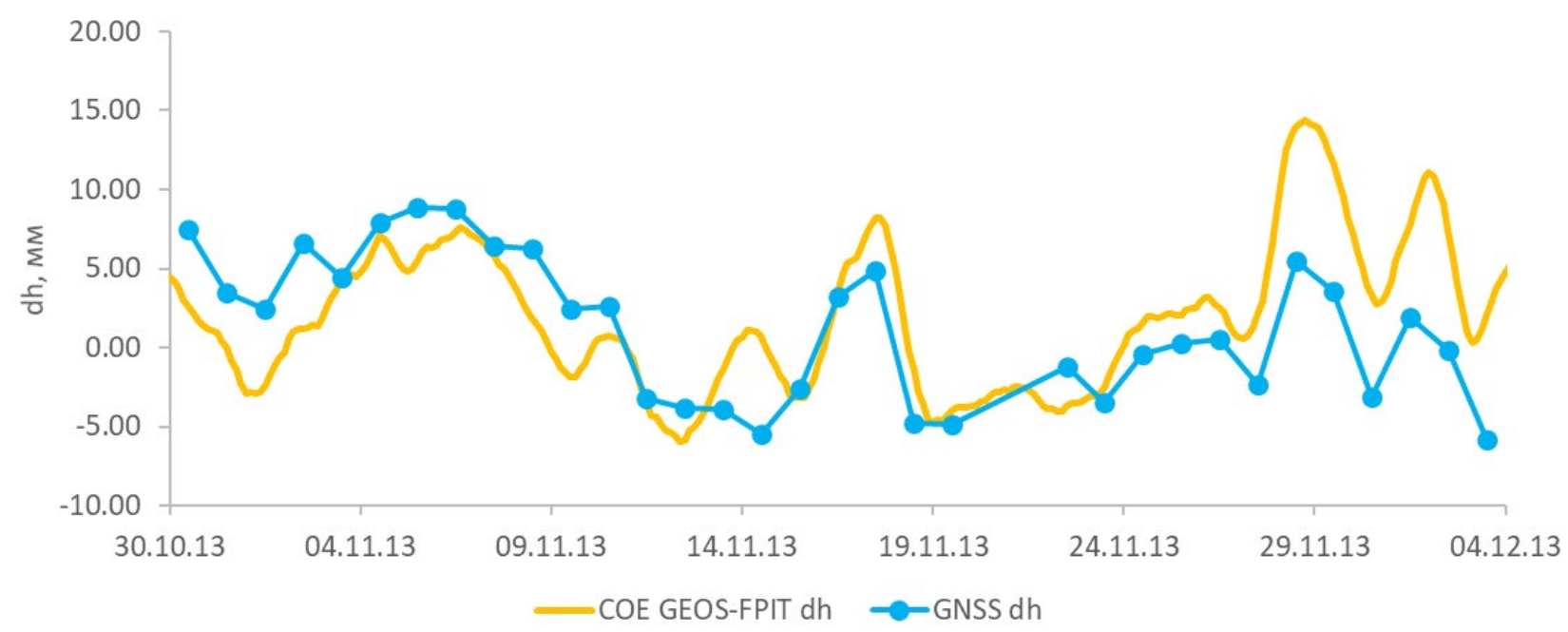

Рис. 3. Сопоставление рядов высотной компоненты, полученных из модельных данных (GEOS-FPIT) и измеренных на станциях с помощью ГНСС 


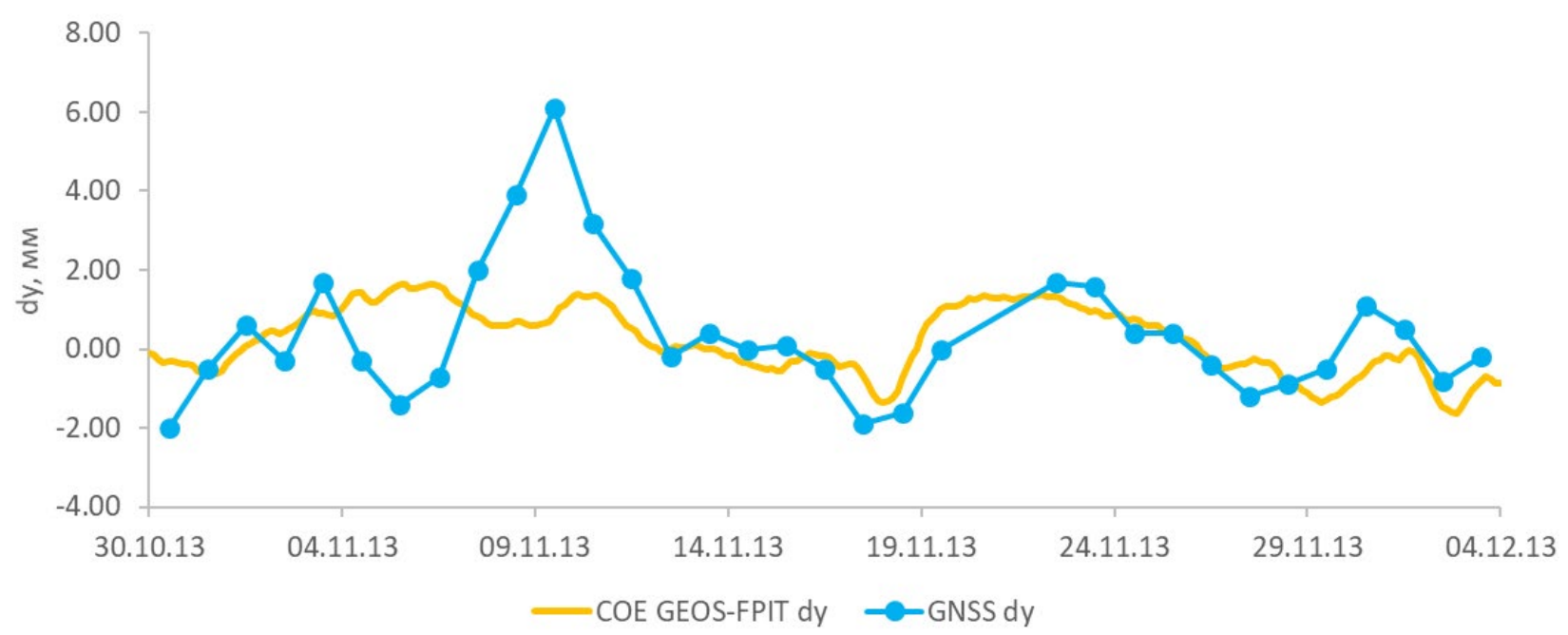

Рис. 4. Сопоставление рядов восточной компоненты, полученных из модельных данных

(GEOS-FPIT) и измеренных на станциях с помощью ГНСС

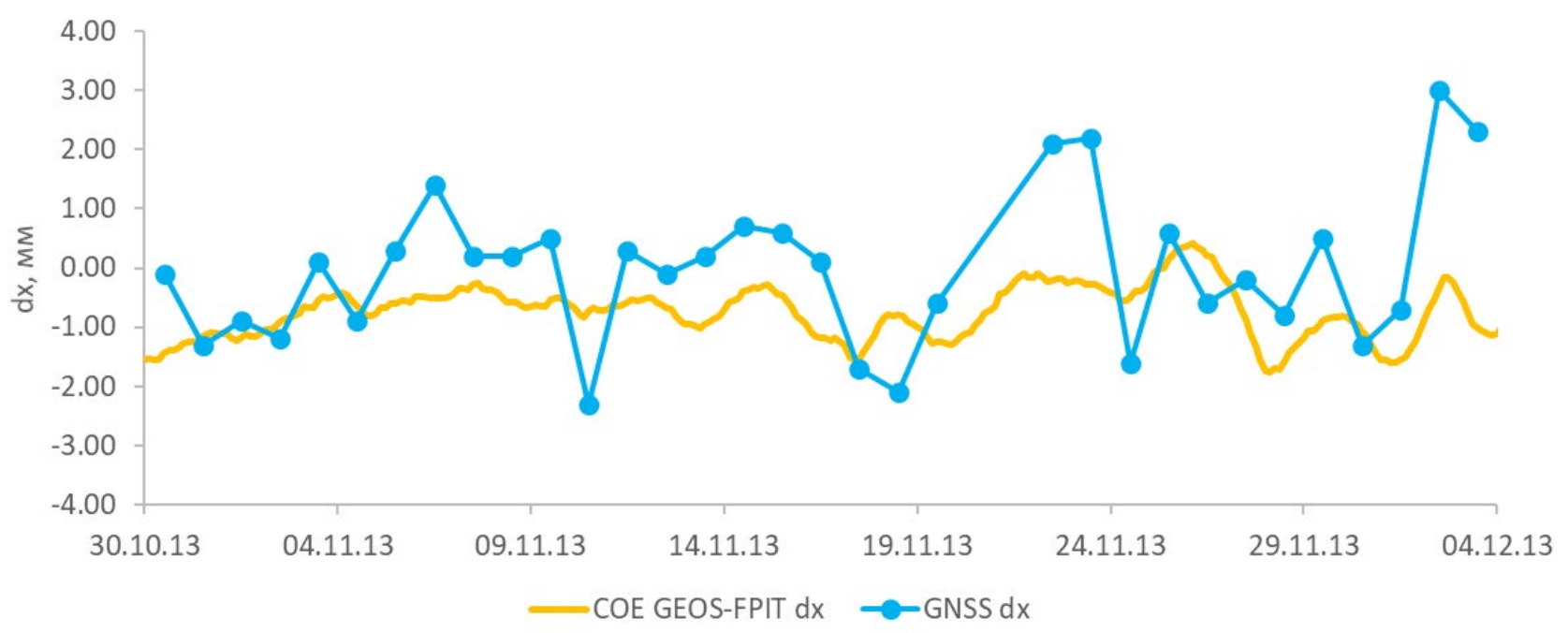

Рис. 5. Сопоставление рядов северной компоненты, полученных из модельных данных

(GEOS-FPIT) и измеренных на станциях с помощью ГНСС

Как можно хорошо видеть, смещения высотной координаты наиболее коррелированы с модельными данными. Корреляция в изменениях плановых координат слабее, но все же отчетливо проявляется. При этом вариации среднесуточных значений координат мониторинговой станции PS34, полученные методом РРР, позволяют уверенно идентифицировать деформации земной коры величиной порядка 5 мм. Это говорит, с одной стороны, о сравнительно высокой точности результатов применения метода РРР, а с другой, о необходимости применения внешних моделей атмосферных нагрузок для интерпретации этих результатов. Применение таких моделей может позволить обеспечить нормативную точность наблюдений за осадками и горизонтальными смещениями бетонных плотин методом РРP [18].

\section{Заключение}

Результаты исследования показали, что абсолютные значения координат (как плановых, так и высотных) точек мониторинга, определенных методом РРР, достаточно сильно подвержены влиянию атмосферных нагрузок, возникающих из-за изменения атмосферного давления. Однако уже сейчас для долговременного контроля положения опорных пунктов мониторинга в комплексных системах могут быть использованы и абсолютные значе- 
ния координат, которые невозможно определить дифференциальными методами.

Дальнейшие исследования по применению метода РРР для мониторинга гидротехнических сооружений будут направлены на обработку и анализ более длинных рядов измерений, и сопоставление этих результатов с измерениями, выполненными с помощью традиционных технологий. Анализ временных рядов измерений каждой мониторинговой станции Загорской ГАЭС-2 позволит, помимо всего прочего, оценить и другие источники ошибок, оказывающие влияние на точность определения координат, в частности локальные неоднородности поля водяного пара между станциями мониторинга [19].

\section{БИБЛИОГРАФИЧЕСКИЙ СПИСОК}

1. Кафтан В. И., Устинов А. В. Применение глобальных навигационных спутниковых систем для мониторинга деформаций гидротехнических сооружений // Гидротехническое строительство. - 2012. - № 12. - С. 11-19.

2. Шоломицкий А. А., Лагутина Е. К., Соболева Е. Л. Высокоточные геодезические измерения при деформационном мониторинге аквапарка // Вестник СГУГиТ. - 2017. - Т. 22, № 3. - С. 45-59.

3. Устинов А. В. Результаты мониторинга вертикальных перемещений в процессе компенсационного нагнетания на опытном участке Загорской ГАЭС-2 // Вестник СГУГиТ. - 2018. T. 23, № 4. - С. 128-141.

4. Методика метрологической поверки ГНСС приемников системы мониторинга высоконапорной ГЭС / А. П. Карпик, Н. С. Косарев, К. М. Антонович, А. П. Решетов, А. В. Устинов // Вестник СГУГиТ. - 2019. - Т. 24, № 4. - С. 34-43.

5. Cranenbroeck J. GNSS-technologies application for structural deformation monitoring // Вестник СГГА. - 2012. - Вып. 1 (17). - С. 29-40.

6. Устинов А. В. Технология спутникового геодезического мониторинга гидротехнических сооружений // Гидротехническое строительство. - 2014. - № 6. - С. 39-43.

7. Behr J., Hudnut K., King N. Monitoring structural deformation at Pacoima dam, California using continuous GPS // In Proceedings of the 11th International Technical Meeting of the Satellite Division of the Institute of Navigation, Nashville, TN, USA, 15-18 September 1998. - P. 59-68.

8. Estimating and Comparing Dam Deformation Using Classical and GNSS Techniques / R. Barzaghi, N. E. Cazzaniga, C. I. De Gaetani, L. Pinto, V. Tornatore // Sensors. - 2018. - Vol. 18. - P. 756.

9. Monitoring displacements of an earthen dam using GNSS and remote sensing / G. Dardanelli, G. La Loggia, N. Perfetti, F. Capodici, L. Puccio, A. Maltese // SPIE Remote Sens. 2014. - Vol. 923928. - P. 16.

10. Bond J., Kim D., Fletcher J. Structural Monitoring of the Mactaquac Dam using GPS Sensors //
In 5th Canadian conference on geotechnique and natural hazards. - Kelowna, Canada, 2011. - 40 p.

11. Real-time kinematic PPP GPS for structure monitoring applied on the Severn Suspension Bridge, UK / X. Tang, G. Roberts, X. Li, C. Hancock // Advances in Space Research. - 2017. Vol. 60 (5). - P. 925-937.

12. Yigit C. O., Gurlek E. Experimental testing of high-rate GNSS precise point positioning (PPP) method for detecting dynamic vertical displacement response of engineering structures // Geomatics, Natural Hazards and Risk. - 2017. - Vol. 8 (2). P. 893-904.

13. Калинников В. В., Устинов А. В., Загретдинов Р. В. Результаты экспериментальных исследований применения технологии РРP для глобальных навигационных спутниковых систем мониторинга Саяно-Шушенской ГЭС // Гидротехническое строительство. - 2020. - № 2. C. 2-7.

14. IERS Conventions (1996) / D. D. McCarthy, G. Petit (Eds.). - Frank-furt and Main : Central Bureau of IERS, 1997. $-278 \mathrm{p}$.

15. Kalinnikov V., Khutorova O. Diurnal variations in integrated water vapor derived from a GPS ground network in the Volga-Ural region of Russia // Annales Geophysicae. - 2017. - No. 35. P. 453-464.

16. The Precise Point Positioning Method (PPP) in environmental monitoring applications / V. V. Kalinnikov, A. V. Ustinov, R. V. Zagretdinov, A. V. Tertyshnikov, N. S. Kosarev // Proc. SPIE 11208, 25th International Symposium on Atmospheric and Ocean Optics: Atmospheric Physics, 112086S (18 December 2019). doi: 10.1117/12.2539130.

17. International Mass Loading Service (IMLS) [Electronic resource]. - Mode of access: http://massloading.net/.

18. П 83-2001. Рекомендации по анализу данных и проведению натурных наблюдений за осадками и горизонтальными смещениями бетонных плотин. - СПб. : ОАО «ВНИИГ им. Б. Е. Веденеева», 2001. - 24 c. 
19. Калинников В. В., Устинов А. В., Загретдинов Р. В. Влияние неоднородностей поля водяного пара в приземном слое атмосферы в районе водохранилищ на результаты спутникового мониторинга гидротехнических сооружений // Гидротехническое строительство. - 2018. № 3. - C. 19-25.

Получено 30.04.2020

(C) В. В. Калинников, А. В. Устинов, Н. С. Косарев, 2020

\title{
IMPACT OF ATMOSPHERIC LOADINGS ON THE RESULTS OF GNSS MONITORING OF MAIN BUILDING OF ZAGORSKAYA PSPP-2 BY PPP METHOD
}

\author{
Vladislav V. Kalinnikov \\ Innopolis University, 1, Universitetskaya St., Innopolis, 420500, Russia, Ph. D., Chief Project Engineer, \\ Center of Geographic Information Systems, e-mail: vlad-kalinnikov@mail.ru
}

\section{Alexander V. Ustinov}

Branch of JSC "Institute Hydroproject" - "CSGNEO", 2, Volokolamsk Highway, Moscow, 125993, Russia, Head of Department, e-mail: a.ustinov@hydroproject.ru; Siberian State University of Geosystems and Technologies, 10, Plakhotnogo St., Novosibirsk, 630108, Russia, Senior Lecturer, Department of Engineering Geodesy and Mine Surveying

\section{Nikolay S. Kosarev}

Siberian State University of Geosystems and Technology, 10 Plakhotnogo St., Novosibirsk, 630108, Russia, Ph. D., Associate Professor, Department of Engineering Geodesy and Mine Surveying, phone: (913)706-91-95, e-mail: kosarevnsk@yandex.ru

The possibility of using the Precise Point Positioning (PPP) method in the system of integrated monitoring of hydraulic structures is study. Example of measurements in the system of monitoring the Zagorskaya PSPP-2 is shown. The absolute values of the coordinates of monitoring points determined by the PPP method are quite strongly affected by atmospheric loads arising from changes in atmospheric pressure. According to theoretical studies, vertical displacements due to this effect can be up to $25 \mathrm{~mm}$, horizontal up to $1 / 3$ of this value. The results of comparative analysis are obtained and the conclusions are done. The average daily values of the PS34 monitoring station coordinates calculated by the PPP method in the TropoGNSS software product are highly correlate with the series of crustal deformations in the area of Zagorskaya PSPP-2, calculated using the International Mass Loading Service online service, and the vertical coordinate is more correlated with the model data than the horizontal coordinates. Variations in the average daily values of the coordinates of the monitoring station allow us to identify crustal deformations of the order of $5 \mathrm{~mm}$. This indicates a relatively high accuracy of the results of the PPP method and the need to apply external models of atmospheric loads. The use of external models of atmospheric loads can to ensure the required accuracy of observations of vertical and horizontal displacements of concrete dams by the PPP method.

Key words: Zagorskaya PSPP-2, hydraulic structures, automated monitoring, GNSS, atmospheric loads, PPP, TropoGNSS.

\section{REFERENCES}

1. Kaftan, V. I., \& Ustinov, A. V. (2012). Use of global navigation satellite systems for monitoring deformations of hydraulic constructions. Gidrotehnicheskoe stroitel'stvo [Hydraulic Engineering], 12, 11-19 [in Russian].

2. Sholomitsky, A. A., Lagutina, E. K., \& Soboleva, E. L. (2017). High Precision Geodetic Measurements at Deformation Monitoring of Aquapark.
Vestnik SGUGiT [Vestnik SSUGT], 22(3), 45-59 [in Russian].

3. Ustinov, A. V. (2018). The results of the monitoring of vertical displacements in the process of compensation grouting at the experimental site of Zagorskaya PSP-2. Vestnik SGUGiT [Vestnik SSUGT], 23(4), 128-141 [in Russian]. 
4. Karpik, A. P., Kosarev, N. S., Antonovich, K. M., Reshetov, A. P., \& Ustinov, A. V. (2019). Method of metrological inspection of GNSS receivers of a high-connector HEPS monitoring system. Vestnik SGUGiT [Vestnik SSUGT], 24(4), 34-43 [in Russian].

5. Cranenbroeck, J. (2012). GNSS-technologies application for structural deformation monitoring. Vestnik SGGA [Vestnik SSGA], 17(1), 29-40 [in Russian].

6. Ustinov, A. V. (2014). Technology of satellite geodetic monitoring of hydropower structures. Gidrotehnicheskoe stroitel'stvo [Hydraulic Engineering], 6, 39-43 [in Russian].

7. Behr, J., Hudnut, K., \& King, N. (1998) Monitoring structural deformation at Pacoima dam, California using continuous GPS. In Proceedings of the 11th International Technical Meeting of the Satellite Division of the Institute of Navigation, 15-18 September 1998 (pp. 59-68). Nashville, TN, USA.

8. Barzaghi, R., Cazzaniga, N. E., De Gaetani, C. I., Pinto, L., \& Tornatore, V. (2018) Estimating and Comparing Dam Deformation Using Classical and GNSS Techniques. Sensors, 18, P. 756.

9. Dardanelli, G., La Loggia, G., Perfetti, N., Capodici, F., Puccio, L., \& Maltese, A. (2014). Monitoring displacements of an earthen dam using GNSS and remote sensing. SPIE Remote Sens., 923928, P. 16.

10. Bond, J., Kim, D., \& Fletcher, J. (2011). Structural Monitoring of the Mactaquac Dam using GPS Sensors. In 5th Canadian Conference on $\mathrm{Ge}$ otechnique and Natural Hazards (40 p.). Kelowna, Canada.

11. Tang, X., Roberts, G., Li, X., \& Hancock, C. (2017). Real-time kinematic PPP GPS for structure monitoring applied on the Severn Suspension Bridge, UK. Advances in Space Research, 60(5), 925-937.

Received 30.04.2020
12. Yigit, C. O., \& Gurlek, E. (2017). Experimental testing of high-rate GNSS precise point positioning (PPP) method for detecting dynamic vertical displacement response of engineering structures. Geomatics, Natural Hazards and Risk, 8(2), 893-904.

13. Kalinnikov, V. V., Ustinov, A. V., \& Zagretdinov, R. V. (2020). The results of experimental studies on the use of PPP technology for GNSS monitoring of Sayano-Shushenskaya HPP. Gidrotehnicheskoe stroitel'stvo [Hydraulic engineering], 2, 2-7 [in Russian].

14. McCarthy, D. D., \& Petit, G. (Eds.). (1996). IERS Conventions. Frank-furt and Main: Central Bureau of IERS, $278 \mathrm{p}$.

15. Kalinnikov, V., \& Khutorova, O. (2017). Diurnal variations in integrated water vapor derived from a GPS ground network in the Volga-Ural region of Russia. Annales Geophysicae, 35, 453-464.

16. Kalinnikov, V. V., Ustinov, A. V., Zagretdinov, R. V., Tertyshnikov, A. V., \& Kosarev, N. S. (2019). The Precise Point Positioning Method (PPP) in environmental monitoring applications. Proc. SPIE 11208, 25th International Symposium on Atmospheric and Ocean Optics: Atmospheric Physics, 112086S (18 December 2019). doi: 10.1117/12.2539130.

17. International Mass Loading Service (IMLS). (n. d.). Retrieved from http://massloading.net/

18. P 83-2001. (2001). Recommendations on Data Analysis and Field Observation of Precipitation and Horizontal Shifts of Concrete Dams. St. Petersburg: JSC "Vedeneev VNIIG", 24 p. [in Russian].

19. Kalinnikov, V. V., Ustinov, A. V., \& Zagretdinov, R. V. (2018). Influence of Irregularities of Water Vapor Field in Surface Layer of the Atmosphere on the Results of Satellite Monitoring of Hydropower Structures in Region of Reservoirs. Gidrotehnicheskoe stroitel'stvo [Hydraulic Engineering], 3, 19-25 [in Russian].

(C) V. V. Kalinnikov, A. V. Ustinov, N. S. Kosarev, 2020 
УДК 528:796

DOI: $10.33764 / 2411-1759-2020-25-3-42-52$

\section{ГЕОДЕЗИЧЕСКИЙ МОНИТОРИНГ ПРИ ЭКСПЛУАТАЦИИ ФУТБОЛЬНЫХ СТАДИОНОВ ЧЕМПИОНАТА МИРА 2018}

\section{Николай Владимирович Канашин}

Петербургский государственный университет путей сообщения Императора Александра I, 190031, Россия, г. Санкт-Петербург, Московский пр., 9, кандидат технических наук, доцент, тел. (812)457-85-38, e-mail: nikolay_kanashin@mail.ru

\section{Дмитрий Андреевич Афонин}

Петербургский государственный университет путей сообщения Императора Александра I, 190031, Россия, г. Санкт-Петербург, Московский пр., 9, кандидат технических наук, доцент, тел. (812)457-85-38, e-mail: afonin83@yandex.ru

Технологии геодезических работ при мониторинге различных сооружений, несмотря на исследования множества авторов, по-прежнему могут быть сопряжены с рядом трудностей, вызванных влиянием различных факторов. Целью статьи является изложение опыта выполнения геодезического мониторинга футбольных стадионов «Ростов Арена» и «Калининград» при сжатых сроках работ, необходимости высокой точности измерений и неблагоприятных для их выполнения условиях. Приведены два метода выполнения мониторинга - с созданием съемочной сети проложением ходов полигонометрии в сочетании со способом боковых пунктов и развитием ходов электронно-блочной тахеометрии. Изложены технология и особенности математической обработки измерений на каждом объекте. Приведены результаты рассмотренных методов, где показано, что применение способа боковых пунктов и электронно-блочной тахеометрии обеспечивает выполнение измерений с высокой точностью даже в неблагоприятных для наблюдений условиях. Изложены практические выводы и рекомендации. Статья может быть полезна специалистам в области мониторинга и геодезического контроля деформаций сооружений.

Ключевые слова: мониторинг сооружений, геодезические работы, контроль деформаций, плановые смещения, полигонометрия, электронно-блочная тахеометрия, повышение точности.

\section{Введение}

Геодезический мониторинг является необходимым этапом строительства и эксплуатации инженерных сооружений $[1,2]$. Способы его выполнения на различных объектах достаточно полно исследованы и изложены в литературе [3-24], однако разнообразие условий наблюдений, требования к точности измерений, экономические причины и иные факторы могут приводить к затруднениям в геодезических работах. С такой ситуацией столкнулись сотрудники кафедры «Инженерная геодезия» Петербургского государственного университета путей сообщения при геодезическом мониторинге планового положения построенных к Чемпионату мира 2018 г. стадионов «Ростов Арена» и «Калининград», где объем и расположение контролируемых элементов сооружений, высо- кие требования к точности измерений и сжатые сроки вынудили искать способы, позволяющие выполнять геодезический контроль в таких условиях без потерь в трудоемкости и экономической эффективности работ.

Стадион «Ростов Арена», рассчитанный на 43472 зрительских места, расположен на левом берегу р. Дон в городе Ростов-на-Дону. Основными несущими конструкциями сооружения являются монолитный железобетонный каркас, состоящий из колонн, пилонов, стен, балок перекрытий и балок трибун, а также стальные конструкции покрытия. Фундамент свайный в виде монолитных железобетонных ростверков. Основными несущими элементами покрытия являются консоли, уравновешенные оттяжками. Кровля мембранная, подконструкция представляет арочную систему из круглых труб, жестко примыкающих к консоли. Для контроля планового положения 
объекта пленочными отражателями закреплены 88 деформационных марок, 19 из которых закреплены на внешнем торце по периметру кровли, 23 - на ее опорных железобетонных частях, 23 - на несущих металлоконструкциях кровли и остальные - на несущих железобетонных колоннах в уровне второго этажа по периметру сооружения (рис. 1).

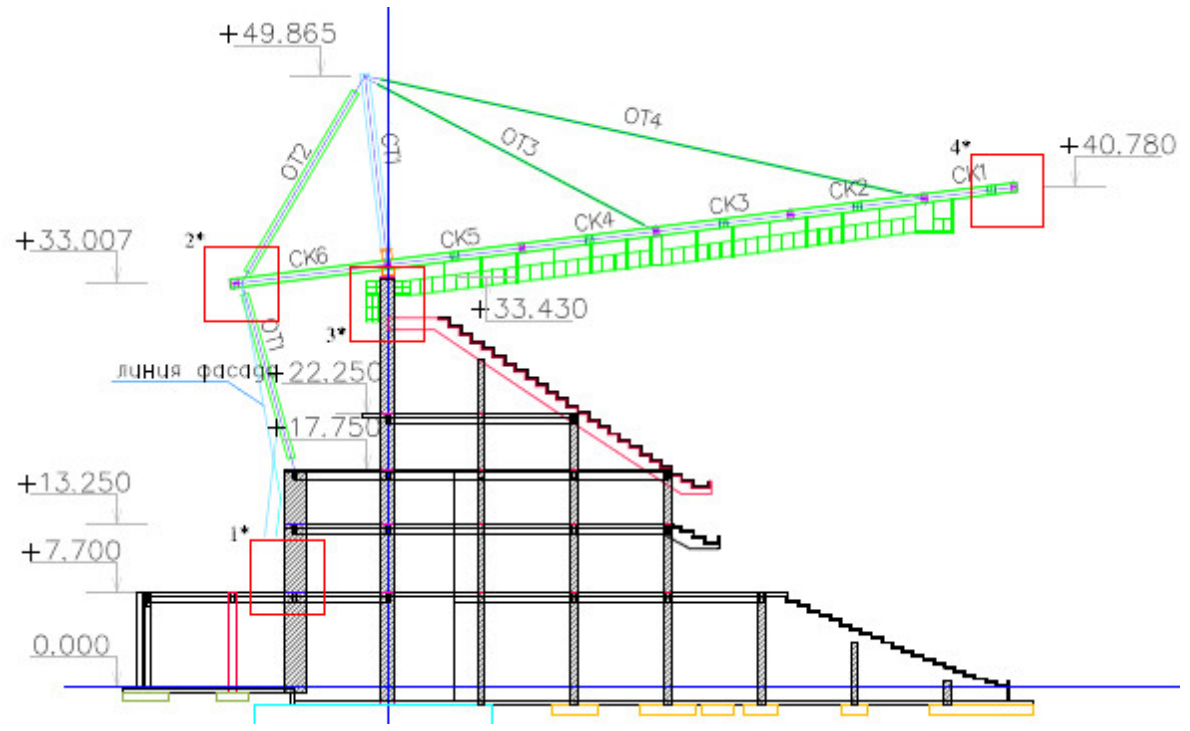

Рис. 1. Схема расположения контролируемых элементов на стадионе «Ростов Арена»: $1 *-4 *$ - контролируемые элементы, закрепленные деформационными марками

Футбольный стадион «Калининград» представляет собой четырехуровневое сооружение с тремя ярусами открытых трибун и рассчитан на 35000 зрителей. Фундаментом сооружения на свайном основании, основными несущими конструкциями трибун и подтрибунных помещений является стальной каркас, состоящий из колонн, балок перекрытий, наклонных балок трибун, связей и диафрагм. Плановые деформационные марки закреплены пленочными отражателями на стальных опорных колоннах в количестве 100 штук. При этом 20 марок расположены в основании колонн снаружи стадиона, а остальные 80 - на верхних ярусах внутри него (рис. 2).

В соответствии с [2] на обоих объектах для выполнения работ были разработаны программы мониторинга, согласно которым средняя квадратическая погрешность измерения горизонтальных перемещений принята равной $m_{\mathrm{s}}=5$ мм. Учитывая, что перемещение представляет разность положений марки в циклах $i+1$ и $i$, исходя из принципа равных влияний вычислили среднюю квадратическую погрешность определения планового положения марок $m_{s i}$ в каждом цикле наблюдений

$$
\begin{gathered}
m_{S}=\sqrt{m_{s_{i+1}}^{2}+m_{s_{i}}^{2}}=m_{s_{i}} \sqrt{2} ; \\
m_{s_{i}}=\frac{m_{S}}{\sqrt{2}}=3,5 \mathrm{MM}
\end{gathered}
$$

и среднюю квадратическую погрешность определения координат марок $m_{x}$ и $m_{y}$ в каждом цикле наблюдений

$$
\begin{gathered}
m_{s i}=\sqrt{m_{x}^{2}+m_{y}^{2}} ; \\
m_{x}=m_{y}=\frac{m_{s_{i}}}{\sqrt{2}}=2,4 \text { мм. }
\end{gathered}
$$

Исходная геодезическая сеть, представленная четырьмя пунктами принудительного центрирования, на каждом стадионе имела свои особенности. Так, на стадионе «Калининград» оптическая видимость была обеспечена только между парами смежных пунктов, а на стадионе «Ростов Арена» она отсутствовала полностью при невозможности включения в общий состав наблюдений некоторых из них по различным причинам (ограничение доступа, дефекты создания и иные). 


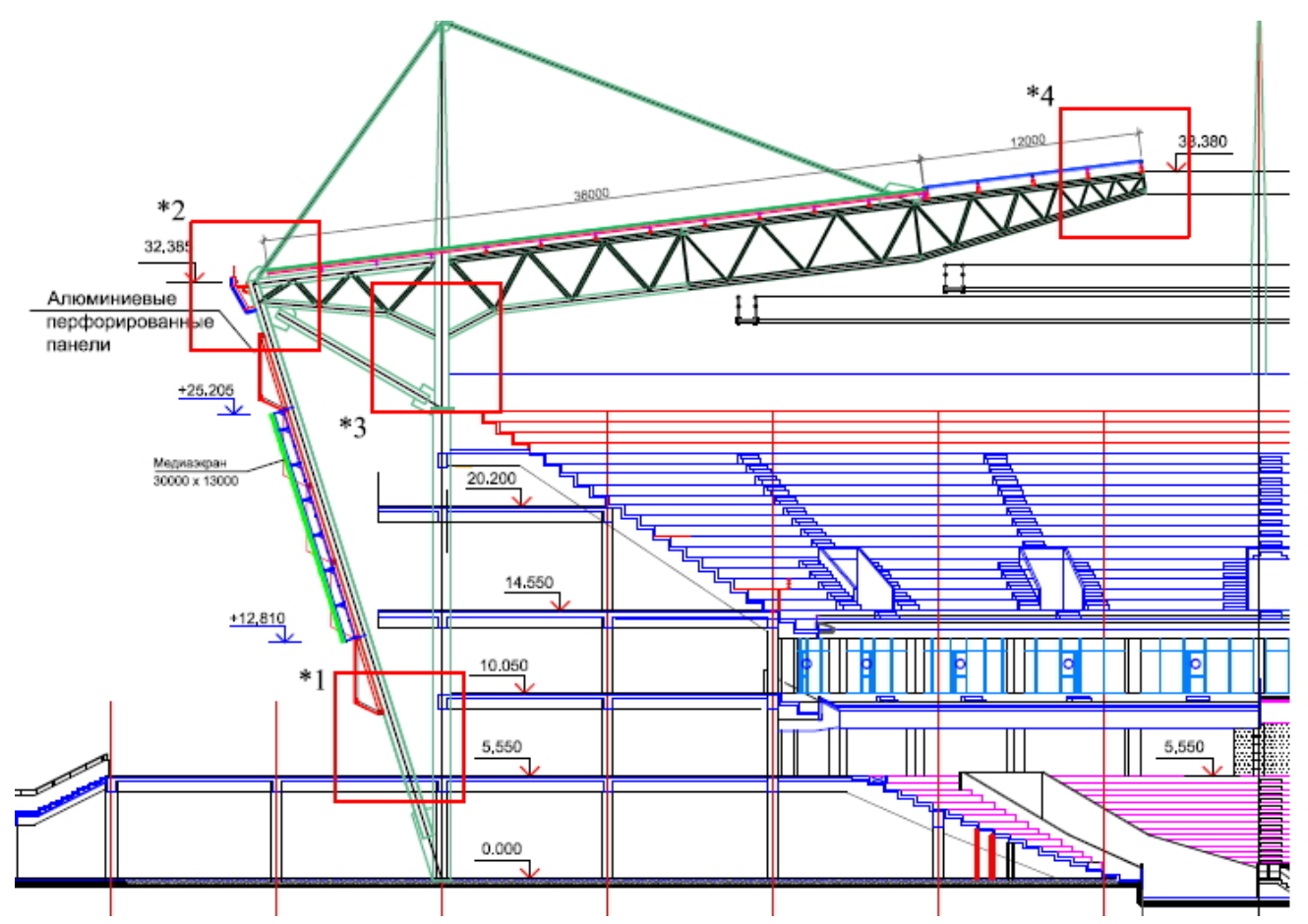

Рис. 2. Схема расположения контролируемых элементов на стадионе «Калининград»: $1 *-4 *$ - контролируемые элементы, закрепленные деформационными марками

Оптическая видимость с исходных пунктов на деформационные марки на объекте отсутствовала. Расположение марок как внутри, так и по внешнему периметру стадиона вынуждала создавать съемочную сеть единственным способом - проложением системы ходов полигонометрии, однако оно же не позволяло выполнять требование инструкции [25] для минимальной длины стороны хода вплоть до 2-го разряда включительно, что приводило к невозможности обеспечения точности наблюдений.

\section{Методы и материаль}

Геодезические работы на каждом объекте были выполнены разными исполнителями при использовании одного электронного тахеометра, имеющего априорную среднюю квадратическую погрешность измерения углов $m \beta=2 "$ и относительную погрешность измерения длин линий $m_{D}=2 \mathrm{Mм}+2 \mathrm{Mм} \times 1$ км (на призму). Поэтому были применены различные способы создания съемочной сети, показанные ниже.

На стадионе «Ростов Арена» проложили систему ходов полигонометрии с использо- ванием способа боковых пунктов, который заключается в добавлении в ход дополнительных точек и измерении с них или на них горизонтальных углов и расстояний до основных пунктов (рис. 3).

Данный прием известен в литературе [26], где указано, что он позволяет получить надежный контроль измерений в ходе полигонометрии, однако степень его эффекта не раскрывается. В качестве боковых пунктов использовали деформационные марки и исходные пункты, непосредственно измеряя расстояния до них с пункта наблюдения (расстояние $d_{2}$ на рис. 3 ), и косвенно как недоступные - со смежных точек хода (расстояния $d_{1}$ и $d_{3}$ на рис. 3 ). Кроме того, также косвенным путем были измерены расстояния между боковыми пунктами, а также между смежными точками хода (рис. 4).

Измерения горизонтальных углов при создании съемочной сети выполнены двумя приемами с одновременным измерением длин сторон хода. Предварительные координаты деформационных марок определены одновременно с проложением ходов полярной засечкой при двух положениях вертикального круга инструмента. 


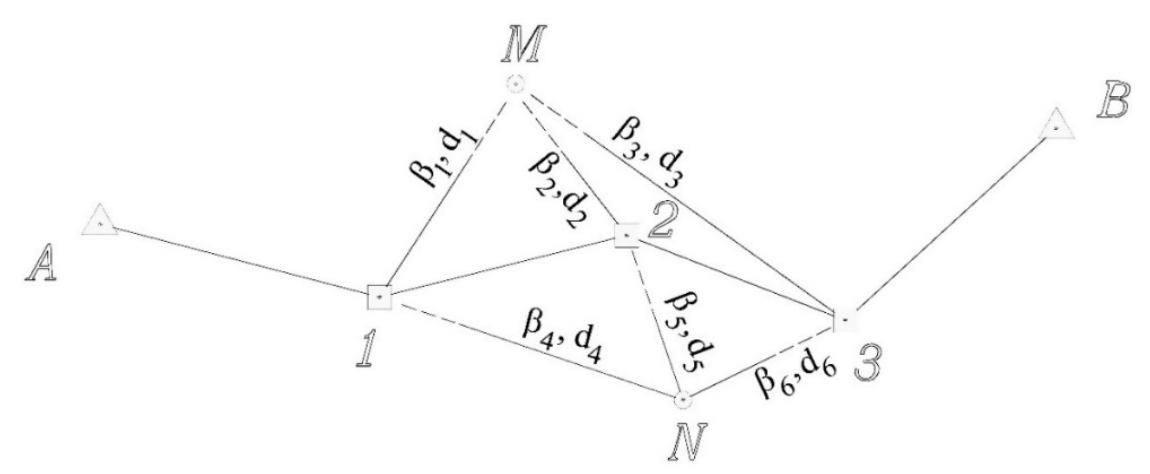

Рис. 3. Схема хода полигонометрии с боковыми пунктами:

А, В - исходные пункты; $1-3$ - пункты хода; M, N - боковые пункты; $\beta 1$ - $\beta 6$ - измеренные горизонтальные направления; $\mathrm{d} 1$ - d6 - измеренные горизонтальные проложения

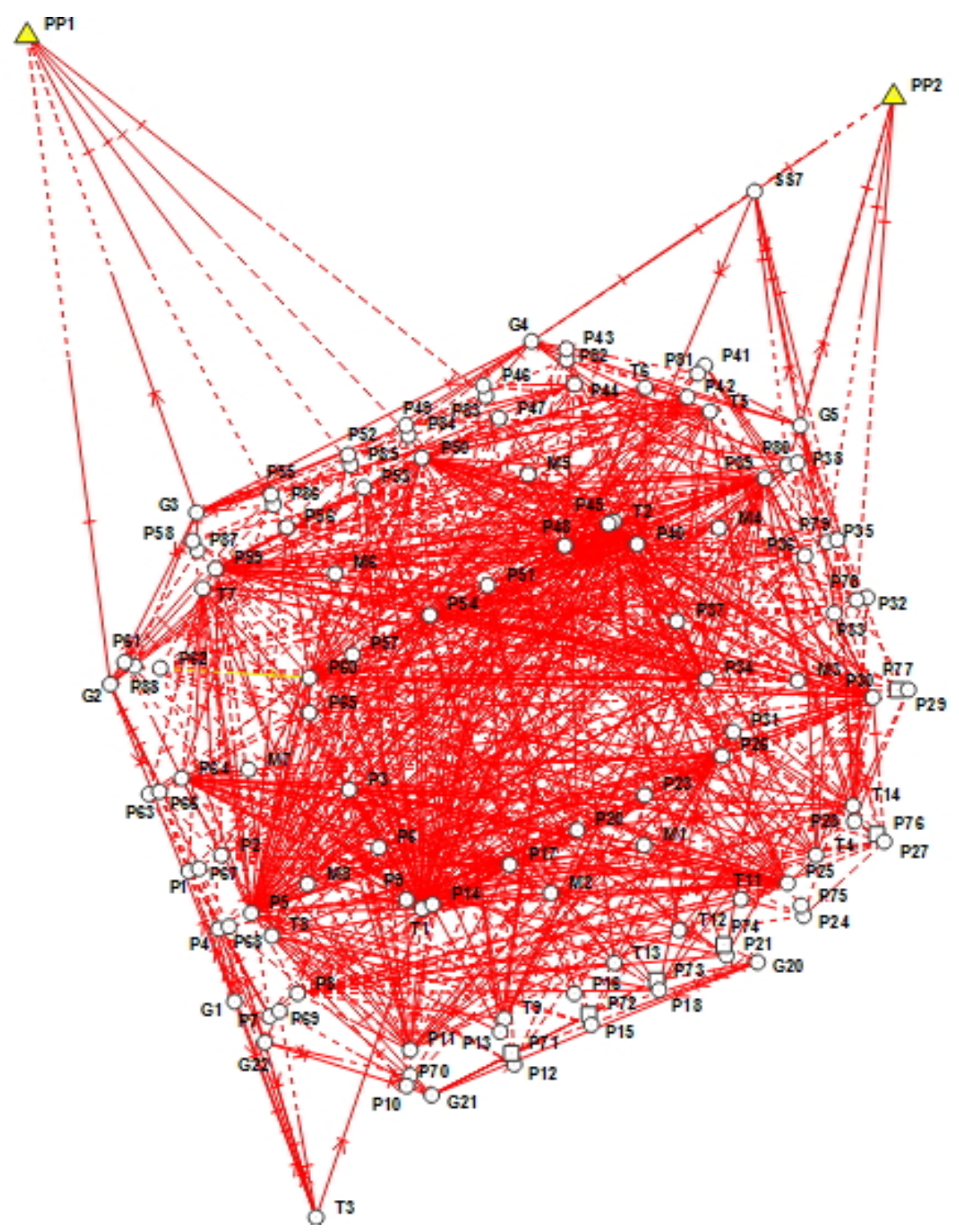

Рис. 4. Схема плановой съемочной сети при геодезическом мониторинге стадиона «Ростов Арена»:

P1 - P88 - деформационные марки; РP1 - РP2 - исходные пункты 
На стадионе «Калининград» с целью сокращения трудоемкости работ воспользовались технологией электронной блочной тахеометрии, применение которой при выполнении различных работ также изложено в литературе [27].

Полевые работы выполнялись поэтапно. На первом этапе для наблюдения расположенных по периметру внешнего контура стадиона деформационных марок проложили замкнутый ход электронно-блочной та- хеометрии. Линейно-угловые наблюдения выполнили одним приемом на все пункты. Станции и связующие точки выбирались таким образом, чтобы с одной станции было видно не менее двух связующих точек с предыдущей станции и две деформационные марки, при этом одна из деформационных марок одновременно является и связующей точкой, а одна из связующих точек является общей сразу для трех смежных станций (рис. 5).

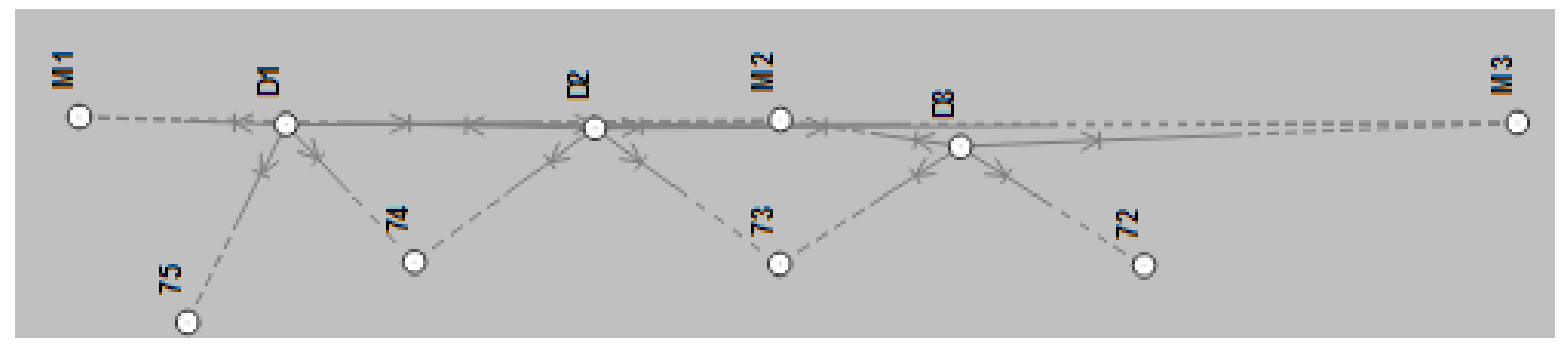

Рис. 5. Пример участка электронно-блочной тахеометрии

Так, на станции $D 1$ выполнены наблюдения на марки 74-75 и связующие точки $M 1$ и $M 2$, а на следующей станции $D 2$ - на деформационные марки 74 и 73, где марка 74 выступает связующей со станцией $D 1$, и три связующие точки $M 1, M 2$ и $M 3$, где точка $M 3$ определена для связи с последующими станциями. На станции $D 3$ выполнены наблюдения на деформационные марки 73 и 72, при этом марка 73 выступает связующей со станцией $D 2$ и двумя связующими точками $M 2, M 3$ и т. д.

В качестве связующих точек $M$ использовали два комплекта отражательных систем, состоящих из призменного отражателя и трегера, которые устанавливались на бетонный парапет, при этом контур трегера обводили маркером с целью исключения погрешностей за центрировку и редукцию при необходимости повторной установки марки.

На втором этапе работ осуществили привязку хода электронно-блочной тахеометрии к исходным пунктам, выполнив наблюдения с них на видимые деформационные марки и связующие точки.
На третьем этапе работ между точками $M$, расположенными по диагонали стадиона, был проложен разомкнутый ход полигонометрии с одновременным наблюдением во внутренней части сооружения шести вспомогательных пунктов съемочной сети, закрепленных пленочными отражателями на бетонных поверхностях несущих конструкций. Наблюдения в ходе выполнили двумя приемами. Расположение вспомогательных пунктов обеспечивало благоприятные условия выполнения многократной линейно-угловой засечки со свободных станций в разных местах внутренней части стадиона.

На завершающем четвертом этапе методом свободного станционирования относительно вспомогательных пунктов полярной засечкой определили плановое положение деформационных марок внутри стадиона, при этом каждая марка наблюдалась не менее чем с двух станций (рис. 6) с одновременным измерением расстояний между ними по методике, изложенной в работе [28]. 


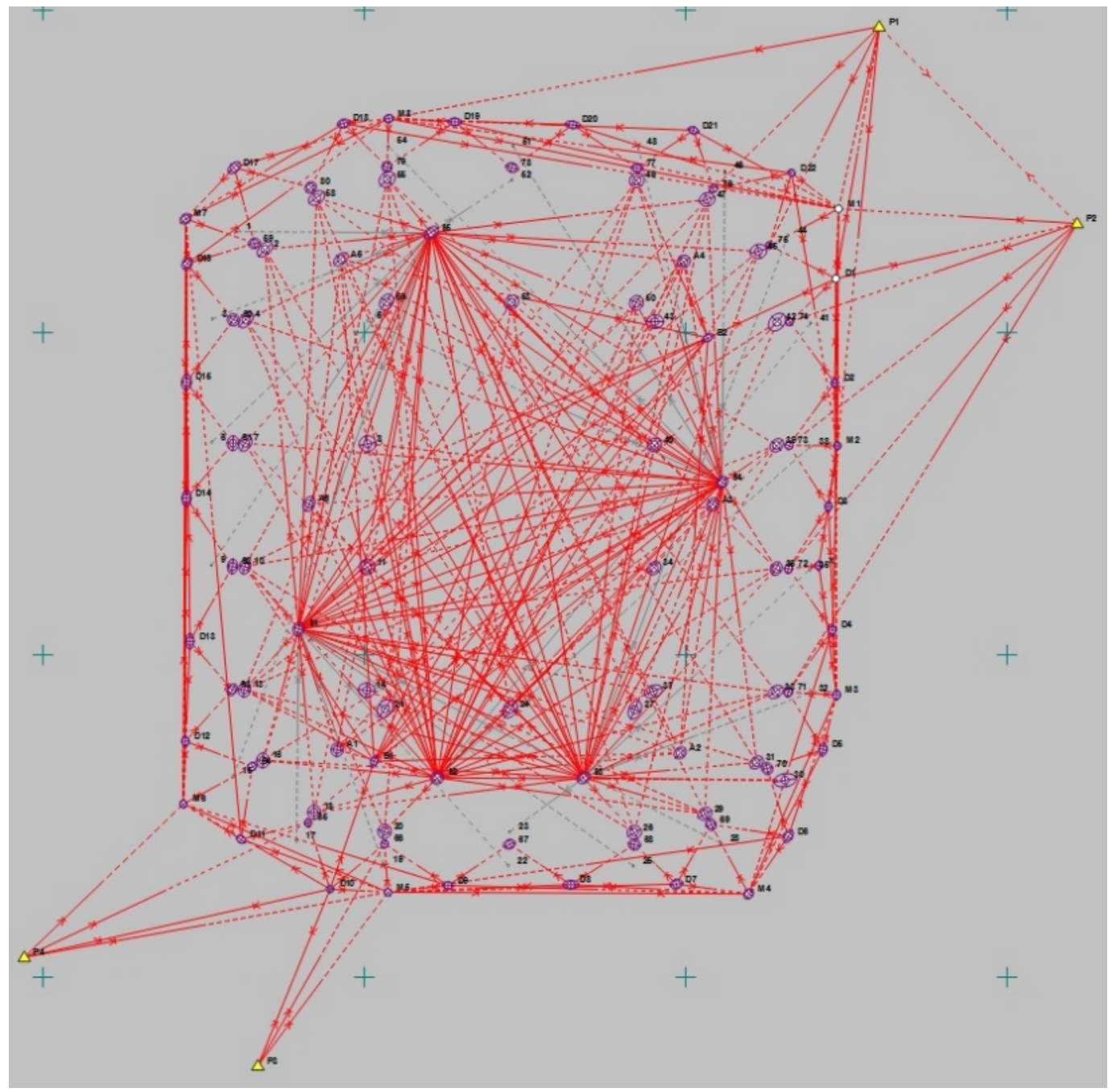

Рис. 6. Схема плановой съемочной сети при геодезическом мониторинге стадиона «Калининград»

Математическую обработку измерений на объектах выполнили в системе CREDO DAT 5.1. Исходя из априорных значений средних квадратических погрешностей, измеренным косвенным образом недоступным расстояниям вычисляли индивидуальные средние квадратические погрешности с целью пони- жения веса таких измерений по известной формуле оценки точности функций измеренных величин. Наиболее детально вопрос точности измерения недоступных расстояний электронным тахеометром исследован в работе [29], где выведена формула расчета их средней квадратической погрешности

$$
m_{d}=\sqrt{\left(\frac{d_{1}-d_{2} \cdot \cos \beta}{d}\right)^{2} \cdot m_{s}^{2}+\left(\frac{d_{2}-d_{1} \cdot \cos \beta}{d}\right)^{2} \cdot m_{s}^{2}+\left(\frac{d_{1} \cdot d_{2} \cdot \sin \beta}{d}\right)^{2} \cdot \frac{m_{\beta}^{2}}{\rho^{2}}}
$$

где $m_{d}$ - средняя квадратическая погрешность измерения недоступного расстояния; $m_{s}-$ априорная средняя квадратическая погрешность линейных измерений; $m_{\beta}-$ средняя квадратическая погрешность угловых измерений; $\rho$ - число секунд в радиане, равное 206265 ; $d_{1}$ и $d_{2}-$ непосредственно измеренные расстояния до точек, между которыми определяется недоступное расстояние.

После уравнивания измерений выполняли анализ поправок с целью выявления грубых 
погрешностей или некачественных измерений. Теоретические основы корректности такого подхода доказаны в работе [30], где показано, что грубая погрешность допущена в таком измерении, где величина поправки $\delta$ превышает его предельную погрешность

$$
\delta>\Delta=t m,
$$

где $\Delta$ - предельная погрешность; $t$ - коэффициент доверительной вероятности; $m$ - априорное значение средней квадратической погрешности.

Заметим, что некачественными измерениями считали такие, где величины поправок близки к предельной погрешности, но не превышают ее. Учитывая существенную избыточность измерений на обоих объектах, такие наблюдения исключали из обработки с повторным уравниванием всей сети.

\section{Результать}

Изложенные выше способы наблюдений позволили включить в съемочную сеть все деформационные марки и получить оценку точности измерений на каждую из них. По результатам их математической обработки средние квадратические погрешности определения координат марок на каждом объекте не превысили допустимых значений 2,4 мм, что позволяет сделать вывод об эффективно- сти обоих рассмотренных методов мониторинга в условиях необходимости обеспечения высокой точности наблюдений и сжатости сроков работ.

Для оценки эффективности способа боковых пунктов при математической обработке измерений на стадионе «Ростов Арена» выполнили два варианта уравнивания - с включением боковых пунктов в съемочную сеть и без таких пунктов. Это позволило опытным путем установить, что применение боковых пунктов при проложении ходов полигонометрии повышает точность определения координат съемочной сети в 1,5-2 раза. При этом основное влияние на нее оказывают измерения, выполненные с точек хода полигонометрии на боковые пункты, и в меньшей степени - измерения, связывающие смежные из них.

\section{Заключение}

Безусловно, изложенные методы мониторинга не являются единственно возможными при работе в приведенных выше условиях и не лишены ряда недостатков, главным из которых является увеличение трудоемкости полевых и камеральных работ в сравнении с традиционными методами измерений. Однако при должной квалификации исполнителей эта величина несущественна.

\section{БИБЛИОГРАФИЧЕСКИЙ СПИСОК}

1. СНиП 3.01.03-84: свод правил СП 126.13330.2012. Геодезические работы в строительстве. Актуализированная редакция. - М., 2011. -77 c.

2. ГОСТ 31937-2011. Здания и сооружения. Правила обследования и мониторинга технического состояния. - М., 2011. - 54 с.

3. Олейник А. М. Организация системы геодезического мониторинга объектов нефтегазового комплекса в криолитозоне // Интерэкспо ГЕОСибирь-2012. VIII Междунар. науч. конгр. : Междунар. науч. конф. «Геодезия, геоинформатика, картография и маркшейдерия» : сб. материалов в 3 т. (Новосибирск, 10-20 апреля 2012 г.). Новосибирск : СГГА, 2012. Т. 1. - С. 166-170.

4. Лазарев В. М. Система геодезического обеспечения мониторинга оползневых процессво на территории города Томска // Интерэкспо ГЕОСибирь-2012. VIII Междунар. науч. конгр. :
Междунар. науч. конф. «Геодезия, геоинформатика, картография и маркшейдерия» : сб. материалов в 3 т. (Новосибирск, 10-20 апреля 2012 г.). Новосибирск : СГГА, 2012. Т. 1. - С. 77-83.

5. Ямбаев Х. К., Ященко В. Р. Геодезический мониторинг движений земной коры: состояние, возможности, перспектива // Интерэкспо ГЕОСибирь-2012. VIII Междунар. науч. конгр. : Междунар. науч. конф. «Геодезия, геоинформатика, картография и маркшейдерия» : сб. материалов в 3 т. (Новосибирск, 10-20 апреля 2012 г.). Новосибирск : СГГА, 2012. Т. 3. - С. 139-155.

6. Середович В. А., Середович А. В. Геодезический мониторинг деформаций Усть-Каменогорского судоходного шлюза // Интерэкспо ГЕОСибирь-2012. VIII Междунар. науч. конгр. : Междунар. науч. конф. «Геодезия, геоинформатика, картография и маркшейдерия» : сб. матери- 
алов в 3 т. (Новосибирск, 10-20 апреля 2012 г.). Новосибирск : СГГА, 2012. Т. 3. - С. 127-133.

7. Геодезическое обеспечение геодинамического мониторинга объектов недропользования / А. А. Панжин, А. Д. Сашурин, А. Н. Панжина, Б. Т. Мазуров // Вестник СГУГиТ. - 2016. Вып. 4 (34). - С. 26-39.

8. Богомолова Н. Н. Методика мониторинга тоннелей на основе комплексного применения геодезических средств измерений и методов статистического анализа // Записки горного института. - 2013. - Т. 204. - С. 40-45.

9. Устинов А. В. Технология спутникового геодезического мониторинга гидротехничесикх сооружений // Гидротехническое строительство. - 2014. - № 6. - С. 39-43.

10. Информационная система геодезического мониторинга деформаций транспортных сооружений / М. Я. Брынь, А. А. Никитчин, В. В. Федянин, А. Д. Хомоненко // Наука и транспорт. 2013. - № 2. - С. 58-60.

11. Ознамец В. В., Дегбеньон О. П. А. Геодезическое обеспечение мониторинга береговой линии (на примере берега Атланческого океана Республики Бенин) // Изв. вузов. Геодезия и аэрофотосъемка. - 2018. - № 3. - С. 249-256.

12. Шоломицкий А. А., Лагутина Е. К., Соболева Е. Л. Высокоточные геодезические измерения при деформационном мониторинге аквапарка // Вестник СГУГиТ. - 2017. - Т. 22, № 3. C. $45-59$.

13. Применение современных автоматизированных геодезических приборов для мониторинга гидротехнических сооружений ГЭС / В. Г. Сальников, В. А. Скрипников, М. А. Скрипникова, Т. А. Хлебникова // Вестник СГУГиТ. 2018. - T. 23, № 3. - C. 108-124.

14. Kontogianni V. Induced deformation during tunnel excavation: Evidence from geodetic monitoring // Engineering Geology. - 2005. - Vol. 79, Issues 1-2. - P. 115-126.

15. New integrated geodetic monitoring system at Stromboli volcano (Italy) / G. Puglisi, A. Bonaccorso, M. Mattia, M. Aloisi, A. Bonforte, O. Campisi, M. Cantarero, G. Falzone, B. Puglisi, M. Rossi // Engineering Geology. - 2005. - Vol. 79, Issues 1-2. P. 13-31.

16. Geodetic monitoring and geotechnical analyses of subsidence induced settlements of historic structures / C. Castagnetti, R. Cosentini, R. Lancellotta, A. Capra // Structural Control and Health Monitoring. - 2017. - Vol. 24, Issue 12. - P. 42-49.

17. Geodetic monitoring of the subsidence in the Po River Delta (Italy) / N. Cenni, M. Fabris, S. Fiaschi, V. Achilli, M. Floris, A. Menin, M. Mone- go, P. Riccardi // Geophysical Research Abstracts. 2019. - Vol. 21. - P. 1-11.

18. Geodetic monitoring methods of high-rise constructions deformations with modern technologies application / M. Kuttykadamov, K. Rysbekov, I. Milev, K. Ystykul, B. Bektur // Journal of Theoretical and Applied Information Technology. 2016. - Vol. 93. - P. 24-31.

19. Nazirov J., Davlatshoev S., Kozlov D. Geodetic Monitoring of Large-Span Underground Facilities During Construction of the Rogun Hydroelectric Power Station // Power Technology and Engineering. - 2018. - Vol. 52. - P. 400-404.

20. Горохова Е. И. Геомониторинг инженерных сооружений и прогнозирование их деформаций по данным лазерного сканирования // Вестник СГУГиТ. - 2016. - Вып. 2 (34). - С. 65-72.

21. Маркузе Ю. И., Куонг Л. А. Исследование алгоритма для анализа деформаций геодезических пунктов при наблюдении за горизонтальными смещениями гидротехнических сооружений // Геодезия и картография. - 2017. - № 7. - С. 23-30.

22. Мониторинг деформационных процессов природного происхождения при изыскательских работах на площадке АЭС / О. Н. Галаганов, Т. В. Гусева, И. С. Крупенникова, А. Н. Мокрова, Н. К. Розенберг // Мониторинг. Наука и технологии. - 2017. - № 2 (31). - С. 15-23.

23. Брынь М. Я., Никитчин А. А., Толстов Е. Г. Геодезический мониторинг объектов инфраструктуры железнодорожного транспорта спутниковыми методами // Транспорт Российской Федерации. - 2010. - № 4 (29). - С. 58-60.

24. Брынь М. Я., Толстов Е. Г., Богомолова Н. Н. Геодезические наблюдения за деформациями сооружаемых тоннелей // Путь и путевое хозяйство. - 2013. - № 9. - С. 16-19.

25. Инструкция по полигонометрии и трилатерации. - М. : Недра, 1976. - 104 с.

26. Асур В. Л., Кутузов М. Н., Муравин М. М. Высшая геодезия. - Изд. 2, перераб. и доп. - М. : Недра, 1979. - 398 с.

27. Вальков В. А. Геодезические наблюдения за процессом деформирования высотных сооружений с использованием технологии наземного лазерного сканирования: дис. ... канд. техн. наук. - Санкт-Петербург, 2015. - 146 с.

28. Канашин Н. В., Никитчин А. А. Геодезический мониторинг строительства стадиона «Спартак» в г. Москве // Геопрофи. - 2014. № 3. - C. $8-11$.

29. Афонин Д. А. Построение геодезической разбивочной сети, закрепляемой пленочными отражателями // Записки Горного института. 2012. - T. 199. - C. 301-308. 
30. Коугия В. А. Избранные труды : монография / под ред. М. Я. Брыня - СПб. : Петер- бургский государственный университет путей сообщения, 2012. - 448 с.

Получено 25.05.2020

(C) Н. В. Канашин, Д. А. Афонин, 2020

\section{GEODETIC MONITORING DURING THE OPERATION THE FOOTBALL STADIUMS OF THE WORLD CHAMPIONSHIP 2018}

\section{Nikolay V. Kanashin}

Emperor Alexander I Saint Petersburg State Transport University, 9, Moskovsky Prospekt, Saint Petersburg, 190031, Russia, Ph. D., Associate Professor, phone: (812)457-85-38, e-mail: nikolay_kanashin@mail.ru.

\section{Dmitry A. Afonin}

Emperor Alexander I Saint Petersburg State Transport University, 9, Moskovsky Prospekt, Saint Petersburg, 190031, Russia, Ph. D., Associate Professor, phone: (812)457-85-38, e-mail: afonin83@yandex.ru

The technologies of geodetic works in monitoring of various structures can still be associated with a number of difficulties caused by the influence of different factors despite the studies of many authors on that theme. The article describes the high accuracy geodetic monitoring of the football stadiums "Rostov Arena" and "Kaliningrad" that took place in a short time frame and in adverse weather conditions. The article gives two geodetic monitoring methods such as creating serving network by side-points method and electronic block tacheometry. The technology and the adjustment of measurements made during monitoring are described in the article. The results show that the use of the side-points method and electronic block tacheometry ensures high accuracy measurements even in adverse conditions for observations. Practical conclusions and recommendations are set out. The article may be useful for specialists in the field of monitoring and geodetic control of deformations of structures.

Key words: geodetic monitoring, deformation control, horizontal displacements, polygonometry, electronic block tacheometry, accuracy increase.

\section{REFERENCES}

1. Construction Rules and Regulations. Code of practice SP 126.13330.2012. (2011). Geodetic works in construction. Updated edition]. Moscow: Ministry of Regional Development [in Russian].

2. Standarts Russian Federation. (2014). GOST 31937-2011. Buildings and constructions. Rules for inspection and monitoring of technical condition. Moscow: Ministry of Regional Development [in Russian].

3. Oleynik, A. M. (2012). Organization of a geodetic monitoring system for oil and gas facilities in the permafrost zone. In Sbornik materialov Interekspo GEO-Sibir'-2012: Mezhdunarodnoy nauchnoy konferentsii: T. 1. Geodeziya, geoinformatika, kartografiya i marksheyderiya [Proceedings of Interexpo GEO-Siberia-2012: International Scientific Conference: Vol. 1. Geodesy, Geoinformatics, Cartography and Mine Surveying] (pp. 166-170). Novosibirsk: SSGA Publ. [in Russian].
4. Lazarev, V. M. (2012). The system of geodetic support for monitoring landslide processes in the city of Tomsk. In Sbornik materialov Interekspo GEO-Sibir'-2012: Mezhdunarodnoy nauchnoy konferentsii: T. 1. Geodeziya, geoinformatika, kartografiya i marksheyderiya [Proceedings of Interexpo GEO-Siberia-2012: International Scientific Conference: Vol. 1. Geodesy, Geoinformatics, Cartography and Mine Surveying] (pp. 77-83). Novosibirsk: SSGA Publ. [in Russian].

5. Yambaev, Kh. K., \& Yashchenko, V. R. (2012). Geodetic monitoring of movements of the earth's crust: state, capabilities, perspective. In Sbornik materialov Interekspo GEO-Sibir'-2012: Mezhdunarodnoy nauchnoy konferentsii: T. 3. Geodeziya, geoinformatika, kartografiya i marksheyderiya [Proceedings of Interexpo GEO-Siberia-2012: International Scientific Conference: Vol. 3. Geodesy, Geoinformatics, Cartography and Mine Surveying] (pp 139-155). Novosibirsk: SSGA Publ. [in Russian]. 
6. Seredovich, V. A., \& Seredovich, A. V. (2012). Geodetic monitoring of deformations of the Ust-Kamenogorsk shipping lock In Sbornik materialov Interekspo GEO-Sibir'-2012: Mezhdunarodnoy nauchnoy konferentsii: T. 3. Geodeziya, geoinformatika, kartografiya i marksheyderiya [Proceedings of Interexpo GEO-Siberia-2012: International Scientific Conference: Vol. 3. Geodesy, Geoinformatics, Cartography and Mine Surveying] (pp. 127-133). Novosibirsk: SSGA Publ. [in Russian].

7. Panzhin, A. A. Sashurin, A. D., Panzhina, A. N., \& Mazurov, B. T. (2016). Geodetic support of geodynamic monitoring of subsoil use objects. Vestnik SGUGiT [Vestnik SSUGT], 4(34), 26-39 [in Russian].

8. Bogomolova, N. N. (2013). Tunnel monitoring technique based on the integrated use of geodetic measuring instruments and statistical analysis methods. Zapiski gornogo instituta [Journal of Mining Institute], 204, 40-45 [in Russian].

9. Ustinov, A.V. (2014). Technology of satellite geodetic monitoring of hydraulic structures. Gidrotekhnicheskoe stroitel'stvo [Hydraulic Engineering], 6, 39-43 [in Russian].

10. Bryn', M. Ya., Nikitchin, A. A., Fedyanin, V. V., \& Khomonenko, A. D. (2013). Information system for geodetic monitoring of deformations of transport structures Nauka i transport. [Science and Transport], 2, 58-60 [in Russian].

11. Oznamets, V. V., \& Degben'on, O. P. A. (2018). Geodetic support for monitoring the coastline (on the example of the Atlantic coast of the Republic of Benin). Izvestiya vusov. Geodeziya i aerofotos"emka [Izvestiya Vusov. Geodesy and Aerophotography], 3, 249-256 [in Russian].

12. Sholomitskiy, A. A., Lagutina, E. K., \& Soboleva, E. L. (2016). High-precision geodetic measurements in deformation monitoring of the water park. Vestnik SGUGiT [Vestnik SSUGT], 22(3), 45-59 [in Russian].

13. Sal'nikov, V. G., Skripnikov, V. A., Skripnikova, M. A., \& Khlebnikova, T. A. (2018). The use of modern automated geodetic instruments for monitoring hydraulic structures of hydroelectric power plants. Vestnik SGUGiT [Vestnik SSUGT], 23(3), 108-124 [in Russian].

14. Kontogianni, V. (2005). Induced deformation during tunnel excavation: Evidence from geodetic monitoring. Engineering Geology, 79(1-2), 115-126.

15. Puglisi, G., Bo-naccorso, A., Mattia, M., Aloisi, M., Bonforte, A., Campisi, O., Cantarero, M., Falzone, G., Puglisi, B., \& Rossi, M. (2005). New integrated geodetic monitoring system at Stromboli volcano (Italy). Engineering Geology, 79(1-2), 13-31.
16. Castagnetti, C., Cosentini, R., Lancellotta, R., \& Capra, A. (2017). Geodetic monitoring and geotechnical analyses of subsidence induced settlements of historic structures. Structural Control and Health Monitoring, 24(12), 42-49.

17. Cenni, N., Fabris, M., Fiaschi, S., Achilli, V., Floris, M., Menin, A., Monego, M. \& Riccardi, P. (2019). Geodetic monitoring of the subsidence in the Po River Delta (Italy). Geophysical Research Abstracts, 21, 1-11.

18. Kuttykadamov, M., Rysbekov, K., Milev, I., Ystykul, K., \& Bektur, B. (2016). Geodetic monitoring methods of high-rise constructions deformations with modern technologies application. Journal of Theoretical and Applied Information Technology, 93, 24-31.

19. Nazirov, J., Davlatshoev, S., \& Kozlov, D. (2018). Geodetic Monitoring of Large-Span Underground Facilities During Construction of the Rogun Hydroelectric Power Station. Power Technology and Engineering, 52, 400-404.

20. Gorokhova, E. I. (2016). Geomonitoring of engineering structures and forecasting their deformations using laser scanning data. Vestnik SGUGiT [Vestnik SSUGT], 2(34), 65-72 [in Russian].

21. Markuze, Yu. I., \& Kuong, L. A. (2017). The study of the algorithm for the analysis of deformations of geodetic points when observing the horizontal displacements of hydraulic structures. Geodeziya i kartografiya [Geodesy and Cartography], 7, 23-30 [in Russian].

22. Galaganov, O. N., Guseva, T. V., Krupennikova, I. S., Mokrova, A. N., \& Rozenberg, N. K. (2017). Monitoring of deformation processes of natural origin during survey work at the NPP site. Monitoring. Nauka i tekhnologii [Monitoring. Science and Technology], 2(31), 15-23 [in Russian].

23. Bryn', M. Ya., Nikitchin, A. A., \& Tolstov, E. G. (2010). Geodetic monitoring of railway transport infrastructure facilities by satellite methods. Transport rossiyskoy Federatsii [Transport of the Russian Federation], 4(29), 58-60 [in Russian].

24. Bryn', M. Ya., Tolstov, E. G., \& Bogomolova, N. N. (2013). Geodetic observations of deformations of tunnels under construction. Put' i putevoe khozyaystvo [Path and Track Facilities], 9, 16-19 [in Russian].

25. Instruktsiya po poligonometrii i trilateratsii [Polygonometry and trilateration instructions]. (1976). Moscow: Nedra Publ., 104 p. [in Russian].

26. Asur, V. L., Kutuzov, M. N., \& Muravin, M. M. (1979). Vysshaya geodeziya [The higher geodesy]. Moscow: Nedra Publ., 398 p. [in Russian].

27. Val'kov, V. A. (2015). Geodetic survey of the high-rise structures deformation using terrestrial 
laser scanning technology. Candidate's thesis. Sankt-Peterburg, 146 p. [in Russian].

28. Kanashin, N. V., \& Nikitchin, A. A. (2014).

Geodetic monitoring of the construction of the Spartak Stadium in Moscow. Geoprofi [Geoprofi], 3, 8-11 [in Russian].

29. Afonin, D. A. (2012). Construction of a geodetic alignment network fixed by film reflectors.

Received 25.05.2020
Zapiski gornogo instituta [Journal of Mining Institute], 199, 301-308 [in Russian].

30. Kougiya, V. A. (2012). Izbrannye trudy [Selected works]. M. Ya. Bryn' (Ed). Saint Petersburg: Petersburg State University of Railway Engineering Publ., 448 p. [in Russian].

(C) N. V. Kanashin, D. A. Afonin, 2020 
УДК 001.891.573:528.482:626

DOI: $10.33764 / 2411-1759-2020-25-3-53-62$

\section{АНАЛИЗ ВХОДНЫХ ВОЗДЕЙСТВУЮЩИХ ФАКТОРОВ И ВЫБОР ТИПА МАТЕМАТИЧЕСКОЙ МОДЕЛИ НА ЭТАПАХ ИХ СТРУКТУРНОЙ И ПАРАМЕТРИЧЕСКОЙ ИДЕНТИФИКАЦИИ ДЛЯ ИЗУЧЕНИЯ ДЕФОРМАЦИОННОГО СОСТОЯНИЯ ПЛОТИНЫ САЯНО-ШУШЕНСКОЙ ГЭС В ПЕРИОД 2013-2016 ГОДОВ}

\section{Наталья Николаевна Кобелева}

Сибирский государственный университет геосистем и технологий, 630108, Россия, г. Новосибирск, ул. Плахотного, 10 , кандидат технических наук, доцент кафедры космической и физической геодезии, тел. (383)361-01-59, e-mail: n.n.kobeleva@mail.ru

\section{Валерий Степанович Хорочилов}

Сибирский государственный университет геосистем и технологий, 630108, Россия, г. Новосибирск, ул. Плахотного, 10, доктор технических наук, профессор кафедры космической и физической геодезии, тел. (383)361-01-59, e-mail: Khoroshilovvs@mail.ru

Оценка эксплуатационного состояния гидротехнического сооружения и его техническая безопасность должны выполняться путем сопоставления полученных количественных и качественных диагностических показателей с их критериальными значениями. С этой целью должны быть разработаны прогнозные математические модели поведения сооружения, которые рекомендуется откалибровать по данным натурных наблюдений. В статье рассматриваются особенности построения прогнозных математических моделей для изучения деформационного процесса перемещений гребня плотины Саяно-Шушенской ГЭС. Для различных сочетаний входных воздействующих факторов, включающих результаты натурных наблюдений и расчетные значения составляющих перемещений, проведены исследования наиболее удачно сконструированных прогнозных математических моделей, на основе которых выполнено прогнозирование контролируемых точек тела плотины для различных временных этапов ее эксплуатации. Представлены преимущества применения построенных прогнозных моделей для различных температурных условий работы сооружения (средний, теплый и холодный в температурном отношении года).

Ключевые слова: высоконапорная плотина, геодезические данные, прогнозная математическая модель, структурная и параметрическая идентификация, прогнозирование, перемещение контролируемых точек, дискретность математической модели, деформация сооружения.

\section{Введение}

Одной из важнейших задач при эксплуатации высоконапорных плотин является обеспечение их надежной и безопасной работы $[1,2]$, а учитывая тот факт, что многие из этих сооружений эксплуатируются уже продолжительное время, то вероятность возникновения и развития негативных процессов существенно повышается.

Для контроля технического состояния тела плотины Саяно-Шушенской ГЭС (СШГЭС) в качестве одного из диагностических показателей приняты радиальные перемещения гребня плотины ключевой секции 33, измеренные обратными отвесами, и соответствующие им значения таких параметров как гидростатическое давление, а также температура бетона тела плотины в нижней и верхней базовых точках [3].

Натурные геодезические наблюдения являются одними из наиболее важных и незаменимых при изучении состояния высоконапорных плотин в процессе их эксплуатации [4-8]. Именно эти данные служат основой для построения прогнозных математических моделей в целях анализа механизма протекающих в этих сооружениях деформационных процессов [9-16].

\section{Методы исследований}

В процессе эксплуатации плотины СШГЭС воздействие температурного фактора являет- 
ся вторым по значимости после гидростатического давления. Так, в зимнее время года в результате этого воздействия плотина наклоняется в сторону нижнего бьефа, т. е. в ту же сторону, что и от воздействия гидростатической нагрузки. Вследствие зимней сработки водохранилища $[3,17,18]$ это воздействие не ведет к ухудшению напряженного состояния тела плотины. В то же время, в летний период, за счет прогрева низовой грани плотина наклоняется в направлении, противоположном действию гидростатической нагрузки. А это уже несет опасность для отремонтированных зон плотины за счет нарушения установленного определенного баланса между значениями температурной и гидростатической составляющими перемещений в периоды заполнения водохранилища (май - сентябрь) и его начальной сработки (вторая половина сентября-октября).

Выявить эти составляющие перемещений возможно расчетным путем на основе конечно-элементного анализа состояния сооружения в процессе построения температурного поля плотины. Так, в работе [19] на основе подобного анализа за периоды работы плотины с 2004 по 2015 г. были выделены: благоприятный (теплый) в температурном отношении год; средний и неблагоприятный (холодный) годы. Ранее в работе [9] мы интерпретировали данное обстоятельство как работу сооружения в штатном (средний в температурном отношении год) и нештатном режимах работы (теплый и холодный годы). При прогнозировании перемещений тела плотины это позволяло вводить поправку в виде транспортного запаздывания в конечные результаты прогнозирования.

С целью устранения угрозы нарушения целостности отремонтированных зон тела плотины следует снижать уровень гидростатического напора в зимний период и допускать его повышение в летний период работы сооружения. Подобные рекомендации были положены в основу регулирования диспетчерского графика работы водохранилища при разработке правил использования водных ресурсов (ПИВР) Саяно-Шушенской ГЭС [19]. Данные рекомендации по скорости наполнения водохранилища в период эксплуатации 2013-2016 гг. показали их эффективность с точки зрения обеспечения безопасной работы сооружения.

Последовательность выполнения оценивания параметров для строящихся математических моделей складывалась из двух основных этапов. На первом этапе оценивались параметры $\hat{\phi}, \hat{\beta}$ по математическому ожиданию, а на втором - свойства шума по остаточной дисперсии.

\section{Результаты исследований}

Ранее в $[9,10]$ были представлены различные прогнозные математические модели в виде рекуррентных уравнений различных типов для описания поведения плотины СШГЭС после аварии 2009 г. При построении моделей были использованы следующие входные воздействующие факторы: $U_{k}$ гидростатическое давление (уровень верхнего бьефа); $T_{k \text {.низ }}$ и $T_{k \text {.верх }}$ - температура бетона тела плотины в нижней и верхней базовых точках. Дискретность исходных данных составляла 15 и 30 дней.

Для последующих исследований была выбрана динамическая модель 3-го типа (декорреляция входных факторов) с двумя входными воздействиями $\Delta x\left(\Delta U_{k}, \Delta T_{k}\right)$ с возможностью последовательного ввода основных коррелирующих факторов в модель:

$$
\begin{aligned}
& U_{k}=\phi_{1} U_{k-1}+\beta_{1} U_{k}+U_{0} ; \\
& x_{k}=\phi_{2} x_{k-1}+\beta_{2} T_{k}+x_{0} ; \\
& \Delta x_{k}=\phi_{3} \Delta x_{k-1}+\beta_{3} \Delta U_{k}+\Delta x_{0}+\gamma \omega_{k} .
\end{aligned}
$$

Отметим, что на этапе структурной идентификации модели существенное влияние оказывает выбор входных воздействий, дискретность наблюдений и, как результат этого влияния, - величины значений остаточных ошибок шумовой компоненты в процессе конструирования модели, по которым оценивается их разброс с использованием стандарта $\sigma_{k}$ и строятся графики автокорреляционной функции. 
Для построения математических моделей были использованы входные воздействия в следующих сочетаниях:

- $U_{k}$ (гидростатическое давление) и $T_{k \text {.низ }}$ (температура бетона тела плотины в нижней базовой точке), как результаты натурных наблюдений;

- $U_{k}$ и $\Delta T_{\text {расч. }}$ (температурная составляющая перемещений, полученная на основе конечно-элементной модели);

- $\Delta U_{\text {расч. }}$ (гидростатическая составляющая перемещений) и $\Delta T_{\text {расч. }}$, полученные на основе конечно-элементной модели.

Выбранный нами 2013 г. для построения прогнозных математических моделей в качестве периода основания прогноза характеризуется как «средний» в температурном отношении год.

Построенные математические модели 3-го типа с декорреляцией входных воздействий $x\left(U_{k}, T_{k}\right)$ и дискретностью наблюдений через каждые 3 дня представлены ниже:

$$
\begin{aligned}
& U_{k}=0,8974 U_{k-1}+0,1578 T_{\text {к.низ }}+52,747 ; \\
& x_{k}=0,9342 x_{k-1}+0,1323 T_{\kappa . \text { низ }}+6,432 ; \\
& \Delta x_{k}=0,4210 \Delta x_{k-1}+1,2924 \Delta U_{k}-0,059+0,6197 \omega_{k} ; \\
& \omega_{k}=0,1428 \omega_{k-1}+0,2383 \omega_{k-2}+\xi_{k} ; \\
& U_{k}=0,8866 U_{k-1}-0,0581 \Delta T_{\text {расч. }}+61,299 ; \\
& x_{k}=0,9142 x_{k-1}-0,0812 \Delta T_{\text {расч. }}+8,552 ; \\
& \Delta x_{k}=0,4238 \Delta x_{k-1}+1,3320 \Delta U_{k}-0,087+0,6190 \omega_{k} ; \\
& \omega_{k}=0,1421 \omega_{k-1}+0,2471 \omega_{k-2}+\xi_{k} ; \\
& U_{k}=0,8822 U_{k-1}-0,1993 \Delta T_{\text {расч. }}+4,476 ; \\
& x_{k}=0,9140 x_{k-1}-0,0808 \Delta T_{\text {расч. }}+2,553 ; \\
& \Delta x_{k}=0,4772 \Delta x_{k-1}+0,4033 \Delta U_{k}+0,024+0,4826 \omega_{k} ; \\
& \omega_{k}=0,5286 \omega_{k-1}+0,0910 \omega_{k-2}+\xi_{k} .
\end{aligned}
$$

Порядок модели авторегрессии для описания шумовой компоненты был определен на основе анализа построенных графиков автокорреляционных функций по остаточным ошибкам (рис. 1) для всех строящихся моделей [20, 21].

Представленные на рис. 1 графики свидетельствуют о том, что описание процесса шума следует производить моделями авторегрессии 2-го порядка вида:

$$
\omega_{k}=\mu \omega_{k-1}+\eta \omega_{k-2}+\xi_{k},
$$

где $\mu, \eta$ - оцениваемые параметры.

Для данной группы математических моделей можно констатировать следующее.

Качество структурной идентификации для всех трех математических моделей сле- дует признать высоким, о чем свидетельствует вид их автокорреляционных функций, построенных по остаточным ошибкам моделирования (см. рис. 1).

На наш взгляд, это вызвано тем, что на этапах структурной и параметрической идентификации моделей осуществлен корректный выбор типа математической модели, входных воздействующих факторов и дискретности результатов наблюдений через каждые 3 дня. Данное обстоятельство дает возможность использования математической модели (2) для прогнозирования радиальных перемещений тела плотины по результатам натурных наблюдений при штатных ситуациях работы плотины (средний в температурном отношении год). 


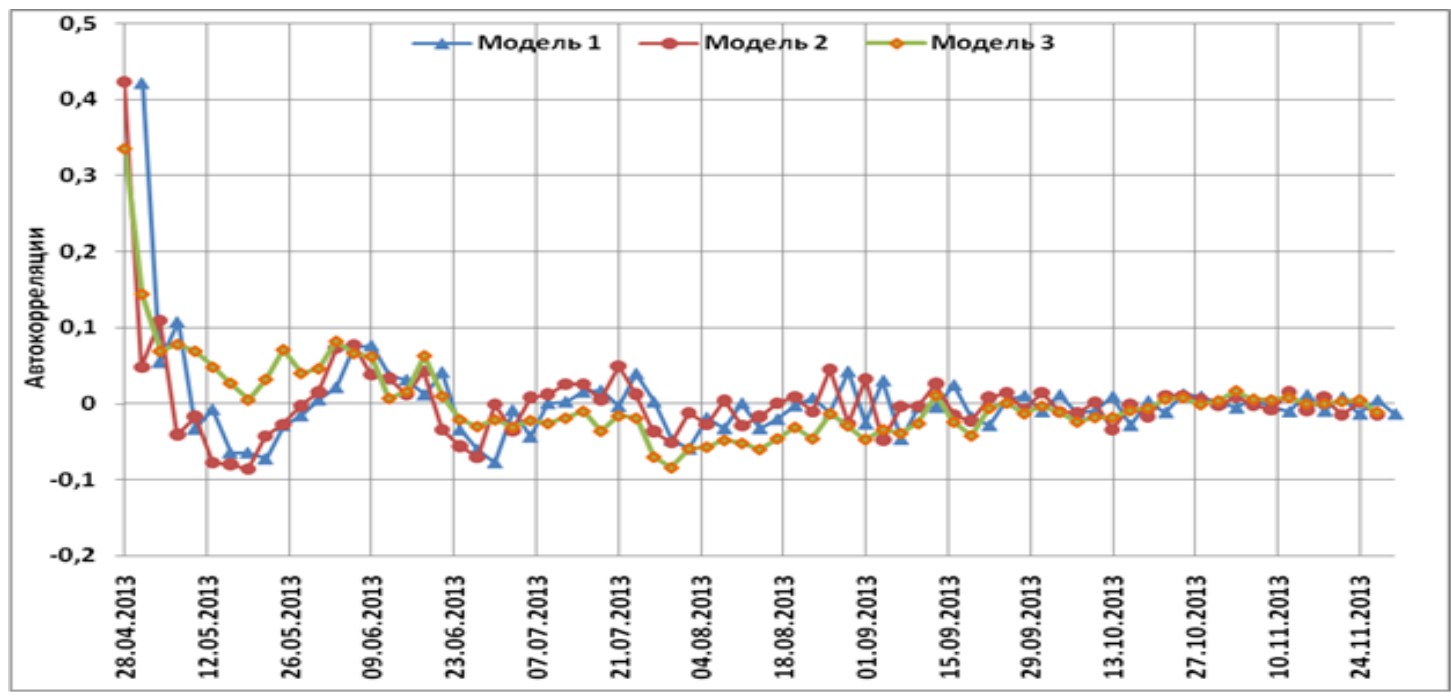

Рис. 1. Вид автокорреляционных функций для данной группы моделей (декорреляция входных воздействий)

Также имеется возможность применения прогнозной модели (3) для прогнозирования радиальных перемещений при нештатных ситуациях (холодный и теплый годы) с использованием результатов натурных наблюдений и расчетных значений составляющих перемещений или же модели (4) с использованием расчетных значений составляющих перемещений (гидростатической и температурной).

Для последующего прогнозирования поведения плотины СШГЭС на 2016 г. была использована построенная прогнозная модель (3) с декорреляцией входных воздействий путем их последовательного ввода в модель с дискретностью наблюдений через каждые 3 дня, которая имеет вид:

$$
\begin{aligned}
& U_{k}=0,8866 U_{k-1}-0,0581 \Delta T_{\text {расч. }}+61,299 ; \\
& x_{k}=0,9142 x_{k-1}-0,0812 \Delta T_{\text {расч. }}+8,552 ; \\
& \Delta x_{k}=0,4238 \Delta x_{k-1}+1,3320 \Delta U_{k}-0,087+0,6190 \omega_{k} ; \\
& \omega_{k}=0,1421 \omega_{k-1}+0,2471 \omega_{k-2}+\xi_{k} .
\end{aligned}
$$

В качестве входных воздействующих факторов были использованы: $U_{k}-$ гидростатическое давление (уровень верхнего бьефа как результаты натурных наблюдений) и $\Delta T_{\text {расч. }}$ - температурная составляющая перемещений (полученная на основе конечноэлементной модели).

На рис. 2, 3 представлены графики изменения воздействующих факторов: изменения верхнего бьефа и температурной составляющей перемещений за 2013 г. (период основания прогноза, на котором строилась прогнозная модель), на которые наложены изменения этих же факторов за 2016 г. (период для прогнозирования) по данным из работы [22].

На рис. 4 представлены графики результатов измеренных и прогнозных значений составляющих радиальных перемещений контролируемых точек плотины по модели (3) для периода эксплуатации в 2016 г. Здесь же представлен график прогнозных значений составляющих радиальных перемещений, рассчитанных по гидростатической и температурной составляющим перемещений в результате построения конечно-элементной модели [22]. Достаточно очевидно преимущество применения для целей прогнозирования построенной математической модели (3). 


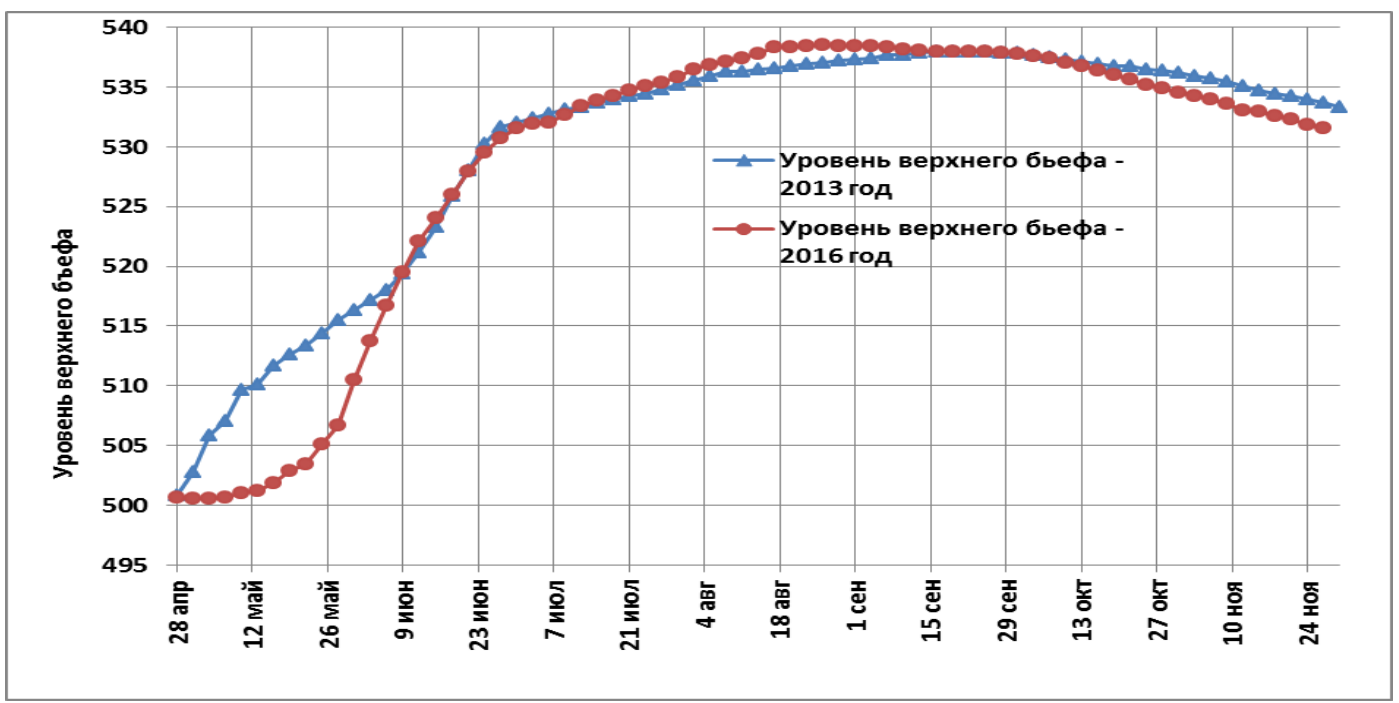

Рис. 2. Графики изменения уровня верхнего бьефа за 2013 и 2016 гг.

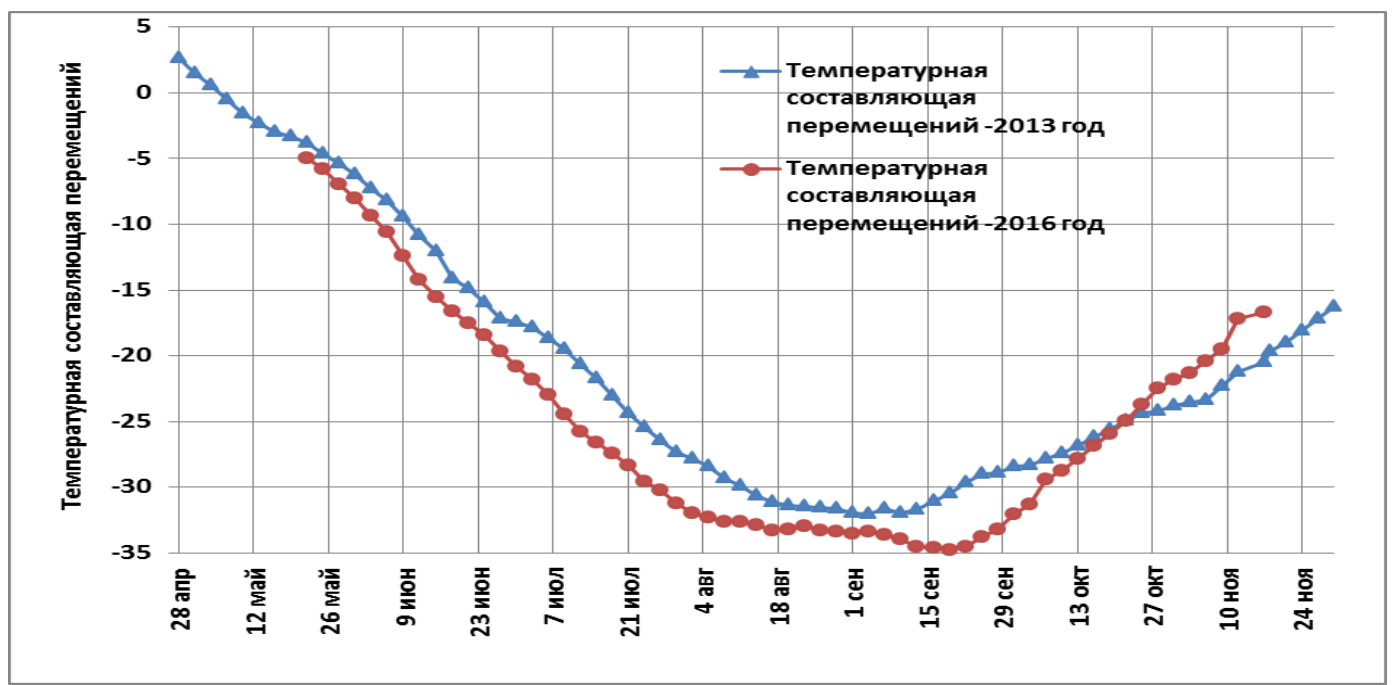

Рис. 3. Графики изменения температурной составляющей перемещений за 2013 и 2016 гг.

Вычисленная средняя квадратическая ошибка, полученная по разностям между прогнозными (модель 3) и измеренными перемещениями контролируемых точек плотины для этапа эксплуатации 2016 г., составила величину 1,5 мм. Выполненные ранее расчеты по прогнозированию перемещения контролируемых точек плотины СШГЭС после аварии 2009 г. с применением прогнозных моделей $[9,10]$ позволили получить неплохие результаты прогнозирования. Однако при этом пришлось строить достаточно сложные по своей структуре математические модели.

В процессе выполненных исследований при выборе в качестве входных воздействий результатов натурных наблюдений (уровень верхнего бьефа) и расчетных значений температурной составляющей перемещений $\left(U_{k}, \Delta T_{\text {расч. }}\right)$ с дискретностью данных через каждые 3 дня позволили на данном этапе исследований построить более качественные прогнозные модели.

Стоит особо отметить, что выполненное по ним прогнозирование по данным предыдущих исследований при изучении поведения плотины после аварии 2009 г. обеспечило получение равнозначных точных результатов прогнозирования, что и показано на графиках (рис. 5). 


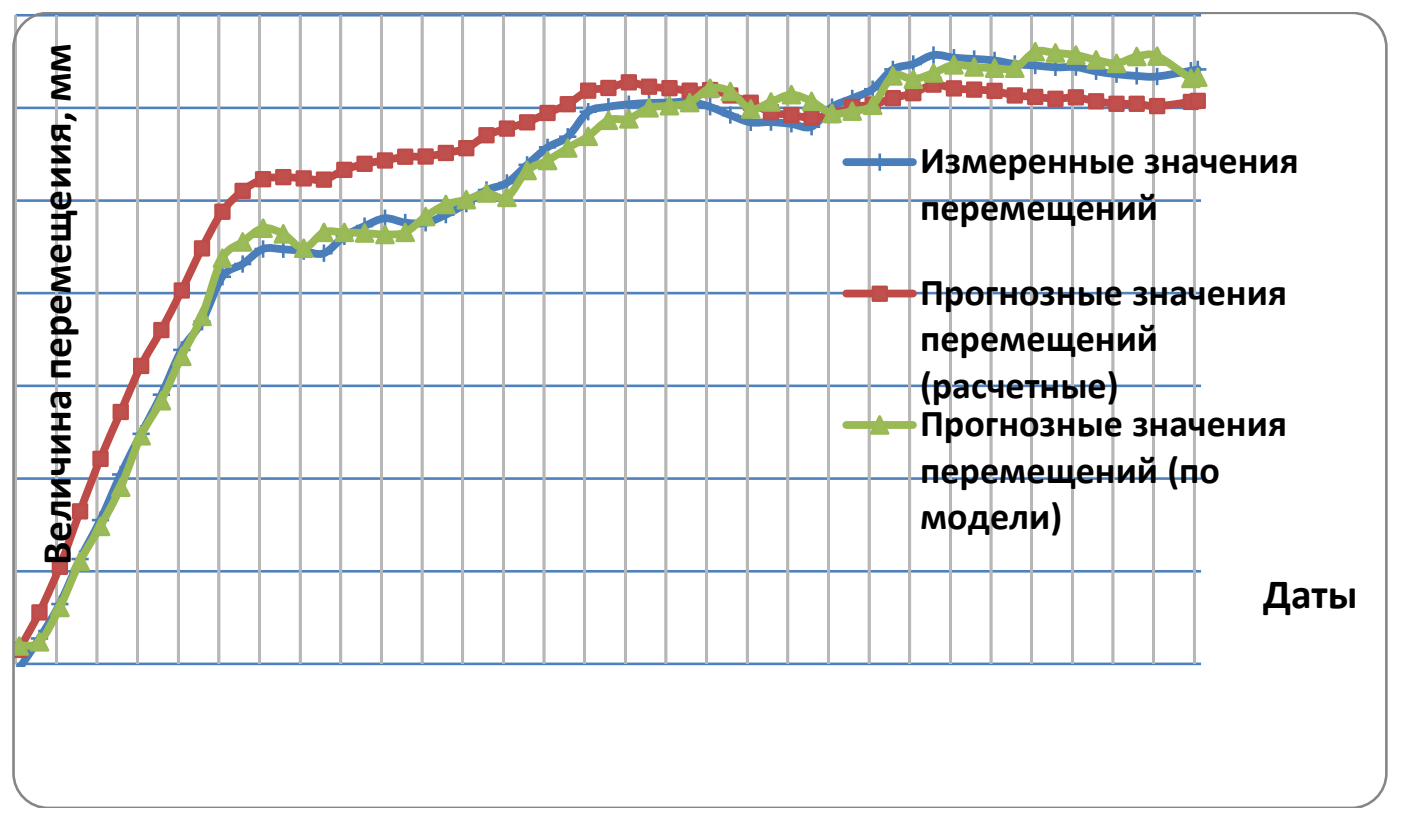

Рис. 4. График изменения измеренных составляющих перемещений и их прогнозных значений, рассчитанных для этапа эксплуатации плотины в 2016 г.

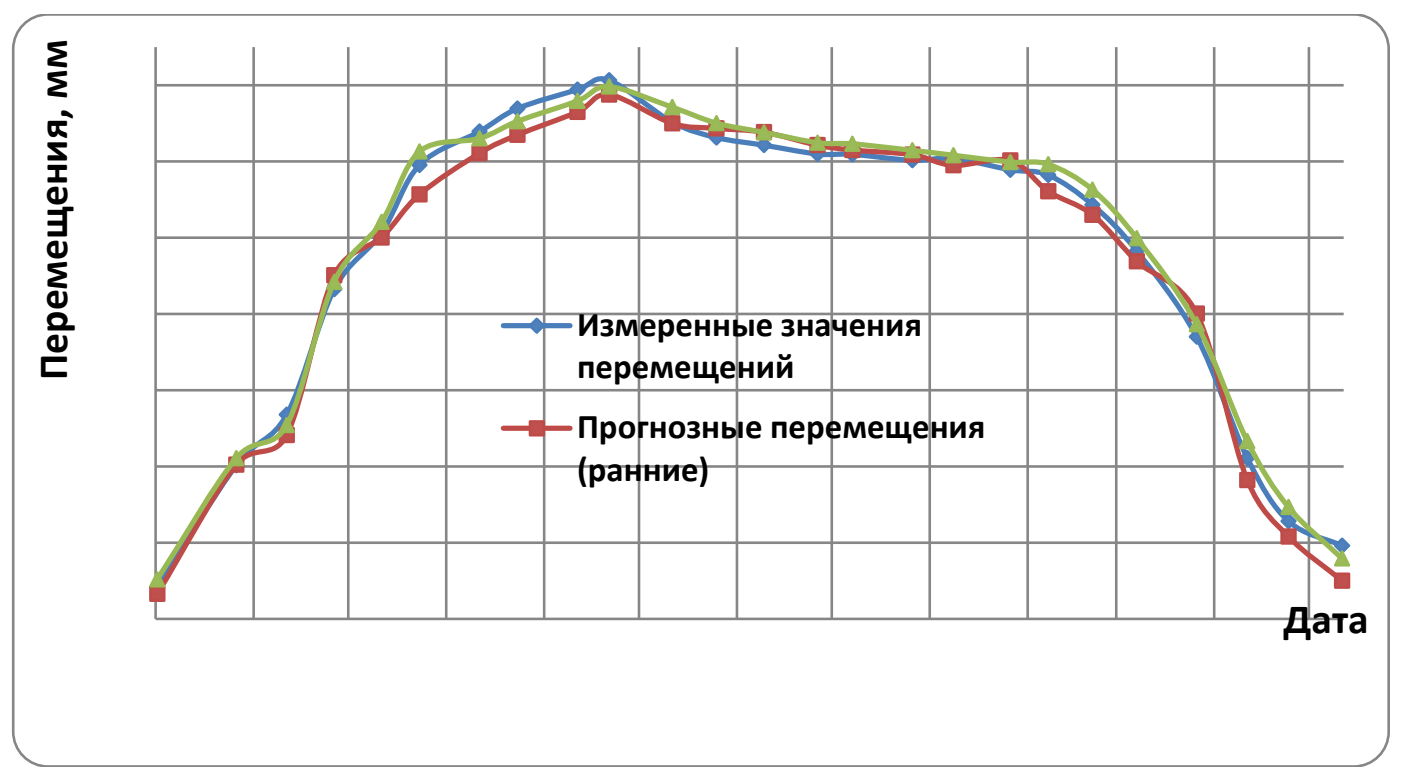

Рис. 5. График изменения радиальных перемещений и их прогнозных значений по модели (3) и ранее известных результатов прогнозирования из работ $[3,4]$ для ранних этапов эксплуатации плотины за 2009-2010 гг.

Это свидетельствует о том, что для выбранных входных воздействующих факторов построенные прогнозные модели с декорреляцией входных воздействий путем их последовательного ввода в модель возможно применять для прогнозирования практически всех возможных состояний плотины, т. е. для большинства штатных и нештатных ситуа- ций (теплого, среднего и холодного годов). Очевидно, это объясняется тем, что входное воздействие в виде расчетных значений температурной составляющей перемещений в достаточно полной мере отражает изменение температуры по всему телу плотины, включая и ее изменения в нижней и верхней базовых точках. А применение такого мето- 
дического приема, как введение транспортного запаздывания [9] в окончательные результаты прогнозирования, позволило получить качественные результаты.

Отметим также, что такой важный параметр, как дискретность математической модели через каждые 3 дня, который характеризует цикличность натурных наблюдений при условии охвата основных закономерностей развития исследуемого процесса деформации плотины и изменений основных воздействующих факторов, позволил построить достаточно корректные с точки зрения структурной идентификации прогнозные математические модели.

\section{Bblводbl}

1. Корректный выбор входных воздействующих факторов и типа математической модели на этапах структурной и параметрической идентификации обеспечил для дан- ной группы математических моделей возможность их применения для различных температурных условий работы сооружения (средний, теплый и холодный в температурном отношении года).

2. Средняя квадратическая ошибка прогнозирования на 2016 г. с использованием прогнозной математической модели (3) с введением транспортного запаздывания в окончательные результаты прогнозирования в сравнении с результатами измеренных радиальных перемещений составила 1,5 мм.

3. Выполненное прогнозирование с помощью модели (3) с использованием ранее известных данных о воздействующих фактоpax за 2009 г. позволило осуществить прогнозирование на этот год и сравнить полученные результаты с результатами ранее выполненного прогнозирования. В итоге результаты раннего и вновь выполненного прогнозирования оказались примерно равнозначными.

\section{БИБЛИОГРАФИЧЕСКИЙ СПИСОК}

1. Ardito R., Maier G., Massalongo G. Diagnostic analysis of concrete dams based on seasonal hydrostatic loading // Engineering Structures. 2008. - No. 30. - P. 3176-3185. doi: 10.1016/j.engstruct.2008.04.008.

2. РД 153-34.2-21.342-00. Методика определения критериев безопасности гидротехнических сооружений. - М. : РАО «ЕЭС России», 2001. $22 \mathrm{c}$.

3. Вульфович Н. А., Гордон Л. А., Стефаненко Н. И. Арочно-гравитационная плотина СаяноШушенской ГЭС (Оценка технического состояния по данным натурных наблюдений). - СПб. : ВНИИГ им. Б. Е. Веденеева, 2012. - 204 с.

4. Гордон Л. А., Скворцова А. Е. Актуализация критериев безопасности для основных диагностических показателей плотины Саяно-Шушенской ГЭС // Гидротехническое строительство. - 2013. - № 11. - С. 22-31.

5. Гордон Л. А., Затеев В. Б., Стефаненко Н. И. Оценка безопасности плотины Саяно-Шушенской ГЭС (по данным натурных перемещений) // Изв. Всероссийского научно-исследовательского института гидротехники им. Б. Е. Веденеева. 2005. - T. 244. - C. 55-64.

6. Дурчева В. Н., Пучкова С. М., Загрядский И. И. Учет сезонных изменений схемы работы бетонных плотин при анализе данных натурных измерений // Изв. Всероссийского научно-исследовательского института гидротехники им. Б. Е. Веденеева. - 2000. - Т. 237. C. $45-53$.

7. Гуляев Ю. П. Прогнозирование деформации сооружений на основе результатов геодезических наблюдений. - Новосибирск : СГГА, 2008. - 256 c.

8. Газиев Э. Г. Анализ современного напряженно-деформированного состояния арочногравитационной плотины Саяно-Шушенской ГЭС // Гидротехническое строительство. - 2010. № 9. - C. 48-57.

9. Prediction of the movement process of the high-head dam of Sayano-Shushenskaya hydroelectric power plant during operation after the accident in 2009 / V. S. Khoroshilov, B. T. Mazurov, K. M. Antonovich, A. I. Kalenitskiy, V. G. Kolmogorov // International Journal of Advanced Biotechnology and Research (IJBR). - 2017. - Vol. 8, Issue 4. P. 1096-1106.

10. Khoroshilov V. S. Mathematical Modelling of Sayano-Shushenskaya Dam Displacement Process after 2009 Accident // International Journal of Engineering Research in Africa. - 2018. - Vol. 39. - P. 47-59. doi: 10.4028/www.scientific.net/JERA.39.47.

11. Александров Ю. Н. Использование расчетной модели плотины Саяно-Шушенской ГЭС 
для оценки и прогнозирования ее состояния // Гидротехническое строительство. - 2008. - № 11. С. 64-69.

12. Костылев В. С. Применение математической модели «сооружение-основание» к анализу изменений в кинематических показателях бетонной арочно-гравитационной плотины СаяноШушенской ГЭС за 2004-2012 гг. // Гидротехническое строительство. - 2013. - № 4. - С. 37-46.

13. Гуляев Ю. П., Хорошилов В. С., Кобелева Н. Н. Построение прогнозной математической модели процесса перемещений плотины СаяноШушенской ГЭС (2004-2007 годы) // Изв. вузов. Геодезия и аэрофотосъемка. - 2015. - № 4. C. 16-20.

14. Хорошилов В. С., Кобелева Н. Н., Губонин П. Н. Математическое моделирование деформационного процесса для изучения перемещений плотины Саяно-Шушенской ГЭС на основе динамической модели (2004-2007 гг.) // Изв. вузов. Строительство. - 2015. - № 2 (686). - С. 49-58.

15. Кобелева Н. Н., Хорошилов В. С. Построение по геодезическим данным прогнозной модели процесса перемещений гребня плотины Саяно-Шушенской ГЭС (на этапе эксплуатации 2007-2009 годов) // Вестник СГУГиТ. - 2015. Вып. 4 (32). - С. 5-12.

16. Кобелева Н. Н., Хорошилов В. С. Построение математических моделей для прогнозирования горизонтальных перемещений плотины Саяно-Шушенской ГЭС для периода эксплуата- ции 2007-2009 гг. // Вестник СГУГиТ. - 2016. Вып. 2 (34). - С. 73-86.

17. Aleksandrov Yu. N. Temperature conditions in the first column of the Sayano-Shushenskaya HPP dam from field observation data // Power Technology and Engineering. - 2016. - Vol. 50, No. 2. P. 130-141. doi: 10.1007/s10749-016-0673-z/.

18. Евстифеев А. Д., Костылев В. С., Храпков А. А. Определение прогнозных значений температур для точек наблюдения, расположенных в теле бетонной арочно-гравитационной плотины // Изв. Всероссийского научно-исследовательского института гидротехники им. Б. Е. Веденеева. 2012. - Т. 267. - С. - 54-62.

19. Вульфович Н. А., Потехин Л. П. Влияние температурного состояния плотины СаяноШушенской ГЭС на режимы наполнения водохранилища // Гидротехническое строительство. 2016. - № 9. - С. 7-16.

20. Бокс Дж., Дженкинс Г. Анализ временных рядов. Прогноз и управление. Вып. 1. - М. : Мир, 1974. - 405 с.

21. Бокс Дж., Дженкинс Г. Анализ временных рядов. Прогноз и управление. Вып. 2. - М. : Мир, 1974. $-197 \mathrm{c}$.

22. Вульфович Н. А., Потехин Л. П. Об ограничениях интенсивности наполнения и опорожнения водохранилища бетонных плотин (на примере арочно-гравитационной плотины СаяноШушенской ГЭС) // Гидротехническое строительство. - 2017. - № 12. - С.11-19.

Получено 15.04.2020

(C) Н. Н. Кобелева, В. С. Хорошилов, 2020

\section{ANALYSIS OF INPUT INFLUENCING FACTORS AND SELECTION OF THE TYPE OF A MATHEMATICAL MODEL AT THE STAGES OF THEIR STRUCTURAL AND PARAMETRIC IDENTIFICATION FOR STUDYING DEFORMATION STATE OF THE SAYANO-SHUSHENSKAYA HPP DAM IN 2013-2016}

\section{Natalia N. Kobeleva}

Siberian State University of Geosystems and Technologies, 10, Plakhotnogo St., Novosibirsk, 630108, Russia, Ph. D., Associate Professor, Department of Space and Physical Geodesy, phone: (383)361-01-59, e-mail: n.n.kobeleva@mail.ru

\section{Valery S. Khoroshilov}

Siberian State University of Geosystems and Technologies, 10, Plakhotnogo St., Novosibirsk, 630108, Russia, St., Ph. D., Professor, Department of Space and Physical Geodesy, phone: (383)361-01-59, e-mail: khoroshilovvs@mail.ru

Assessment of the operational state of a hydraulic structure and its technical safety should be carried out by comparing the obtained quantitative and qualitative diagnostic indicators with their criteria values. For this purpose, predictive mathematical models of the structure's behavior should be developed, which are recommended to be calibrated according to field observations. The article considers features of constructing 
predictive mathematical models for studying deformation process of displacements of the dam crest of the Sayano-Shushenskaya hydroelectric power plant. For various combinations of input influencing factors, including the results of field observations and calculated values of component displacements, the most successfully designed predictive mathematical models were studied, on the basis of which the dam body points were forecasted for stages of its operation in different times. The advantages of using the created forecast models for various temperature conditions of the structure (medium, warm and cold temperatures of year) are presented.

Key words: high-pressure dam, geodetic data, forecast mathematical model, structural and parametric identification, forecasting, movements of controlled points, discreteness of the mathematical model, deformations of a construction.

\section{REFERENCES}

1. Ardito, R., Maier, G., \& Massalongo, G. (2008). Diagnostic analysis of concrete dams based on seasonal hydrostatic loading. Engineering Structures, 30, 3176-3185. doi: 10.1016/j.engstruct.2008.04.008 [in Russian].

2. Ruling Document RD 153-34.2-21.342-00. (2001). Method of determining criteria of safety of hydraulic installations. Moscow: RAO "EES Rossii", 22 p. [in Russian].

3. Vul'fovich, N. A., Gordon, L. A., \& Stefanenko, N. I. (2012). Arch-gravity dam SayanoShushenskaya HPP (assessment of technical condition according to field observations). Izvestiya Vserossiyskogo nauchno-issledovatel'skogo instituta gidrotekhniki im. B. E. Vedeneeva [Bulletin of the All-Russian Scientific Research Institute of Hydraulic Engineering. B. E. Vedeneeva], 204 p. [in Russian].

4. Gordon, L. A., \& Skvortsova, A. E. (2013). Updating security criteria for essential diagnostic indicators dam Sayano-Shushenskaya HPP. Gidrotekhnicheskoe stroitel'stvo [Hydrotechnical Construction], 11, 22-31 [in Russian].

5. Gordon, L. A., Zateev, V. B., \& Stefanenko, N. I. (2005). Safety assessment of dam SayanoShushenskaya HPP (according to natural movements). Izvestiya Vserossiyskogo nauchnoissledovatel'skogo instituta gidrotekhniki im. B. E. Vedeneeva [Bulletin of the B. E. Vedeneev All Russia Institute of Hydraulic Engineering], 244, 55-64 [in Russian].

6. Durcheva, V. N., Puchkova, S. M., \& Zagryadskiy, I. I. (2008). Treatment of seasonal changes in schemes of work concrete plotin when analyzing data in situ measurements. Izvestiya Vserossiyskogo nauchno-issledovatel'skogo instituta gidrotekhniki im. B. E. Vedeneeva [Bulletin of the B. E. Vedeneev All Russia Institute of Hydraulic Engineering], 237, 45-53 [in Russian].

7. Gulyaev, Yu. P. (2008). Prognozirovanie deformatsii sooruzheniy na osnove rezul'tatov geodezi- cheskikh nablyudeniy [Prediction of deformation of the structures on the basis of the results of geodetic observations]. Novosibirsk: SSGA Publ., 256 p. [in Russian].

8. Gaziev, E. G. (2010). Analysis of stress-strain State of arch-gravity dam Sayano-Shushenskaya HPP. Gidrotekhnicheskoe stroitel'stvo [Hydrotechnical Construction], 9, 48-57 [in Russian].

9. Khoroshilov, V. S., Mazurov, B. T., Antonovich, K. M., Kalentsky, A. I., \& Kolmogorov, V. G. (2017). Prediction of the movement process of the high-head dam of Sayano-Shushenskaya hydroelectric power plant during operation after the accident in 2009. International Journal of Advanced Biotechnology and Research (IJBR), 8(4), 1096-1106.

10. Khoroshilov, V. S. (2018). Mathematical Modelling of Sayano-Shushenskaya Dam Displacement Process after 2009 Accident. International Journal of Engineering Research in Africa, 39, 47-59. doi:10.4028/www.scientific.net/JERA.39.47.

11. Aleksandrov, Yu. N. (2008). Use the design model of the dam Sayano-Shushenskaya HPP for assessing and predicting its State. Gidrotekhnicheskoe stroitel'stvo [Hydrotechnical Construction], 11, 64-69 [in Russian].

12. Kostylev, V. S. (2013). Application of mathematical construction model-base "to analyse changes in kinematic indicators concrete arch-gravity dam Sayano-Shushenskaya HPP for 2004-2012 biennium. Gidrotekhnicheskoe stroitel'stvo [Hydrotechnical Construction], 4, 37-46 [in Russian].

13. Gulyaev, Yu. P., Khoroshilov, V. S., \& Kobeleva, N. N. (2015). Build predictive mathematical model of process of displacement of the dam Sayano-Shushenskaya HPP (2004-2007). Izvestia vuzov. Geodeziya i aerofotos"emka [Izvestia Vuzov. Geodesy and Aerophotography], 4, 16-20 [in Russian].

14. Khoroshilov, V. S., Kobeleva, N. N., \& Gubonin, P. N. (2015). Mathematical modeling of deformation process to study the movements of Sa- 
yano-Shushenskaya HPP dam based on dynamic models (2004-2007). Izvestiya vuzov. Stroitel'stvo [News of Higher Educational Institutions. Construction], 2(686), 49-58 [in Russian].

15. Kobeleva, N. N., \& Khoroshilov, V. S. (2015). Building on geodetic data forecast model process moves Crest Sayano-Shushenskaya HPP (during the operational phase 2007-2009). Vestnik SGUGiT [Vestnik SSUGT], 4(32), 5-12 [in Russian].

16. Kobeleva, N. N., \& Khoroshilov, V. S. (2016). Construction of mathematical models for predicting the horizontal displacement of the dam SayanoShushenskaya hydroelectric power plant for operation period of the 2007-2009 biennium. Vestnik SGUGiT [Vestnik SSUGT], 2(34), 73-86 [in Russian].

17. Aleksandrov, Yu. N. (2016). Temperature conditions in the first column of the SayanoShushenskaya HPP dam from field observation data. Power Technology and Engineering, 50(2), 130-141. doi:10.1007/s10749-016-0673-z/.

18. Evstifeev, A. D., Kostylev, V. S., \& Khrapkov, A. A. (2012) Definition of forecast temperature values for points in the body of a concrete archgravity dam. Izvestiya Vserossiyskogo nauchnoissledovatel'skogo instituta gidrotekhniki im. B. E.
Vedeneeva [Bulletin of the B. E. Vedeneev All Russia Institute of Hydraulic Engineering], 267, 54-62 [in Russian].

19. Vul'fovich, N. A., \& Potekhin L. P. (2016). The influence of the temperature state of the dam of the Sayano-Shushenskaya hydroelectric power station on the filling regimes of the reservoir. Gidrotekhnicheskoe stroitel'stvo [Hydrotechnical Construction], 9, 7-16 [in Russian].

20. Boxing, J., \& Jenkins, G. (1974). Analiz vremennykh ryadov. Prognoz i upravlenie: Vyp. 1 [Time Series Analysis. Forecast and management: Issue 1]. Moscow: Mir Publ., 405 p. [in Russian]. Issue 2. $197 \mathrm{~s}$.

21. Boxing, J., \& Jenkins, G. (1974). Analiz vremennykh ryadov. Prognoz $i$ upravlenie: Vyp. 2 [Time Series Analysis. Forecast and management: Issue 2]. Moscow: Mir Publ., 197 p. [in Russian].

22. Vul'fovich, N. A., \& Potekhin L. P. (2017). On the restrictions on the intensity of filling and emptying of the reservoir of concrete dams (on the example of the arch-gravity dam of the SayanoShushenskaya hydroelectric power station). Gidrotekhnicheskoe stroitel'stvo [Hydrotechnical Construction], 12, 11-19 [in Russian].

(C) N. N. Kobeleva, V. S. Khoroshilov, 2020 
УДК 528.024.1/.6:528.54

DOI: $10.33764 / 2411-1759-2020-25-3-63-71$

\section{СОВЕРШЕНСТВОВАНИЕ МЕТОДИКИ ВЫПОЛНЕНИЯ ВЫСОКОТОЧНОГО НИВЕЛИРОВАНИЯ ЦИФРОВЫМИ НИВЕЛИРАМИ В УСЛОВИЯХ НЕДОСТАТОЧНОЙ ОСВЕЩЕННОСТИ ШТРИХКОДОВЫХ РЕЕК}

\section{Валерий Геннадьевич Сальников}

Сибирский государственный университет геосистем и технологий, 630108, Россия, г. Новосибирск, ул. Плахотного, 10, кандидат технических наук, зав. кафедрой инженерной геодезии и маркшейдерского дела, тел. (913)932-62-20, e-mail: salnikov@ssga.ru

Выполнение высокоточного геометрического нивелирования короткими лучами с целью обеспечения процесса строительства и эксплуатации инженерных сооружений и применяемого на них промышленного оборудования производится нивелирами с визуальным отсчитыванием или цифровыми нивелирами при значительном влиянии возмущающих воздействий, основными из которых являются влияние вибрации от работающего оборудования, резкий перепад температур воздуха, а также недостаточная и неравномерная освещенность метрических или штрихкодовых реек. Целью данной статьи является совершенствование методики выполнения высокоточного нивелирования цифровыми нивелирами в условиях недостаточной освещенности штрихкодовых реек. В статье рассматривается влияние недостаточной освещенности штрихкодовых реек на методику работы на нивелирной станции цифровыми нивелирами. Из-за неравномерной и недостаточной освещенности рейки приемное устройство цифрового нивелира (ПЗС-линейка) не позволяет уверенно выполнять считывание штрихкода, его обработку и выдачу на блок индикации отсчета в метрической системе. Поэтому для уверенного выполнения измерения превышения на станции освещенность пары штрихкодовых реек должна быть достаточной, практически одинаковой и равномерной. В статье приводятся результаты исследований применения конструкции штрихкодовой рейки, оснащенной, для обеспечения достаточного и равномерного ее освещения, светодиодами.

Ключевые слова: высокоточное геометрическое нивелирование, цифровой нивелир, штрихкодовая рейка, светодиоды, освещенность рейки.

\section{Введение}

В настоящее время при выполнении геометрического нивелирования на промышленных площадках широко применяются цифровые нивелиры, обеспечивающие среднюю квадратическую ошибку измерения превышения порядка 0,3-0,5 мм на 1 км двойного хода $[1,2]$. Во время выполнения высокоточного геометрического нивелирования возникает целый ряд возмущающих факторов, влияющих на точность нивелирования, к которым относятся рефракция, повышенная температура воздуха, вибрация от действующих механизмов, недостаточная освещенность и т. д. Выполнить качественные измерения под влиянием указанных возмущающих факторов довольно сложно. К настоящему времени выполнен целый ряд исследований влияния указанных факторов [3-6] и даны рекомендации по их значитель- ному ослаблению. Вместе с тем, с появлением в геодезическом производстве цифровых нивелиров возникает задача обеспечения равномерного освещения штрихкодовой рейки практически по всей ее длине [7]. В противном случае не будет обеспечено уверенное отсчитывание (распознавание кодовых штрихов по рейке), и отчитывающее устройство цифрового нивелира, например, типа Trimble Dini 0.3 на дисплее выдаст ошибку, свидетельствующую о недостаточной освещенности штрихкодовой рейки.

Необходимо отметить, что влияние фактора недостаточной освещенности метрической рейки при использовании нивелиров с визуальным отсчитыванием не является критичным, так как глаз наблюдателя быстро адаптируется к существующему уровню освещенности, причем она может быть различной на отдельных участках этой рейки [8]. 
Выполненные к настоящему времени исследования показали [7], что обеспечение достаточной освещенности штрихкодовой рейки с помощью ручного фонаря в целом ряде случаев вызывает дополнительные сбои и ошибки, обусловленные работой собственно электронной системы цифрового нивелира. Исследованиями также установлено $[8,9]$, что предельно допустимый уровень освещенности штрихкодовой рейки с применением ручных фонарей, при котором СКО взятия отчета будет находиться в пределах 0,2-0,5 мм, не должен превосходить 20 люкс. Одновременно с обеспечением необходимой освещенности штрихкодовой рейки помощник геодезиста обязан с помощью круглого уровня установить ее вертикально и удерживать в таком положении в течение 15-20 с.

В течение этого времени помощник геодезиста одной рукой должен непрерывно удерживать штрихкодовую рейку в отвесном положении, а другой - этим ручным фонарем освещать ее шкалу. В этом случае, как правило, не удается круглый уровень удерживать в нуль-пункте, так как приходиться поочередно освещать уровень и шкалу рейки. В условиях недостаточной освещенности или ее отсутствия помощник геодезиста, после установки рейки по уровню, интуитивно полагает, что пузырек круглого уровня рейки остается в нуль-пункте, и уделяет свое внимание освещению ручным фонарем рейки. В 20-30 \% случаев, после взятия отчета цифровым нивелиром, помощник геодезиста дает команду наблюдателю, что необходимо повторить измерения из-за того, что пузырек на рейке был смещен относительно нульпункта [10].

Также имеют место случаи попадания луча фонаря в глаза помощника геодезиста или наблюдателя, что приводит к временному ухудшению зрительной способности одного или обоих и к увеличению времени на выполнение нивелирования.

В связи с этим автор данной статьи при выполнении нивелирования в условиях недостаточной освещенности или ее отсутствия предлагает для обеспечения равномерного освещения штрихкодовой рейки применять светодиоды. В этом случае значительно упростится работа помощника геодезиста и основное внимание он будет уделять удержанию рейки в отвесном положении, что, в свою очередь, уменьшит число повторных измерений превышения на станции.

\section{Подготовка к эксперименту}

Для выполнения экспериментальных исследований применения светодиодов при геометрическом нивелировании была использована метровая светодиодная полоска напряжением 6 вольт, подключенная к блоку питания. Основным источником питания служили 4 щелочные батарейки типа АА, установленные в блок питания. Непосредственно блок питания крепился на обратную сторону рейки.

Светодиодная полоска была наклеена на внутреннюю часть пластикового уголка размером $30 \times 30 \times 1000$ мм, который крепился на боковую грань рейки (рис. 1).
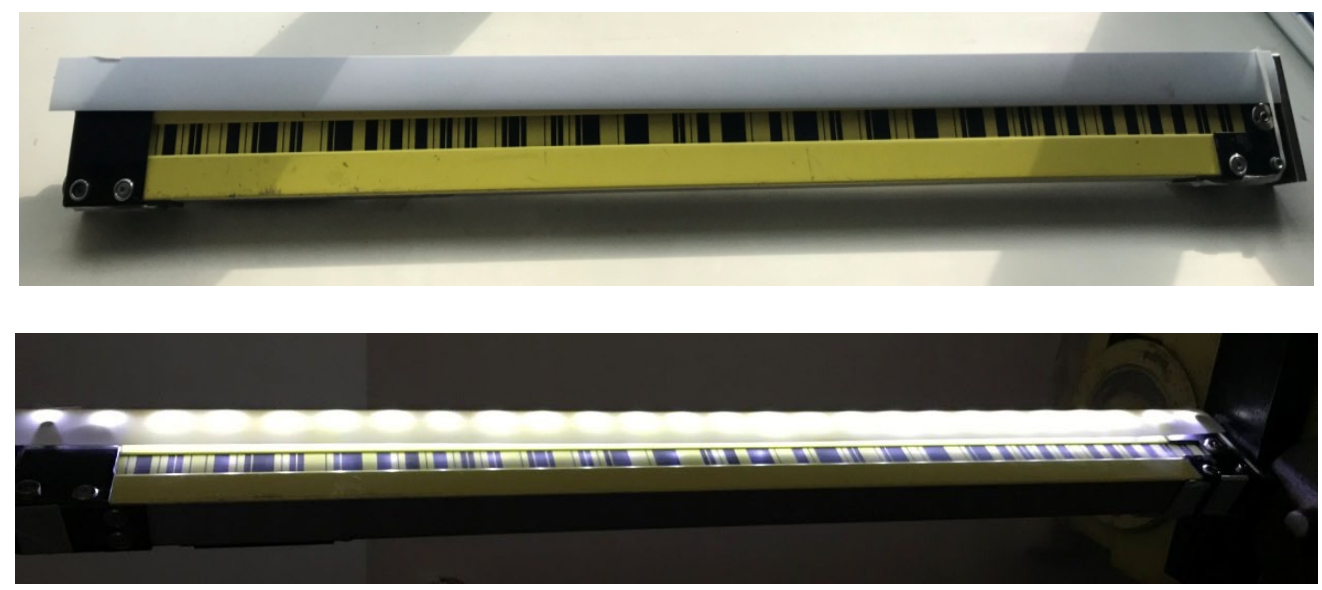

Рис. 1. Схема установки светодиодной полосы на рейке 
Согласно (рис. 2, a), 100-процентное распространение света от светодиодов будет направлено на наблюдателя и в объектив цифрового нивелира, что повлечет за собой сбой при взятии отчета. Для уменьшения этого влияния нами применялся пластиковый уголок (рис. 2, б), что при данном расположении распространения луча света от светодиодов на 30-40\% обеспечивает уменьшение освещенности и положительно влияет на взятие отчета цифровым нивелиром. Можно

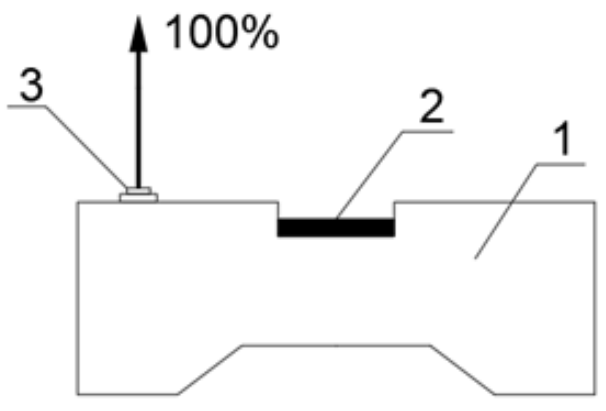

a)

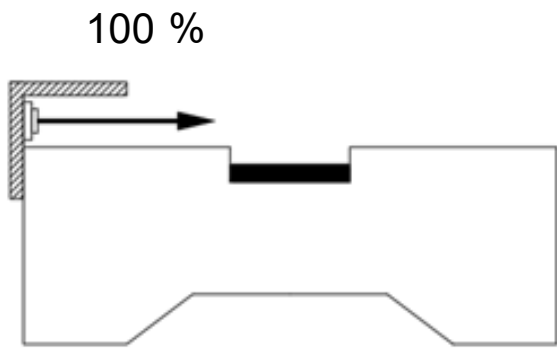

в) также расположить светодиодную полосу на самом уголке (рис. 2, г), но это позволит использовать поток света только на 10-20 \%.

Автором установлено, что оптимальным местом установки светодиодной ленты является положение (рис. 2, в), при котором поток света используется на $100 \%$ и распространяется параллельно штрихкодовой полосе на рейке, при этом не мешает наблюдателю и не создает засветки при взятии отчета цифровым нивелиром.

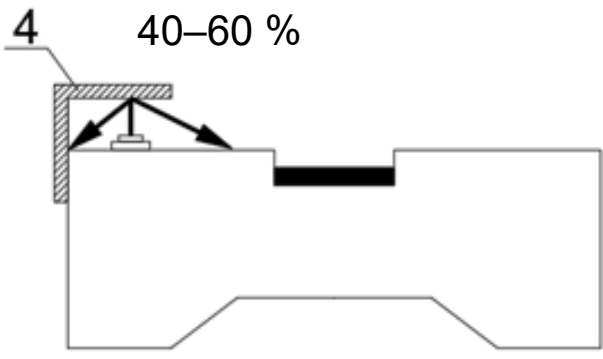

б)

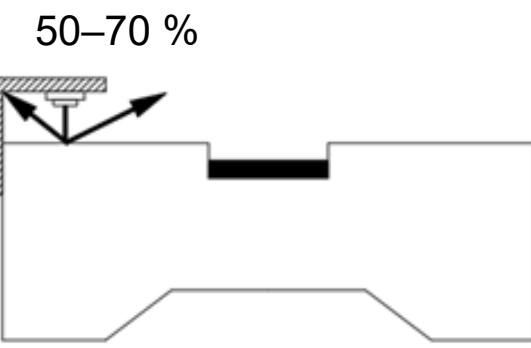

2)

Рис. 2. Схема установки светодиодной полосы на рейке:

a) поток света направлен на нивелир; б) поток света направлен в уголок; в) поток света направлен параллельно штрихкодовой полоске рейки; г) поток света направлен в корпус рейке; 1 - штрихкодовая рейка; 2 - инварная полоса; 3 - светодиодная лента; 4 - пластиковый уголок

\section{Методы и материаль}

Исследование проводились в лабораторных условиях при постоянной температуре плюс $24{ }^{\circ} \mathrm{C}$ [11] с применением цифрового нивелира Trimble dini 0.3 и двух двухметровых штрихкодовых реек, на которые были установлены светодиодные полосы (рис. 2, в) с блоками питания. Освещенность измерялась цифровым люксомером СЕМ DT-1308.

При выполнении наблюдений была использована стандартная программа высокоточного геометрического нивелирования короткими лучами $[10,12-14]$ с длиной визирного луча 5, 10, 15 и 20 м. Задняя и передняя рейки были установлены на осадочные марки и на протяжении всего времени оставались неподвижными.

Для определения эталонного превышения использовался высокоточный оптический нивелир Н-05. При выполнении измерений освещенность составила 22-23 люкс. Эталонное превышения измерялось пять раз при двух горизонтах нивелира и длине визирного луча 5,0 м. Нивелирование производилось с использованием основной и дополнительной шкал инварной рейки с отсчитыванием до десятой доли деления отсчетного барабана, при этом наведение биссектора на каждый штрих производилось дважды $[15,16]$. 
Измеренное эталонное превышение оказалось равным $h=1,00 \pm 0,1$ мм. После этого для определения влияния неравномерной и недостаточной освещенности штрихкодовой рейки были составлены четыре программы измерений, представленных на рис. 3.

Первая программа «темно-темно». Данная программа измерений выполнялась при общей освещенности помещения порядка 5-6 люкс [17]. Цифровой нивелир устанавливался на расстоянии 5,0 м от задней и передней реек. На первом этапе выполнения измерений подсветка на рейке была полностью выключена. При выполнении измерений цифровой нивелир выдавал ошибку так как отчетное устройство при данной освещенности не позволяло производить отчет по рейке. Затем подсветка на задней и передней рейках была включена, и превышение между задней и передней рейками измерялось двенадцать раз со сменой горизонта прибора (табл. 1). Далее высчитывались СКО определения превышения на станции по формуле Бесселя [18]

$$
m_{\mathrm{cT}}=\sqrt{\frac{\left[v^{2}\right]}{n-1}},
$$

где $v^{2}$ - сумма квадратов вероятных ошибок; $n-$ количество измерений.

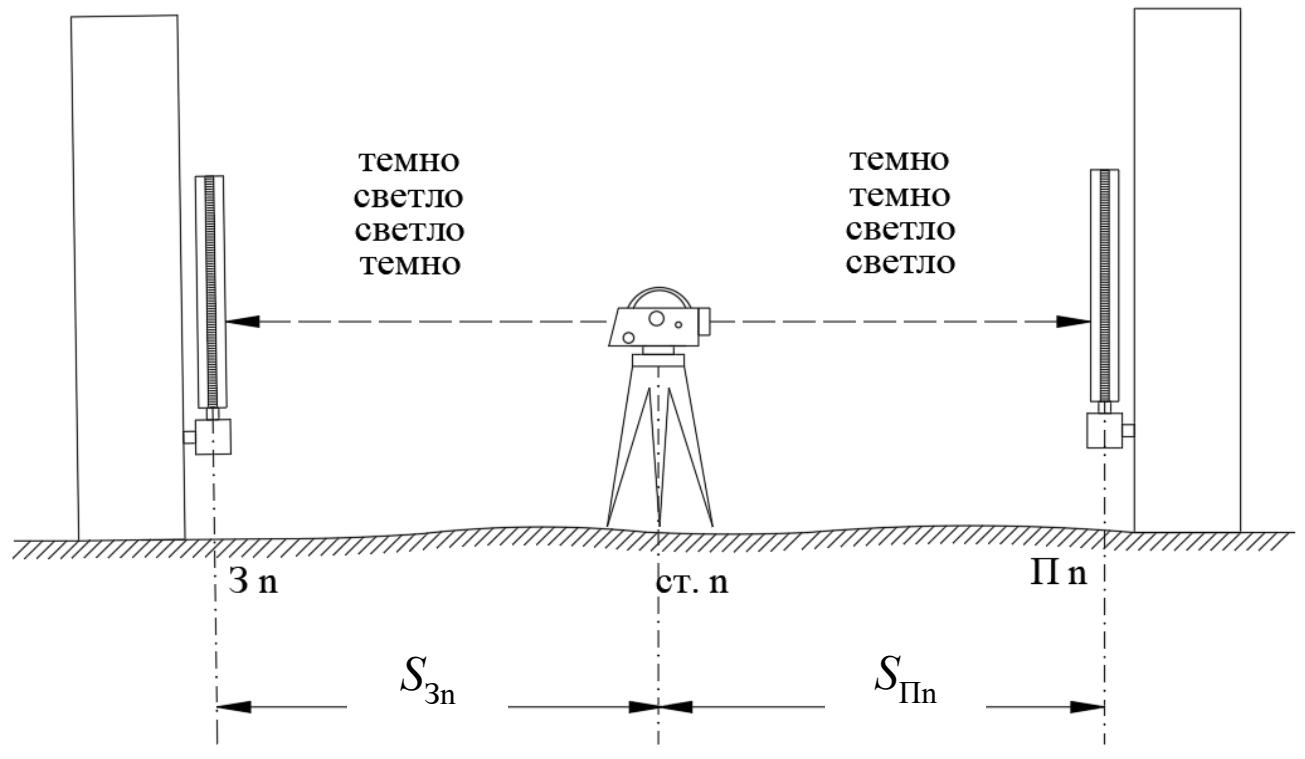

Рис. 3. Схема выполнения измерений

Таблица 1

Программа измерений «темно-темно»

\begin{tabular}{|c|c|c|c|c|c|}
\hline \multirow{2}{*}{$№$} & \multicolumn{2}{|c|}{$S$, м } & мм & мм & мм \\
\cline { 2 - 6 } & темно & темно & $H$ & $H$ cp- $j$ & $(H \text { cp-j })^{2}$ \\
\hline 1 & 4,89 & 4,92 & 1,00 & 0,04 & 0,0016 \\
\hline 2 & 4,90 & 4,90 & 1,10 & $-0,06$ & 0,0036 \\
\hline 3 & 4,90 & 4,90 & 1,00 & 0,04 & 0,0016 \\
\hline 4 & 4,89 & 4,90 & 1,00 & 0,04 & 0,0016 \\
\hline 5 & 4,89 & 4,90 & 1,10 & $-0,06$ & 0,0036 \\
\hline 6 & 4,90 & 4,91 & 1,00 & 0,04 & 0,0016 \\
\hline 7 & 4,89 & 4,91 & 1,10 & $-0,06$ & 0,0036 \\
\hline 8 & 4,90 & 4,92 & 1,10 & $-0,06$ & 0,0036 \\
\hline 9 & 4,90 & 4,90 & 1,10 & $-0,06$ & 0,0036 \\
\hline 10 & 4,90 & 4,90 & 1,00 & 0,04 & 0,0016 \\
\hline 11 & 4,90 & 4,90 & 1,00 & 0,04 & 0,0016 \\
\hline 12 & 4,89 & 4,90 & 1,00 & 0,04 & 0,0016 \\
\hline среднее & 4,90 & 4,91 & 1,04 & сумм & 0,0290 \\
\hline
\end{tabular}


После этого измерения выполнялись при длине визирного луча 10, 15 и 20 м [19, 20].

Вторая программа «светло-темно». Данная программа измерений контролировалась лампами дневного освещения. Над задней рейкой включалась лампа дневного освещения, освещенность составляла 19-20 люкс, при этом передняя рейка оставалась без включенных ламп дневного освещения и освещенность составила 8-9 люкс. Было установлено, что при освещенности в 8-9 люкс отчетное устройство цифрового нивелира не может взять отчет. Поэтому подсветка на передней рейке была включена, но лампы дневного освещения оставались выключенными. Далее измерения выполнялись по аналогичной программе с установкой цифрового нивелира на расстоянии $5,10,15$ и 20 м от задней и передней реек.

Третья программа «светло-светло». Данная программа измерений была выполнена с включенными лампами дневного освещения над задней и передней рейками и выключенной светодиодной подсветкой. Далее измерения выполнялись по аналогичной программе с установкой цифрового нивелира на расстоянии $5,10,15$ и 20 м от задней и передней реек.

И, наконец, при использовании четвертой программы «темно-светло» измерения, как и во второй программе, контролировались лампами дневного освещения. Задняя рейка оставалась без включенных ламп дневного освещения и освещенность при этом составила 8-9 люкс, а над передней рейкой включалась лампа дневного освещения, обеспечивающая освещенность 19-20 люкс. При освещенности в 8-9 люкс цифровой нивелир также не смог взять отчет и поэтому подсветка на задней рейке была включена, но лампы дневного освещения оставались выключенными. Далее измерения выполнялись с установкой цифрового нивелира на расстоянии 5, 10, 15 и 20 м от задней и передней реек.

Во время выполнения измерений по первой программе, после набора двенадцати превышений, был выполнен умышленный «засвет» ручным фонарем участка задней рейки размером 300 мм. Разность в изменении превышения при умышленном «засвете» составила 0,2 мм.

\section{Результаты}

Результаты оценки точности выполненных измерений по четырем программам представлены в табл. 2.

Результаты оценки точности выполненных измерений

\begin{tabular}{|c|c|c|c|}
\hline темно & темно & \multirow{2}{*}{ H, мм } & \multirow{2}{*}{ Мст, мм } \\
\hline$S_{3, \mathrm{M}}$ & $S_{\text {п, }}$ & 1,04 & 0,05 \\
\hline 4,90 & 4,91 & 1,06 & 0,05 \\
\hline 9,86 & 9,88 & 1,49 & 0,03 \\
\hline 14,96 & 14,87 & 1,73 & 0,05 \\
\hline 19,81 & 19,84 & & 0,03 \\
\hline светло & темно & 1,07 & 0,07 \\
\hline 4,89 & 4,91 & 1,19 & 0,05 \\
\hline 10,01 & 10,03 & 1,48 & 0,05 \\
\hline 14,96 & 14,87 & 1,74 & 0,05 \\
\hline 19,83 & 19,84 & & 0,05 \\
\hline светло & светло & 1,16 & 0,05 \\
\hline 4,89 & 4,90 & 1,06 & 0,05 \\
\hline 9,86 & 9,87 & 1,46 & \\
\hline 14,97 & 14,87 & 1,75 & 0,05 \\
\hline 19,81 & 19,83 & & 0,04 \\
\hline темно & светло & 1,14 & 0,05 \\
\hline 4,90 & 4,91 & 1,18 & 0,05 \\
\hline 10,01 & 10,03 & 1,46 & \\
\hline 14,96 & 14,87 & 1,71 & \\
\hline 19,82 & 19,84 & & \\
\hline
\end{tabular}




\section{Заключение}

По результатам, приведенным в табл. 2, можно сделать следующие выводы:

- с увеличением расстояния от цифрового нивелира до рейки изменяется значение эталонного превышения на 0,5 мМ, но СКО измерения превышения на станции остается в пределах от 0,03 до 0,07 мм;

- использование света от светодиодной ленты позволяет выполнять измерения по программе «темно-темно», как при дневном освещении. Распространение света от светодиодной ленты равномерное и нет «засветок» по штрихкодовой рейке, как при использовании ручного фонаря;

- использование в качестве подсветки светодиодной ленты позволяет помощнику геодезиста сосредоточиться только на установке рейки по круглому уровню;

- разработана оптимальная схема установки светодиодной ленты на рейку, которая позволяет использовать 100 \% светового потока от диодов.

\section{БИБЛИОГРАФИЧЕСКИЙ СПИСОК}

1. ГОСТ 10528-90. Нивелиры. Общие технические условия. - М. : Изд-во стандартов, 2003. $29 \mathrm{c}$.

2. ГКИНП (ГНТА)-03-010-03.2004. Инструкция по нивелированию I, II, III и IV классов. М. : ЦНИИГАиК, 2004. - 226 с.

3. Исследование влияния рефракции на результаты нивелирования цифровыми нивелирами / Г. А. Уставич, Е. Л. Соболева, Н. М. Рябова, В. Г. Сальников // Геодезия и картография. 2011. - № 5. - С. 3-9.

4. Исследование штрих-кодовых реек цифровых нивелиров / Г. А. Уставич, Н. М. Рябова, В. Г. Сальников, А. Н. Теплых // Вестник СГГА. 2010. - Вып. 2 (13). - С. 3-8.

5. Исследование цифровых нивелиров и реек / Г. А. Уставич, Н. М. Рябова, В. Г. Сальников, М. Е. Рахымбердина // Геодезия и картография. 2011. - № 4. - C. 9-15.

6. Малков А. Г. Об оценке точности измерения превышений на станции геометрического нивелирования // ГЕО-Сибирь-2009. V Междунар. науч. конгр. : сб. материалов в 6 т. (Новосибирск, 20-24 апреля 2009 г.). - Новосибирск : СГГА, 2009. Т. 1, ч. 1. - С. 82-84.

7. Рябова Н. М. Исследование влияния различной освещенности на отсчеты по рейке // Интерэкспо ГЕО-Сибирь-2013. IX Междунар. науч. конгр. : Междунар. науч. конф. «Геодезия, геоинформатика, картография, маркшейдерия» : сб. материалов в 3 т. (Новосибирск, 15-26 апреля 2013 г.). - Новосибирск: СГГА, 2013. Т. 1. C. $42-45$.

8. Головина Л. А. Зависимость точности нивелирования от освещенности объекта // Инновационное социально ориентированное развитие России : сборник научных трудов по материалам I Всероссийской научно-практической конфе- ренции 31 октября 2016 г. - Томск : НОО «Профессиональная наука», 2016. - С. 374-377.

9. Новоселов Д. Б., Новоселов Б. А. Исследование работы высокоточного цифрового нивелира в условиях недостаточной освещенности // Интерэкспо ГЕО-Сибирь-2013. IX Междунар. науч. конгр. : Междунар. науч. конф. «Геодезия, геоинформатика, картография, маркшейдерия» : сб. материалов в 3 т. (Новосибирск, 15-26 апреля 2013 г.). - Новосибирск : СГГА, 2013. Т. 1. C. $117-121$.

10. Малков А. Г., Брыскин Р. М. Современная методика высокоточного геометрического нивелирования // Интерэкспо ГЕО-Сибирь. XV Междунар. науч. конгр. : Междунар. науч. конф. «Геодезия, геоинформатика, картография, маркшейдерия» : сб. материалов в 9 т. (Новосибирск, 23-26 апреля 2019 г.), - Новосибирск : СГУГиТ, 2019. T. 1. № 2. - C. 32-38.

11. Никонов А. В., Чешева И. Н., Лифашина Г. В. Влияние перепадов температуры окружающей среды на главное условие цифрового нивелира при наблюдениях за осадками фундаментов зданий и сооружений // Вестник СГУГиТ. 2016. - № 2 (34). - С. 24-33.

12. Новиков Ю. А., Краев А. Н. Геодезические наблюдения за осадками здания в рамках проведения геотехнического мониторинга // Вестник СГУГиТ. - 2019. - Т. 24, № 1. C. $28-41$.

13. Уставич Г. А., Шаульский В. Ф., Винокурова О. И. Разработка и совершенствование технологии государственного нивелирования I, II, III и IV классов // Геодезия и картография. 2003. - № 8. - C. 5-11.

14. Шоломицкий А. А., Лагутина Е. К., Соболева Е. Л. Высокоточные геодезические измерения при деформационном мониторинге аквапар- 
ка // Вестник СГУГиТ. - 2017. - Т. 22, № 3. C. $45-59$.

15. Определение средней квадратической ошибки измерения превышения на станции цифровым нивелиром / А. В. Никонов, Е. Л. Соболева, Н. М. Рябова, Т. М. Медведская // Интерэкспо ГЕО-Сибирь-2015. ХІ Междунар. науч. конгр. : Междунар. науч. конф. «Геодезия, геоинформатика, картография, маркшейдерия» : сб. материалов в 2 т. (Новосибирск, 13-25 апреля 2015 г.). Новосибирск : СГУГиТ, 2015. Т. 1. - С. 77-84.

16. Рахымбердина М. Е. Исследование по совершенствованию высокоточного инженерногеодезического нивелирования цифровыми нивелирами и электронными тахеометрами : автореф. дис. канд. техн. наук. - Новосибирск, 2013. - 24 с.

17. Попов Б. А., Реджепов М. Б. Влияние освещенности территории на точность нивелирования // Актуальные проблемы землеустройства, кадастра и природообустройства : материа- лы I международной научно-практической конференции факультета землеустройства и кадастров ВГАУ. - Воронеж: ВГАУ, 2019. C. $257-261$.

18. Нефедова Г. А., Ащеулов В. А. Теория математической обработки геодезических измерений в конспективном изложении : учеб. пособие. - Новосибирск : СГГА, 2009. - 140 с.

19. Шальнева В. Д. Использование программы excel для обработки журнала нивелирования // Инновационное развитие науки и образования : сборник статей VI Международной научнопрактической конференции. В 2 ч. - Пенза : МЦНС, 2019. - С. 66-70.

20. Уставич Г. А., Сальников В. Г., Рябова Н. М. Схема полевого высотного стенда для поверки системы «цифровой нивелир - штрих-кодовые рейки» // Изв. вузов. Геодезия и аэрофотосъемка. - 2014. - № 4/С. - С. 51-55.

\section{IMPROVEMENT OF HIGH-PRECISION LEVELLING METHOD BY DIGITAL LEVELS IN THE CONDITION OF NON-SUFFICIENT LIGHT INTENSITY OF LINED ROD}

\section{Valerij G. Salnikov}

Siberian State University of Geosystems and Technologies, 10, Plakhotnogo St., Novosibirsk, 630108, Russia, Ph. D., Head of Engineering Geodesy and Mining Department, phone: (913)932-62-20, e-mail: salnikov@ssga.ru

The performing of high-precision geometric leveling by short beams with the purpose of control for the process of building and exploitation of engineering structures and industrial equipment is carried out with visual reading levels or digital levels in case there are a lot of disturbance effects, the basic of which are the vibrations of some equipment in operation, rapid temperature changes, and also non-sufficient and irregular light intensity of bar-code or lined rods. The purpose of the article is the improvement of high-precision leveling method performance by digital levels in the condition of insufficient light intensity of bar-code rods. The article considers the influence of insufficient light intensity of bar-code rods on the leveling station work by digital levels. Due to irregular and insufficient light intensity of the rod the receiver of the digital level does not allow to read distinctly the bar-code and to perform its processing and output to the indication unit in metric system. That's why for accurate measurement on the station the light intensity of the rods should be sufficient, nearly similar and regular. The article gives the results of using the rod, equipped with lightemitting diodes to provide its sufficient and regular lighting.

Key words: high-precision geometric leveling, digital level, bar-code rod, light-emitting diodes, light intensity of rod.

\section{REFERENCE}

1. Standarts Russian Federation. (2003). GOST 10528-90. Levels. General technical conditions. Moscow: IPK Publ., 29 p. [in Russian].

2. Geodetic, cartographic instructions, norms and regulations. (2004). GKINP (GNTA)-03-010- 03.2004.
Leveling guidelines. Classes I, II, III and IV. Moscow: CNIIGAiK Publ., 226 p. [in Russian].

3.Ustavich, G. A., Soboleva, E. L., Rjabova, N. M., \& Sal'nikov V. G. (2011). Study of refraction influence on digital leveling results. Geodezija i karto- 
grafija [Geodesy and Cartography], 5, 3-9 [in Russian].

4. Ustavich, G. A., Ryabova, N. M., Salnikov, V. G., \& Teplykh, A. N. (2010). Study of digital level bar code rods. Vestnik SGGA [Vestnik SSGA], 2(13), 3-8 [in Russian].

5. Ustavich, G. A., Rjabova, N. M., Sal'nikov, V. G., \& Rahymberdina, M. E. (2011). Issledovanie cifrovyh nivelirov i reek. Geodezija i kartografija [Geodesy and Cartography], 4, 9-15 [in Russian].

6. Malkov, A. G. (2009). About estimation of elevation measurement accuracy on geodetic leveling station. In Sbornik materialov GEO-Sibir'-2009. N. 1, ch. 1 [Proceedings of GEO-Siberia-2009: Vol. 1, Part 1] (pp. 82-84). Novosibirsk: SSGA Publ. [in Russian].

7. Rjabova, N. M. (2013). Study of different light intensity influence on rod reading. In Sbornik materialov Interekspo GEO-Sibir'-2013: Mezhdunarodnoy nauchnoy konferentsii: T. 1. Geodezija, geoinformatika, kartografija, markshejderija [Proceedings of Interexpo GEO-Siberia-2013: International Scientific Conference: Vol. 1. Geodesy, Geoinformatics, Cartography, Mine Surveying] (pp. 42-45). Novosibirsk: SSGA Publ. [in Russian].

8. Golovina, L. A. (2016). Dependance of leveling accuracy on light intensity of object. In Sbornik nauchnyh trudov po materialam I Vserossijskoj nauchno-prakticheskoj konferencii: Innovacionnoe social'no orientirovannoe razvitie Rossii [Collection of Scientific Papers Based on the Materials of the 1st All-Russian Scientific and Practical Conference Innovative Socially Oriented Development of Russia] (pp. 374-377). Tomsk: NOO "Professional'naja nauka" [in Russian].

9. Novoselov, D. B., \& Novoselov, B. A. (2013). Study of high-precision digital level work in conditions of light deficiency. In Sbornik materialov Interekspo GEO-Sibir'-2013: Mezhdunarodnoy nauchnoy konferentsii: T. 1. Geodezija, geoinformatika, kartografija, markshejderija [Proceedings of Interexpo GEO-Siberia-2013: International Scientific Conference: Vol. 1. Geodesy, Geoinformatics, Cartography, Mine Surveying] (pp. 117-121). Novosibirsk: SSGA Publ. [in Russian].

10. Malkov, A.G., \& Bryskin, R. M. (2019). Modern methods of high-precision geometric leveling. In Sbornik materialov Interekspo GEO-Sibir'2019: Mezhdunarodnoy nauchnoy konferentsii: T. 1, No. 2. Geodezija, geoinformatika, kartografija, markshejderija [Proceedings of Interexpo GEOSiberia-2019: International Scientific Conference: Vol. 1, No. 2. Geodesy, Geoinformatics, Cartog- raphy, Mine Surveying] (pp. 32-38). Novosibirsk: SSUGT Publ. [in Russian].

11. Nikonov, A. V., Chesheva, I. N., \& Lifashina, G. V. (2016). Influence of environmental temperature changes on the main condition of digital level when surveying foundation settlement of building and structures. Vestnik SGUGiT [Vestnik SSUGT], 2(34), 24-33 [in Russian].

12. Novikov, Ju. A., \& Kraev, A. N. (2019). Geodetic survey of building settlement in geotechnical monitoring provision. Vestnik SGUGiT [Vestnik SSUGT], 24(1), 28-41 [in Russian].

13. Ustavich, G. A., Shaul'skij, V. F., \& Vinokurova O. I. (2003). Design and development of state leveling technology, I, II, III and IV class. Geodezija $i$ kartografija [Geodesy and Cartography], 8, 5-11 [in Russian].

14. Sholomickij, A. A., Lagutina, E. K., \& Soboleva, E. L. (2017). High-precision geodetic measurements in Aquapark deformation monitoring. Vestnik SGUGiT [Vestnik SSUGT], 22(3), 45-59 [in Russian].

15. Nikonov, A. V., Soboleva, E. L., Rjabova, N. M., \& Medvedskaja, T. M. (2015). Determination of mean square error of elevation measurement on the station by digital level. In Sbornik materialov Interekspo GEO-Sibir'-2015: Mezhdunarodnoy nauchnoy konferentsii: T. 1. Geodezija, geoinformatika, kartografija, markshejderija [Proceedings of Interexpo GEO-Siberia-2015: International Scientific Conference: Vol. 1. Geodesy, Geoinformatics, Cartography, Mine Surveying] (pp. 77-84). Novosibirsk: SSUGT Publ. [in Russian].

16. Rahymberdina, M. E. (2013). Research for improvement of high-precision engineering-geodetic leveling by digital levels and total stations. Extended abstract of candidate's thesis. Novosibirsk, 24 p. [in Russian].

17. Popov, B. A., \& Redzhepov, M. B. (2019). Influence of territory light intensity on leveling accuracy. In Sbornik materialov I mezhdunarodnoj nauchno-prakticheskoj konferencii fakul'teta zemleustrojstva i kadastrov VGAU: Aktual'nye problemy zemleustrojstva, kadastra $i$ prirodoobustrojstva [Proccedings of the 1st International Scientific and Practical Conference of the Faculty of Land Management and Cadastres of the VSAU: Actual Problems of Land Management, Cadastre and Environmental Management] (pp. 257-261). Voronez: VGAU Publ. [in Russian].

18. Nefedova, G. A., \& Ashheulov V. A. (2009). Teorija matematicheskoj obrabotki geodezicheskih izmerenij $v$ konspektivnom izlozhenii [Theory of mathematical processing of geodetic measurements 
in summary]. Novosibirsk: SSGA Publ., 140 p. [in Russian].

19. Shal'neva, V. D. (2019). Use of MS Excel for level notes. In Sbornik statej VI Mezhdunarodnoj nauchno-prakticheskoj konferencii: Innovacionnoe razvitie nauki i obrazovanija [Proceedings of the VI International Scientific and Practical Conference Innovative Development of Science and Education]

Received 13.05.2020 (pp. 66-70). Penza: MCNS Publ. [in Russian].

20. Ustavich, G. A., Sal'nikov, V. G., \& Rjabova, N. M. (2014). Scheme of field tall testing stand for verification of system "digital level - bar code rods". Izvestiya vuzov. Geodeziya $i$ aerofotos"emka [Izvestiya Vuzov. Geodesy and Aerophotography], S/4, 51-55 [in Russian].

(C) V. G. Salnikov, 2020 
УДК 629.783:004.457

DOI: $10.33764 / 2411-1759-2020-25-3-72-88$

\title{
АНАЛИЗ КАЧЕСТВА СПУТНИКОВЫХ ИЗМЕРЕНИЙ С ПОМОЩЬЮ ПРОГРАММНОЙ УТИЛИТЫ ТЕQС
}

\author{
Вячеслав Евгеньевич Терещенко \\ Сибирский государственный университет геосистем и технологий, 630108, Россия, г. Новосибирск, \\ ул. Плахотного, 10, аспирант, тел. (953)766-70-14, e-mail: taboretzvigyn@mail.ru
}

Выполнены анализ и оценка качества измерений глобальных навигационных спутниковых систем (ГНСС), полученных с пунктов сетей дифференциальных геодезических станций (ДГС) различных уровней: региональной сети ДГС Новосибирской области (ДГС НСО); государственной фундаментальной астрономо-геодезической сети (ФАГС); глобальной сети Международной ГНСС-службы (МГС). Показана актуальность использования различных региональных (коммерческих, отраслевых) сетей ДГС в опорной геодезической основе государства при формировании единой системы координатно-временного обеспечения. В статье приведены результаты оценки качества ГНСС-измерений по следующим основным критериям: количество отбракованных измерений, ионосферная задержка, эффект многопутности, отношение «сигнал - шум», сдвиги шкал времени часов приемника относительно часов спутника. Оценены основные погрешности, влияющие на качество приема спутниковых измерений, и сделаны выводы о возможности включения сети ДГС Новосибирской области в один из уровней опорной геодезической сети. Сравнение качества ГНСС-измерений пунктов сетей различного уровня показало, что по всем критериям оценки качества ГНСС-измерения, выполняемые на пунктах сети ДГС Новосибирской области, не уступают измерениям, выполняемым на пунктах ФАГС, а также по всем критериям, за исключением отношения «сигнал - шум», соответствуют измерениям, проводимым на пунктах сети МГС.

Ключевые слова: глобальные навигационные спутниковые системы, ГНСС-измерения, дифференциальная геодезическая станция, анализ качества ГНСС-измерений, программная утилита Теqс, спутниковая геодезическая сеть.

\section{Введение}

По состоянию на 2019 г. в Российской Федерации насчитывается более 2000 дифференциальных геодезических станций, установленных и обслуживаемых различными коммерческими и государственными геодезическими компаниями [1-4], и их количество растет. Это связано с тем, что развитие сетей дает возможность эффективнее выполнять геодезические и маркшейдерские измерения, топографические съемки, инженерные изыскания и прочие виды геодезических работ.

Другой, не менее важной целью создания сетей спутниковых ДГС может стать закрепление единого координатно-временного и навигационного обеспечения (КВНО) на территории государства. Таким образом, современные геодезические сети ДГС одновременно можно отнести к двум сегментам единой системы КВНО: решение фундамен- тальных задач и формирование искусственных навигационных полей [5].

Среди проблем использования ДГС в России, упомянутых в работах [6-9], остро стоит проблема недостаточного количества ДГС в составе государственной геодезической сети, реализующих координатную основу ГСК-2011. По данным Федерального научно-технического центра геодезии, картографии и инфраструктуры пространственных данных (ЦГКиИПД) [10], к началу 2020 г. количество пунктов фундаментальной астрономо-геодезической сети составляет 53. Такое количество не позволяет осуществлять привязку объектов при выполнении различных видов геодезических работ к координатной основе ГСК-2011 на большей части территории страны с той точностью, с которой она создана [11]. В то же время множество региональных ДГС, входящих в различные не связанные между собой коммерческие геодезические сети, 
не способствует установлению единой однородной общегосударственной структуры. Региональные сети ДГС позволяют решать задачи, связанные с формированием единой системы КВНО и задачи региональной геодинамики посредством анализа поля смещений пунктов, вызванных естественными геофизическими процессами [12]. Включение таких ДГС в общую структуру формирования государственной координатной основы может принести большую пользу профессиональному и научному геодезическому сообществу.

Однако в России в настоящее время не приняты нормативно-технические документы, регламентирующие развертывание, уравнивание и применение сетей ДГС. Это позволяет различным геодезических компаниям устанавливать пункты с постоянно действующим оборудованием удобным для себя способом, с приемлемой для собственных нужд точностью [13] и уравнивать сети пунктов в системах координат, зачастую отличных от государственных.

Несмотря на различия в уровнях сетей ДГС и системах координат, в которых составлены каталоги координат, их основной задачей является прием радиосигналов от навигационных космических аппаратов (КА) для передачи точных координат на требуемые участки геодезических работ. Современные пункты ДГС расположены в зоне широко открытого радиогоризонта, вдали от границ тектонических плит, посторонних источников радиоизлучения и прочих источников погрешностей, влияющих на качество позиционирования. Такие условия соблюдены как для пунктов Международной ГНСС службы (МГС, англ. - International GNSS Service), так и для пунктов ФАГС и различных региональных сетей ДГС. Анализ и сравнение качества ГНСС-измерений, полученных с пунктов таких сетей, поможет сделать выводы о возможности использования пунктов региональных сетей ДГС в качестве вспомогательного элемента при формировании единой государственной системы КВНО России.

\section{Постановка задачи}

В работе [14] предлагается структура единой геодезической координатной основы, создание которой достигается путем объединения и уравнивания существующих сетей ДГС, таких как ФАГС, высокоточная геодезическая сеть, различные наземные навигационные системы и региональные, коммерческие или отраслевые сети ДГС. Для реализации единой геодезической координатной основы в публикациях $[5,14]$ предлагается создание двухуровневой структуры опорной геодезической сети (ОГС).

Первый уровень должен обеспечивать решение задач КВНО и геофизических наблюдений с наивысшей точностью и максимальной оперативностью путем объединения следующих элементов:

- фундаментальная астрономо-геодезическая сеть;

- высокоточная геодезическая сеть;

- сертифицированные региональные сети референцных станций (ДГС-1)*;

- наземные навигационные системы (HHC-1) типа Locata.

Второй уровень ОГС является, в большей степени, вспомогательным и обеспечивает дублирование функций сети первого уровня для повышения надежности формирования единой системы КВНО.

Этот уровень включает:

- спутниковую геодезическую сеть 1-го класса (СГС-1);

- классическую астрономо-геодезическую сеть 1-4-го класса (АГС);

- ДГС, не прошедшие сертификацию (ДГС-2 - «станции-кандидаты»);

- наземные навигационные системы типа eLoran (HHC-2).

В перспективе такой подход позволит создать в России современную высокоточную координатную основу и значительно повысить эффективность реализации единой системы КВНО России.

* В работах $[5,14]$ вместо термина «дифференциальная геодезическая станция» использован термин «постоянно действующая базовая станция». 
Критерии включения ДГС в тот или иной уровень ОГС многочисленны.

К основным относят: способ установки ГНСС-оборудования; тип и уровень точности аппаратуры; геодинамическую активность района; метеорологические условия и прочие факторы, влияющие на качество принятия радиосигнала.

Существует ряд обязательных и рекомендуемых требований для пунктов, входящих в сеть МГС, изложенных в директиве [15]. Соблюдение таких требований при развертывании сетей ДГС в России создаст условия для формирования высокоточной и стабильной системы КВНО, и, возможно, интеграции таких сетей или их фрагментов в Международную земную отсчетную основу (International Terrestrial Reference Frame). Для пунктов ФАГС и пунктов региональных сетей ДГС не все требования соблюдены.

Например, часть 2.1.15 в директиве [15] содержит следующее обязательное требование: «...следует избегать установки антенн на крышах зданий или сооружений, за исключением особых обстоятельств, которые следует обсудить с Центральным бюро МГС». Однако целью данной работы стоит сравнение качества ГНСС-измерений, полученных с пунктов региональной сети ДГС, пунктов ФАГС и пунктов сети МГС в уже сложившейся ситуации. На основании анализа качества ГНСС-измерений с пунктов региональных сетей ДГС, а также сравнения качества с измерениями, полученными с пунктов сетей национального и глобального масштаба, можно дать рекомендацию о включении отдельных ДГС или сетей ДГС в первый или второй уровень ОГС (ДГС-1 или ДГС-2).

В ходе исследования был проведен анализ и сравнение качества ГНСС-измерений, полученных с пунктов сетей ДГС Новосибирской области (ДГС НСО), ФАГС и МГС, с помощью свободно распространяемой программной утилиты Теqс, разработанной и поддерживаемой компанией University Navstar Consortium (UNAVCO), США.

\section{Программная утилита Теqс}

Программная утилита Теqс предназначена для трансформирования, редактирования, проверки и оценки качества спутниковых измерений. Название утилиты соответствует функциям, которые она выполняет: преобразование (Translating), редактирование (Editing) и проверка (оценка) качества (Quality Checking) ГНСС-измерений. Утилита Teqc не интерактивная: для выполнения всех действий используется интерфейс командной строки.

В ходе проверки и оценки качества утилитой Теqс вычисляются некоторые показатели качества входных данных и указываются проблемы с ГНСС измерениями, записанными в файлах. Утилита Теqс может оценить качество приема сигналов ГНСС и проверять режим работы приемника с использованием данных других приемников. Теqс читает формат RINEX и множество сырых двоичных форматов.

Опция проверки качества дополнительно использует данные эфемерид КА в навигационных файлах для улучшения результатов оценки качества ГНСС-измерений. Данная опция позволяет оценить качество радиосигнала во время обнаружения каждого КА, сформировать сводную таблицу статистики и создать полный отчет об оценке качества, учитывая влияние эффекта многопутности, ионосферную задержку, отношение полезного сигнала к радиошуму, и прочие поддающиеся численной оценке виды погрешностей [16].

\section{Ход работь}

В ходе проведения исследования с помощью программной утилиты Теqс были проанализированы ГНСС-измерения 19 пунктов сети ДГС НСО, 18 пунктов ФАГС и 20 пунктов сети МГС, на предмет качества приема спутниковых измерений. Все измерения, участвующие в исследовании, получены на почти годовом интервале с 01.01.2018 по 16.12.2018. В обработку принимались 24-часовые файлы измерений дискретностью 30 секунд. Файлы, имеющие пробелы в принятии сигналов более $10 \%$ от суточного интервала, были исключены из обработки. Количество включенных в обработку суточных файлов измерений составило от 7 до 10 в каждом месяце 2018 г. Исключением из этого правила были только пункты сети ДГС НСО, из- 
мерения с которых в феврале, апреле, мае и сентябре не были доступны. Помимо файлов измерений в обработке участвовали файлы эфемерид ГЛОНАСС и GPS, полученные из навигационного сообщения для всех пунктов с целью улучшения оценки качества ГНСС измерений и составления полного отчета.

ГНСС измерения пунктов ДГС НСО взяты с сайта государственного бюджетного учреждения «Центр навигационных и геоинформационных технологий Новосибирской области» [17]. В научных целях авторизированным пользователям сайта предоставлен доступ к файлам спутниковых измерений. ГНССизмерения пунктов ФАГС получены с сервера ЦГКиИПД [10]. ГНСС-измерения пунктов МГC получены с FTP-сервера центра SOPAC (Scripps Orbit and Permanent Array Center) центр вычисления точных орбит и координат спутников ГНСС, поддерживаемый институтом океанографии им. Скриппса, США [18].

Полный отчет об оценке качества ГНССизмерений приводится в файле с текстовым расширением «.xxS», где $\mathrm{xx}$ - год проведенных измерений. Файл содержит перечень следующих основных критериев оценки качества:

- начало и конец записи файла измерений, дискретность;

- схематичный график ASCII, демонстрирующий принятие сигнала каждым спутником на соответствующем временном интер- вале (на рис. 1 представлен фрагмент графика из полного отчета об оценке качества Теqс, на котором каждый символ является индикатором качества приема сигнала по времени для каждого спутника в записанном файле);

- сводную таблицу, отображающую количество измерений каждого спутника на каждой несущей частоте или коде L1, L2, P1, P2, C/A, и L2C выше и ниже маски возвышения;

- количество полных кодовых и фазовых измерений, количество удаленных измерений по любой причине (ниже маски возвышения, отсутствуют кодовые или фазовые данные, плохое отношение уровня сигнала к шуму), количество полных, пригодных для обработки измерений;

- смещение часов приемника и скорость смещения часов приемника;

- таблицу и диаграмму среднеквадратической погрешности ионосферной задержки для интервалов возвышения каждого спутника;

- линейные комбинации многопутности (MP1 и MP2) сигнала каждого спутника на различные интервалы возвышения на соответствующих частотах L1, L2, P1 и L1, L2, P2;

- таблицу и диаграмму значений отношения уровня сигнала к уровню шума на частотах L1 и L2.

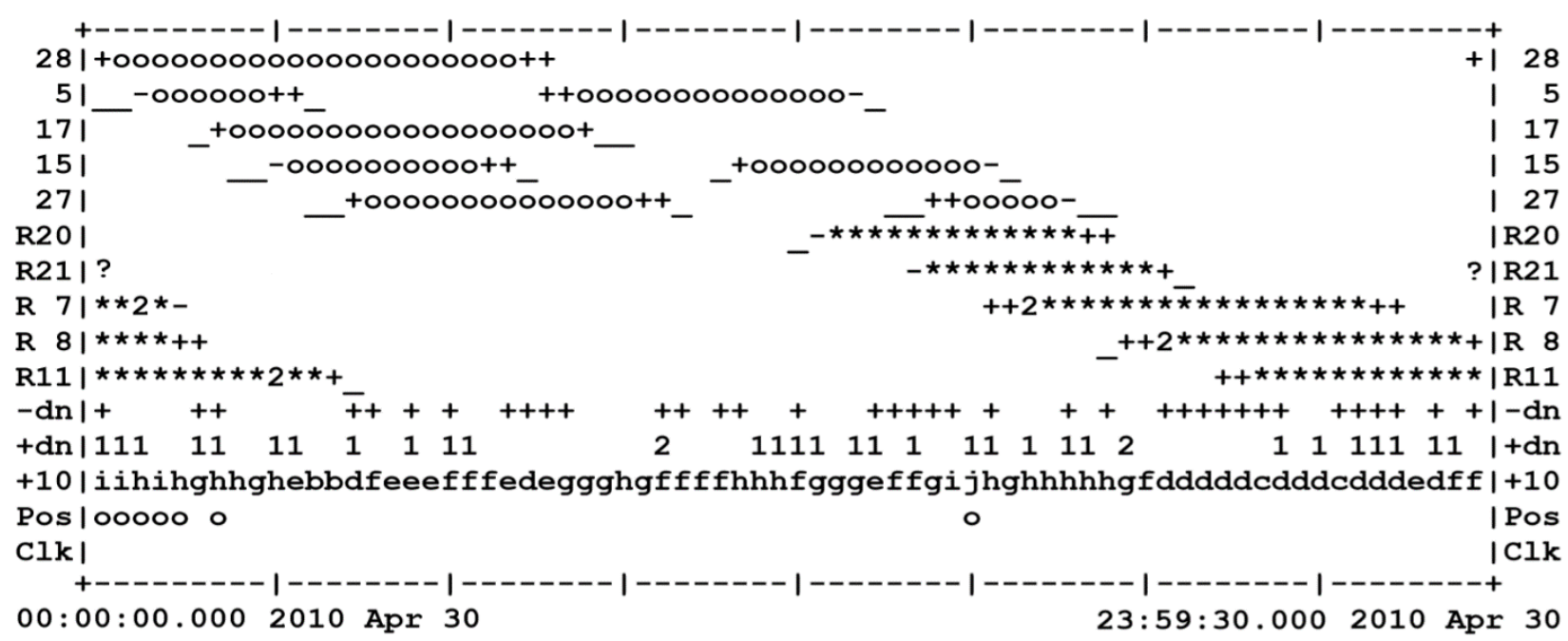

Рис. 1. Фрагмент графической части отчета об оценке качества ГНСС-измерений 


\section{Результаты оценки качества ГНСС-измерений}

\section{Количество отбракованных измерений}

В полном отчете об оценке качества ГНССизмерений указано общее количество полученных измерений; общее количество измерений, полученных в диапазоне установленной маски возвышения; количество непрерывных измерений, полученных в диапазоне маски возвышения; количество удаленных измерений и другие параметры.

На рис. 2, $a$ приведена гистограмма отношения (вертикальная шкала) количества полных измерений выше маски возвышения к общему числу возможных измерений выше маски возвышения. Маска возвышения установлена на значении 10 градусов. Представленные результаты характеризуют среднегодовое значение отношения. Чем выше это отношение, тем меньше прерывистых измерений и срывов циклов на соответствующем пункте. На гистограммах рис. 3 отношение количества полных измерений к общему числу возможных приведено по каждому месяцу для каждого участвовавшего в исследовании пункта сетей ДГС НСО, ФАГС, МГС. По горизонтальной шкале на всех гистограммах далее приведены четырехзначные идентификаторы пунктов.

Среди факторов, влияющих на снижение качества приема радиосигналов, помимо неоптимальной спутниковой геометрии, расположения пунктов в местах наличия радиопомех или физических препятствий прохождения сигнала, существуют прочие, поддающиеся численной оценке. К ним относятся: задержка прохождения сигнала в ионизированном слое атмосферы, переотражение сигнала от различных предметов (многопутность), отношение принятого приемником сигнала к уровню сопутствующего шума, смещение шкалы часов приемника относительно шкалы часов спутника и другие. По перечисленным факторам далее проведена оценка и сравнение качества принимаемых радиосигналов пунктами сетей ДГС НСО, ФАГС, МГС между собой.

\section{Ионосферная задержка}

Ионосферная задержка - изменение скорости распространения электромагнитного излучения, транслируемого спутником и принима- емым приемником, при прохождении ионизированной части атмосферы. Ионосферные условия постоянно меняются и влияют на скорость распространения радиосигналов ГНСС. Ионосферная задержка является существенным источником погрешности при обработке спутниковых измерений и зависит от частоты распространения радиосигнала, поэтому вычисления производятся для обеих частот L1 и L2 [19]. Погрешность позиционирования, вследствие задержки радиосигнала в ионосфере, может достигать десятков метров. Она зависит, в первую очередь, от возвышения спутника над горизонтом, так как сигнал от спутника до приемника при малом угле возвышения пересекает более толстый слой ионосферы, чем при угле, близком к зениту. По оценкам [16], у горизонта она в 5 раз выше, чем в зените. Также этот вид погрешности зависит от географической широты расположения приемника, сезона и времени суток измерений, уровня солнечной активности, препятствий на пути радиосигнала и прочих факторов [20].

В полном отчете об оценке качества Теqс приводится диаграмма увеличения погрешности в зависимости от углового возвышения спутника и вычисленное количество срывов циклов фазовых измерений (ionospheric phase slips) на интервалах возвышения от 90-85 до 5-0 градусов. На рис. 2, $\sigma$ представлена гистограмма, на которой схематично показано среднегодовое количество срывов циклов вследствие ионосферной задержки по обеим частотам по каждой станции, выше установленной маски возвышения. На гистограмме (рис. 4) представлено количество срывов, вызванных влиянием ионосферной задержки по каждому месяцу в течение года для каждого пункта сетей ДГС НСО, ФАГС, МГС. Вертикальная шкала гистограмм характеризует количество срывов.

\section{Многопутность}

Эффект многопутности возникает из-за наличия отражающей поверхности возле приемника при трансляции радиосигнала, но иногда возможно отражение сигналов от самого спутника. Не существует общей модели эффекта многопутности из-за непостоянной спутниковой геометрии. Влияние многопутности может быть оценено с помощью вы- 
числения скользящего среднего (moving average) по линейным комбинациям кода и фазы несущей на частотах L1 и L2 MP1 и MP2 (это комбинации, характеризующие погрешность в измерениях вследствие эффекта многопутности). MP1 является линейной комбинацией P1, L1 и L2, а MP2 является линейной комбинацией P2, L1 и L2 [21]. Характер изменения эффекта многопутности в зависимости от углового возвышения спутника указывает на то, что сигнал от спутников при малом угле возвышения над горизонтом имеет более высокую вероятность переотражения. Как следствие, погрешность, вызванная влиянием этого эффекта, увеличивается.

В полном отчете об оценке качества Теqс приводится диаграмма, содержащая сводку значений комбинаций многопутности MP1 и MP2 для каждого спутника, и осредненное значение для пункта. В отчете графически и численно представлены распределения значений MP1 и MP2 по интервалам возвышения спутников от 90-85 до 5-0 градусов. Вычисленные комбинации многопутности на частотах L1 и L2 усреднены по всем спутникам для каждой станции. На гистограмме (рис. 2, в) приведены среднегодовые значения МР1 и МР2; на гистограммах (рис. 5) - среднемесячные значения MP1 и MP2 для пунктов сетей ДГС НСО, ФАГС, МГС. По вертикальной шкале отложены значения средних комбинаций многопутности (mean MP1 и mean MP2) в метрах.

Отночение «сигнал-иум»

Уровень шума в системе приемного ГНСС-оборудования определяет, насколько точно могут быть измерены псевдодальности и фазы несущей. Качество принятого сигнала тем выше, чем больше отношение уровня сигнала к уровню шума на определенной частоте. Причины низкого отношения «сигнал - шум» могут быть вызваны ионосферными возмущениями, эффектом многопутности, электромагнитной интерференцией, неоптимальным геометрическим положением спутников, различными резонансными явлениями и прочими факторами. Отношение «сигнал - шум» - относительная величина - измеряется по логарифмической шкале, а единицей измерения принят децибел (Дб) [16].
В полном отчете об оценке качества Теqс приведено графическое и численное представление отношения «сигнал - шум» для частот L1 и L2 (SN1 и SN2) в соответствии с интервалами возвышения спутников в Дб; стандартное отклонение (1 сигма); количество измерений $-n$, используемых при вычислении SN1 и SN2. На рис. 2, г приведена гистограмма среднегодовых значений отношения «сигнал - шум» для каждого пункта сетей ДГС НСО, ФАГС, МГС, рассчитанных по спутникам выше маски возвышения - SN1 и SN2. На рис. 6 приведены гистограммы отношения «сигнал - шум» для каждого пункта осредненные по каждому месяцу года. По вертикальной шкале отложены единицы измерения отношения «сигнал - шум» в децибелах.

\section{Смешение шкальв времени часов приемника относительно часов спутника}

Полный отчет об оценке качества Теqс показывает смещение шкалы часов приемника в определенных интервалах времени знаками «+» или «-», означающими либо положительный, либо отрицательный миллисекундный сброс часов. Пустая строка означает, что нет сброса часов. В отчете об оценке качества содержатся значения следующих рассчитанных параметров часов приемника: количество обнаруженных миллисекундных сбросов часов приемника (clock offsets); общее смещение часов приемника (clock drift); скорость смещения часов приемника (rate of clock drift); среднее время между сбросами.

В ходе оценки качества на годовом интервале пунктов сетей ДГС НСО, ФАГС, МГС полный отчет об оценке качества Теqс не показал сбросы часов приемника и смещения шкал часов ни на одном пункте. Поэтому графически этот критерий оценки не представлен.

Представленные на рис. 2 результаты отражают среднегодовые значения перечисленных видов погрешностей по всем пунктам, участвующим в исследовании. Однако с течением времени, под воздействием сезонных флуктуаций и других периодических и эпизодических эффектов (атмосферная, литосферная, антропогенная активность) представленные виды погрешностей могут оказывать воздействие на спутниковые измерения с различной степенью влияния. 
Гистограммы (среднегодовое значение)

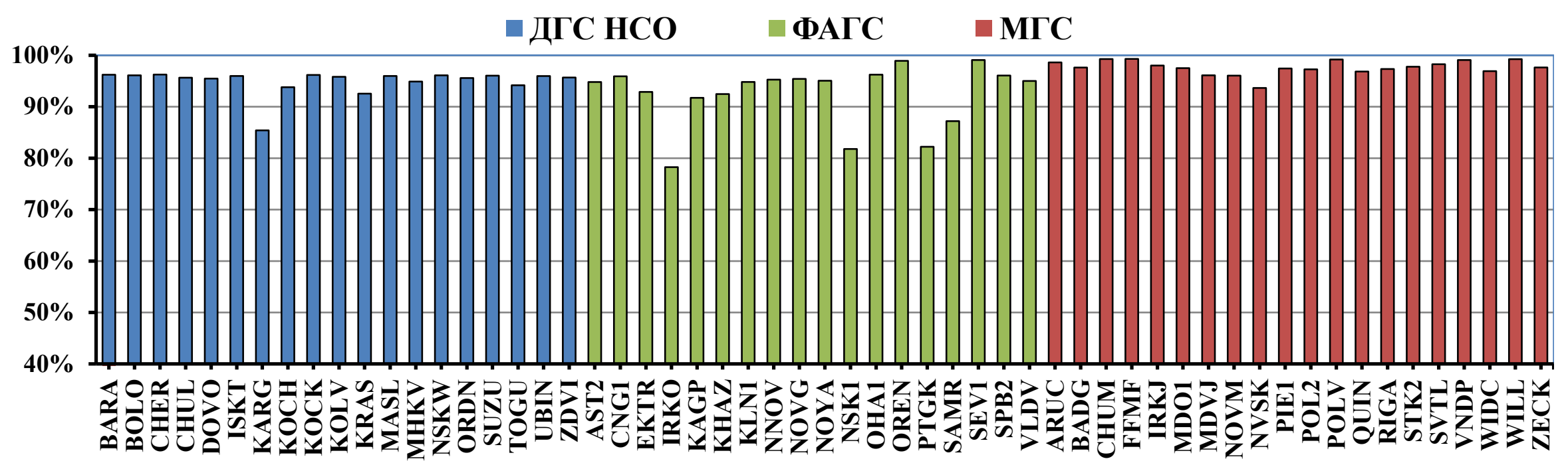

a)

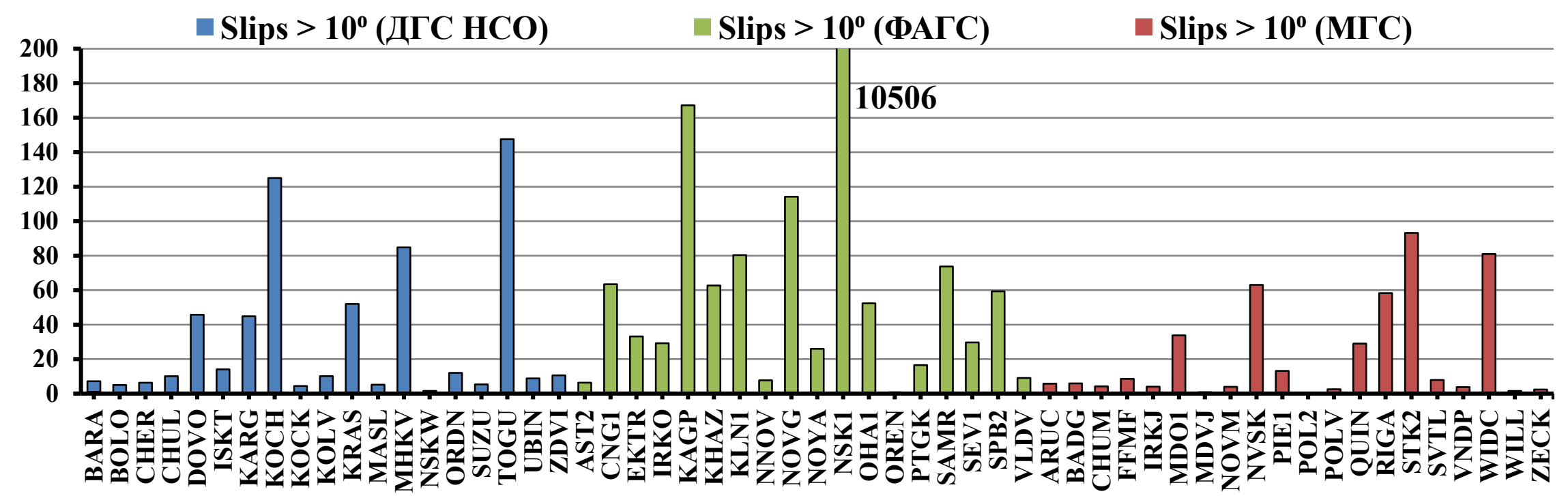




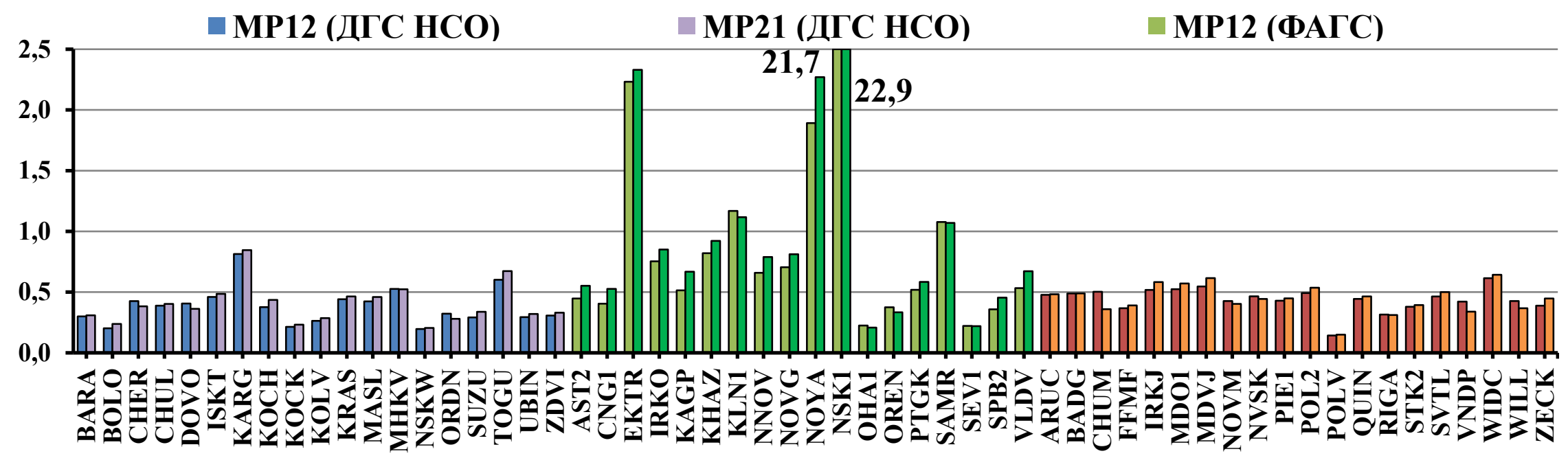

в)

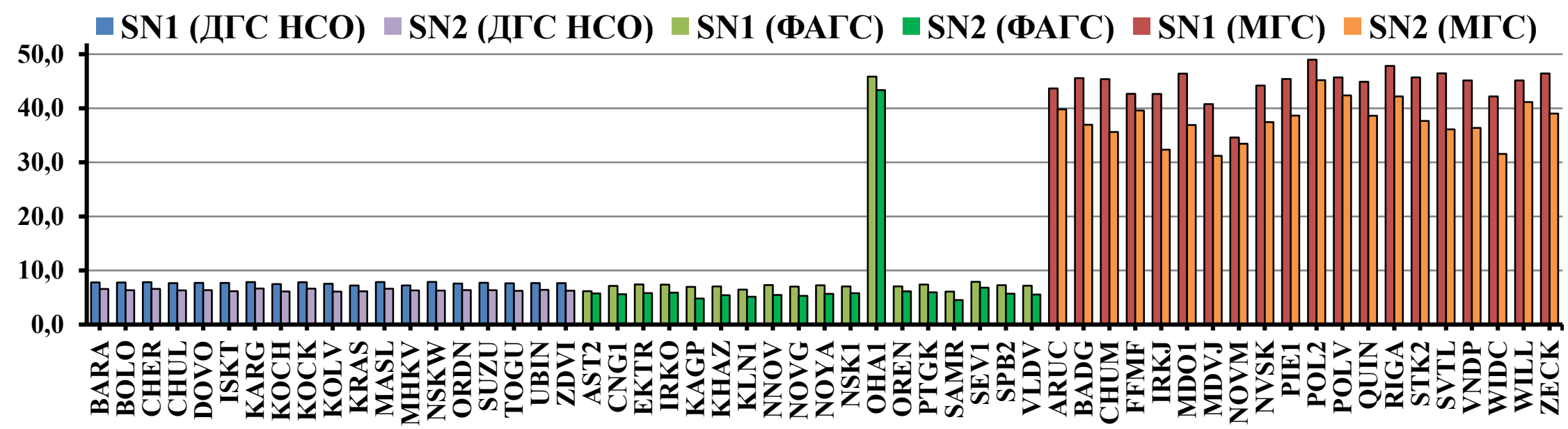

2)

Рис. 2. Гистограммы оценки качества ГНСС-измерений:

a) гистограмма отношения полных измерений к общему числу возможных; б) гистограмма количества срывов, вызванных влиянием ионосферной задержки, выше маски возвышения; в) гистограмма осредненных комбинаций многопутности для частот L1 и L2; г) гистограмма среднего отношения уровня сигнала к уровню шума для частот L1 и L2 
Гистограммы (среднемесячное значение)

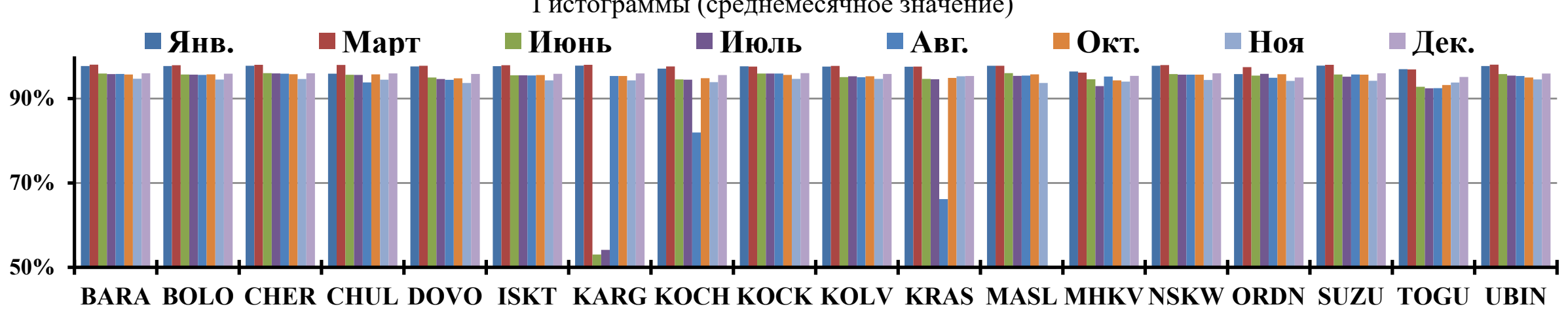

a)

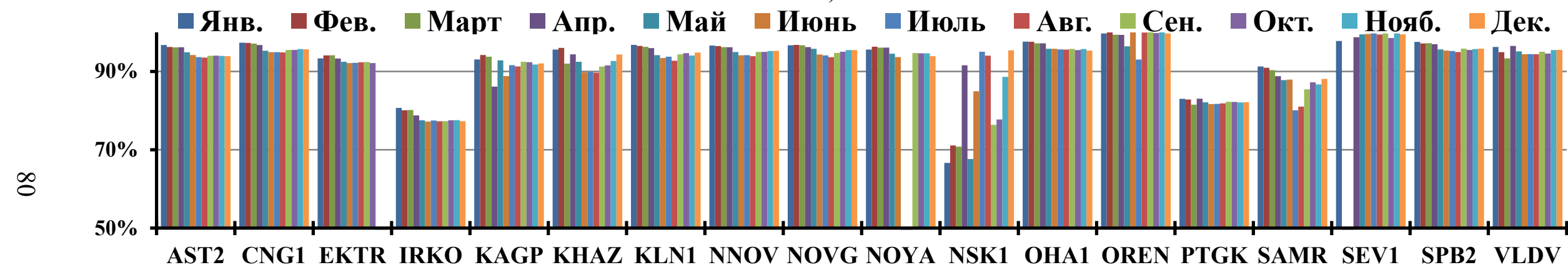

б)

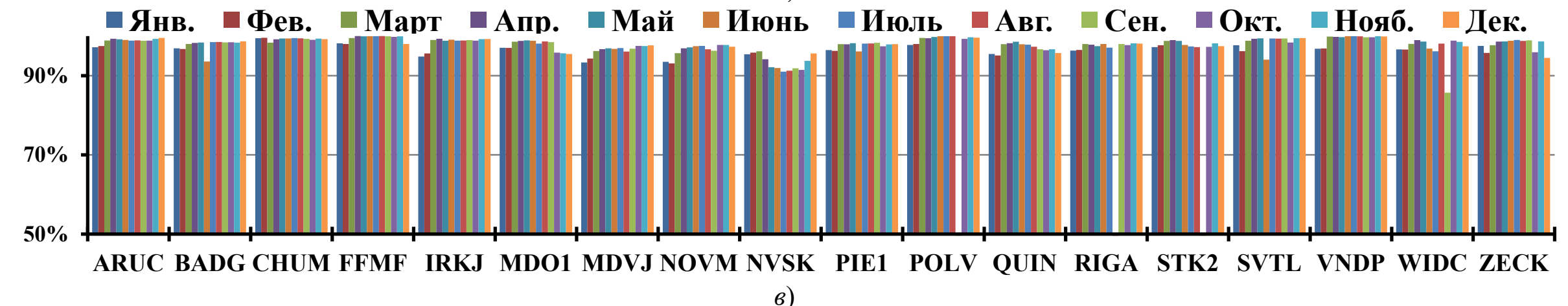

Рис. 3. Гистограммы отношения полных измерений к общему числу возможных в течение года по каждому пункту:

a) по пунктам сети ДГС НСО; б) по пунктам ФАГС; в) по пунктам сети МГС 


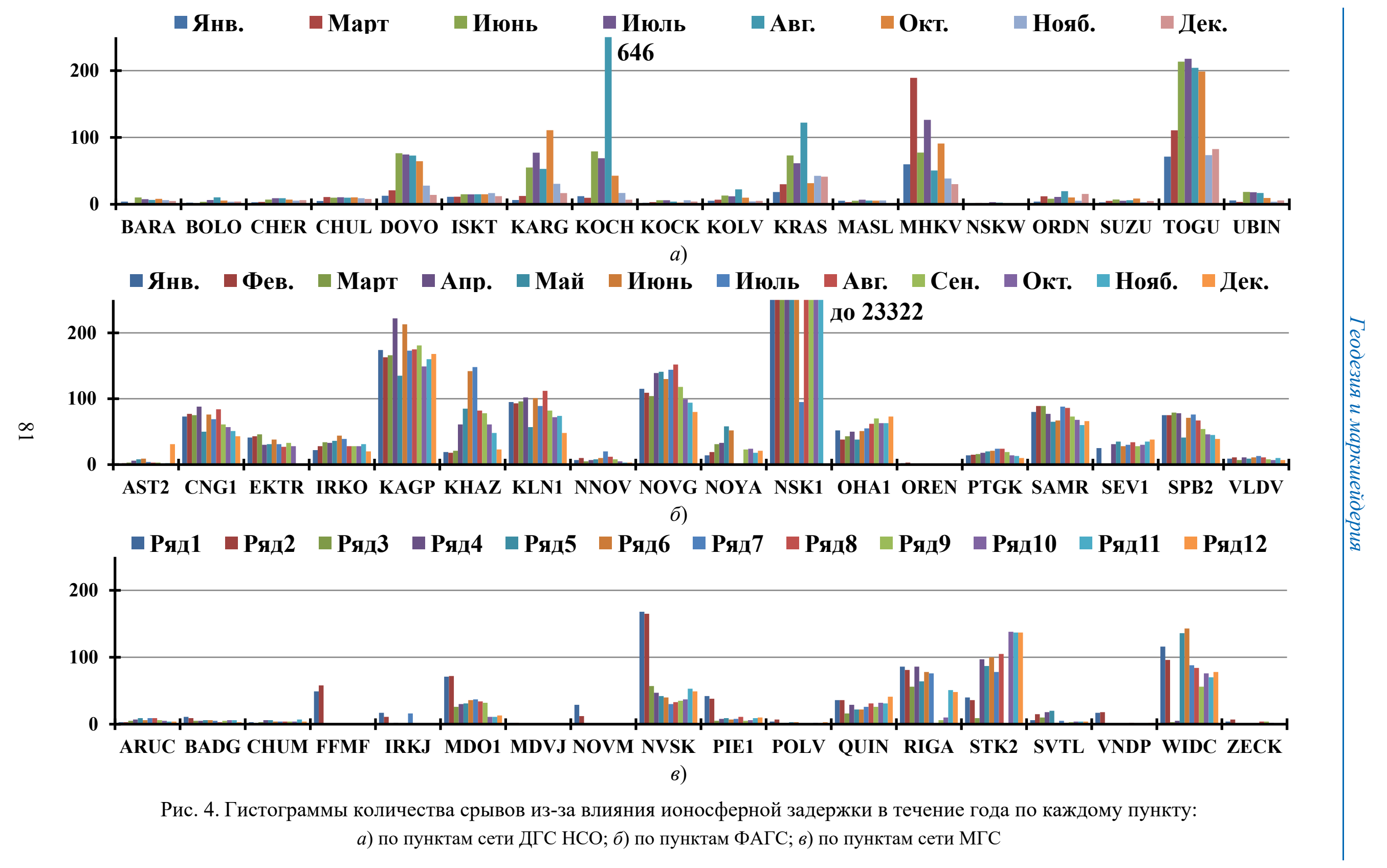




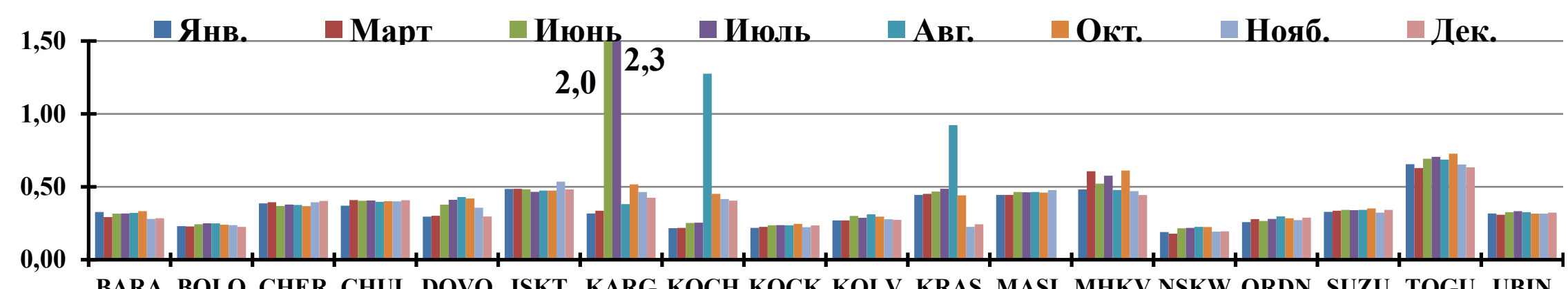

BARA BOLO CHER CHUL DOVO ISKT KARG KOCH KOCK KOLV KRAS MASL MHKV NSKW ORDN SUZU TOGU UBIN a)

Янв. Фев. Март Апр. Май Июнь Июль Авг. Сен. Окт. Нояб. Дек.

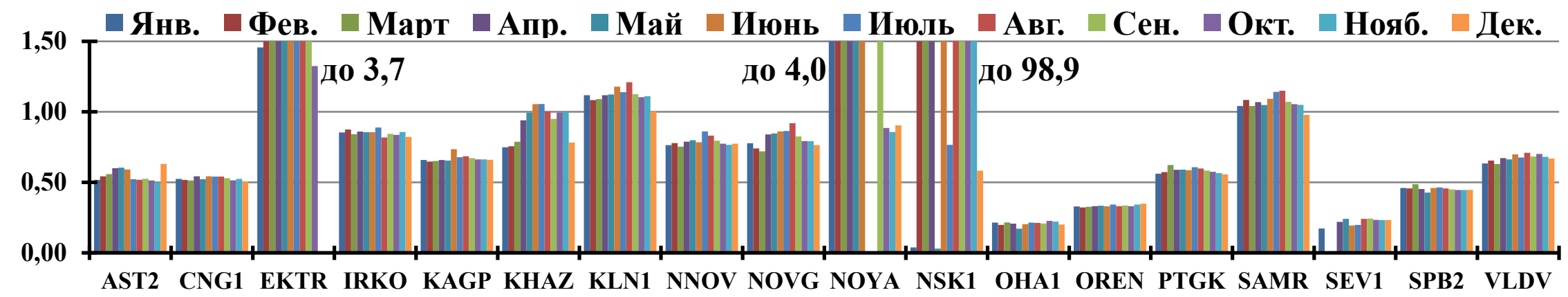

б)

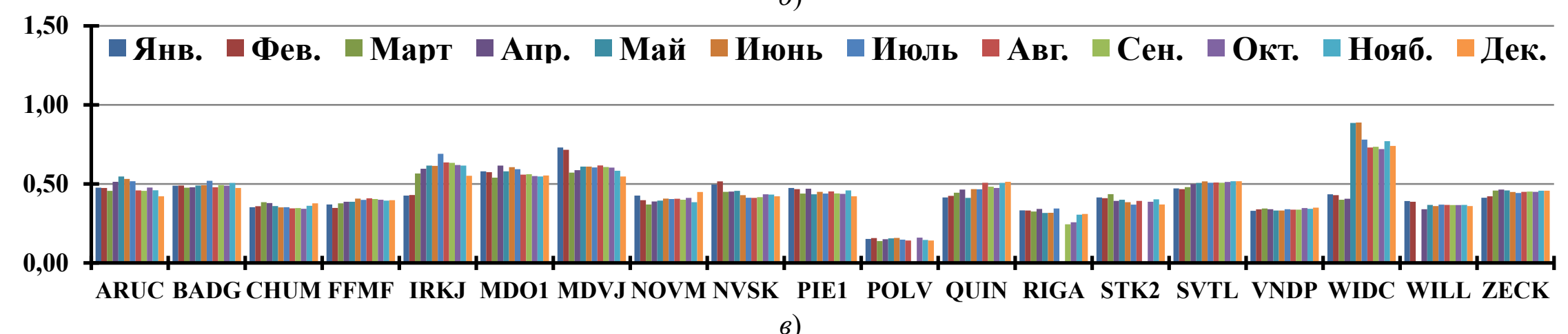

Рис. 5. Гистограммы осредненных комбинаций многопутности для частоты L2 в течение года по каждому пункту:

a) по пунктам сети ДГС НСО; б) по пунктам ФАГС; в) по пунктам сети МГС 


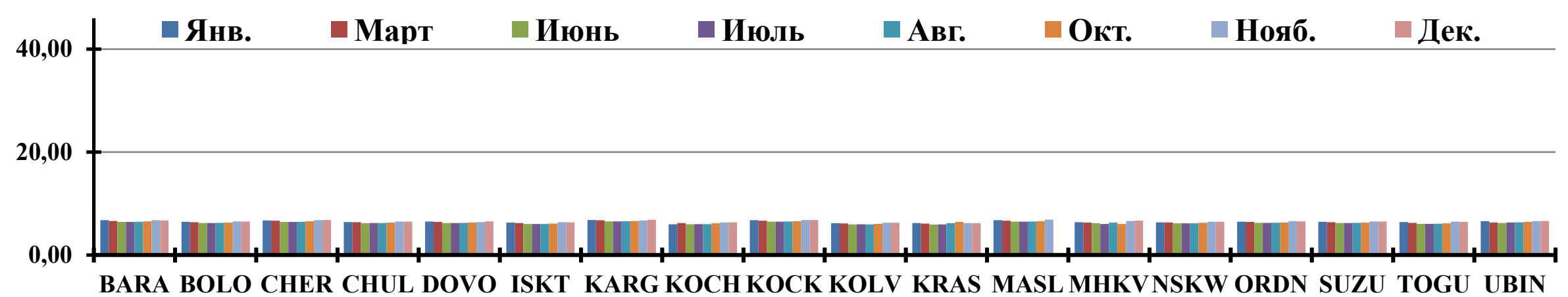
a)

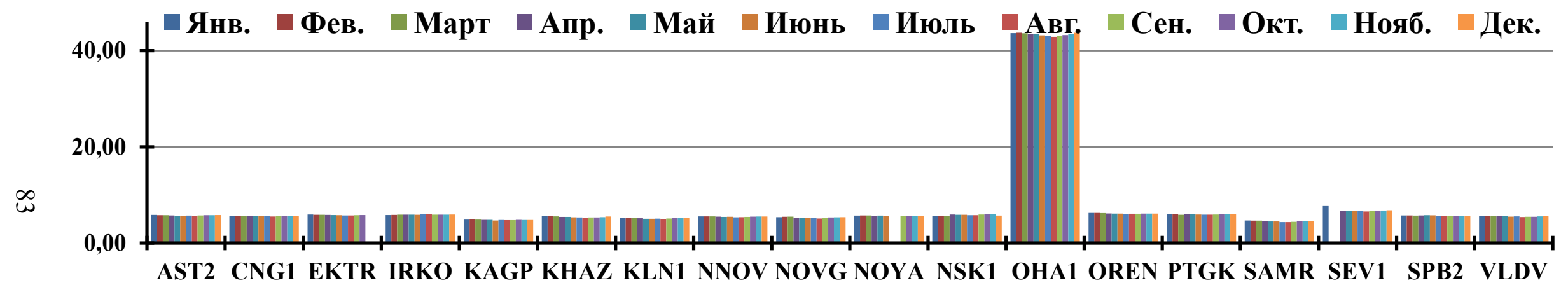

б)

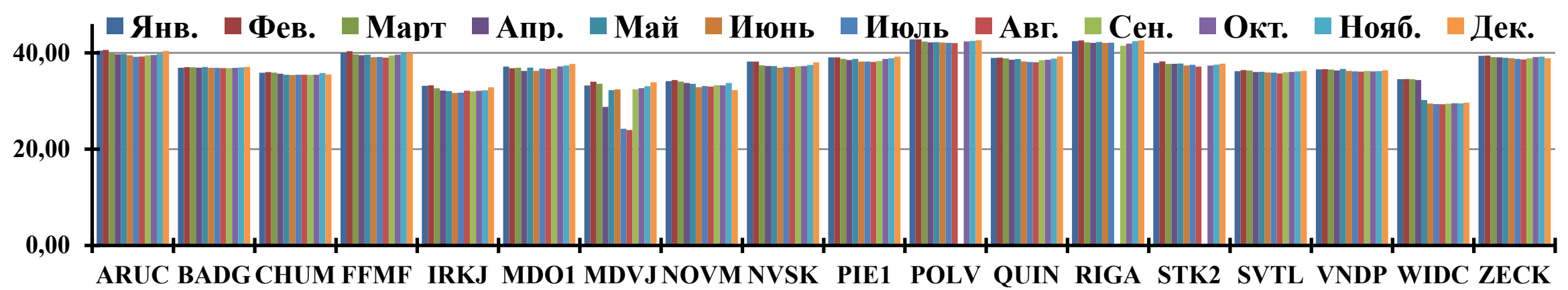

в)

Рис. 6. Гистограммы среднего отношения «сигнал - шум» для частоты L2 в течение года по каждому пункту:

a) по пунктам сети ДГС НСО; б) по пунктам ФАГС; в) по пунктам сети МГС 
Для отражения изменений влияния данных видов погрешностей в течение года по выбранным пунктам на гистограммах (см. рис. 3-6) приведены величины погрешностей, осредненные на месячном интервале.

Погрешность, вызванная влиянием эффекта многопутности, и отношение «сигнал шум» в полном отчете об оценке качества определены для двух частот L1 и L2. В ходе исследования выявлено, что результаты оценки качества слабо зависят от частоты, на которой передается радиосигнал. Это подтверждают результаты, приведенные на рис. 2, в, 2, поэтому на рис. 5, 6 для нормальной визуализации приведены результаты оценки качества только по частоте L2.

\section{Выводы}

Количество отбракованных измерений. По осредненному на годовом интервале отношению полных измерений к общему числу возможных в пределах маски возвышения установлено, что ни на одном пункте сети МГС среднее количество отбракованных измерений не превышает $6 \%$. На пунктах сети ДГС НСО среднегодовое количество отбракованных измерений не превышает $7 \%$, за исключением пункта KARG. Как видно на гистограмме (см. рис. 5,a), в июне и июле 2018 г. на данном пункте выявлен значительный эффект многопутности. На четырех пунктах сети ФАГС среднее количество отбракованных измерений составляет более $14 \%$.

Высокий процент отбракованных измерений свидетельствует о том, что измерения, проводимые на пунктах, подвержены факторам, влияющим на снижение качества приема радиосигналов и точности результатов позиционирования. К таким факторам относятся погрешности, количественные оценки которых описаны далее.

Ионосферная задержка. При оценке качества спутниковых измерений установлено, что количество зафиксированных срывов циклов ниже маски возвышения 10 градусов превосходит количество срывов выше этой отметки в среднем по большинству пунктов в 5-6 раз.

Среднегодовое количество срывов циклов фазовых измерений вследствие задержки прохождения радиосигнала через ионосферный слой атмосферы, вычисленных по обеим частотам выше маски возвышения, на пунктах сетей ДГС НСО и МГС меньше, чем на пунктах ФАГС более чем в 2 раза.

На гистограммах (см. рис. 4) видно, что количество срывов на каждом пункте любой сети с течением года относительно постоянно. В общем случае количество отбракованных измерений вследствие данного вида погрешности незначительно и не превышает $0,1 \%$ от общего количества измерений. Для пунктов сети ДГС НСО это 0,05\%, для пунктов сети МГС - 0,07\%, для пунктов ФАГС $0,1 \%$. Для пунктов ФАГС расчет проводился без учета пункта NSK1, на котором выявлено аномальное количество срывов (см. рис. 2, $\sigma$ и рис. 4,6 ). На этом пункте среднее количество срывов превосходит среднее количество срывов по всем остальным пунктам на 2-3 порядка и составляет около $25 \%$ от среднесуточного количества принимаемых измерений. Такая аномальная величина наблюдалась в течение 10 месяцев, что, безусловно, ощутимо сказывается на точности результатов высокоточного позиционирования.

Эффект многопутности. Как видно на гистограммах (см. рис. 2, в и рис. 5), среднегодовая погрешность ГНСС-измерений вследствие эффекта переотражения сигнала на пунктах ФАГС превышает соответствующую погрешность на пунктах других сетей. На пунктах ФАГС, в сравнении с пунктами сети ДГС НСО, по комбинациям МР1 и МР2 в среднем она больше в 2 раза и составляет 0,76 и 0,85 м, тогда как на пунктах ДГС НСО в среднем она равна 0,37 и 0,39 м. На пунктах сети МГС среднегодовая погрешность многопутности по комбинациям MP1 и МP2 в среднем составляет 0,44 и 0,45 м.

В расчет средних значений не были включены результаты, полученные с пункта ФАГC NSK1. На этом пункте погрешность, вызванная эффектом многопутности, превышает среднюю погрешность по всем остальным пунктам почти в 100 раз. Выявленная аномальная погрешность может быть следствием того, что вблизи пункта NSK1 расположены предметы, поверхность которых имеет высокую степень рефлективности, 
или имеют место сбои в системе приемного оборудования. Поскольку на пункте NSK1 в течение 2018 г. также наблюдались аномальные погрешности, связанные с задержкой распространения сигнала в ионосфере, то точность позиционирования и точность сформированной базовой линии с использованием данного пункта может не удовлетворять ожидаемую. Выявленная аномальная погрешность многопутности в течение года оказывала влияние на пункт NSK1 на протяжении 8 месяцев. Если в настоящее время погрешности продолжают влиять на прием радиосигнала в той же степени, операторам пункта NSK1 необходимо обратить внимание на выявленный факт и устранить негативные причины, снижающие качество приема радиосигналов навигационных спутников.

Авторы работы [22] утверждают, что если процентная доля пунктов в сети со значениями средних комбинаций многопутности MP1 и MP2, не превышающих 0,5 м, составляет более $85 \%$, то такую сеть ДГС можно считать устойчивой к влиянию погрешности, вызванной эффектом многопутности. Сеть ДГС НСО (включая дополнительные 12 пунктов второй очереди) и сеть МГС этому критерию удовлетворяют, а ФАГС, исходя из анализа выбранных пунктов, нет.

Отношение «сигнал - шум». Как видно на гистограммах (см. рис. 2, г и рис. 6), отношение уровня полученного сигнала к уровню сопутствующего шума в приемном оборудовании сильно отличается на пунктах сети МГС в сравнении с пунктами ФАГС и ДГС НСО. Средний уровень SN1 и SN2 для пунктов этой сети составляет 44,5 и 37,6 Дб. На пунктах сети ДГС НСО и ФАГС в среднем это отношение в 5-6 раз меньше и составляет 7,7 и 6,6 Дб для ДГС НСО и 9,2 и 7,7 Дб для ФАГС. Только на пункте ФАГС ОНА1 отношение «сигнал-шум» сопоставимо с результатами пунктов сети МГС. В течение года по всем пунктам сетей ДГС НСО, ФАГС, МГС значение отношения «сигнал - шум» колебалось незначительно. Существенных выбросов значений на установленном временном интервале не обнаружено.

Отношение полезного сигнала к уровню сопутствующего шума зависит от приемного оборудования и наличия вблизи пунктов источников постороннего радиоизлучения. Поскольку маловероятно, что на всех пунктах ДГС НСО и ФАГС, участвующих в исследовании, постороннее радиоизлучение влияет в приблизительно равной мере, то различия в полученных результатах можно объяснить различием в требованиях, определенных для оборудования, используемого для приема радиосигналов навигационных спутников. Приемное оборудование, устанавливаемое на пунктах МГС, должно удовлетворять современным требованиям, определенным в документе [15]. Такие требования позволяют гарантировать высокое качество приема радиосигналов и обеспечить поддержание сети МГС в качестве передовой глобальной спутниковой сети.

Смещение шкаль времени часов приемника относительно часов спутника. В ходе оценки качества с помощью утилиты Теqс смещение шкал времени часов (clock offsets), a также общий дрейф часов (clock drift) ни по одному пункту любой сети не показали значения, отличные от нуля. Данному виду погрешности в большей степени подвержены спутниковые приемники, имеющие менее точные кварцевые стандарты частоты, чем приемники, устанавливаемые на постоянно действующих ДГС. Также данная погрешность будет определена в случае малого количества видимых спутников, когда приемник не сможет синхронизировать часы со всеми КА.

Анализируя гистограммы на рис. 3-6, можно заметить интересный факт. По всем пунктам сетей ДГС НСО, ФАГС, МГС очевидно закономерное изменение погрешности, вызванной задержкой сигнала в ионосфере, и погрешности многопутности в зависимости от времени года. В общем случае погрешности возрастают к середине года и к концу года уменьшаются. Аналогично с критерием отношение «сигнал - шум». На гистограммах по большинству пунктов можно заметить уменьшение отношения «сигнал - шум» летом и увеличение зимой. Колебание значений критериев оценки качества происходит на уровне 5-10 \%. Вероятно, данный факт связан с изменением солнечной активности (все пункты, участвующие в исследовании, расположены в северном полушарии). 


\section{Заключение}

При анализе спутниковых измерений, полученных с пунктов региональной сети ДГС НСО, ни на одном пункте на годовом интервале не выявлено существенных погрешностей при принятии радиосигналов навигационных спутников. Основные погрешности спутниковых измерений приблизительно в равной мере влияют на все пункты сети ДГС НСО. Качество ГНСС-измерений, полученных с этих пунктов, в среднем по каждому из вышеприведенных критериев превосходит качество измерений, полученных с пунктов ФАГС, и соответствует качеству измерений, полученных с пунктов МГС. За исключением показателя отношение «сигнал - шум», по которому качество измерений пунктов сети МГС превосходит качество измерений пунктов сетей ДГС НСО и ФАГС в среднем в 5-6 раз. По приведенным результатам можно сделать выводы о том, что с точки зрения качества проводимых ГНСС-измерений пункты сети ДГС НСО не уступают пунктам ФАГС. Поэтому исходя из тех критериев, по которым была проведена оценка качества, включение сети ДГС НСО в первый уровень ОГС может быть обоснованным.

Вышеперечисленные критерии оценки качества принимаемых радиосигналов можно использовать для анализа ГНСС-измерений, полученных с любых ДГС или сетей ДГС, например [1-4], чтобы судить о возможности включения их в тот или иной уровень ОГС. Анализ качества с помощью программной утилиты Теqс позволяет оценить численные характеристики основных погрешностей, сопровождающих процесс высокоточного спутникового позиционирования. Это дает возможность определить слабые места в системе приема радиосигналов пунктами сетей ДГС, что важно для эффективного развития геодезической координатной основы и системы КВНО Российской Федерации.

\section{БИБЛИОГРАФИЧЕСКИЙ СПИСОК}

1. НП ОСВСП Некоммерческое партнерство операторов сетей высокоточного спутникового позиционирования [Электронный ресурс]. - Режим доступа: http://nposvsp.ru/.

2. Сервис предоставления RTK поправок, получаемых сетью постоянно действующих базовых станций SmartNet [Электронный pecypc]. Режим доступа: http://smartnet-ru.com/.

3. Система спутниковых измерений сетью постоянно действующих базовых станций HIVE [Электронный ресурс]. - Режим доступа: https://hive.geosystems.aero/.

4. Инфраструктурный проект группы компаний EFT GROUP. Сеть референцных ГНСCстанций EFT-CORS [Электронный ресурс]. - Peжим доступа: http://eftgroup.ru/.

5. Карпик А. П., Липатников Л. А., Лагутина Е. К. О направлении развития опорной геодезической сети России как элемента единой системы координатно-временного и навигационного обеспечения // Гироскопия и навигация. 2016. - Т. 24, № 2 (93). - С. 87-94.

6. Проблемы и перспективы развития активных спутниковых геодезических сетей в России и их интеграции в ITRF / В. С. Вдовин, В. В. Дворкин, А. П. Карпик, Л. А. Липатников, С. Д. Сорокин, Г. М. Стеблов // Вестник СГУГиТ. - 2018. - Т. 23. № 1. - С. 6-27.

7. Демьянов Г. В., Майоров А. Н., Побединский Г. Г. Проблемы непрерывного совершен- ствования ГГС и геоцентрической системы координат России // Геопрофи. - 2011. - № 4.

8. Герасимов А. П. Проблемы спутниковых дифференциальных геодезических станций // Геопрофи. - 2012. - № 3. - С. 52-53.

9. Анализ состояния государственной геодезической сети России с учетом существующих и перспективных требований / Е. М. Мазурова, К. М. Антонович, Е. К. Лагутина, Л. А. Липатников // Вестник СГГА. - 2014. - Вып. 3 (27). - С. 84-89.

10. Федеральное государственное бюджетное учреждение «Центр геодезии, картографии и инфраструктуры пространственных данных» [Электронный ресурс]. - Режим доступа: https://cgkipd.ru.

11. Сурнин Ю. В. О корректном применении международной терминологии «Reference System» и «Reference Frame» к понятиям «система координат» и «координатная основа» в геодезической практике России // Геодезия и картография. - 2015. - № 8. - С. 3-9.

12. Терещенко В. Е., Лагутина Е. К. Сравнение относительных смещений пунктов сети постоянно действующих базовых станций Новосибирской области, полученных с использованием различных онлайн-сервисов обработки спутниковых измерений // Вестник СГУГиТ. 2019. - T. 24, № 2. - C. 76-94.

13. Лагутина Е. К. Апробация методики включения сети постоянно действующих базо- 
вых станций Новосибирской области в государственную геодезическую сеть // Вестник СГУГиТ. - 2016. - № 3(35). - С. 35-42.

14. Липатников Л. А. Эксперимент по формированию геоцентрической земной координатной основы на территории РФ и ближнего зарубежья // Вестник СГУГиТ. - 2016. № 3(35). - C. 16-26.

15. Site Guidelines - IGS [Электронный ресурс]. - Режим доступа: https://kb.igs.org/hc/enus/articles/202011433.

16. Teqc Tutorial: Basics of Teqc Use and Teqc Products - 2014 [Электронный ресурс]. - Режим доступа: https://www.unavco.org/software/dataprocessing/teqc/teqc.html.

17. Государственное бюджетное учреждение «Центр навигационных и геоинформационных технологий Новосибирской области» [Электронный ресурс]. - Режим доступа: http://rtk.nso.ru/ spiderweb/frmIndex.aspx.
18. SOPAC - Scripps Orbit and Permanent Array Center [Электронный pecypc]. - Режим доступа: http://sopac.ucsd.edu/dataBrowser.shtml.

19. Minchan Kim, Jiwon Seo, Jiyun Lee. A comprehensive method for GNSS data quality determination to improve ionospheric data analysis // Sensors 2014 (14), 14971-14993; 23 pages. doi:10.3390/s140814971.

20. Косарев Н. С. Исследование методики контроля фазовых ГНСС-измерений по имитационным данным GPS // Вестник СГУГиТ. 2016. - Вып. 1 (33). - С. 6-13.

21. Danijel Šugar, Petar Sučić, Željko Bačić Examination of Site Suitability for GNSS // Proc of SIG: International Symposium on Engineering Geodesy, (2016). - P. 255-266. Varaždin, Croatia.

22. Yaxuan Hu, Lin Cheng, Xiong Wang Quality analysis of the campaign GPS stations observation in Northeast and North China // Geodesy and Geodynamics 2016. - Vol. 7 (12), March 2016. - pp. 87-94.

Получено 10.06.2020

(C) B. E. Терещенко, 2020

\section{QUALITY ANALYSIS OF GNSS OBSERVATIONS OF REFERENCE STATIONS NETWORK WITH THE TEQC UTILITY}

\section{Vyacheslav E. Tereshchenko}

Siberian State University of Geosystems and Technologies, 10, Plakhotnogo St., Novosibirsk, 630108, Russia, Ph. D. Student, phone: (953)766-70-14, e-mail: taboretzvigyn@mail.ru

The measurements of Global Navigation Satellite System (GNSS) obtained from different reference stations: Novosibirsk Region reference stations network, Russian state reference stations network - Fundamental Astronomical and Geodetic Networks (FAGN) and stations of International GNSS service (IGS) are checked and analyzed. The relevance of the usage of regional (commercial or industrial) reference stations in state foundation geodetic framework for formation of a unified system of coordinate-time and navigation support is shown. The article describes quality analysis results of the GNSS measurements by the main criteria: number of rejected measurements, ionospheric delay, multipath effect, signal-to-noise ratio, receiver clock slips. The main errors affecting satellite measurements are estimated. The conclusions about the possibility of including the Novosibirsk Region reference stations network into one of the levels of the state foundation geodetic framework are drawn. The comparison of quality of the GNSS measurements showed that according to all criteria of quality the GNSS measurements of the Novosibirsk Region reference stations network are not worse than GNSS measurements of FAGN. According to all criteria the GNSS measurements of the Novosibirsk Region reference stations network approximately corresponds to GNSS measurements of IGS stations, except the signal-to-noise ratio criterion.

Key words: Global Navigation Satellite Systems, GNSS observations, quality checking of GNSS observations, reference station, reference stations network, Teqc utility.

\section{REFERENCES}

1. Nekommercheskoe partnerstvo operatorov setey vysokotochnogo sputnikovogo pozitsionirovaniya [Nonprofit partnership of high precision satellite positioning networks]. (n. d.). Retrieved from http://nposvsp.ru/index.php?id=6 [in Russian].
2. Servis predostavleniya RTK popravok poluchaemykh set'yu postoyanno deystvuyushchikh bazovykh stantsiy SmartNet [The service provision of RTK corrections received by the network of perma- 
nently operating base stations SmartNet]. (n. d.). Retrieved from http://smartnet-ru.com/ [in Russian].

3. Sistema sputnikovykh izmereniy set'yu postoyanno deystvuyushchikh bazovykh stantsiy HIVE [The system of satellite measurements getting by the permanently operating base stations HIVE]. (n. d.). Retrieved from https://hive.geosystems.aero/ [in Russian].

4. Infrastrukturnyy proekt gruppy kompaniy EFT GROUP. Set' referentsnykh GNSS-stantsiy EFT-CORS [Infrastructure project of EFT GROUP. The network of reference GNSS-stations EFT-COURSE]. (n. d.). Retrieved from http://eftgroup.ru/ [in Russian].

5. Karpik, A. P., Lipatnikov, L. A., \& Lagutina, E. K. (2016). Prospective development of the Russian geodetic reference network as a component part of the unified system for positioning, navigation, and timing. Giroskopija $i$ navigacija [Gyroscopy and Navigation], 24, 2(93), 264-268 doi: 10.1134/S207510871603007X [in Russian].

6. Vdovin, V. S., Dvorkin, V. V., Karpik, A. P., Lipatnikov, L. A., Sorokin, S. D., \& Steblov, G. M. (2018). Current state and future development of active satellite geodetic networks in Russia and their integration into ITRF. Vestnik SGUGiT [Vestnik SSUGT], 23(1), 6-27 [in Russian].

7. Demyanov, G. V., Mayorov, A. N., \& Pobedinskiy, G. G. (2011). Problems of continuous improvement of the state geodetic network and Russian geocentric coordinate system. Geoprofi [Geoprofi], 4, 15-21 [in Russian].

8. Gerasimov, A. P. (2012). Problems of differential geodetic reference stations. Geoprofi [Geoprofi], 3, 52-53 [in Russian].

9. Mazurova, E. M., Antonovich, K. M., Lagutina, E. K., \& Lipatnikov, L. A. (2014) Analysis of the Russian national reference network condition considering modern and prospective requirements. Vestnik SGUGiT [Vestnik SSUGT], 3(27), 84-89 [in Russian].

10. Federal'noe gosudarstvennoe byudzhetnoe uchrezhdenie "Centr geodezii, kartografii $i$ infrastruktury prostranstvennyh dannyh" [Federal State Budget Institution "Center for Geodesy, Cartography and Spatial Data Infrastructure"]. (n. d.). Retrieved from https://cgkipd.ru [in Russian].

11. Surnin, Yu. V. (2015). About correct application of international terminology "Reference System" and "Reference Frame" to "koordinatnaya sistema" and "koordinatnaya osnova" in practice of geodesy in Rus- sia. Geodezija i kartografija [Geodesy and Cartography], 8, 3-9 [in Russian].

12. Tereshchenko, V. E., Lagutina, E. K. (2019). Determining of Novosibirsk Region reference stations offsets by comparison method of free online GNSS post-processing services. Vestnik SGUGiT [Vestnik SSUGT], 24(2), 76-94 [in Russian].

13. Lagutina, E. K. (2016). Testing methods of integration regional cors network and the russianstate geodetic network. Vestnik SGUGiT [Vestnik SSUGT], 3(35), 35-40 [in Russian].

14. Lipatnikov, L. A. (2016). Implementation of a geocentric terrestrial reference frame for the territory of Russia and bordering countries. Vestnik SGUGiT [Vestnik SSUGT], 3(35), 16-24 [in Russian].

15. Site Guidelines - IGS. (n. d.). Retrieved from https://kb.igs.org/hc/en-us/articles/202011433

16. Teqc Tutorial: Basics of Teqc Use and Teqc Products (2014). (n. d.). Retrieved from https://www.unavco.org/software/data-processing/teqc/ teqc.html.

17. Gosudarstvennoe byudzhetnoe uchrezhdenie "Tsentr navigatsionnykh $i$ geoinformatsionnykh tekhnologiy Novosibirskoy oblasti" [State Budgetary Institution "Center for Navigation and Geoinformation Technologies of the Novosibirsk Region"]. (n. d.). Retrieved from http://rtk.nso.ru/spiderweb/frmIndex.aspx [in Russian].

18. SOPAC - Scripps Orbit and Permanent Array Center. (n. d.). Retrieved from http://sopac.ucsd.edu/ dataBrowser.shtml.

19. Minchan Kim, Jiwon Seo, Jiyun Lee (2014). A comprehensive method for GNSS data quality determination to improve ionospheric data analysis. Published 2014 in Sensors, 14971-14993. doi: 10.3390/s140814971.

20. Kosarev, N. S. (2016). Research method of control phase GNSS measurements based on simulation data. Vestnik SGUGiT [Vestnik SSUGT], 33(1), 6-13 [in Russian].

21. Danijel Šugar, Petar Sučić, Željko Bačić (2016). Examination of Site Suitability for GNSS. Proc of SIG: International Symposium on Engineering Geodesy, ISBN 978-953-59018-0-8 pp. 255-266. Varaždin, Croatia.

Yaxuan $\mathrm{Hu}$, Lin Cheng, Xiong Wang Quality analysis of the campaign GPS stations observation in Northeast and North China (2016). Geodesy and Geodynamics. - Vol. 7 (12), pp. 87-94. doi: 10.1016/j.geog.2016.03.008. 
УДК 528.236

DOI: $10.33764 / 2411-1759-2020-25-3-89-106$

\title{
ГЛОБАЛЬНАЯ СИСТЕМА ОТСЧЕТА И ЕЕ ЛОКАЛЬНАЯ РЕАЛИЗАЦИЯ - ГОСУДАРСТВЕННАЯ СИСТЕМА КООРДИНАТ 2011 ГОДА
}

\author{
Вячеслав Евгеньевич Терещенко \\ Сибирский государственный университет геосистем и технологий, 630108, Россия, г. Новосибирск, \\ ул. Плахотного, 10, аспирант, тел. (953)766-70-14, e-mail: taboretzvigyn@mail.ru
}

\section{Андрей Васильевич Радченко}

Институт физики прочности и материаловедения Сибирского отделения Российской академии наук, 634055, Россия, г. Томск, пр. Академический, 2/4, e-mail: andreyradchenko8@gmail.com

\section{Вячеслав Анатольевич Мелкий}

Институт морской геологии и геофизики Дальневосточного отделения Российской академии наук, 693022, г. Южно-Сахалинск, ул. Науки, 1б, доктор технических наук, ведущий научный сотрудник лаборатории вулканологии и вулканоопасности, тел. (984)139-70-77, e-mail: vamelkiy@mail.ru

В статье освещается вопрос интерпретации сетей спутниковых дифференциальных геодезических станций как локальной реализации глобальной системы отсчета. Приведено обоснование предложенного подхода и показаны его преимущества. В частности, высшее звено в структуре формирования российской государственной координатной основы (системы координат ГСК-2011) - фундаментальная астрономогеодезическая сеть, она является региональной реализацией глобальной системы отсчета. Создание ГСК-2011 велось с ориентировкой на глобальную международную земную систему отсчета (ITRS), однако геодинамические процессы, влияющие на смещение опорных пунктов относительно центра масс Земли, играют разную роль во временно́й эволюции систем. В системе ГСК-2011 такие процессы учету не подлежат, поскольку система создана для ведения в ней различных видов прикладной геодезической и картографической деятельности, в которой учет постоянного изменения координат опорных пунктов почти никогда не подразумевается. В этой связи асинхронность движения российской государственной системы координат ГСК-2011 с международной земной системой отсчета ITRS стала приводить к рассогласованности результатов высокоточных спутниковых измерений, выполненных в разное время, разными методами. Исходя из этого необходимость поиска способа согласования ГСК-2011 с глобальной системой отсчета является актуальной. В статье приводятся скорости изменения параметров связи вышеупомянутых систем, при помощи которых становится возможным согласование результатов высокоточного позиционирования, выполняемого в различных системах, различными методами на различную эпоху. Эксперимент, проведенный во второй части статьи, это подтверждает.

Ключевые слова: высокоточное позиционирование, глобальные навигационные спутниковые системы, ГСК-2011, ГНСС-измерения, дифференциальная геодезическая станция, метод РРР, параметры связи систем координат, система координат, система отсчета.

\section{Введение}

В современной мировой геодезической практике глобальные навигационные спутниковые системы (ГНСС) стали незаменимым инструментом как для высокоточного определения положения точки в пространстве, так и при формировании системы координатновременного и навигационного обеспечения (КВНО). Современные методические и технологические решения способствуют повышению точности и эффективности применения спутниковых систем для формирования еди- ной системы КВНО в мировом и национальных масштабах. Для этого расширяются и уплотняются сети дифференциальных геодезических станций (ДГС), являющиеся практической реализацией заданной системы.

Координатная основа и система КВНО Российской Федерации также развивается с применением технологий ГНСС. Расширение и уплотнение сети пунктов, реализующих российскую систему ГСК-2011, ведется с некоторым отставанием от передовых стран - лидеров в сфере формирования общемировой координатно-временной 
основы. Однако развитие российской государственной координатной основы ускоряется. За 2019 г., количество пунктов фундаментальной астрономо-геодезической сети (ФАГС), реализующих систему ГСК-2011, с установленным постоянно действующим оборудованием выросло с 45 до 53, включая развертывание новых пунктов за пределами границ России.

Разработкой методологических основ применения на практике координатной основы ГСК-2011 занимаются многие эксперты, о чем докладывают в сборниках научных трудов и на различных конференциях. Работы [1-3] посвящены описанию построения ГСК-2011. Работы [4-6] посвящены проблемам использования этой координатной основы в геодезической практике.

Ключевая проблема заключается в корректном согласовании национальной системы координат ГСК-2011 с международной (глобальной) системой отсчета (International Terrestrial Reference System - ITRS) в долгосрочной перспективе. Основным фактором, вносящим несоответствие в результаты высокоточного позиционирования, является различие в учете глобальных и региональных геодинамических процессов. Современные требования к точности определения координат (а также нормальных высот и значений силы тяжести) обуславливают необходимость учета временно́го фактора, поскольку координаты, нормальные высоты и значения ускорения силы тяжести связаны с перманентным влиянием глобальных и региональных геодинамических процессов.

Изучение и учет геодинамических процессов стали краеугольным камнем при формировании системы КВНО как общемирового масштаба, так и масштабов отдельных государств или их объединений. Установление связи национальных (региональных) координатных основ с международными (глобальными) обеспечит возможность достижения высокого уровня точности при проведении работ в системах, отличных от систем полета спутников ГНСС на территориях значительной протяженности, и повысит эффективность применения технологий ГНСС при использовании различных методов позиционирования.

\section{Текущее состояние}

Международная земная система отсчета ITRS - это совокупность договоренностей и основополагающих принципов построения общеземной геоцентрической системы координат, принятых Международным Астрономическим Союзом в 1991 г., касающихся определения начала центра системы, ориентации осей, инерциальности, фундаментальных геодезических постоянных, параметров общеземного эллипсоида, параметров гравитационного поля и прочих параметров. Начало отсчета находится в центре масс Земли. Ориентация координатных осей в теле Земли определяется из наблюдений Международной службы вращения Земли (International Earth Rotation and Reference Systems Service - IERS) и Международной ассоциацией геодезии (МАГ) (International Association of Geodesy - IAG), являющейся одной из семи ассоциаций Международного геодезического и геофизического союза (МГГС) (International Union of Geodesy and Geophysics - IUGG). В настоящее время Российская Федерация является действительным членом МГГС и МАГ [3].

Реализация ITRS - это Международная земная отсчетная основа (International Terrestrial Reference Frame - ITRF). Это совокупность опорных пунктов, на которых основана система ITRS, расположенных по всей территории земного шара, включающая пункты Международной ГНСС службы (МГС) (International GNSS Service - IGS). На январь 2020 г., по данным [7], количество пунктов МГС в мире достигает 509, на территории России - 22, из них уникальных - 18 .

Движения пунктов ITRF вследствие геодинамических процессов определены с точностью до $10^{-4}$ м/год и приведены на сайте ITRF [8]. Для того чтобы положение и ориентировка координатной основы относительно истинной оси вращения Земли и экватора оставались неизменными, несмотря на движение тектонических плит, скорости и направления движения пунктов, реализующих данную основу, должны быть учтены. B ITRF они учтены, что делает эту систему самой точной общеземной геоцентрической системой. Тектоническая активность не влияет 
на смещение или разворот координатных осей системы или смещение начала отсчета (геоцентра), так как основным условием определения и учета скоростей движения пунктов является принцип минимизации остаточных скоростей движения всех пунктов сети.

Системы, в которые происходит пересчет вычисленных геоцентрических координат для использования в прикладных геодезических целях (национальные, региональные, локальные/местные), являются статическими системами координат, так как собственные движения опорных пунктов в данном случае не предусмотрены. Это связано с тем, что постоянное изменение координат пунктов негативно сказывается на эффективности выполнения геодезических работ и значительно затрудняет их проведение. Кинематическими системами называют системы отсчета, в которых предусмотрена временна́я эволюция пунктов, практически реализующих их. К ним относятся глобальные системы отсчета. Глобальными называют такие системы, в которых осуществляется определение координат находящихся на орбите спутников, а сеть пунктов развернута на территории значительной части земного шара и уравнена совместно.

Постановлением Правительства Российской Федерации от 24 ноября 2016 г. № 1240 [9] в качестве единой государственной системы координат для использования при осуществлении геодезических и картографических работ установлена геодезическая система координат ГСК-2011. Так как эта система предназначена для прикладного геодезического и картографического производства, координаты пунктов, реализующих данную систему, не должны быть зависимыми от времени, т. е. система ГСК-2011 должна быть статической. Предложения по переходу на кинематическую версию системы ГCК-2011 по аналогии с системой ITRF не в полной мере состоятельны, поскольку:

- во-первых, система ITRF не предназначена для ведения в ней прикладных геодезических работ и для этого не используется, а ГСК-2011, согласно нормативно-технической документации $[9,10]$, предназначена именно для этого;

- во-вторых, пункты системы ITRF расположены по всему земному шару, а пункты
ГСК-2011 максимум на $10 \%$ его поверхности, что не позволяет судить о глобальных тектонических процессах общемирового масштаба, необходимых для соблюдения принципа минимизации остаточных скоростей движения всех пунктов сети;

- в-третьих, средняя годовая скорость движения пунктов на Евразийской тектонической плите различна, и в разных районах она варьируется от 1 до 5 см/год, что при ведении высокоточных геодезических работ требует введения поправок, вычисление которых связано с разработкой национальной модели скоростей движения пунктов земной поверхности (ее разработка на сегодняшнем этапе развития не возможна по следующей причине);

- в-четвертых, низкая плотность опорных пунктов с постоянно действующим оборудованием на территории страны не позволит привязать к ним новые пункты на большей части территории с точностью, достаточной для мониторинга, учета и прогнозирования геодинамических процессов.

Исходя из вышесказанного система ГСК-2011, созданная для ведения геодезических и картографических работ, реализованная набором пунктов ФАГС, ВГС, СГС, де-факто является локальной реализацией глобальной системы отсчета. По ГНССизмерениям постоянно действующих пунктов ФАГС определены их собственные движения в глобальной отсчетной основе ITRF [11] и в системе координат ГСК-2011 [12]. На эпоху 2011,0 статические параметры связи этих систем приведены в приказе Росреестра от 23 марта 2016 г. № П/0134 «Об утверждении геометрических и физических числовых геодезических параметров государственной геодезической системы координат 2011 года» [13]. Таким образом, установлена взаимосвязь систем ГCК-2011 и ITRF. Однако движение этих систем друг относительно друга происходит несинхронно, о чем эксперты неоднократно упоминали в публикациях [14-16], что ведет к систематическому увеличению погрешностей при трансформации координат. Рост погрешности соответствует среднегодовой скорости движения тектонических плит и внутриплитовых блоков, на которых расположены пункты ФАГС. 
В этой связи́ не замечать нарастания погрешностей в результатах высокоточного позиционирования уже нельзя. Это проявляется в следующем:

- при уравнивании сетей с опорой на пункты, реализующие глобальную систему отсчета, возникают существенные погрешности и расхождения в результатах, полученных на одних и тех же пунктах, но в разное время;

- результаты координатных определений, вычисленные по методу точного точечного позиционирования (Precise Point Positioning РPР), не соответствуют результатам, полученным с применением наиболее распространенного метода относительного позиционирования от пунктов региональных сетей ДГС. В работе [17] приведены разницы координат, вычисленные данными методами на территории Новосибирской области.

Для разрешения проблем оптимальным вариантом может стать не введение зависимости от времени для координат опорных пунктов, а определение взаимосвязи локальной реализации глобальной системы отсчета (ГСК-2011) с самой глобальной системой отсчета (ITRS). Связь кинематической и статической систем координат можно установить только с применением параметров трансформации, зависящих от времени.

Статья [17] посвящена разработке методики установления такой связи. В ней по предложенной методике определена взаимосвязь глобальной системы отсчета с ее локальной реализацией пунктами сети ДГС, расположенной на территории Новосибирской области (ДГС НСО). Поскольку территория России располагается на четырех тектонических плитах и некотором количестве внутриплитовых блоков, скорости и направления движения которых могут отличаться [18], то для определения строгой взаимосвязи с глобальной системой отсчета такая связь должна быть дифференцирована для каждого региона России и сопоставлена с общефедеральными результатами взаимосвязи ГСК-2011 с глобальной системой отсчета [19].

Поэтому первая цель данной работы заключается в вычислении кинематических параметров связи системы ГСК-2011 с глобальной отсчетной основой ITRF на эпоху $t_{0}$.
Это обусловит движение этих систем относительно друг друга, но актуальными полученные данные будут оставаться только для измерений, выполненных на Евразийской тектонической плите. Вторая цель работы заключается в освещении практической стороны предложенного подхода. Рассмотрение системы ГСК-2011 как локальной (региональной) реализации глобальной системы отсчета не исключает возможности ведения в ней любых видов прикладной геодезической или картографической деятельности. Предложенный подход, напротив, создает условия корректного согласования результатов высокоточного позиционирования, выполненного в глобальной (кинематической) системе отсчета, с результатами, полученными с применением спутниковых геодезических сетей, являющихся локальной (статической) реализацией глобальной системы отсчета, в которых временна́я эволюция координат пунктов не предусмотрена.

\section{Вычисление кинематических параметров связи системы ГСК-2011 \\ с глобальной отсчетной основой ITRF}

Вычисление кинематических параметров связи систем координат характеризуется определением компонентов движения одной системы относительно другой. Рассматривая ГСК-2011 как локальную (региональную) реализацию глобальной системы отсчета, сетями опорных пунктов ФАГС, ВГС, СГС, определить компоненты движения относительно ITRF можно, полагая, что система ГСК-2011 неподвижна, а изменения положения пунктов происходят в системе ITRF. Построение и уравнивание системы ГСК-2011 было проведено с использованием пунктов МГС для обеспечения согласованности с координатной основой ITRF. На сайте ЦГКИПД [12] в разделе «Список координат и скоростей пунктов, участвовавших в первичном построении системы координат ГСК-2011 на эпоху 1 января 2011 года» приведен список пунктов, используемых при построении системы ГСК-2011. Их количество в списке 46.

Сопоставив приведенные в списке пункты со списком существующих в настоящее время пунктов ФАГС, можно сделать вывод, что из числа ныне существующих пунктов 
ФАГС при первичном построении системы ГСК-2011 были использованы только 15. Остальной 31 пункт - пункты сети МГС, расположенные на территории России и ближнего зарубежья.

Пункты МГС характеризуются высокой стабильностью положения относительно друг друга. Расположенные в зоне развернутой сети пунктов ФАГС, пункты МГС также отражают движение ITRF относительно ГСК-2011, как и пункты ФАГС. На текущий момент на территории России функционируют 52 пункта ФАГС и 22 пункта МГС. Их расположение приведено на рис. 1.

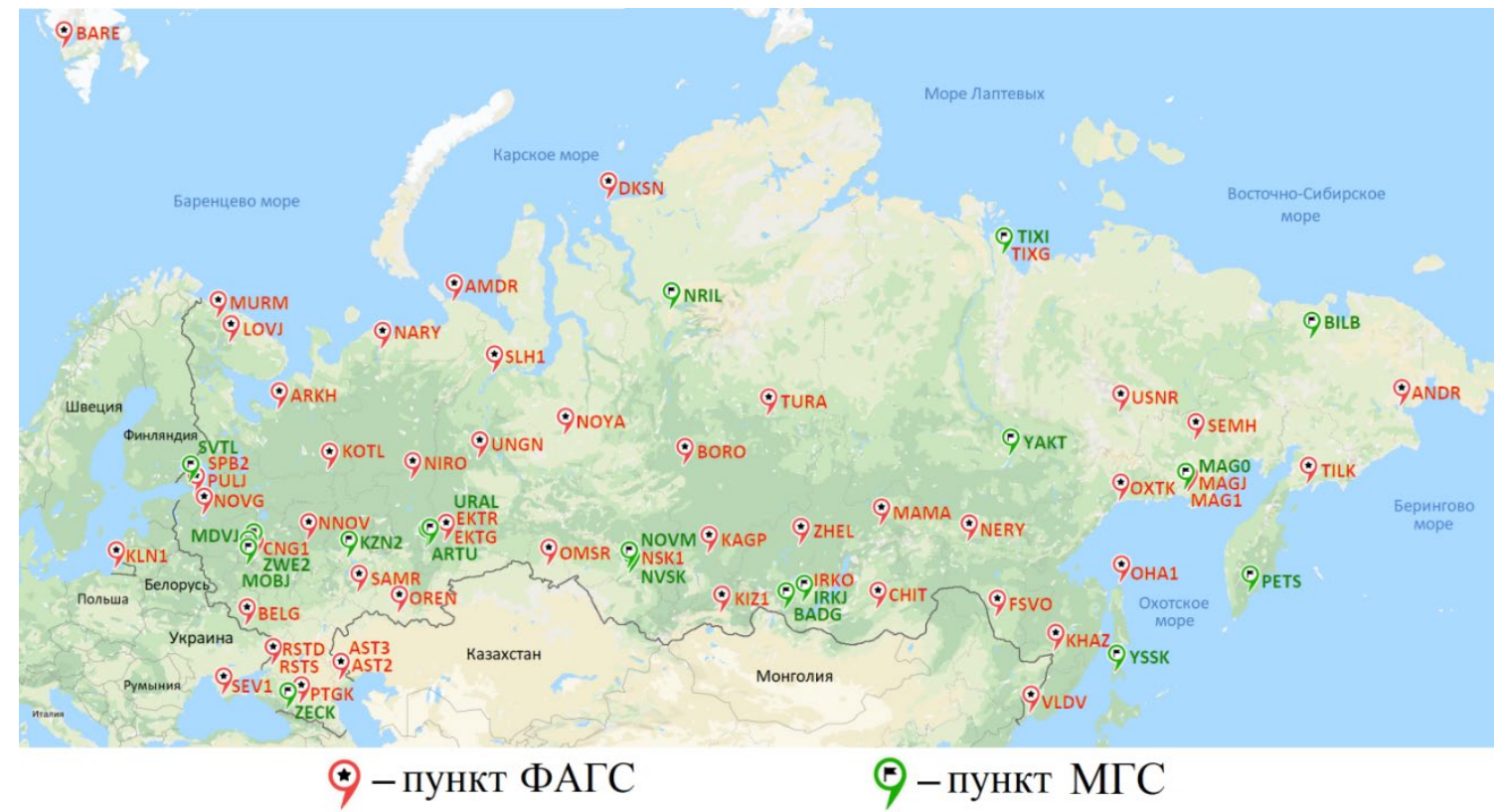

Рис. 1. Пункты ФАГС и МГС, расположенные на территории России

Для расчета компонентов движения системы ITRF относительно ГСК-2011 были приняты в обработку ГНСС-измерения 22 пунктов ФАГС и 17 пунктов МГС. Принцип отбора пунктов ФАГС для включения в обработку заключался в том, чтобы на начало 2020 г. станция функционировала не менее 2 лет. Для пунктов МГС принцип отбора заключался в том, чтобы ГНСС измерения были доступны на эпохи, близкие 2011,0 и 2020,0.

В табл. 1 представлен список и сведения о пунктах, ГНСС-измерения которых приняты в обработку. Обработка всех ГНСС-измерений проводилась с использованием метода РPР с помощью онлайнсервисов высокоточного позиционирования CSRS-PPP и TrimbleRTX. Их эффективность подтверждена в работах [20-22]. Движение пунктов обуславливается разностью координат, рассчитанных на начальную и текущую эпохи.

Все результаты усреднены на 5-суточном интервале. Точность полученных результа- тов характеризуется среднеквадратической погрешностью (СКП) на уровне не более 1,3 см в системе ITRF-2014. Оценка точности результатов приведена в отчете об обработке ГНСС-измерений и соответствует оценке точности по «внутренней» сходимости.

Связь систем координат устанавливается с помощью формулы:

$$
\left(\begin{array}{c}
X_{2} \\
Y_{2} \\
Z_{2}
\end{array}\right)=\left(\begin{array}{c}
X_{1} \\
Y_{1} \\
Z_{1}
\end{array}\right)+\left(\begin{array}{c}
T_{x} \\
T_{y} \\
T_{z}
\end{array}\right)+\left(\begin{array}{ccc}
D & -R_{z} & R_{y} \\
R_{z} & D & -R_{x} \\
-R_{y} & R_{x} & D
\end{array}\right) \cdot\left(\begin{array}{c}
X_{1} \\
Y_{1} \\
Z_{1}
\end{array}\right),
$$

где $R_{x}, R_{y}, R_{z}$ - параметры разворота координатных осей первой системы относительно второй; $\left(\overline{T_{x}, T_{y}, T_{z}}\right)^{T}$ - вектор смещения центра первой системы относительно второй; $D$ - масштабный коэффициент; $\left(\overline{X_{1}, Y_{1}, Z_{1}}\right)^{T}-$ вектор положения пункта в первой системе 
координат; $\left(\overline{X_{2}, Y_{2}, Z_{2}}\right)^{T}$ - вектор положения пункта во второй системе координат.

Уровень точности, отсчетный эллипсоид, геоцентричность и принципы ориентации в теле Земли систем ITRF-2014 и ГСК-2011 в соответствии с [13] идентичны друг другу. Различия между ними есть только в составе геодезических пунктов, реализующих данные системы, и в способах определения скоростей движения пунктов вследствие геодинамических процессов.

Таблица 1

Список и информация о пунктах, ГНСС измерения которых использованы для вычисления компонентов движения ITRF-2014 относительно ГСК-2011

\begin{tabular}{|c|c|c|c|c|c|c|}
\hline № & Пункт & Сегмент & Местоположение & $\begin{array}{c}\text { Начальная эпоха } \\
\text { (год, день года) }\end{array}$ & $\begin{array}{l}\text { Текущая эпоха } \\
\text { (год, день года) }\end{array}$ & $\begin{array}{c}\text { Разность } \\
\text { эпох (лет) } \\
\end{array}$ \\
\hline 1 & CNG1 & RGS & Москва & 2017,315 & 2020,001 & 2,14 \\
\hline 2 & CHIT & RGS & Чита & 2017,300 & 2020,001 & 2,18 \\
\hline 3 & VLDV* & RGS & Владивосток* & 2017,315 & 2020,001 & 2,14 \\
\hline 4 & NOYA & RGS & Ноябрьск & 2017,315 & 2020,001 & 2,14 \\
\hline 5 & SAMR & RGS & Самара & 2017,315 & 2020,001 & 2,14 \\
\hline 6 & ARKH & Росреестр & Архангельск & 2017,315 & 2020,002 & 2,14 \\
\hline 7 & MURM & Росреестр & Мурманск & 2017,315 & 2019,362 & 2,13 \\
\hline 8 & KOTL & Росреестр & Котлас & 2017,315 & 2020,002 & 2,14 \\
\hline 9 & OHA $1 *$ & Росреестр & Oxa* & 2017,315 & 2020,002 & 2,14 \\
\hline 10 & SEV1 & Росреестр & Севастополь & 2017,315 & 2020,002 & 2,14 \\
\hline 11 & BELG & Росреестр & Белгород & 2017,315 & 2020,002 & 2,14 \\
\hline 12 & SPB2 & Росреестр & Санкт-Петербург & 2017,315 & 2020,002 & 2,14 \\
\hline 13 & KHAZ* & Росреестр & Хабаровск* & 2017,315 & 2020,002 & 2,14 \\
\hline 14 & KAGP & Росреестр & Красноярск & 2017,315 & 2019,290 & 1,93 \\
\hline 15 & KLN1 & Росреестр & Калининград & 2017,315 & 2020,002 & 2,14 \\
\hline 16 & IRKO & Росреестр & Иркутск & 2017,315 & 2020,002 & 2,14 \\
\hline 17 & PTGK & Росреестр & Пятигорск & 2017,315 & 2020,002 & 2,14 \\
\hline 18 & NOVG & Росреестр & Вел. Новгород & 2017,315 & 2020,002 & 2,14 \\
\hline 19 & NNOV & Росреестр & Ниж. Новгород & 2017,315 & 2020,002 & 2,14 \\
\hline 20 & PULJ* & Росреестр & Пулково* & 2017,316 & 2020,002 & 2,14 \\
\hline 21 & OREN* & Росреестр & Оренбург* & 2017,316 & 2020,002 & 2,14 \\
\hline 22 & MOBJ & PAH & Обнинск & 2017,315 & 2020,001 & 2,14 \\
\hline 23 & TIXG & PAH & Тикси & 2017,315 & 2020,001 & 2,14 \\
\hline 24 & LOVJ & PAH & Ловозеро & 2017,315 & 2020,001 & 2,14 \\
\hline 25 & MDVJ & МГС & Менделеево & 2011,002 & 2020,001 & 9,00 \\
\hline 26 & IRKJ & МГС & Иркутск & 2011,002 & 2020,001 & 9,00 \\
\hline 27 & NVSK & МГС & Новосибирск & 2011,002 & 2020,001 & 9,00 \\
\hline 28 & YSSK* & МГС & Юж.-Сахалинск* & 2011,002 & 2020,001 & 9,00 \\
\hline 29 & BADG & МГС & Бадары & 2011,015 & 2020,001 & 8,96 \\
\hline 30 & SVTL & МГС & Светлое & 2011,002 & 2020,001 & 9,00 \\
\hline 31 & ZECK & МГС & Зеленчукское & 2011,004 & 2020,001 & 8,99 \\
\hline 32 & YAKT & МГС & Якутск & 2011,002 & 2020,001 & 9,00 \\
\hline 33 & MAG0* & МГС & Магадан* & 2012,002 & 2019,364 & 7,99 \\
\hline 34 & PETS* & МГС & Петропавловск-Кам.* & 2011,002 & 2020,001 & 9,00 \\
\hline 35 & TIXI & МГС & Тикси & 2011,002 & 2020,001 & 9,00 \\
\hline 36 & ARTU & МГС & Арти & 2011,002 & 2020,001 & 9,00 \\
\hline 37 & BILB* & МГС & Билибино* & 2011,002 & 2020,001 & 9,00 \\
\hline 38 & NRIL & МГС & Норильск & 2011,002 & 2020,001 & 9,00 \\
\hline 39 & NOVM & МГС & Новосибирск & 2011,002 & 2020,001 & 9,00 \\
\hline
\end{tabular}


Параметры связи этих систем на эпоху 2011,0 приведены в Приказе Росреестра от 23.03.2016 № П/0134 [13], где в строке элементы сдвига начала координатных осей одной системы относительно другой соответствуют по осям: $X-(0,002 \pm 0,010 \mathrm{M})$; $Y-(-0,003 \pm 0,020 \mathrm{м}) ; Z-(-0,003 \pm 0,010 \mathrm{м})$. В силу того, что точность определения центра массы Земли (геоцентра) ограничена вышеприведенными значениями, а также того, что изменения положения пунктов на поверхности земли незначительно влияют на смещение центра массы, вектор сдвига центра системы ITRF-2014 относительно ГСК-2011 $\left(\overline{T_{x}, T_{y}, T_{z}}\right)^{T}$ в данном исследовании положим равными нулю, как и скорости их изменения.

В работах $[23,24]$ при трансформации систем координат масштабный коэффициент $(D)$ обоснованно интерпретируется как сдвиг одной системы относительно другой по высоте над поверхностью эллипсоида. При условии, что обе системы имеют идентичный отсчетный эллипсоид, априорный сдвиг по высоте при трансформации координат из одной системы в другую равен нулю. В данном случае эллипсоиды систем ITRF-2014 и ГСК-2011 идентичны, поэтому в настоящем исследовании масштабный коэффициент при расчете компонентов движения следует игнорировать.

Таким образом, для определения параметров связи систем ITRF-2014 и ГСК-2011 уравнение необходимо разрешить только относительно углов разворота вокруг координатных осей $R_{x}, R_{y}, R_{z}$. Вычисленные углы разворота обусловят смещение систем относительно друг друга вследствие движения Евразийской тектонической плиты. Результатом представления полученных решений в единицах измерений в год будут скорости изменения компонентов движения системы ITRF-2014 относительно ГСК-2011 на начальную эпоху.

Однако часть расположенных на территории России пунктов, входящих в состав ФАГС и МГС, находьтся не на Евразийской тектонической плите. Включение таких пунктов в совместную обработку с остальными сопровождалось существенным увеличением остаточных невязок на всех пунктах. Это связано с различиями в скоростях и направлениях движений тектонических плит, на которых находятся пункты. На рис. 2 в топоцентрической системе координат приведены скорости и направления движения выбранных пунктов, рассчитанные методом РРР. Остаточные невязки характеризуют объективный контроль качества результатов высокоточного позиционирования точки на начальную и текущую эпохи. Повышенная остаточная невязка на каком-либо пункте в сравнении с остальными может быть следствием двух причин. Первая связана с тем, что на данном пункте результаты позиционирования получены с большей погрешностью, чем на других пунктах. Вторая - с тем, что скорость и направление движения данного пункта значительно отличаются от общего движения, вычисленного по большинству пунктов.

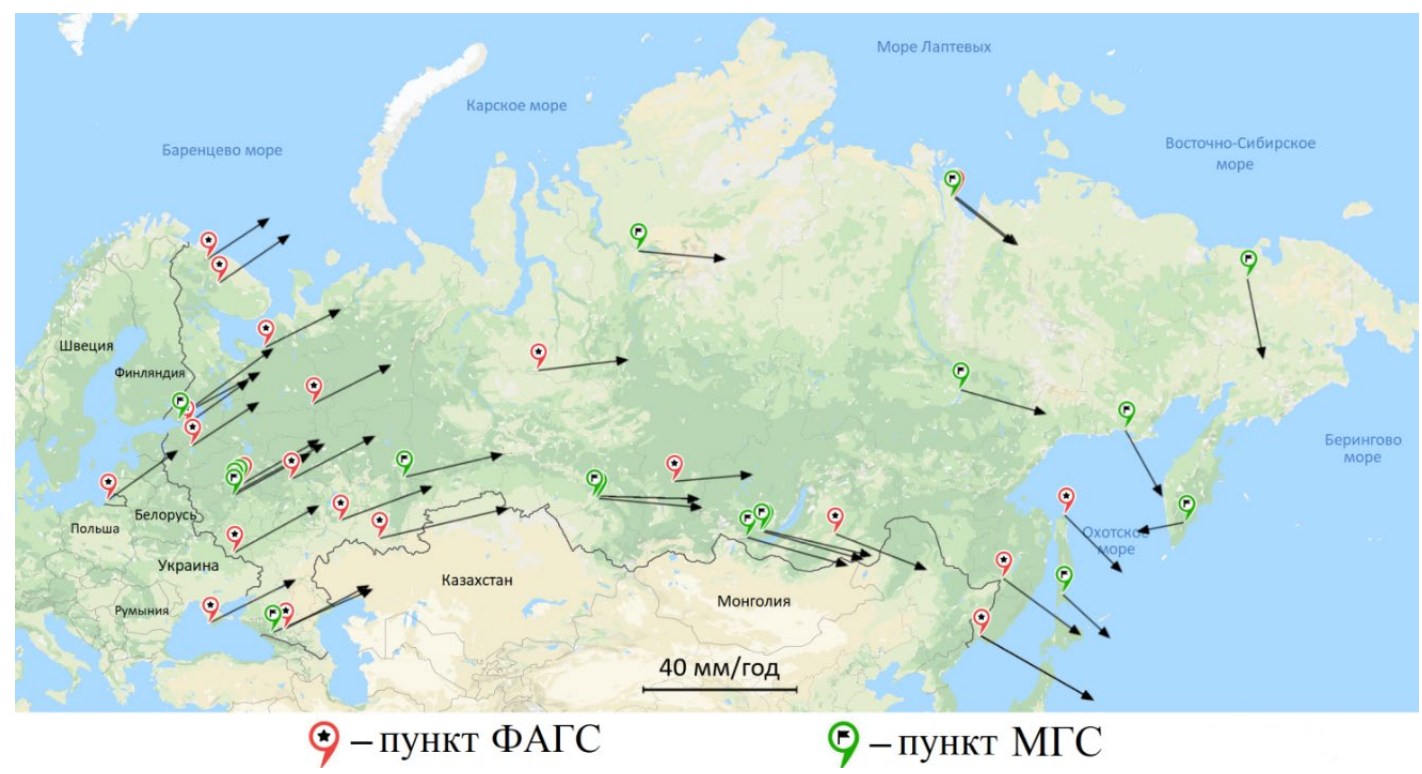

Рис. 2. Скорости и направления движения пунктов ФАГС и МГС 
Принцип отбраковки пунктов, вносящих погрешность в определение компонентов движения ITRF-2014 относительно ГСК-2011, по причине нахождения на другой тектонической плите или из-за низкой точности вычисленных координат заключался в следующем. Остаточная невязка на пункте по любой из координат не должна превышать среднеквадратическое отклонение $(1 \sigma)$, рассчитанное по всем пунктам по соответствующей координате. Таких пунктов выявлено 9. В табл. 1 они помечены символом «*». Эти пункты находятся не на Евразийской тектонической плите, за исключением PULJ и OREN. Bce 9 пунктов исключены из списка пунктов, используемых для определения компонентов движения ITRF-2014 относительно ГСК-2011. На рис. 3 приведена гистограмма, на которой по вертикальной шкале отложены значения остаточных невязок на пунктах, по которым вычислены компоненты движения, в метрах.После отбраковки пунктов, вносящих погрешности в определение движения ITRF-2014 относительно ГСК-2011, средняя остаточная 3D-невязка по всем пунктам составляет $0,006 \mathrm{M}$, что позволяет судить о вычисленных параметрах связи систем координат с погрешностью не ниже, чем погрешность высокоточного позиционирования по методу РРР.

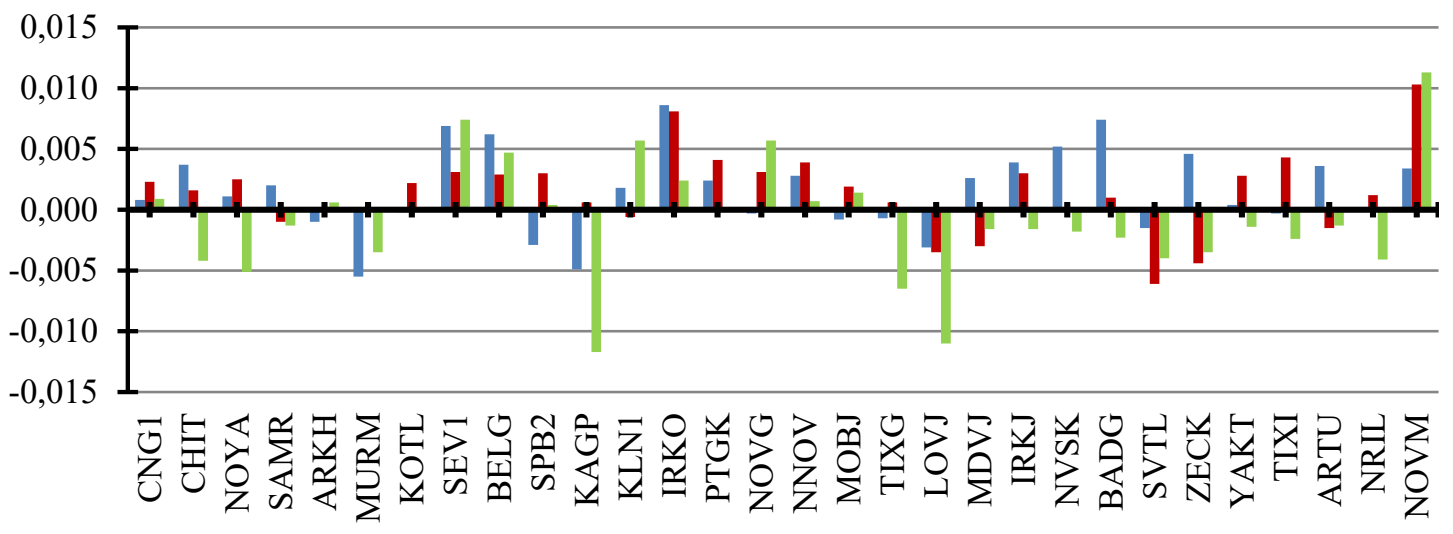

Рис. 3. Остаточные невязки на пунктах, участвующих в вычислении компонентов движения ITRF-2014 относительно ГСК-2011:

- по оси $X ; \quad$ - по оси $Y$; - п по оси $Z$

Так как движение ITRF-2014 относительно ГСК-2011 по большей части характеризуется движением Евразийской тектонической плиты, то полученные результаты целесообразно сравнить с компонентами движения, определенными для моделей движений тектонических плит. Для сравнения выбраны популярные модели движения тектонических плит NUVEL-1A и ITRF2008. Их компоненты движения приведены в работах $[25,26]$ соответственно. Обе модели не имеют относительного вращения по отношению к какомулибо участку Земли (no-net-rotation), т. е. движение каждой плиты определено относительно средневзвешенного значения скоростей движения всех плит, что позволяет представить движение земной поверхности относительно приблизительного центра Земли.

В работе [17] вычислены компоненты движения сети ДГС НСО относительно глобаль- ной отсчетной основы ITRF-2014. Данная сеть также является локальной реализацией глобальной системы отчета, так как установленное оборудование непрерывно принимает радиосигналы спутников ГНСС, координаты которых заданы в глобальной системе отсчета, а координаты пунктов уравнены в той же системе. Сеть ДГС НСО расположена на сравнительно малом участке земной поверхности, но в зоне развернутой сети пунктов ФАГС, поэтому компоненты движения должны соответствовать компонентам движения, рассчитанным для сети федерального масштаба (если данный район не подвержен аномальной сейсмической активности).

В работе [17] рассчитано движение локальной реализации глобальной отчетной основы пунктами сети ДГС НСО относительно ITRF-2014 по 6 компонентам (3 компоненты смещения центра одной системы относитель- 
но другой и 3 компоненты вращения вокруг координатных осей, с игнорированием масштабного коэффициента). Для корректного сравнения с вычисленными компонентами движения ITRF-2014 относительно ГСК-2011 6-компонентное движение пересчитано в 3-компонентное. В табл. 2 приведены:

- вычисленная в данной работе скорость движения ITRF-2014 относительно ГСК-2011 по 3 компонентам вращения вокруг координатных осей на эпоху 2011,0;
- вычисленная в работе [17] скорость движения ITRF-2014 относительно локальной реализации глобальной системы отсчета пунктами сети ДГС НСО по 3 компонентам вращения вокруг координатных осей на эпоxy 2010,5 ;

- скорости движения Евразийской тектонической плиты, определенные для общемировых моделей движения земной поверхности NUVEL-1А и ITRF2008.

Компоненты движения ФАГС и ДГС НСО по отношению к ITRF-2014

Таблища 2 и скорости движения Евразийской тектонической плиты

\begin{tabular}{|l|c|c|c|}
\hline $\begin{array}{c}\text { Относительное движение } \\
\text { и движение по моделям }\end{array}$ & $\begin{array}{c}\text { Разворот по оси } X \\
\text { (сек/год) }\end{array}$ & $\begin{array}{c}\text { Разворот по оси } Y \\
\text { (сек/год) }\end{array}$ & $\begin{array}{c}\text { Разворот по оси } Z \\
\text { (сек/год) }\end{array}$ \\
\hline ГСК-2011 $\rightarrow$ ITRF-2014 & $-0,000073$ & $-0,000518$ & 0,000684 \\
ДГС НСО $\rightarrow$ ITRF-2014 & $-0,000072$ & $-0,000451$ & 0,000827 \\
По модели NUVEL-1A & $-0,000202$ & $-0,000494$ & 0,000650 \\
По модели ITRF2008 & $-0,000083$ & $-0,000534$ & 0,000750 \\
\hline
\end{tabular}

Как видно из табл. 2, компоненты движения вокруг оси $X$, приведенные в модели NUVEL-1A, несколько отличаются от результатов, рассчитанных другими способами, и модели ITRF2008. Вероятно, это связано с тем, что компоненты движения модели NUVEL-1A были определены в 1994 г. с использованием менее точных методов и средств измерений. Различие в компонентах движения, определенных другими способами, не представляются критическими. В проекции на поверхность земного эллипсоида скорости, рассчитанные, как квадратный корень из суммы квадратов значений скоростей вращения вокруг координатных осей, варьируются от 27 до 29 мм в год.

Вычисленные параметры связи по методике, предложенной в работе [17], обуславливают движение системы ГСК-2011 относительно ITRF-2014 вследствие движения Евразийской тектонической плиты (или наоборот, если изменить знак компонентов движения на противоположный). Предложенный и реализованный подход к определению взаимосвязи глобальной системы отсчета (используемой для обеспечения полетов спутников ГНСС) с ее локальной реализацией пунктами сетей ДГС (используемой для обеспечения инженерно-технических ра- бот на территории России) позволяет корректно, с высоким уровнем точности согласовывать результаты высокоточного позиционирования, получаемые на различные эпохи ГНСС-измерений различными методами (методом РРР и методом относительного позиционирования). Практическая часть исследования предложенного подхода изложена далее.

\section{Практическая сторона вопроса интерпретации сетей ДГС как практической реализации глобальной системы отсчета}

Развернутая сеть пунктов МГС и международная земная система отсчета ITRS задают некоторую «уровенную поверхность», относительно которой стало возможным вести работы по созданию и развитию национальных координатных основ в любом месте Земли. Достижение и сохранение в долгосрочной перспективе уровня точности, сопоставимого с точностью системы отсчета ITRS, возможно только при развертывании сети опорных пунктов по всему земному шару. Национальные и региональные координатные основы должны быть ориентированы на глобальную общемировую систему отсчета для обеспечения высокой точности про- 
ведения работ с использованием опорных пунктов ДГС и технологий ГНСС.

При разработке ГСК-2011 такая ориентировка имела место [27] (в уравнивании сети опорных пунктов на эпоху 2011,0 участвовал 31 пункт МГС). Однако малое количество пунктов на территории России, а также отсутствие четких разъяснений в нормативнотехнической документации о степени влияния геодинамических процессов на стабильность опорной геодезической основы России не позволяют осуществить корректную взаимосвязь российской координатной основы с общемировой.

Вычисленные выше кинематические параметры связи позволяют компенсировать возникающие расхождения и призваны адекватно представлять движение систем относительно друг друга, включая такие места, где до ближайшего опорного пункта расстояние порядка 1000 км. Для проверки этого утверждения выполнен эксперимент, заключающийся в сравнении координат пунктов ДГС, находящихся на удалении от пунктов ФАГС и МГС от нескольких до 1000 км и более, вычисленных следующими методами. Первый метод - это классический метод РРР, реализуемый уже упомянутыми онлайнсервисами высокоточного позиционирования CSRS-PPP и TrimbleRTX. В этом случае peзультаты позиционирования представлены в системе ITRF-2014. Второй метод - это метод относительного позиционирования от ближайших пунктов ФАГС. В работах [28] описана методика определения координат пунктов в системе ГСК-2011, которая заключается в вычислении векторов сверхдлинных базовых линий от пунктов ФАГС до определяемых. Она реализована на примере сети пунктов ДГС НСО. В этом случае результаты высокоточного позиционирования представлены в системе ГСК-2011.

Для проведения текущего эксперимента выбраны ГНСС-измерения 122 пунктов сети ДГС Федерального бюро технической инвентаризации, полученные с портала спутниковых систем точного позиционирования [30]; ГНСС измерения 7 пунктов сети ДГС республики Крым, полученные с того же портала; ГНСС измерения 30 пунктов сети ДГС НСО, предоставленные в научных целях Государственным бюджетным учреждением «Центр навигационных и геоинформационных технологий Новосибирской области» [17]. Все ГНСС-измерения опорных и определяемых пунктов, а также точные эфемериды спутников получены на промежутке с 20 по 25 февраля 2020 г. (средняя эпоха 2020,14), дискретностью 30 с. На рис. 4 представлен фрагмент карты с обозначенными на ней определяемыми пунктами, участвующими в эксперименте, и пунктами ФАГС.

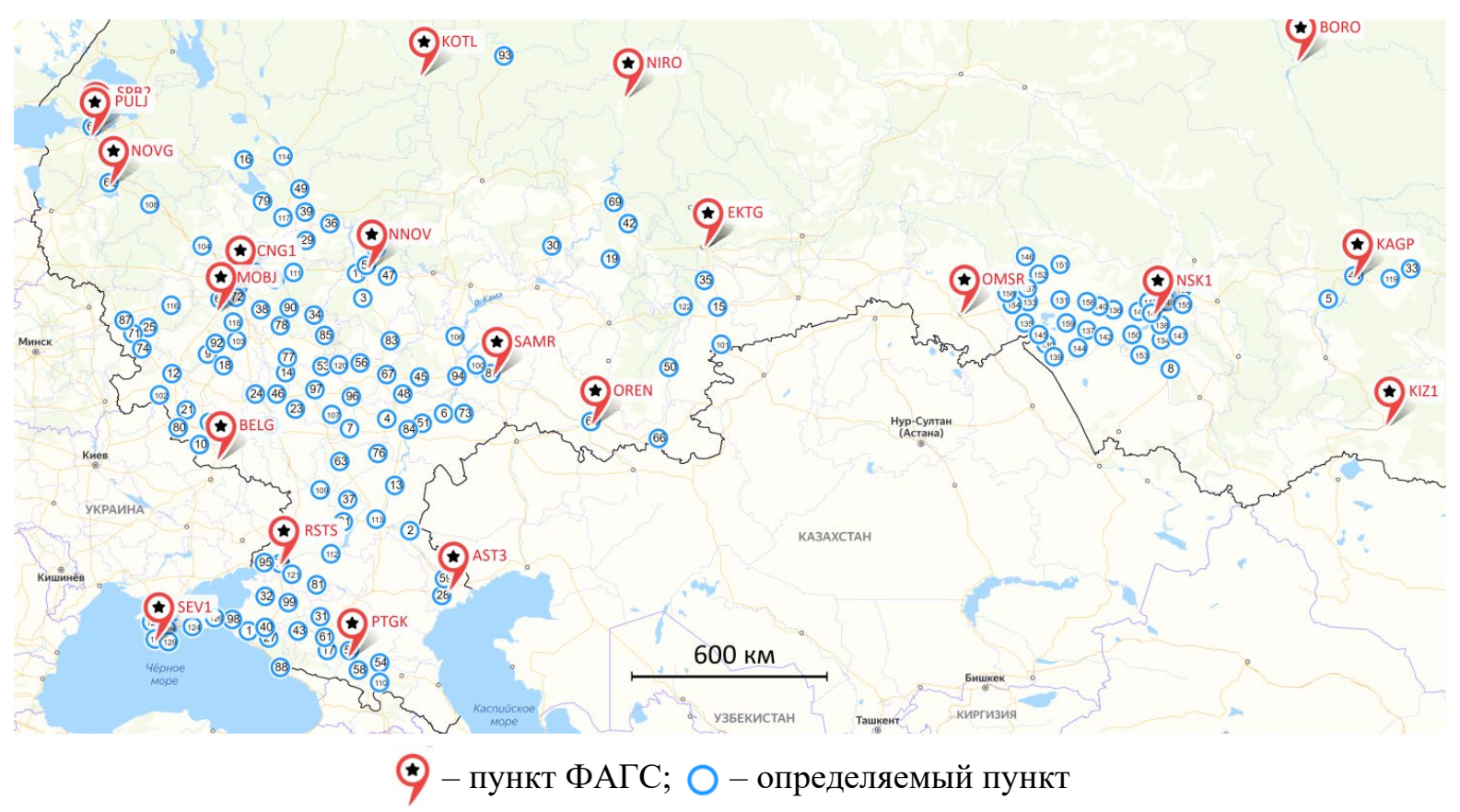

Рис. 4. Фрагмент карты с опорными и определяемыми пунктами 
Для обработки ГНСС измерений методом относительного позиционирования использовано программное обеспечение Trimble Business Centre v. 4.0. Координаты определяемых пунктов вычислены посредством обработки базовых линий, образованных между группой ближних определяемых пунктов с ближайшими 3-5 пунктами ФАГС, расстояние до которых не превышало 1000 км, с последующим уравниванием образованного геодезического построения с опорой на пункты ФАГС. Например, координаты пунктов сети ДГС НСО рассчитаны от ближайших к ним пунктов ФАГС: NSK1, OMSR, KAGP, KIZ1. Максимальная СКП результатов координатных определений по всем 159 пунктам составила: по координатам $X, Y, Z-0,009,0,008,0,017$ м соответственно, при осредненной СКП по всем пунктам по координатам $X, Y, Z-0,004$, 0,004, 0,007 м соответственно. Для результатов, полученных методом РРР, максимальная СКП составила: по координатам $X, Y, Z$ 0,015, 0,015, 0,021 м соответственно, при осредненной СКП по всем пунктам по координатам $X, Y, Z-0,005,0,005,0,007$ м соответственно. Приведенная оценка точности произведена программным обеспечением, используемым при обработке измерений, и соответствует оценке точности по «внутренней» сходимости.

На следующем этапе полученные результаты координатных определений методом относительного позиционирования редуцированы на текущую эпоху с применением вычисленных компонентов движения ITRF-2014 относительно ГСК-2011 (см. табл. 2).

Таким образом, разность вычисленных координат различными методами значительно сокращается, при том, что разность начальной и текущей эпох составляет более чем 9 лет. На рис. 5 по всем 159 пунктам приведены разности решений, полученных методом РРР и методом относительного позиционирования без внесения поправки (синий цвет) за движение систем относительно друг друга, а также разности, полученные методом РРР и методом относительного позиционирования с внесением поправки (красный цвет), рассчитанной в первой части работы. Под понятием «разности решений» понимается разность квадратных корней из суммы квадратов значений координат $X, Y, Z$ (3D-вектор). Значения, отложенные по горизонтальной шкале, представлены в метрах.

Кинематические параметры связи ITRF-2014 и ГСК-2011, вычисленные по трем компонентам (вращение вокруг каждой координатной оси), позволяют установить скорость движения ITRF-2014 относительно ГСК-2011. Ключевая проблема, заключающаяся в согласовании результатов высокоточного позиционирования, выполняемого разными методами, в разных системах координат и на различные эпохи проведения измерений может быть решена с использованием вычисленных, зависящих от времени параметров связи.

Как видно на рис. 5, применяя полученные параметры, можно существенно сократить разность координатных определений и утверждать, что степень соответствия результатов высокоточного позиционирования, выполненного разными методами, значительно возросла. Это подтверждают следующие результаты.

Средняя разность результатов (3D-вектор) высокоточного позиционирования методом РРР и относительным методом из анализа результатов 159 пунктов ДГС составляет 0,242 м при максимальной и минимальной разностях 0,255 и 0,223 м соответственно. В то же время средняя разность результатов высокоточного позиционирования методом РРР и относительным методом с внесением поправки за движение ITRF-2014 относительно ГСК-2011 составляет 0,019 м, при максимальной и минимальной разностях 0,049 и 0,007 м соответственно. Таким образом, полученные результаты позволяют констатировать, что введение поправок за движение систем относительно друг друга обеспечивает согласованность результатов высокоточного позиционирования, выполняемого разными методами в разных системах координат и на различные эпохи измерений на большей части территории страны с точностью, соответствующей современной точности высокоточного спутникового позиционирования. 


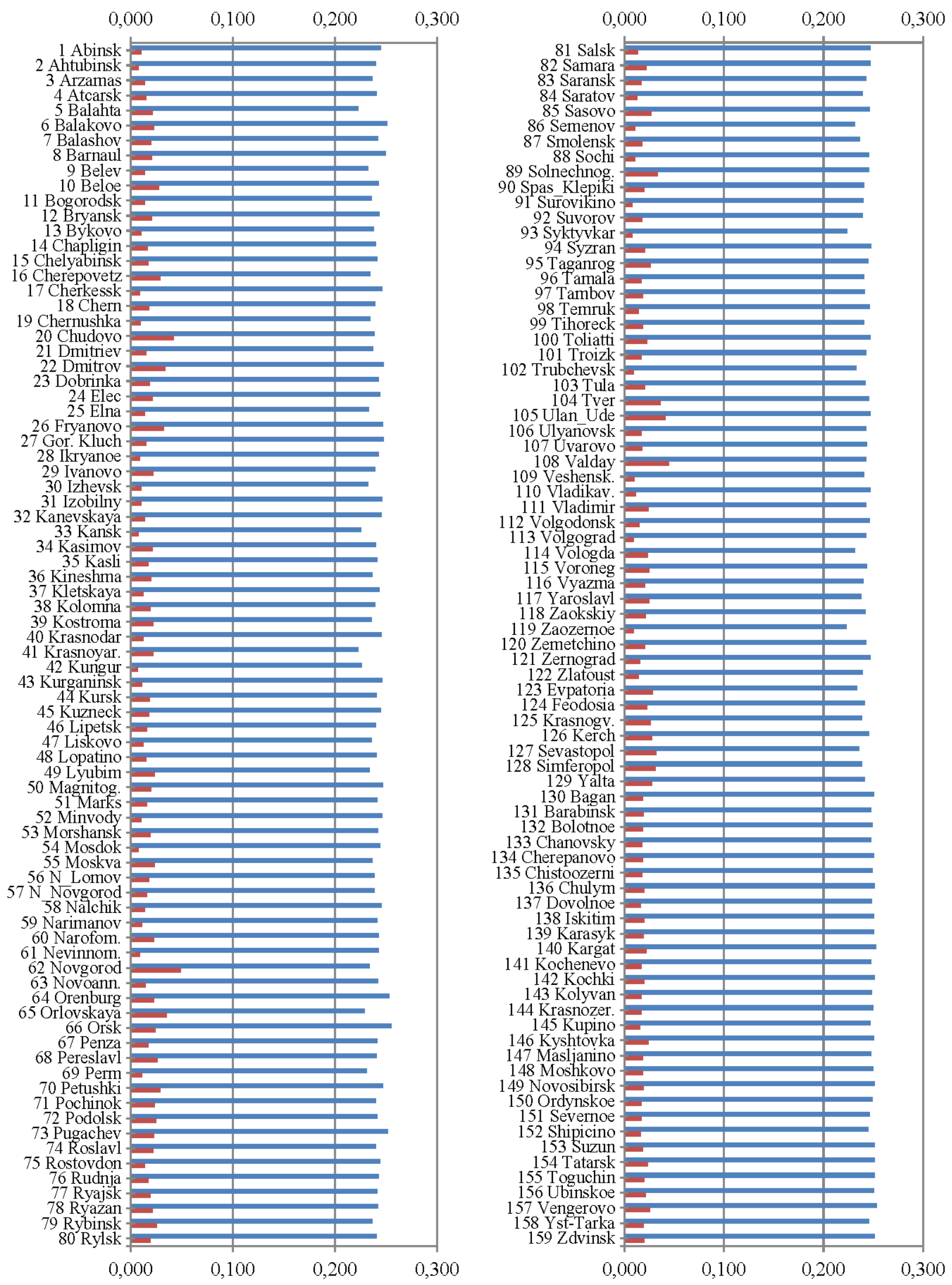

Рис. 5. Разности координат с внесением поправки и без внесения поправки за движение систем относительно друг друга и без

- разности координат без внесения поправки за движение систем относительно друг друга; - разности координат с внесением поправки за движение систем относительно друг друга 


\section{Заключение}

Проведенный в данной статье эксперимент доказал состоятельность описанного подхода по реализации вычисленных, зависящих от времени параметров связи систем ITRF-2014 и ГСК-2011 в качестве инструмента, обеспечивающего согласованность результатов высокоточного позиционирования, выполняемого разными методами на разные эпохи проведенных ГНСС измерений. Полученные кинематические параметры позволяют улучшить согласованность результатов более чем в 12 раз (с 0,242 до 0,019 м). Следовательно, можно утверждать, что результаты высокоточного позиционирования методом РРР и методом относительного позиционирования соответствуют друг другу на уровне точности не ниже точности современного высокоточного спутникового позиционирования. Максимально достижимый уровень точности определения координат методом РPР на сегодняшний день соответствует примерно 0,010-0,030 м. Максимально достижимый уровень точности определения координат методом относительного позиционирования зависит от дальности до опорного пункта и также соответствует 0,010-0,030 м. Точность координатных преобразований, которую можно оценить, проанализировав график остаточных невязок (см. рис. 3), не уступает точности позиционирования. Исходя из этого средняя разность, полученная по определяемым 159 пунктам, равная 0,019 м, говорит о том, что проведенный эксперимент можно считать удачным.

Что касается практической стороны предложенного подхода, то она заключается в следующем. Методика, предложенная в работе [17] и апробированная в данной работе, создает условия для практического использования на территории отдельных регионов России передового метода высокоточного позиционирования РРP, обеспечивая совместимость его результатов с результатами относительно метода высокоточного спутникового позиционирования. В дальнейшем полученные компоненты движения системы ГСК-2011 относительно ITRF-2014 могут быть использованы для определения координат точки на Евразийской тектонической плите в системе ГСК-2011 методом РPР. Для перспектив дальнейшего развития в данном направлении требуется разработка национальной модели движения земной поверхности на территории всей страны и ближнего зарубежья, что связано со значительным уплотнением государственной сети опорных пунктов ДГС.

Практическая сторона предложенного подхода актуальна в свете недостаточной обоснованности развития системы ГСК-2011 как кинематической государственной отчетной основы. Такая модель имеет больше недостатков, чем преимуществ, учитывая параллельное, но закрытое развитие системы П3-90. ПЗ-90 является основой геодезического обеспечения системы ГЛОНАСС, а также основным инструментом в определении геодезических параметров Земли [32]. В координаты пунктов, реализующих систему П3-90, входит поправка за геодинамические процессы для повышения точности контроля орбитальной группировки спутников ГЛОНАСС, поэтому данную систему можно считать кинематической. Однако применение П3-90, в основном, осуществляется в военных целях, а пункты расположены на территориях военных частей, что делает невозможным получение доступа к измерительной информации и координатам станций. Потому для научно-исследовательской деятельности физическая реализация системы П3-90 широкому кругу пользователей недоступна.

Также в заключении необходимо отметить сравнительно короткий временной промежуток доступных ГНСС-измерений с пунктов сети ФАГС и их малое количество. В исследовании приняты в обработку измерения пунктов ФАГС с разностью начальной и текущей эпох около 2 лет, в то время как для пунктов сети МГС такая разность составила более 9 лет. Это связано с тем, что данные ГНСС-измерений с пунктов ФАГС появились в открытом доступе недавно, и технология их предоставления в настоящий момент отрабатывается. Однако предпринятые шаги в данном направлении уже позволяют делать некоторые выво- 
ды. Необходимо продолжать развитие в этой области, включая развертывание новых пунктов ДГС с постоянно действующим оборудованием, и, главное, организацию доставки бесперебойного потока информации от них широкому кругу пользователей, a также сохранение этой информации на сервере в долгосрочной перспективе. Это позволит перейти на качественно новый уровень развития КВНО в России, так как ценность опорных пунктов ДГС заключается в их истории.

\section{БИБЛИОГРАФИЧЕСКИЙ СПИСОК}

1. Горобец В. П., Ефимов Г. Н., Столяров И. А. Опыт Российской Федерации по установлению государственной системы координат 2011 года // Вестник СГУГиТ. - 2015. - Вып. 2 (30). C. 24-37.

2. Современное состояние и направления развития геодезического обеспечения РФ. Системы координат / В. П. Горобец, Г. В. Демьянов, А. Н. Майоров, Г. Г. Побединский // Геопрофи. 2013. - № 6. - С. 4-9.

3. Государственная геоцентрическая система координат Российской Федерации / В. П. Горобец, Г. В. Демьянов, Г. Г. Побединский, Л. И. Яблонский // Интерэкспо ГЕОСибирь-2013. IX Междунар. науч. конгр. : Пленарное заседание : сб. материалов в 2 т. (Новосибирск, 15-26 апреля 2013 г.). - Новосибирск : СГГА, 2013. Т. 2. - С. 76-94.

4. Проблемы и перспективы развития активных спутниковых геодезических сетей в России и их интеграции в ITRF / В. С. Вдовин, В. В. Дворкин, А. П. Карпик, Л. А. Липатников, С. Д. Сорокин, Г. М. Стеблов // Вестник СГУГиТ. - 2018. - Т. 23. № 1. - С. 6-27.

5. Демьянов Г. В., Майоров А. Н., Побединский Г. Г. Проблемы непрерывного совершенствования ГГС и геоцентрической системы координат России // Геопрофи. - 2011. - № 4.

6. Попрыгин В. А., Третьяков В. И. ГСК-2011. Проблемы перехода // Геопрофи. - 2018. - № 1. C. $8-12$.

7. International GNSS Service [Электронный pecypc]. - Режим доступа : http://www.igs.org/.

8. ITRF2014: A new release of the International Terrestrial Reference Frame modeling nonlinear station motions: ITRF2014 / Z. Altamimi, P. Rebischung, L. Métivier, X. Collilieux // Journal of Geophysical Research: Solid Earth. - 2016. DOI: 10.1002/2016JB013098.

9. Об установлении государственных систем координат, государственной системы высот и государственной гравиметрической системы [Электронный ресурс] : постановление Правительства РФ от 24 ноября 2016 года № 1240. - Доступ из справ.-правовой системы «Кодекс/Техэксперт».
10. ГОСТ 32453-2017. Глобальная навигационная спутниковая система. Системы координат. Методы преобразований координат определяемых точек. Введен в действие Приказом Федерального агентства по техническому регулированию и метрологии от 12 сентября 2017 г. № 1055-ст. М. - Доступ из справ.-правовой системы «Кодекс/Техэксперт».

11. Липатников Л. А. Эксперимент по формированию геоцентрической земной координатной основы на территории России и ближнего зарубежья // Вестник СГУГиТ. - 2016. Вып. 3 (35). - С. 16-24.

12. Федеральное государственное бюджетное учреждение «Центр геодезии, картографии и инфраструктуры пространственных данных» [Электронный pecypc]. - Режим доступа: https://cgkipd.ru.

13. Об утверждении геометрических и физических числовых геодезических параметров государственной геодезической системы координат 2011 года : приказ Росреестра от 23.03.2016 № П/0134. - Доступ из справ.-правовой системы «Кодекс/Техэксперт».

14. Демьянов Г. В., Майоров А. Н., Побединский Г. Г. Вопросы построения государственной геоцентрической системы координат Российской Федерации // Геодезия и картография. - 2011. № 11. - С. 17-25.

15. Липатников Л. А. Проверка опубликованных значений скоростей пунктов ФАГС в новой государственной системе координат ГСК-2011 // Интерэкспо ГЕО-Сибирь-2016. XII Междунар. науч. конгр. : Междунар. науч. конф. «Геодезия, геоинформатика, картография, маркшейдерия» : сб. материалов в 2 т. (Новосибирск, 18-22 апреля 2016 г.). - Новосибирск : СГУГиТ, 2016. Т. 1. - С. 86-91.

16. Бовшин Н. А. Высокоточные координатные GNSS-определения в системе ГСК-2011 // Геодезия и картография. - 2019. - Т. 80. - № 2. C. 2-14. DOI: 10.22389/0016-71262019-944-2-2-14.

17. Карпик А. П., Терещенко В. Е. Методика связи глобальной системы отсчета с ее локальной реализацией пунктами сетей дифференци- 
альных геодезических станций // Геодезия и картография. -2020 . - № 7. - С. 17-38.

18. Обиденко В. И. Методология геодезического обеспечения цифровой экономики Российской Федерации // Геодезия и картография. - 2019. - Т. 80. - № 12. - С. 42-55. DOI: 10.22389/0016-7126-2019-954-12-42-55.

19. Бовшин Н. А. Оптимизация условий применения системы ГСК-2011 в Дальневосточном регионе // Геодезия и картография. - 2019. T. 80. - № 9. - C. 2-9. DOI: 10.22389/001671262019-951-9-2-9.

20. Терещенко В. Е., Лагутина Е. К. Сравнение относительных смещений пунктов сети постоянно действующих базовых станций Новосибирской области, полученных с использованием различных онлайн-сервисов обработки спутниковых измерений // Вестник СГУГиТ. - 2019. T. 24, № 2. - C. 76-94.

21. Шевчук С. О., Малютина К. И., Липатников Л. А. Перспективы использования свободного программного обеспечения для постобработки ГНСС-измерений // Вестник СГУГиТ. - 2018. T. 23, № 1. - C. 65-84.

22. Islam A. Kandil, Mahmoud El-Mewafiand Ahmed Awaad. Analysis of GNSS Accuracy of Relative Positioning and Precise Positioning Based on Online Service. // International Journal of Scientific Engineering and Research. - 2017. - Vol. 5 (12). C. 94-103.

23. Струков А. А. Совершенствование методики определения положения пунктов локальных спутниковых геодезических сетей в общеземной и референцной системах координат : автореф. дис. ... канд. техн. наук: 25.00.32 / Струков Алексей Алексеевич ; Сибирская государственная геодезическая академия. - Новосибирск, 2013. - $174 \mathrm{c}$.

24. Гиенко Е. Г., Сурнин Ю. В. Об интерпретации масштабного параметра при согласовании локальных спутниковых геодезических сетей с государственной координатной основой // Интерэкспо Гео-Сибирь-2009. V Междунар. науч. конгр.: Междунар. науч. конф. «Геодезия, геоинформатика, картография, маркшейдерия» : сб. материалов в 6 т. (Новосибирск, 20-24 апреля 2009 г.). - Новосибирск : СГГА, 2009. Т. 1. № 2. C. 321-324.

Получено 10.06.2020
25. IERS Technical Note 21. IERS Conventions / D.D. McCarthy (ed.) - Paris: Central Bureau of IERS. - Observatoire de Paris. - July 1996. 95 р. - Англ.

26. Altamimi, Z., Métivier, L. \& Collilieux, X. ITRF2008 plate motion model // Journal of Geophysical Research. - 2012. - Vol. 117. DOI: 10.1029/2011JB008930

27. Андреев В. К. Роль и место в исследованиях по геодезическому обеспечению системы ГЛОНАСС в рамках НИР «Развитие» государственных единых систем координат ГСК-2011 и ПЗ-90, высокоточного определения координат и гравитационного поля Земли // Доклад на заседании секции № 3 НТС ФГУП ЦНИИмаш по вопросу «Общий замысел геодезических направлений исследований в рамках НИР «Развитие» от 28 мая 2013 года. - М. : ЦНИИГАиК, 2013. - 14 c.

28. Шендрик Н. К. Шитиков П. К. Опыт определения положения пунктов сети ПДБС Новосибирской области в ГСК-2011 // Геопрофи. 2018. - № 6. - С. 46-49.

29. Лагутина Е. К. Апробация методики включения сети постоянно действующих базовых станций Новосибирской области в государственную геодезическую сеть // Вестник СГУГиТ. - 2016. - Вып. 3 (35). - С. 35-40.

30. АО Ростехинвентаризация - «Федеральное бюро технической инвентаризации» [Электронный ресурс]. - Режим доступа: гнсс.рф.

31. Государственное бюджетное учреждение «Центр навигационных и геоинформационных технологий Новосибирской области» [Электронный ресурс]. - Режим доступа: http://rtk.nso.ru/spiderweb/frmIndex.aspx.

32. Вдовин В. С. Общий замысел геодезических направлений исследований в рамках НИР «Развитие». Исследование проблемных вопросов геодезического обеспечения системы ГЛОНАСС. Исследование проблемных вопросов навигационно-геодезического обеспечения объектов ракетно-космической техники // Доклад на заседании секции № 3 НТС ФГУП ЦНИИмаш по вопросу «Общий замысел геодезических направлений исследований в рамках НИР «Развитие» от 28 мая 2013 года. М. : ЦНИИГАиК, 2013. - 20 с.

(C) B. E. Терещенко, А. В. Радченко, В. А. Мелкий, 2020 


\section{GLOBAL REFERENCE SYSTEM AND ITS LOCAL REALIZATION - RUSSIAN STATE COORDINATE SYSTEM GSK-2011}

\section{Vyacheslav E. Tereshchenko}

Siberian State University of Geosystems and Technologies, 10, Plakhotnogo St., Novosibirsk, 630108, Russia, Ph. D. Student, phone: (953)766-70-14, e-mail: taboretzvigyn@mail.ru

\section{Andrey V. Radchenko}

Institute of Strength Physics and Materials Science of the Siberian Branch of the Russian Academy of Sciences, 2/4, Prospect Akademicheskii St., Tomsk, 634055, Russia, e-mail: andreyradchenko8@gmail.com

\section{Vyacheslav A. Melkiy}

Institute of Marine Geology and Geophysics of the Far Eastern Branch of the Russian Academy of Sciences, 1b, Nauki St., Yuzhno-Sakhalinsk, 693022, Russia, D. Sc., Leading Researcher, Laboratory of Volcanology and Volcano Hazard, phone: (984)139-70-77, e-mail: vamelkiy@mail.ru

The article highlights the issue of interpreting reference stations networks as a local realization of the global reference system. The substantiation of the proposed approach is given and its advantages are shown. The rationale for the proposed approach is given and its advantages are shown. In particular, the top block in the structure of the formation of the Russian state coordinate system (GSK-2011) is the fundamental astronomical and geodetic network. It is a regional realization of a global reference system. The creation of GSK-2011 was carried out with a focus on the global International Terrestrial Reference System (ITRS) however geodynamic processes affecting the displacement of reference points relative to the center of the Earth's masses play a different role in the time evolution of systems. Such processes in GSK-2011 are not subject to accounting, since the system was created to conduct various types of applied geodetic and cartographic activities in it. In this case, taking into account the constant change in the coordinates of reference points is almost never implied. In this regard, the asynchronous movement of the Russian state coordinate system (GSK-2011) with the global reference system (ITRS) began to lead to inconsistencies in the results of high-precision positioning performed at different times, by different methods. Based on this, the necessity to find a way of matching GSK-2011 to ITRS is urgent. The article presents the rates of change of the match parameters of the above-mentioned systems. These parameters make it possible to match the results of highprecision positioning performed in different reference systems using different methods of positioning for different epochs of the GNSS observations. The experiment carried out in the second part of the article confirms this.

Key words: coordinate system, coordinate system transformation parameters, Global Navigation Satellite Systems (GNSS), GNSS observations, GSK-2011, high-precision positioning, Precise Point Positioning technique, reference station, reference system.

\section{REFERENCE}

1. Center for Geodesy, Cartography and Spatial Data Infrastructure. (n. d.). Retrieved from https://cgkipd.ru [in Russian].

2. Gorobec, V. P., Efimov, G. N., \& Stolyarov, I. A. (2015). Experience of the Russian Federation on an establishment of the state system of coordinates of 2011. Vestnik SGGA [Vestnik SSGA], 2(30), 24-37 [in Russian].

3. Gorobec, V. P., Demianov, G. V., Mayorov, A. N., Pobedinsky, G. G. (2013). The current state and directions of development of geodetic support of the Russian Federation. Coordinate systems. Geoprofi [Geoprofi], 6, 4-9 [in Russian].
4. Gorobec, V. P., Dem'yanov, G. V., Pobedinskij, G. G., \& Yablonskij, L. I. (2013). State geocentric coordinate system of the Russian Federation. In Sbornik materialov Interekspo GEO-Sibir'-2013: Plenarnoe zasedanie [Proceedings of Interexpo GEO-Siberia-2013: Plenary Session] (pp. 76-94). Novosibirsk: SSGA Publ. [in Russian].

5. Vdovin, V. S., Dvorkin, V. V., Karpik, A. P., Lipatnikov, L. A., Sorokin, S. D., \& Steblov, G. M. (2018). Current state and future development of active satellite geodetic networks in Russia and their integration into ITRF. Vestnik SGUGiT [Vestnik SSUGT], 23(1), 6-27 [in Russian]. 
6. Demyanov, G. V., Mayorov, A. N., \& Pobedinskiy, G. G. (2011). Problems of continuous improvement of the state geodetic network and Russian geocentric coordinate system. Geoprofi [Geoprofi], 4, 15-21 [in Russian].

7. Poprygin, V. A., \& Tret'yakov, V. I. (2018). GSK-2011. Problems of transition. Geoprofi [Geoprofi], 1, 8-12 [in Russian].

8. International GNSS Service. (n. d.). Retrieved from http://www.igs.org/.

9. Altamimi, Z., Rebischung, P., Métivier, L., \& Collilieux, X. (2016). ITRF2014: A new release of the International Terrestrial Reference Frame modeling nonlinear station motions: ITRF2014. Journal of Geophysical Research: Solid Earth. doi: 10.1002/2016JB013098.

10. Resolution of the Government of the Russian Federation No. 1240 of November 24, 2016. [About adoption of state reference systems, state height system and state gravimetric system]. Retrieved from Codex/Techexpert online database [in Russian].

11. Standarts Russian Federation. (2017). GOST 32453-2017. Global navigation satellite system. Coordinate systems. Methods of the determined points coordinate transformation. Moscow: Author [in Russian].

12. Lipatnikov, L. A. (2016). Implementation of a geocentric terrestrial reference frame for the territory of Russia and bordering countries. Vestnik SGUGiT [Vestnik SSUGT], 3(35), 16-24 [in Russian].

13. Order of Rosreestr No. P/0134 of March 23, 2016. About adoption of geometrical and physical numeric geodetic parameters for state geodetic reference system system of the year 1995 (SK-95). Retrieved from Codex/Techexpert online database [in Russian].

14. Demianov, G. V., Mayorov, A. N., \& Pobedinsky, G. G. (2011). Questions of constructing the state geocentric coordinate system in Russian Federation. Geodezija i kartografija [Geodesy and Cartography], 11, 17-25 [in Russian].

15. Lipatnikov, L. A. (2016). Validation of the published velocities of FAGS reference points in the new reference frame GSC-2011. In Sbornik materialov Interekspo GEO-Sibir'-2016: Mezhdunarodnoy nauchnoy konferentsii: T. 1. Geodeziya, geoinformatika, kartografiya, marksheyderiya [Proceedings of Interexpo GEO-Siberia-2016: International Scientific Conference: Vol. 1. Geodesy, Geoinformation, Cartography, Mine Surveying] (pp. 86-91). Novosibirsk: SSUGT Publ. [in Russian].

16. Bovshin, N. A. (2019). High-precision GNSS-positioning in GSK-2011 reference frame.
Geodezija $i$ kartografija [Geodesy and Cartography], 80(2), 2-14. doi: 10.22389/0016-7126-2019944-2-2-14 [in Russian].

17. Karpik, A. P., \& Tereshchenko, V. E. (2020). Technique for relation global reference system and local realization of global reference sys-tem by continuously operated reference stations. Geodezija i kartografija [Geodesy and Cartography], 7, 17-38 [in Russian].

18. Obidenko, V. I. (2019). The methodology of geodetic supporting Russian Federation digital economy. Geodezia i kartografia [Geodesy and Cartography], 80(12), 42-55. doi: 10.22389/001671262019-954-12-42-55 [in Russian].

19. Bovshin, N. A. (2019). On perfecting the employment of GSK-2011 reference frame in the Far East territory. Geodezia i kartografia [Geodesy and Cartography], 80(9), 2-9. doi: 10.22389/00167126-2019-951-9-2-9 [in Russian].

20. Tereshchenko, V. E., \& Lagutina, E. K. (2019). Determining of Novosibirsk Region reference stations offsets by comparison method of free online GNSS post-processing services. Vestnik SGUGiT [Vestnik SSUGT], 24(2), 76-94 [in Russian].

21. Shevchuk, S. O., Malyutina, K. I., \& Lipatnikov. L. A. (2018). Prospects of using free software for GNSS measurements post-processing. Vestnik SGUGiT [Vestnik SSUGT], 23(1), 65-84 [in Russian].

22. Islam A. Kandil, \& Mahmoud ElMewafiand Ahmed Awaad. (2017). Analysis of GNSS Accuracy of Relative Positioning and Precise Positioning Based on Online Service. International Journal of Scientific Engineering and Research, 5(12), 94-103.

23. Strukov, A. A. (2013). Improving the technique of positioning points of local geodetic network in global and reference coordinate systems. Abstract of candidate's thesis. Novosibirsk: Siberian State Geodesy Academy, 24 p. [in Russian].

24. Gienko, E. G., \& Surnin, Yu.V. (2008). Interpretation of a scale parameter in alignment of local Satellite geodetic networks with state reference. In Sbornik materialov GEO-Sibir'-2009: T. 1, ch. 2 [Proceedings of Interexpo GEO-Siberia-2009: Vol. 1, Part 2] (pp. 321-324). Novosibirsk: SSGA Publ. [in Russian].

25. IERS Technical Note 21. IERS Conventions. (1996). D. D. McCarthy (ed.). Paris: Central Bureau of IERS. Observatoire de Paris, $95 \mathrm{p}$.

26. Altamimi, Z., Métivier, L. \& Collilieux, X. (2012). ITRF2008 plate motion model. Journal of Geophysical Research, 117, B07402. doi: 10.1029/2011JB008930. 
27. Andreev, V. K. (2013). Role and place in geodetic support research of the GLONASS system as part of research work "Development" of state unified coordinate systems GSK-2011 and PZ-90, highprecision positioning and the gravitational field of the Earth. Doklad na zasedanii sekcii № 3 NTS FGUP CNIImash po voprosu "Obshchij zamysel geode-zicheskih napravlenij issledovanij $v$ ramkah NIR "Razvitie" ot 28 maya 2013 goda. [Report at the Meeting of Section No. 3 of the Scientific and Technical Council of the Federal State Unitary Enterprise CNIImash on the issue "The General Concept of Geodetic Research Directions as Part of Research Work "Development" May 28, 2013] (14 p.). Moscow: CNIIGAiK Publ. [in Russian].

28. Shendrik, N. K., \& Shitikov, P. K. (2018). The experience of determining the location of the Novosibirsk region CORS network in GSK-2011. Geoprofi [Geoprofi], 6, 46-49 [in Russian].

29. Lagutina, E. K. (2016). Testing methods of integration regional CORS network and the Russian state geodetic network. Vestnik SGUGiT [Vestnik SSUGT], 3(35), 35-40 [in Russian].
30. JSC Rostekhinventarizatsiya - "Federal Bureau of Technical Inventory". (n. d.). Retrieved from гнсс.рф [in Russian].

31. State Budgetary Institution "Center for Navigation and Geoinformation Technologies of the Novosibirsk Region". (n. d.). Retrieved from http://rtk.nso.ru/spiderweb/frmIndex.aspx [in Russian].

32. Vdovin, V. S. (2013). The general concept of geodetic research directions as part of research work "Development". Investigate of problematic issues of the GLONASS geodetic support. Investigation of problematic issues of navigation and geodetic support of military and space technology objects. Doklad na zasedanii sekcii № 3 NTS FGUP CNIImash po voprosu "Obshchij zamysel geode-zicheskih napravlenij issledovanij v ramkah NIR "Razvitie" ot 28 maya 2013 goda. [Report at the Meeting of Section No. 3 of the Scientific and Technical Council of the Federal State Unitary Enterprise CNIImash on the Issue "The General Concept of Geodetic Research Directions as Part of Research Work "Development" May 28, 2013] (20 p.). Moscow: CNIIGAiK, Publ. [in Russian].

Received 10.06.2020

(C) V. E. Tereshchenko, A. V. Radchenko, V. A. Melkiy, 2020 
УДК 528.482:621.644

DOI: $10.33764 / 2411-1759-2020-25-3-107-116$

\section{ИССЛЕДОВАНИЕ ТЕХНОЛОГИЙ ГЕОДЕЗИЧЕСКОГО МОНИТОРИНГА ДЕФОРМАЦИЙ ДНА В ЗОНЕ РАСПОЛОЖЕНИЯ ПОДВОДНЫХ ПЕРЕХОДОВ МАГИСТРАЛЬНЫХ ТРУБОПРОВОДОВ}

\section{Анатолий Иванович Уваров}

Омский государственный аграрный университет имени П. А. Столыпина, 644008, Россия, г. Омск, ул. Сибаковская, 4, кандидат технических наук, доцент кафедры геодезии и дистанционного зондирования, тел. (913)977-00-25, e-mail: ai.uvarov@omgau.org

\section{Лилия Анатольевна Пронина}

Омский государственный аграрный университет имени П. А. Столыпина, 644008, Россия, г. Омск, ул. Сибаковская, 4, кандидат технических наук, доцент кафедры геодезии и дистанционного зондирования, тел. (904)582-93-92, e-mail: la.pronina@omgau.org

Отмечено, что в результате взаимодействии геодинамического комплекса реки с окружающей средой появляются изменения русла, которые влекут за собой плановые и высотные деформации водной артерии. Поэтому при строительстве и эксплуатации инженерных сооружений необходимо их учитывать. Исследование русловых деформаций, в большей части высотных, в районах строительства или расположения действующих сооружений является весьма актуальной задачей для обеспечения их устойчивой, безаварийной работы. Установлено, что для исследования русловых деформаций используются две наиболее распространенных технологии. Первой является технология совмещения планов русловой съемки, а второй - совмещения поперечных профилей реки по закрепленным знаками на берегу гидростворам. Представлены результаты исследования технологии определения деформаций русла при их геодезическом мониторинге. Оценена точность изображения подводного рельефа на планах. Исследовано влияние погрешностей совмещения планов на точность определения количественных измерителей деформации.

Ключевые слова: геодезический мониторинг, русловые деформации, деформации дна, планы русловой съемки, геодезические пункты, оценка точности.

\section{Введение}

Любая река представляет собой сложный гидродинамический комплекс, взаимодействующий с окружающей средой. Следствием такого взаимодействия являются деформации русла, представляющие собой изменение береговой линии - плановые деформации и изменения высот дна - высотные деформации. При этом русловые деформации имеют обратимый характер, то есть имеют место размыв и намыв береговой линии, уменьшение и увеличение высот дна.

Анализ мониторинга за русловыми деформациями по закрепленным на местности реперам методами дешифрирования разновременных космоснимков и фиксацией береговой линии с применением спутникового позиционирования рассмотрен в работе [1].
Вопросами, связанными с русловыми деформациями в акватории рек, занимались отечественные ученые [2-6]. Выполняя работы на берегах водных артерий, очень часто возникает необходимость передачи высот с одного берега на другой, решения подобных задач с помощью ГНСС-приемников, обеспечивающих заданную точность определения высот, приведены в работе [7].

При строительстве и эксплуатации инженерных сооружений, располагаемых в русле реки, особенно таких, как подводные переходы магистральных нефтегазопроводов, необходимо учитывать процесс русловых деформаций. В настоящее время в России функционирует более чем по 1000 подводных переходов магистральных трубопроводов в системах «Газпрома» и АК «Транснефть» [8]. 


\section{Методы и материаль}

Русловые деформации имеют как естественное происхождение - меандрирование, так и связанное с человеческой деятельностью. Любое вмешательство в гидрологический режим реки вызывает русловые деформации. Так, строительство ГЭС в Новосибирске в свое время вызвало русловые деформации реки Оби на протяжении более чем 200 км ниже по течению. Добыча песка для нужд строительства со дна реки Иртыш в районе города Омска в 70-е гг. XX в. привела к углублению русла на несколько метров, в результате чего оголились городские набережные, обмелели водозаборы и вход в речной порт. На рис. 1 представлен фрагмент трехмерной модели, полученной по результатам инженерно-геодезических изысканий, подводного перехода магистрального нефтепровода. На фрагменте виден участок оголенной в результате русловых деформаций трубы нефтепровода.

Таким образом, исследование русловых деформаций, особенно высотных, в районе строительства или расположения действующих сооружений является весьма актуальной задачей при обеспечении их устойчивой, безаварийной работы. Методики оценки горизонтальных и вертикальных русловых деформаций предложены отечественными учеными в работах [9-14]. При исследованиях плановых русловых деформаций в настоящее время широко применяются ГИС-технологии и методы дистанционного зондирования [15]. Вопросами применение современных автоматизированных геодезических приборов для мониторинга гидротехнических сооружений, возведенных на водных ресурсах, занимались такие ученые, как Сальников В. Г., Никонов А. В. и др. [16, 17], но в своих работах они не рассматривали русловые деформации и влияния на них возведенных сооружений. Опыт зарубежных исследований в области применения математических моделей водных артерий при решении инженерно-технических задач рассмотрен в работах [18-21].

Для исследования русловых деформаций используются две наиболее распространенных технологии. Первая - совмещения планов русловой съемки, вторая - совмещения поперечных профилей реки по закрепленным знаками на берегу гидростворам. Под планом русловой съемки пронимают топографический план акватории с прилегающей береговой полосой шириной до 250 м. Основной особенностью исследования высотных русловых деформаций является то, что подводный рельеф визуально не наблюдается, поэтому их оценка ведется по моделям планам, профилям, цифровым моделям местности (ЦММ).

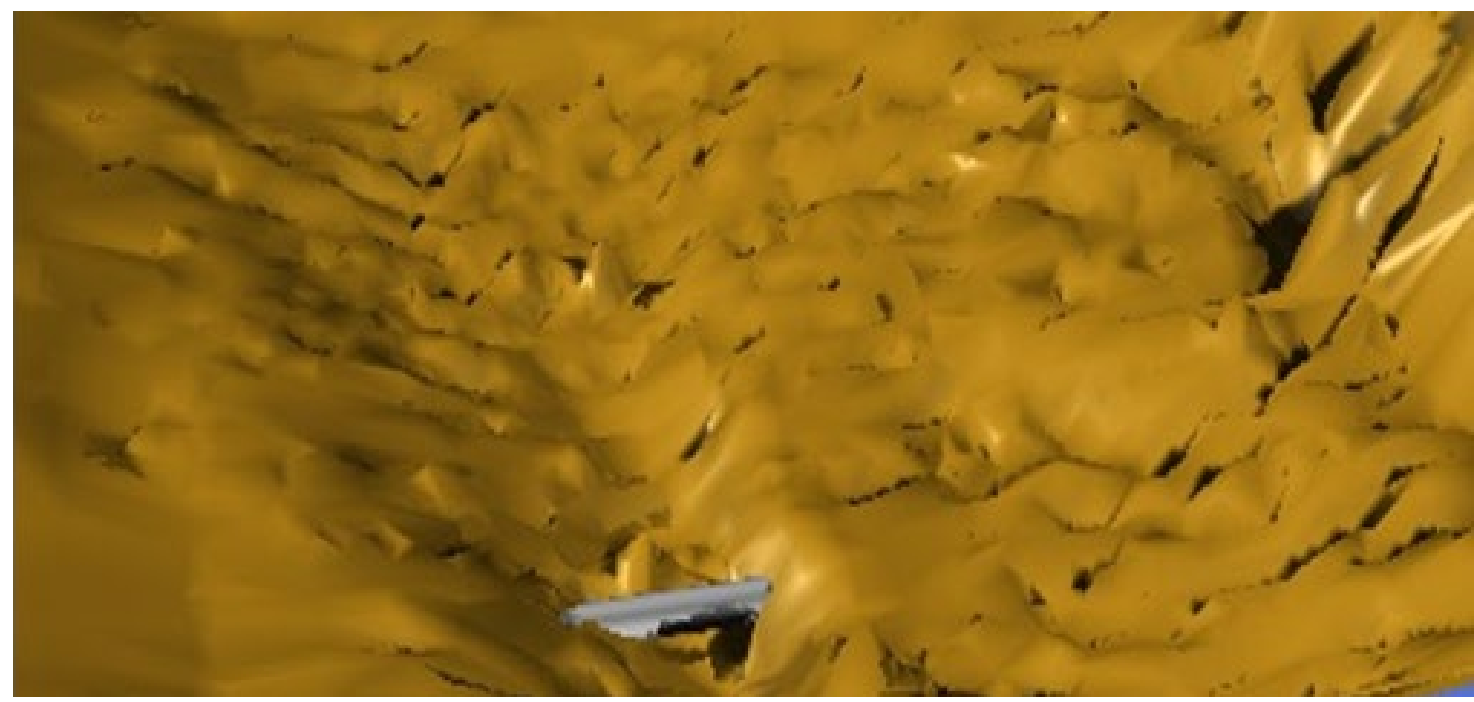

Рис. 1. Фрагмент трехмерной модели подводного перехода с оголенным в результате русловых деформаций участком трубы 
Первая из вышеперечисленных технология определения русловых деформаций заключается в сопоставлении или наложении планов разных лет съемки. Величина высотной деформации определяется по смещению одноименных горизонталей на сопоставляемых планах. Достоверность результатов зависит от точности изображения рельефа на таких планах, точности положения опорных точек, по которым сопоставляются планы и точности ориентирования по опорным точкам.

Требования по точности изображения рельефа на топографических материалах изложены в действующих нормативных документах. В соответствии с СП 47.13330 [18] средние ошибки съемки рельефа и его изображения на инженерно-топографических планах относительно ближайших точек съемочного обоснования в разных условиях не должны превышать от $1 / 4$ до $1 / 3$ от принятой высоты сечения рельефа.

$$
\begin{gathered}
\text { при } r=0 ; m_{H}=\sqrt{m_{\text {пл }}^{2} \cdot \operatorname{tg}^{2} v+0,67 \cdot m_{\text {гл }}^{2}+1,39 \cdot \operatorname{tg}^{2} v \cdot m_{\text {инт. }}^{2}+0,67 \cdot m_{\text {д.с. }}^{2}+m_{\text {т.ш. }}^{2}} ; \\
\text { при } r=0,5 ; m_{H}=\sqrt{m_{\text {пл }}^{2} \cdot \operatorname{tg}^{2} v+0,83 \cdot m_{\text {гл }}^{2}+1,53 \cdot \operatorname{tg}^{2} v \cdot m_{\text {инт. }}^{2}+0,83 \cdot m_{\text {д.с. }}^{2}+m_{\text {т.ш. }}^{2}} ; \\
\quad \text { при } r=1 ; \quad m_{H}=\sqrt{m_{\text {пл }}^{2} \cdot \operatorname{tg}^{2} v+m_{\text {гл }}^{2}+1,67 \cdot \operatorname{tg}^{2} v \cdot m_{\text {инт. }}^{2}+m_{\text {д.с. }}^{2}+m_{\text {т.ш. }}^{2}} \cdot
\end{gathered}
$$

где $m_{\text {пл }}, m_{\text {гл }}, m_{\text {инт. }}, m_{\text {д.с. }}, m_{\text {т.ш. }}$, соответственно средние квадратические погрешности определения планового положения точки при наземной съемке 0,5 м, согласно [23], для русловой съемки допускается до 1,5 мм на плане; погрешность измерения глубины; погрешность интерполирования горизонтали; погрешность, учитывающая детальности съемки (за обобщение рельефа); погрешность за топографическую шероховатость. Значения погрешностей взяты из нормативных документов или вычислены по предложенным Н. А. Буденковым формулам. Коэффициент корреляции $-r$, в соответствии с методикой, разработанной Н. А. Буденковым, предлагается принимать равным 1,0, если между промерными точками проходят не менее двух горизонталей $r=0,5$, если между промерными точками располагается одна горизонталь. Корреляционная зависимость отсутствует, если заложение го- ризонталей превышает расстояние между промерными точками.

Данные представленные в таблице, показывают, что фактическая точность при углах наклона более $2^{\circ}$ на объектах 2 и 3 ниже ожидаемой. С учетом того, что геодезические работы на исследуемых объектах были выполнены качественно, снижение точности может быть объяснено влиянием каких-то факторов, которые не учитывают формулы (1). Оказалось, что эти объекты расположены на реках с грядовым движением донных наносов, которое формирует грядовые формы репредположить, что причиной снижения фактической точности планов является наличие грядовых форм подводного рельефа, характерные точки, которых оказались в междугалсовых расстояниях, так как подводный рельеф визуально не наблюдается. льефа очень сложной структуры. Можно 
Погрешности, характеризующие точность изображения подводного рельефа на планах исследуемых объектов

\begin{tabular}{|c|c|c|c|c|c|c|c|c|}
\hline \multirow{3}{*}{$\begin{array}{c}\text { Название } \\
\text { объекта (реки) }\end{array}$} & \multirow{3}{*}{$\begin{array}{c}\text { Масштаб плана } \\
\text { русловой } \\
\text { съемки }\end{array}$} & \multirow{3}{*}{$\begin{array}{c}\text { Высота } \\
\text { сечения } \\
\text { рельефа, м }\end{array}$} & \multicolumn{6}{|c|}{$\begin{array}{c}\text { Значения средних квадратических } \\
\text { погрешностей, характеризующих точность } \\
\text { изображения подводного рельефа, м }\end{array}$} \\
\hline & & & \multicolumn{3}{|c|}{ теоретические } & \multicolumn{3}{|c|}{ фактические } \\
\hline & & & $2^{\circ}$ & $4^{\circ}$ & $6^{\circ}$ & $2^{\circ}$ & $4^{\circ}$ & $6^{\circ}$ \\
\hline Юган & $1: 1000$ & 1 & 0,3 & 0,4 & 0,4 & 0,3 & 0,4 & 0,4 \\
\hline Юганская Обь & $1: 2000$ & 1 & 0,3 & 0,5 & 0,8 & 0,3 & 0,7 & 0,9 \\
\hline Иртыш & $1: 5000$ & 2 & 0,6 & 0,8 & 1,0 & 0,6 & 1,0 & 1,4 \\
\hline
\end{tabular}

Учитывая приведенные в таблице значения погрешностей, характеризующих точность изображения подводного рельефа, при мониторинге русловых деформаций сопоставлением планов, достоверной, с вероятностью 0,95 , следует полагать величину высотной деформации (размыва или намыва) вдвое превышающей эти погрешности.

Использование современных промерных комплексов для съемки рек, в которых определение планового положения промерных точек осуществляется приемниками глобальных навигационных спутниковых систем, измерение глубин цифровыми эхолотами, а также технологий компьютерной обработки измерений с возможностью автоматически выбирать характерные промерные точки на галсе и обеспечивать минимальную величину погрешностей за обобщение рельефа, значительно повысит точность изображения подводного рельефа. Однако это решает проблему в настоящее время только частично, поскольку для сопоставления будет использоваться один из планов менее точный, полученный ранее по традиционным технологиям съемки.

Другим важным фактором, влияющим на точность определения деформаций дна, является технологический процесс адекватного совмещения планов. Оптимальным вариантом является совмещение планов по квадратам координатной сетки. Но очень часто планы составлены в разных, в том числе, условных системах координат. И совмещение их возможно по опознанным контурным точкам или геодезическим пунктам (обычно реперам), нанесенным на план.

Рассмотрим вариант, при котором на совмещаемых планах имеется минимум инфор- мации, используемой в качестве опорной. В качестве объекта исследования взят план участка русловой съемки масштаба 1:1000 с высотой сечения рельефа 1,0 м. На участке имеется два репера, которые располагаются на разных берегах. Исследование выполнено методом моделирования.

Целью исследования является установить зависимость между ошибкой ориентирования совмещаемых планов и точностью определения величин деформации. Для этого был смоделирован процесс, в котором происходило смещение или разворот базиса в пределах графической точности плана. При этом на исследуемых планах определялись высоты (методом аналитического интерполирования) одноименных точек по наложенной координатной сетке. Высоты определялись дважды до продольного смещения базиса и после. Измерено 850 точек и получено столько же расхождений высот. Расхождения высот объясняются разворотом плана.

Математическая обработка полученных результатов показала, что среднее квадратическое значение расхождений составило $0,1 \mathrm{M}$. Проверка полученных расхождений на соответствие нормальному закону распределения вероятностей, показала, что кривая распределения, построенная по гистограммам, несколько отличается от теоретической (рис. 2). Полученные значения эксцесса и асимметрии составили, соответственно $E=0,30$, а $S_{k}=0,071$. Использование критерия Пирсона для проверки гипотезы на нормальное распределения, показало, что вероятность подтверждения гипотезы о нормальном распределении близка нулю [24-25]. 


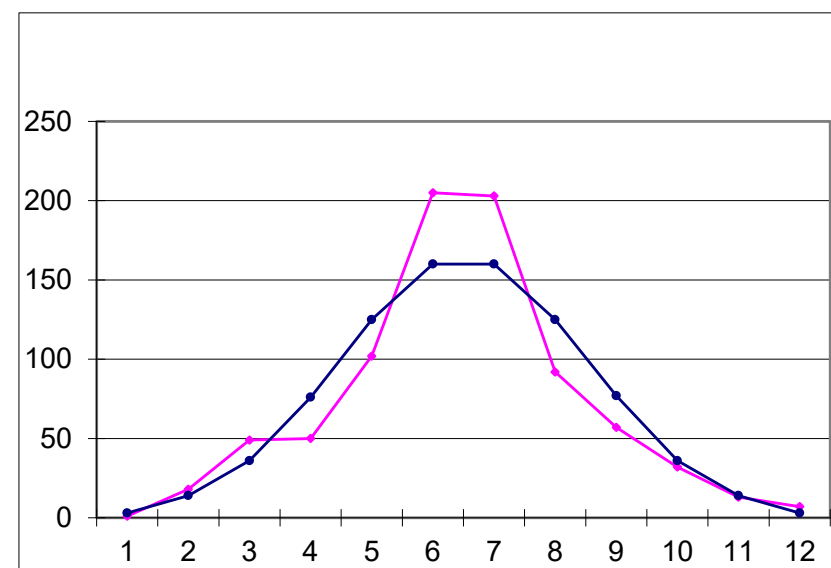

Рис. 2. Кривая распределения вероятностей

(красным цветом - эмпирическая, синим - теоретическая)

То есть на исследуемые разности высот влияют как случайные факторы - интерполирование высот, так и не случайные факторы, связанные с ориентированием (разворотом планов). Величины погрешностей, вызванных разворотом планов, можно вычис- лить, зная расстояние от базиса до данной точки и угол наклона местности.

Тем не менее, исследование показало, что разворот планов в пределах графической точности не вызывает значительных расхождений в высотах, даже при больших уклонах местности, это объясняется тем, что точки смещаются параллельно горизонталям (рис. 3, a). Более существенное влияние оказывает поперечный сдвиг базиca, так как в современных компьютерных технологиях при совмещении двух планов по базису производится как бы изменение масштаба второго плана, с целью совмещения длин двух базисов. При этом возможны два случая.

Первый, согласно рис. 3, б: точки двух планов на одном берегу совмещаются, а на другом берегу их расхождение устраняется изменением масштаба, то есть вытягиванием. В этом случае все точки по направлениям, параллельным базису, смещаются на разные величины $C_{i}$.

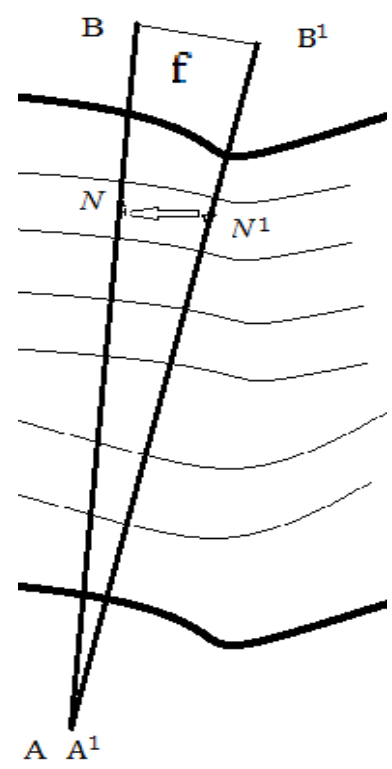

a)

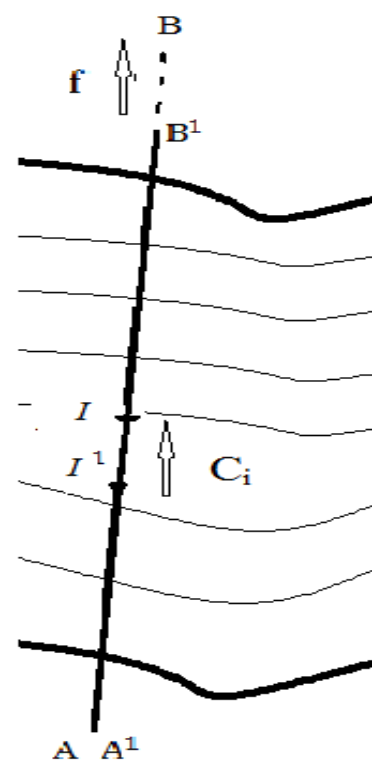

б)

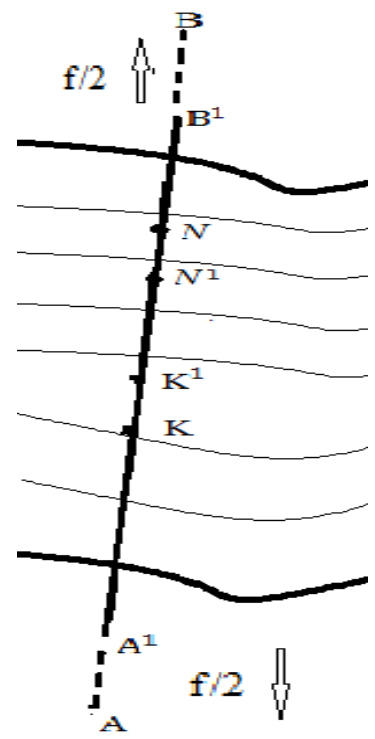

в)

Рис. 3. Ошибки в высоте точек, вызванные погрешностями ориентирования планов по двум опорным точкам:

a) смещение точек параллельно горизонталям; б) точки двух планов на одном берегу совмещаются, а на другом берегу их расхождение устраняется изменением масштаба; в) точки смещаются на величину, равную половине невязки 
Рассмотрим это на примере точки $I$ на базисе, которая сместится на величину, определяемую по формуле:

$$
C_{i}=\frac{f}{\mathrm{~b}} \cdot L_{i},
$$

где $C_{i}$ - величина смещения; $f$ - расхождение базисных точек $B-B^{1}$; Б - длина базиса $A B$; $L_{i}$ - расстояние от базисной точки $A$ на одном берегу до точки $I^{1}$ на базисе. При этом возникают погрешности в высотах, величины которых можно рассчитать для каждой конкретной точки $I^{1}$ (любые смещения в плане действуют на ошибки высот, они вычисляются через тангенс угла наклона $\operatorname{tg} v$ ). Высоты получат поправки $\Delta H_{i}$, вычисленные по формуле

$$
\Delta H_{i}=C_{i} \cdot \operatorname{tg} v .
$$

В этом случае все точки смещаются по направлению, параллельно базису от середины базисной линии к краям (рис. 3, в) на величину, определяемую по формуле

$$
c^{\prime}=\frac{f}{2 \mathrm{~b}} \cdot L_{i}^{\prime} .
$$

На производстве часто приходится совмещать планы по трем исходным точкам, причем две из них - геодезические пункты, которые сохранились на двух берегах, третья хорошо опознаваемая точка местности. Первые две точки обычно совмещаются в пределах графической точности, а третья не совпадает, поэтому приходится выполнять масштабирование по третьему направлению.
Смещение точек можно рассчитать аналогично, по методике, описанной выше.

\section{Обсуждение}

Результаты выполненных исследований показали, что разворот планов вокруг базиса в пределах графической точности не вызывает дополнительных погрешностей определения высотной деформации. Дополнительные погрешности в высотах уменьшаются при увеличении длины базиса, поэтому рекомендуется иметь на объекте несколько опорных точек, удаленных от перехода магистрального трубопровода.

При использовании технологии определения русловых деформаций совмещением планов разных лет съемки можно использовать как электронные, так и традиционные формы представления топографической информации. Исследованиями [1] установлено, что электронные (цифровые) планы русловых съемок, полученные сканированием и оцифровкой планов на традиционных носителях, равноточны исходным.

\section{Заключение}

Таким образом, точность определения высотных деформаций методом сопоставления планов зависит в основном от точности изображения рельефа на этих планах. Современные технологии совмещения планов позволяют минимизировать влияние погрешностей ориентирования на точность определения количественных измерителей деформации.

\section{БИБЛИОГРАФИЧЕСКИЙ СПИСОК}

1. Коркин С. Е., Исыпов В. А. Эрозионные процессы рельефообразования // Геоморфология и физическая география Сибири в XXI веке Материалы Всероссийской научно-практической конференции, посвященной 100-летию со дня рождения заслуженного работника высшей школы Российской Федерации, почетного члена Русского географического общества, профессора, доктора географических наук Земцова Алексея Анисимовича. - 2020. - С. 37-40.

2. К вопросу о русловых деформациях в акватории реки Иртыш / Е. Ю. Гордеева, В. А. Зименс, И. С. Агофонов, С. А. Крапивная // Техника и технологии строительства. - 2019. - № 3 (19). C. $4-9$.

3. Дебольская Е. И. Деформации криволинейных русел, подверженных термоэрозии // Coвременные проблемы водохранилищ и их водосборов. Труды VII Всероссийской научнопрактической конференции с международным участием : в 3 томах. - 2019. - С. 76-81.

4. Бадера В. В. Геодезические методы определения русловой деформации береговой овражной эрозии при проектировании и строительстве инженерных сооружений на реках : учеб. пособие. - Омск : Сибирская государственная авто- 
мобильно-дорожная академия (СибАДИ), 2007. $52 \mathrm{c}$.

5. Савичев О. Г. Способ оценки русловых деформаций при отсутствии русловых съемок // Coвременные проблемы географии и геологии : сборник к 100-летию открытия естественного отделения в Томском государственном университете: материалы IV Всероссийской научно-практической конференции с международным участием. Томск : Национальный исследовательский Томский государственный университет, 2017. С. 391-395.

6. Дегтярев В. В. Расчет русловых деформаций в условиях регулирования речного стока // Охрана природы, гидротехническое строительство, инженерное оборудование : тезисы докладов научно-технической конференции. - Новосибирск: Новосибирский государственный архитектурно-строительный университет (Сибстрин), 1991. - C. 41-42.

7. Popielarczyk D. RTK Water Level Determination in Precise Inland Bathymetric Measurements // 25 th International Technical Meeting of the Satellite-Division of the Institute-ofNavigation (September 17-21, 2012). - Ol'shtyn, Pol'sha : Varminsko-Mazurskiy universitet. 2012. - P. 1158-1163.

8. Седышев М. Е., Уваров А. И., Хлынцева Е. О. Геодезический мониторинг русловых деформаций в местах строительства и эксплуатации подводных переходов магистральных трубопроводов через реки Западной Сибири : монография. Омск : ОмГАУ, 2005. - 153 с.

9. Савичев О. Г., Решетько М. В. Методы ориентировочной количественной оценки твердого стока и русловых деформаций для равнинных рек таежной зоны Западной Сибири // Инженерные изыскания. - 2012. - № 1.- С. 52-56.

10. Савичев О. Г. Методика оценки русловых деформаций рек Западной Сибири // Геосферные исследования. - 2016. - № 1. - С. 140-151.

11. Кораблева О. В. Оценка устойчивости русла реки Керженец // Орфановские чтения, сборник статей по материалам Всероссийской научнопрактической конференции. - Ульяновск : Ульяновский государственный педагогический университет им. И. Н. Ульянова, 2015. - С. 12-16.

12. Антроповский В. И., Гребенников Г. Г. Оценка русловых деформаций карстовых рек с подводными переходами магистральных трубопроводов при наличии результатов натурных исследований // Двадцать шестое пленарное межвузовское координационное совещание по проблеме эрозионных, русловых и устьевых процессов. Доклады и краткие сообщения. - Ар- замас : Арзамасский государственный педагогический университет им. А. П. Гайдара, Межвузовский научно-координационный совет по проблеме эрозионных, русловых и устьевых процессов при МГУ, 2011. - С. 58-60.

13. Антроповский В. И., Гребенников Г. Г. Оценка русловых деформаций карстовых рек с подводными переходами магистральных трубопроводов при недостатке и отсутствии результатов натурных исследований // Проблемы региональной экологии. - 2013. - № 5. - С. 158-162.

14. Кораблева О. В. Характеристика русловых деформаций и оценка устойчивости русла реки Керженец // Труды Государственного Природного Биосферного Заповедника «Керженский» Государственный Природный Заповедник «Керженский». - Нижний Новгород : Литера, 2015. - C. 97-103.

15. Шибких А. А., Боенко К. А., Марусин К. В. Использование ГИС-технологий и дистанционных методов исследования плановых русловых деформаций (на примере участков рек бассейна Верхней Оби) // III Всесибирский медикоэкологический форум. Сборник материалов в рамках XIII медико-экологической выставки «Человек. Экология. Здоровье». - Барнаул : ЗАО «Алтайская ярмарка», 2008. - С. 91-94.

16. Применение современных автоматизированных геодезических приборов для мониторинга гидротехнических сооружений ГЭС / В. Г. Сальников, В. А. Скрипников, М. А. Скрипникова, Т. А. Хлебникова // Вестник СГУГиТ. - 2018. T. 23, № 3. - C. 108-124.

17. Никонов А. В., Чешева И. Н., Рябова Н. М. Разработка программы геодезического мониторинга деформаций гидротехнического сооружения ГРЭС - двухступенчатого перепада // Интерэкспо ГЕО-Сибирь. XIV Междунар. науч. конгр. : Междунар. науч. конф. «Геодезия, геоинформатика, картография, маркшейдерия» : сб. материалов (23-27 апреля 2018 г., Новосибирск). - Новосибирск : СГУГиТ, 2018. - С. 3-12.

18. СП 47.13330.2016. Инженерные изыскания для строительства. Основные положения. Актуализированная редакция СНиП 11-02-96. М. : Стандартинформ, 2017. - 84 c.

19. Churuksaeva V., Starchenko A. Mathematical Modeling of a River Stream Based on a Shallow Water Approach // Procedia Computer Science. 2015. - Vol. 66. - P. 200-209.

20. Korablina A. D., Arkhipkin V. S., Samborski T. V. Modeling features formation storm surge in a dynamic system white sea - Mouth area northern Dvina River // Vestnik Moskovskogo Universiteta, Seriya 5: Geografiya. - 2016. - Vol. 1. - P. 78-86. 
21. Matskevich N. A., Chubarov L. B. Exact Solutions to Shallow Water Equations for a Water Oscillation Problem in an Idealized Basin and Their Use in Verifying Some Numerical Algorithms./ Numerical Analysis and Applications. - 2019. Vol. 12, Issue 3. - P. 234-250.

22. Буденков Н. А., Ганьшин В. Н. Геодезические работы при речных и озерных изысканиях. - М. : Недра, 1979. - 159 с.

23. Experimental and numerical study on velocity fields and water surface profile in a stronglycurved 90 degrees open channel bend / A. Gholami,
A A Akhtari, Y. Minatour, H. Bonakdari, A. A. Javadi // Engineering Applications of Computational Fluid Mechanics. - 2014. - Vol. 8, Issue 3. P. 447-461.

24. Гмурман В. Е. Теория вероятностей и математическая статистики : учебник. - 9-е изд. М. : Высш. шк., стереотип, 2003. - 479 с.

25. Нефедова Г. А., Ащеулов В. А. Теория математической обработки геодезических измерений в конспективном изложении : учеб. пособие. - Новосибирск : СГГА, 2009. - 140 с.

\section{RESEARCH OF TECHNOLOGIES OF GEODESIC MONITORING OF BOTTOM DEFORMATIONS IN THE AREA OF LOCATION OF UNDERWATER TRANSITIONS OF MAIN PIPELINES}

\section{Anatoly I. Uvarov}

Omsk State Agrarian University named after P. A. Stolypin, 4, Sibakovskaya St., Omsk, 644008, Russia, Ph. D., Associate Professor, Department of Geodesy and Remote Sensing, phone: (913)977-00-25, e-mail: ai.uvarov@omgau.org

\section{Lilia A. Pronina}

Omsk State Agrarian University named after P. A. Stolypin, 4, Sibakovskaya St., Omsk, 644008, Russia, Ph. D., Associate Professor, Department of Geodesy and Remote Sensing, phone: (904)582-93-92, e-mail: la.pronina@omgau.org

It is noted that as a result of the interaction of the geodynamic complex of the river with the environment, changes in the channel appear, which entail planned and high-altitude deformations of the water artery. Therefore, in the construction and operation of engineering structures, they must be taken into account. The study of channel deformations, mostly high-altitude, in the areas of construction or the location of existing structures is a very urgent task to ensure their stable, trouble-free operation. It is established that for the study of channel deformations, two of the most common technologies are used. The first is the technology of combining plans for channel surveys, and the second is the combination of transverse profiles of the river using hydraulic rams fixed by signs on the shore. The results of a study of the technology for determining channel deformations during their geodetic monitoring are presented. The accuracy of the image of the underwater relief on the plans is estimated. The influence of the errors of combining plans on the accuracy of determining quantitative strain gauges is investigated.

Key words: geodetic monitoring, channel deformations, bottom deformations, channel survey plans, geodetic points, accuracy assessment.

\section{REFERENCES}

1 Korkin, S. E., \& Isypov V. A. (2020). Erosion processes of relief formation. In Sbornik materialov Vserossiyskoy nauchno-prakticheskoy konferentsii, posvyashchennoy 100-letiyu so dnya rozhdeniya zasluzhennogo rabotnika vysshey shkoly Rossiyskoy Federatsii, pochetnogo chlena Russkogo geograficheskogo obshchestva, professora, doktora ge- ograficheskikh nauk Zemtsova Alekseya Anisimovicha: Geomorfologiya $i$ fizicheskaya geografiya Sibiri $v$ XXI veke [Proceedings of the All-Russian Scientific and Practical Conference Dedicated to the 100th Anniversary of the Honored Worker of a Higher School of the Russian Federation, an Honorary Member of the Russian Geographical Society, 
Professor, Doctor of Geographical Sciences Zemtsov Alexei Anisimovich: Geomorphology and Physical Geography of Siberia in the 21st century] (pp. 37-40) [in Russian].

2. Gordeeva E. Yu., Zimens, V. A., Agofonov, I. S., $\&$ Nettle, S. A. (2019). On the issue of channel deformations in the Irtysh river. Tekhnika i tekhnologii stroitel'stva [Technique and Construction Technology], 3(19), 4-9 [in Russian].

3. Debolskaya, E. I. (2019). Deformations of curved channels subject to thermoerosion. In Trudy VII Vserossiyskoy nauchno-prakticheskoy konferentsii s mezhdunarodnym uchastiem: Sovremennye problemy vodokhranilishch $i$ ikh vodosborov [Proceedings of the VII All-Russian Scientific and Practical Conference with International Participation: Modern Problems of Reservoirs and their Catchments] (pp.76-81) [in Russian].

4. Badera, V. V. (2007). Geodezicheskie metody opredeleniya ruslovoy deformatsii beregovoy ovrazhnoy erozii pri proektirovanii i stroitel'stve inzhenernykh sooruzheniy na rekakh [Geodetic methods for determining channel deformation of coastal ravine erosion in the design and construction of engineering structures on rivers]. Omsk Siberian State Automobile and Highway Academy (SibADI) Publ., 52 p. [in Russian].

5. Savichev, O. G. (2017). Method for assessing channel deformations in the absence of channel surveys. In Sbornik materialov IV Vserossiyskoy nauchno-prakticheskoy konferentsii s mezhdunarodnym uchastiem: Sbornik $k$ 100-letiyu otkrytiya estestvennogo otdeleniya $v$ Tomskom gosudarstvennom universitete: Sovremennye problemy geografii i geologii [Proceedings of the IV All-Russian Scientific and Practical Conference with International Participation: Collection on the 100th anniversary of the Opening of the Natural Branch at Tomsk State University: Modern Problems of Geography and Geology] (pp. 391-395). Tomsk: National Research Tomsk State University Publ. [in Russian].

6. Degtyarev, V. V. (1991). Calculation of channel deformations in the conditions of river flow regulation. In Tezisy dokladov nauchnotekhnicheskoy konferentsii: Okhrana prirody, gidrotekhnicheskoe stroitel'stvo, inzhenernoe oborudovanie [Abstracts of Scientific and Technical Conferences: Nature Protection, Hydraulic Engineering Construction, Engineering Equipment] (pp. 41-42). Novosibirsk: Novosibirsk State University of Architecture and Civil Engineering (Sibstrin) Publ. [in Russian].

7. Popielarczyk D. (2012). RTK Water Level Determination in Precise Inland Bathymetric Measurements. 25th International Technical Meeting of the Satellite-Division of the Institute-of-Navigation, Sep. 17-21 (pp. 1158-1163). Ol'shtyn, Pol'sha: Varminsko-Mazurskiy Universitet.

8. Sedyshev, M. E., Uvarov, A. I., \& Khlyntseva, E. O. (2005). Geodezicheskiy monitoring ruslo$v y k h$ deformatsiy $v$ mestakh stroitel'stva $i$ ekspluatatsii podvodnykh perekhodov magistral'nykh truboprovodov cherez reki Zapadnoy Sibiri [Geodetic monitoring of channel deformations in the places of construction and operation of underwater crossings of main pipelines across the rivers of Western Siberia]. Omsk: OmGAU Publ., 153 p. [in Russian].

9. Savichev, O. G., \& Reshetko, M. V. (2012). Methods of approximate quantitative assessment of solid runoff and channel deformations for plain rivers of the taiga zone of Western Siberia. Inzhenernye izyskaniya [Engineering Surveys], 1, 52-56 [in Russian].

10. Savichev, O. G. (2016). Methodology for assessing channel deformations of rivers in Western Siberia. Geosfernye issledovaniya [Geosphere Studies], 1, 140-151 [in Russian].

11. Korableva, O. V. (2015). Assessment of the stability of the Kerzhenets river bed. In Sbornik materialov Vserossiyskoy nauchno-prakticheskoy konferentsii: Orfanovskie chteniya [Proceedings of the All-Russian Scientific and Practical Conference: Orfanov Readings] (pp. 12-16). Ulyanovsk: Ulyanovsk State Pedagogical University named after I. N. Ulyanov, Department of Geography, Geographical and Geoecological Education Publ. [in Russian].

12. Antropovsky, V. I., \& Grebennikov, G. G. (2011). Assessment of channel deformations of karst rivers with underwater crossings of main pipelines in the presence of field research results. In Dvadtsat' shestoe plenarnoe mezhvuzovskoe koordinatsionnoe soveshchanie po probleme erozionnykh, ruslovykh $i$ ust'evykh protsessov. Doklady i kratkie soobshcheniya [Twenty-sixth Plenary Inter-University Coordination Meeting on the Problem of Erosion, Channel and Wellhead Processes. Reports and Brief coCommunication] (pp. 58-60). Arzamas: Arzamas State Pedagogical University named after A. P. Gaidar, Interuniversity Scientific Coordination Council on the problem of erosion, channel and wellhead processes at Moscow State University, Publ. [in Russian].

13. Antropovsky, V. I., \& Grebennikov, G. G. (2013). Assessment of channel deformations of karst rivers with underwater crossings of main pipelines with a lack and absence of results of field studies. Problemy regional'noy ekologii [Problems of Regional Ecology], 5, 158-162 [in Russian].

14. Korableva, O. V. (2015). Characterization of channel deformations and assessment of the stability 
of the Kerzhenets riverbed. In Trudy Gosudarstvennogo Prirodnogo Biosfernogo Zapovednika "Kerzhenskiy": Gosudarstvennyy Prirodnyy Zapovednik "Kerzhenskiy" [Transactions of the State Natural Biosphere Reserve "Kerzhenskiy": State Natural Reserve "Kerzhenskiy"] (pp. 97-103). Nizhny Novgorod: Litera Publ. [in Russian].

15. Shibkih, A. A., Boenko, K. A., \& Marusin, K. V. (2008). Use of GIS-technologies and distance methods for studying planned channel deformations (on the example of sections of rivers of the upper $\mathrm{Ob}$ basin). In Sbornik materialov v ramkakh XIII mediko-ekologicheskoy vystavki "Chelovek. Ekologiya. Zdorov'e": III Vsesibirskiy mediko-ekologicheskiy forum [Proceedings of the XIII Medical and Environmental Exhibition "Man. Ecology. Health": III All-Siberian Medical and Environmental Forum] (pp. 91-94). Barnaul: CJSC Altai Fair Publ. [in Russian].

16. Salnikov, V. G., Skripnikov, V. A., Skripnikova, M. A., \& Khlebnikova T. A. (2018). The use of modern automated geodetic instruments for monitoring hydraulic structures of hydroelectric plants. Vestnik SGUGiT [Vestnik SSUGT], 23(3), 108-124 [in Russian].

17. Nikonov, A. V., Chesheva, I. N., \& Ryabova N. M. (2018). Development of a program for geodetic monitoring of deformations of a hydraulic power plant at a state district power station - a two-stage differential Nikonov. In Sbornik materialov Interekspo GEOSibir'-2018: Mezhdunarodnoy nauchnoy konferentsii: Geodezija, geoinformatika, kartografija, markshejderija [Proceedings of Interexpo GEO-Siberia-2018: International Scientific Conference: Geodesy, Geoinformatics, Cartography, Mine Surveying] (pp. 3-12). Novosibirsk: SSUGT Publ. [in Russian].

18. Code of practice SP 47.13330.2016. (2017). Engineering surveys for construction. The main pro- visions. Updated edition of SNiP 11-02-96. Moscow: Standartinform, 84 p. [in Russian].

19. Churuksaeva, V., \& Starchenko, A. (2015). Mathematical Modeling of a River Stream Based on a Shallow Water Approach. Procedia Computer Science, 66, 200-209.

20. Korablina, A. D., Arkhipkin, V. S., \& Samborski, T. V. (2016). Modeling features formation storm surge in a dynamic system white sea - Mouth area northern Dvina River. Vestnik Moskovskogo Universiteta. Seriya 5: Geografiya, 1, 78-86.

21. Matskevich, N. A., \& Chubarov, L. B. (2019). Exact Solutions to Shallow Water Equations for a Water Oscillation Problem in an Idealized Basin and Their Use in Verifying Some Numerical Algorithms. Numerical Analysis and Applications, 12(3), 234-250.

22. Budenkov, N. A., \& Ganshin, V. N. (1979). Geodezicheskie raboty pri rechnykh $i$ ozernykh izyskaniyakh [Geodetic work in river and lake surveys]. Moscow: Nedra Publ., 159 p. [in Russian].

23. Gholami, A., Akhtari A. A., Minatour, Y., Bonakdari, H., \& Javadi, A. A. (2014). Experimental and numerical study on velocity fields and water surface profile in a strongly-curved 90 degrees open channel bend. Engineering Applications of Computational Fluid Mechanics, 8(3), 447-461.

24. Gmurman, V. Ye. (2003). Teoriya veroyatnostey i matematicheskaya statistiki [Probability theory and mathematical statistics] (9th ed.). Moscow: Higher School, Stereotip, 479 p. [in Russian].

25. Nefedova, G. A., \& Ashcheulov, V. A. (2009). Teoriya matematicheskoy obrabotki geodezicheskikh izmereniy $v$ konspektivnom izlozhenii [Theory of mathematical processing of geodetic measurements in a summary]. Novosibirsk: SSGA Publ., 140 p. [in Russian]. 
УДК 528.482

DOI: $10.33764 / 2411-1759-2020-25-3-117-126$

\section{ГЕОДЕЗИЧЕСКИЙ МОНИТОРИНГ БОЛЬШЕПРОЛЕТНЫХ СООРУЖЕНИЙ С ПРОСТРАНСТВЕННОЙ МЕТАЛЛИЧЕСКОЙ КОНСТРУКЦИЕЙ}

\section{Андрей Аркадвевич Шоломицкий}

Сибирский государственный университет геосистем и технологий, 630108, Россия, г. Новосибирск, ул. Плахотного, 10, доктор технических наук, профессор кафедры инженерной геодезии и маркшейдерского дела, тел. (383)343-29-55, e-mail: sholomitskij@mail.ru

\section{Бахтиер Назруллович Ахмедов}

Сибирский государственный университет геосистем и технологий, 630108, Россия, г. Новосибирск, ул. Плахотного 10, аспирант кафедры инженерной геодезии и маркшейдерского дела, тел. (953)873-09-06, e-mail: khudobakhsh@inbox.ru

В статье приводятся оценка результатов геодезических измерений и выводы, полученные при наблюдении за деформациями во время строительства и эксплуатации большепролетного сооружения с перекрытием типа «пространственная оболочка», находящегося на территории с опасными природными и сейсмическими процессами и жарким климатом. На основании результатов измерений вертикальной и горизонтальной составляющих деформации выполнен анализ реального поведения конструкций в этих условиях. Оценивая деформации на разных стадиях и параметры окружающей среды, можно установить решающие параметры и допуски для поведения реальной пространственной металлической конструкции. Приведены данные измерений трех циклов наблюдений при строительстве объекта и трех циклов после его ввода в эксплуатацию, на основании которых сделан вывод, что конструкция испытывает небольшие закономерные деформации, которые соответствуют расчетным.

Ключевые слова: пространственная конструкция, мониторинг, деформации, геодезические измерения, большепролетное сооружение, нагрузка, расчетная модель, нагрузка, параметры среды.

\section{Введение}

Металл является традиционным материалом, из которого строятся конструкции большепролетных сооружений. Металлические конструкции имеют высокую прочность, легко монтируются и имеют современный эстетический вид. В настоящее время строительная индустрия все чаще использует конструкции перекрытий из металла [1-6] для строительства пространственных конструкций сложной геометрической формы. Возведение сооружений с металлической конструкцией все шире применяется в зонах повышенной сейсмичности.

Несмотря на особые технические условия для возведения сооружений с пространственной металлической конструкцией в 30нах повышенной сейсмичности, большепролетные сооружения строятся очень высоки- ми темпами и являются важными объектами инфраструктуры каждой развивающейся страны. Такая тенденция характерна и для стран Центральной Азии. В Таджикистане возведено несколько таких сооружений с разными конструктивными решениями. Например, Дворец водных видов спорта, построенный по системе пространственной модульной конструкции (рис. 1).

Использование новых архитектурных и строительных технологий повышает необходимость обратной связи в виде периодических геодезических измерений, во время строительства и эксплуатации для проверки их фактического поведения в заданных условиях. Полученные данные могут быть использованы для уточнения расчетных моделей и оптимизации проектирования новых сооружений со сходными конструкциями $[7,8]$. 


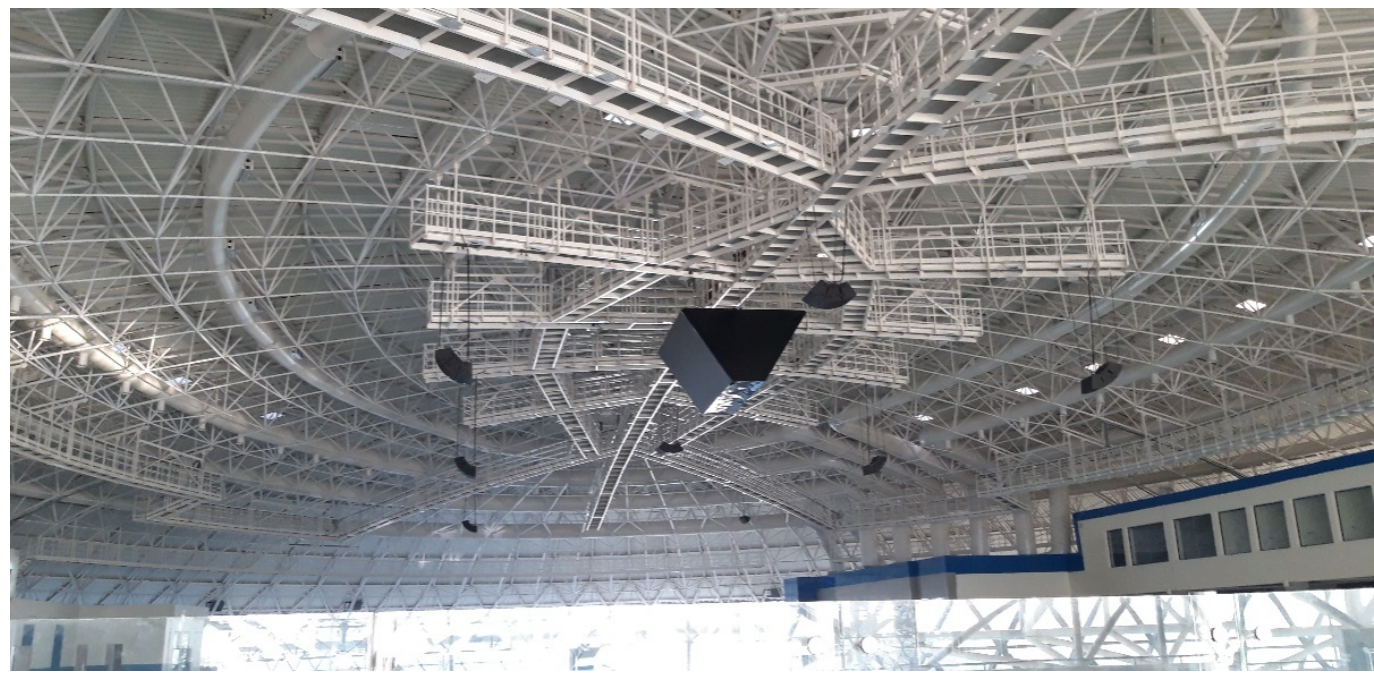

Рис. 1. Перекрытие дворца водных видов спорта в г. Душанбе

\section{Общцая информация об объекте}

Строительство металлической конструкции Дворца водных видов спорта на 2000 посадочных мест на улице Карамова города Душанбе началось в марте 2017 г., монтаж модульной конструкции оболочки завершился в декабре 2017 г. Еще в течение года продолжались работы по монтажу витражей,

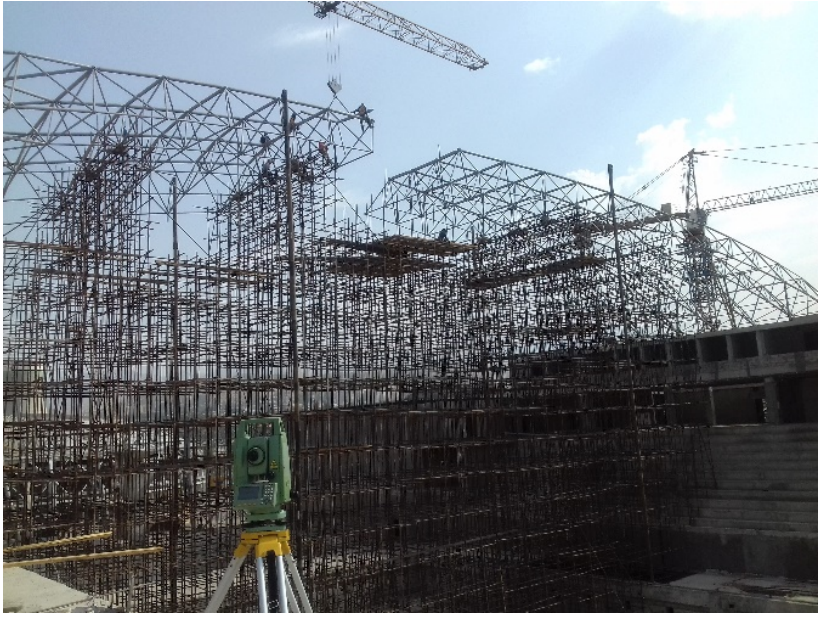

a) устройству кровли, инженерных коммуникаций и других работ. В конце 2018 г. завершились все работы повышающие нагрузки на несущие конструкции оболочки.

С мая 2019 г. сооружение сдано в эксплуатацию. Пример конструкции во время строительства (рис. $2, a$ ) и вид готовой смонтированной модульной конструкции показан на рис. $2, \sigma$.

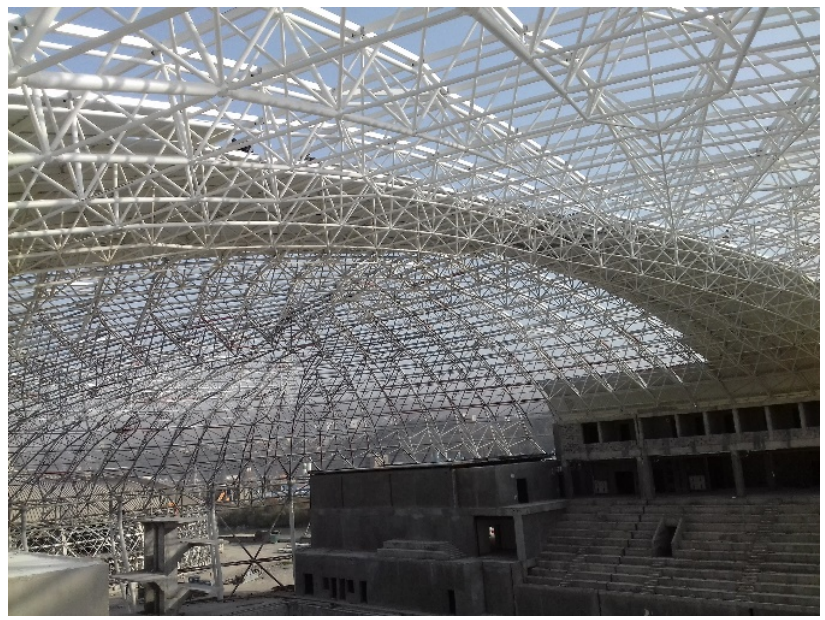

б)

Рис. 2. Общий вид металлической модульной конструкции:

a) в процессе монтажа; б) готовая смонтированная конструкция оболочки

Сооружение имеет форму эллипса в плане размером 118,94 м на 93,94 м. Основная конструкция, поддерживающая кровельную систему, состоит из пространственной металлической конструкции - оболочки, стоящей на металлических колоннах высотой 28,30 м. Арки в поперечном и продольном направлениях усилены продольными и боковыми связями, и весь каркас создает пространственную несущую систему - пространственную 
оболочку. Несущая конструкция оболочки крепится к железобетонным фундаментам с помощью шарнирных опор. Монтаж конструкции оболочки был выполнен с высокой точностью (фактическое отклонение в плане от проекта не превышало 12 мм, а вертикальное - 20 мм).

С целью проведения мониторинга для определения фактического поведения той или иной пространственной конструкции используются геодезические методы измерения [9-15], зачастую в совокупности с различными датчиками. Современная литература по системам автоматизированного мониторинга очень обширна и в рамках одной статьи ее осветить затруднительно, поэтому авторы только обозначили основные направления. Технические регламенты для строительства и эксплуатации зданий и сооруже- ний требуют систематического измерения перемещений и деформаций [16] при строительстве и при эксплуатации объектов. Целесообразно выполнять регулярное проведение измерений деформационных явлений в соответствующих интервалах - циклах измерений или эпохах измерений.

Деформационные марки для мониторинга устанавливаются при тесном взаимодействии с конструкторами-проектировщиками в местах ожидаемых максимальных сосредоточенных деформаций.

Согласно расчетной модели, деформации происходят в основном в центральной части покрытия (рис. 3, $a$, зона окрашена красным цветом), а при сейсмическом воздействии и перемещении узлов в боковых частях (рис. 3, б). Максимальная величина деформации по расчету 266 мм (рис. 3).

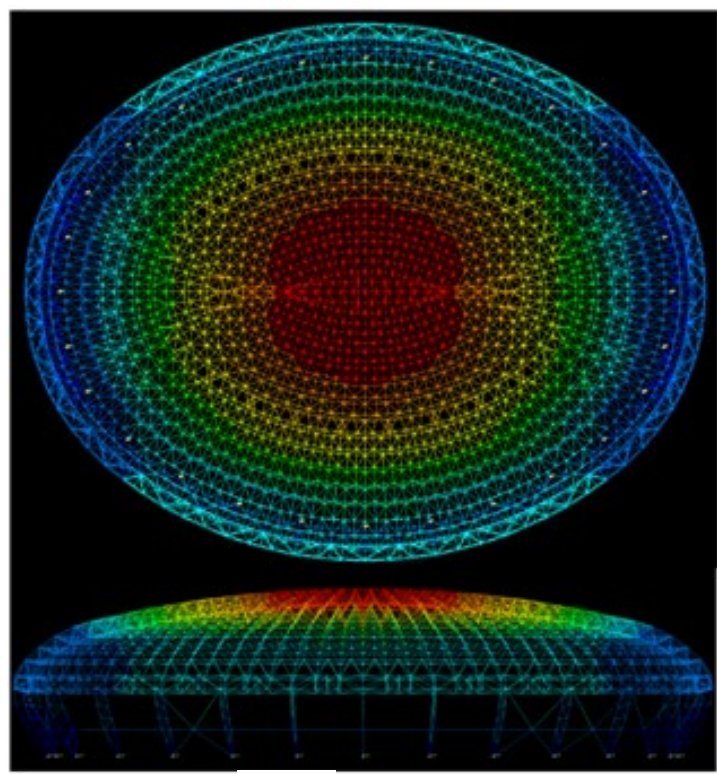

a)

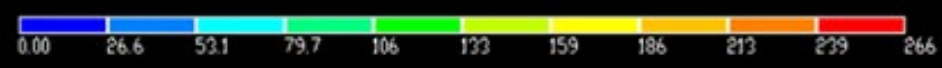

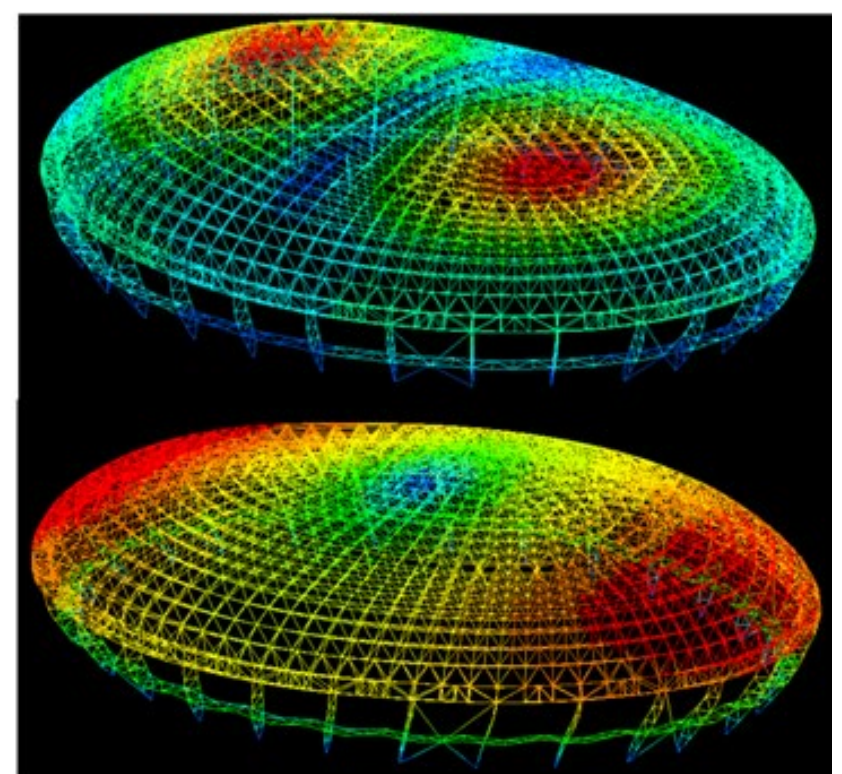

б)

Рис. 3. Расчетная модель деформации конструкции:

a) в статических условиях; б) при сейсмических воздействиях

\section{Технологическая схема проведения мониторинга деформаций больщепролетных сооружений}

После завершения строительства геометрические параметры конструкции постепенно изменяются из-за резьбовых соединений узлов (шарнирных узлов). Другими важными факторами, влияющими на деформацию, являются погодные условия, особенно влияние температуры и влажности, сейсмические, а также сезонные воздействия. Из-за инсоляции алюминиевая конструкция крыши нагревается, и это приводит к удлинению стрежней 
и откручиванию в узлах соединений металлической конструкции. Сооружение находится в зоне с жарким летним климатом и большим перепадом температур зимой, подвергается атмосферным воздействиям, снеговой и ветровой нагрузкам. Температура воздуха внутри поддерживается системой кондиционирования $+18{ }^{\circ} \mathrm{C}$, летом снаружи поднимется до $+50{ }^{\circ} \mathrm{C}$, зимой падает до $-14{ }^{\circ} \mathrm{C}$.

С момента полного завершения монтажа металлической конструкции периодически проводятся наблюдения за смещениями и деформациями. С 2018 г. выполнено 6 циклов измерений, 3 из них были проведены во время строительства, при возрастании нагрузки на металлический каркас.

Поведение наблюдаемой конструкции оболочки оценивается на основе результатов геодезических измерений по установленным маркам на нижних поясах конструкции крыши. С целью проведения мониторинга за перемещениями и деформациями, во время изготовления металлоконструкции на заводе были сделаны отверстия для закрепления геодезических деформационных марок на нижних шарах оболочки (рис. 4).

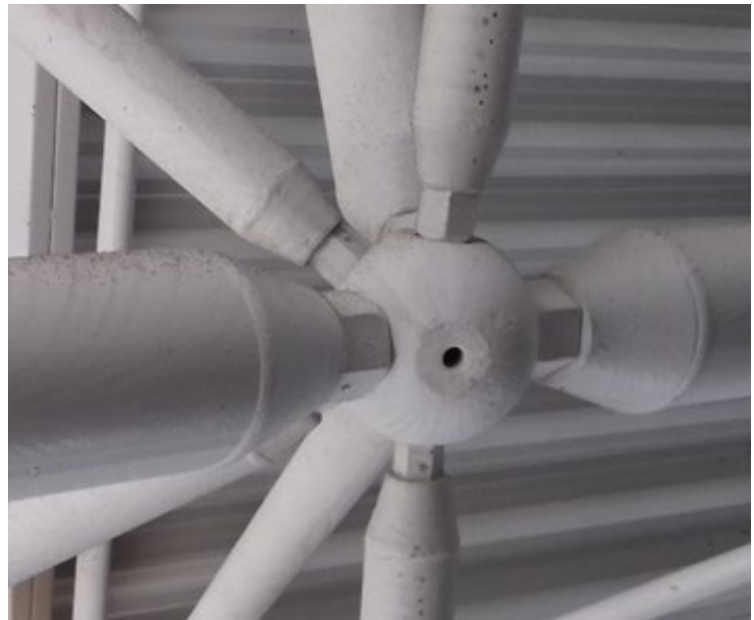

a)

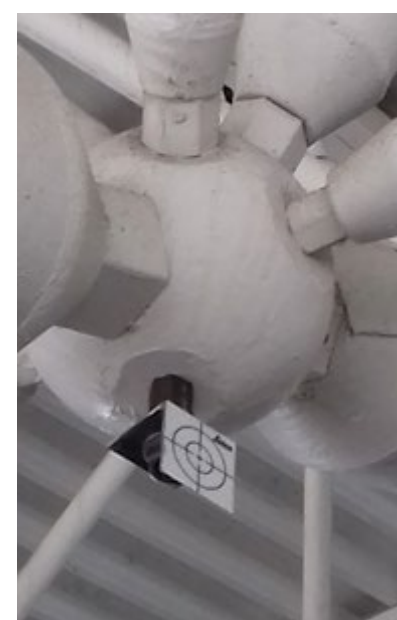

б)

Рис. 4. Конструкция геодезической марки:

a) металлический шар с отверстием; б) установленная геодезическая марка

Эти марки помогли провести измерения и создать исполнительные схемы, определить отклонения от проектного положения и дать оценку качеству монтажных работ.

Вся конструкция состоит из 1250 шаров на нижнем поясе, на 57 из них симметрично установлены измерительные марки. Сеть геодезических пунктов по внутреннему контуру и деформационных марок для наблюдения за перекрытием, их расположение в плане показаны на рис. 5. Геодезическая сеть состоит из 8 пунктов, расположенных на бетонном покрытии вспомогательных помещений внутри спортивного зала.

Технология мониторинга основана на методе измерений тахеометром линейно-угловой сети с трех и более свободных станций.
Геодезические марки обозначены порядковыми номерами от 1 до 57, а опорные геодезические пункты - буквой $R$. Точки, откуда обеспечивается видимость на деформационные марки перекрытия, обозначены знаками геодезических станций и нумерацией I, II, III.

Для выполнения измерений используется условная система координат, в которой ось $X$ параллельна продольной оси сооружения, ось $Y$ перпендикулярна ей. Путем сравнения координат полученных в разные циклы, можно оценить деформации в продольном, поперечном и вертикальном направлениях.

На рис. 6 и 7 показаны профили по главным сечениям сооружения: продольный профиль по линии марок $29-1$ (см. рис. 6) и поперечный, по линии марок 45 - 17. 


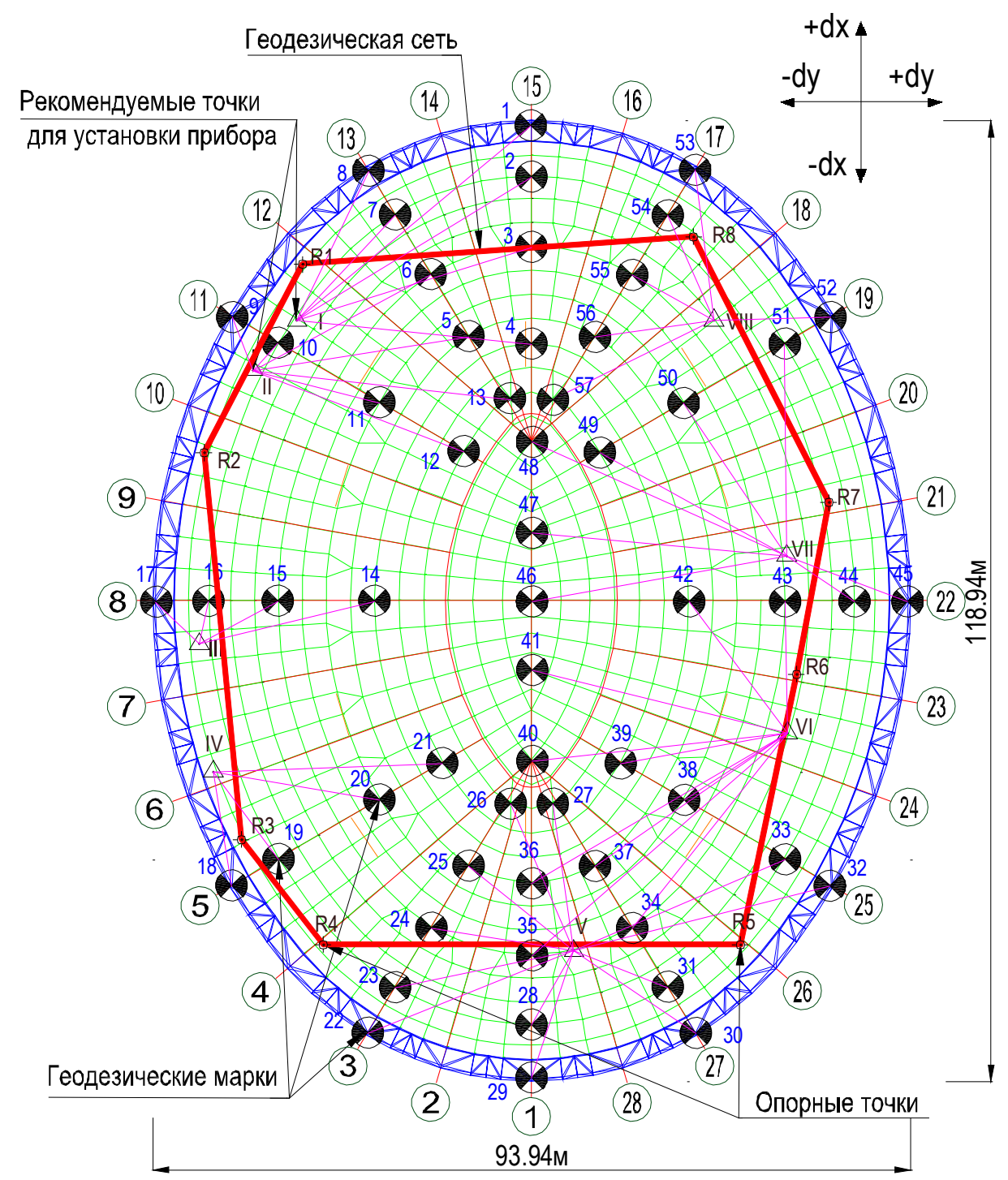

Рис. 5. Схема расположения геодезических марок

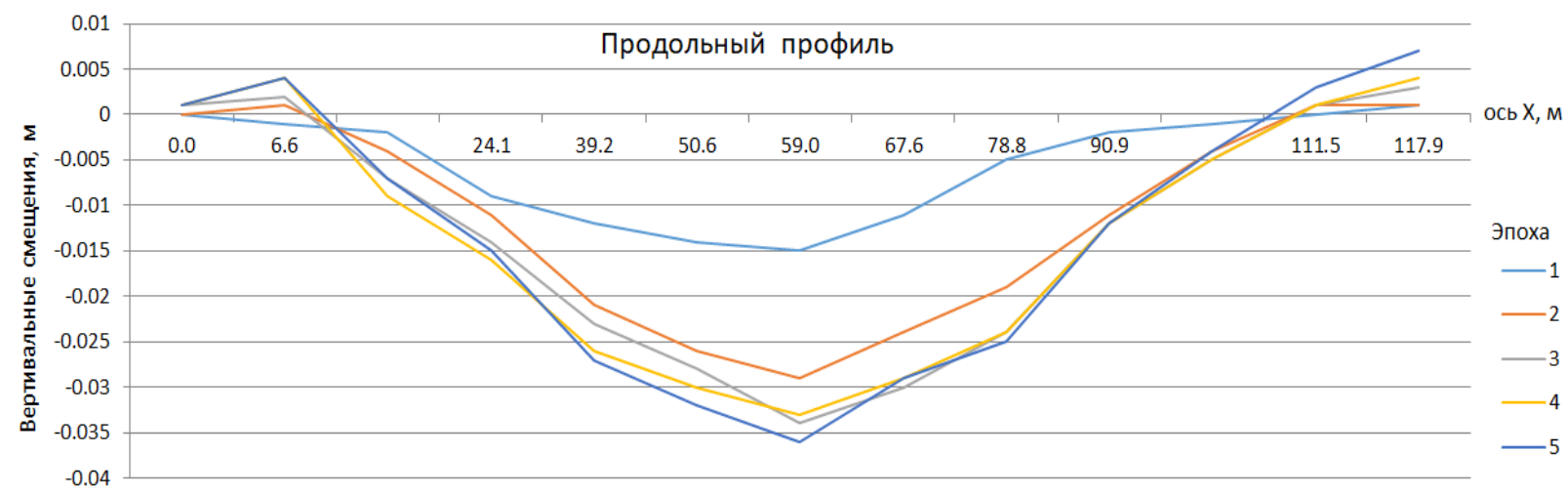

Рис. 6. Продольный профиль (29 - 1) 


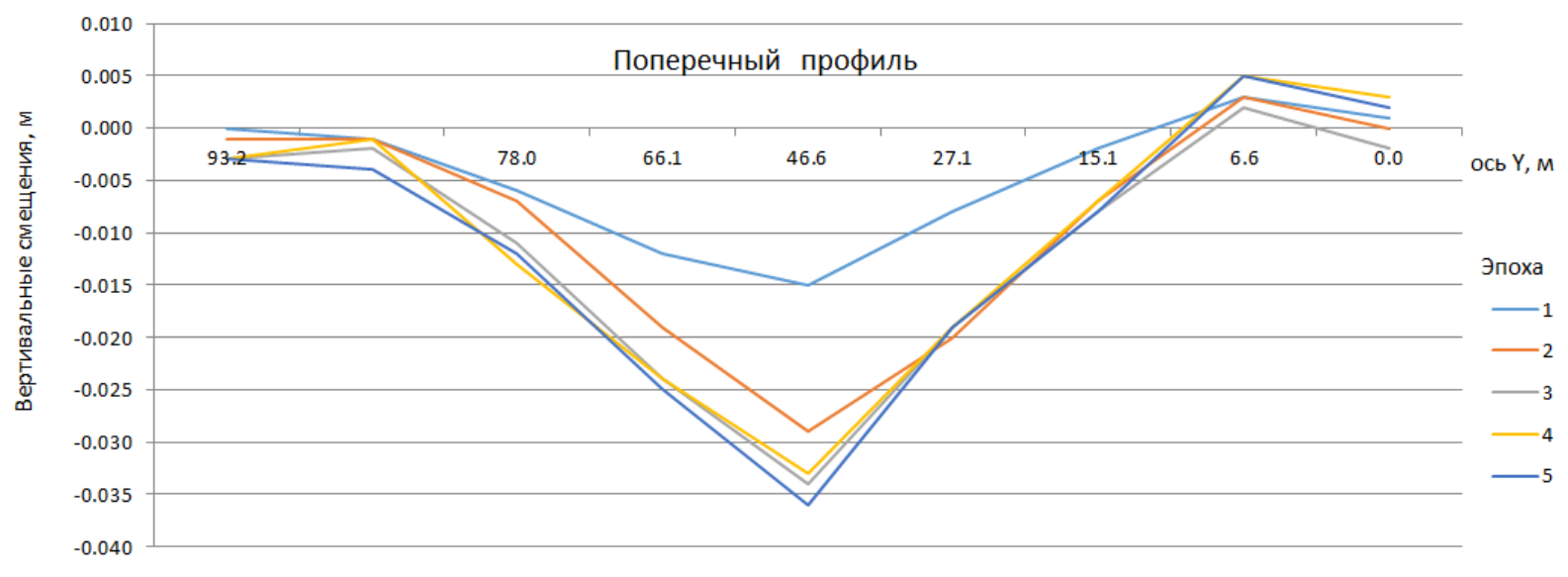

Рис. 7. Поперечный профиль (45 - 17)

На графиках рис. 6 и 7 цифрами подписаны эпохи измерений на разные даты, начальный цикл измерений был проведен 15.05.2018 г., 1 - 25.08.2018 г., 2 - 15.05.2019 г., 3 15.08.2019 г., 4 - 03.12.2019 г., 5 - 15.03.2020 г. Эти графики показывают, что по мере возрастания нагрузки, связанной с монтажем кровли и технологического оборудования на эпоху 1 и 2, вертикальные оседания возрастают, и в последующие эпохи - стабилизируются, и изменяются в незначительных пределах. Фактические максимальные деформации по высоте, для точки 46, были 36 мм, что составляет $13,5 \%$ от предельно допустимой, максимальное поднятие +7 мм на точке 19. В таблице приведены поверхности деформаций по соответствующим осям, относительно начального цикла измерений. Деформации в вертикальной плоскости (по оси Z) имеют вполне объяснимые причины и закономерности, увеличиваются от начального цикла в соответствии с возрастанием нагрузки и уменьшаются в последних циклах, после стабилизации нагрузки.

Деформации в горизонтальной плоскости тоже имеют некоторую закономерность, хотя и не такую выраженную, как по оси $Z$. Поверхности отклонений по осям $X$ и $Y$ показывают, что деформационные марки имеют смещения по оси $X$ от -18 мм до +30 мм, и по оси $Y$ от -15 мм до +16 мм, причем эти деформации имеют не равномерный, а со- средоточенный характер.

Значения деформации сильно зависят от воздействия температуры окружающей среды и динамических воздействий. В жаркий период присходят вертикальные движения средней части оболочки вниз - прогиб крыши, а боковые части по контуру имеют вертикальное смещение вверх. В частности, вертикальная деформация сильно зависит от температуры окружающей среды с сезонными изменениями до 20 мм.

Общий вес нагрузки от элементов кровли на конструкцию в эпоху 1 (см. рис. 6,7 ) составлял 71 т. В промежуток наблюдения $1-2$ были закончены работы по монтажу подвесных мостков в полном объеме. Общий вес подвесной нагрузки от веса мостков составлял 110 т. Также в этот период были закончены работы по монтажу витража со стеклами. Общий вес конструкции витража составляет 125 т. Вес стеклянной конструкции 156 т. Общий вес нагрузки на металлические конструкции на эпоху 2 составил 391 т.

Поверхности на эпохи 2 и 3 (рис. 6, 7) показывают, что после завершения основных монтажных работ процесс деформации замедлился, и поведение перекрытия стабилизировалось, хотя в этот период еще велись работы по монтажу инженерных коммуникации внутри помещении. После этого на структуру в основном влияет воздействие температуры окружающей среды. 
Деформации по координатным осям на эпохи измерений

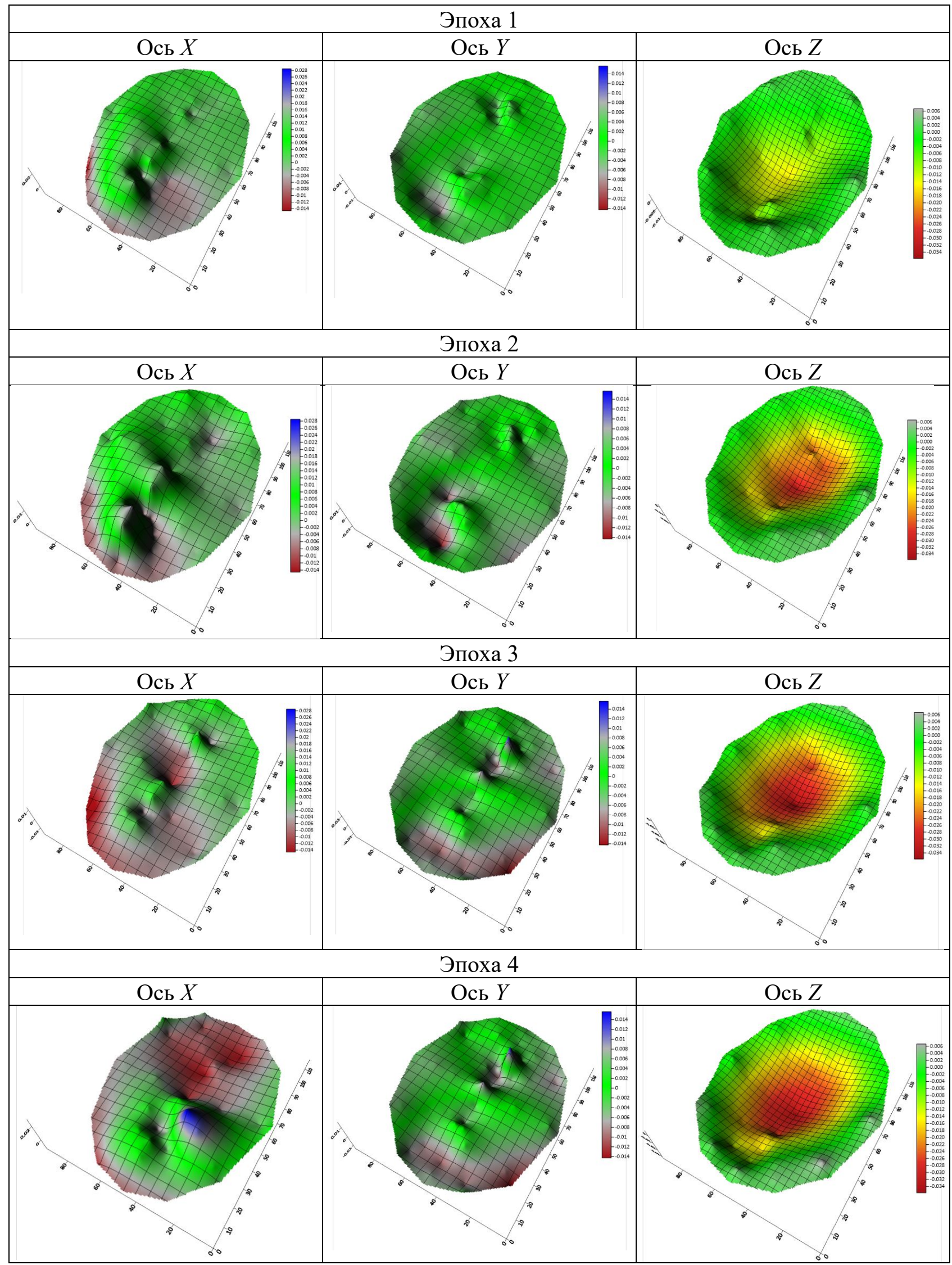




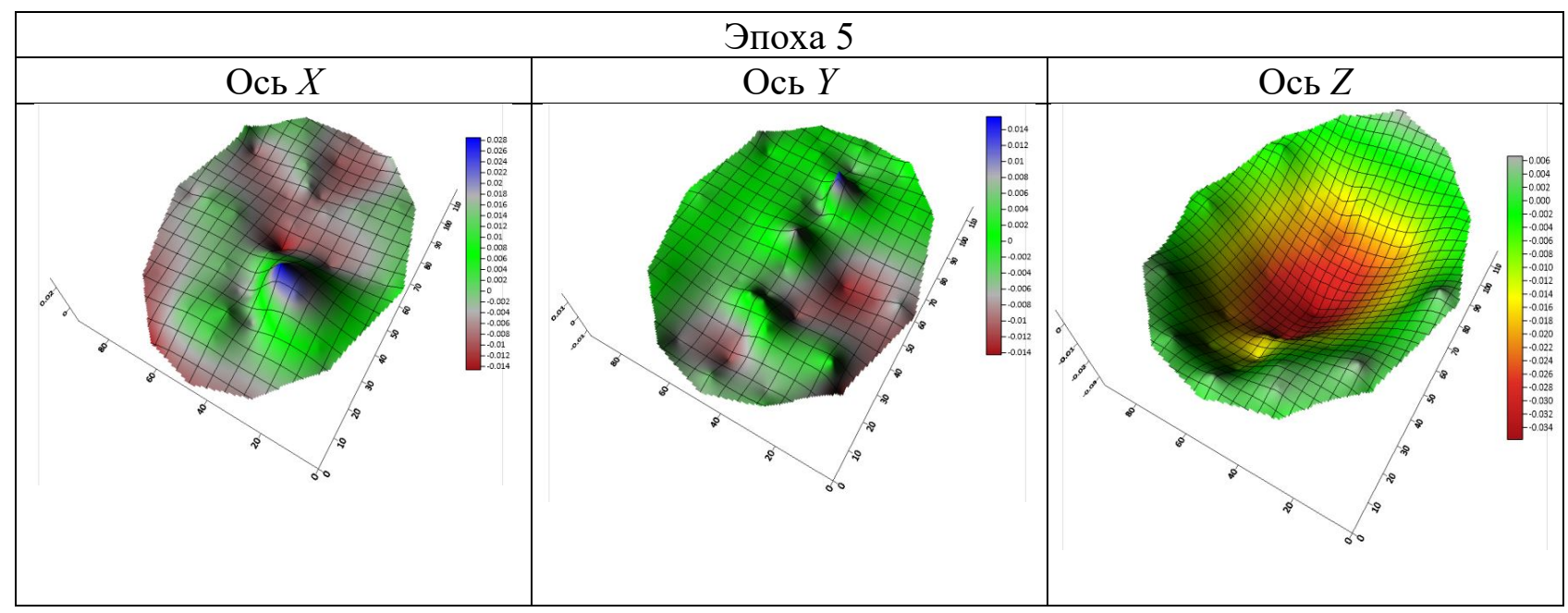

\section{Заключение}

Оценка результатов геодезических измерений оболочки большепролетного сооружения с металлической пространственной конструкцией за более чем два года показала эффективность использования традиционных геодезических методов для мониторинга конструкций аналогичного типа. Результаты геодезических измерений свидетельствуют о том, что фактические значения деформаций являются невысокими и соответствуют теоретической модели деформации для объекта. Исходя из этой модели и геодезических измерений конструкций в процессе мониторинга в течение двухлетних измерений, для статического поведения конструкции можно считать допустимым значение вертикальной деформации до 40 мм. А для горизонтальных перемещений по оси $X$ и $Y$ допустимыми можно считать \pm 30 мм. Следует отметить, что до настоящего времени конструкция надежна и устойчива. На этапе строительства сооружение выдержало землетрясение в 6 баллов. Поэтому крайне важно оценить динамику изменений, чтобы определить потенциально слабые места в конструкции, где в будущем можно ожидать появления нестабильного поведения конструкции.

Следует продолжать мониторинг, чтобы получить дополнительную информацию о поведении конструкции во время ее эксплуатации. Данные, полученные по результатам геодезических измерений, можно использовать для уточнения модели статического поведения конструкции, ее мониторинга и проектирования новых несущих металлических конструкций большепролетных сооружений.

\section{БИБЛИОГРАФИЧЕСКИЙ СПИСОК}

1. Spampinato A. Stadio Olimpico di Roma [Electronic resource] // The world Stadiums. - Mode of access: https://is.gd/48Hknu.

2. Knowles E. Stansted Airport, Main Terminal [Electronic resource] // Engineering timelines. - Mode of access: http://www.engineering-timelines.com/ scripts/engineeringItem.asp? $\mathrm{id}=235$.

3. Vinnitskaya I. MyZeil Shopping Mall / Studio Fuksas [Electronic resource] // ArchDaily. - Mode of access: http:// www.archdaily.com/243128/myzeilshopping-mall-studio-fuksas.

4. Jewel N. 2014 China Flower Expo Pavilions Resemble Giant Floating Flower Petals [Electronic resource] // Inhabitat. - Mode of access: https://inhabitat.com/2014-china-flower-expo-pavilionsresemble-giant-floating-flower-petals/.
5. Dale N. Waterloo International Terminal [Electronic resource] // Engineering timelines. - Mode of access: http://www.engineering-timelines.com/ scripts/engineeringItem. asp? $\mathrm{id}=243$.

6. Popp P., Sans O. L. London 2012 Velodrome [Electronic resource] // Detail-online. Mode of access: http://www.detail-online.com/ article/london-2012-velodrome-16431.

7. Daniel R., Alberto S. Response of large span steel frames subjected to horizontal and vertical seismic motions [Electronic resource] // Proceedings of the 13th World Conference on Earthquake Engineering. Paper number 1404. - Mode of access: https://www.iitk.ac.in/nicee/wcee/article/13_1404.pdf.

8. Research on Construction Monitoring of Large-Span Steel Pipe Truss Structure / K. L. Chen, 
G. Q. Yuan, L. K. Wang, W. Z. Zhang, X. K. Wang [Electronic resource] // Open Journal of Civil Engineering. - 2019. - Vol. 9. - P. 255-267. - Mode of access: https://doi.org/10.4236/ ojce.2019.94018 f.

9. Математические модели и техническая реализация GOCA - онлайн-системы геодезического мониторинга и оповещения о деформациях природных и техногенных объектов, основанная на точных спутниковых (GNSS) и наземных геодезических наблюдениях (LPS/LS) / Р. Ягер, П. Шпон, Т. Шайхутдинов, Т. И. Горохова, А. Ю. ЯНКУШ // СИББЕЗОПАСНОСТЬ-СПАССИБ2012. Совершенствование системы управления, предотвращения и демпфирования последствий чрезвычайных ситуаций регионов и проблемы жизнедеятельности населения: сб. материалов Междунар. науч. конгр., 25-27 сент. 2012 г., Новосибирск. - Новосибирск : СГГА, 2012. C. 194-217.

10. Главинский Д. В. Методика непрерывного автоматизированного мониторинга строительных конструкций покрытия в ледовом дворце «Уральская молния» // Мониторинг. Наука и безопасность. - 2011. - № 3. - С. 64-68.

11. Автоматизированный контроль конструктивной безопасности уникальных объектов, включая высотные и широкопролетные / В. В. Гурьев, В. М. Дорофеев, Д. А. Лысов, Н. В. Назьмов // Строительная механика инжене- рных конструкций и сооружений. - 2011. № 2. - C. 55-61.

12. Практический опыт устройства стационарных автоматизированных систем мониторинга строительных конструкций на олимпийских объектах в городе Сочи / И. Е. Штунцайгер, Д. А. Лысов, А. С. Денисов, А. О. Слободенюк, А. И. Кугачев // Строительство и реконструкция. - 2015.- № 4 (60). - С. 67-71.

13. Шоломицкий А. А., Лагутина Е. К., Соболева Е. Л. Высокоточные геодезические измерения при деформационном мониторинге аквапарка // Вестник СГУГиТ. - 2017. - Т. 22, № 3. C. $45-59$.

14. Mogilny S., Sholomitskii A., Lagutina E. Bim and forecasting deformations in monitoring structures // GeoScience Engineering. - 2019. Vol. LXV, No. 3. - P. 50-57. Doi: 10.35180/gse2019-0018.

15. Шоломицкий А. А., Лагутина Е. К., Соболева Е. Л. Использование лазерного сканирования для мониторинга большепролетных coоружений // Вестник СГУГиТ. - 2018. - Т. 23, № 2. C. $43-57$.

16. МДС 13-22.2009. Методика геодезического мониторинга технического состояния высотных зданий и уникальных зданий и сооружений. - М. : ОАО «ЦПП», ООО «Тектоплан», 2010. $-76 \mathrm{c}$.

\section{GEODESIC MONITORING OF LARGE-SPAN CONSTRUCTIONS WITH SPATIAL METAL STRUCTURE}

\section{Andrei A. Sholomitskii}

Sibirian State University of Geosystems and Technologies, 10, Plakhotnogo St., Novosibirsk, 630108, Russia, Dr. Sc., Professor, Department of Engineering Geodesy and Mine Surveying, phone: (383)343-29-55, e-mail: sholomitskij@mail.ru

\section{Bakhtiyor N. Akhmedov}

Siberian State University of Geosystems and Technologies, 10, Plakhotnogo St., Novosibirsk, 630108, Russia, Ph. D. Student, Department of Engineering Geodesy and Mine Surveying, phone: (953)873-09-06, e-mail: khudobakhsh@inbox.ru

The article draws the estimation of geodetic measurement results and conclusions, obtained at observation of deformations during the construction and exploitation of large span structure with bridging of space shell type, located on the territory with hazardous natural and seismic processes and hot climate. On the basis of measurement results of the vertical and horizontal deformation constituents the analysis of actual behavior of the constructions in these conditions was performed. Estimating the deformations on different stages and environmental parameters one can set critical parameters and tolerance for the behavior of a real spatial metal structure. The article draws the data of three observation cycles carried out during the construction process 
and three ones performed after the start of operation. The observations allowed making a conclusion that the structure undergoes little appropriate deformations, which correspond to the designed ones.

Key words: spatial construction, monitoring, deformation, geodetic measurements, large span structure, calculated model, load, building load, environmental parameters.

\section{REFERENCES}

1. Spampinato, A. (2019). Stadio Olimpico di Roma. The World Stadiums. Retrieved from https://is.gd/48Hknu.

2. Knowles, E. (2019). Stansted Airport, Main Terminal. Engineering Timelines. Retrieved from http://www.engineering-timelines.com/scripts/ engineeringItem.asp? $\mathrm{id}=235$.

3. Vinnitskaya, I. (2017). MyZeil Shopping Mall / StudioFuksas. ArchDaily. Retrieved from http://www.archdaily.com/243128/myzeil-shoppingmall-studio-fuksas.

4. Jewel, N. (2013). 2014 China Flower Expo Pavilions Resemble Giant Floating Flower Petals. Inhabitat. Retrieved from https://inhabitat.com/2014china-flower-expo-pavilions-resemble-giant-floatingflower-petals/.

5. Dale, N. (2018). Waterloo International Terminal. Engineering Timelines. Retrieved from $\mathrm{http} / / / \mathrm{www}$.engineering-timelines.com/scripts/ engineeringItem.asp? $\mathrm{id}=243$.

6. Popp, P., \& Sans, O. L. (2012). London 2012 - Velodrome. Detail-online. Retrieved from http://www.detail-online.com/article/london-2012velodrome-16431.

7. Daniel, R., \& Alberto, S. (2004). Response of large span steel frames subjected to horizontal and vertical seismic motions. Proceedings of the 13th World Conference on Earthquake Engineering. Paper number 1404. Retrieved from https:// www.iitk.ac.in/nicee/wcee/article/13_1404.pdf.

8. Chen, K. L., Yuan, G. Q., Wang, L. K., Zhang, W. Z., \& Wang, X. K. (2019). Research on Construction Monitoring of Large-Span Steel Pipe Truss Structure. Open Journal of Civil Engineering, 9, 255-267. Retrieved from https://doi.org/10.4236/ojce.2019.94018.

9. Jager, R., Shpon, P., Shajhutdinov, T., Gorohova, T., \& Jankush, A. (2012). Mathematical models and technical realization of GOCA - online systems of geodetic monitoring and reporting about deformations of natural and technogenic objects, based on high-precision satellite and ground-based geodetic survey (LPS/LS). In SIBBEZOPASNOST'SPASSIB-2012. Sovershenstvovaniye sistemy upravleniya, predo-tvrashcheniya $i$ dempfirovaniya posledstviy chrezvychaynykh situatsiy regionov $i$ problemy zhiznedeyatel'nosti naseleniya [Improvement of the Control System, Prevention and Damping of the Consequences of Emergency Situations of the Regions and the Problems of the Life of the Population] (pp. 194-217). Novosibirsk: SSGA Publ. [in Russian].

10. Glavinskij, D. V. (2011). The method of continuous automated monitoring of roof structures in ice arena "Ural'skaja molnija". Monitoring. Nauka $i$ bezopasnost' [Monitoring. Science and Security], 3, 64-68 [in Russian].

11. Gur'ev, V. V., Dorofeev, V. M., Lysov, D. A., \& Naz'mov, N. V. (2011). Automated control of structural safety of unique objects including highaltitude and large span ones. Stroitel'naja mehanika inzhenernyh konstrukcij $i$ sooruzhenij [Structural Mechanics of Engineering Structures and Structures], 2, 55-61 [in Russian].

12. Shtuncajger, I. E., Lysov, D. A., Denisov, A. S., Slobodenjuk, A. O., \& Kugachev, A. I. (2015). Practical experience of construction of stationary automated monitoring systems for building structures of Olympic objects in the city of Sochi. Stroitel'stvo $i$ rekonstrukcija [Construction and Reconstruction], 4(60), 67-71 [in Russian].

13. Sholomickii, A. A., Lagutina, E. K., \& Soboleva, E. L. (2017). High-precision geodetic measurements in deformation monitoring of Aquapark. Vestnik SGUGiT [Vestnik SSUGT], 22(3), 45-59 [in Russian].

14. Mogilny, S., Sholomitskii, A., \& Lagutina E. (2019). BIM and forecasting deformations in monitoring structures. Geo Science Engineering, LXV(3), 50-57. doi: 10.35180/gse-2019-0018.

15. Sholomickii, A. A., Lagutina, E. K., \& Soboleva E. L. (2018). The use of laser scanning for monitoring large span structures. Vestnik SGUGiT [Vestnik SSUGT], 23(2), 43-57 [in Russian].

16. The method of geodetic monitoring of technical conditions of high-altitude buildings and unique buildings and structures. MDS 13-22.2009. (2010). Moscow: OAO "CPP", OOO "Tektoplan" Publ., 76 p. [in Russian]. 
УДК 004.414.2:625.1

DOI: $10.33764 / 2411-1759-2020-25-3-127-138$

\section{МЕТОДИКА СОЗДАНИЯ ЦИФРОВЫХ ПРОЕКТОВ ДЛЯ АВТОМАТИЗИРОВАННЫХ СИСТЕМ УПРАВЛЕНИЯ СТРОИТЕЛЬНОЙ ЖЕЛЕЗНОДОРОЖНОЙ ТЕХНИКОЙ}

\section{Владимир Васильевич Щербаков}

Сибирский государственный университет путей сообщения, 630049, Россия, г. Новосибирск, ул. Дуси Ковальчук, 191, кандидат технических наук, доцент, заведующий кафедрой «Инженерная геодезия», тел. (913)912-86-91, e-mail: vvs@stu.ru

В статье рассмотрены методы создания цифровых проектов для автоматизированных систем управления CAУ-3D, специфика создания цифровых проектов и отличие методических решений для железных дорог. Показаны преимущества разработанной методики оцифровки пути по отношению к пересчету проектных координат из местной системы координат в новую систему координат для обеспечения работы САУ-3D. Приведена структурная схема создания цифрового проекта по данным оцифровки пути с использованием АПК «Профиль» и проектных геометрических параметров. Показаны примеры использования традиционной проектной документации с целью получения исходных данных для создания цифровых проектов.

Ключевые слова: методика создания цифровых проектов, системы координат, системы автоматизированного управления (САУ-3D), инженерно-геодезическое обеспечение ремонта железных дорог.

\section{Введение}

Строительство и ремонт железнодорожного пути выполняется комплексом различных строительных машин, включая специализированные железнодорожные машины [1]. За последние годы в Российской Федерации созданы и разрабатываются новые современные высокопроизводительные строительные машины [2]. Новые машины оборудуются системами управления выправкой пути, включая автоматизированные системы САУ-2D, к которым относятся системы с копировальной струной, применяются методы управления выправкой пути и приборы, в основе которых лежит метод ГСИ «График стрел изгиба», например система управления выправкой пути WIN ALC (Австрия). В российских системах управления «Магистраль» и $\mathrm{AC}$ «Навигатор» используются параметрические данные для выправки пути, например радиус кривой, длина переходных и круговой кривой, применяются системы управления выправкой пути с лазерными построителями плоскости типа EM-SAT (АвстрияИталия). Кроме того, существуют и другие аналогичные системы управления выправкой пути [3], а также системы контроля геометрических параметров индикаторного типа. Наличие систем управления (СУ) выправкой пути и контроля геометрических параметров у строительных железнодорожных машин требует геодезического обеспечения как при подготовке, так и в процессе строительства или ремонта (для некоторых типов машин геодезического обеспечения). Комплекс геодезических работ включает создание опорной геодезической сети, разбивочные работы, вынос проекта в натуру в плане и профиле, геодезический контроль строительномонтажных работ, операционный контроль отдельных видов работ, исполнительные съемки. Комплекс геодезических работ трудоемкий и не всегда обеспечивает необходимую производительность, особенно в «окно». Для обеспечения работы современных высокопроизводительных строительных железнодорожных машин автоматизация геодезического обеспечения особенно актуальна. Автоматизация отдельных видов геодезических работ обеспечивает повышение производительности, но наибольший эффект можно получить, используя автоматизированные геодезические средства и методы для управ- 
ления строительными процессами, включая автоматизированное управление строительными машинами. К таким средствам измерения относятся спутниковые приемники ГНСС и робот-тахеометр, которые могут выполнять измерения в автоматизированном режиме в аппаратно-программных комплексах типа CAУ-3D, при этом применение роботатахеометра предусматривает использование опорной геодезической сети. Одной из важнейших задач практического применения САУ-3D является создание цифрового проекта ЦП [3-7] на участок строительства (ремонта) для реализации проектных решений с использованием комплекса машин, оборудованных CAУ-3D. Для этого необходимо создание 3D-модели объекта строительства (ремонта), на практике используются цифровые модели местности (ЦММ), цифровые модели рельефа (ЦМР), а также системы автоматизиванного проектирования (САПР) и ГИС-технологии. Создание цифрового проекта при этом зависит от объекта строительства, например строительства автомобильной дороги [8-10].

Опыт применения CAУ-3D на автомобильных дорогах показывает, что наиболее часто САУ-3D используются для планировочных работ земляного полотна, при устройстве дорожных одежд. САУ-3D устанавливаются на автогрейдер, бульдозер, уплотнители и другие машины, при этом применяется импортное оборудование, напримep Leica (iCON-80), Trimble (3D LPS), Topcon (RoverGrade 3D), а также CAУ-3D других производителей геодезического оборудования $[11,12]$. Анализ методов создания цифровых проектов показал, что одной из проблем, в настоящее время ограничивающих создание цифровых проектов (ЦП) и соответственно практическое применение САУ-3D, является отсутствие нормативной базы, регулирующей и регламентирующей применение современных геодезических технологий $[13-16,6]$. К таким технологиям относятся лазерное сканирование и беспилотные летательные аппараты (БПЛА), обеспечивающие высокую эффективность создания цифровых моделей местности, цифровых моделей рельефа и цифровых моделей пути (ЦМП).
Второй, не менее важной составляющей практического применения САУ-3D является программное обеспечение (ПО) для обработки цифровых данных ЦММ, ЦМР, ЦМП, а также для создания цифровых проектов. Программное обеспечение в России представлено системами автоматического проектирования, включая наиболее известные: «Кредо-Диалог» (Республика Беларусь), «Топоматик Robur», «IndorCAD» (Россия), ПО компании Autodesk (США). Проектные решения, полученные в данных ПО, конвертируются в форматы DXF 3D-модели проектных поверхностей для САУ-3D. Проектные поверхности создаются для каждого проектного слоя и соответственно используются на соответствующих этапах строительства, включая планировочные работы по созданию земляного полотна, устройству дорожных одежд, основания и покрытия. Опыт применения САУ-3D в России и за рубежом на строительстве автомобильных дорог показал, что производительность повышается на $70 \%$, сокращение сроков выполнения работ происходит в 1,5-2 раза [8]. Несмотря на высокие технико-экономические показатели применения САУ-3D, широкое внедрение ограничено отсутствием нормативной базы не только для применения БПЛА и лазерного сканирования (как уже отмечалось), но и непосредственно САУ-3D. Второй ограничивающий фактор применения САУ-3D психологический, связанный с переходом от традиционных разбивочных работ с использованием разбивочных чертежей (документ привычный и понятный для геодезистов и дорожных мастеров) к ЦП с набором цифровых данных, структура и форматы которых не могут применяться для выноса в натуру проектных данных с использованием традиционных средств и методов. Ограничения применения САУ-3D связаны не только со строительством автомобильных дорог, аналогичные ограничения характерны и для других видов строительства и ремонта, включая железные дороги. При этом если при строительстве автомобильных дорог применяются импортные системы, то специализированные железнодорожные машины отечественного производства не используют 
импортные САУ-3D. Цифровые проекты, применяющиеся на автомобильных дорогах или при строительстве промышленных сооружений, неприемлемы для железных дорог с учетом специфики работы строительных железнодорожных машин и обеспечения безопасности на железных дорогах, поэтому используются другие методы создания цифровых проектов для САУ-3D с целью управления строительными железнодорожными машинами $[14,7]$.

\section{Специфика создания цифровыхмоделей для жселезных дорог}

Специфика создания цифровых моделей пути и цифровых проектов для САУ-3D, применяющихся для специализированных железнодорожных машин, заключается в следующем.

1. Объекты инфраструктуры имеют пространственную привязку к оси пути, при этом контроль геометрических параметров для обеспечения безопасности движения выполняется относительно оси пути (габариты приближения строений).

2. Проектные сдвижки рассчитываются относительно оси пути (рихтовка в плане и подъемка в профиле), пространственное положение балластной призмы и другие параметры верхнего строения пути нормируются и контролируются относительно оси железнодорожного пути.

3. Для обеспечения проектных решений создается местная (МСК) и связанная с ней линейная система координат (Км + Пк + м).

4. Проектные данные на участок ремонта содержат пространственные данные (координаты оси пути в МСК) и геометрические параметры, включая проектные расстояния до объектов инфраструктуры, например проектные расстояния от оси пути до опор контактной сети, проектное междупутье, рихтовки и подъемки рассчитываются относительно оси существующего пути.

5. Ограничение временного интервала выполнения работ, включая наиболее жесткие требования к выполнению графика работ,выполнение ремонта в «окно».
6. Строительные машины для выполнения технологического процесса ремонта имеют различные задачи на каждом этапе работ и существенно отличаются как конструктивно, так и по функциональным задачам.

7. Требования к обеспечению точности пространственного положения оси пути и взаимного положения смежных точек пути отличаются в 20 раз.

8. Проектная документация на ремонт включает проектные пространственные данные и специфические, характерные только для железных дорог, определяющие смещение пути в плане и профиле относительно существующего пути геометрические параметры.

Исходя из приведенной в п. 1-8 специфики требований к системам координат, проектным геометрическим и пространственным данным железных дорог, разработана методика создания цифровых проектов для систем контроля геометрических параметров вырезки балласта (СКВБ) [17, 18], систем контроля качества уплотнения балласта (СКУБ) [19], САУ-3D [20, 21] с использованием АПК «Профиль» и МЛС «Сканпуть» $[22,23]$.

Данные системы созданы впервые в России для строительства и ремонта железнодорожного пути в едином комплексе, включая единое для всех машин координатное пространство, единый цифровой проект, общую структуру и форматы данных для САУ-3D и других систем контроля и управления. САУ-3D создаются на базе робота-тахеометра и спутниковых приемников позиционирования ГНСС, обеспечивающих определение пространственного положения подвижных объектов. Пространственное положение оси пути в CAУ-3D на базе ГНСС определяется в системе координат ITRF-2014, а проектные данные (координаты оси пути и других объектов) на участок ремонта традиционно представлены в местной системе координат.

Преобразование (пересчет координат) из одной системы в другую выполняется с использованием ГОСТ 32453-2017 [24], вклю- 
чая конвертеры координат, пересчет координат MCK-ITRF-2014 в AutoCAD, PHOTOMOD GeoCalculator и т. д., при этом проблемой является преобразование нормальных высот в геодезические и обратно с приемлемой точностью [25-27]. Разработаны алгоритмы, позволяющие при определенных условиях получать приемлемую точность определения высотных отметок при пересчете координат, но это связано с дополнительными измерениями и организационными проблемами, а также с большим объемом вычислений для получения исходных данных [25]. Практический опыт показал сложность реализации данных решений с приемлемой для ремонта железнодорожного пути точностью $[13,28]$.

Для реализации пересчета координат необходимо изменить требования к существующей нормативной базе $[15,16,6]$ по созданию опорной геодезической сети, методики изменений, а самое главное - peзультаты пересчета не гарантируют приемлемую точность получения высотных отметок. Поэтому в путеизмерительных комплексах Trimble Gedo Vorsys Amberg GRP VX 3000 применяются роботы-тахеометры и САУ-2D (WIN ALC) [3, 4]. При этом производительность создания ЦП с использованием тахеометров и применения системы выправки WIN ALC в 2-4 раза ниже в зависимости от количества кривых на участке ремонта по отношению к САУ-3D на базе ГНСС, а трудозатраты значительно выше, так как съемку пути необходимо выполнять перед проходом каждой строительной железнодорожной машины на всех этапах ремонта, общее количество циклов измерения составляет от 6 до 10.

С учетом высокой трудоемкости работ актуальной задачей является применение на железных дорогах CAУ-3D на базе ГНСС не только для планировочных работ по земляному полотну, но и постановки пути в проектное положение. В результате многолетних исследований найдено оптимальное решение по алгоритму и методике создания цифровых проектов для обеспечения работы CAУ-3D на базе ГНСС на железных дорогах $[14,7]$.

\section{Методика создания цифровых проектов}

В основе предлагаемых решений лежит возможность использования для выноса проектных данных в натуру геометрических параметров, определяющих проектные смещения пути относительно существующего пространственного положения пути. В данном решении использовалась одна из особенностей проектной документации на ремонт железнодорожного пути, а именно наличие эпюры рихтовок и продольного профиля, в которых приведены проектные данные (рихтовка и подъемка) смещения пути относительно существующего пространственного положения пути. Это позволяет использовать систему координат ITRF-2014 [29] без какихлибо преобразований пространственных проектных данных (МСК) с целью создания ЦП для САУ-3D.

Сущность создания цифрового проекта заключается в оцифровке ремонтного железнодорожного пути с использованием АПК «Профиль» (до начала ремонта) и использовании традиционной проектной документации (проектный профиль, эпюра рихтовок) для корректировки координат положения существующего пути. Создание цифровых проектов для САУ-3D строительных железнодорожных машин включает несколько этапов и выполняется последовательно в соответствии со структурной схемой, приведенной на рис. 1.

Данные технические решения согласуются с комплексом подготовительных работ до начала ремонта и выполняются одновременно для обеспечения проверки (контроля) проектных решений на участке ремонта, актуализации проекта необходимых разбивочных работ для обеспечения работы (САУ-3D). Таким образом, натурная съемка АПК «Профиль» для оцифровки пути обеспечивает, кроме создания ЦП, актуализацию проекта и разбивочные работы, что снижает стоимость создания ЦП (за счет комплексного подхода).

Оцифровка выполняется АПК «Профиль», МЛС «Сканпуть» и другими специализированными измерительными системами. 


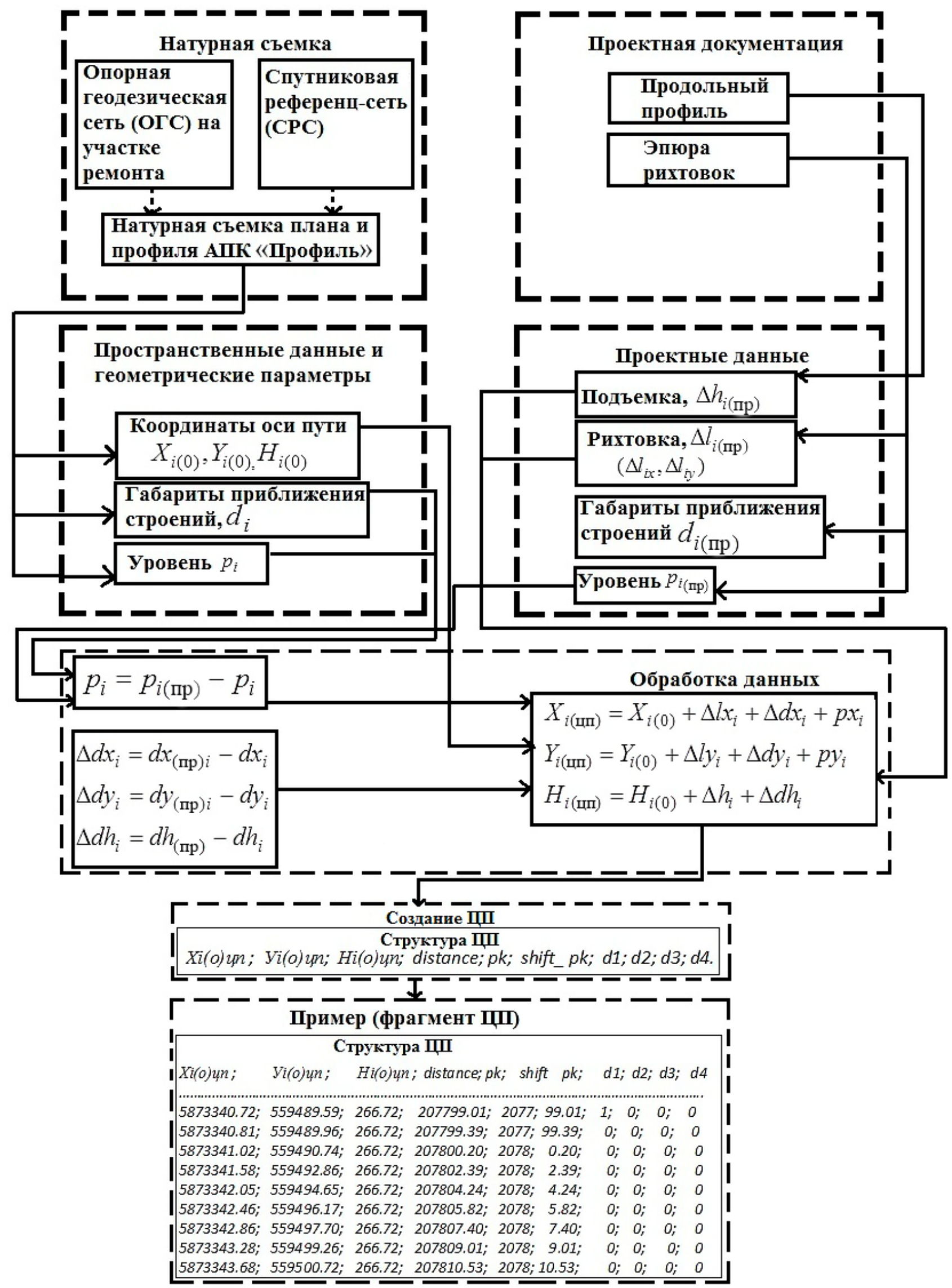

Рис. 1. Структурная схема создания цифровых проектов для САУ-3D 
В качестве опорной геодезической основы используются реперная сеть на участке ремонта (созданная на этапе проектноизыскательских работ) и спутниковая референц-сеть для обеспечения натурной съемки АПК «Профиль» дифференциальными поправками. Данные натурной съемки, координаты оси пути $X, Y, H)$, габариты приближения строений $d$, и уровень (превышение между рельсовыми нитями), $p$ необходимы для цифрового описания железнодорожного пути. Уровень необходим в ЦП для редукции координат фазовых центров спутниковых антенн на головки рельса, при этом по уровню в кривых также определяется базовая (реперная) рельсовая нитка. Габариты приближения строений необходимы для актуализации проектных данных, обусловленных влиянием динамических факторов в промежутке времени от изысканий до строительства. Проектная документация (продольный профиль и эпюра рихтовок) в традиционных форматах необходима для корректировки пространственного положения оси существующего ремонтного пути и получения нового проектного положения оси пути, которое и составляет основу цифрового проекта. Данные проектной документации, величины рихтовки $l_{i}\left(\right.$ пр), подъемки $h_{i}($ пр) и уровня $p$ (пр) в $i$-х точках проекта (см. рис. 1) используются для корректировки координат оси пути в плане и профиле, а также геометрии рельсовой колеи. Таким образом, исходными данными для ЦП являются данные натурной съемки, включая пространственное положение оси пути в системе координат ITRF-2014 (WGS-84) и проектные данные, которые определяют относительные величины в плане и профиле (рихтовка, подъемка и уровень), характеризующие взаимное положение существующего (до ремонта) и проектного пространственного положения пути. Координаты оси пути $X_{(0)}, Y_{(0)}, H_{(0)}$ в системе координат ITRF-2014, являющейся основой работы CAУ-3D, полученные при выполнении натурной съемки, корректируются проектными значениями рихтовки, подъемки - по формулам

$$
\begin{aligned}
& X_{i(0) \text { цп }}=X_{i(0)}+\Delta l x_{i}+\Delta d x_{i}+p x_{i} ; \\
& Y_{i(0) \text { цп }}=Y_{i(0)}+\Delta l y_{i}+\Delta d y_{i}+p y_{i} ; \\
& H_{i(0) \text { цп }}=H_{i(0)}+\Delta h_{i}+\Delta d h_{i},
\end{aligned}
$$

где $X_{i(0) ц п}, Y_{i(0) \text { цा }}, H_{i(0) \text { цा }}-$ проектные координаты оси пути цифрового проекта; $X_{i(0)}$, $Y_{i(0)}, H_{i(0)}$ - координаты оси существующего пути (до ремонта); $\Delta l x_{i}, \Delta l y_{i}$ - составляющие рихтовки по соответствующим координатам; $\Delta h_{i}$ - проектная подъемка; $\Delta d x_{i}$, $\Delta d y_{i}, \Delta d h_{i}-$ составляющие актуализации по соответствующим координатам; $p x_{i}, p y_{i}-$ составляющие редукции по соответствующим координатам.

Значения $\Delta d x_{i}, \Delta d y_{i}, \quad \Delta d h_{i}$ пространственного положения оси пути, обусловленные актуализацией, рассчитываются по разности фактических габаритов приближения строений на момент изысканий и фактических габаритов приближения строений на начало ремонта в заданных сечениях пути, например положение оси пути относительно опор контактной сети (ОКС), по формулам

$$
\begin{aligned}
& \Delta d x_{i}=d x_{(\text {пр) } i}-d x_{i} ; \\
& \Delta d y_{i}=d y_{(\text {пр })}-d y_{i} ; \\
& \Delta d h_{i}=d h_{(\text {пр) }}-d h_{i},
\end{aligned}
$$

где $d x_{i}, d y_{i}, d h_{i}$ - фактические габариты приближения строений; $d x_{(п р) i}, d y_{(\text {пр) } i}, d h_{(\text {пр) }}-$ проектные габариты приближения строений.

Значение $\Delta p_{i}=p_{i(\text { пр) }}-p_{i} \quad$ определяется по разности проектного и фактического значения уровня.

Параметры цифрового проекта для САУ-3D и систем контроля строительной железнодорожной машины включают данные оси пути $X_{i(0) \text { цп, }} Y_{i(0) \text { цп, }} H_{i(0) ц п}$ и параметры, обеспечивающие функциональные возможности на каждом этапе ремонта.

\section{Структура цифрового проекта}

Структура данных цифрового проекта представлена в заголовке ЦП [14]

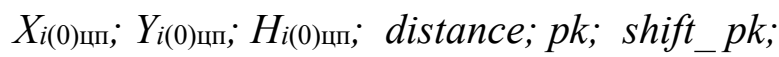
$d 1 ; d 2 ; d 3 ; d 4$. 
Описание структуры:

$X i(0) ц п$ - координата оси пути X; Yi(0)цп - координата оси пути $Y$; Hi(0)цп - высотная отметка оси пути; distance - пикет (в метрах); pk - номер пикета; shift_pk- сдвиг на пикете $(\Pi К+) ; d 1$ - топокод (1 - признак наличия начала пикета, на карте будет отображен символ пикета); $d 2, d 3, d 4$ - служебные поля для параметров контроля.

Фрагмент цифрового проекта на участок ремонта пути для САУ-3D (ЭЛБ-4С) представлен в фрагменте ЦП.

Фрагмент ЦП на участок ремонта:

Xi(0)цп; $\quad Y i(0) ц \Pi ; \quad H i(0) ц \Pi ; \quad$ distance; $p k ; \quad$ shift $\quad p k ; \quad d 1 ; d 2 ; d 3 ; d 4$

$5873340.72 ; 559489.59 ; 266.72 ; 207799.01 ; 2077 ; 99.01 ; \quad 1 ; 0 ; \quad 0 ; \quad 0$

5873340.81; 559489.96; 266.72; 207799.39; 2077; 99.39; $0 ; \quad 0 ; \quad 0 ; \quad 0$

5873341.02; 559490.74; 266.72; 207800.20; 2078; $0.20 ; \quad 0 ; \quad 0 ; \quad 0 ; \quad 0$

5873341.58; 559492.86; 266.72; 207802.39; 2078; 2.39; $0 ; \quad 0 ; \quad 0 ; \quad 0$

$5873342.05 ; \quad 559494.65 ; 266.72 ; 207804.24 ; 2078 ; 4.24 ; \quad 0 ; \quad 0 ; \quad 0 ; \quad 0$

$5873342.46 ; \quad 559496.17 ; \quad 266.72 ; \quad 207805.82 ; \quad 2078 ; \quad 5.82 ; \quad 0 ; \quad 0 ; \quad 0 ; \quad 0$

5873342.86; 559497.70; 266.72; 207807.40; 2078; 7.40; $0 ; \quad 0 ; \quad 0 ; \quad 0$

$5873343.28 ; \quad 559499.26 ; \quad 266.72 ; \quad 207809.01 ; 2078 ; \quad 9.01 ; \quad 0 ; \quad 0 ; \quad 0 ; \quad 0$

$5873343.68 ; \quad 559500.72 ; 266.72 ; 207810.53 ; 2078 ; 10.53 ; \quad 0 ; \quad 0 ; \quad 0 ; \quad 0$

Пример формирования ЦП с использованием традиционной проектной документации приведен на рис. 2.

С использованием проектной традиционной документации (см. рис. 2) формируются базы данных (БД) по следующим проектным параметрам: distance; pk; shift_pk; d1;d2; d3.

Таким образом, реализуются проектные решения в цифровой модели пути с учетом специфики ремонта железнодорожного пути. Точность реализации проектных решений зависит от точности измерения координат приемниками ГНСС, обработки данных (фильтрация и сглаживание), соответствия цифровых данных проектным решениям, расчета сдвижек и подъемок с использованием алгоритмов САУ-3D и отработки перемещений подъемно-рихтовочным устройством (ПРУ) по управляющим сигналам на величину расчетных значений, а также влиянием упругих сил рельсовой плети при ее перемещении в неуплотненном или частично уплотненном балласте. Оценка точности при реализации проектных решений с использованием САУ-3D показала, что отклонения от проектных данных в контрольных сечениях составляют 20 мм [30, 28], что соответствует нормативным требованиям $[13,14]$.

\section{Заключение}

Преимущества разработанной методики создания цифровых проектов для использования САУ-3D при ремонте железнодорожного пути заключаются в обеспечении приемлемой точности реализации проектных решений при ремонте железнодорожного пути и использовании линейными строительными организациями возможности создавать цифровые проекты собственными силами при отсутствии нормативно-технической базы на проектноизыскательские работы по созданию ЦП. Главным достоинством предлагаемой методики является возможность использования тра- 
диционных проектов на ремонт железнодорожного пути при отсутствии единых стандартов для ЦП, так как создание цифровых проектов специализированными проектными организациями ОАО «РЖД» в настоящее время не выполняется из-за отсутствия требований к структуре и форматам данных, а также ограничений, связанных с разработкой и внедрением нормативной базы применения CAУ-3D.
Таким образом, разработанные методика, алгоритмы и программное обеспечение позволяют реализовать проектные решения с использованием САУ-3D с точностью, соответствующей нормативным требованиям, и возможностью создания ЦП в путевых машинных станциях при сохранении качества проектных решений традиционных проектов на ремонт железнодорожного пути.

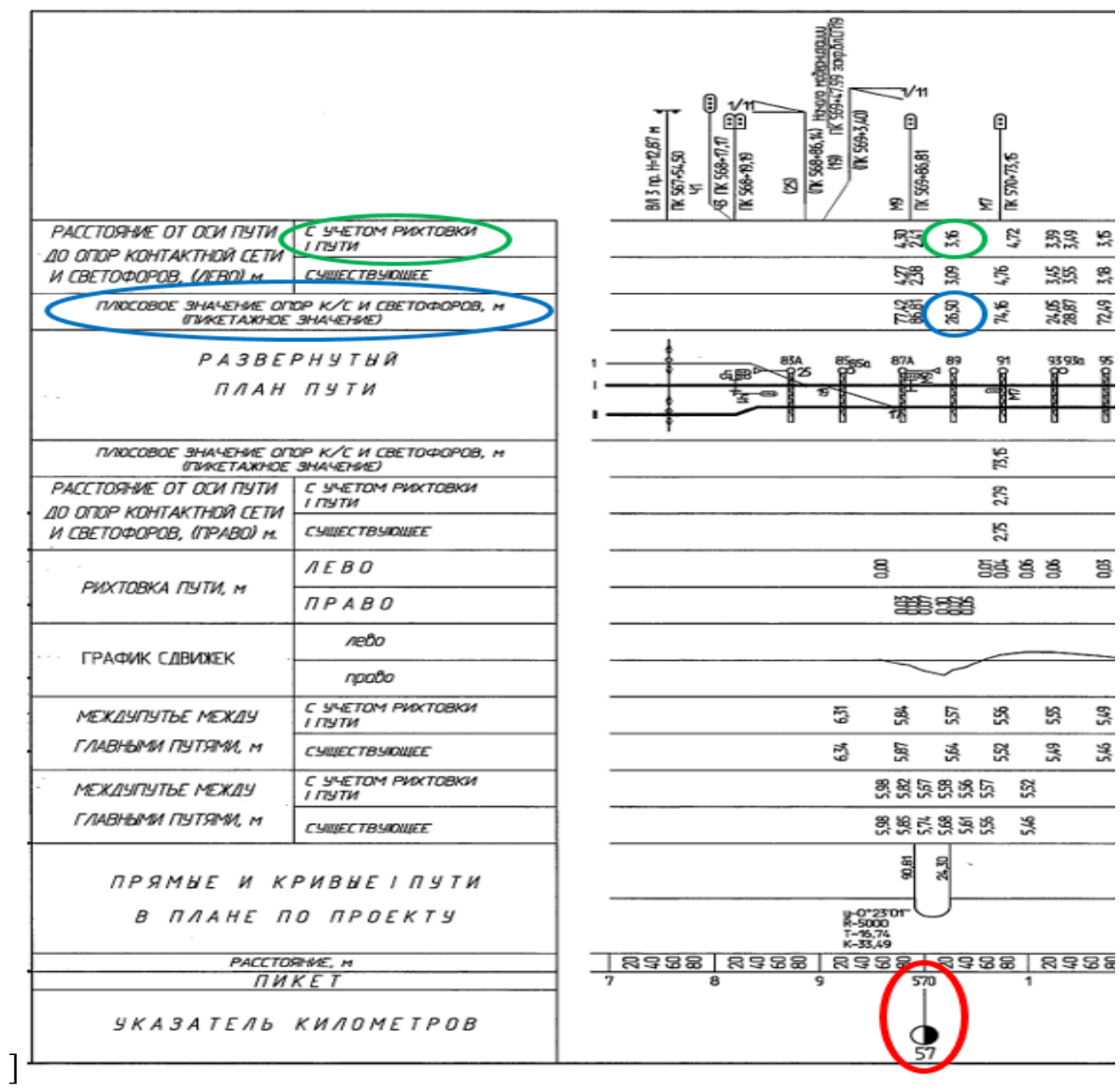

Рис. 2. Фрагмент проектной документации (эпюра рихтовок) формирования исходными данными для создания цифрового проекта: красным цветом выделен пикетаж; синим - ПК+; зеленым - рихтовки

\section{БИБЛИОГРАФИЧЕСКИЙ СПИСОК}

1. Верховых Г. В. Приоритетные задачи инфраструктурного комплекса // Железнодорожный транспорт. - 2020. - № 2. - С. 52-56.

2. Гринчар Н. Г. Современные и перспективные путевые машины легкого типа для очистки рельсошпальной решетки // Путь и путевое хозяйство. - 2019. - № 9. - С. 18-21.
3. Ермаков В. М., Мануйло Д. С. Требования к путевым машинам для реализации цифровых технологий ремонта пути // Железнодорожный транспорт. - 2019. - № 9. - С. 30-33.

4. Эффективность эксплуатации пути в едином координатном пространстве / В. М. Ермаков, О. А. Янович, Т. В. Косарикова, Т. М. Шерокова // 
Путь и путевое хозяйство. - 2019. - № 12. C. $10-12$.

5. Розенберг И. Н., Дулин С. К., Якушев Д. А. Технологии мобильного лазерного сканирования для железнодорожной инфраструктуры // Железнодорожный транспорт. - 2018. - № 8. - С. 32-35.

6. СП 233.1326000.2015. Инфраструктура железнодорожного транспорта. Высокоточная координатная система. - М. : Федеральное агентство по техническому регулированию и метрологии, 2015.

7. Щербаков В. В., Ковалева О. В., Щербаков И. В. Цифровые модели пути - основа геодезического обеспечения проектирования, строительства (ремонта) и эксплуатации железных дорог // Геодезия и картография. - 2016. - № 3. С. $12-16$.

8. Кулижников А. М., Ануфриев А. А., Колесников И. П. Нормативная база для САУ 3D // САПР и ГИС автомобильных дорог. - 2014. № 2. - C. 38-41.

9. Райкова Л. С., Петренко Д. А. Строительство автомобильных дорог на основе 3D-моделей // САПР и ГИС автомобильных дорог. - 2014. № 2 (3). - C. 81-85.

10. Скворцов А. В. Нормативно-техническое обеспечение ВІМ автомобильных дорог // САПР и ГИС автомобильных дорог. - 2014. - № 2. C. 22-32.

11. Topcon Machine Control. 3D systems [Электронный pecypc]. - Режим доступа: http://www.topconpositioning.com/products/machin econtrol $/ 3 \mathrm{~d}$.

12. Trimble Heavy Civil Construction. Machine Control [Электронный pecypc]. - Режим доступа: http://construchion.trimble.com/products/machinecontrol.

13. Об утверждении и введении в действие откорректированной редакции технических условий на работы по реконструкции (модернизации) и ремонту железнодорожного пути : распоряжение ОАО «РЖД» от 18.01.2013 № 75p (21.01.2015) (с изм. от 19.12.2018).

14. Геодезическое обеспечение ремонта (модернизации) железнодорожного пути с применением ГНСС и систем автоматизированного управления на их базе : распоряжение ОАО «РЖД» № 3214 от 31.12.2015.

15. СП 47.13330.2012. Инженерные изыскания для строительства. Основные положения. Актуализированная редакция СНиП 11.02-96 [Электронный ресурс]. - Режим доступа: base.garant.ru.

16. СП 126.13330.2012. Геодезические работы в строительстве. Актуализированная редакция
СНиП 3.01-84 [Электронный ресурс]. - Режим доступа: base.garant.ru.

17. Пат. 187173 Российская Федерация, RU 1МПК Е01В 27|10. Щебнеочистительная машина / В. В. Щербаков, А. И. Пименов, И. А. Бунцев, И. В. Щербаков ; заявитель и патентообладатель ОАО «Сибдорпроект» 2018128963/11 ; заявл. 06.08.2018; опубл. 22.02.2019; Бюл. № 6.

18. Vladimir Shcherbakov, Ivan Buntsev and Olga Kovaleva. Development of a control system for a ballast cleaning machine using GNSS // E3S Web of Conferences, Innovative Technologies in Environmental Science and Education (ITESE-2019). - 2019. Volume 135 (2019). - 02003. - Mode of access: https://doi.org/10.1051/e3sconf/201913502003.

19. Пат. Российской Федерации 2703819, МПК 51 Е01В 27/02. Способ автоматического контроля качества уплотнения балластного слоя рельсового пути и устройство для его осуществления / И. В. Щербаков, А. Л. Манаков, А. В. Воробьевский, А. И. Пименов, К. В. Голубкин, В. В. Щербаков. ; заявитель и патентообладатель СГУПС, ООО «Сибдорпроект» ; заявл. 18.12.2018; опубл. 22.10.2019, Бюл. № 30.

20. Пат. Российская Федерация 2551637, МПК Е01B35/00. Устройство для выправки железнодорожного пути и способ выправки железнодорожного пути / В. В. Щербаков, И. В. Щербаков, А. Н. Модестов, И. А. Бунцев, В. П. Славкин. ; заявитель и патентообладатель Щербаков В. В. ; заявл. 22.07.2013 ; опубл. 27.05.2015. Бюл. № 15.

21. Vladimir Shcherbakov, Alexander Karpik, Marina Barsuk. Automation of Railroad Construction Technology Using Surveying Methods // Advances in Intelligent Systems and Computing, VIII International Scientific Siberian Transport Forum TransSiberia 2019, Volume 2. - 2019. - Volume 1116 (2020). DOI: 10.1007/978-3-030-37919-3.

22. Пат. 116862 Российская Федерация, МПК 51 Е 01 В 35/00 В61К 9/08. Устройство для определения пространственных параметров инфраструктуры железной дороги / В. В. Щербаков, В. Д. Верескун, В. А. Герасимов, А. Н. Модестов, А. С. Тараканов ; заявитель и патентообладатель В. В. Щербаков. - 2011150328/11 ; заявл. 14.06.2011; опубл. 10.06.2012.

23. Щербаков И. В. Аппаратно-программный комплекс «Профиль-М» для определения пространственных и геометрических параметров рельсовой колеи // ВестникСГУГиТ. - 2017. Вып. 3 (22). - С. 45-60.

24. ГОСТ 32453-2017. Глобальная навигационная спутниковая система. Системы координат. Методы преобразования координат определяе- 
мых точек (с поправками). - М. : Стандартинформ, 2017.

25. Алгоритм вычисления геодезической высоты по пространственным прямоугольным координатам / В. Н. Баландин, М. Я. Брынь, С. П. Ишменецкий, А. Ю. Матвеев, А. В. Юськевич // Геодезия и картография. - 2006. - № 6. - С. 15-16.

26. Залуцкий В. Т. Усовершенствование алгоритма преобразований координат при переходе от ГСК в МСК города и обратно // Геодезия и картография. -2017 . - № 9. - С. 2-7.

27. Кашанин Н. В., Сухарев И. И. Исследование точности интерполирования отметок продольного профиля железной дороги различными методами // Вестник СГУГиТ. - 2017. - Вып. 2 (22). C. 36-43.

28. Разработка систем автоматизированного управления выправкой пути на базе ГНСС /
В. В. Щербаков, А. И. Пименов, И. А. Бунцев, И. В. Шербаков, О. В. Ковалева // Транспортное строительство. - 2015. - № 9. - С. 22-25.

29. Проблемы и перспективы развития активных спутниковых геодезических сетей в России и их интеграции в ITRF / В. С. Вдовин, В. В. Дворкин, А. П. Карпик, Л. А. Липатников, С. Д. Сорокин, Г. М. Стеблов // Вестник СГУГиТ. 2018. - Вып. 1 (23). - С. 45-60.

30. Комягин С. А. Оценка точности постановки пути в проектное положение с использованием САУ-3D // Интерэкспо ГЕО-Сибирь. XV Междунар. науч. конгр., 24-26 апреля 2019 г., Новосибирск : сб. материалов в 9 т. Т. 1 : Междунар. науч. конф. «Геодезия, геоинформатика, картография, маркшейдерия». - Новосибирск : СГУГиТ, 2019. - Т. 1. - С. 119-129.

Получено 15.05.2020

(C) В. В. Щербаков, 2020

\section{METHOD OF CREATING DIGITAL PROJECTS FOR AUTOMATED CONTROL SYSTEMS OF CONSTRUCTION RAILWAY ENGINEERING}

\section{Vladimir V. Shcherbakov}

Siberian Transport University, 191, Dusi Kovalchuk St., Novosibirsk, 630049, Russia, Ph. D., Associate Professor, Head of the Department of Engineering geodesy, phone: (913)912-86-91, e-mail: vvs@stu.ru

The article describes the methods of creating digital projects for automated control systems, the specifics of creating digital projects and the difference between methodological solutions for railways. The advantages of the developed methodology for digitizing the path with respect to the conversion of design coordinates from the MSC to a new coordinate system to ensure the operation of SAU-3D are shown. The block diagram of creating a digital project based on the digitization of the path using the hardware-software complex "Profile" and design geometric parameters. Examples of using traditional project documentation to obtain initial design data for creating digital projects are shown.

Key words: methodology for creating digital projects, coordinate systems, automated control systems, engineering and geodetic support for railroad repairs.

\section{REFERENCES}

1. Verkhovykh, G. V. (2020). Priority tasks of the infrastructure complex. Zheleznodo-rozhnyy transport [Railway Transport], 2, 52-56 [in Russian].

2. Grinchar, N. G. (2019). Modern and promising lightweight track machines for cleaning the railsleeper grid. Put' $i$ putevoe khozyaystvo [Path and Track Facilitie], 9, 18-21 [in Russian].

3. Ermakov, V. M., \& Manuylo, D. S. (2019). Trebovaniya $\mathrm{k}$ putevym mashinam dlya realizatsii tsifrovykh tekhnologiy remonta puti. Zheleznodorozh- nyy transport [Railway Transport], 9, 30-33 [in Russian].

4. Ermakov, V. M., Yanovich, O. A., Kosarikova, T. V., \& Sherokova, T. M. (2019). The efficiency of the operation of the path in a single coordinate space. Put' i putevoe khozyaystvo [Path and Track Facilitie], 12, 10-12 [in Russian].

5. Rosenberg, I. N., Dulin, S. K., \& Yakushev, D. A. (2018). Mobile laser scanning technologies for railway infrastructure. Zheleznodorozhnyy transport [Railway Transport], 8, 32-35 [in Russian]. 
6. Code of Practice 233.1326000.2015. (2015). Railway infrastructure High precision coordinate system. Moscow: Federal Agency for Technical Regulation and Metrolog Publ. [in Russian].

7. Shcherbakov, V. V., Kovaleva, O. V., \& Shcherbakov, I. V. (2016). Digital track models - the basis of geodetic support for the design, construction (repair) and operation of railways. Geodeziya i kartografiya [Geodesy and Cartography], 3, 12-16 [in Russian].

8. Kulizhnikov, A. M., Anufriev, A. A., \& Kolesnikov, I. P. (2014). The regulatory framework for selfpropelled guns 3D. SAPR i GIS avtomobil'nykh dorog [CAD and GIS for Roads], 2, 38-41 [in Russian].

9. Raikova, L. S., \& Petrenko, D. A. (2014). Construction of roads based on 3D-models. SAPR $i$ GIS avtomobil'nykh dorog [CAD and GIS for Roads], 2(3), 81-85 [in Russian].

10. Skvortsov, A. V. (2014). Regulatory and technical support of BIM roads. SAPR $i$ GIS avtomobil'nykh dorog [CAD and GIS for Roads], 2, 22-32 [in Russian].

11. Topcon Machine Control. 3D systems. (n. d.). Retrieved from http://www.topconpositioning.com/ products/machinecontrol $/ 3 \mathrm{~d}$.

12. Trimble Heavy Civil Construction. Machine Control. (n. d.). Retrieved from http://construchion. trimble.com/products/machine-control.

13. Order of Russian Railways of January 18, 2013 No. 75r (January 21, 2015) (as amended on December 19, 2018). On approval and implementation of the revised edition of the technical specifications for reconstruction (modernization) and repair of the railway track. Retrieved from ConsultantPlus online database [in Russian].

14. Order of Russian Railways No. 3214 of Desember 31, 2015.Geodetic support for repair (modernization) of the railway using GNSS and automated control systems based on them. Retrieved from ConsultantPlus online database [in Russian].

15. Code of Practice 47.13330.2012. Engineering surveys for construction. The main provisions. Updated edition of SNiP 11.02-96. Retrieved from Garant online database [in Russian].

16. Code of Practice 126.13330.2012. Geodetic works in construction. Updated edition of SNiP 3.01-84. Retrieved from Garant online database [in Russian].

17. Shcherbakov, V. V., Pimenov, A. I., Buntsev I. A., \& Shcherbakov I. V. (2019). Patent 187173 Russian Federation. Gravel cleaning machine [in Russian].

18. Shcherbakov, V., Buntsev, I., \& Kovaleva, O. (2019). Development of a control system for a ballast cleaning machine using GNSS. E3S Web of Conferences, Innovative Technologies in Environmental Science and Education (ITESE-2019), 135(2019), 02003. Retrieved from https://doi.org/10.1051/e3sconf/201913502003.

19. Shcherbakov, I. V., Manakov, A. L., Vorobevsky, A. V., Pimenov, A. I., Golubkin, K. V., \& Shcherbakov, V. V. (2019). Patent Russian Federation 2703819. The method of automatic quality control of the compaction of the ballast layer of the rail track and a device for its implementation [in Russian].

20. Shcherbakov, V. V., Shcherbakov, I. V., Modestov, A. N., Buntsev, I. A., \& Slavkin, V. P. (2015). Patent Russian Federation 2551637. A device for straightening a railway track and a method for straightening a railway track [in Russian].

21. Shcherbakov, V., Karpik, A., \& Barsuk, M. (2019). Automation of Railroad Construction Technology Using Surveying Methods. Advances in Intelligent Systems and Computing, VIII International Scientific Siberian Transport Forum TransSiberia 2019, 1116(2020). doi: 10.1007/978-3-030-37919-3.

22. Shcherbakov, V. V., Vereskun, V. D., Gerasimov, V. A., Modestov, A. N., \& Tarakanov, A. S. (2012). Patent 116862 Russian Federation. A device for determining the spatial parameters of the railway infrastructure [in Russian].

23. Shcherbakov, I. V. (2017). Profile-M Hardware and Software Suite for Determining the Spatial and Geometric Parameters of the Track Gauge. Vestnik SGUGiT [Vestnik SSUGT], 22(3), 45-60 [in Russian].

24. Standards Russian Federation. (2017). GOST 32453-2017. Global Navigation Satellite System. Coordinate systems. Methods for transforming coordinates of defined points. Moscow: Standartinform Publ. [in Russian].

25. Balandin, V. N., Bryn', M. Ya., Ishmenetskiy, S. P., Matveev, A. Yu., \& Yus'kevich, A. V. (2006). Algorithm for calculating the geodetic height of spatial rectangular coordinates. Geodeziya i kartografiya [Geodesy and Cartography], 6, 15-16 [in Russian].

26. Zalutsky, V. T. (2017). Improvement of the coordinate transformation algorithm during the transition from the GSK to the MSC of the city and vice versa. Geodeziya i kartografiya [Geodesy and Cartography], 9, 2-7 [in Russian].

27. Kanashin, N. V., \& Sukharev, I. I. (2017). Investigation of the accuracy of marks interpolation of the railway longitudinal profile by different methods. Vestnik SGUGiT [Vestnik SSUGT], 22(2), 3643 [in Russian].

28. Shcherbakov, V. V., Pimenov, A. I., Buntsev, I. A., Sherbakov, I. V., \& Kovaleva, O. V. 
(2015). Development of automated track straightening control systems based on GNSS. Transportnoe stroitel'stvo [Transport Construction], 9, 22-25 [in Russian].

29. Vdovin, V. S., Dvorkin, V. V., Karpik, A. P., Lipatnikov, L. A., Sorokin, S. D., \& Steblov, G. M. (2018). Current state and future development of active satellite geodetic networks in Russia and their integration into ITRF. Vestnik SGUGiT [Vestnik SSUGT], 23(1), 45-60 [in Russian].

Received 15.05.2020
30. Komyagin, S. A. (2019). Evaluation of the accuracy of statement of the way to the project status with ACS-3D. In Sbornik materialov Interekspo GEO-Sibir'-2019: Mezhdunarodnoy nauchnoy konferentsii: T. 1, No. 1. Geodeziya, geoinformatika, kartografiya, marksheyderiya [Proceedings of Interexpo GEO-Siberia-2019: International Scientific Conference: Vol. 1, No. 1 [Geodesy, Geoinformatics, Cartography, Mine Surveying] (pp. 119-129). Novosibirsk: SSUGT Publ. [in Russian].

(C) V.V. Shcherbakov, 2020 


\title{
ДИСТАНЦИОННОЕ ЗОНДИРОВАНИЕ ЗЕМЛИ, ФОТОГРАММЕТРИЯ
}

\author{
УДК 504(571.645) \\ DOI: $10.33764 / 2411-1759-2020-25-3-139-150$
}

\section{АНАЛИЗ ИЗМЕНЕНИЙ СОСТОЯНИЯ ЭКОСИСТЕМ НА ОСТРОВЕ АТЛАСОВА (КУРИЛЬСКИЕ ОСТРОВА)}

\section{Алексей Александрович Верхотуров}

Институт морской геологии и геофизики Дальневосточного отделения Российской академии наук, 693022, Россия, г. Южно-Сахалинск, Россия, ул. Науки, 1Б, кандидат технических наук, старший научный сотрудник Центра коллективного пользования, e-mail: ussr-91@mail.ru

Территория Курильских островов представляет собой цепь вулканических построек и подвержена, в определенной степени, вулканоопасности. Остров Атласова сложен продуктами деятельности вулкана Алаид, для которого характерна эффузивно-эксплозивная деятельность. В статье приводится анализ изменений состояния экосистем острова Атласова, которые периодически подвергаются воздействию при активизации деятельности вулкана Алаид. При эксплозивных извержениях на поверхность выносится большое количество пирокластического материала: глыбы, бомбы, тефра, лапилли и вулканический пепел, который переносится в атмосфере на очень большие расстояния. Экосистемы подвергаются воздействию при выпадении пирокластики на значительной площади островной суши. В настоящем исследовании была поставлена цель по выявлению на основе многозональных космических снимков среднего разрешения характера и масштабов изменений состояния экосистем, подвергавшихся воздействию вулканических извержений. Анализ данных, полученных с космических систем Landsat и Sentinel за период с 1972 по 2020 г., в геоинформационной среде позволил проследить динамику и характер сукцессий на пораженной территории по рассчитанным значениям вегетационного индекса NDVI. Методики, выработанные в процессе изучения данного вопроса, могут в дальнейшем способствовать оперативной оценке последствий для экосистем при мониторинге эффузивно-эксплозивных извержений и прогнозе вулканоопасности для территорий, прилегающих к вулканическим постройкам.

Ключевые слова: вегетационный индекс, вулканические эксплозии, дистанционное зондирование Земли, Landsat, многозональные космические снимки, мониторинг, спектральные характеристики, Sentinel, экосистема.

\section{Введение}

Вся геохимическая эволюция внешней оболочки Земли - не что иное, как трансформирование вулканических продуктов, вынесенных в разное время из ее недр. За 4,5 млрд лет, начиная с первых стадий формирования планеты, на поверхность вынесено столько вещества, что его можно было бы разместить ровным слоем мощностью 35-40 км. В XX в. только на суше из- вержено столько твердых вулканических продуктов, что вес их выбросов составил примерно 1,5 млрд т / год. Объем излияний в срединно-океанических хребтах в несколько раз больше этой величины [1].

Характер извержений зависит от приуроченности вулканического аппарата к разломным зонам в земной коре. Выделяют два типа вулканов: мантийные, приуроченные к узлам пересечения островной дуги поперечными глубинными разломами (Алаид, 
Эбеко, Тятя), и коровые, расположенные вне зоны поперечных разломов, с разноглубинными очагами, включая приповерхностные периферические очаги [2-4]. Извержения первых проходят в виде эффузий лавовых потоков, которые перемежаются эксплозивной деятельностью умеренного характера (стромболианского или умеренно плинианского типа). Подобные извержения хорошо изучены [5-8].

Твердые продукты извержений вулкана Алаид представлены породами основного химического состава - базальтами и андезито-базальтами [9]. При эксплозиях вулкан выбрасывает на поверхность большое количество вулканокластических пород. Эксплозивные выбросы вулканов нередко приводят к катастрофическим последствиям для эко- систем, значительному материальному ущербу и человеческим жертвам.

В исследовании ставилась цель - выявить характер и масштабы изменений состояния экосистем, подвергавшихся воздействию извержений вулкана Алаид, на основе использования многозональных космических снимков среднего разрешения (рис. 1). При достижении поставленной цели решался ряд задач, а именно подбор качественных многозональных космических снимков, выработка алгоритма обработки и подготовки материалов, выделение численных выражений естественных границ, соответствующих различному состоянию экосистем, и проведение пространственновременного анализа изменений NDVI на острове Атласова.

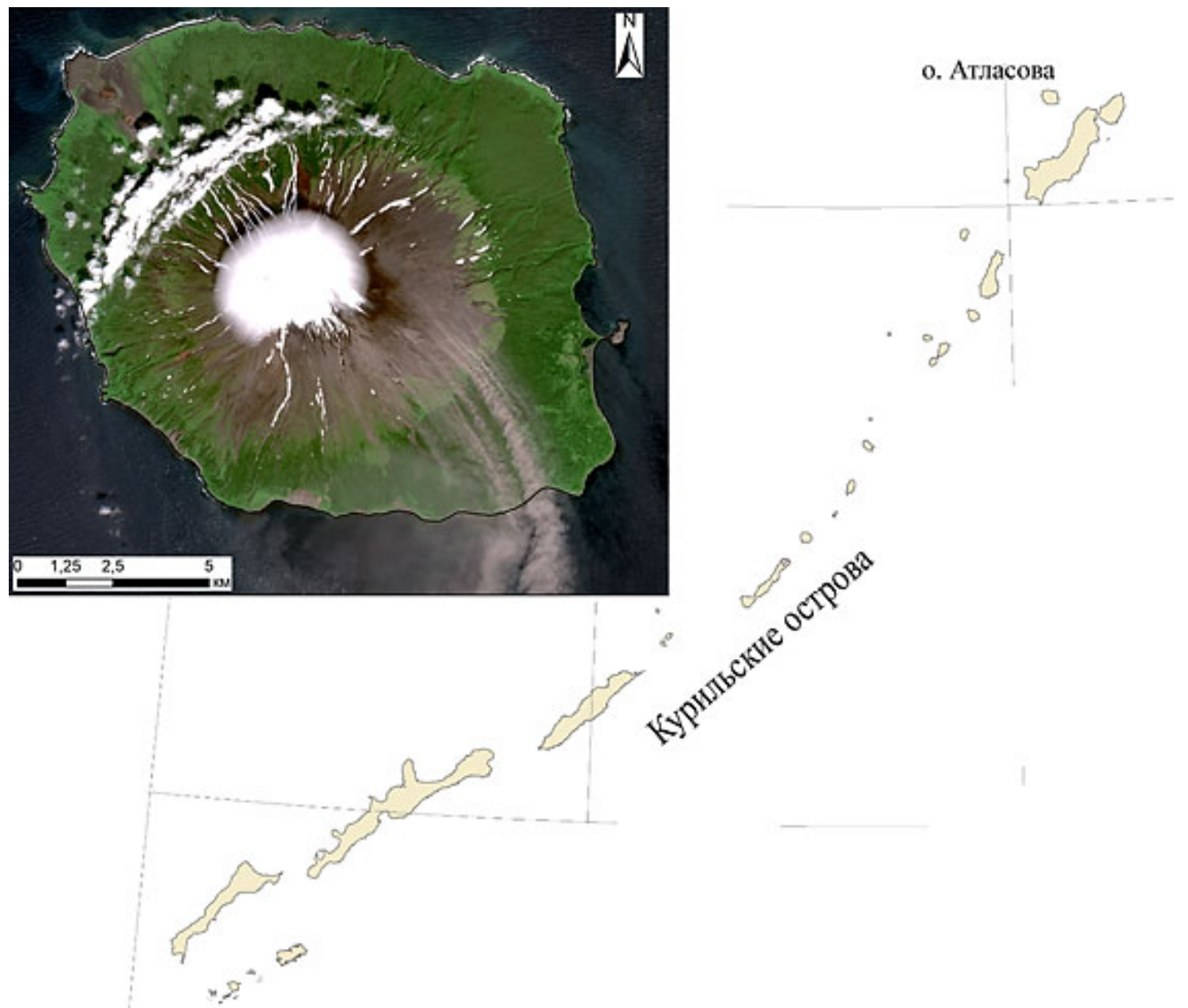

Рис. 1. Местоположение о. Атласова в Большой Курильской гряде

(извержение 21.08.2018) 


\section{Материалы и методы исследования}

Основными материалами для проведения исследования являлись доступные космические снимки среднего пространственного разрешения систем Landsat 1-8 и Sentinel-2 в период с 1972 по 2020 г. [10, 11]. Выбор снимков определялся следующими критериями:

- момент съемки должен быть в вегетационный период (июль - сентябрь);

- отсутствие или незначительное покрытие интересующей области облаками.

Современные геоинформационные системы (QGIS, ArcGIS) обладают широким функционалом для подготовки, обработки растров, векторизации и подсчета пространственноколичественных показателей [12-17]. В данном исследовании предлагается следующий алгоритм подготовки материалов для последующего анализа воздействия вулканических извержений на экосистемы территории (рис. 2).
В качестве оценочного средства состояния экосистем в течение нескольких десятилетий, находящихся под воздействием периодических вулканических извержений, применялся нормализованный относительный вегетационный индекс (NDVI) [18-20]:

$$
\mathrm{NDVI}=\left(\frac{\rho_{N I R}-\rho_{R E D}}{\rho_{N I R}+\rho_{R E D}}\right),
$$

где $\rho_{N I R}$ - отражение в ближней инфракрасной области спектра;

$\rho_{R E D}$ - отражение в красной области спектра.

В исследовании были использованы космические снимки с различных космических аппаратов, отличающихся техническими характеристиками, в том числе набором и порядковым номером каналов, необходимых для произведения расчетов в ГИС растровых изображений NDVI (табл. 1).

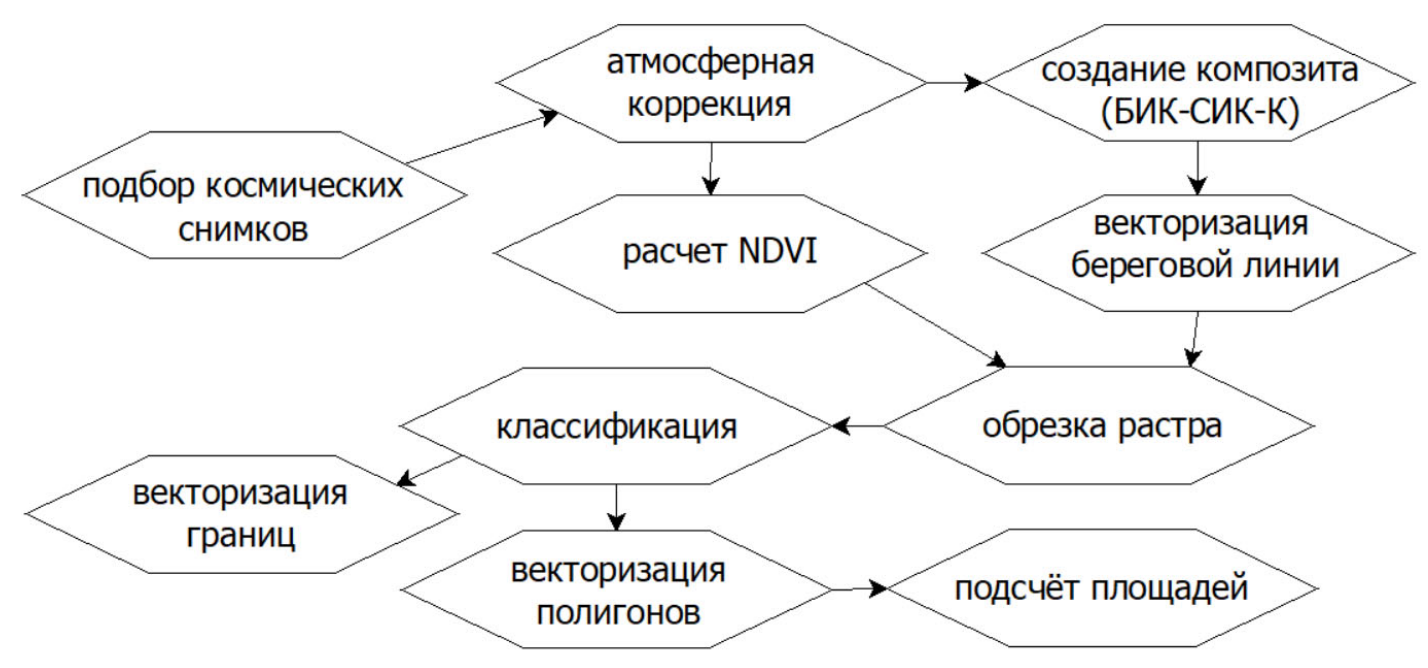

Рис. 2. Алгоритм подготовки материалов для последующего анализа

Таблийа 1

Используемые для расчета NDVI каналы

\begin{tabular}{|c|c|c|c|c|}
\hline \multirow{3}{*}{ Область спектра } & \multicolumn{4}{|c|}{ Спутник / Сенсор / Пространственное разрешение, м } \\
\cline { 2 - 5 } & $\begin{array}{c}\text { Landsat 1 } \\
\text { / MSS / 80 }\end{array}$ & $\begin{array}{c}\text { Landsat 4 } \\
\text { / MSS / 80 }\end{array}$ & $\begin{array}{c}\text { Landsat 7 } \\
\text { / ETM+ / 30 }\end{array}$ & $\begin{array}{c}\text { Sentinel-2 } \\
\text { / MSI / 10 }\end{array}$ \\
\cline { 2 - 5 } & \multicolumn{4}{|c|}{ № канала / спектральный диапазон, нм } \\
\hline красная & $5 / 600-700$ & $2 / 600-700$ & $3 / 630-690$ & $4 / 704$ \\
\hline ближняя ИК & $7 / 800-1100$ & $4 / 800-1100$ & $4 / 770-900$ & $8 / 842$ \\
\hline
\end{tabular}


Изучаемая территория имеет островное положение и обладает благоприятными условиями для повсеместного развития на мелководье морских водорослей, у которых показатель NDVI может достигать 0,7. По этой причине невозможно достоверно определить береговую линию, используя вегетационный индекс, который обычно уверенно выделяет водную поверхность по отрицательным значениям. В связи с этим, для решения задачи разграничения водной поверхности и суши был использован композитный снимок из ближнего, среднего инфракрасного и красного каналов (рис. 3, г). На основе полученного изображения был создан векторный слой береговой линии, основная роль которого заключалась в обрезке растров в контуре острова. Выполнение этих действий позволило ускорить дальнейшие операции с данными в среде ГИС.

Для площадной оценки районов с различными значениями NDVI производилась обучаемая классификация с последующей векторизацией полигонов (рис. 3, $a-8$ ).

\section{Результаты}

Вулкан Алаид имеет самую высокую постройку (2 339 м) и является одним из самых активных на Курильских островах [21]. За последнее столетие на вулкане зафиксировано 12 извержений эксплозивно-эффузивного типа [9].

Наиболее мощными проявлениями его деятельности, которые заключались в существенной перестройке рельефа, береговой линии и привели к гибельным последствиям для экосистем, выступили три достаточно хорошо описанные в научной литературе извержения: трещинные, произошедшие в нижней части конуса вулкана, - прорыв Такетоми у восточного берега (1933-1934 гг.) и прорыв Олимпийский в северо-западной части острова (1972 г.), а также вершинное извержение 1981 г., которое отличалось мощными эруптивными выбросами, сформировавшими пепловые тучи.

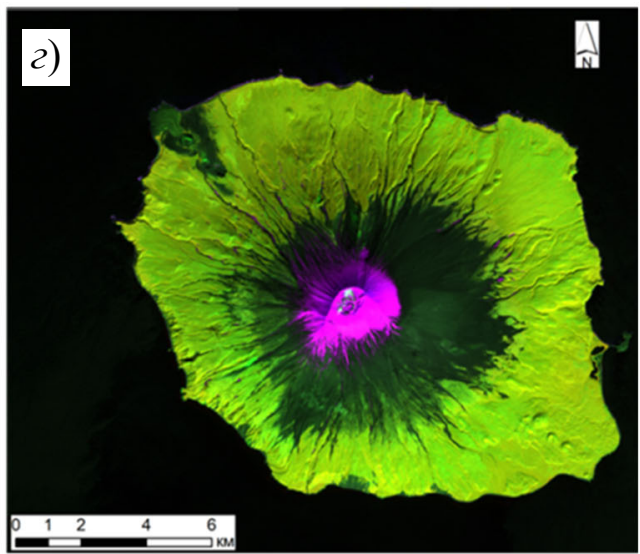

б)
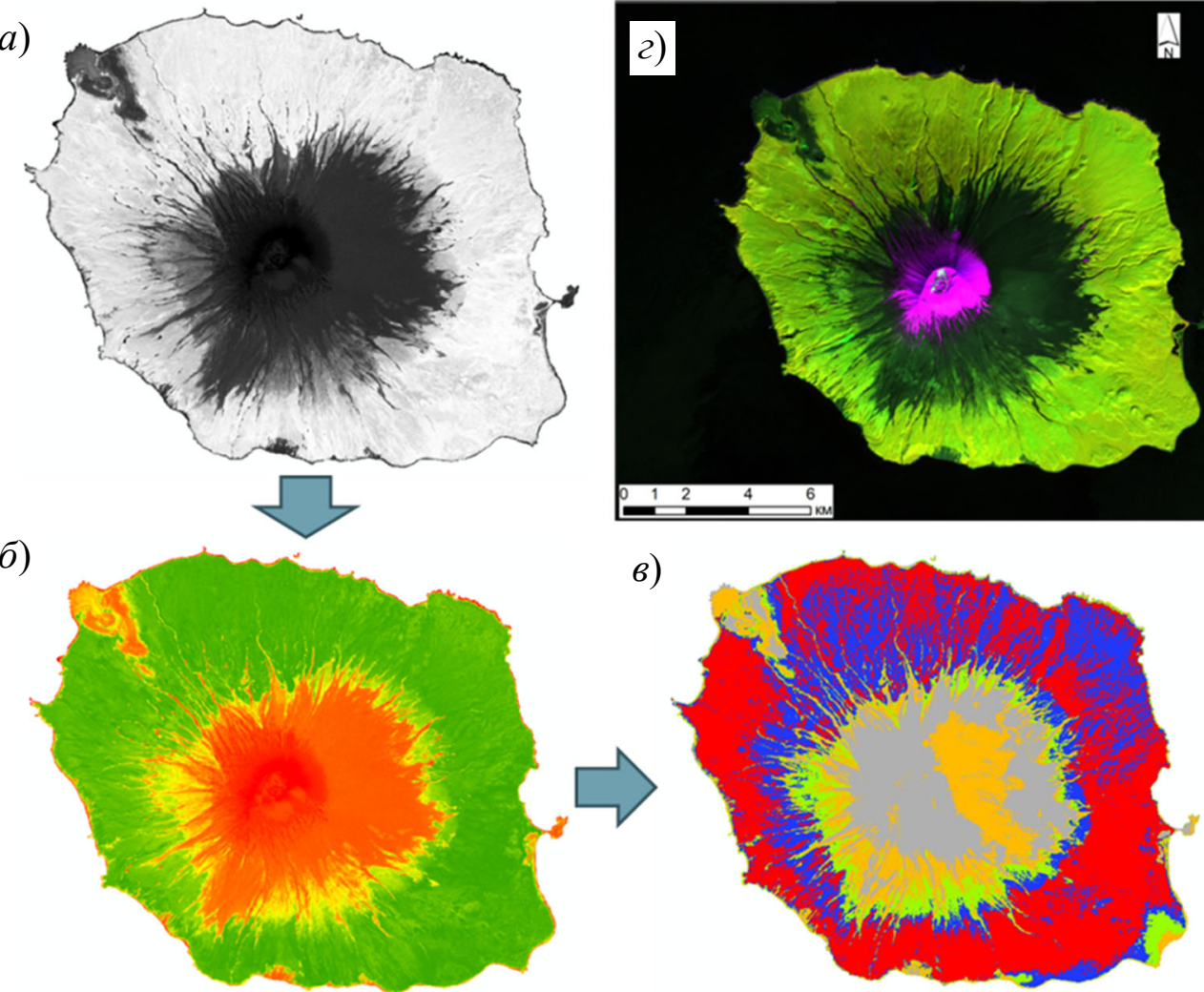

Рис. 3. Стадии подготовки материала:

a) рассчитанное изображение NDVI в оттенках серого; б) изображение NDVI в краснозеленой гамме; в) классифицированное изображение; г) композитный снимок (8-11-4) 
Наиболее изученным является извержение Олимпийского прорыва в 1972 г. Вязкие базальтовые лавовые потоки излились из побочных кратеров, образовавшихся вдоль трещины северо-западного направления на конусе вулкана порциями, натекшими одна на другую. В результате неоднократного перекрытия отдельных порций лавовые потоки сформировали покров мощностью 35-60 м и длиной около 1 км, где монолитная лава переслаивается с глыбовой, в которой отмечены глыбы размерами от 0,1 до 1,5 м [22].

Лавовые потоки, излившиеся из конусов, образовали новый полуостров, на котором, естественно, не было никакой растительности. Для первичной сукцессии на лавовых полях требуется длительный период. Согласно данным С. Ю. Гришина этот период может составлять 1,5-2 тыс. лет [23].

Извержения магматического материала основного состава почти всегда происходят с эксплозивными выбросами шлаков, разнообразных бомб и глыб. Тефровые отложения Олимпийского прорыва представлены ювенильным пирокластическим материалом автохтонного происхождения. Тефра по мере удаления от кратера дифференцируется по крупности, удельной массе и агрегатному состоянию. Различают отложения трех зон: 1) прикратерной, 2) промежуточной, 3) удаленной [7].

Тефра выбрасывалась во всех направлениях, но основной ее объем накрыл северовосточный сектор на расстояние до 5 км. Общий объем изверженных вулканитов составил около 150 млн м ${ }^{3}$, в том числе 100 млн м ${ }^{3}$ представлено пирокластикой [15]. В результате бомбардировки тефрой была поражена растительность на значительной территории, в частности вызвана гибель ольховника, у которого была сбита листва, ободраны почки и кора. На удаленных территориях механические повреждения нанесли меньший урон, однако повреждение листьев и запыление фотосинтетического аппарата отрицательно повлияли на жизненность растений. Цементирование моросью и туманами тонкого пепла на листве и ветвях приводило к их обламыванию. Негативно действовало химическое отравление водорастворимыми веществами и кислотными дождями [24].

Для работы были подобраны космические снимки, имеющиеся в архиве USGS, удовлетворяющие критериям, указанным ранее, и пригодные для фиксирования изменений состояния экосистем исследуемой территории с временным интервалом (7-17 лет). Выполнен анализ 5 сцен. Для обеспечения большей корректности сравнения в степени сезонного развития фитомассы, снимки выбирались с близкими датами съемки (конец августа - начало сентября). Исключением является снимок от 27.07.1983, выбранный по причине отсутствия лучшего варианта в этот временной интервал.

В связи с тем, что с июня 2003 г. ряды данных Landsat-7 пополнялись с пробелами, сцена за 2007 г. была скомбинирована со сценой за 2006 г. Благодаря этому удалось избежать значительного искажения показаний NDVI из-за отсутствия данных. В ходе проведения исследований пришлось столкнуться с еще одной существенной проблемой - малым количеством снимков, на которых отсутствует облачность на всей территории острова, поэтому приходилось комбинировать снимки с близкими датами съемки.

После проведения атмосферной коррекции и расчета NDVI в геоинформационной среде был получен временной ряд карт-схем, отражающих состояние и развитие растительного покрова (рис. 4).

Проведенный пространственно-временной анализ изменений вегетационного индекса по территории острова позволил выделить численные выражения естественных границ, соответствующих различному состоянию экосистем.

Каждая NDVI сцена была расклассифицирована на пять категорий по значению индекса и переведена в векторный формат для подсчета площади полигонов на весь остров и отдельно на район Олимпийского прорыва (табл. 2, 3). 

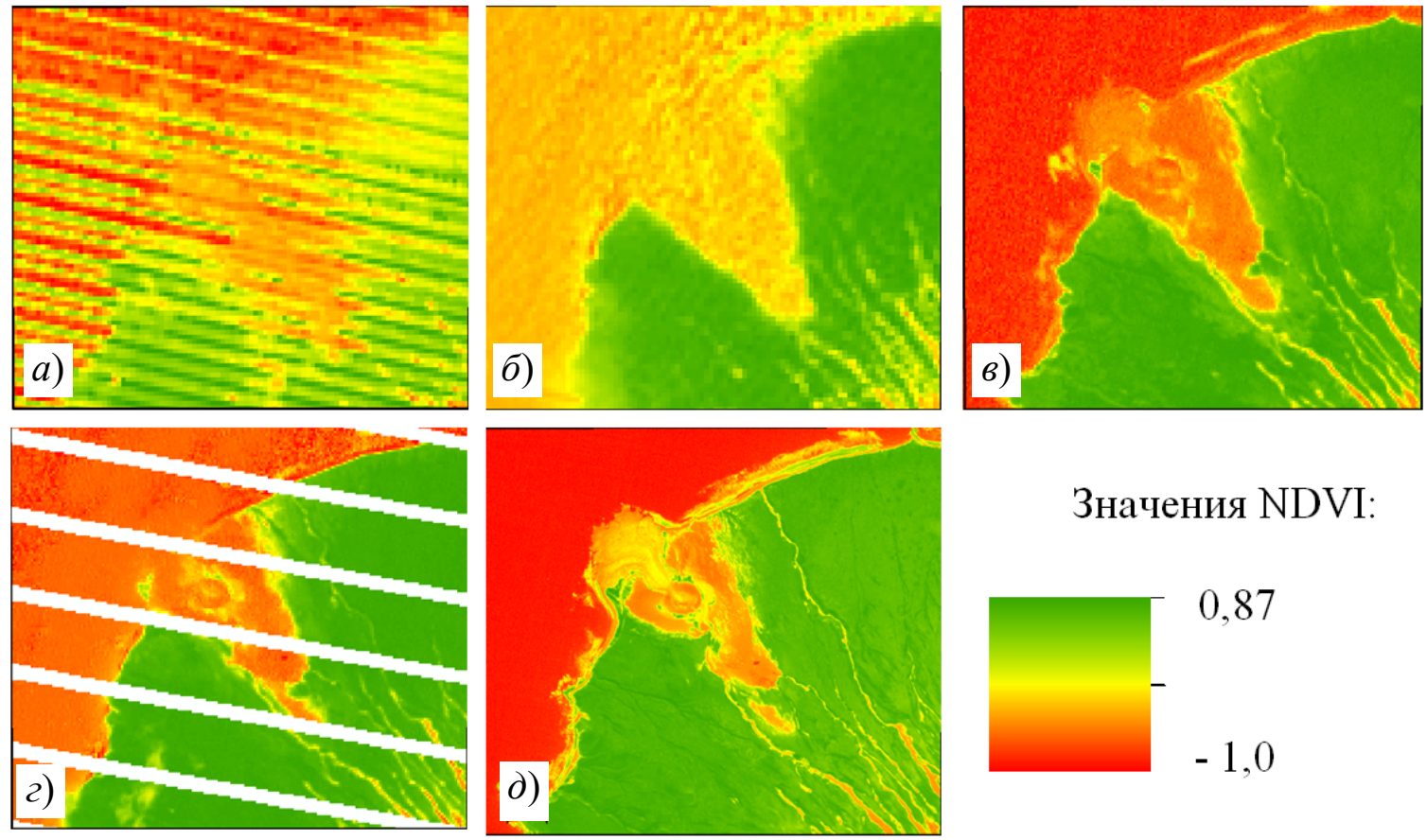

Значения NDVI:

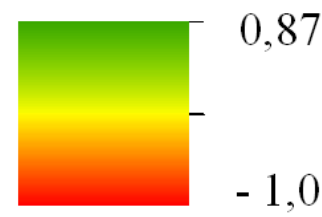

Рис. 4. Результаты расчета NDVI на пораженной территории на примере Олимпийского прорыва:

а) 1972 г.; б) 1983 г.; в) 2001 г.; г) 2007 г.; д) 2018 г.

Суммарные площади полигонов с различными значениями NDVI

Таблиия 2

по годам на о. Атласова, га

\begin{tabular}{|l|c|c|c|c|c|}
\hline \multirow{2}{*}{$\begin{array}{c}\text { Значение NDVI } \\
\text { (соответствие } \\
\text { природным объектам) }\end{array}$} & 08.09 .1972 & 27.07 .1983 & 14.09 .2001 & $\begin{array}{c}27.08 .2006 / \\
07.08 .2007\end{array}$ & 10.09 .2018 \\
\hline$<0$ (скальные породы) & 2710,21 & 2570,68 & 3377,21 & 2721,51 & 695,93 \\
\hline $0-0,1$ (рыхлые породы) & 1092,12 & 2384,39 & 1073,36 & 904,09 & 2857,54 \\
\hline $\begin{array}{l}0,1-0,4 \text { (слабый растительный } \\
\text { покров) }\end{array}$ & 2341,42 & 1649,16 & 1595,27 & 1641,71 & 1832,52 \\
\hline $\begin{array}{l}0,4-0,65 \text { (средний растительный } \\
\text { покров) }\end{array}$ & 5262,78 & 2927,93 & 4887,11 & 1880,11 & 1769,04 \\
\hline $\begin{array}{l}>0,65 \text { (густой растительный } \\
\text { покров) }\end{array}$ & 3941,68 & 5816,05 & 4415,26 & 8200,79 & 8193,18 \\
\hline
\end{tabular}

Суммарные площади полигонов с различными значениями NDVI

Таблица 3

по годам на Олимпийском прорыве, га

\begin{tabular}{|l|c|c|c|c|c|}
\hline \multirow{2}{*}{$\begin{array}{c}\text { Значение NDVI } \\
\text { (соответствие природным объ- } \\
\text { ектам) }\end{array}$} & \multicolumn{5}{|c|}{ Дата съемки } \\
\cline { 2 - 6 } & 08.09 .1972 & 27.07 .1983 & 14.09 .2001 & $\begin{array}{c}27.08 .2006 / \\
07.08 .2007\end{array}$ & 10.09 .2018 \\
\hline$<0$ (скальные породы) & 671,61 & 292,08 & 190,8 & 129,41 & 109,15 \\
\hline $0-0,1$ (рыхлые породы) & 191,67 & 250,32 & 163,17 & 138,07 & 113,35 \\
\hline $\begin{array}{l}0,1-0,4 \text { (слабый растительный } \\
\text { покров) }\end{array}$ & 445,59 & 200,64 & 188,82 & 181,32 & 350,04 \\
\hline $\begin{array}{l}0,4-0,65 \text { (средний растительный } \\
\text { покров) }\end{array}$ & 468,28 & 358,65 & 600,12 & 235,97 & 163,07 \\
\hline $\begin{array}{l}>0,65 \text { (густой растительный } \\
\text { покров) }\end{array}$ & 218,44 & 893,9 & 852,68 & 1310,82 & 1259,98 \\
\hline
\end{tabular}




\section{Обсуждение}

Полученные результаты пространственно-временного анализа указывают на закономерную реакцию экосистем на последствия эффузивных и эксплозивных извержений, заключающуюся в непрерывном восстановлении растительного покрова (рис. 5). За границу, разделяющую районы с нарушенным и сплошным растительным покровом, принято значение NDVI, равное 0,4.

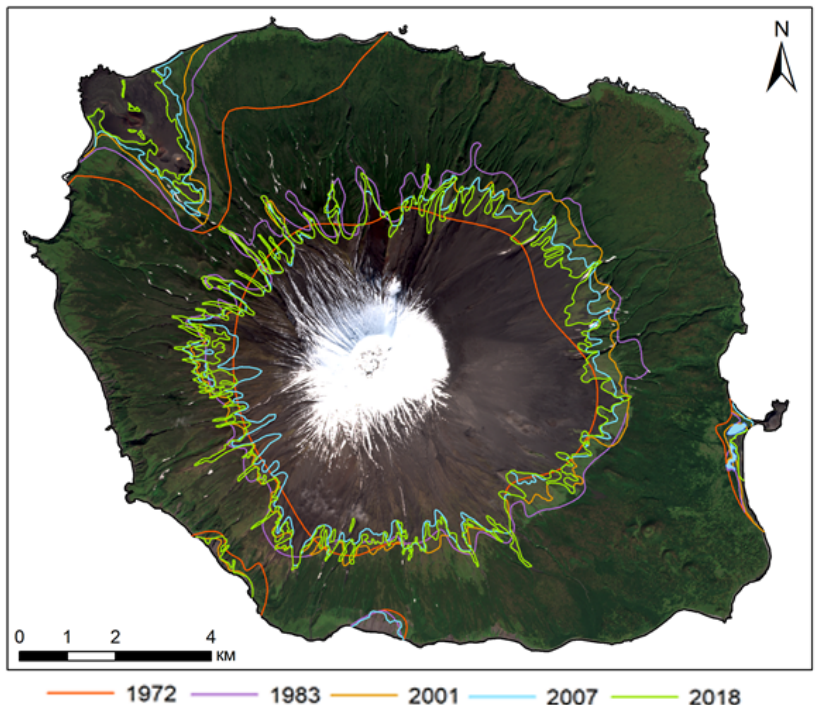

Рис. 5. Границы со значением NDVI $=0,4$ по данным космической съемки в различные годы

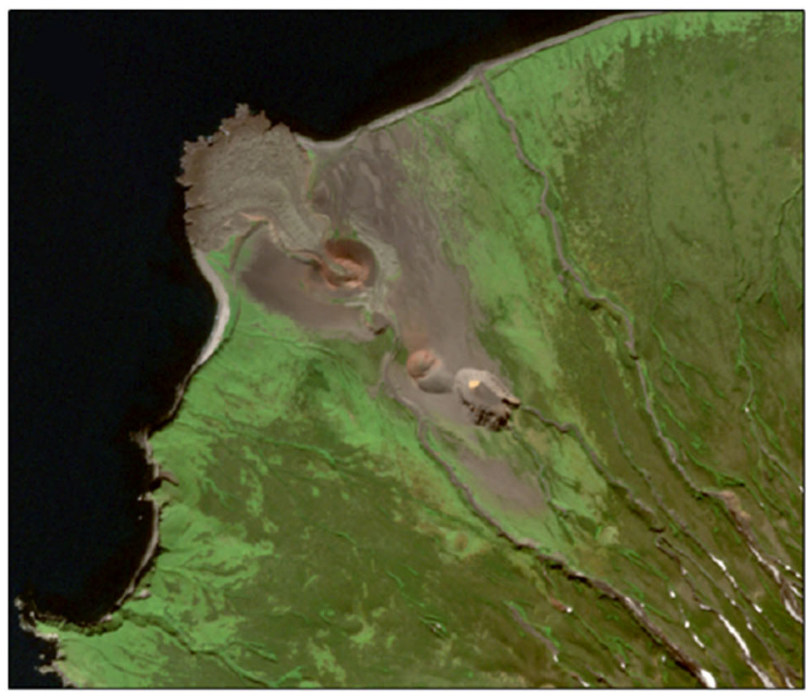

Ввиду отсутствия материалов, масштабы первоначальных последствий извержения 1933-1934 гг. на экосистемы острова оценить затруднительно, но поскольку извержение произошло в море, то вероятность существенного воздействия крайне мала. Тем не менее, с 1972 по 2018 г. узкая полоска вдоль юго-восточного побережья со слабым развитием растительного покрова сузилась в среднем с 370 до 122 м. В районе Олимпийского прорыва (1 995,59 га) площадь территории, полностью лишенной растительного покрова, за 46 лет сократилась на 25,77 \%. Высокая степень развития фитомассы увеличилась с $34,41 \%$ (непосредственно после извержения) до 62,76 \% к 1983 г. до 71,3\% в 2018 г. от общей площади. Наиболее худшим зарастанием характеризуются районы эксплозивных воронок и лавовых потоков (рис. 6).

Потоки глыбовой лавы, пересыпанные средне- или мелкообломочным материалом, к 2006 г. были покрыты на 30-50 \% мхами. Участие лишайников в растительном покрове было незначительно [25]. В настоящее время сосудистые растения суммарно покрывают 3,7 га (3,53 \%) из 104,88 га поверхности лавового поля. Чаще других встречаются пеннелиант кустарниковый (Pennellianthus frutescens), анафалис жемчужный (Anaphalis margaritacea), папоротник - щитовник широкий (Dryopteris expansa), полынь пушистая (Artemisia opulenta).

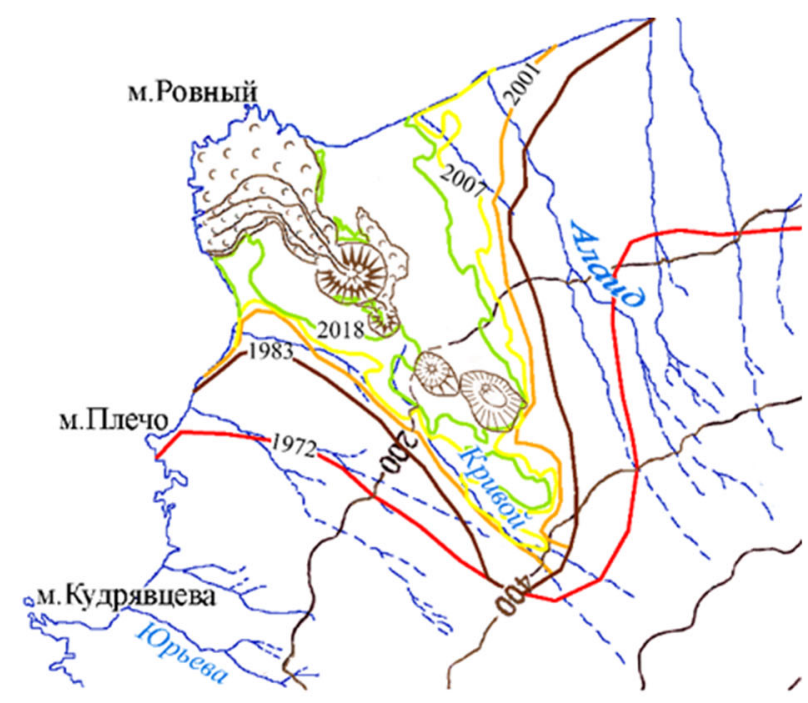

Рис. 6. Границы со значением NDVI = 0,4 по данным космической съемки в различные годы в районе Олимпийского прорыва 
Единично на лаве отмечаются небольшие кустики ольховника (Duschekia kamtschatica), приуроченные либо к трещинам между глыбами и местам аккумуляции щебнистого мелкозема. Подножия потоков заросли в большей степени, здесь встречаются группы ольховника высотой до 1-1,5 м, а также участки сомкнутой травянистой растительности [25].

Полученные в работе результаты достаточно хорошо коррелируют с результатами других исследователей [25], где на основе дешифрирования аэрофотоснимка за 1980 г. площадь пораженной растительности определена в 8 км² (против 7,47 км² на 1983 г. по нашим данным). Однако в год извержения площадь пораженного растительного покро-

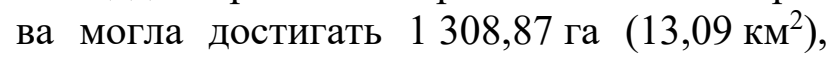
что косвенно указывает на незначительную мощность отложения тефры (до $30 \mathrm{~cm}$, по данным С. Ю. Гришина) на большой территории, где была повреждена растительность.

Извержение центрального кратера 1981 г. оказало значительное негативное воздействие на экосистемы острова. Наибольшему ущербу подверглись северо-восточный и восточный склоны вулкана, где выпал наибольший объем тефры. Здесь на 1983 г. верхняя граница сплошного растительного покрова отступила вниз по склону на расстояние от 380 до 1500 м, по отношению к 1972 г. Однако динамика восстановления растительного покрова весьма ощутима. Так, к 2018 г. на многих участках граница NDVI $=0,4$ вернулась к положению 1972 г. Исключениями здесь являются наиболее сильно пострадавшие участки на северо-восточном склоне, где граница все еще находится на расстоянии 300-800 м.

На юго-западном склоне восстановление растительного покрова было нарушено эффузивно-эксплозивным извержением 2016 г., которое сопровождалось пепловыми выбросами и излиянием небольшого лавового потока, длиной около 300 м [19]. В результате граничное значение вегетационного индекса в 2018 г., по сравнению со своим положением на 2007 г., отдалилось от вулканической постройки на 140-530 м.
По наблюдениям зоолога В. Л. Костенко извержения серьезно изменили состояние зоокомпонентов экосистем. Погибли все насекомые в зоне поражения. В результате пеплопада были полностью уничтожены или впоследствии погибли от голода полевки-экономки. Другие грызуны (серая крыса) остались между крупными валунами в литоральной зоне, где питались выбросами моря [26].

Восстановление растительного покрова сопровождается заселением территории животными. В заплесковых лужах на лавовых потоках В. А. Рашидовым обнаружена «цветная» вода различных оттенков, обусловленных наличием пурпурных фототрофных бактерий, что свидетельствует о стабильном характере функционирования экосистем на территории. В районе Олимпийского прорыва существует колония наземных улиток Bradybaenidae, которые успешно пережили извержение вулкана. В 2006 г. в районе прорыва полевки встречались единично, а крысы не наблюдались. Семья лисиц осталась на своем индивидуальном участке. В трех километрах к югу от лавового потока, на мысу сохранилось лежбище сивучей (40-50 зверей) [26]. Вне зоны непосредственного воздействия извержения все компоненты экосистем сохранились.

\section{Заключение}

Результаты проведенного исследования подтверждают опасность воздействия вулканических процессов на экосистемы, а также существенную опасность ведения хозяйственной деятельности в таких районах.

Динамика и характер восстановления растительного покрова после таких периодических катастрофических событий, как эффузивно-эксплозивные извержения вулкана Алаид, могут быть оценены и охарактеризованы на больших площадях с помощью доступных данных дистанционного зондирования среднего разрешения [27-29], следовательно, способствовать лучшему пониманию сущности факторов вулканического воздействия и реакции экосистем на них. 
Установлено, что за границу, разделяющую районы с нарушенным и сплошным растительным покровом в подобных природно-климатических условиях, можно принимать значение NDVI, равное 0,4.

Темпы восстановления экосистем напрямую зависят от масштабов вулканических извержений. Так, наиболее худшим зарастанием характеризуются районы эксплозивных воронок и лавовых потоков, а также территории с отложениями тефры мощностью более 30 см. В остальных случаях восстановле- ние сплошного растительного покрова происходит в течение 25-50 лет.

Методы, разработанные в процессе исследования этого вопроса, могут в дальнейшем способствовать оперативной оценке воздействия на экосистемы при мониторинге эффузивно-взрывных извержений и прогнозировании вулканической опасности для территорий, прилегающих к вулканам подобного типа.

\section{БИБЛИОГРАФИЧЕСКИЙ СПИСОК}

1. Действующие вулканы Камчатки: в 2-х т. / Отв. ред. С. А. Федотов, Ю. П. Масуренков. М. : Наука. - 1991. - Т. 1. - 302 с.

2. Сывороткин В. Л. Извержения вулканов // Пространство и Время. - 2017. - № 1 (27). C. $196-213$.

3. Pearce J. A., Parkinson I. J. Trace element models for mantle melting: application to volcanic arc petrogenesis // Geological Society, London, Special Publications. - 1993. - Vol. 76. No 1. - P. 373-403. DOI: 10.1144/GSL.SP.1993.076.01.19.

4. Мартынов Ю. А., Х Ханчук А. И., К Кимуpa Ю. И., Рыбин А. В., Мартынов А. Ю Геохимия и петрогенезис вулканических пород Курильской островной дуги // Петрология. - 2010. T. 18, № 5. - С. 512-535.

5. Федотов С. А., Хренов А. П., Чирков А. М. Большое трещинное Толбачинское извержение 1975 г., Камчатка // Доклады АН СССР. - 1976. Т. 228, № 5. - C. 1193-1196.

6. Большое трещинное Толбачинское извержение, Камчатка 1975-1976 гг. / Под ред. С. А. Федотова. - М. : Наука, 1984. - 637 с.

7. Малеев В. Ф. Вулканиты : справочник. М. : Недра, 1980. - 240 с.

8. Ярославцева Т. В., Рапута В. Ф. Моделирование продуктов вулканического извержения // Вестник СГУГиТ. - 2012. - Вып. 3 (19). C. $89-95$.

9. Alaid // Сайт Global Volcanism Program GVP of the Smithsonian Institution [Электронный pecypc]. - Режим доступа: https://volcano.si.edu/volcano.cfm?vn=290390\#bgv n 201704.

10. Landsat Missions // Сайт United States Geological Survey (USGS) [Электронный ресурс]. Режим доступа: https://www.usgs.gov/land-resources/ nli/landsat/landsat-satellite-missions.
11. Landsat Missions // Сайт European Space Agency (ESA) [Электронный ресурс]. Режим доступа: https://sentinel.esa.int/web/ sentinel/missions.

12. Карпик А. П. Методологические и технологические основы геоинформационного обеспечения территорий : монография. - Новосибирск: СГГА, 2004. - $260 \mathrm{c}$.

13. Сизов А. П., Хабаров Д. А., Хабарова И. А. Новые подходы к разработке методики формирования семантической информации мониторинга земель на основе обработки и анализа картографической информации // Изв. вузов. Геодезия и аэрофотосъемка. - 2018. - Т. 62, № 4. - C. 434-441.

14. Наумова В. В., Горячев И. Н. ГИС-портал «Геология и геофизика Дальнего Востока России»: интеграция пространственных данных и сервисов // Геоинформатика. - 2013. - № 2. C. $12-19$.

15. Teltscher K., Fassnacht F. E. Using multispectral Landsat and Sentinel-2 satellite data to investigate vegetation change at Mount St. Helens since the great volcanic eruption in 1980 // Journal of Mountain Science. - 2018. - Vol. 15, Iss. 9. P. 1851-1867. DOI: 10.1007/s11629-018-4869-6.

16. Ash fall impact on vegetation: a remote sensing approach of the Oldoinyo Lengai 2007-08 eruption / A. Schutter, M. Kervyn, F. Canters, S. A. Bosshard-Stadlin, M. A. M. Songo, H. B. Mattsson // Journal of Applied Volcanology. - 2015. - Vol. 4, No 15. - P. 1-18. doi: 10.1186/s13617-015-0032-z.

17. Геоинформационное биогеографическое картографирование состояния островных экосистем по данным дистанционного зондирования Земли / И. В. Никулина, И. Г. Минервин, В. А. Мелкий, А. В. Радченко // Вестник СГУГиТ. - 2020. - Т. 25, № 1. - С. 194-210. 
18. Черепанов А. С. Вегетационные индексы // Геоматика. - 2011. - № 2. - С. 98-102.

19. Index Data Dase (The IDB Project): A database for remote sensing indices [Электронный pecypc]. - Режим доступа: https://www.indexdatabase.de/db/a-single.php?id=1.

20. Никитина Ю. Г., Олзоев Б. Н. Картографическое отображение структуры ландшафтов острова Ольхон и Приольхонья по разновременным космическим снимкам Landsat // Вестник СГУГиТ. - 2017. - Т. 22, № 2. - С. 103-119.

21. Вулканическая активность на Курильских островах в XXI в. / А. В. Рыбин, М. В. Чибисова, А. В. Дегтерев, В. Б. Гурьянов // Вестник Дальневосточного отделения РАН. - 2017. - № 1. C. 51-61.

22. Вещественный состав продуктов извержения вулкана Алаид в 1981 г. / Г. Б. Флеров, Б. В. Иванов, В. Н. Андреев, В. А. Будников, И. А. Меняйлов // Вулканология и сейсмология. 1982. - № 6. - С. 27-43.

23. Гришин С. Ю. Излияние лавовых потоков на Курильских островах в XX и начале XXI века: масштабы и глубина изменения экосистем // Изв. Русского географического общества. - 2014. T. 146, № 6. - С. 1-13.

24. Гришин С. Ю., Я Яковлева А. Н., Шляхов С. А. Воздействие извержения вулкана Алаид (Курильские острова) в 1972 г. на экосистемы // Вулканология и сейсмология. - 2009. № 4. - С. 30-43.

25. Растительный и почвенный покров острова Атласова (Курильские острова) / С. Ю. Гришин,
В. Ю. Баркалов, В. П. Верхолат, В. А. Рашидов, С. А. Шляхов, А.Н. Яковлева // Комаровские чтения. - 2009. - № 56. - С. 64-119.

26. Рашидов В. А., Аникин Л. П. Полевые работы на вулкане Алаид (о. Атласова, Курильские острова) в 2019 году // Вестник КРАУНЦ. Науки о Земле. - 2014. - № 2, Вып. 24. C. 198-203.

27. Методика комплексного использования данных дистанционного зондирования для оценки масштаба опасности природных катастроф, вызванных извержениями вулканов / А. П. Хренов, А. Н. Платэ, В. В. Зайцев, В. Е. Шкарин // Дистанционное зондирование земных покровов и атмосферы аэрокосмическими средствами : сб. докладов Всеросс. науч. конф. (Муром, 20-22 июня 2001). - Муром : Муромский институт Вл. ГУ, 2001. - С. 410-414.

28. Верхотуров А. А., Мелкий В. А. Организация системы мониторинга и оценки состояния вулканоопасных территорий // Национальная научно-практическая конференция «Регулирование земельно-имущественных отношений в России: правовое и геопространственное обеспечение, оценка недвижимости, экология, технологические решения» : сб. материалов в 2-х т. - Новосибирск : СГУГиТ, 2018. T. 2. - С. 167-172.

29. Мелкий В. А., Верхотуров А. А. Геоинформационное и картографическое обеспечение мониторинга для оценки состояния природнотехногенных комплексов Сахалинской области // Геоконтекст. - 2016. - Вып. 4. - С. 30-44.

Получено 12.05.2020

(C) A. A. Bepхотуров, 2020

\section{ANALYSIS OF CHANGES IN THE STATE OF ECOSYSTEMS ON ATLASOVA ISLAND (KURIL ISLANDS)}

\section{Alexey A. Verkhoturov}

Institute of Marine Geology and Geophysics of the Far Eastern branch of the Russian Academy of Sciences, 1B, Nauki St., Yuzhno-Sakhalinsk, Russia, 693022, Ph. D., Senior Researcher, Center for Collective Use, e-mail: ussr-91@mail.ru

The territory of the Kuril Islands is a chain of volcanic structures and is subject, to certain extent, to volcanic hazards. Atlasova Island is composed of products of the Alaid volcano, which is characterized by effusive and explosive activity. The article analyzes the changes in ecosystems on Atlasov island, which are periodically caused by the Alaid volcano eruption. Large amount of pyroclastic material are brought to the surface during explosive eruptions: blocks, bombs, tephra, lapilli and volcanic ash, which is transported in the atmosphere over very long distances. Ecosystems are affected by pyroclastic deposition over a large area of island land. The purpose of this study was to identify the nature and extent of changes in the state of ecosystems affected by volcanic eruptions from multi-zone satellite images of medium resolution. Analysis of data obtained from space systems Landsat and Sentinel for the period 1972 to 2020, in GIS environment al- 
lowed us to trace the dynamics and character of the successions to the affected areas on the calculated values of the vegetation index NDVI. Techniques developed in the process of studying this issue can further facilitate rapid assessment of impacts on ecosystems at the effusive-explosive eruptions and forecast volcanic hazard for surrounding areas.

Key words: vegetation index, volcanic eruptions, remote sensing of the Earth, Landsat, multi-zone satellite images, monitoring, spectral characteristics, Sentinel, ecosystem.

\section{REFERENCES}

1. Fedotov, S. A., \& Masurenkov, Yu. P. (Eds.). (1991). Deystvuyushchie vulkany Kamchatki: T. 1 [Active volcanoes of Kamchatka: Vol. 1]. Moscow: Nauka Publ., 302 p. [in Russian].

2. Syvorotkin, V. L. (2017). Volcanic Eruption. Prostranstvo $i$ vremya [Space and Time], 1(27), 196-213 [in Russian].

3. Pearce, J. A., \& Parkinson, I. J. (1993). Trace element models for mantle melting: application to volcanic arc petrogenesis. Geological Society, London, Special Publications, 76(1), 373-403. doi: 10.1144/GSL.SP.1993.076.01.19.

4. Martynov, Yu. A., Khanchuk, A. I., Martynov, A. Yu., Kimura, J.-I., \& Rybin, A. V. (2010). Geochemistry and Petrogenesis of Volcanic Rocks in the Kuril Island Arc. Petrology, 18(5), 489-513. doi: $10.1134 / \mathrm{S} 0869591110050048$ [in Russian].

5. Fedotov, S. A., Khrenov, A. P., \& Chirkov, A. M. (1976). The Great Tolbachik Fissure Eruption 1975, Kamchatka. Doklady Akademii Nauk SSSR [Reports of the USSR Academy of Sciences], 228, 1193-1196 [in Russian].

6. Fedotov, S. A. (Ed.). (1984). Bol'shoe treshchinnoe Tolbachinskoe izverzhenie, Kamchatka, 1975-1976 gg. [The Great Tolbachik Fissure Eruption 1975-1976 in Kamchatka]. Moscow: Nauka Publ., 637 p. [in Russian].

7. Maleev, V. F. (1980). Vulkanity [Vulcanites]. Moscow: Nedra Publ., 240 p. [in Russian].

8. Jaroslavtseva, T. V., \& Raputa, V. F. (2012). Modelling of volcanic eruption products. Vestnik SGUGiT [Vestnik SSUGT], 3(19), 89-95 [in Russian].

9. Alaid. (n. d.). Global Volcanism Program GVP of the Smithsonian Institution. Website. Retrieved from https://volcano.si.edu/volcano.cfm?vn=290390\#bgvn 201704.

10. Landsat Missions. (n. d.). United States Geological Survey (USGS). Retrieved from https://www.usgs.gov/land-resources/nli/landsat/ landsat-satellite-missions.

11. Landsat Missions. (n. d.). European Space Agency (ESA). Retrieved from https://sentinel.esa.int/ $\mathrm{web} /$ sentinel $/$ missions.

12. Karpik, A. P. (2004). Metodologicheskie $i$ tekhnologicheskie osnovy geoinformatsionnogo obespecheniya territoriy: monografiya [Methodological and Technological foundations of GIS software territories: monograph]. Novosibirsk: SSGA Publ., 260 p. [in Russian].

13. Sizov, A. P., Khabarov, D. A., \& Khabarova, I. A. (2018). New approaches to development of the Method of Formation the semantic data of Land monitoring based on the Processing and Analysis of cartographic information. Izvestiya vuzov. Geodeziya i aerofotos"emka [Izvestiya Vuzov. Geodesy and Aerophotography], 62(4), 434-441 [in Russian].

14. Naumova, V. V., \& Goryachev, I. N. (2013). GIS portal "Geology and Geophysics of the Russian Far East": integration of spatial data and services. Geoinformatika [Geoinformatics], 2, 12-19 [in Russian].

15. Teltscher, K., \& Fassnacht, F. E. (2018). Using multispectral Landsat and Sentinel-2 satellite data to investigate vegetation change at Mount St. Helens since the great volcanic eruption in 1980. Journal of Mountain Science, 15(9), 1851-1867. doi: 10.1007/s11629-018-4869-6.

16. Schutter, A., Kervyn, M., Canter, F., Bosshard-Stadlin, S. A., Songo, M. A. M., \& Mattsson, H. B. (2015) Ash fall impact on vegetation: a remote sensing approach of the Oldoinyo Lengai 2007-08 eruption. Journal of Applied Volcanology, 4(15), 1-18. doi: 10.1186/s13617-015-0032-z.

17. Nikulina, I. V., Minervin, I. G., Melkiy, V. A., \& Radchenko, A. V. (2020). Geoinformation biogeographic mapping of island ecosystems by remote sensing data. Vestnik SGUGiT [Vestnik SSUGT], 25(1), 194-210 [in Russian].

18. Cherepanov, A. S. (2011). Vegetative indexes. Geomatika [Geomatics], 2, 98-102 [in Russian].

19. Index Data Dase (The IDB Project): A database for remote sensing indices. (n. d.). Retrieved from https://www.indexdatabase.de/db/asingle.php? $\mathrm{id}=1$.

20. Nikitina, Y. G., \& Olzoev B. N. (2017). Mapping of landscape structure of Olhkhon island and Priolhkhon region by multi-temporal satellite images Landsat. Vestnik SGUGiT [Vestnik SSUGT], 22(2), 103-119 [in Russian]. 
21. Rybin, A. V., Chibisova, M. V., Degterev, A. V., \& Guryanov, V. B. (2017). Volcanic eruptions in the Kuril Islands during XXI century. Vestnik Dal'nevostochnogo otdeleniya RAN [Vestnik of the Far East Branch of the Russian Academy of Sciences], 1, 51-61 [in Russian].

22. Flerov, G. B., Ivanov, B. V., Andreev, V. N. Budnikov, V. A., \& Menyailov, I. A. (1982). The material composition of the products of the eruption of the Alaid volcano in 1981. Vulkanologiya i seysmologiya [Journal of Volcanology and Seismology], 6, 27-43 [in Russian].

23. Grishin, S. Yu. (2014). Outpouring of lava flows on the Kuril Islands in XX and the beginning of XXI centuries: scope and depth of ecosystem changes. Izvestiya Russkogo geograficheskogo obshchestva [Bulletin Russian Geographical Society], 146(6), 1-13 [in Russian].

24. Grishin, S. Yu., Yakovleva, A. N., \& Shlyakhov, S. A. (2009). Impact of the Alaid volcano eruption (Kuril Islands) in 1972 on ecosystems. Vulkanologiya i seysmologiya [Journal of Volcanology and Seismology], 4, 30-43 [in Russian].

25. Grishin, S. Yu., Barkalov, V. Yu., Verholat, V. P., Rashidov, V. A., Shlyakhov, S. A., \& Yakovleva, A. N. (2009). Vegetation and Soil cover of the Atlasov Island (Kuril Islands). Komarovskie chteniya [Readings from Komarov], 56, 64-119 [in Russian].

26. Rashidov, V. A., \& Anikin, L. P. (2014). Field work on the Alaid volcano (Atlasov Island, Kuril Islands) in 2019. Vestnik KRAUNTS. Nauki o
Zemle [Bulletin of Kamchatka Regional Association "Educational-Scientific Center". Earth Sciences], 2(24), 198-203 [in Russian].

27. Khrenov, A. P., Plate, A. N., Zaitsev, V. V., $\&$ Shkarin, V. E. (2001). Method of integrated use of remote sensing data for assessing the scale of natural disasters caused by volcanic eruptions. In Sbornik dokladov Vserossiyskoy nauchnoy konferentsii: Distantsionnoe zondirovanie zemnykh pokrovov $i$ atmosfery aerokosmicheskimi sredstvami [Proceedings of All-Russian Scientific Conferense. Remote Sensing of the Earth's Surface and Atmosphere by Aerospace Means] (pp. 410-414). Murom: Murom Institute of Higher Education Publ. [in Russian].

28. Verhoturov, A. A., \& Melkiy, V. A. (2018). Organization of monitoring and evaluation system of the state of volcano-dangerous territories. In Sbornik materialov Natsional'noy nauchnoprakticheskoy konferentsii: T. 2. Regulirovanie zemel'no-imushchestvennykh otnosheniy $v$ Rossii: pravovoe $i$ geoprostranstv. obespechenie, otsenka nedvizhimosti, ekologiya, tekhnologicheskie resheniya [Proceedings of National Scientific and Practical Conference: Vol. 2. Regulation of land and Property Relations in Russia: Legal and Geospatial. Software, Real Estate Valuation, Ecology, Technological Solutions.] (167-172 pp.). Novosibirsk: SSUGT Publ. [in Russian].

29. Melky, V. A., \& Verkhoturov, A. A. (2016). Geoinformation and cartographic monitoring support for assessing the state of natural and technogenic complexes of the Sakhalin region. Geokontekst [Geocontext], 4, 30-44 [in Russian]. 
УДК 528.8:621.644

DOI: $10.33764 / 2411-1759-2020-25-3-151-159$

\section{ИСПОЛЬЗОВАНИЕ ДАННЫХ ДИСТАНЦИОННОГО ЗОНДИРОВАНИЯ ЗЕМЛИ ПРИ ФОРМИРОВАНИИ ГЕОИНФОРМАЦИОННОГО ПРОСТРАНСТВА ТРУБОПРОВОДНОГО ТРАНСПОРТА}

\section{Даниил Валентинович Долгополов}

АО «СпейсИнфо Геоматикс», 127490, Россия, г. Москва, ул. Декабристов, 51, кандидат технических наук, технический директор, тел. (905)714-13-77, e-mail: daniil.dolgopolov@gmail.com

В статье рассматриваются основные подходы к использованию материалов аэрокосмической съемки при формировании геоинформационного пространства территорий строительства и эксплуатации трубопроводного транспорта. Одной из основных проблем при наполнении корпоративных геоинформационных систем трубопроводного транспорта является определить состав данных дистанционного зондирования Земли (ДЗ3), необходимый и достаточный для решения производственных задач подразделений, а также требования к периодичности их обновления. Цель настоящей работы - выделить базовые потребности в использовании данных ДЗ3 при формировании геоинформационного пространства трубопроводного транспорта и определить требования к материалам ДЗ3 для их удовлетворения. Отдельно в статье рассматривается возможность использования материалов ДЗ3 как источника информации при актуализации векторных пространственных данных, приводятся результаты анализа возможностей дешифрирования объектов трубопроводного транспорта и инфраструктуры по материалам аэрокосмической съемки разного пространственного разрешения.

Ключевые слова: дистанционное зондирование, аэрокосмическая съемка, геоинформационное пространство, магистральные трубопроводы, объекты трубопроводного транспорта.

\section{Введение}

Изучение территории прохождения магистральных трубопроводов (МТ), оценка современного состояния природно-технической среды в настоящее время уже не могут осуществляться традиционными методами, поскольку масштабы и темпы изменения природной среды в зонах строительства и эксплуатации трубопроводной системы настолько велики, что охватить подробным наземным изучением столь протяженные территории в единый момент времени не представляется возможным [1-4].

Данные дистанционного зондирования Земли (ДДЗ3), полученные с космических носителей, позволяют организовать информационное обеспечение для оперативного эффективного мониторинга протяженных зон, через которые проходят магистральные трубопроводы [5-7].

Данные дистанционного зондирования должны использоваться в корпоративных ГИС трубопроводного транспорта в качестве объективного, постоянно пополняемого источника информации о местоположении объектов, а также как возможный источник актуализации векторных пространственных данных [8-10]. Целью настоящего исследования было определить базовые потребности в материалах дистанционного зондирования Земли, которые возникают при формировании геоинформационного пространства трубопроводного транспорта, в том числе, при создании корпоративных геоинформационных систем, а также сформировать требования к этим материалам.

\section{Результаты исследований}

ДД33 могут быть использованы при решении широкого круга задач производственных подразделений по различным направлениям деятельности, в том числе в рамках технической эксплуатации, проектирования, капитального строительства и реконструкции, обеспечения безопасности, управления собственностью, земельно-имущественными отношениями и т. д.

Территория, обеспечиваемая материалами дистанционного зондирования Земли, должна включать линейную часть трубопроводов, площадные объекты, а также соответ- 
ствующие зоны интересов: охранные зоны, зоны минимально допустимых расстояний, иные буферные зоны в зависимости от конкретных прикладных задач, реализуемых в рамках корпоративных ГИС. Помимо этого, данными дистанционного зондирования могут обеспечиваться другие территории, в том числе зоны проектируемых и строящихся объектов $[11,12]$.
При выполнении различных видов дистанционных наблюдений природно-технической среды аэрокосмическими средствами излучение объектов регистрируется с использованием различных методов и различной по принципу работы съемочной аппаратуры (рис. 1).

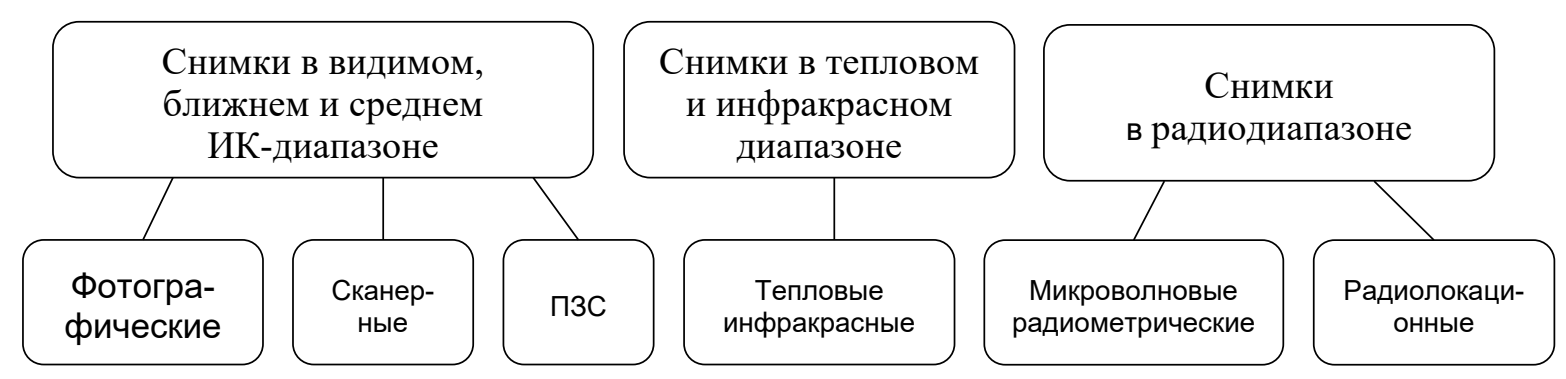

Рис. 1. Классификация дистанционных методов по технологии получения информации

Возможности использования результатов мониторинга зависят, главным образом, от спектрального диапазона съемки, который отображает физическую сущность характеристик объектов, зафиксированных на снимках, и от технологии получения этих снимков, определяющей их качество, изобразительные и измерительные свойства [13]. Возможный состав данных дистанционного зондирования по типам съемки, диапазонам и пространственному разрешению приведен на рис. 2 .

Основным источником информации для решения наибольшего числа задач являются аэрокосмические изображения, получаемые в оптическом диапазоне длин волн. В то же время для решения отдельных задач могут быть востребованы данные космической радиолокационной съемки (задачи определения динамики поверхности Земли, объектов МТ в зонах сложных природно-климатических условий), тепловой съемки, материалы воздушного лазерного сканирования (задачи построения цифровой модели рельефа (ЦМР) и последующего анализа его изменения) [14-18].

Качество аэрокосмической информации видимого диапазона напрямую зависит от охвата территории, пространственного и временного разрешения съемочных систем, последнее определяется повторяемостью съемок территории, обеспечивая данными, необходимыми для решения задач картографи- рования динамики состояния природно-технической среды [19-21]. Состав данных ДЗ3 предполагает три основных массива данных, которые условно можно разбить на уровни в зависимости от пространственного разрешения материалов ДЗ3.

I уровень. Обзорное покрытие космической съемкой среднего разрешения (5-30 м) на территорию/регион деятельности компании. Для создания покрытия первого уровня могут быть использованы, например, данные Landsat и Sentinel, являющиеся наиболее доступными.

II уровень. Базовое покрытие космической съемкой высокого разрешения (1-5 м) линейной части и прилегающих территорий объектов инфраструктуры МТ с заданной степенью актуальности и пространственного разрешения в соответствии с потребностями пользователей.

III уровень. Детальные материалы дистанционного зондирования сверхвысокого разрешения $(<1 \mathrm{~m})$, полученных с различного типа носителя (космическая съемка, аэросъемка, съемка с БПЛА), выполняемых по запросам подразделений компании на существующие, строящиеся и проектируемые объекты, получаемые в рамках существующих бизнес-процессов: капитального строительства, реконструкции, эксплуатации, мониторинга трубопроводных систем, мероприятий по обеспечению промышленной и экологической безопасности и т. д. 


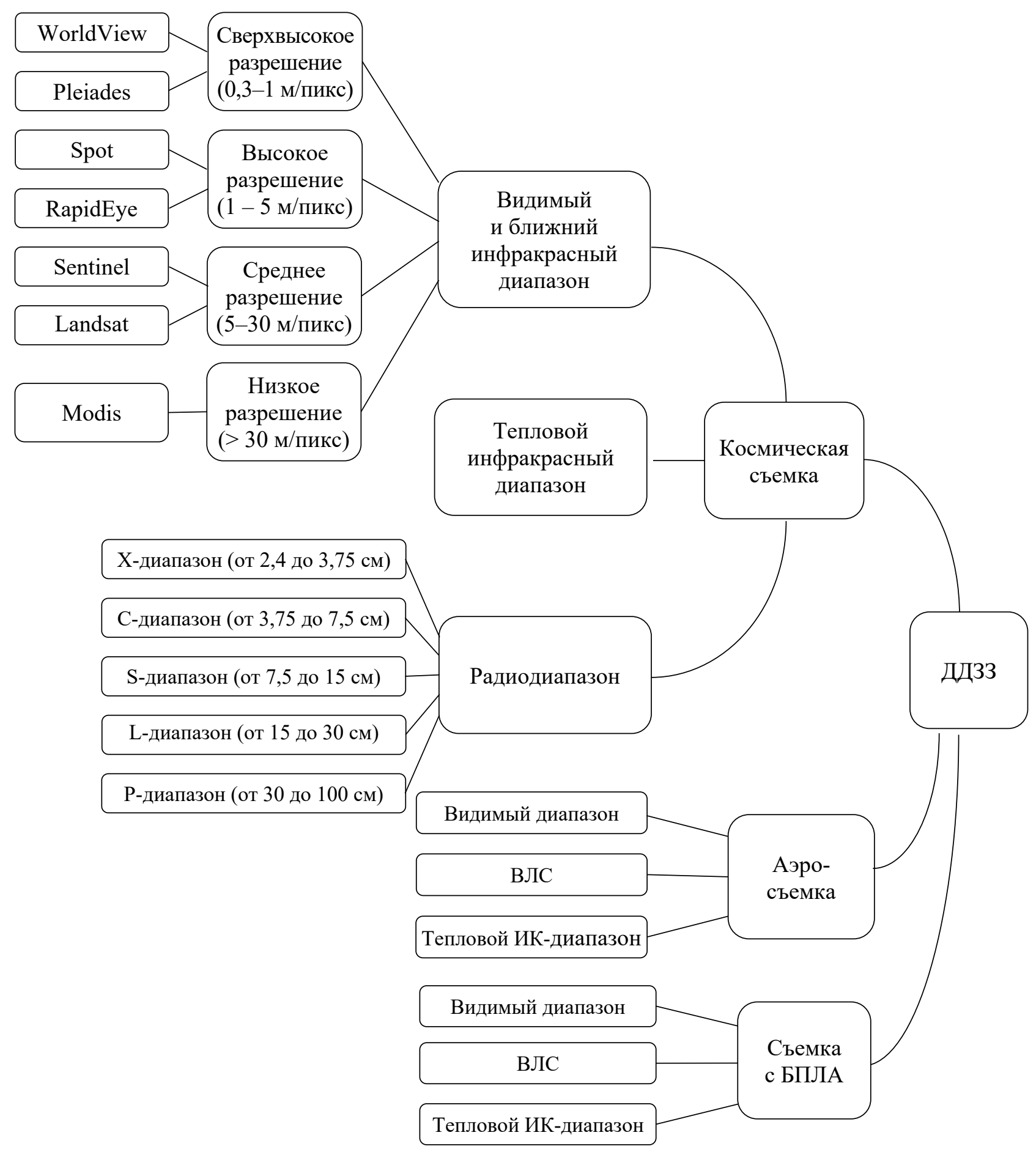

Рис. 2. Возможный состав данных дистанционного зондирования по типам съемки, диапазонам и пространственному разрешению

Перспективный для использования в корпоративных ГИС перечень космических съемочных систем по уровням пространственного разрешения приведен в табл. 1.

Среди базовых потребностей в использовании данных Д33 при формировании геоинформационного пространства трубопро- водного транспорта можно отметить:

- формирование базовой мультимасштабной пространственной основы;

- обновление единой цифровой картографической основы;

- инвентаризация существующих объектов трубопроводной сети. 
Съемочные системы по уровням пространственного разрешения

\begin{tabular}{|l|c|c|}
\hline \multicolumn{1}{|c|}{ Тип аэрокосмической съемки } & $\begin{array}{c}\text { Пространственное } \\
\text { разрешение, } \mathbf{m} / \text { пикс }\end{array}$ & Съемочная система \\
\hline 1. Аэрофотосъемка & 0,06 & Аэрофотосъемка \\
\hline \multirow{2}{*}{$\begin{array}{l}\text { 2. Космическая съемка сверхвысокого } \\
\text { разрешения (0,3-1 м/пикс) }\end{array}$} & 0,31 & WorldView 3,4 \\
\hline 3. Космическая съемка высокого разрешения & 0,46 & GeoEye \\
\cline { 2 - 3 } $\begin{array}{l}\text { (1-5 м/пикс) } \\
\text { 4. Космическая съемка среднего разрешения } \\
\text { (5-30 м/пикс) }\end{array}$ & 0,5 & Pleiades-1A/1B \\
\hline $\begin{array}{l}5 . \text { Космическая съемка низкого разрешения } \\
(>30 \text { м/пикс) }\end{array}$ & 2,5 & SPOT 5 \\
\cline { 2 - 3 } & 10,5 & PlanetScope \\
\hline
\end{tabular}

\section{Формирование \\ базовой мультимасштабной пространственной основы}

Данные дистанционного зондирования Земли, в первую очередь материалы космической съемки в видимом диапазоне, могут использоваться в геоинформационных системах для пространственной основы в качестве дополнительного к картографическому представлению, объективного, постоянно пополняемого и актуализируемого источника информации о территории местоположения объектов трубопроводного транспорта а также как возможный источник актуализации векторных пространственных данных, в том числе единой цифровой картографической основы.

Для формирования базовой мультимасштабной пространственной основы могут быть использованы следующие наборы данных Д3З:

- космическая съемка среднего разрешения от 5-30 м - обзорное покрытие космической съемкой, данные должны быть представлены на всю территорию России;

- космическая съемка высокого разрешения (1-5 м) - базовое покрытие космической съемкой линейной части и прилегающих территорий объектов инфраструктуры МТ (не менее 10 км от оси МТ);

- космическая съемка сверхвысокого разрешения $(<1$ м), используется для детализации базовой пространственной основы вдоль трассы трубопровода. Должна также использоваться космическая съемка, выполняемая по запросам подразделений компании на существующие, строящиеся и проектируемые объекты, получаемые в рамках существующих бизнес-процессов компании.

\section{Обновление единой цифровой картографической основы}

Единая цифровая картографическая основа должна поддерживаться в актуальном состоянии, в первую очередь в зоне интересов подразделений компании, в т. ч. на территориях прохождения МТ. Данные космической съемки, наряду с другими методами инструментального дистанционного обследования (цифровая аэрофотосъемка (ЦАФС), воздушное лазерное сканирование (ВЛС) и т. Д.), могут являться одним из основных источником обновления единой цифровой картографической основы [22].

В то же время специфика современных данных дистанционного зондирования такова, что для обеспечения задачи обновления единой цифровой картографической основы данных одной съемочной системы недостаточно. Связано это с комплексом причин: данные сверхвысокого разрешения (1 м на пиксель и крупнее) имеют высокую стоимость, небольшой пространственный охват, качество и само наличие данных во многом определяется наличием облачности, временем года съемки и т. д.

Для обновления среднемасштабных и мелкомасштабных карт должна использоваться 
космическая съемка среднего разрешения. Для обновления крупномасштабных карт космическая съемка высокого разрешения.

Для уточнения/детализации базовой картографической основы вдоль коридора трассы могут использоваться данные космической съемки сверхвысокого разрешения (<1 м), наряду с другими методами инструментального дистанционного обследования (АФС, ВЛС и т. д.).

Ключевые требования к данным Д33: актуальность, пространственное разрешение, точность материалов ДЗ3 должны соответствовать основным положениям по созданию и обновлению карт по материалам космической съемки.

\section{Инвентаризация существующих объектов МТ}

Базы пространственных данных об объектах МТ должны поддерживаться в актуальном состоянии. Для решения задачи инвентаризации и контроля фактического положения объектов МТ целесообразно использовать данные космической съемки сверхвысокого разрешения $(<1$ м), а также материалы АФС и съемки с БПЛА, обеспечивающие необходимую точность и детализацию для корректного распознавания объектов и уточнения их пространственного положения, состояния объектов и окружающей обстановки [23-25].

Учитывая высокую стоимость пространственных данных сверхвысокого разрешения на протяженную территорию, при выборе материалов ДЗЗ следует учитывать возможность получения необходимого результата, так как распознавание объектов трубопроводных сетей связано с разрешением пространственных данных (табл. 2).

В связи с регулярными работами по строительству и реконструкции трубопроводной системы данные работы должны проводиться систематически.

Таблиия 2

Возможности дешифрирования объектов трубопроводного транспорта и инфраструктуры по материалам аэрокосмической съемки

\begin{tabular}{|c|c|c|c|c|}
\hline \multicolumn{3}{|c|}{$\begin{array}{c}\text { Возможность распознавания объектов } \\
\text { трубопроводного транспорта } \\
\text { на аэрокосмических изображениях }\end{array}$} & \multirow[t]{2}{*}{$\begin{array}{c}\text { Объекты трубопроводного транспорта } \\
\text { и инфраструктуры }\end{array}$} & \multirow[t]{2}{*}{$\begin{array}{c}\text { Тип } \\
\text { геометрии }\end{array}$} \\
\hline $1,5 \mathrm{~m} /$ пикс & $0,5 \mathrm{~m} /$ пикс & $0,1 \mathrm{м} /$ пикс & & \\
\hline \multirow{19}{*}{ Да } & \multirow{19}{*}{ Да } & \multirow{19}{*}{ Да } & Антенно-мачтовые сооружения & полигональная \\
\hline & & & Громоотводы & полигональная \\
\hline & & & Защитные валы резервуарных парков & линейная \\
\hline & & & Здания & полигональная \\
\hline & & & КПП СОД & линейная \\
\hline & & & Мачты освещения & полигональная \\
\hline & & & Мосты & полигональная \\
\hline & & & Столбы фермовые & точечная \\
\hline & & & Оси дорог, улиц и проездов & линейная \\
\hline & & & Оси технологических эстакад & линейная \\
\hline & & & Ось МТ & линейная \\
\hline & & & Пересечения МТ & точечная \\
\hline & & & Пересечения вдоль трассовых проездов & точечная \\
\hline & & & Противоэрозионные валы & линейная \\
\hline & & & Резервуары крупные & полигональная \\
\hline & & & Сооружения & полигональная \\
\hline & & & НПC & точечная \\
\hline & & & Технологическое оборудование контур & полигональная \\
\hline & & & Схематический контур площадки & полигональная \\
\hline
\end{tabular}


Окончание табл. 2

\begin{tabular}{|c|c|c|c|c|}
\hline \multicolumn{3}{|c|}{$\begin{array}{c}\text { Возможность распознавания объектов } \\
\text { трубопроводного транспорта } \\
\text { на аэрокосмических изображениях }\end{array}$} & \multirow[t]{2}{*}{$\begin{array}{c}\text { Объекты трубопроводного транспорта } \\
\text { и инфраструктуры }\end{array}$} & \multirow[t]{2}{*}{$\begin{array}{l}\text { Тип } \\
\text { геометрии }\end{array}$} \\
\hline $1,5 \mathrm{~m} /$ пикс & $0,5 \mathrm{~m} /$ пикс & $0,1 \mathrm{M} /$ пикс & & \\
\hline \multirow{28}{*}{ Нет } & & & Аншлаги & линейная \\
\hline & & & Вантузные тройники & точечная \\
\hline & & & Верх/низ отсыпки площадки & линейная \\
\hline & & & Водопропускные трубы (ВПТ) & линейная \\
\hline & & & Громоотводы & точечная \\
\hline & & & Задвижки больших диаметров & точечная \\
\hline & & & Защитные футляры & линейная \\
\hline & & & Колодцы отбора давления & точечная \\
\hline & & & Мачты освещения & точечная \\
\hline & & & Ограждения & линейная \\
\hline & & & Опоры ЛЭП (столбы) & точечная \\
\hline & & & Опоры ограждения & точечная \\
\hline & & & Оси пешеходных дорожек & линейная \\
\hline & & & Площадки обслуживания & полигональная \\
\hline & & & Покрытия & полигональная \\
\hline & & & $\begin{array}{c}\text { Покрытия оборудованных переездов } \\
\text { через МТ }\end{array}$ & полигональная \\
\hline & & & Резервуары & полигональная \\
\hline & & & Технологические эстакады & полигональная \\
\hline & & & Технологическое оборудование элементы & полигональная \\
\hline & & & Трансформаторы & полигональная \\
\hline & & & Технологические трубопроводы & линейная \\
\hline & \multirow{7}{*}{ Нет } & & $\begin{array}{l}\text { Значения километража магистральных за- } \\
\text { движек }\end{array}$ & линейная \\
\hline & & & Дорожные знаки и указатели & точечная \\
\hline & & & Задвижки небольших диаметров & точечная \\
\hline & & & Километровые столбы & точечная \\
\hline & & & КИП & точечная \\
\hline & & & $\begin{array}{c}\text { Монолитные реперы с защитными } \\
\text { колодцами }\end{array}$ & точечная \\
\hline & & & Охранные таблички & точечная \\
\hline
\end{tabular}

\section{Заключение}

В результате исследования были получены следующие основные результаты.

1. Данные ДЗ3 необходимы при формировании геоинформационного пространства трубопроводного транспорта как источник актуальной и объективной информации. В зависимости от пространственного разрешения материалы Д3З можно разделить на три уровня: обзорное покрытие космической съемкой среднего разрешения; базовое покрытие линейной части и прилегающих территорий и детальные материалы дистанционного зондирования.

2. Выявлены базовые потребности в использовании данных ДЗ3 при построении корпоративных ГИС трубопроводного транспорта и определены требования к материалам аэрокосмической съемки для следующих задач:

- формирование базовой мультимасштабной пространственной основы;

- обновление единой цифровой картографической основы;

- инвентаризация существующих объектов трубопроводной сети.

3. Проведенный анализ показал возможности дешифрирования объектов трубопроводного транспорта и инфраструктуры по материалам аэрокосмической съемки с пространственным разрешением от 1,5 м/пикс и выше (см. табл. 2). 


\section{БИБЛИОГРАФИЧЕСКИЙ СПИСОК}

1. Аэрокосмический мониторинг объектов нефтегазового комплекса / под ред. В. Г. Бондуpa. - М. : Научный мир, 2012. -560 c.

2. Бондур В. Г. Аэрокосмические методы и технологии мониторинга нефтегазоносных территорий и объектов нефтегазового комплекса // Исследование Земли из космоса. - 2010. - № 6 . C. 3-17.

3. Хренов Н. Н. Основы комплексной диагностики северных трубопроводов. Аэрокосмические методы и обработка материалов съемок. М. : Газойл-пресс, 2003. - 352 с.

4. Лисин Ю. В., Александров А. А. Мониторинг магистральных нефтепроводов в сложных геологических условиях // Наука и технологии трубопроводного транспорта нефти и нефтепродуктов. - 2013. - № 2 (10). - С. 22-27.

5. Лисин Ю. В. Создание системы координатно-временного обеспечения магистральных нефтепроводов // Изв. вузов. Машиностроение. 2013. - № 2. - С. 73-79.

6. Balogun L. F., Matori A. N., Lawal D. U. Geovisualization of Subsurface Pipelines: A 3D Approach // Modern Appl. Sci. - 2011. - Vol. 5. - № 4. P. 158-165.

7. Assistant Design System of Urban Underground Pipeline Based on 3D Virtual City / J. He, Y. Zou1, Y. Ma, G. Chen // Procedia Environmental Sciences - 2011. - Vol. 11. - P. 1352-1358.

8. Карпик А. П., Лисицкий Д. В. Электронное геопространство - сущность и концептуальные основы // Геодезия и картография. -2009 . - № 5 . C. $41-44$

9. Аврунев Е. И., Карпик А. П., Мелкий В. А. Принципы формирования единого геопространства территорий [Электронный ресурс] // Проблемы геологии и освоения недр. Труды XXIII Международного симпозиума имени академика М. А. Усова студентов и молодых ученых, посвященного 120-летию со дня рождения академика К.И. Сатпаева, 120-летию со дня рождения профессора К. В. Радугина : в 2-х т. 2019. - Т. 1. - С. 428-429. - Режим доступа: conference tpu-2019-C11 V1.pdf.

10. Возможности визуального дешифрирования магистральных трубопроводов и объектов инфраструктуры по спутниковым изображениям высокого и сверхвысокого пространственного разрешения / Д. В. Долгополов, Д. В. Никонов, А. В. Полуянова, В. А. Мелкий // Вестник СГУГиТ. - 2019. - Т. 24, № 3. - С. 65-81.

11. Марахтанов В. П., Топчиев А. Г. Технология геотехнического мониторинга магистраль- ных газопроводов на территории криолитозоны Западной Сибири // Успехи современного естествознания. - 2016. - № 9. - С. 131-136.

12. Корсей С. Г., Дьякова Н. Б. ГИС-технологии в трубопроводном транспорте // ArcReview. 2002. - № 2 (21). - С. 17-18.

13. Мониторинг природной среды аэрокосмическими средствами : учеб. пособие для студентов вузов / В. А. Малинников, А. Ф. Стеценко, А. Е. Алтынов, С. М. Попов. - М. : МИИГАиК, 2008. - 145 c.

14. Авиационное тепловизионное зондирование геологической среды / К. М. Каримов, В. Л. Онегов, С. Н. Кокутин, В. Н. Соколов, Л. К. Каримова, В. Ф. Васев // Геология, геофизика и разработка нефтяных и газовых месторождений. - 2009. - № 5. - С. 24-31.

15. Дистанционное тепловизионное зондирование Земли при решении геологических задач / К. М. Каримов, В. Л. Онегов, С. Н. Кокутин, В. Н. Соколов, В. Ф. Васев // Георесурсы. 2009.- № 1 (29) - С. 38-42.

16. Ковалевский Н. П., Томшина Т. В. Возможности мониторинга потенциально опасных участков магистрального углеводородного трубопровода на основе космических данных дистанционного зондирования Земли // Космонавтика и ракетостроение. - 2015. - № 5 (84). - С. 136-140.

17. Баборыкин М. Ю. Мониторинг опасных геологических процессов на линейных объектах // Инженерные изыскания. - 2013. - № 10-11. C. 44-55.

18. Баборыкин М. Ю., Жидиляева Е. В., Погосян А. Г. Факторы геологической опасности при проектировании и эксплуатации трубопроводов и их мониторинг // Газовая промышленность. - 2015. - № 11 (730). - С. 40-46.

19. Савиных В. П., Кучко А. С., Стеценко А. Ф. Аэрокосмическая фотосъемка : учеб. для вузов. - М. : Картгеоцентр-Геодезиздат, 1997. $-378 \mathrm{c}$.

20. Дворкин Б. А., Дудкин С. А. Новейшие и перспективные спутники дистанционного зондирования Земли // Геоматика. - 2013. № 2 (19). - C. 18-38.

21. Избранные проблемы и перспективные вопросы землеустройства, кадастров и развития территорий - 2017 : коллективная монография / В. В. Абросимов, Е. И. Аврунев, О. М. Антонова и др. / Отв. ред. А. П. Сизов. - М. : Русайнс, 2018. - 262 c.

22. Рыльский И. А. Лазерное сканирование и космическая съемка - соревнование или парт- 
нерство // Геоматика. - 2016. - № 1 (30). C. $10-18$.

23. Zirnig W., Hausamann D., Schreier G. HighResolution Remote Sensing Used to Monitor Natural Gas Pipelines // Earth Observation Magazine. 2002. - No. 11. - P. 12-17.

24. Monitoring of gas pipelines - a civil UAV application / D. Hausamann, W. Zirnig, G. Schreier,
P. Strobl // Aircraft Engineering and Aerospace Technology. - 2005. - Vol. 77, No. 5. - P. 352-360. https://doi.org/10.1108/00022660510617077.

25. Оценка точности 3D-моделей, построенных с использованием беспилотных авиационных систем / Е. И. Аврунев, Х. К. Ямбаев, О. А. Опритова, А. В. Чернов, Д. В. Гоголев // Вестник СГУГиТ. - 2018. - Т. 23, № 3. - С. 211-228.

Получено 20.03.2020

(C) Д. В. Долгополов, 2020

\section{USE OF EARTH REMOTE SENSING DATA FOR FORMATION OF GEODATA SPACE OF PIPELINE TRANSPORT}

\section{Daniil V. Dolgopolov}

JSC "SpacInfo Geomatics", 51, Dekabristov St., Moscow, 127490, Russia, Ph. D., Technical Director, phone: (905)714-13-77, e-mail: daniil.dolgopolov@gmail.com

The article considers the main approaches to the use of aerospace survey materials in the formation of geoinformation space of territories of construction and operation of pipeline transport. An important problem when filling corporate geoinformation systems for pipeline transport is the task of determining the composition of remote sensing Data, as well as the requirements for the frequency of their updating. The purpose of this work is to identify the basic needs for using remote sensing data in the formation of the geo- information space of pipeline transport and to determine the requirements for remote sensing materials to meet them. The article also considers the possibility of using remote sensing materials as a source of information when updating vector spatial data, and provides the results of analyzing the possibilities of decrypting pipeline transport and infrastructure objects based on aerospace survey materials of different spatial resolutions.

Key words: remote sensing, aerospace surveying, geo-information space, main pipelines, objects of pipeline transport.

\section{REFERENCES}

1. Bondur, V. G. (Ed.). (2012). Aerokosmicheskiy monitoring ob"ektov neftegazovogo kompleksa [Aerospace monitoring of Oil and Gas complex]. Moscow: Scientific World Publ., 560 p. [in Russian].

2. Bondur, V. G. (2010). Aerospace monitoring of oil and gas areas and oil and gas facilities. Issledovanie Zemli iz kosmosa [Exploring the Earth from Space], 6, 3-17 [in Russian].

3. Khrenov, N. N. (2003). Osnovy kompleksnoy diagnostiki severnykh truboprovodov. Aerokosmicheskie metody i obrabotka materialov s"emok [Fundamentals of complex diagnostics of Northern pipelines. Aerospace methods and processing of survey materials]. Moscow: Gazoyl-press Publ., 352 p. [in Russian].

4. Lisin, Yu. V., \& Aleksandrov, A. A. (2013). Monitoring of Main Oil Pipelines in Difficult Geological Conditions. Nauka $i$ tekhnologii truboprovodnogo transporta nefti i nefteproduktov [Sci- ence and Technology of Pipeline Transport of Oil and Oil Products], 2(10), 22-27 [in Russian].

5. Lisin, Yu. V. (2013). Creation of a System for Coordinate and Time Support of Main Oil Pipelines. Izvestiya vuzov. Mashinostroenie [Proceedings of Higher Educational Institutions. Machine Building], 2, 69-75 [in Russian].

6. Balogun, L. F., Matori, A. N., \& Lawal, D. U. (2011). Geovisualization of Subsurface Pipelines: A 3D Approach. Modern Applied Science, 5(4), 158-165.

7. He, J., Zou1, Y., Ma, Y., \& Chen, G. (2011). Assistant Design System of Urban Underground Pipeline Based on 3D Virtual City. Procedia Environmental Sciences, 11, 1352-1358.

8. Karpik, A. P., \& Lisitskiy, D. V. (2009). Electronic geospace - essence and conceptual framework. Geodeziya i kartografiya [Geodesy and Cartography], 5, 41-44 [in Russian]. 
9. Avrunev, E. I., Karpik, A. P., \& Melkiy, V. A. (2019). Principles of forming unified geospatial area. In: Problems of geology and subsoil development. In Sbornik Trudov XXIII Mezhdunarodnogo simpoziuma imeni akademika $M$. A. Usova studentov i molodykh uchenykh, posvyashchennogo 120-letiyu so dnya rozhdeniya akademika K. I. Satpaeva, 120-letiyu so dnya rozhdeniya professora K. V. Radugina: T. 1. Problemy geologii $i$ osvoeniya nedr [Proceedings of XXIII International Symposium named after academician M. A. Usov, students and young scientists, dedicated to the 120 th anniversary of the birth of academician $K$. I. Satpayev, the 120th anniversary of the birth of Professor K. V. Radugin: Vol. 1. Problems of Geology and Subsoil Development] (pp. 428-429). Retrieved from conference_tpu-2019-C11_V1.pdf [in Russian].

10. Dolgopolov, D. V. Nikonov, D. V., Poluyanova, A. V., \& Melkiy, V. A. (2019). Possibilities of visual interpretation of trunk pipelines and infrastructure facilities using satellite images of high and ultra-high spatial resolution. Vestnik SGUGiT [Vestnik SSUGT], 24(3), 65-81 [in Russian].

11. Marakhtanov, V. P., \& Topchiev, A. G. (2016). Technology for geotechnical monitoring of main gas pipelines on the territory the permafrost zone of Western Siberia. Uspekhi sovremennogo estestvoznaniya [Advances in Current Natural Sciences], 9, 131-136 [in Russian].

12. Korsey, S. G., \& Dyakova, N. B. (2002). GIS technologies in Pipeline transport. ArcReview, 2(21), 17-18 [in Russian].

13. Malinnikov, V. A.,

Stetsenko, A. F., Altynov, A. E., \& Popov, S. M. (2008). Monitoring prirodnoy sredy aerokosmicheskimi sredstvami [Monitoring of the natural environment by aerospace means]. Moscow: MIIGAiK Publ., 145 p. [in Russian].

14. Karimov, K. M., Onegov, V. L., Kokutin, S. N., Sokolov, V. N., Karimova, L. K., \& Vasev, V. F. (2009). Aerial thermal image sensing of geological environment. Geologiya, geofizika $i$ razrabotka neftyanykh i gazovykh mestorozhdeniy [Geology, Geophysics, and Development of Oil and Gas Fields], 5, 24-31 [in Russian].

15. Karimov, K. M., Onegov, V. L., Kokutin, S. N., Sokolov, V. N., \& Vasev, V. F. (2009). Remote thermal image sensing of the earth in geological ex- ploration. Georesursy [Georesources], 1(29), 38-42 [in Russian].

16. Kovalevsky, N. P., \& Tomshina, T. V. (2015). Possibilities of Monitoring Potentially Dangerous Sites of the Major Transmission Hydrocarbon Pipeline on the Basis of Space-Based Earth Observation Data. Kosmonavtika $i$ raketostroenie [Cosmonautics and Rocket Engineering], 5(84), 136-140 [in Russian].

17. Baborykin, M. Yu. (2013). Monitoring of hazardous geological processes at linear objects. Inzhenernye izyskaniya [Engineering Survey], No 1011, 44-55 [in Russian].

18. Baborykin, M. Yu., Zhidilyaeva, E. V., \& Pogosyan, A. G. (2015). Factors of geological hazard in the design and operation of pipelines and their monitoring. Gazovaya promyshlennost' [Gas Industry], 11(730), 40-46 [in Russian].

19. Savinykh, V. P., Kuchko, A. S., \& Stetsenko, A. F. (1997). Aerokosmicheskaya fotos"emka [Aerospace photography]. Moscow: KartgeotsentrGeodezizdat Publ., 378 p. [in Russian].

20. Dvorkin, B. A., \& Dudkin, S. A. (2013). The newest and most promising remote sensing satellites of the Earth. Geomatika [Geomatics], 2(19), 18-38 [in Russian].

21. Abrosimov, V. V., Avrunev, E. I., \& Antonova, O. M. (2018). Izbrannye problemy i perspektivnye voprosy zemleustroystva, kadastrov $i$ razvitiya territoriy - 2017 [Selected problems and perspective issues of land management, cadastre and development of territories - 2017]. A.P. Sizov (Ed.). Moscow: Rusayns Publ., 262 p. [in Russian].

22. Ryl'skiy, I. A. (2016). Laser scanning and space photography-competition or partnership. Geomatika [Geomatics], 1(30), 10-18 [in Russian].

23. Zirnig, W., Hausamann, D., \& Schreier, G. (2002). High-Resolution Remote Sensing Used to Monitor Natural Gas Pipe-lines. Earth Observation Magazine, 11, 12-17.

24. Hausamann, D., Zirnig, W., Schreier, G. \& Strobl, P. (2005). Monitoring of gas pipelines a civil UAV application. Aircraft Engineering and Aerospace Technology, 77(5), 352-360.

25. Avrunev, E. I., Yambaev, H. K., Opritova, O. A., Chernov, A. V., \& Gogolev, D. V. (2018). Assessment of the accuracy of 3D models built using unmanned aircraft systems. Vestnik SGUGiT [Vestnik SSUGT], 23(2), 211-228 [in Russian]. 
УДК 519.876.5:71(470.53)

DOI: $10.33764 / 2411-1759-2020-25-3-160-168$

\section{ОСОБЕННОСТИ СОЗДАНИЯ ТРЕХМЕРНОЙ ЦИФРОВОЙ МОДЕЛИ ЦЕНТРАЛЬНОГО ПЛАНИРОВОЧНОГО РАЙОНА ГОРОДА ПЕРМИ ПО ДАННЫМ АЭРОФОТОСЪЕМКИ}

\section{Артем Сергеевич Зарипов}

Пермский государственный национальный исследовательский университет, 614990, Россия, г. Пермь, ул. Букирева, 15, магистрант, тел. (952)31-75-022, e-mail: artemiy790@yandex.ru

Целью работы было создание подробной цифровой модели Центрального планировочного района (ЦПР) города Перми. В качестве основного метода была использована аэрофотосъемка с беспилотного летательного аппарата. Уникальность работы заключается в комбинировании двух типов БПЛА в рамках одного проекта. Актуальность исследования обоснована комбинированным использованием двух типов БПЛА, что позволило отснять с высокой детальностью обширную территорию со сложными границами. Объект съемки представлял собой обширную по площади и сложную по структуре городскую территорию. Для повышения качества геопривязки итоговых данных съемка происходила с использованием опорных точек, расставленных на всей площади, покрываемой полетами. Результатом работы стал ортофотоплан с пространственным разрешением 2 см на пиксель, а также цифровая модель местности и объемная трехмерная модель с разрешением 11 и 3 см соответственно. Благодаря использованию опорных точек точность привязки, как плановая, так и высотная, составляет в среднем меньше 3 см и не превышает ни в одной точке 5 см. На геопортале ортофотоплан используется в качестве доступной подключаемой подробной крупномасштабной подложки, а трехмерная модель оптимизирована для просмотра в браузере и доступна для просмотра с любых ракурсов.

Ключевые слова: беспилотный летательный аппарат, аэрофотосъемка, фотограмметрия, цифровая модель поверхности, ортофотоплан, градостроительное планирование.

\section{Введение}

В настоящее время происходит беспрецедентный рост популярности применения БПЛА для выполнения самых разных по своей направленности задач [1]. Однако большинство исследований по этой тематике проводятся на достаточно ограниченной по площади территории и только при помощи одного типа БПЛА, в то время как при съемке обширных объектов, таких как, например город, возникает целый ряд дополнительных проблем. Современный уровень развития аэрофотосъемочного оборудования позволяет выполнять достаточно масштабные по своему объему проекты, площадь съемки которых уже сейчас может достигать площади целого города. Обладая необходимым оборудованием для проведения как наземных геодезических, так и аэрофотосъемочных работ, становится возможным создать цифровую модель практически любого населенного пункта.
В данной статье подробно описана методика проведения аэрофотосъемочных работ на сложной и неоднородной территории населенного пункта с использованием опорных точек и двух типов БПЛА. Рассмотрено создание высокодетальной цифровой модели местности (ЦММ) центрального планировочного района города Перми [2].

Основой успешного выполнения работы является грамотное планирование схемы полетов над городом, комбинирование нескольких БПЛА в рамках одного проекта, а также обязательное использование высокоточных геодезических приемников для достижения корректной географической привязки результата в пространстве заданной системы координат.

Подобные проекты успешно реализуются в разных городах России, например, аналогичная работа была выполнена в 2016 г. для территории г. Новосибирска. Также БПЛА применялись для создания ортофотопланов и последующего проведения кадастровых 
работ по материалам беспилотной аэрофотосъемки в г. Екатеринбурге [3] и территории учебно-научной базы Предуралье в Пермском крае [4]. Также существует успешный опыт использования БПЛА для трехмерного моделирования городской застройки [5]. В зарубежных странах работы по созданию ортофотопланов и трехмерных цифровых моделей городов выполняются регулярно. Особенности технологии рассмотрены в работах $[6,7]$ на примере городов Корпус Кристи в США и Куритиба в Бразилии.

Выбор типа БПЛА зависит от цели съемки, для которой он будет применен. Условно можно выделить два основных вида беспилотников: самолетный и коптерный, он же мультироторный. Первый используется для проведения аэрофотосъемки обширных по площади территорий, например, лесных массивов или сельскохозяйственных угодий. При помощи второго чаще снимаются компактно локализованные объекты и различные инженерные сооружения со сложной геометрией, которые необходимо облететь вокруг.

Целью работы было создание цифровой модели местности центральной части г. Перми и оценка ее применимости, характеристик, точности.
Для ее достижения были поставлены и решены следующие задачи:

- деление территории на участки для съемки;

- расстановка опорных точек;

- выполнение основных полетов;

- обработка данных;

- проведение дополнительных корректирующих съемок;

- оценка точности ЦММ на основе опорных точек;

- использование результатов работы для наполнения интернет-портала информационной системы обеспечения градостроительной деятельности города Перми.

\section{Методы и материалы}

Аэрофотосъемка происходила при помощи двух видов БПЛА - самолетного и мультироторного. Первый использовался для выполнения основных полетов, так как имеет куда большую скорость и полосу захвата, a второй применялся для дополнительной съемки отдельных участков территории, которые было невозможно правильно смоделировать на основе данных, полученных с БПЛА самолетного типа. Более подробно характеристики БПЛА приведены в таблице.

Характеристики БПЛА, используемых в проекте

\begin{tabular}{|l|c|c|c|c|c|c|}
\hline Типа БПЛА & $\begin{array}{c}\text { Фокусное } \\
\text { расстояние } \\
\text { камеры, мм }\end{array}$ & $\begin{array}{c}\text { Высота } \\
\text { полета, } \\
\text { м }\end{array}$ & $\begin{array}{c}\text { Скорость } \\
\text { полета, } \\
\text { км/ч }\end{array}$ & $\begin{array}{c}\text { Ширина } \\
\text { полосы } \\
\text { охвата, } \mathrm{M}\end{array}$ & $\begin{array}{c}\text { Площадь } \\
\text { съемки за один } \\
\text { полет, } \text { м }^{2}\end{array}$ & $\begin{array}{c}\text { Время } \\
\text { в полете, } \\
\text { минут }\end{array}$ \\
\hline Самолет & 70 & 290 & 70 & До 800 & 600000 & 35 \\
\hline Квадрокоптер & 45 & 150 & 50 & До 300 & 200000 & 25 \\
\hline
\end{tabular}

Первым этапом работ является изучение территории по данным космической съемки. Необходимо получить и установить точные границы территории, на которой планируется аэрофотосъемка. Для этого хорошо подходит открытое ПО SAS Planet, которое позволяет работать с векторными пространственными данными, подгружая растровые подложки из интернета. Затем следует этап разбиения всей снимаемой территории на участки, которые можно будет охватить за один полет на БПЛА. Исходя из общей площади объекта в

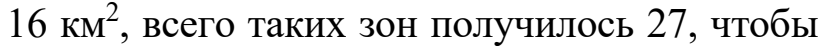
заснять весь ЦПР г. Перми (рис. 1).

Следующим шагом является расстановка на местности опорных точек - отмеченных либо ярко выраженных объектов на земной поверхности, координаты которых достоверно измерены при помощи высокоточного геодезического оборудования. Общее количество таких отметок зависит от площади снимаемой территории, которая в данном проекте равна 16 км$^{2}$, но достаточной считается плотность, равная 10 опорным точкам 


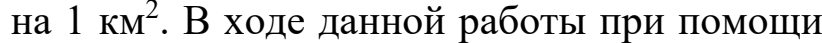
геодезического GPS-ГЛОНАСC приемника марки Sokkia GRX 3 было установлено порядка 200 отметок на местности. Параметры точности соответствуют 5 мм в плане и 10 мм по высоте. Планирование расстановки опорных точек, как правило, также проходит в ПО SAS Planet.

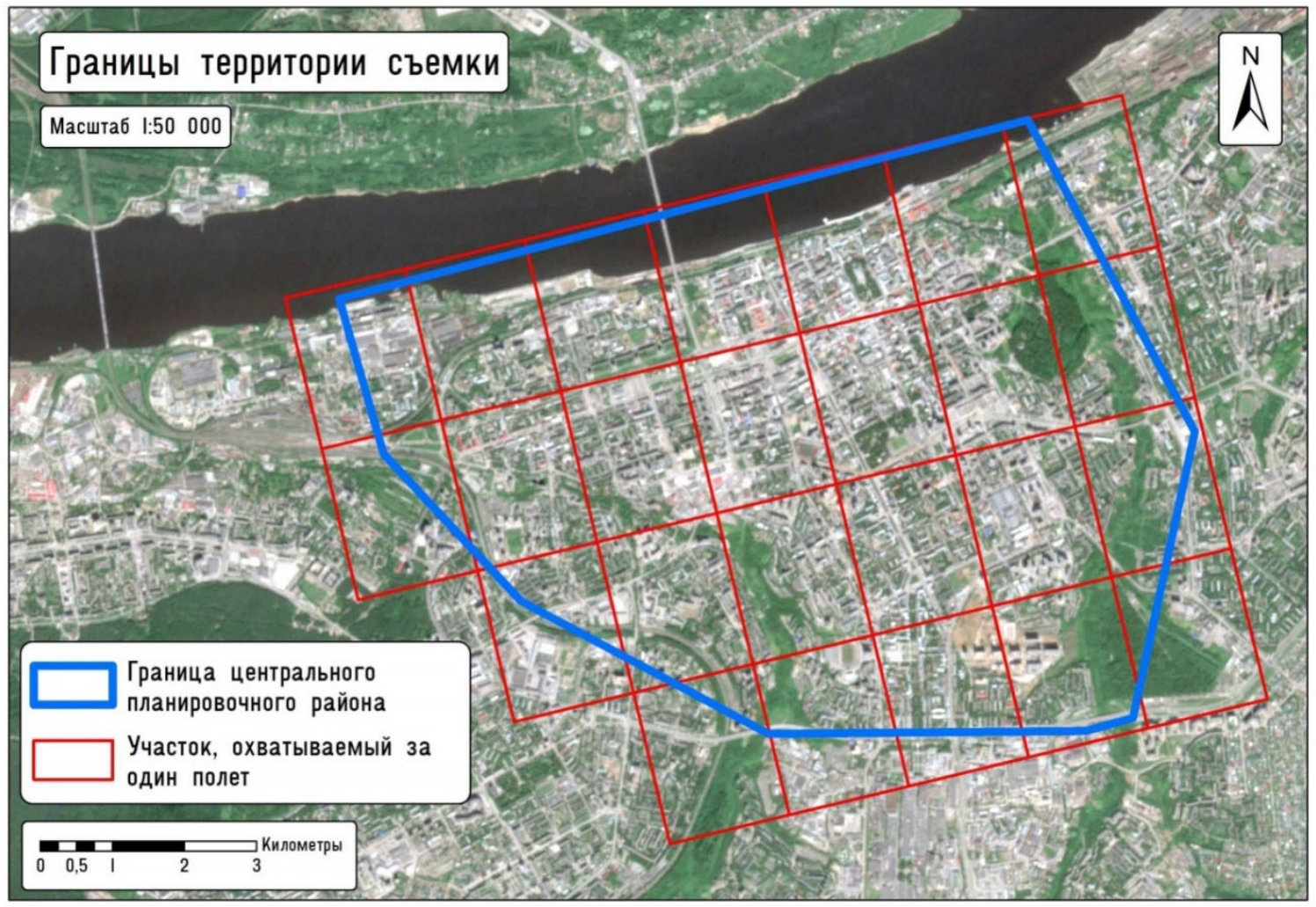

Рис. 1. Территория ЦПР г. Перми и выделенные зоны для проведения съемки

Далее производилась съемка территории с БПЛА. Так как ее площадь достаточно велика, рационально было применять БПЛА именно самолетного типа, которые имеют более высокую скорость полета и производительность съемки. Как уже было сказано выше, всего было выполнено 25 полетов, при этом 15 из них были при положении камеры строго в надир для фиксации общей ситуации, и еще 10 запусков были сделаны при положении камеры под углом в 30 градусов, для съемки не только крыш домов, но и фасадов зданий. Планирование полета проходило в специализированном программном обеспечении Mission Planner (рис. 2), где задаются и автоматически рассчитываются такие параметры, как высота полета, ширина полосы охвата, фокусное расстояние объектива камеры, требуемое пространственное разрешение.
Дополнительные съемки для уточнения ЦММ проходили при помощи дронамультикоптера, так как именно такая конструкция лучше всего подходит для съемки небольших по площади и протяженности участков. Аппарат может быть использован для получения снимков, пригодных для создания и обновления карт и планов местности, формирования ЦММ, 3D-моделей зданий и объектов, тепловизионных карт, проведения панорамной съемки, а также в интересах мониторинга развития чрезвычайных ситуаций (ЧС) [8]. В качестве съемочной аппаратуры использовались бытовые цифровые беззеркальные фотокамеры Sony RX 1 и Olympus Pen-E, которые получили широкое применение в фотограмметрии. По материалам аэросъемок такими камерами оперативно обновляются и создаются планы на локальные участки местности [9]. 


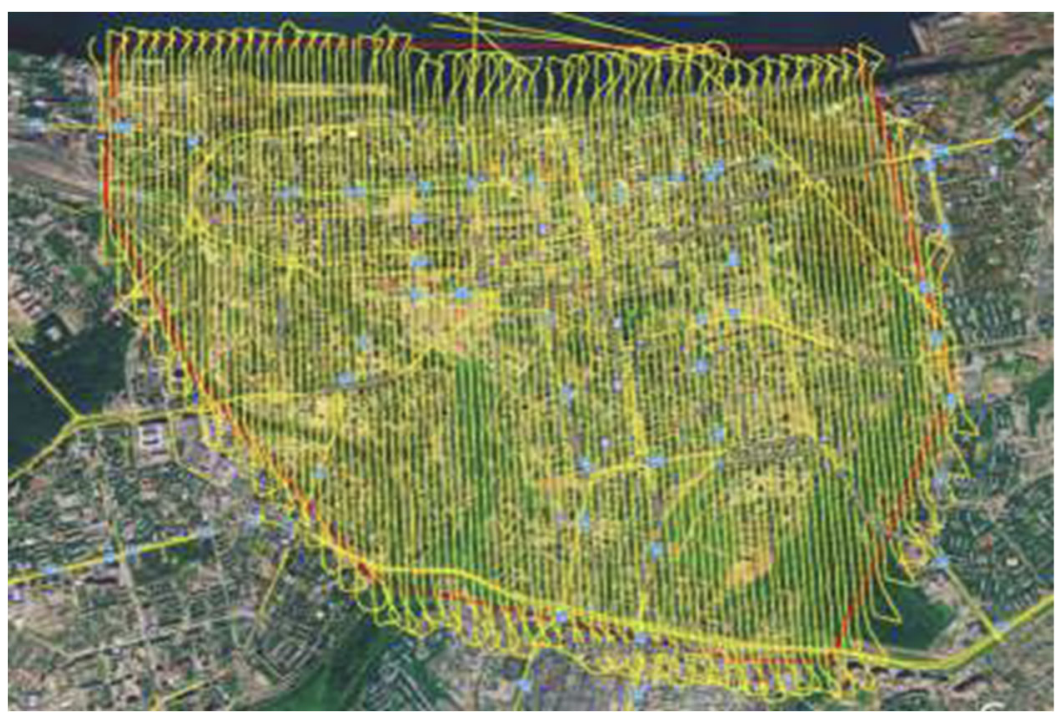

Рис. 2. Схема основных полетов БПЛА

Общее количество изображений, сделанных за период полевого этапа, составляет порядка 22000 снимков, выполненных с продольным и поперечным перекрытием 76 и 77 \% соответственно. После того, как были выполнены все запланированные вылеты, проходит предварительная обработка изображений. Она состоит из нескольких этапов:

1) цветовая коррекция изображений;

2) присвоение снимкам привязки в пространстве;

3) предварительная фотограмметрическая обработка;

4) выявление неточностей и проблемных участков на ЦММ;

5) фиксация их на картосхеме, по которой в дальнейшем будет осуществляться досъемка либо пересъемка территории.

Исходными данными, полученными в процессе аэрофотосъемки, являются фотографии и данные об их местоположении в момент спуска затвора камеры. Изображения были сохранены в формат RAW-файлов, которые используются при съемке сложных объектов, а также во время продолжительных полетов, так как условия освещения в процессе съемки меняются, что влияет и на качество изображений. Цветокорекция была выполнена средствами ПО Adobe Lightroom.

Следующим этапом было присвоение снимкам пространственной привязки. Это является необходимым условием для того, чтобы программы для фотограмметрической обработки смогли с ними работать. Процедура была вручную выполнена в той же программе, в которой происходило планирование полетного задания - Mission Planner. Taким образом была получена таблица, в которой напротив каждой записи с именем фотографии прописаны координаты в заданной системе координат, как правило, WGS-84.

Обработка данных проходила в программе Agisoft Metashape - это программное обеспечение для фотограмметрической обработки материалов аэрофотосъемки, позволяющее создавать 3D-модели, ортофотопланы и ЦММ. У программного обеспечения нет ограничений на количество изображений, т. е. это зависит только от мощности компьютера [10]. Процесс работы с материалами аэрофотосъемки включал в себя следующие шаги.

1. Загрузка данных в проект.

На этом этапе были добавлены и упорядочены все исходные данные (фотографии и таблицы с информацией о привязке снимков и опорных точек).

2. Выравнивание.

После того как изображения были загружены в Metashape, необходимо определить положение и ориентацию камеры для каждого кадра и построить разреженное облако точек. Эти операции выполняются на этапе выравнивания. 
3. Расстановка опорных точек.

Точки используются для выполнения более точной пространственной привязки готового ортофотоплана и ЦММ в заданной системе координат. Координаты опорных точек определены в городской системе координат г. Перми, в которой и были зафиксированы точки. Данная система координат - локальная, с центром в центральной части города и используется для проведения кадастровых и геодезических работ строго на территории г. Перми. Сама опорная точка представляет собой отмеченный либо характерный объект на земной поверхности, точные координаты которого зафиксированы при помощи высокоточного геодезического GPS-приемника.

4. Построение плотного облака точек.

Основываясь на рассчитанных положениях камер, были построены плотные облака точек, которые затем использовались для построения полигональной модели, карты высот или тайловой модели.

5. Построение карты высот.

Agisoft Metashape позволяет отображать модель поверхности в виде регулярной сетки значений высоты, то есть создавать карту высот (DSM).
6. Построение ортофотоплана.

Ортофотоплан строится на основании исходных снимков (что позволяет создавать результирующее изображение высокого разрешения) и реконструированной модели.

7. Построение тайловой модели.

Формат иерархических тайлов полезен при создании моделей объектов большой площади (например, городов), так как позволяет визуализировать большие 3D-модели с высоким разрешением и детализацией (рис. 3). Тайловая модель построена на основании плотного облака точек, а текстура - из исходных фотографий [11].

После завершения фотограмметрической обработки производился поиск артефактов, которые всегда возникают ввиду сложности городского ландшафта. Наиболее часто встречались ошибки, связанные со сложной геометрией зданий или с неправильным наложением текстуры на фасады домов. Исправить это можно, лишь совершив дополнительную съемку вокруг интересующего строения или целого квартала с помощью квадрокоптера. Затем полученные в процессе дополнительной съемки данные были совмещены с первоначальными.
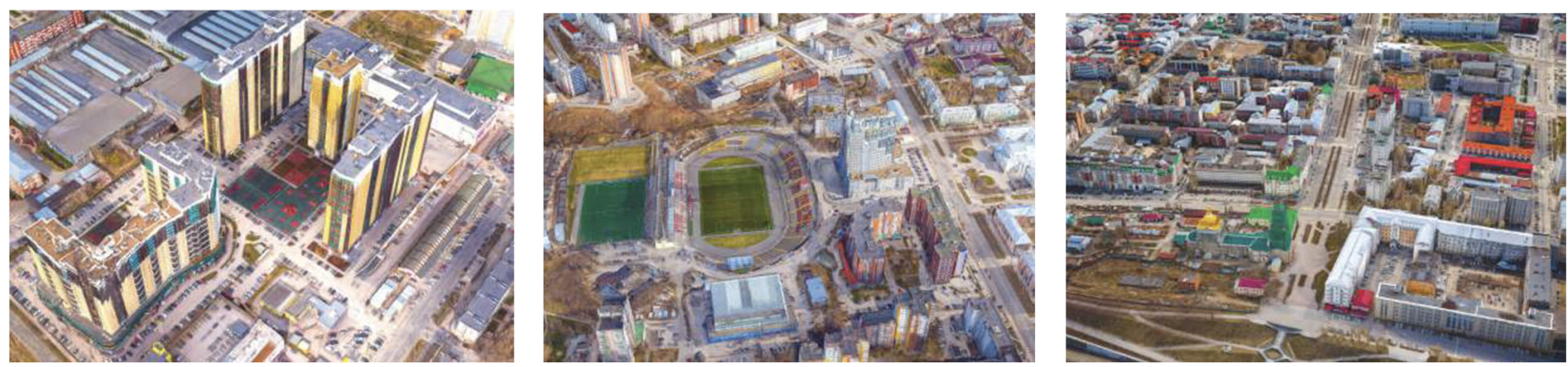

Рис. 3. Приближенные фрагменты тайловой модели

\section{Результаты}

Результатом выполненной работы является ортофотоплан, трехмерная модель г. Перми и ЦММ с пространственным разрешением 2, 3 и 11 см на пиксель соответственно.

Первые два продукта интегрированы в качестве пространственных данных для webприложения ИСОГД (информационной системы обеспечения градостроительной дея- тельности) [12]. Ортофотоплан можно подключить в качестве крупномасштабной высокодетальной подложки (рис. 4), а тайловая модель отвечает за трехмерное отображение.

Благодаря использованию опорных точек удалось достигнуть высокого качества пространственной привязки итоговых данных. Точность, как плановая, так и высотная, составляет в среднем меньше 3 см и не превышает ни в одной опорной точке $5 \mathrm{~cm}$. В совокупности с ошибкой $5 \mathrm{~cm}$, которую может 
давать используемый геодезический GPS- план, так же, как и ЦММ, можно использоГЛОНАСС-приемник при измерении коор- вать при решении задач градостроительного динат, можно говорить о том, что ортофото- планирования (рис. 5).

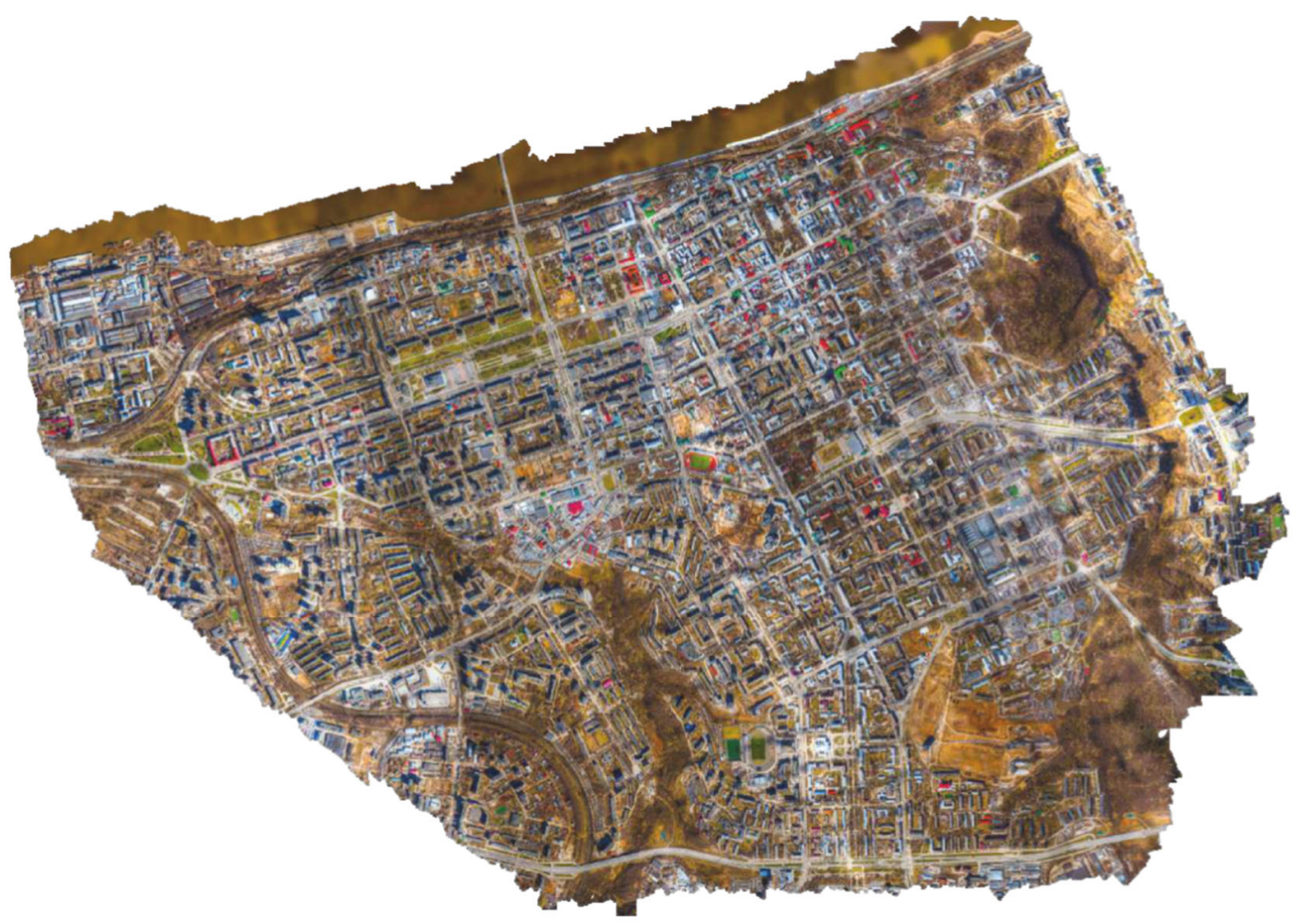

Рис. 4. Ортофотоплан ЦПР г. Перми

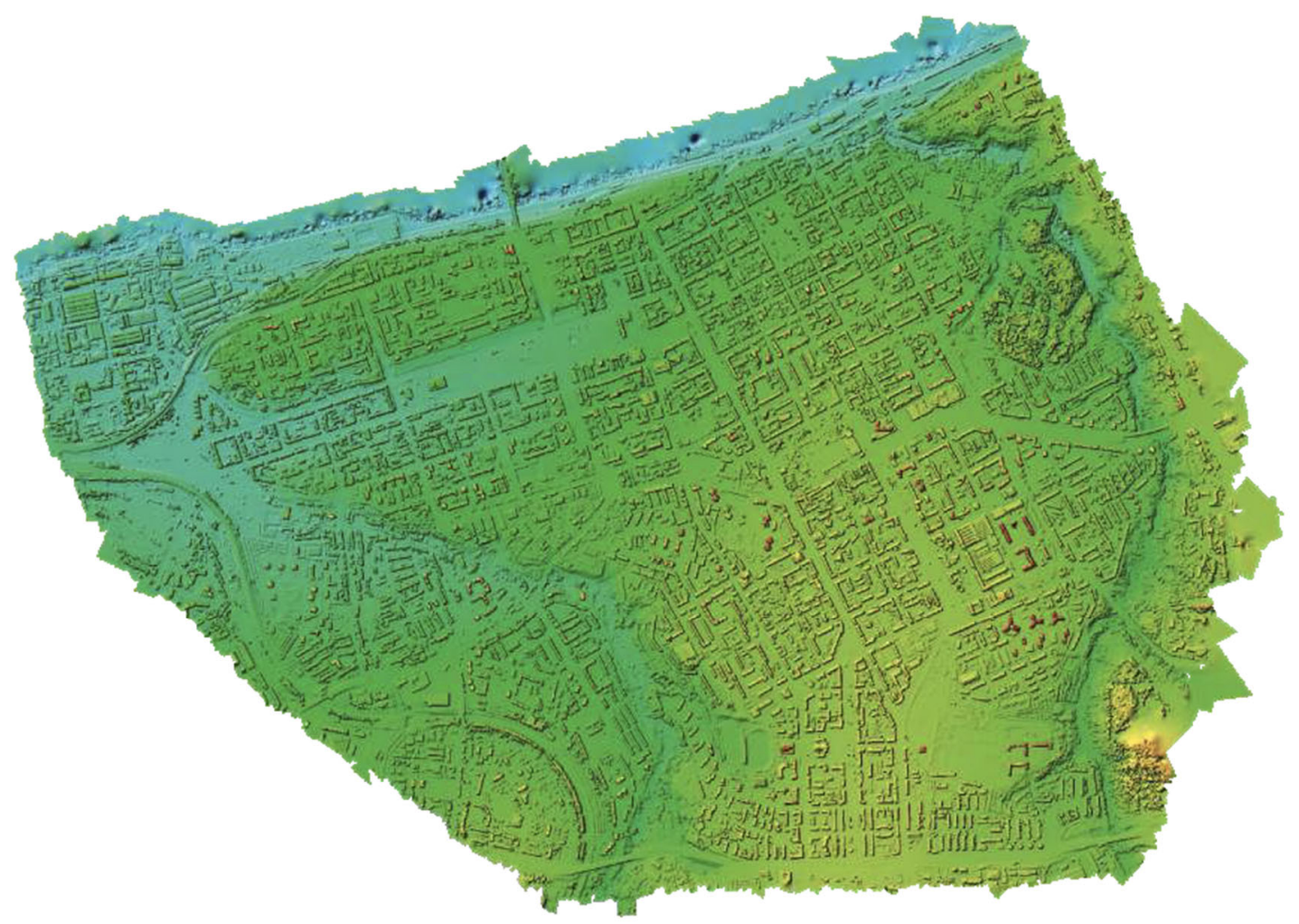

Рис. 5. ЦММ центральной части г. Перми 
Оценка точности ЦМП выполнена по величине невязки между 193 опорными точками в программе Agisoft Metashape. Среднее значение ошибки составило 2,945 cм, минимальное значение 1,874 см, максимальное - 4,857 см. В качестве контрольных точек использовались те, которые не применялись для привязки ортофотоплана и ЦММ. Всего таких было 10 штук, средняя ошибка относительно которых составляет $1,578 \mathrm{~cm}$, минимальное значение 0,823 см, максимальное - 3,995 см. Дальнейшая процедура наложения координат опорных точек на ортофотоплан также не показала расхождений между местоположением опорной точки на снимке и ее фактическими визуализированными координатами.

\section{Обсуждение и заключение}

Современный уровень развития аэрофотосъемочного оборудования позволяет выполнять достаточно масштабные по своему объему проекты для крупных населенных пунктов. В настоящей работе было рассмотрено создание высокодетальной ЦММ и трехмерной модели центральной части г. Перми, что подтверждает эффективность использования БПЛА в качестве альтернативы принятым методам наземных геодезических изысканий. Созданная ЦМП по своей геометрической точности и детальности является одной из лучших в России. Уникальность выполненного проекта заключается в следующих аспектах:

- методика комбинирования двух типов БПЛА при съемке сложной по своей структуре городской территории;

- масштабность проекта, который включал в себя съемку территории площадью $16 \mathrm{KM}^{2}$;

- использование опорных точек в количестве около 200 штук на всей площади съемки, что позволило создать топологически корректную и геометрически точную модель пространства;

- интеграция данных с интернет-порталом информационной системы обеспечения градостроительной деятельности.

К недостаткам можно нести высокие временные затраты на проведение съемки и обработку данных, а также несовершенство самого алгоритма аэрофотосъемки, изза чего могут возникать проблемы со съемкой сложных ландшафтов, некоторых зданий, строений, и сооружений по типу мостов, дамб и эстакад.

Применение аэрофотосъемки значительно расширяет привычные возможности для исследования пространства и получения информации о нем. Так, воздушное фотограмметрическое сканирование позволяет в сжатые сроки создавать объемные трехмерные реалистичные модели объектов реального мира достаточно высокого качества. Большей детальности можно добиться только при помощи лазерного сканирования, однако на сегодняшний день лидарная съемка менее доступна для массового использования по причине высокой стоимости. Весьма перспективным и все более активно применяемым на практике является совместное использование данных наземного и воздушного лазерного сканирования (локации) и цифровой аэрофотосъемки [13]. Такой подход особенно эффективен при обследовании объектов, включающих сложные инженерные сооружения, например, электрические подстанции [14]

\section{Благодарности}

Выражаем признательность администрации г. Перми за предоставленное право пользоваться воздушным пространством и финансирование проекта. Также благодарим компанию «FPV-Пермь» за содействие в проведении съемок и доступ к необходимому оборудованию.

\section{БИБЛИОГРАФИЧЕСКИЙ СПИСОК}

1. Choudhary M. What are popular uses of drones? [Electronic resource]. - Geospatial World. Mode of access: https://www.geospatialworld.net/ article/what-are-popular-uses-of-drones (дата обращения 29.02.2020).
2. Генеральный план города Перми (2001-2020 гг.) [Электронный ресурс] : решение Пермской городской думы от 17.12.2010 № 205. Доступ из справ.-правовой системы «ГАРАНТ». 
3. Пация А. М. Анализ применения аэрофотосъемки с БПЛА для выполнения сплошного межевания населенных пунктов // Интерэкспо ГЕО-Сибирь. XIV Междунар. науч. конгр. : Междунар. науч. конф. «Экономическое развитие Сибири и Дальнего Востока. Экономика природопользования, землеустройство, лесоустройство, управление недвижимостью» : сб. материалов в 2 т. (Новосибирск, 23-27 апреля 2018 г.) - Новосибирск : СГУГиТ, 2018. Т. 2. C. $125-133$.

4. Бузмаков С. А., Санников П. Ю., Андреев Д. Н. Подготовка и применение материалов аэрофотосъемки для изучения лесов // Изв. Самарского научного центра Российской академии наук - 2016. - № 2. - С. 313-316.

5. Опритова О. А. Исследование возможностей применения беспилотных авиационных систем для моделирования объектов недвижимости // Вестник СГУГИТ. - 2018. - Т. 23, № 3. C. $248-257$.

6. Corpus Christi, Texas Steps into 3D GeoDesign and Emerges a Winner / Mai Ward [Electronic resource]. - 2012. - Mode of access: https://www.geoconnexion.com (дата обращения 5.06.2020).

7. Luciene Stamato Delazari, Leonardo Ercolin Filho. Mapping a University Campus in Brazil Creating Indoor and Outdoor Maps for a Routing Application [Electronic resource] // GIM International. - 2019. - Mode of access: https://www.giminternational.com (дата обращения 5.06.2020).

8. Барбасов В. К. Устройство и технические характеристики топографического БПЛА мультироторного типа // Интерэкспо ГЕО-Сибирь-
2013. IX Междунар. науч. конгр. : Междунар. науч. конф. «Дистанционные методы зондирования Земли и фотограмметрия, мониторинг окружающей среды, геоэкология» : сб. материалов в 2 т. (Новосибирск, 15-26 апреля 2013 г.). - Новосибирск : СГГА, 2013. Т. 1. - С. 1-5.

9. Ессин А. С., Ессин С. С. Особенности фотограмметрической обработки материалов цифровой аэрофотосъемки с БПЛА // ГЕО-Сибирь2010. VI Междунар. науч. конгр. : сб. материалов в 6 т. (Новосибирск, 19-29 апреля 2010 Г. ). Новосибирск : СГГА, 2010. Т. 1, ч. 1. - С. 1-4.

10. Тихонов А. А., Акматов Д. Ж. Обзор программ для обработки данных аэрофотосъемки // Горный информационно-аналитический бюллетень. - 2018. - № 12. - С. 192-198.

11. Руководство пользователя Agisoft Metashape Professional Edition, версия 1.5 [Электронный pecypc]. - Режим доступа: https://www.agisoft.com/ pdf/metashape-pro_1_5 ru.pdf (дата обращения 29.02.2020).

12. Градостроительный кодекс Российской Федерации [Электронный ресурс] : федер. закон от 29.12.2004 № 190-Ф3. - Доступ из справ.правовой системы «КонсультантПлюс».

13. When Photogrammetry Meets Lidar: Towards the Airborne Hybrid Era [Electronic resource] / I. Toschi, F. Remondino, T. Hauck, K. Wenzel // GIM International. - Mode of access: https://www.gim-international.com (дата обращения 8.03.2020).

14. Медведев Е. М. Методы лазерной локации и цифровой аэрофотосъемки при выполнении инженерных изысканий // Экспозиция Нефть Газ. - 2010. - № 4. - С. 10-12.

Получено 15.04.2020

(C) A. C. 3арипов, 2020

\section{CREATING A THREE-DIMENSIONAL DIGITAL SURFACE MODEL OF THE CENTRAL PLANNING DISTRICT OF PERM BASED ON AERIAL SURVEY DATA}

\section{Artem S. Zaripov}

Perm State University, 15, Bukireva St., Perm, 614990, Russia, Master Student, phone: (952)31-75-022, e-mail: artemiy790@yandex.ru

The aim of the work was to create a detailed digital model of the Central Planning District (DPC) of Perm. Aerial photography from an unmanned aerial vehicle was used as the main method. The uniqueness of the work lies in the combination of two types of UAVs in one project. The relevance of the research is substantiated by combined use of two UAVs types, which made it possible to shoot vast territory with complex boundaries in high resolution. The subject was a vast urban area with a complex structure. To improve the quality of geo-referencing of the final data, the survey was carried out using reference signs placed over the entire area covered by flights. The result of the work was an orthomosaic with a spatial resolution of $2 \mathrm{~cm}$ per pixel, as well as a digital terrain model and a three-dimensional model with a resolution of 11 and $3 \mathrm{~cm}$, 
respectively. Thanks to the use of reference signs, the reference accuracy, both planned and high, is in average less than $3 \mathrm{~cm}$ and does not exceed $5 \mathrm{~cm}$ in any sign. On the geoportal, the orthophotomap is used as an accessible, connected, large-scale detailed substrate, and the three-dimensional model is optimized for viewing in a browser and viewable from any angle.

Key words: unmanned aerial vehicle, aerial photography, photogrammetry, digital surface model, orthophotomap, urban planning.

\section{REFERENCES}

1. Choudhary, M. (n. d.). What are popular uses of drones? // Geospatial World. Retrived from https://www.geospatialworld.net/article/what-arepopular-uses-of-drones (accessed 02.29.2020) [in Russian].

2. Decision of the Perm City Council of December 17, 2010 No. 205. General plan of the city of Perm (2001-2020). Retrieved from Garant online database [in Russian].

3. Patia, A. M. (2018). Analysis of the use of aerial photography with UAVs to perform continuous surveying of settlements. In Sbornik materialov Interekspo GEO-Sibir'-2018: Mezhdunarodnoy nauchnoy konferentsii: T. 2. Ekonomicheskoe razvitie Sibiri i Dal'nego Vostoka. Ekonomika prirodopol'zovaniia, zemleustroistvo, lesoustroistvo, upravlenii e nedvizhimost'iu [Proceedings of Interexpo GEO-Siberia-2015: International Scientific Conference: Vol. 2. Economic Development of Siberia and the Far East. Enviromental Economics, Land Management, Forestry Management and Property Management] (pp. 125-133). Novosibirsk: SSUGT Publ. [in Russian].

4. Buzmakov, S. A., Sannikov, P. Yu., \& Andreev, D. N. (2016). Preparation and use of aerial photography materials for the study of forests. Izvestiya Samarskogo nauchnogo tsentra Rossiyskoy akademii nauk [Bulletin of the Samara Scientific Center of the Russian Academy of Sciences], 2, 313316 [in Russian].

5. Opritova, O. A. (2018). Study of the possibilities of using unmanned aircraft systems for modeling real estate objects. Vestnik SGUGiT [Vestnik SSUGT], 23(3), 248-257 [in Russian].

6. Corpus Christi, Texas Steps into 3D GeoDesign and Emerges a Winner. (2012). Retrieved from https://www.geoconnexion.com (дата обращения 5.06.2020).

7. Luciene Stamato Delazari, \& Leonardo Ercolin Filho. (2019). Mapping a University Campus in Brazil - Creating Indoor and Outdoor Maps for a Routing Application. In GIM International.
Retrieved from https://www.gim-international.com (дата обращения 05.06.2020).

8. Barbasov, V. K. (2013). The device and technical characteristics of the topographic UAV multirotor type. In Sbornik materialov Interekspo GEOSibir'-2013: Mezhdunarodnoy nauchnoy konferentsii: T. 1. Distantsionnye metody zondirovaniya Zemli i fotogrammetriya, monitoring okruzhayushchey sredy, geoekologiya [Proceedings of Interexpo GEO-Siberia2013: International Scientific Conference: Vol. 1. Remote Sensing Methods of the Earth and Photogrammetry, Environmental Monitoring, Geoecology] (pp. 1-5). Novosibirsk: SSGA Publ. [in Russian].

9. Essin, A. S., \& Essin, S. S. (2010). Features of the photogrammetric processing of digital aerial photography materials from UAVs. In Sbornik materialov Interekspo GEO-Sibir'-2010: T. 1, ch. 1 [Proceedings of Interexpo GEO-Siberia-2010

10. : Vol. 1, Part 1] (pp. 1-4). Novosibirsk: SSGA Publ. [in Russian].

11. Tikhonov, A. A., \& Akmatov, D. Zh. (2018). Overview of programs for processing aerial photography data. Gornyy informatsionnoanaliticheskiy byulleten' [Mining Information and Analytical Bulletin], 12, 192-198 [in Russian].

12. Agisoft Metashape Professional Edition User Guide, version 1.5. (n. d.). Retrieved from https://www.agisoft.com/pdf/metashape-

pro_1_5_en.pdf (accessed 02.29.2020).

13. Federal Law of December 29, 2004 No. 190FZ. Town Planning Code of the Russian Federation. Retrieved from ConsultantPlus online database [in Russian].

14. Toschi, I., Remondino, F., Hauck, T., \& Wenzel, K. (n. d.). When Photogrammetry Meets Lidar: Towards the Airborne Hybrid Era. In GIM International. Retrieved from https://www.giminternational.com (accessed March 8, 2020).

15. Medvedev, E. M. (2010). Methods of laser location and digital aerial photography during engineering surveys. Ekspozitsiya Neft' Gaz [Exposition Oil Gas], 4, 10-12 [in Russian]. 
УДК 629.783:581.9(470.620)

DOI: $10.33764 / 2411-1759-2020-25-3-169-180$

\section{МОНИТОРИНГ БЕРЕГА ВЕРБЯНОЙ КОСЫ ПО СПУТНИКОВЫМ ДАННЫМ}

\section{Вячеслав Владимирович Крыленко}

Институт океанологии им. П. П. Ширшова РАН, 117997, Россия, г. Москва, Нахимовский пр., 36, кандидат географических наук, старший научный сотрудник, тел. (861)412-80-89, e-mail: krylenko.slava@gmail.com

\section{Марина Владимировна Крыленко}

Институт океанологии им. П. П. Ширшова РАН, 117997, Россия, г. Москва, Нахимовский пр., 36, кандидат географических наук, ведущий научный сотрудник, тел. (861)412-80-89, e-mail: krylenko@mail.ru

Вербяной косой называют сформировавшуюся в течение последних 200 лет юго-западную часть морского края дельты р. Кубани. Для оценки тенденций современного развития этой аккумулятивной формы, динамики берега, интенсивности эрозионно-аккумулятивных процессов и эффективности существующих берегозащитных сооружений выполнены комплексные мониторинговые исследования, которые включали анализ данных дистанционного зондирования и картографического материала. Динамика берега Вербяной косы определяется совместным действием природных и антропогенных факторов. Береговая линия западной части косы за последние полвека выдвинулась на 200-400 м, восточнее берег отступил на 30-200 м. Хозяйственное освоение прилегающей к косе территории (разведка и добыча природного газа) вызвало необходимость стабилизации берега, для чего в 2007 г. была сооружена берегозащитная дамба. Мониторинг показал, что после создания дамбы наблюдается стабилизация берега Вербяной косы, но продолжаются изменения рельефа подводного берегового склона, связанные с адаптацией береговой системы к новым условиям. В настоящее время Вербяная коса развивается как природно-техногенная система.

Ключевые слова: Азовское море, аккумулятивная форма, дистанционные методы, морской край дельты, рельеф, динамика берега, мониторинг.

\section{Введение}

Глобальная направленность береговых процессов в настоящее время характеризуется повсеместным отступанием берегов, связанным с подъемом уровня Мирового океана и дефицитом твердого материала в береговой зоне. Интенсификация эрозии берегов и отступание береговой линии аккумулятивных береговых форм вызывает разрушение прибрежных ландшафтов и гражданских, промышленных и транспортных объектов, нанося значительный экономический ущерб. Для создания планов комплексного управления прибрежной зоной, которые позволяют минимизировать возможные негативные последствия для природы и экономический ущерб, необходимы постоянные мониторинговые исследования динамики берега [1]. Наиболее точные результаты могут дать натурные геодезические изыскания, проводимые непосредственно на морском берегу. Однако стоимость и трудоемкость таких изыска- ний высока, поэтому при исследовании крупных береговых аккумулятивных форм рельефа, наряду с традиционными геодезическими методами, целесообразно использовать современные дистанционные методы.

Вербяная коса - это исторически сложившееся название аккумулятивной береговой формы барьерного типа, расположенной на юго-восточном побережье Азовского моря. Она является частью морского края дельты р. Кубани (рис. 1) и как единое аккумулятивное тело сформировалась в течение последних 200 лет (рис. 2) под влиянием одновременного действия природных и антропогенных процессов.

Исследования динамики морского края дельты р. Кубани начались еще с середины XIX в. [2]. В 1958 г. ученые ЧЭНИС ИО АН СССР выполнили комплексные исследования устьевой зоны р. Кубани [3]. С 1971 г. А. А. Иванов развернул наблюдения за перестройками пляжа и подводного склона Темрюкского залива [4]. 


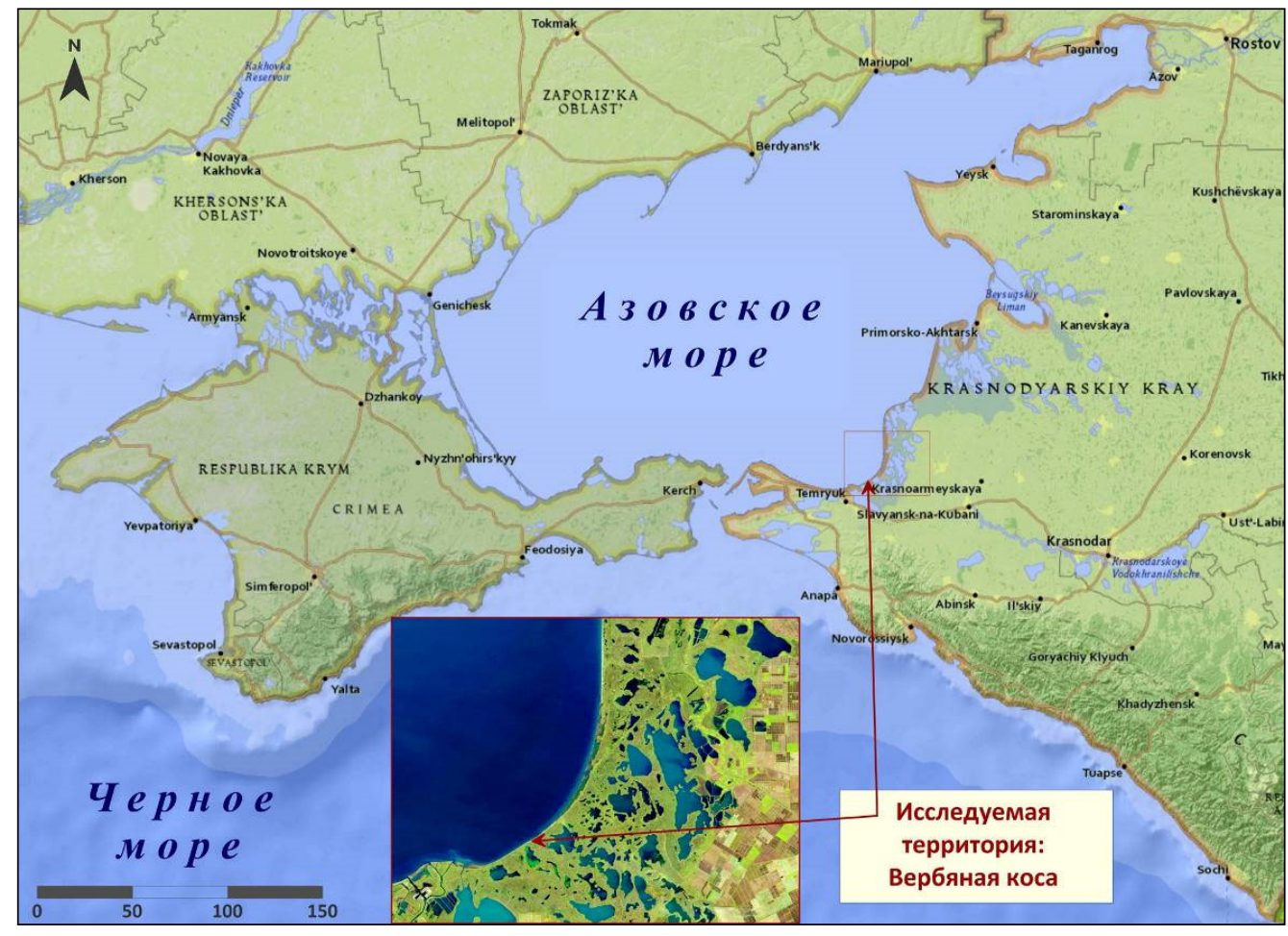

Рис. 1. Схема расположения исследуемого участка
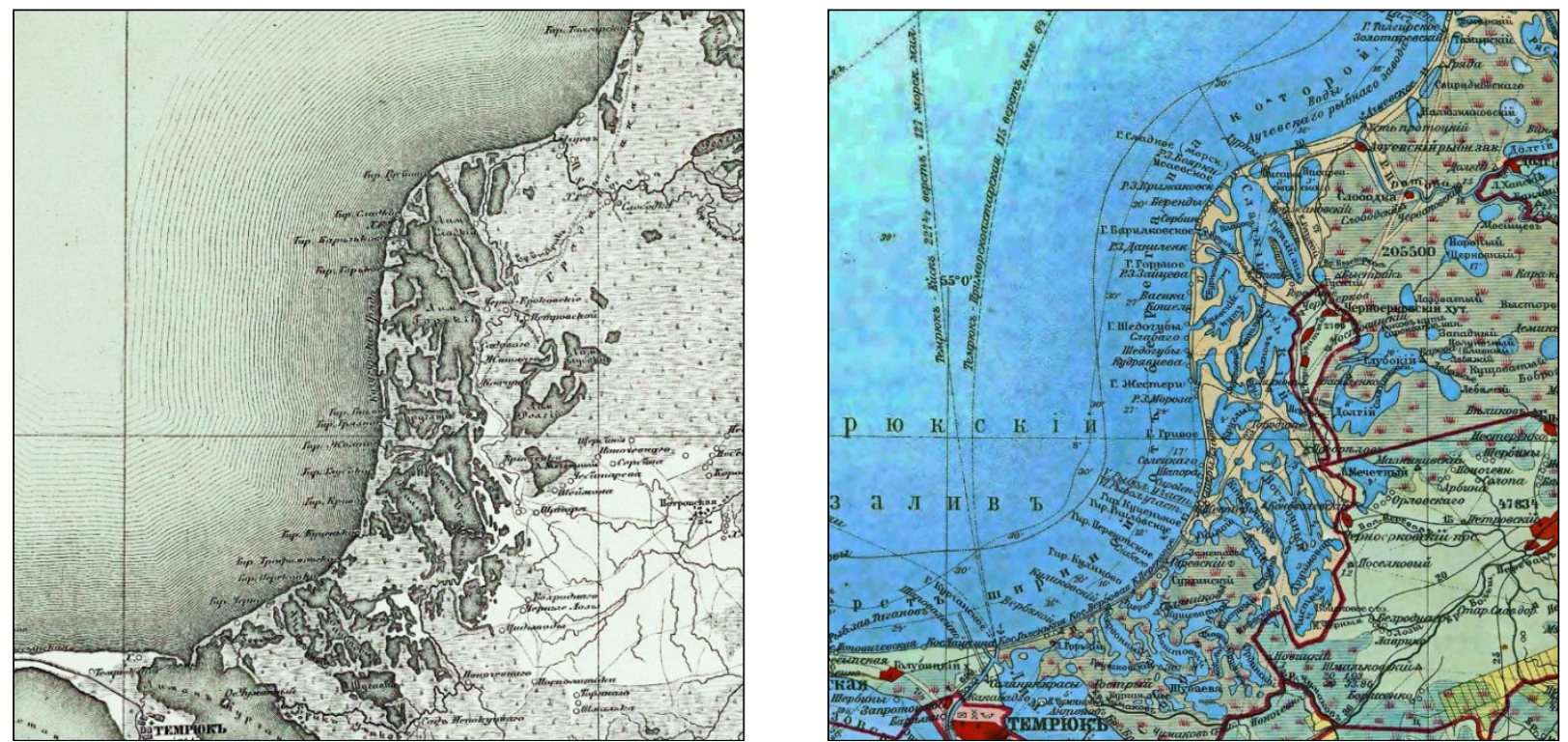

Рис. 2. Берег в районе Вербяной косы: карты 1871 г. (слева) и 1902 г. (справа)

С середины XX в. на развитие берега Вербяной косы оказывается прямое или косвенное антропогенное воздействие. Создание в 1973-1976 гг. Краснодарского водохранилища и ряда гидротехнических сооружений значительно сократили объем твердого стока р. Кубани. В результате колебаний солености Азовского моря сократилась продуктивность популяций раковинных моллюсков, створки которых (ракуша) являются важным пляжеобразующим материалом. Практически по всей длине морского края дельты р. Кубани сформировался режим дефицита пляжеобразующих наносов. В 1970-х гг. почти 48-километровый участок берега морского края дельты от Соловьевского гирла до Сладковского гирла (гирло - местное название пролива, соединяющего акваторию ла- 
гуны с морем), подвергался размыву или находился в неустойчивом равновесии. Некоторое увеличение аккумуляции в конце 1980-х - начале 1990-х гг. было вызвано возрастанием твердого стока р. Кубани [5].

Для стабилизации размываемого берега и защиты хозяйственных (скважины по добыче природного газа) и природных (Рамсарские водно-болотные угодья) объектов в пределах Вербяной косы в 2007 г. был создан комплекс берегозащитных сооружений протяженностью 8,6 км [6]. В ходе строительства берегозащитного сооружения и в последующий период осуществлялся мониторинг Вербяной косы, включающий ежегодные топографо-батиметрические измерения надводной части и подводного склона аккумулятивной формы [5]. К сожалению, высокая изменчивость пляжа, подводных валов затрудняет получение достоверных сведений об их реальной динамике между съемками, проводимыми раз в год.

В представленной работе на основе данных, полученных со спутниковых снимков разных лет, проанализированы особенности динамики береговой линии и прибрежного рельефа Вербяной косы в период со второй половины XX в. до настоящего времени. Для выявления общих тенденций развития берега за еще более продолжительный период полученные данные были сопоставлены с архивными географическими картами (см. рис. 2).

\section{Материальи и методы}

Для мониторинга высокодинамичных природных процессов в береговой зоне Вербяной косы было выбрано использование данных спутникового зондирования. Спутниковые снимки применялись для определения положения береговой линии и его изменений, с целью выделения областей размыва и аккумуляции. Кроме того, современные спутниковые данные позволяют включать в число исследуемых объектов не только берег, но и прилегающую акваторию $[7,8]$.

Для дешифрирования объектов прибрежной зоны (в контактной области «суша - вода») применялись как визуальные [9], так и численные методы, основанные на спектральных свойствах водной поверхности.
Для исследования береговой зоны наиболее пригодны данные спутников сверхвысокого (около 1 м) разрешения: IKONOS, QuickBird, World View-1, World View-2, GeoEye-1, способных выполнять съемку в различных диапазонах спектра. Однако, архив выполненных съемок на исследуемую территорию мал. Природным процессам в районе Вербяной косы присуща высокая внутригодовая и межгодовая динамика, что вызывает необходимость использовать спутниковые данные, получаемые на регулярной основе. Ранее, в работах $[7,10]$ использовались снимки спутников серии LANDSAT и ASTER, удовлетворяющие требованиям временного охвата, периодичности съемки. Однако данные этих спутников имеют невысокое пространственное разрешение, что снижает их пригодность для детального картографирования береговой зоны.

По сочетанию характеристик оптимальными оказались данные с некоммерческих спутников Sentinel-2, оснащенных оптикоэлектронным мультиспектральным сенсором (MultiSpectral Instrument - MSI), выполняющим съемку в 13 спектральных каналах $[11,12]$. Спутник Sentinel-2А был запущен в 2015 г., Sentinel-2B - в 2017 г. В пользу выбора данных Sentinel-2 [13] послужила высокая частота съемки; пространственный охват; наличие необходимых для определения границы «суша - море» спектральных каналов. Детальности снимков Sentinel-2 (10 м в пикселе) достаточно для точного определения положения береговой линии. Критериями отбора снимков служили: дата съемки, необходимый пространственный охват, минимальная облачность, качество изображения, мутность воды и состояние поверхности моря [14]. Поскольку штормовое волнение приводит к взмучиванию воды и искажает контур береговой линии, затрудняя определение положения линии уреза, выбирались снимки в период штиля. Для обработки снимков применялось программное обеспечение ScanEx Image Processor. Маска водной поверхности рассчитывалась с использованием формулы «normalized difference water index» (NDWI): NDWI = $($ Green - NIR $) /($ Green + NIR $)$, где Green 
и NIR - соответственно зеленый и ближний инфракрасный спектральные каналы [15].

Для определения величин долгопериодной динамики исследуемого участка были использованы архивные космические снимки 1960-70-х гг., выполненные Геологической службой США [16]. Поскольку географическая «привязка» снимков отсутствовала, была проведена геометрическая коррекция снимков. Кроме того, была проведена коррекция привязки топографической карты РККА масштаба 1 : 50 000, составленной в 1943 г. на этот район. Привязка и оценка ее точности производились по контрольным точкам, представленным сохранившимися до настоящего времени точечными (здания) и линейными (дороги) объектами, имеющимися как на корректируемой карте, так и на современных снимках сверхвысокого разрешения с известными параметрами съемочных камер. Привязка по формам рельефа не производилась, так как за прошедшее время они могли существенно трансформироваться. Обработка растров и векторных данных производилась с использованием пакета Scanex Image Processor. Трансформация растра или вектора проводилась по полиноминальной модели второй или третьей степени. Оцениваемая точность плановой привязки архивных карт и космических снимков лежит в пределах 5-10 м, что достаточно для выявления и оценки величин долгопериодной динамики. Материалы собраны в ГИС с использованием технологии Scanex WEB GeoMixer.

\section{Вербяная коса как часть морского края дельты р. Кубани}

Морфологически Вербяная коса является участком берегового бара - аккумулятивной формы рельефа, образовавшейся в результате преобладающего поперечного перемещения и отложения наносов, которая примыкает с востока к устью Петрушиного рукава в дельте р. Кубани (рис. 3). Морской край дельты р. Кубани представляет собой аккумулятивный контур «дельты выполнения» протяженностью около 115 км от устья Петрушина рукава (г. Темрюк) до оконечности Ачуевской косы (г. Приморско-Ахтарск). Большая часть ее площади представлена плавнями, ограниченными аккумулятивными формами грядами. Гряды представляют собой древние песчано-ракушечные морские береговые или песчаные речные прирусловые валы, маркирующие отдельные этапы развития дельты. В формировании этих валов на разных этапах эволюции дельты и в разных ее частях определяющим было влияние речного аллювия или морских наносов [17-19].

С морской стороны дельта прикрыта современным береговым валом. На приустьевых участках основным источником наносов для формирования этого аккумулятивного тела является речной аллювий, преимущественно песок. Материал под действием волн вовлекается во вдольбереговой перенос и перемещается на смежные участки берега. С удалением от устий повышается роль биогенного материала, поступающего со дна Азовского моря. В вогнутых участках берега и на входах в заливы происходит аккумуляция материала, формируются бары и пересыпи. В итоге, морской край дельты р. Кубани, с геоморфологической точки зрения, является сложной аккумулятивной формой окаймляющего типа. Фактически, это единая береговая аккумулятивная форма, с чередующимися участками аккумуляции, транспорта и размыва.

В пределах Вербяной косы имеется несколько естественных или искусственных водотоков, через которые происходит сброс воды из лиманов, лагун и каналов. На западе коса примыкает к Петрушиному рукаву р. Кубани (см. рис. 3). Далее, к востоку, расположены гирла Соловьевское, Новокуликовское, Куликовское, Зозулиевское. В пределах тыльной части аккумулятивного тела имеется множество искусственных каналов.

Для р. Кубани характерна высокая изменчивость объемов жидкого и твердого стока из-за природных и антропогенных факторов [17, 19]. В периоды поступления большого объема твердого стока в Азовское море происходит выдвижение дельты на приустьевых участках. В периоды дефицита наносов происходит выравнивание дельтовых выступов и образование выраженной аккумулятивно-абразионной дуги, опирающейся концами на выступы коренного берега или приустьевые участки. 


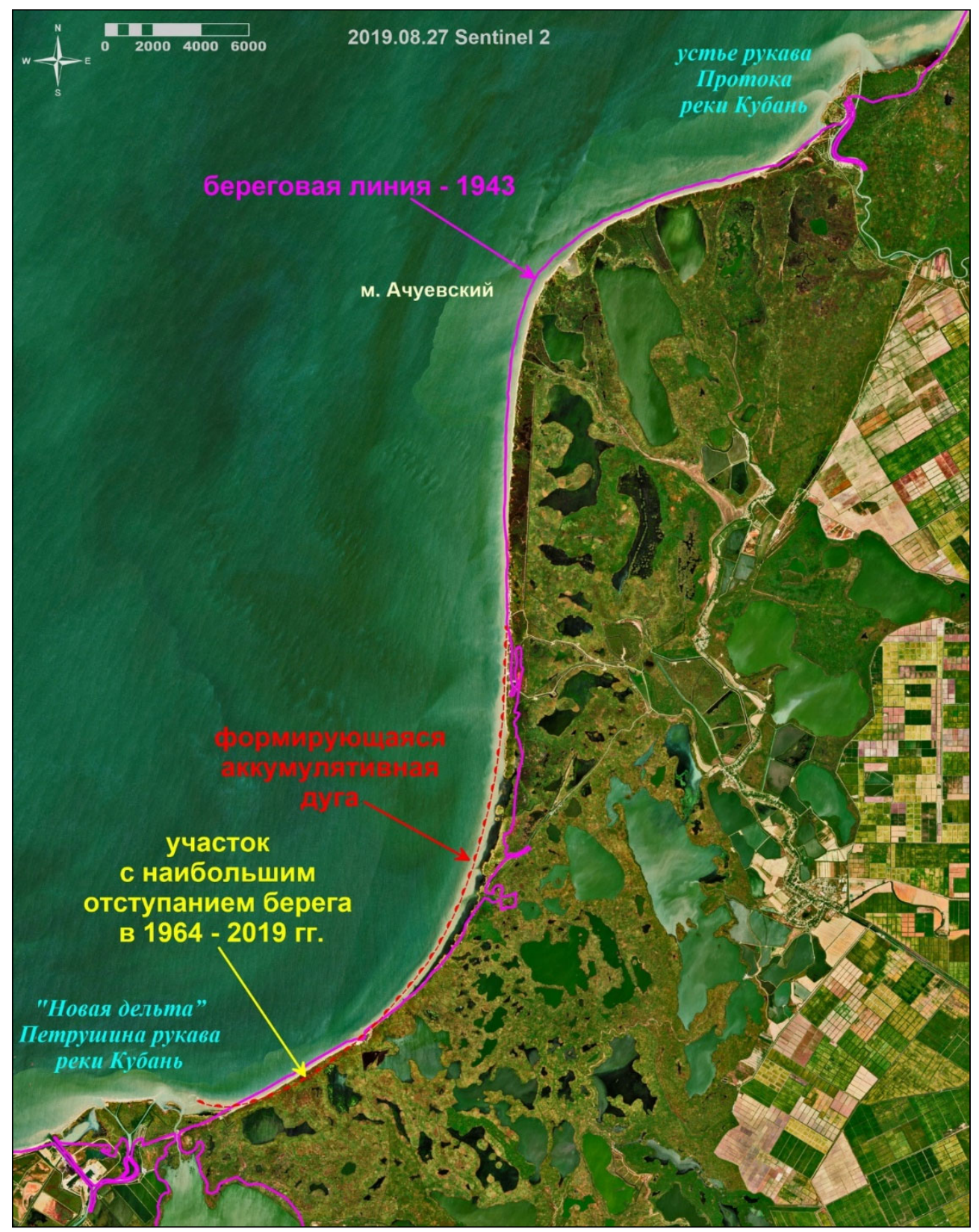

Рис. 3. Вербяная коса и динамика ее берега

\section{Строение и литодинамика Вербяной косы}

Анализ топографических карт и космических снимков показал, что разные участки Вербяной косы в разные временные периоды развивались по-разному. Наибольшие скорости роста дельты (до $60 \mathrm{~m} /$ год) наблюдались в период 1940-1970 гг. (рис. 4, а). Общее выдвижение дельты в акваторию Азовского моря составило около 2 км. По мере роста дельты существенно менялся волновой ре- жим приустьевого участка. Западный участок косы, примыкающий к Соловьевскому гирлу, в 1964-1971 гг. находился в квазистационарном состоянии. С 1971 по 2019 г. берег на этом участке, защищаемый от волнения растущей дельтой Петрушина рукава, выдвинулся на 200-400 м (рис. 4, $a$, ) ). Восточнее Соловьевского гирла, где экранирующее действие дельты Петрушина рукава ослабевало, преобладал размыв, скорость которого существенно различалась на разных участках. На западной части, до Ново- 
Куликовского гирла, значительное отступание (30-40 м) наблюдалось в период 1964-1971 гг. Позднее, скорость отступания на этом участке существенно снизилась. Восточнее НовоКуликовского гирла в период 1964-1971 гг. берег был стабилен, позднее начался размыв, его величина уменьшалась с Ю3 к СВ. В целом, на размываемых участках Вербяной косы между Куликовским и Соловьевским гирлами за период с 1973 по 2006 г. береговая линия отступила на 80-200 м. В 2003-2006 гг. была размыта грунтовая дорога в тыльной части Вербяной косы [20].

На Ю3 краю аккумулятивной дуги в условиях сильных северо-восточных штормов, обеспечивающих подход волн под острым углом к береговой линии, возникают вдольбереговые течения [5]. Наносы при этом смещаются в сторону взморья Соловьевского гирла. Дельта Петрушиного рукава Кубани на этом участке блокирует волнение западных румбов и способствует устойчивой аккумуляции наносов. На рис. 4, $a$, в видно, что на этом участке берег выдвинулся на $400-500 \mathrm{M}$.
Участок между гирлами Соловьевское и Куликовское относится к центральной части аккумулятивной дуги, где эта дуга еще не выработалась до равновесного состояния. Именно на этом участке наблюдалось наибольшее отступание берега (рис. 4, a), а впоследствии была сооружена защитная дамба (рис. 5). Мониторинговые наблюдения за перестройками пляжа и подводного склона после строительства волногасящей дамбы [5] показали, что прогрессирующее ранее отступание берега прекратилось. Несмотря на прохождение нескольких штормов экстремальной силы (в 2007, 2014, 2017 гг.), линия уреза в течение всего периода почти не отступала от положения 2007 г. Наблюдались лишь локальные изменения рельефа пляжа во время штормов, носящие знакопеременный характер. Дамба прекратила поперечный уход наносов из приурезовой зоны на лиманно-лагунную сторону аккумулятивной формы. Таким образом, построенное волногасящее сооружение на данном участке обеспечивает стабильность берега.

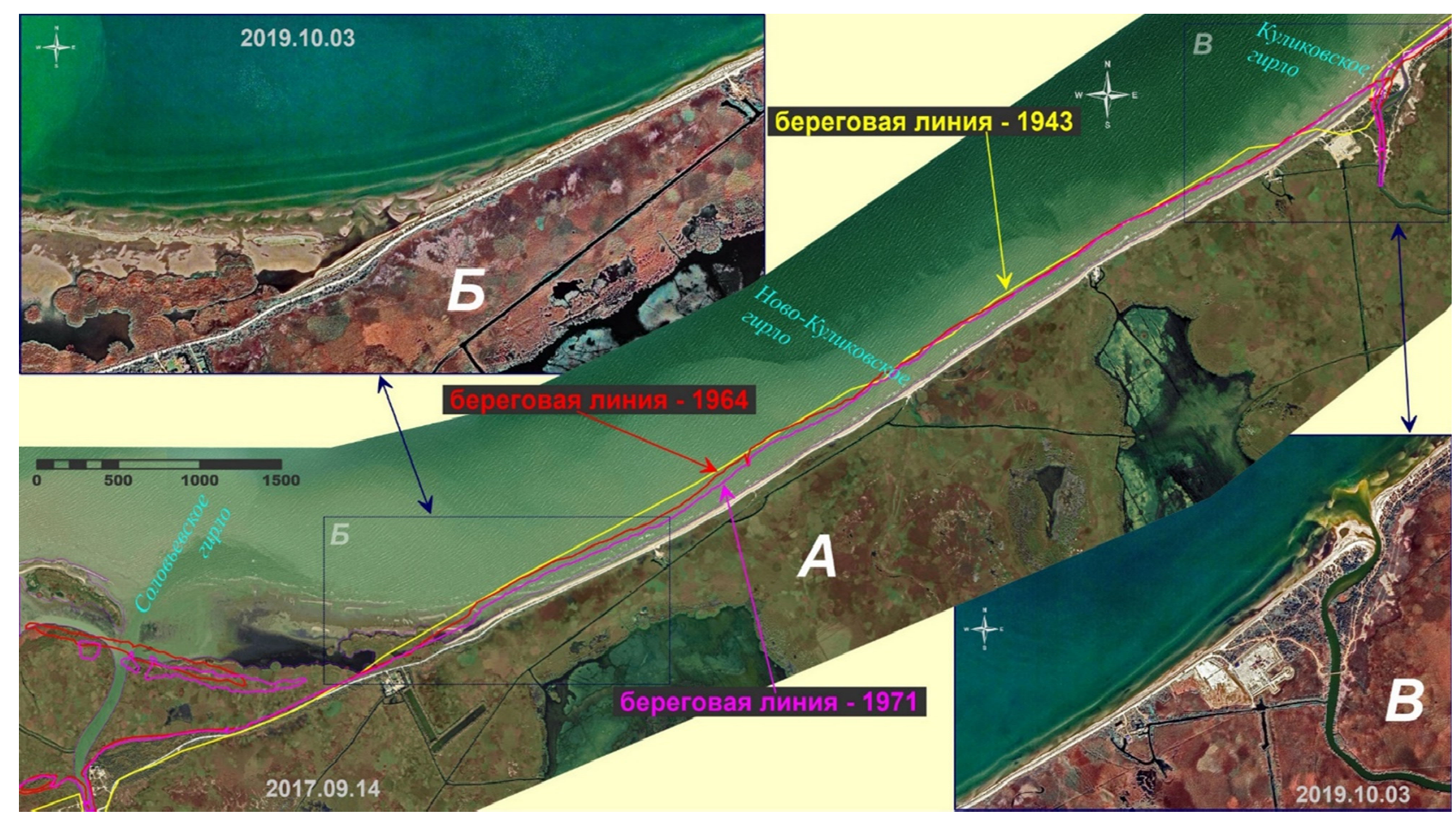

Рис. 4. Динамика берега Вербяной косы 
Севернее Куликовского гирла, вплоть до устья Морского Сбросного канала, конфигурация берега способствует формированию подводного бара. Бар формируется вдоль линии аккумулятивной дуги с равновесным морфо-литодинамическим режимом [19] (см. рис. 3). Этого участка не достигают наносы, движущиеся с севера (со стороны устья Протоки), и с юга (со стороны устья Петрушина рукава). Вероятно, при сохранении объемов речного твердого стока, наблюдавшихся в первой половине XX в., эти два встречных потока наносов могли встретиться. В результате тут могла бы сформироваться полноценная пересыпь. Однако, в современных условиях, объем и гранулометрический состав имеющихся наносов пляжеобразующей крупности достаточен лишь для формирования цепи отмелей вдоль гребня подводного бара. Анализ космических снимков показывает, что с 1964 по 1971 г. морской край этого бара незначительно выдвинулся в сторону моря. Впоследствии, с 1971 по 2016 г., морской край сместился к берегу, величина этого смещения составила около 50 м. Тыльный край бара одновременно надвинулся на лагуну. Поскольку разрушение наиболее крупных волн происходит на морской стороне бара, в лагуне сформировались условия для аккумуляции наносов. Мелководная зона быстро осваивается тростниково-рогозовыми зарослями, играющими роль волногасителя. На рис. 6 видно, что с 2003 по 2019 г. граница растительности в лагуне выдвинулась на 50-100 м.
На большей части исследуемого участка вдоль берега протягивается система подводных валов. Для участков с относительно крутым подводным склоном характерны три типа валов: относительно однородный и параллельный берегу двумерный вдольбереговой вал; изменчивый по конфигурации и профилю трехмерный вал и примыкающий вал, который на определенных участках примыкает к пляжу. Такие типы валов формируются на открытом берегу при высоких значениях волновой энергии. Двумерные валы соответствуют наиболее высокому уровню энергии в условиях развитого обрушения и диссипации волн [19]. Когда энергия уменьшается, валы могут мигрировать к берегу и изменяться от двумерных к трехмерным и к примыкающим, при этом высота их уменьшается. Величина и знак изменений структуры подводных валов существенно зависит от силы и направления волнения и уровня моря. При юго-восточных и восточных ветрах (с берега), сопровождающихся сгоном, наблюдается выполаживание подводного склона и уменьшение числа валов [5]. Одновременно прогрессирует размыв подводного склона. Вероятно, подобный феномен объясняется влиянием сильных вдольбереговых течений. При штормах от северо-запада и запада (близких к нормали относительно линии берега) происходит некоторое «сжатие» подводного склона с возрастанием числа подводных валов. При сильных западных штормax 2011-2012 гг. на всех профилях зафиксирована значительная аккумуляция [6].

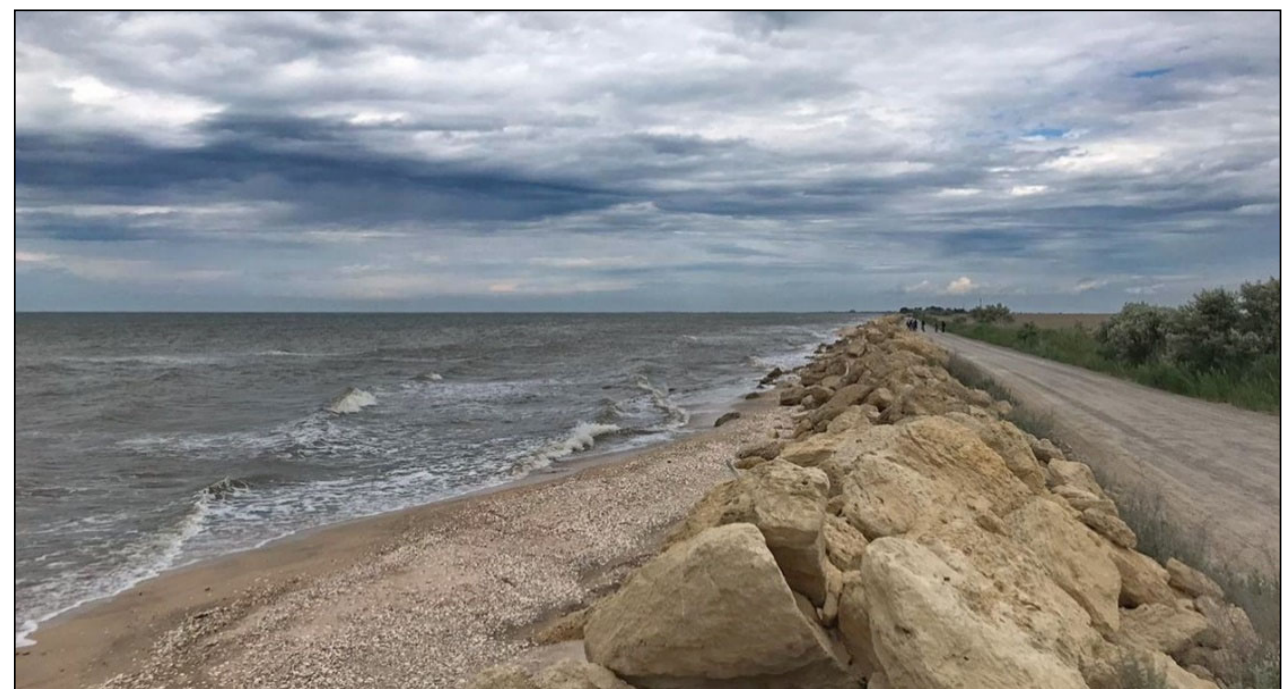

Рис. 5. Волногасящая дамба (фото Н. А. Пикаловой, 2019 г.) 

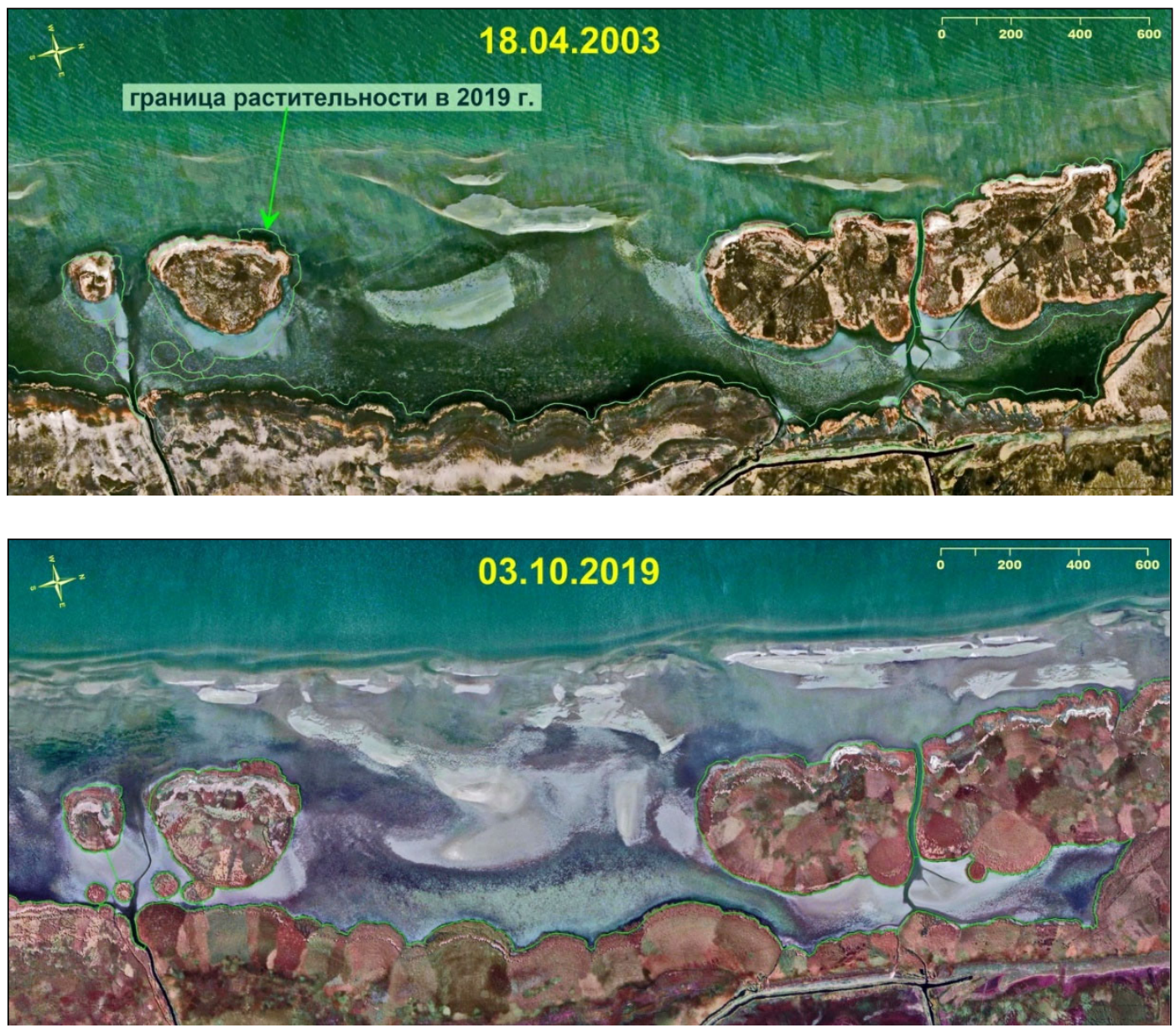

Рис. 6. Освоение растительностью отмелей в лагуне

На участках с низкими значениями волновой энергии - с выраженным подводным баром и широкой прибрежной отмелью отмечены структуры множественных параллельных валов. Эти структуры формируются вдоль гребня бара и в лагуне, валы отстоят друг от друга на примерно одинаковые расстояния 20-30 м (рис. 7). На рис. 7 показаны изменения структуры таких подводных валов в северо-восточной части Вербяной косы. Как видно, изменения конфигурации валов происходят достаточно быстро, а при резком падении уровня валы размываются, превращаясь в пологую отмель.

\section{Заключение}

Использование только наземных геодезических наблюдений за динамикой берега не отвечает современным требованиям к пространственному охвату и частоте монито- ринговых измерений. Применение данных спутниковой съемки высокого разрешения и геоинформационных технологий позволяет осуществлять мониторинг текущих изменений состояния береговой зоны на новом уровне. Исследования, проведенные с применением современных дистанционных методов, позволили существенно дополнить материалы наземного геодезического мониторинга крупной береговой аккумулятивной формы - Вербяной косы. Новые технологии компьютерной обработки пространственных данных позволили использовать архивные карты и космические снимки для получения достоверной информации по долгопериодной динамике исследуемого берега и отдельных компонентов геосистемы.

Анализ топографических карт и космических снимков за 80-летний период показал, что разные участки Вербяной косы в разные временные периоды развивались по-разному. 

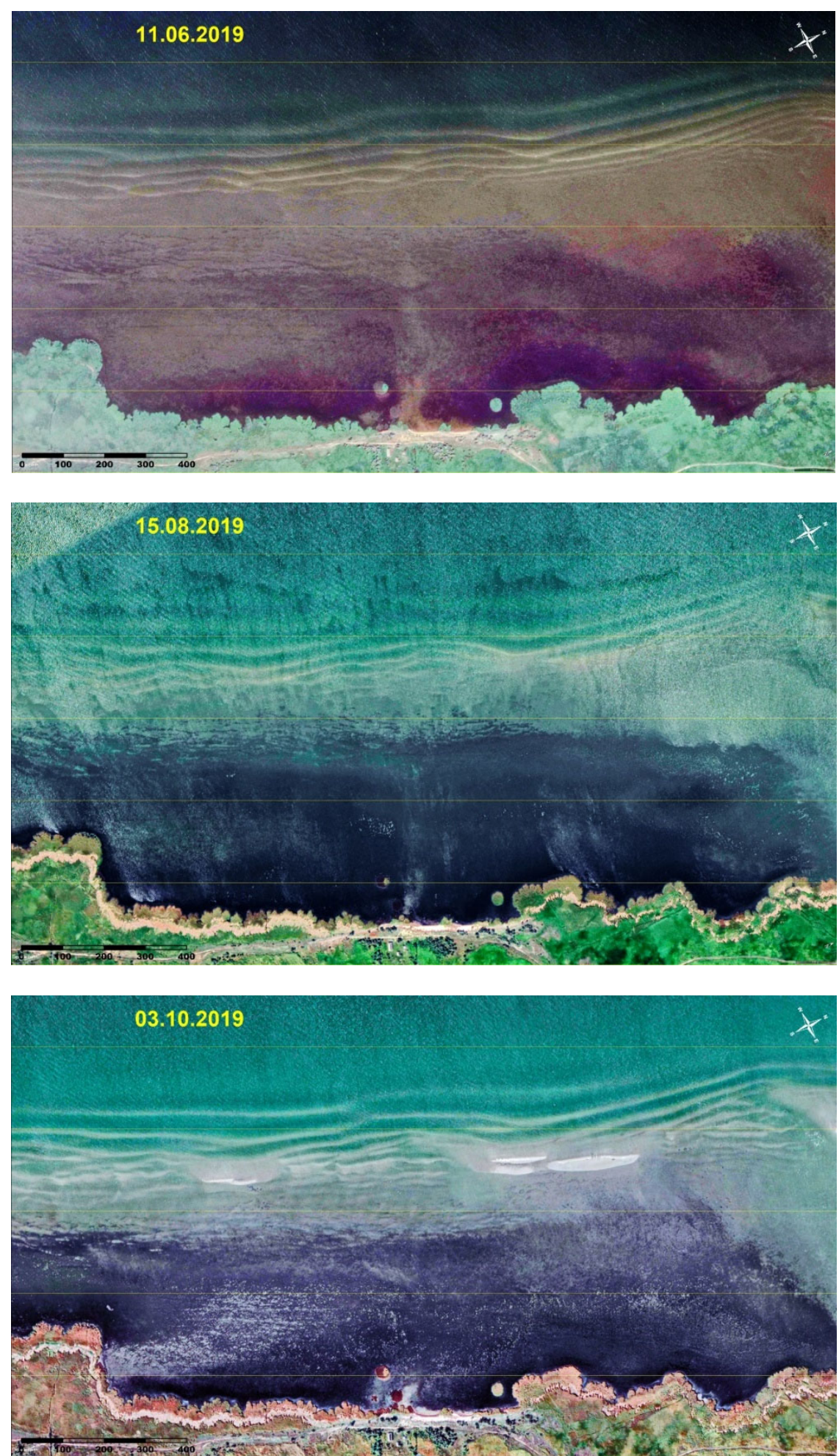

Рис. 7. Динамика и структура системы береговых валов

Формирование Вербяной косы как единого аккумулятивного тела началось лишь после начала поступление аллювия Петрушина рукава р. Кубани непосредственно на берег Азовского моря. В этот период преобладало вдольбереговое перемещение наносов, по- ступающими наносами были перекрыты гирла морских заливов, ставших лагунами. Впоследствии выдвижение дельты Петрушина рукава, которое наблюдалось в середине XX в., изменило волновой режим приустьевого участка Вербяной косы. В резуль- 
тате, береговая линия западной части косы, примыкающей к новой дельте, за последние полвека выдвинулась на 200-400 м. Восточнее, где экранирующее действие дельты Петрушина рукава проявлялось слабее, берег косы отступил на 30-200 м. В настоящее время построенное берегозащитное сооружение обеспечивает стабильность берега, и линия уреза сохраняет положение 2007 г.

Изучение особенностей строения и современной динамики аккумулятивной формы Вербяная коса показало преобладание поперечного движения наносов на данном участке морского края дельты р. Кубани. Характерной чертой современной береговой зоны Вербяной косы является наличие динамичной системы подводных валов. Кроме того, вдоль линии аккумулятивной дуги с равновесным литодинамическим режимом наблюдается формирование подводного бара. Следовательно, данная аккумулятивная форма в настоящее время развивается как бар или пересыпь, а не как коса.

Таким образом, на основе анализа архивных карт и космических снимков, современ- ных данных наземных геодезических изысканий и материалов дистанционного зондирования, установлено, что динамика берега Вербяной косы длительный период определялась выдвижением морского края дельты p. Кубани и изменениями ветро-волнового режима. C середины XX в. важным фактором развития аккумулятивной формы стало антропогенное влияние. В настоящее время Вербяная коса развивается как природнотехногенная система.

\section{Благодарности}

Полевая часть работ выполнена при поддержке РФФИ (проекты 19-45-230004 и 18-05-00333). Систематизация материалов дистанционного зондирования реализована при поддержке РНФ (проект 20-17-00060). Использованы сведения о развитии берега дельты р. Кубани, гидрологических и гидролитодинамических особенностях, полученные при выполнении темы Госзадания № 0149-2019-0014.

\section{БИБЛИОГРАФИЧЕСКИЙ СПИСОК}

1. Kosyan R. D., Krylenko M. V. Modern state and dynamics of the Sea of Azov coasts // Estuarine, Coastal and Shelf Science. - 2019. - Vol. 224. P. 314-323.

2. Данилевский Р. Я. Исследования о Кубанской дельте // Записки Русского Географического Общества. - 1869. - Т. 2. - С. 1-124.

3. Артюхин Ю. В., Федорова С. И. Пространственно-временные черты эволюции морского края дельты Кубани и природные аспекты некоторой ее гидротехнической корректировки. // Защита окружающей среды в нефтегазовом комплексе. - 2007. - № 10. - С. 60-69.

4. Иванов А. А. Динамика наносов на взморье Кубани // Труды ГОИН. - 1984. - Вып. 172. C. $42-50$.

5. Артюхин Ю. В., Федорова С. И. Оценка устойчивости волногасящего сооружения и косы Вербяной по данным геоморфологического мониторинга // Защита окружающей среды в нефтегазовом комплексе. - 2014. - № 11. C. $56-64$.

6. Погорелов А. В. Исследование динамики береговой зоны Азовского моря по данным космических снимков // Защита окружающей среды в нефтегазовом комплексе. - 2011. - № 12. C. $19-27$.

7. Крыленко В. В., Крыленко М. В., Алейников А. А. Исследование подводного рельефа Бакальской банки по данным космических снимков Sentinel-2 // Экологическая безопасность прибрежной и шельфовой зон моря. - 2019. - № 2. C. 30-39.

8. Возможности визуального дешифрирования магистральных трубопроводов и объектов инфраструктуры по спутниковым изображениям высокого и сверхвысокого пространственного разрешения / Д. В. Долгополов, Д. В. Никонов, А. В. Полуянова, В. А. Мелкий // Вестник СГУГиТ. - 2019. - Т. 24, № 3. - С. 65-81.

9. Погорелов А. В., Антоненко М. В. Применение космических снимков в исследовании динамики береговой зоны Азовского моря: возможности и результаты анализа // Вестник Северо-Кавказского государственного технического университета. - 2011. - № 2. - С. 95-98.

10. The operational Copernicus optical high resolution land mission [Electronic resource]. - Mode of access: http://esamultimedia.esa.int/docs/S2Data Sheet.pdf (дата обращения: 15.02.2020). 
11. MultiSpectral Instrument (MSI) [Electronic resource]. - Mode of access: https://sentinel.esa.int/ $\mathrm{web} /$ sentinel/missions/sentinel-2/instrument-payload (дата обращения: 15.01.2020).

12. Sentinel Online technical website [Electronic resource]. - Mode of access: https://sentinel.esa.int/ $\mathrm{web} /$ sentinel/technical-guides/sentinel-2-msi/level-1c/ product-formatting (дата обращения: 10.12.2019).

13. Крыленко В. В., Крыленко М. В., Алейников А. А. Уточнение длины береговой линии Азовского моря с использованием данных спутников Sentinel-2 // Вестник СГУГиТ. - 2019. T. 24, № 4. - C. 78-92.

14. Gao B. C. NDWI - a normalized difference water index for remote sensing of vegetation liquid water from space // Remote Sensing of Environment. - 1996. - Vol. 58. - P. 257-266.

15. U.S. Department of the Interior U.S. Geological Survey (USGS) [Electronic resource]. - Mode of access: http://earthexplorer.usgs.gov.

16. Гидрология дельты и устьевого взморья Кубани / В. Н. Михайлов, Д. В. Магрицкий, А. А. Иванов и др. - М. : ГЕОС, 2010. -728 с.
17. Krylenko M., Kosyan R., Krylenko V. Lagoons of the smallest Russian sea / Part of the series «Estuaries of the World», Chapter: The diversity of Russian estuaries and lagoons exposed to human influence / R. Kosyan (Ed.). - Springer International Publishing, 2017. - P. 111-148.

18. Федорова С. И., Артюхин Ю. В., Кушу Э. Х. Развитие кос на южном фланге дельты Кубани под действием гидрометеорологических и геодинамических факторов // Тридцать третье пленарное межвузовское совещание по проблеме эрозионных, русловых и устьевых процессов. - Нижневартовск : НВГУ, 2018. Т. 2. - С. 159-161.

19. Инженерные решения стабилизации Вербяной косы Темрюкского района / Ю. В. Артюхин, С. И. Федорова, Э. Х. Кушу, В. В. Пинигина, С. К. Герасименко // Защита окружающей среды в нефтегазовом комплексе. - 2007. - № 9. C. $78-82$.

20. Леонтьев И. О. Подводные валы на песчаных берегах // Океанология. - 2011. - Т. 51, №. 1. C. $146-152$.

Получено 14.04.2020

(C) В. В. Крыленко, М. В. Крыленко, 2020

\section{COASTAL MONITORING OF THE VERBYANAYA SPIT BY SATELLITE DATA}

\section{Viacheslav V. Krylenko}

Shirshov Institute of Oceanology RAS, Southern Branch, 36, Nakhimovsky Pr., Moscow, 117997, Russia, Ph. D., Senior Researcher, phone: (86141)2-80-89, e-mail: krylenko.slava@gmail.com

\section{Marina V. Krylenko}

Shirshov Institute of Oceanology RAS, Southern Branch, 36, Nakhimovsky Pr., Moscow, 117997, Russia, Ph. D., Leading Researcher, phone: (86141)2-80-89, e-mail: krylenko@mail.ru

The Verbyanaya spit is the south-western part of the sea edge of the Kuban river Delta, which was formed during the last 200 years. Complex monitoring studies including analysis of remote sensing data and cartographic material were performed for estimation of modern development trends of this accumulative form, coastal dynamics, the intensity of erosion-accumulative processes and the effectiveness of coast protection structures. The coastal dynamics of the Verbyanaya spit during last 150 years was determined by combined action of natural and anthropogenic factors. For last half a century the coastline of spit western part came forward to 200-400 $\mathrm{m}$ and the east spit coast retreated to 30-200 m. Economic development of adjacent area (natural gas exploration and production) has caused the need to stabilize the coast, and coastal protected dam was built in 2007. Monitoring showed that spit coast stabilized after creation of the dam, but changes of the underwater slope relief continued. Currently Verbyanaya spit develops as naturalanthropogenic system.

Key words: Sea of Azov, accumulative form, remote sensing, delta, relief, coastal dynamics, monitoring. 


\section{REFERENCES}

1. Kosyan, R. D., \& Krylenko, M. V. (2019). Modern state and dynamics of the Sea of Azov coasts. Estuarine, Coastal and Shelf Science, 224, 314-323.

2. Danilevsky, R. Ya. (1869). Research on the Kuban Delta. Zapiski RGO [Note of RGS], 2, 1-124 [in Russian].

3. Artyukhin, Yu. V., \& Fedorova, S. I. (2007). Spatial and temporal features of the sea edge evolution of the Kuban Delta and natural aspects of some of its hydrotechnical adjustments. Zashchita okruzhayushchej sredy $v$ neftegazovom komplekse [Environmental Protection in the Oil and Gas Industry], 10, 60-69 [in Russian].

4. Ivanov, A. A. (1984). Dynamics of sediment on the Kuban coast. Trudy GOIN [Proceedings of GOIN], 172, 42-50 [in Russian].

5. Artyukhin, Yu. V., \& Fedorova, S. I. (2014). Assessment of the stability of the wave damping structure and the Verbyanaya spit according to geomorphological monitoring data. Zashchita okruzhayushchej sredy v neftegazovom komplekse [Environmental Protection in the Oil and Gas Industry], 11, 56-64 [in Russian].

6. Pogorelov, A. V. (2011). Study of the coastal zone dynamics of the Sea of Azov based on satellite images. Zashchita okruzhayushchej sredy $v$ neftegazovom komplekse [Environmental Protection in the Oil and Gas Industry], 12, 19-27 [in Russian].

7. Krylenko, V. V., Krylenko, M. V., \& Aleynikov, A. A. (2019). Investigation of the underwater relief of the Bakalskaya Bank based on Sentinel-2 satellite images. Ekologicheskaya bezopasnost' pribrezhnoj $i$ shel'fovoj zon morya [Environmental Safety of Coastal and Offshore Zones of the Sea], 2, 30-39 [in Russian].

8. Dolgopolov, D. V., Nikonov, D. V., Poluyanova, A. V., \& Melky, V. A. (2019). Visual interpretation of main pipelines and infrastructure objects using satellite images of high and ultra-high spatial resolution. Vestnik SGUGiT [Vestnik SSUGT], 24(3), 65-81 [in Russian].

9. Pogorelov, A. V., \& Antonenko, M. V. (2011). Application of satellite images in the study of the coastal zone dynamics of the Sea of Azov: opportunities and results of analysis. Vestnik SeveroKavkazskogo gosudarstvennogo tekhnicheskogo universiteta [Bulletin of the North Caucasus State Technical University], 2, 95-98 [in Russian].

10. The operational Copernicus optical high resolution land mission. (n. d.). Retrieved from http://esamultimedia.esa.int/docs/S2-Data_Sheet.pdf (accessed 15.02.2020).

11. MultiSpectral Instrument (MSI). (n. d.). Retrieved from https://sentinel.esa.int/web/sentinel/ missions/sentinel-2/instrument-payload (accessed 15.01.2020).

12. Sentinel Online technical website. (n. d.). Retrieved from https://sentinel.esa.int/web/ sentinel/technical-guides/sentinel-2-msi/level-1c/productformatting (accessed 10.12.2019).

13. Krylenko, V. V., Krylenko, M. V., \& Aleynikov, A. A. (2019). Specifying the length of the Azov sea coastline using satellite data Sentinel-2. Vestnik SGUGiT [Vestnik SSUGT], 24(4), 78-92 [in Russian].

14. Gao, B. C. (1996). NDWI - a normalized difference water index for remote sensing of vegetation liquid water from space. Remote Sensing of Environment, 58, 257-266.

15. U.S. Department of the Interior U.S. Geological Survey (USGS). (n. d.). Retrieved from http://earthexplorer.usgs.gov.

16. Mikhailov, V. N., Magritsky, D. V., \& Ivanov A. A. (2010). Gidrologiya del'ty i ust'evogo vzmor'ya Kubani [Hydrology of the Delta and Estuarine Coast of Kuban]. Moscow: GEOS Publ., 728 p. [in Russian].

17. Krylenko, M., Kosyan, R., \& Krylenko, V. (2017). Lagoons of the smallest Russian sea / Part of the series "Estuaries of the World", Chapter: The diversity of Russian estuaries and lagoons exposed to human influence (pp. 111-148 p.). Springer International Publishing,

18. Fedorova, S. I., Artyukhin, Yu. V., \& Kushu, E. H. (2018). Development of spits on the southern flank of the Kuban Delta under the influence of hydrometeorological and geodynamic factors. In Sbornik materialov XXXIII mezhvuzovskogo soveshchaniya po probleme erozionnyh, ruslovyh i ust'evyh processov: T. 2 [Proccedings of XXXIII Interuniversity Meeting on the Problem of Erosion, Riverbed and Estuarine Processes: Vol. 2] (pp. 159-161) Nizhnevartovsk: NVGU Publ. [in Russian].

19. Artyukhin, Yu. V., Fedorova, S. I., Kushu, E. H., Pinigina, V. V., \& Gerasimenko, S. K. (2007). Engineering solutions to stabilize the Verbyanaya spit Temryuk district. Zashchita okruzhayushchej sredy v neftegazovom komplekse [Environmental Protection in the Oil and Gas Industry], 9, 78-82 [in Russian].

20. Leontiev, I. O. (2011). Underwater bars on sandy shores. Okeanologiya [Oceanology], 51(1), 146-152 [in Russian]. 


\section{КАРТОГРАФИЯ И ГЕОИНФОРМАТИКА}

УДК 528.91:625:630*3

DOI: $10.33764 / 2411-1759-2020-25-3-181-191$

\section{ИСПОЛЬЗОВАНИЕ ГЕОГРАФИЧЕСКИХ ИНФОРМАЦИОННЫХ СИСТЕМ ПРИ ОЦЕНКЕ ПЛОТНОСТИ ДОРОГ ЛЕСОЗАГОТОВИТЕЛЬНЫХ РАЙОНОВ}

\section{Александр Петрович Мохирев}

Лесосибирский филиал ФГБОУ ВО «Сибирский государственный университет науки и технологий им. академика М. Ф. Решетнева», 662543, Россия, г. Лесосибирск, ул. Победы, 29, кандидат технических наук, доцент, тел. (39145)6-28-03, e-mail: ale-mokhirev@yandex.ru

\section{Сергей Юрьевич Резинкин}

Лесосибирский филиал ФГБОУ ВО «Сибирский государственный университет науки и технологий им. академика М. Ф. Решетнева», 662543, Россия, г. Лесосибирск, ул. Победы, 29, студент магистратуры, тел. (39145)6-28-03, pogz31@mail.ru

\section{Сергей Олегович Медведев}

Лесосибирский филиал ФГБОУ ВО «Сибирский государственный университет науки и технологий им. академика М. Ф. Решетнева», 662543, Россия, г. Лесосибирск, ул. Победы, 29, кандидат экономических наук, доцент, тел. (39145)6-28-03, medvedev_serega@mail.ru

\section{Наталья Александровна Брагина}

Лесосибирский филиал ФГБОУ ВО «Сибирский государственный университет науки и технологий им. академика М. Ф. Решетнева», 662543, Россия, г. Лесосибирск, ул. Победы, 29, студент магистратуры, тел. (39145)6-28-03, bragina.n.a@mail.ru

В России густота лесных дорог значительна ниже, чем в странах с развитой лесной промышленностью. Это отрицательно сказывается на эффективности лесозаготовок и выход древесины с единицы площади. Существуют различные мнения по нормативным и фактическим значениям плотности лесных дорог в лесных регионах России. На сегодняшний день оценку густоты лесных дорог и анализ ее развития возможно провести с использованием современных географических информационных систем (ГИС). В настоящих исследованиях определяется плотность лесных дорог с использованием программного комплекса ArcGis на территории двух лесничеств Красноярского края. Дороги, находящиеся на территории исследуемых участков, оцифрованы и разделены по типам: магистраль круглогодового действия, ветка, лесовозный ус. С использованием инструментов программного комплекса определены протяженности и плотности дорог по их типам. Полученные значения согласуются показателями других исследователей различных регионов России. Результаты данной задачи необходимы для планирования лесозаготовительного производства при поиске оптимальных маршрутов доставки древесины с учетом природно-климатических условий. Использование инструментов ArcGIS позволило автоматизировать значительное число расчетов в исследовании и, в частности, рассчитать плотность дорог, визуализировать полученные данные, а также сформировать базу для дальнейших исследований.

Ключевые слова: плотность дорог, географическая информационная система, лесная дорога, густота дорог, лесная инфраструктура, обработка информации. 


\section{Введение}

Непрерывное и неистощительное лесопользование напрямую зависит от доступности лесных ресурсов. На сегодняшний день вопрос о доступности древесных ресурсов освещен в трудах многих отечественных и зарубежных ученых, предлагаются различные алгоритмы сравнения участков лесного фонда, методики подсчета ренты и стоимости лесовосстановления, формулы для определения плановой рентабельности по участку и др. [1-5]. Различия в мнениях по доступности имеются, но практически все исследователи приходят к выводу, что основной проблемой является неразвитость транспортного освоения лесных территорий. Особенно остро данная проблема стоит в северных лесопромышленных регионах.

Существуют различные мнения ученых о том, какой должна быть нормативная плотность лесных дорог для качественного выполнения лесохозяйственных работ. Исследователями Санкт-Петербургской государственной лесотехнической академии определено, что для полного охвата насаждений лесохозяйственными мероприятиями необходимо минимум 10-15 км лесных дорог на 1 тыс. га земель лесного фонда [1]. По мнению других исследователей [2] - оптимальное значение плотности лесных дорог 6 км/тыс. га. Неясно, что является основой расчета плотности лесных дорог - значения, определенные для оптимального уровня этого показателя, различаются в 2,5 раза. Возможно, расчет производился для разных категорий дорог. Но даже нижняя граница норматива для большинства лесопользователей уже невыполнима. При этом выход древесины с 1 га леса в год находится в прямой зависимости от степени развитости инфраструктуры [2].

Страны с наиболее интенсивным лесным хозяйством (Швеция, Финляндия) обычно характеризуются наибольшей плотностью и лучшим качеством лесных дорог. Высокая степень доступности лесов делает возможным и выгодным проведение в этих странах интенсивного ухода за лесами, что в результате позволяет существенно повысить их продуктивность. В странах Центральной Европы и США вводятся законодательные ограничения на максимальную плотность лесных дорог с целью сохранения экосистемы, тогда как в развивающихся странах наблюдается их активное строительство для увеличения объема заготовки леса, которое часто лишено должных эколого-экономических оснований.

Например, в Финляндии существует специальная методика определения оптимальной плотности сети лесных дорог. Она достигается путем минимизации затрат на строительство и эксплуатацию дороги, а также затрат на перевозку лесоматериалов путем сокращения расстояний перевозки: чем дальше от лесной дороги находится лесосека, тем дороже обходится заготовка древесины; чем плотнее дорожная сеть, тем выше затраты на строительство и эксплуатацию. Таким образом, оптимизация плотности сети дорог сводится к задаче сравнения затрат на перевозку лесоматериалов с затратами на строительство [3].

В России средняя плотность лесных дорог 1,2 км/тыс. га, т. е. меньше по сравнению с другими странами [4]. По мнению С. В. Починкова, сравнение плотности лесных дорог России с другими странами мира некорректно, так как плотность зависит от двух параметров: предельного расстояния трелевки древесины по лесосечным волокам и концентрации экономически доступных лесосырьевых ресурсов. Первый параметр примерно одинаков для всех стран, поэтому в расчете на освоенную лесную территорию плотность лесовозных дорог везде одинакова. Существенна разница в удельной протяженности дорог на $1 \mathrm{~m}^{3}$ заготовки: она зависит от продуктивности насаждений. Если брать всю площадь, то плотность дорог будет тем меньше, чем больше экономически недоступных ресурсов и больше лесов, не вовлеченных в эксплуатацию.

На сегодняшний день в России доля экономически недоступных ресурсов ввиду слабого спроса и слабо развитой транспортной инфраструктуры значительна и колеблется в зависимости от региона и лесничества на уровне 20-80 \% (низкобонитетные леса и насаждения с высокой долей лиственных 
пород). Кроме того, еще достаточно много «нетронутых» лесов. Следовательно, без учета всех этих факторов любые межнациональные сопоставления некорректны [5]. Однако с точкой зрения С. В. Починкова можно не согласиться. Во-первых, низкий выход древесины с 1 га лесной площади в России объясняется, прежде всего, недостаточной плотностью лесных дорог; вовторых, продуктивность насаждений (качество) также зависит от транспортной доступности лесов; в-третьих, низкая плотность транспортной сети является причиной недоступности значительных площадей лесного фонда для промышленной эксплуатации, неэффективной охраны лесов от пожаров и неудовлетворительного объема лесовосстановления [6].

Для наиболее точного и актуального определения плотности лесных дорог целесообразно использовать методы, отображающие пространственное развитие территории. Наиболее подходящими технологиями для решения таких задач являются географические информационные системы. Географические информационные системы для решения задач в лесном хозяйстве и природопользовании в последнее время используют довольно часто [7-9], в том числе и для решения транспортных задач [10-12]. Применение ГИС позволяет оперативно анализировать пространственные данные, визуально отображать результаты анализа планировать лесохозяйственное и лесозаготовительное производство [13-15].

На сегодняшний день существует несколько географических информационноаналитических систем для использования в лесозаготовках, разработанных в основном за рубежом. Одной из первых систем была система ASICAM, разработанная в Чили и использующая эвристический метод и имитационное моделирование, для определения оптимальных маршрутов. В системе MaxTour, разработанной в Квебеке (Канада), используется метод Кларка-Райта для составления оптимальных маршрутов при заранее известном плане поставок, в котором делянки и поставляемые партии четко распределены по потребителям.
Шведская система RuttOpt использует гибридный метод, объединяющий метод поиска с запретами с решением задачи линейного программирования. Система FlowOpt, также разработанная в Швеции, использует методы линейного программирования для решения задач стратегического и тактического планирования транспортного процесса в лесном комплексе.

Исследовав рынок программных продуктов, предназначенных для работы с географической информацией, мы остановили свой выбор на группе настольных продуктов ArcGISforDesktop, разработанный специалистами компании ESRI. ArcGIS обладает большим инструментарием для обработки географической информации, ее хранения, предоставления пользователю в различных видах, глубокого анализа и моделирования различных ситуаций.

\section{Методы и материалы}

В рамках настоящих исследований объектом будут являться Хребтовское и Гремучинское лесничества Красноярского края (рис. 1). Общая площадь земель лесного фонда Гремучинского лесничества составляет 1209495 га, Хребтовского - 824918 га. На данной территории лесозаготовки активно ведутся несколько десятилетий. Площадь освоенных территорий составляет 1383400 га.

Основная часть заготавливаемой древесины автомобильным транспортом вывозится до р. Ангары, далее по воде транспортируется в плотах до г. Лесосибирска. Территория характеризуется равнинным и холмистым рельефом. По лесничествам проложены автомобильные автомагистрали круглогодового действия, связывающие p. Ангару и северные территории лесничества. От данных дорог ответвляются ветки и зимние лесовозные усы.

Для анализа территории и расчета плотности дорог используется программный комплекс ArcGis. Создание цифровой базы данных выполнено с использованием современных технических программных средств ArcGis [16-19]. 


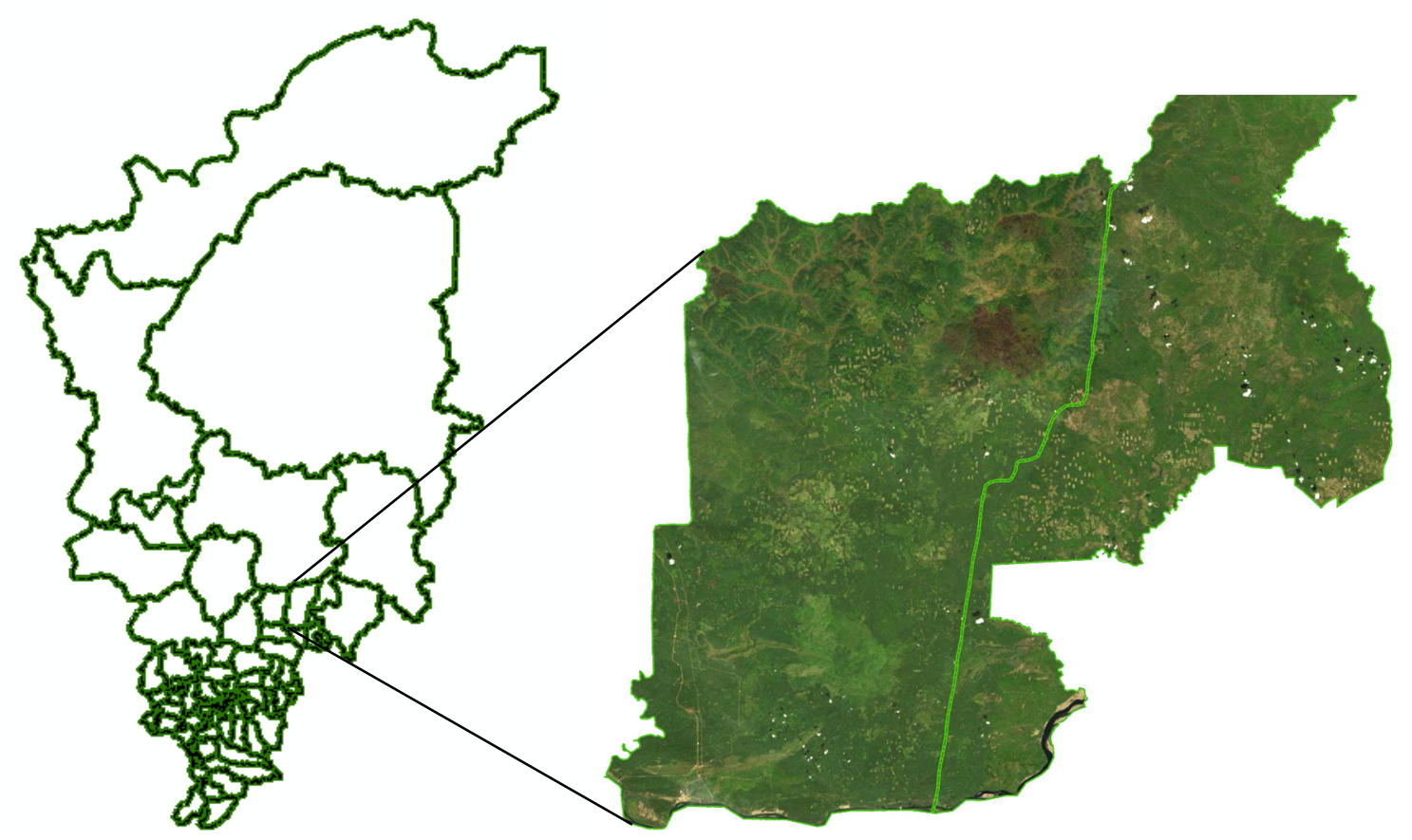

Рис. 1. Расположение исследуемых лесничеств в Красноярском крае

Система ArcGIS представляет собой масштабируемую среду для создания полноценной ГИС. ArcGISDesktop - это набор различных программных приложений для создания, редактирования, глубокого анализа и распространения географической информации. B ArcGIS имеются наборы инструментов и географических данных, используя которые, можно моделировать различные процессы, а на основе полученных результатов прогнозировать развитие ситуации.

Инструмент Line Density вычисляет плотность линейных объектов в окрестности каждой ячейки выходного растра. Плотность вычисляется в единицах длины на единицу площади.

Концептуально, вокруг центра каждой ячейки растра строится окружность, радиус которой равен радиусу поиска. Длина части каждой линии, которая попадает внутрь окружности, умножается на значение величины поля Population (Численность). Эти числа суммируются, и результат делится на площадь круга.

Существующая сеть анализируется относительно уклонов местности. Для этого с помощью инструмента геообработки «Slope» из набора инструментов «SpatialAnalyst» производится обработка полученных данных SRTM [20]. SRTM (Shuttle radar topographic mission) - это радарная топографическая съемка, охватывающая большую часть территории Земли. Исключение составляют самые северные $(>60)$ и самые южные (>54) широты и океаны. По этой причине на части северной территории анализируемых лесничеств уклоны не определены.

\section{Результаты и дискуссия}

Дороги различных категорий оцифрованы и добавлены в систему ArcGIS. На рис. 2 представлены дороги на карте уклонов анализируемых лесничеств.

Как видно из рис. 2 , лесозаготовки и соответственно транспортная сеть развиваются в северо-восточном направлении с преимущественными уклонами на территории менее $7^{\circ}$.

Согласно методике, с использованием инструментов ArcGIS рассчитана плотность дорог относительно всей площади, освоенной лесозаготовками, результаты представлены в таблице. 


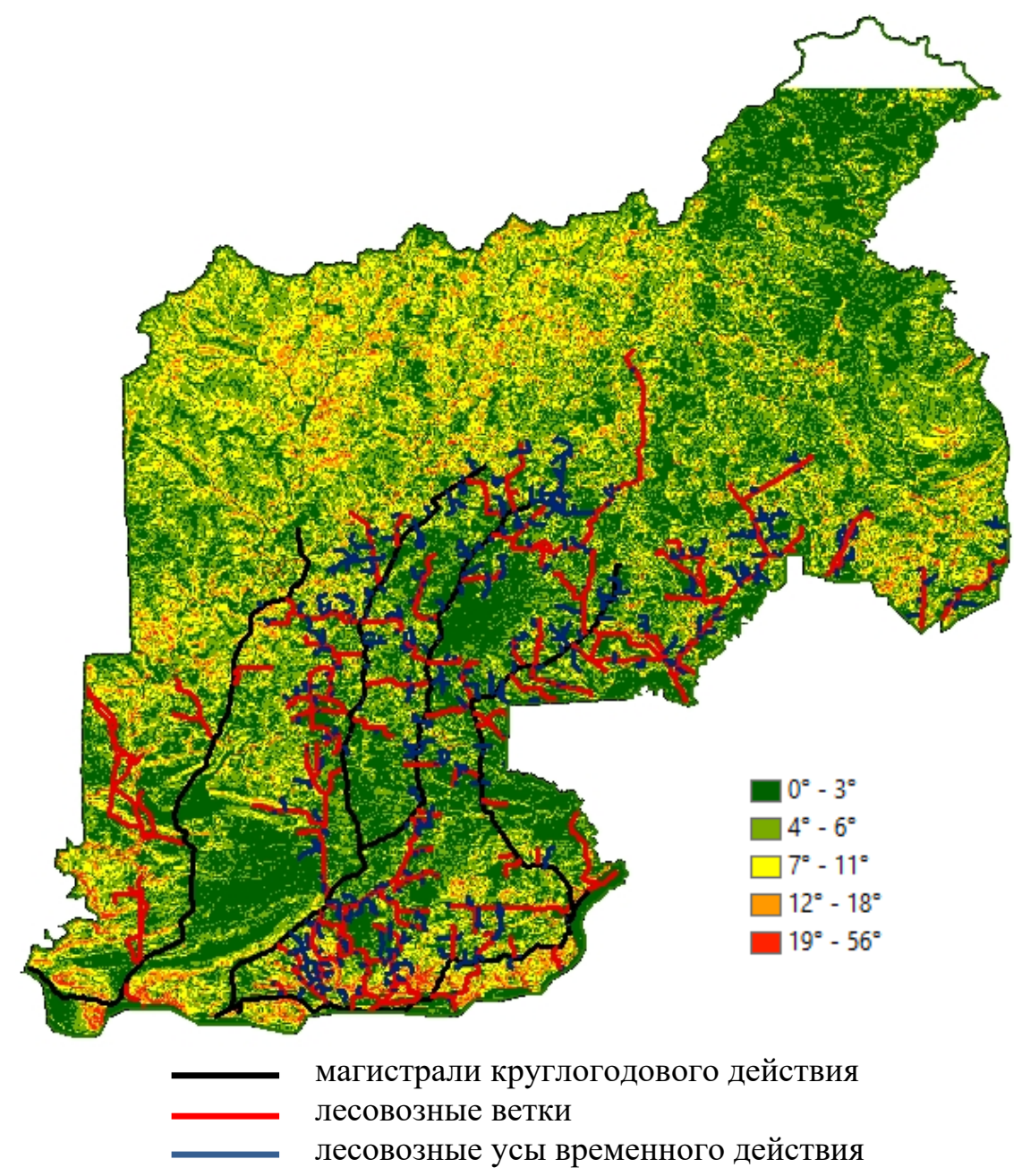

Рис. 2. Транспортная сеть и уклоны анализируемых лесничеств

Показатели транспортной сети территории Хребтовского и Гремучинского лесничеств

\begin{tabular}{|c|c|c|}
\hline \multirow{2}{*}{ Характеристика } & \multicolumn{2}{|c|}{ Показатель по территориям } \\
\hline & общая & освоенная \\
\hline Протяженность всех дорог, км & \multicolumn{2}{|c|}{3911,9} \\
\hline Протяженность магистралей круглогодового действия, км & \multicolumn{2}{|c|}{770,7} \\
\hline Протяженность лесовозных веток, км & \multicolumn{2}{|c|}{1740,1} \\
\hline Протяженность лесовозные усов временного действия, км & \multicolumn{2}{|c|}{1401,1} \\
\hline Плотность всех дорог, км/тыс. га & 1,923 & 2,82 \\
\hline Плотность магистралей круглогодового действия, км/тыс. га & 0,379 & 0,557 \\
\hline Плотность лесовозных веток, км/тыс. га & 0,855 & 1,26 \\
\hline $\begin{array}{l}\text { Плотность лесовозных дорог круглогодового действия и ве- } \\
\text { ток, км/тыс. га }\end{array}$ & 1,234 & 1,817 \\
\hline Плотность лесовозные усы временного действия, км/тыс. га & 0,689 & 1,01 \\
\hline
\end{tabular}

Согласно полученным данным большая часть эксплуатируемых дорог приходится на лесовозные ветки (рис. 3). Предприятия не желают вкладываться в дорогостоящую магистраль круглогодичного действия. Строительство веток позволяет им осваивать террито- рию без больших инвестиций на протяжении 5-10 лет. Магистрали круглогодового имеют наименьшую протяженность, что отрицательно сказывается на транспортных затратах. В целом, плотность лесных дорог (магистрали и ветки) на рассматриваемой терри- 
тории находится в пределах среднего показателя по России. Однако основная часть дорог приходится на $68 \%$ освоенной части лесного фонда. Это говорит о том, что распределение плотности неравномерное, что сказывается на доступности лесных ресурсов и эффективности их транспортировки. Оценивая территориально распределение плотности дорог (рис. 4), можно выделить несколько участков с наибольшей густотой. На основной же части территории данный показатель крайне низкий.
По мнению авторов, такой подход к решению задачи наиболее точно и быстро определяет плотность лесовозных дорог. Данный показатель характеризует развитую инфраструктуру на лесной площади.

Полученные результаты согласуются с известными представлениями [21, 22] о плотности лесовозных дорог. Густота дорог в рассматриваемых лесничествах на порядок ниже, чем в странах с развитой лесной промышленностью.

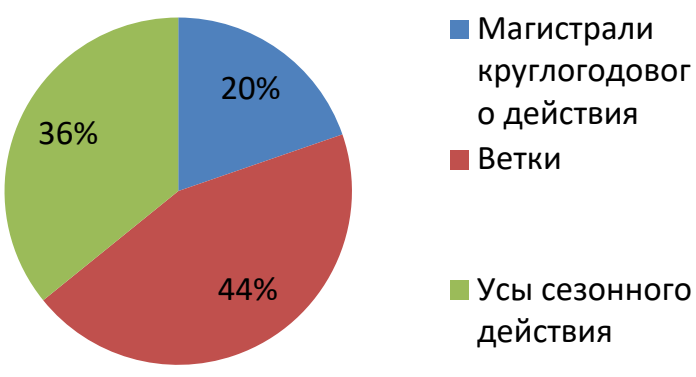

Рис. 3. Распределение типов дорог на рассматриваемой территории

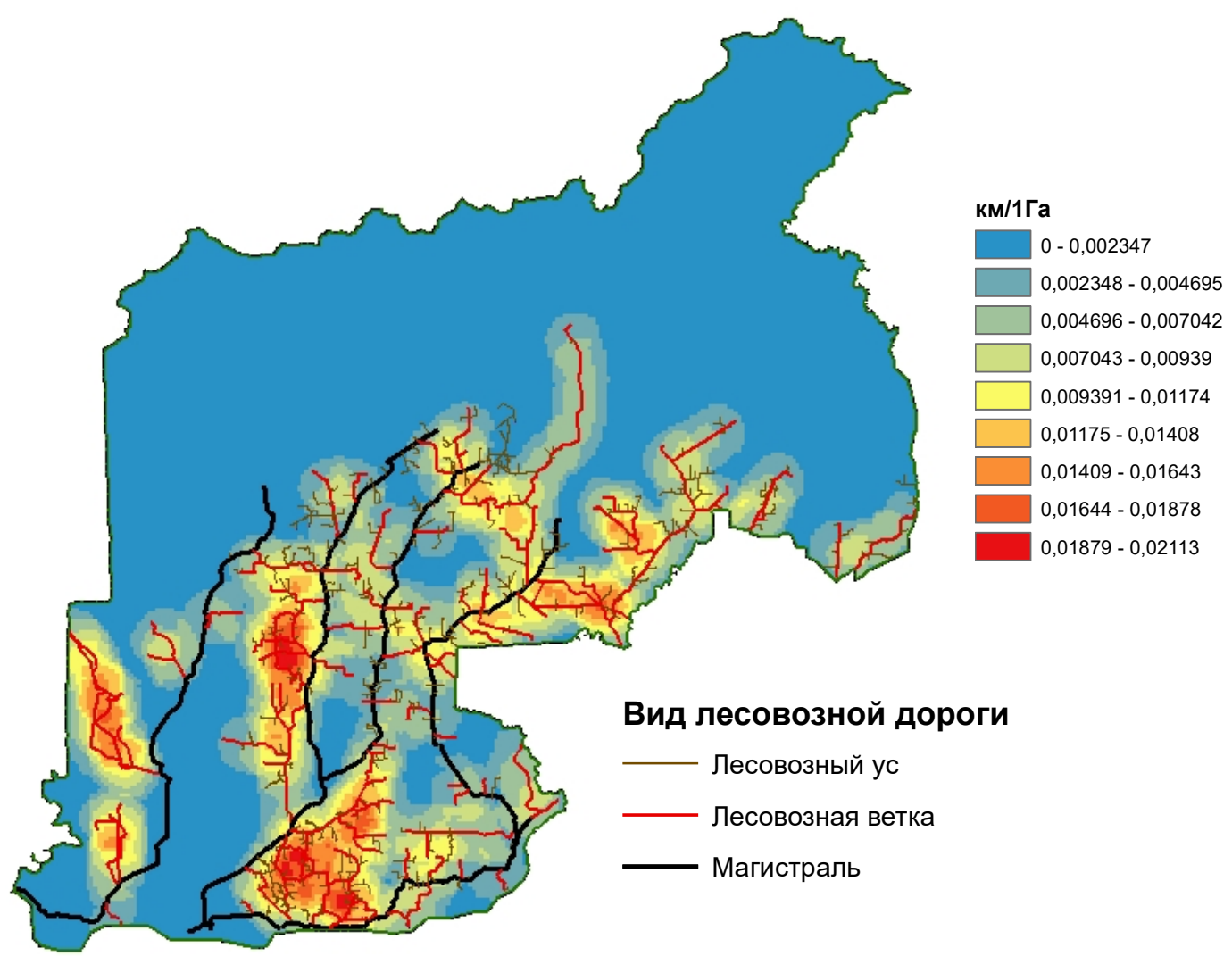

Рис. 4. Территориальное распределение плотности дорог 
Результаты данной задачи необходимы для планирования лесозаготовительного производства при поиске оптимальных маршрутов доставки древесины с учетом природноклиматических условий [23]. Для этого требуется имеющуюся или проектируемую сеть дорог проанализировать с учетом уклонов местности, встречающихся преград в виде рек и ручьев. В первую очередь по сети дорог строится граф. Также данные исследования возможно применять для определения доступности лесных ресурсов в программах развития регионов и лесопромышленных предприятий [24-28].

\section{Заключение}

В результате исследования установлено, что лесозаготовки и соответственно транспортная сеть исследуемых территорий развиваются преимущественно в северо-восточном направлении. Данный факт обусловлен, прежде всего, природно-климатическими особенностями региона, а также меньшим потенциалом в развитии альтернативных направлений. Именно в северо-восточном направлении, как показывает практика, развивается вся лесозаготовительная отрасль Красноярского края, где сохраняются наибольшие запасы нетронутых древостоев.

Использование инструментов ArcGIS позволило автоматизировать значительное число расчетов в исследовании и, в частности, рассчитать плотность дорог, визуализировать полученные данные, а также сформировать базу для дальнейших исследований. Ключевое направление последних - это оценки доступности древесных ресурсов Красноярского края, в том числе его северных регионов. Также важным аспектом, для чего крайне необходимы современные информационные технологии, является соотнесение функционирования как текущего, так и перспективного с жизнедеятельностью коренных малочисленных народов Севера, конфликтные и спорные ситуации с которыми возникают здесь достаточно часто [29].

Картографирование по выше описанным темам, с использованием географических информационных систем позволит анализировать лесную инфраструктуру и актуально планировать ее развитие.

Результатом же продолжающихся исследований должен стать перспективный план развития лесной инфраструктуры Красноярского края с учетом комплекса взаимовлияющих факторов и необходимостью повышения доступности древесных ресурсов.

Исследование выполнено при финансовой поддержке РФФИ, Правительства Красноярского края, Краевого фонда науки и ООО «Красресурс 24» в рамках научного проекта № 20-410-242901 и в рамках проекта «Разработка фундаментальных основ проектирования лесной инфраструктуры как динамически изменяемой системы в условиях деятельности лесозаготовительного производства», № 19-410-240005 поддержанного за счет средств иелевого финансирования, предоставленного РФФИ, Правительством Красноярского края и Краевым фондом науки.

\section{БИБЛИОГРАФИЧЕСКИЙ СПИСОК}

1. Лесные дороги : справочник / под ред. Э. О. Салминена. - СПб. : Лань, 2012. - 496 с.

2. Кислухина И. А., Поливодин Э. С. Финансовые и экологические проблемы строительства лесовозных дорог круглогодового действия // Актуальные проблемы лесного комплекса. 2012. - № 32. - С. 155-160.

3. Герасимов Ю., Катаров В. Лесные дороги / под ред. Э. Вялккю, С. Карвинен. - Йоэнсуу : НИИ леса Финляндии METLA, 2009. - 70 с.

4. Тюрин Н. А., Громская Л. Я. Оптимизация структуры транспортной сети лесозаготовительно- го предприятия // Изв. Санкт-Петербургской лесотехнической академии. - 2009. - № 186. - С. 72-77.

5. Починков С. В. Проблемы российского лесопользования. - Вологда, 2015. - 359 с.

6. Богомолова Е. Ю., Давыдова Г. В. Влияние плотности лесных дорог на объем и качество лесопромышленных и лесохозяйственных работ // Известия Байкальского государственного университета. - 2016. - Т. 26, № 2. - С. 284-290.

7. Пахахинова 3. 3., Батоцыренов Э. А., Бешенцев А. Н. Картографическая регистрация базовых пространственных объектов для монито- 
ринга природопользования // Вестник СГУГиТ. 2016. - № 2 (34). - C. 94-104.

8. Assessment of availability of wood resources using geographic information and analytical systems (the Krasnoyarsk territory as a case study) / A. P. Mokhirev, M. O. Pozdnyakova, S. O. Medvedev, V. O. Mammatov // Journal of Applied Engineering Science. - 2018. - T. 16, № 3. - C. 313-319. DOI: $10.5937 /$ jaes16-16908.

9. Лисицкий Д. В., Хорошилов В. С., Бугаков П.Ю.Картографическое отображение трехмерных моделей местности // Изв. вузов. Геодезия и аэрофотосъемка. - 2012. - № 2/1. - С. 98-102.

10. ГИС в решении транспортных проблем [Электронный ресурс] // ArcReview. - 2016. № 1 (76). - Режим доступа: https://www.dataplus.ru/ news/arcreview/detail.php?ID=23327.

11. ГИС и транспорт [Электронный ресурс] // ArcReview. - 2007. - № 3 (42). - Режим доступа: https://www.dataplus.ru/news/arcreview/detail.php?I $\mathrm{D}=1366$.

12. Gerasimov Yu. Yu., Sokolov A. P., Karjalainen T. GIS-based decision-support program for short-wood transport in Russia // The Nordic-Baltic Conference on Forest Operations (Copenhagen September 23-25, 2008). - Copenhagen : Forest \& Landscape Working Papers, 2008. No. 30.

13. Мохирев А. П., Горяева Е. В., Егармин П. А. Создание геоинформационного ресурса для планирования лесозаготовительного производства // Вестник СГУГиТ. - 2017. - Т. 22, № 2. - C. 137-153.

14. Ромичева Е. В. Методы обработки и визуализации больших данных // Аллея науки. 2017. - T. 3, № 16. - C. 976-982.

15. Bill Franks. Taming the big data tidal wave: finding opportunities in huge data streams with advanced analytics. - John Wiley \& Sons, Inc., 2012. 336 p. - DOI: 10.1002/9781119204275.

16. Jenness J. Dem surface tools for ARCGIS [Electronic resource] // Tools for Graphics and Shapes: Extension for ArcGIS. Jenness Enterprises. Flagstaff, 2013. - 95 p. - Mode of access: http://www.jennessent.com/arcgis/shapes_graphics.htm.

17. ESRI. 3D Analyst-ArcView Extension [Electronic resource]. Review is available at. Mode of access: http://www.esri.com/software/ arcview/ extensions/3dext.html.

18. Yankovich E. P., Baranovskiy N. V., Yankovich K. S. ARCGIS for assessment and display of the probability of forest fire danger // The 9th International Forum on Strategic Technology (IFOST). Advanced Technology: Recent Trends and their Implications. Bangladesh : At Cox's Bazar, 2014. - P. 222-225. DOI: 10.1109/IFOST.2014.6991108.
19. Басаргин А. А., Бугаков П. Ю., Кацко С. Ю. Решение логистических задач на основе обработки геопространственных данных с помощью модуля TRACKING ANALYST в составе ARCGIS // Вестник СГУГиТ. - 2019. - T. 24, № 1. - C. 83-96.

20. Фарбер С. К., Кузьмик Н. С., Брюханов Н. В. Перспективы использования данных SRTM для решения лесных научно-практических задач // Интерэкспо ГЕО-Сибирь-2013. IX Междунар. науч. конгр. : Междунар. науч. конф. «Экономическое развитие Сибири и Дальнего Востока. Экономика природопользования, землеустройство, лесоустройство, управление недвижимостью» : сб. материалов в 4 т. (Новосибирск, 15-26 апреля 2013 г.). - Новосибирск : СГГА, 2013. Т. 4. - С. 85-88.

21. Громская Л. Я., Тюрин Н. А., Козулина В. А. Измерители комплексной оценки транспортного освоения лесов // Труды БГТУ. Лесная и деревообрабатывающая промышленность. 2014. - № 2 (166). - С. 83-85.

22. Мохирев А. П., Болотов О. В. Проектирование сети лесных дорог на примере предприятий Красноярского края : монография. - Красноярск : СибГТУ, 2010. - 178 с.

23. Mokhirev A., Gerasimova M., Pozdnyakova M. Finding the optimal route for transportation of wood [Electronic resource] // IOP Conf. Ser.: Earth Environ, Sci. - 2019. - Vol. 226. - P. 012-053. Mode of access: https://iopscience.iop.org/article/. DOI: $10.1088 / 1755-1315 / 226 / 1 / 012053$.

24. Оценка доступности лесных ресурсов с использованием современных методик на базе географических информационно-аналитических систем / А. П. Мохирев, М. О. Позднякова, С. Ю. Резинкин, В. О. Мамматов // Лесотехнический журнал. - 2017. - № 4 (28). - С. 109-122. DOI: $10.12737 /$ article_5a3cf0de38c188.71430470.

25. Bredstrom D., Jonsson P., Ronnqvist M. Annual planning of harvesting resources in the forest industry // International transactions in operational research. - 2010. - № 17. - P. 155-177.

26. Decisions and methodology for planning the wood fiber flow in the forest supply chain / D. Carlsson, S. D'Amours, A. Martel, M. Rönnqvist // Recent developments in supply chain management ; eds.: R. Koster and W. Delfmann. - Helsinki : University Press, 2008. - P. 11-39.

27. Economic and environmental impacts of transport cost changes on timber and forest product markets in Norway / E. Tromborg et al. // Scandinavian Journal of Forest Research. - 2009. - № 24 (4). P. 354-366. 
28. Мохирев А. П., Резинкин С. Ю. Решение задач планирования лесопромышленного производства с использованием географической информационной системы // Системы. Методы. Технологии. - 2016. - № 2 (30). - С. 169-173. DOI: $10.18324 / 2077-5415-2016-2-169-173$.
29. Самсонова И. В., Неустроева А. Б., Павлова М. Б. Проблемы взаимодействия коренных малочисленных народов Севера и добывающих компаний в Республике Саха (Якутия) // Социодинамика. - 2017. - № 9. - С. 21-37. DOI: 10.25136/2409-7144.2017.9.23852.

Получено 13.03.2020

(C) А. П. Мохирев, С. Ю. Резинкин, С. О. Медведев, Н. А. Брагина, 2020

\title{
USE OF GEOGRAPHIC INFORMATION SYSTEMS IN THE EVALUATION OF THE DENSITY OF ROADS OF FORESTRY AREAS
}

\author{
Aleskandr P. Mokhirev \\ Lesosibirsk Branch of Reshetnev Siberian State University of Science and Technology, 29, Pobedy St., Leso- \\ sibirsk, 662543, Russia, Ph. D., Associate Professor, phone: (39145)6-28-03, e-mail: ale-mokhirev@yandex.ru
}

\section{Sergey Yu. Rezinkin}

Lesosibirsk Branch of Reshetnev Siberian State University of Science and Technology, 29, Pobedy St., Lesosibirsk, 662543, Russia, Master Student, phone: (39145)6-28-03, e-mail: pogz31@mail.ru

\section{Sergey O. Medvedev}

Lesosibirsk Branch of Reshetnev Siberian State University of Science and Technology, 29, Pobedy St., Lesosibirsk, 662543, Russia, Ph. D., Associate Professor, phone: (39145)6-28-03, e-mail: medvedev_serega@mail.ru

\section{Nataliya A. Bragina}

Lesosibirsk Branch of Reshetnev Siberian State University of Science and Technology, 29, Pobedy St., Lesosibirsk, 662543, Russia, Master Student, phone: (39145)6-28-03, e-mail: bragina.n.a@mail.ru

In Russia, the density of forest roads is significantly lower than in countries with developed forest industries. This negatively affects the efficiency of logging and the yield of wood per unit area. There are different opinions about the normative and actual values of the density of forest roads in the forest regions of Russia. Today, it is possible to assess the density of forest roads and analyze its development using modern geographic information systems (GIS). In these studies, the density of forest roads is determined using the ArcGis software package in the two forest districts of Krasnoyarsk Territory. The roads located on the territory of the studied sections are digitized and divided by types: highway of year-round operation, branch, $\log$ ging mustache. Using the tools of the software package, the lengths and densities of roads are determined by their types. The obtained values are consistent with the indicators of other researchers from different regions of Russia. The results of this task are necessary for the planning of logging production when searching for optimal routes for wood delivery, taking into account the natural and climatic conditions. Using ArcGIS tools allowed us to automate a significant number of calculations in the study and, in particular, calculate the density of roads, visualize the data obtained, and also form the basis for further research.

Key words: road density, geographical information system, forest road, road density, forest infrastructure, information processing.

\section{REFERENCES}

1. Salminen E. O. (Ed.). (2012). Lesnye dorogi [Forest roads]. Saint Petersburg: Lan' Publ., 496 p. [in Russian].

2. Kislukhina, I. A., \& Polivodin, Eh. S. (2012). Financial and environmental problems of the construction of logging roads year-round activity. $A k$ - tual'nye problemy lesnogo kompleksa [Actual Problems of Forest Complex], 32, 155-160 [in Russian].

3. Gerasimov, Yu. A., \& Katarov, V. (2009). Lesnye dorogi [Forest roads]. E H. Vyalkkyu, \& S. Karvinen. Joensuu: METLA forest research Institute of Finland. p. 70 [in Russian]. 
4. Tyurin, N. A., \& Gromskaya, L. Ya. (2009). Optimization of the structure of the transport network of logging enterprises. Izvestiya SanktPeterburgskoy lesotekhnicheskoy akademii [Bulletin of Saint-Petersburg Forestry Academy], 186, 72-77 [in Russian].

5. Pochinkov, S. V. (2015). Problemy rossiyskogo lesopol'zovaniya [Problems of Russian forest management]. Vologda, 359 p. [in Russian].

6. Bogomolova, E. Yu., \& Davydova. G. V. (2016) Influence of the density of forest roads on the volume and quality of timber industry and forestry work. Izvestiya Baykal'skogo gosudarstvennogo universiteta [Proceedings of the Baikal State University], 26(2), 284-290 [in Russian].

7. Pakhakhinova, Z. Z., Batotsyrenov, Eh. A., \& Beshentsev, A. N. (2016). Cartographic registration of basic spatial objects for environmental monitoring. Vestnik SGUGiT [Vestnik SSUGT], 2(34), 94-104 [in Russian].

8. Mokhirev, A. P., Pozdnyakova, M. O., Medvedev, S. O., \& Mammatov, V. O. (2018). Assessment of availability of wood resources using geographic information and analytical systems (the Krasnoyarsk territory as a case study). Journal of Applied Engineering Science, 16(3), 313-319. DOI: 10.5937/jaes16-16908.

9. Lisitskij, D. V., KHoroshilov, V. S. \& Bugakov, P. Yu. (2012). Mapping three- dimensional terrain models. Izvestiya vuzov. Geodeziya $i$ aerofotos"emka [Izvestiya vuzov. Geodesy and Aerophotography], 2/1, 98-102 [in Russian].

10. GIS in solving transport problems. (2016). ArcReview, 1(76). Retrieved from https://www.dataplus. ru/news/arcreview/detail.php?ID=23327 [in Russian].

11. GIS and transport. (2007). ArcReview, 3(42). Retrieved from https://www.dataplus.ru/news/ arcreview/ detail.php?ID=1366 [in Russian].

12. Gerasimov, Yu. Yu., Sokolov, A. P., \& Karjalainen T. (2008). GIS-based decision-support program for short-wood transport in Russia. The Nordic-Baltic Conference on Forest Operations: No. 30. Copenhagen: Forest \& Landscape Working Papers.

13. Mokhirev, A. P., Goryaeva, E. V., \& Egarmin, P. A. (2017). Creating a geographic information resource for planning logging operations. Vestnik SGUGiT [Vestnik SSUGT], 22(2), 137-153 [in Russian].

14. Romicheva, E. V. (2017). Methods for processing and visualizing big data. Alleya nauki [Science Alley], 3(16), 976-982 [in Russian].

15. Bill Franks. (2012). Taming the big data tidal wave: finding opportunities in huge data streams with advanced analytics. John Wiley \& Sons, Inc., 336 p. DOI: 10.1002/9781119204275.

16. Jenness J. (2013). Dem surface tools for ARCGIS. Tools for Graphics and Shapes: Extension for ArcGIS. Jenness Enterprises. (95 p.). Flagstaff. Retrieved from http://www.jennessent.com/arcgis/ shapes graphics.htm.

17. ESRI. (n. d.). 3D Analyst-ArcView Extension. Review is available at. Retrieved from http://www.esri.com/software/arcview/extensions/3d ext.html.

18. Yankovich, E. P., Baranovskiy, N. V., \& Yankovich, K. S. (2014). ARCGIS for assessment and display of the probability of forest fire danger. The 9th International Forum on Strategic Technology (IFOST). Advanced Technology: Recent Trends and their Implications (pp. 222-225). Bangladesh: At Cox's Bazar.

19. Basargin, A. A., Bugakov, P. Yu. \& Katsko, S. Yu. (2019). Solving logistics tasks based on processing geospatial data using the tracking ANALYST module in ARCGIS. Vestnik SGUGiT [Vestnik SSUGT], 24(1), 83-96 [in Russian].

20. Farber, S. K., Kuz'mik, N. S., \& Bryukhanov, N. V. (2013). Prospects of use of data of SRTM for the solution of forest scientific and practical tasks. In Sbornik materialov Interekspo GEO-Sibir'2013: Mezhdunarodnoy nauchnoy konferentsii: T. 4. Ekonomicheskoe razvitie Sibiri i Dal'nego Vostoka. Ekonomika prirodopol'zovaniia, zemleustroistvo, lesoustroistvo, upravlenii e nedvizhimost'iu [Proceedings of Interexpo GEO-Siberia-2013: International Scientific Conference: Vol. 4. Economic Development of Siberia and the Far East. Enviromental Economics, Land Management, Forestry Management and Property Management] (pp. 85-88). Novosibirsk: SSGA Publ. [in Russian].

21. Gromskaya, L. Ya., Tyurin, N. A., \& Kozulina, V. A. (2014). Measuring integrated assessment of the transport development of forests. Trudy BGTU. Lesnaya $i$ derevoobrabatyvayushchaya promyshlennost' [Proceedings of BSTU. Forestry and Woodworking Industry], 2(166), 83-85 [in Russian].

22. Mokhirev, A. P., \& Bolotov, O. V. (2010). Proektirovanie seti lesnykh dorog na primere predpriyatiy Krasnoyarskogo kraya [Designing a network of forest roads on the example of enterprises in the Krasnoyarsk territory]. Krasnoyarsk: SibSTU Publ., 178 p. [in Russian].

23. Mokhirev, A., Gerasimova, M. \& Pozdnyakova, M. (2019). Finding the optimal route for transportation of wood. IOP Conf. Ser.: Earth Environ, Sci.: Vol. 226 (pp. 012-053). Retrieved 
from https://iopscience.iop.org/article/. DOI: 10.1088/1755-1315/226/1/012053.

24. Mokhirev, A. P., Pozdnyakova, M. O., Rezinkin, S. Yu., \& Mammatov, V. O. (2017). Assessment of availability of forest resources using modern methods based on geographical information and analytical systems. Lesotekhnicheskiy zhurnal [Forest Engineering Journal], 4(28), 109-122. DOI: $\quad 10.12737 /$ article_5a3cf0de38c188.71430470 [in Russian].

25. Bredstrom, D. Jonsson, P., \& Ronnqvist M. (2010). Annual planning of harvesting resources in the forest industry. International Transactions in Operational Research, 17, 155-177.

26. Carlsson, D., D'Amours, S., Martel, A., \& Rönnqvist, M. (2008). Decisions and methodology for planning the wood fiber flow in the forest supply chain. Recent developments in supply chain man- agement (pp. 11-39). R. Koster \& W. Delfmann (Eds.). Helsinki: University Press.

27. Tromborg E. et al. (2009). Economic and environmental impacts of transport cost changes on timber and forest product markets in Norway. Scandinavian Journal of Forest Research, 24(4), 354-366.

28. Mokhirev A. P. \& Rezinkin S. Yu. (2016). Solving problems of planning timber production using a geographical information system Sistemy. Metody. Tekhnologii [The System. Methods. Technologies], 2(30), 169-173. DOI: 10.18324/20775415-2016-2-169-173 [in Russian].

29. Samsonova, I. V., Neustroeva, A. B. \& Pavlova, M. B. (2017). Problems of interaction between indigenous peoples of the North and mining companies in the Republic of Sakha (Yakutia). Sotsiodinamika [Sociodynamics], 9, 21-37. DOI: 10.25136/2409-7144.2017.9.23852 [in Russian].

Received 13.03.2020

(C) A. P. Mokhirev, S. Yu. Rezinkin, S. O. Medvedev, N. A. Bragina, 2020 
УДК 528.91:502.3:66.014

DOI: $10.33764 / 2411-1759-2020-25-3-192-200$

\section{ИСПОЛЬЗОВАНИЕ КАРТОГРАФИЧЕСКОГО МЕТОДА ИССЛЕДОВАНИЯ ПРИ ИЗУЧЕНИИ ХИМИЧЕСКОГО СОСТАВА ВОЗДУШНОЙ СРЕДЫ ПРОМЫШЛЕННОГО ЦЕНТРА}

\section{Ольга Николаевна Николаева}

Сибирский государственный университет геосистем и технологий, 630108, Россия, г. Новосибирск, ул. Плахотного, 10, доктор технических наук, профессор кафедры экологии и природопользования, тел. (383)361-08-86, e-mail: onixx76@mail.ru

\section{Геннадий Павлович Мартынов}

Сибирский государственный университет геосистем и технологий, 630108, Россия, г. Новосибирск, ул. Плахотного, 10, доцент кафедры высшей математики, тел. (383)343-25-77, e-mail: martynov@ssga.ru

\section{Анастасия Викторовна Могильникова}

Сибирский государственный университет геосистем и технологий, 630108, Россия, г. Новосибирск, ул. Плахотного, 10, обучающийся, тел. (951)384-48-51, e-mail: mogilnikova_nastya@mail.ru

Статья посвящена анализу проблемы снижения концентрации кислорода в атмосферном воздухе крупных населенных пунктов. Высказана гипотеза о взаимосвязи снижения уровня кислорода и сокращения площади городских зеленых насаждений. Предложено использовать картографический метод исследования для получения более полной информации о сокращении площади городского озеленения за длительный промежуток времени. Представлены результаты статистического анализа концентрации кислорода в атмосферном воздухе г. Сочи за 50 лет. Подтвержден факт устойчивого многолетнего тренда снижения концентрации кислорода в атмосферном воздухе г. Сочи по сравнению со значениями в Москве и в среднем по России. Представлена последовательность сбора и обработки разновременных картографических данных за 50 лет, находящихся в свободном доступе. Описаны картографические работы по сопоставлению и анализу собранных материалов в среде ГИС. Сделаны предварительные выводы о работоспособности ранее поставленной гипотезы. Отмечен факт низкой обеспеченности территории г. Сочи картографическими материалами, изданными после 2000 г. и имеющими точную координатную основу. Намечены перспективы дальнейших исследований.

Ключевые слова: статистический анализ, картографический метод исследования, концентрация кислорода, населенные пункты, городское озеленение, цифровые карты, топографические карты, ГИС, ГИС-технологии.

\section{Введение}

Промышленные центры являются основными концентраторами источников техногенного воздействия на локальной территории. Развитие и диверсификация различных отраслей промышленности и транспорта оказывает значительное негативное воздействие на окружающую среду, что проявляется в интенсивном загрязнении всех природных компонентов, входящих в ее состав. При этом наибольшее влияние на здоровье городского населения оказывают нарушения состава атмосферного воздуха, поскольку данный вид загрязнения воздействует на все слои населения как промышленного центра, так и пригородных территорий [1-3]. Наиболее очевидным из негативных факторов является повышение концентрации тех или иных химических элементов и соединений в атмосферном воздухе населенных пунктов, и именно оно зачастую учитывается при ведении экологических и эколого-гигиенических исследований $[1,2]$. При этом недостаточное внимание уделяется такой проблеме, как снижение концентрации кислорода в воздухе городской территории. Хроническая недообеспеченность атмосферным кислородом влечет за собой снижение его концентрации в тканях и органах человеческого организма, изменения состава крови, нарушения памяти, вегето-сосудистой системы и пр. [4]. 
В современных условиях, когда наблюдается интенсивный прирост городских застроенных территорий, одной из причин снижения концентрации кислорода в воздухе городской территории является сокращение площади городских зеленых насаждений. В установлении и изучении данной зависимости важную роль играет картографический метод исследования, который позволяет решить следующие задачи:

- установление территориальных закономерностей концентраций кислорода в атмосферном воздухе промышленного центра;

- анализ динамики сокращения площадей городских зеленых насаждений (в том числе - с использованием многолетних архивных картографических данных) $[5,6]$;

- геопространственное моделирование показателей, выражающих корреляцию концентраций кислорода и обеспеченности зелеными насаждениями на различных участках городской территории.

\section{Материальи и методы}

В качестве района работ был выбран Большой Сочи - агломерация населенных пунктов, расположенная вдоль побережья Черного моря от р. Шепси до р. Псоу. Изначально здесь располагалась цепочка сравнительно небольших курортных городов, однако в ходе подготовки к проведению Олимпиады 2014 г. в результате обширных строительных работ территория практически превратилась в единый населенный пункт площадью 3506 кв. км (для сравнения: площадь Москвы - 2561 кв. км) с населением около 330 тыс. чел. [7].

Система мониторинга за качеством атмосферного воздуха в г. Сочи включает в себя два стационарных поста, расположенных в Центральном и Хостинском районах. Стандартная программа наблюдений Росгидромета не предусматривает определение на этих постах концентрации кислорода в атмосферном воздухе. Поэтому с использованием общедоступных исходных климатических данных [8] были выполнены исследования на основе многолетних (с 1967 по 2015 г.) климатических данных по городу Сочи, которые позволили оценить динамику изменений и возможную взаимосвязь следующих четыpex климатических факторов окружающей среды: температуры воздуха (фактор $X$ ), относительной влажности воздуха (фактор Y), атмосферного давления (фактор $P$ ) и концентрации кислорода в воздухе (фактор $Z$ ). Для проверки гипотезы о нормальности типа распределения каждого фактора и выявления возможных зависимостей факторов между собой применялись методы математической статистики, осуществлялось построение графиков линий регрессии и изучался разброс данных относительно этих линий.

Картографический метод исследования призван помочь выполнить анализ архивных и современных данных о динамике площадей городских зеленых насаждений в г. Сочи. На начальной стадии исследований было принято решение выполнить сбор и геоинформационный анализ архивных и современных источников, представленных в свободном доступе в глобальной сети Интернет.

\section{Результаты и обсуждение}

Результаты статистического анализа данных о динамике изменений основных климатических факторов окружающей среды на территории г. Сочи за 1967-2015 гг. представлены на рис. 1 [9]. Сформированные графики позволили сделать следующие выводы:

- температура воздуха (фактор $X$ ) повышается по годам (рис. $1, a)$, при этом в среднем в июне она составляет примерно $21^{\circ} \mathrm{C}$. Данная тенденция наблюдается регулярно в теплое время года (май - октябрь);

- влажность воздуха (фактор Y) с октября по май практически постоянна (около 75 \%) во времени. Более детально изменения среднемесячной относительной влажности (в процентах) воздуха во времени представлены на рис. 1, б. График отчетливо показывает, что в холодное время года (октябрь - май) средняя влажность воздуха мало меняется по годам. В теплое время (июнь - сентябрь) наблюдается совершенно иная картина: в разные годы значения влажности воздуха составляли от 75 до $85 \%$;

- атмосферное давление (фактор $P$, в гектопаскалях; 1000 гПа эквивалентно 764 мм 
ртутного столба) в теплое время года (май октябрь) имеет тенденцию к понижению во времени (см. рис. 1, в);

- среднемесячная концентрация кислорода (г/куб. м) в воздухе во времени (фактор Z) стабильно снижается, начиная с 1970 г. (см. рис. 1, 2). Особенно ярко выражен этот процесс в зимнее время года (январь - октябрь), когда на большей части зеленых насаждений отсутствует листва и выработка ими кислорода минимальна. Но даже во время вегетационного периода (май - сентябрь) концентрация кислорода находится в диапазоне от 270 до 280 г/куб. м. Это гораздо ниже, чем в населенных пунктах Московской области $[10,11]$, которые не подвергались столь интенсивному сокращению площади озеленения, а также ниже среднего для России значения в 292,2 кг/куб. м (указано осредненное значение за 2000-2013 гг.) [12].

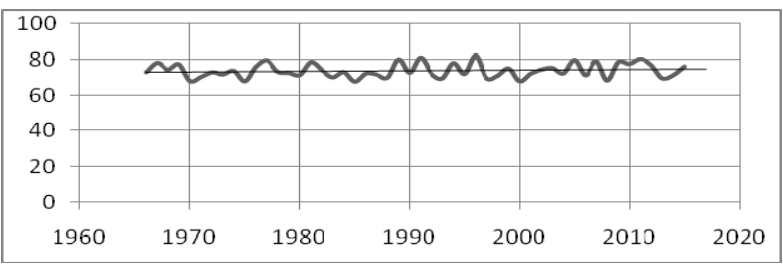

б)

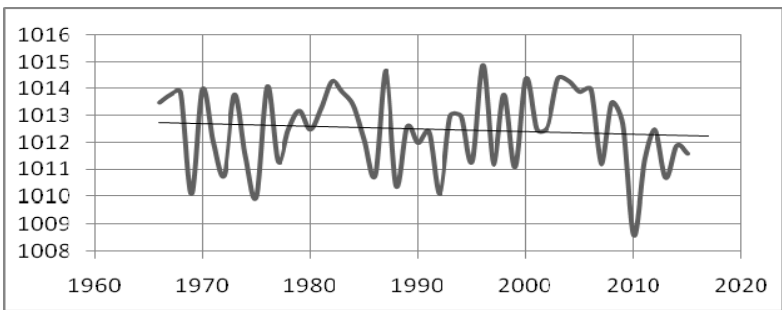

в)

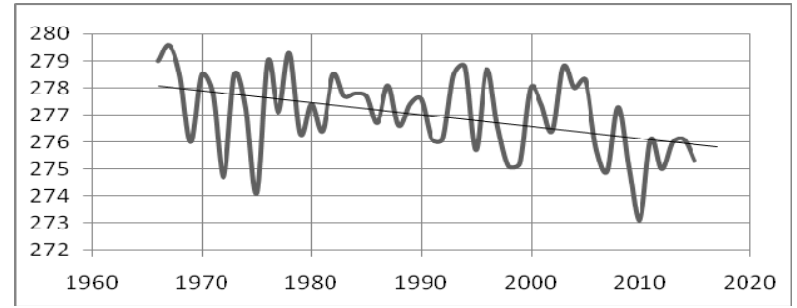

2)

Рис. 1. Динамика изменений температуры воздуха (фактор $X)$, относительной влажности воздуха (фактор $Y$ ), атмосферного давления (фактор $P$ ) и концентрации кислорода в воздухе (фактор $Z)$ :

a) динамика по годам фактора $X$ (июнь); б) динамика по годам фактора $Y$ (март); в) динамика по годам фактора $P$ (июнь); г) динамика по годам фактора $Z$ (июнь)

Для подтверждения достоверности полученных результатов по всем факторам $(X, Y, P$ и $Z$ ) была выполнена проверка на нормальность законов их распределений [9]. Как визуальное сопоставление гистограмм частот наблюдаемых факторов с расчетной увеличенной кривой Гаусса, так и использование метода, изложенного в [13] для более точной проверки нормальности распределений с помощью критерия согласия $\chi^{2}$, установили, что:

- значения концентрации кислорода в атмосферном воздухе г. Сочи в течение всех месяцев года распределены по нормальному закону;

- значения температуры, влажности и давления в течение 9 месяцев года также распределены согласно нормальному закону.
Таким образом, можно сделать вывод о методологической корректности реализации предыдущих этапов статистического исследования.

Далее выполнялась проверка гипотез о парной корреляции вышеперечисленных четырех факторов. С этой целью были рассчитаны коэффициенты парной корреляции. По результатам расчетов было установлено:

- для пары факторов $P, Z$ (атмосферное давление и концентрация кислорода) коэффициент корреляции варьировался в пределах от $(+0,8226)$ до $(+0,5282)$, что позволяет судить о заметной или высокой силе связи между этими факторами по шкале Чеддока;

- для пары факторов $X, Z$ (температура и содержание кислорода) коэффициент корре- 
ляции изменялся в пределах от $(-0,9495)$ до $(-0,8630)$, что свидетельствует о высокой силе связи. Однако в данном случае корреляционная зависимость является обратной. Это соответствует результатам исследований в области физиологии растений, согласно которым, для растений средней полосы России оптимальная для успешного фотосинтеза температура воздуха не должна превышать $25^{\circ} \mathrm{C}$ [14].

- для пар факторов $Y, Z$ (влажность воздуха и интересующий нас признак - содержание кислорода), $P$ и $X$ (атмосферное давление и температура воздуха), $P$ и $Y$ (атмосферное давление и влажность воздуха) корреляционная связь либо отсутствовала, либо оказалась пренебрежимо слабой.

Таким образом, корреляционный анализ позволил подтвердить исходное предположение, что концентрация кислорода в атмосферном воздухе г. Сочи в значительной степени обусловливается биологической деятельностью зеленых насаждений и слабо зависит от других климатических факторов, характерных для прибрежных территорий со сложным предгорным рельефом.

На последнем этапе статистической части исследования выполнялось построение графиков линейной регрессии для зависимых пар факторов $P, Z$ и $X, Z$ и изучение разброса данных наблюдений относительно этих графиков [9]. Прослеживались небольшие отклонения данных наблюдений относительно теоретической линии регрессии, однако в целом для обеих пар факторов зависимость была достаточно четко выражена с помощью уравнения линейной регрессии $[10,11]$.

Исследование уравнений парной линейной регрессии для пары факторов $X, Z$ и пары $P, Z$ позволили сделать следующий прогноз:

- увеличение средней температуры августа на $10{ }^{\circ} \mathrm{C}$ (динамика изменения температуры летних месяцев как раз показывает тенденцию к росту температуры летом) приведет к уменьшению содержания кислорода в 1 куб. м воздуха примерно на 10 г;

- увеличение среднего атмосферного давления этого месяца на 20 гПа приведет к увеличению содержания кислорода в 1 куб. м воздуха приблизительно на 13 г.

Выполнение дальнейших исследований, связанных с установлением причины посто- янной отрицательной динамики концентрации кислорода в атмосферном воздухе г. Сoчи, предполагает изучение процесса сокращения площади городского озеленения. Факт деградации городских зеленых насаждений признается действующей нормативной документацией [15], однако конкретные статистические данные, представленные в открытом доступе, фрагментарны и не могут быть обработаны традиционными статистическими методами. Поэтому было принято решение об использовании картографического метода исследования для обработки архивных и современных картографических материалов на территорию г. Сочи и определения площади городского озеленения в разные годы средствами ГИС-технологий.

Планируемая последовательность выполнения работ включала в себя следующие этапы:

1. Сбор и сортировка архивных картографических материалов на территорию г. Сочи, созданных в период интенсификации развития города (с 1950-х гг. ХХ в. по настоящее время).

2. Геопривязка и приведение в единую систему координат архивных картматериалов.

3. Векторизация архивных картматериалов. Для каждой геопривязанной карты определен следующий перечень слоев: административная граница города (полигон); застроенные территории (без выделения типов застройки); городские зеленые насаждения (без выделения типов насаждений).

4. Определение средствами ГИС по каждой из оцифрованных карт следующих статистических показателей: общая площадь городской территории; общая площадь застроенных территорий; общая площадь, занятая объектами озеленения.

5. Формирование сводной базы данных метрических характеристик зеленых насаждений г. Сочи; сопоставление полученных сведений с отчетными данными органов управления городским хозяйством г. Сочи (для тех лет, на которые эти данные имеются).

6. Сбор архивных и современных материалов дистанционного зондирования Земли (ДЗ3) на территорию г. Сочи.

7. Геопривязка, векторизация и ГИСанализ материалов Д3З по аналогии с действиями, выполнявшимися для архивных картографических материалов. 
8. Дополнение и корректировка сводной базы данных метрических характеристик зеленых насаждений г. Сочи в соответствии с результатами пространственного анализа материалов ДЗ3.

9. Выполнение статистического анализа данных о динамике концентрации кислорода в атмосферном воздухе г. Сочи и данных о динамике площади городского озеленения; формулирование окончательных выводов исследования.

Далее будут более подробно охарактеризованы уже выполненные этапы работ.

Практическая реализация запланированных работ была начата со сбора источников исходных геопространственных данных о планировке и структуре г. Сочи в разные годы. Был выполнен сбор архивных карт, представленных в открытых источниках [16-18]. При этом предпочтение отдавалось топографическим картам, поскольку на них в явном виде представлена координатная сетка и проекция, что облегчало бы процесс их геопривязки. Самая ранняя из найденных карт датировалась 1968 г., самая поздняя 1989 г. Также значительное количество источников было отбраковано из-за отсутствия на них информации о годе составления (обновления). Более свежие картографические источники сводились к разнообразным туристским картам и картосхемам, составленным со значительными искажениями в математической и графической части, и потому для анализа непригодными. Исключение составляет лишь публичная кадастровая карта Сочи [19], которая была использована для получения наиболее актуальной информации.

Для уточнения сведений о современной планировочной структуре г. Сочи были использованы материалы аэрокосмической съемки [20], представленные в открытом доступе.

Систематизация и сопоставление собранных графических материалов выполнялись в ГИС MapInfo. Не для всех отобранных архивных источников удалось добиться идеального совпадения картографического изображения в силу неизбежных погрешностей при сканировании и сшивке, допущенных владельцами карт при их публикации в Интернете. Работа над уточнением координатной привязки таким источников ведется в настоящее время с привлечением специализированных программных средств. Успешно было выполнено совмещение картографических материалов 1968 г., 1989 г. и 2019 г. Их анализ подтвердил предположение о значительном сокращении площадей озеленения г. Сочи за 2-ю половину XX в. и начало XXI в. (рис. 2).

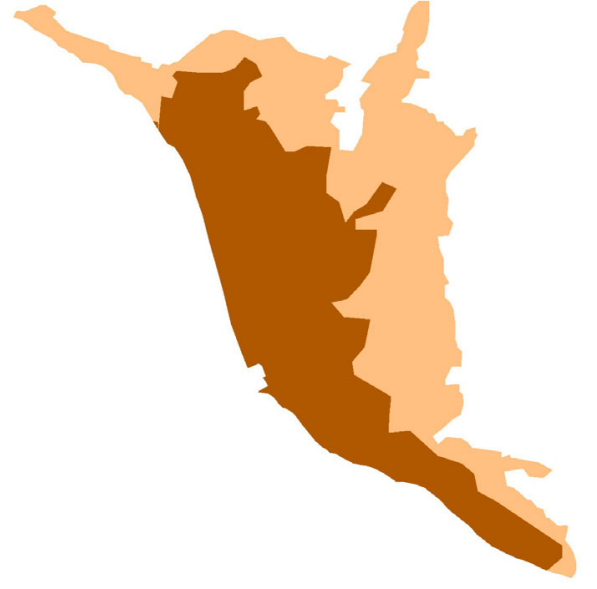

Территория г. Сочи в 1968 г. Территория г. Сочи в 2020 г.

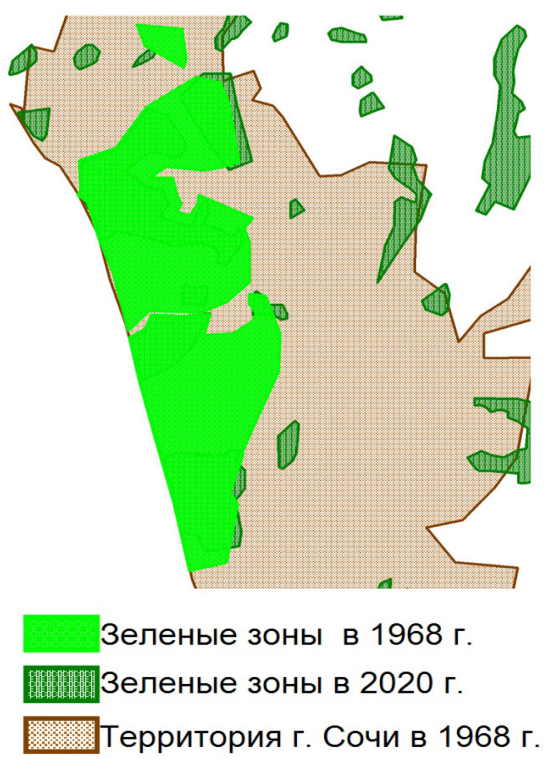

Рис. 2. Предварительные результаты картографического анализа территориальных изменений в г. Сочи:

a) прирост территории г. Сочи с 1968 по 2020 г.; б) сокращение площади зеленых зон в центральной части г. Сочи 
Однако изучение истории территориального развития г. Сочи выявило, что резкое сокращение территорий, занятых зелеными насаждениями, началось в основном после 2000 г. Поэтому для более детального изучения ситуации в период с 2000 по 2020 гг. был произведен заказ дополнительного пакета архивных и современных материалов Д33 высокого пространственного разрешения на Геопортале данных ДЗЗ Роскосмоса.

\section{Заключение}

Выполненные работы позволили сформулировать следующие выводы:

- статистическими исследованиями подтверждено, что начиная с 1970-х гг. в атмосферному воздухе г. Сочи происходит постоянное снижение концентрации кислорода. При этом даже в вегетационный период ее значения находятся в диапазоне от 270 до 280 г/куб. м, что меньше среднероссийского показателя, а также показателя, характерного для г. Москвы (крупного промышленного центра с высокой промышленной и транспортной нагрузкой на окружающую среду). Статистический анализ позволил исключить влияние других климатических факторов, что, с учетом архитектурной и градостроительной истории развития Сочи, позволило сформулировать гипотезу о наличии прямой зависимости между снижением концентрации кислорода и сокращением площадей зеленых насаждений;

- картографический метод исследования позволяет уточнить метрические характеристики городских зеленых насаждений путем визуального и ГИС-анализа архивных и современных картографических материалов и данных Д3З. Наибольшее затруднение, однако, представляет этап сбора исходных данных в силу разрозненности и разобщенности банков архивных картографических произведений, а также низкого графического качества и неясной датировки многих картографических материалов, сканирование и публикация которых выполнялись неспециалистами. Наиболее целесообразным представляется использование для анализа архивных и современных генеральных планов г. Сочи, однако их получение затруднено в силу технических и бюрократических ограничений. Тем не менее, реализованная часть исследований позволила подтвердить гипотезу о наличии прямой зависимости между снижением концентрации кислорода и сокращением площадей зеленых насаждений. Получение архива материалов Д33 за 2000-2020 гг. и их анализ в геоинформационной среде повысят объективность исследований и позволят сформулировать достоверные выводы.

\section{БИБЛИОГРАФИЧЕСКИЙ СПИСОК}

1. Прокопова А. Ю. Загрязнение воздуха один из основных факторов риска для здоровья населения // Смоленский медицинский альманах. - 2015. - № 3. - С. 115-117.

2. Бурима Л. Я. Окружающая среда и здоровье населения // Вестник Прикамского социального института. - 2019. - № 1 (82). - С. 91-99.

3. Ревич Б. А. Приоритетные факторы городской среды, влияющие на качество жизни населения мегаполисов // Проблемы прогнозирования. - 2018. - № 3 (168). - С. 58-66.

4. Литвицкий П. Ф. Гипоксия // Вопросы современной педиатрии. - 2016. - Т. 15, № 1. C. $45-58$.

5. Инвентаризация городских зеленых насаждений средствами ГИС / Л. К. Трубина, О. Н. Николаева, П. И. Муллаярова, Е. И. Баранова // Вестник СГУГиТ. - 2017. - Т. 22, № 3. C. $107-118$.
6. Муллаярова П. И., Николаева О. Н., Трубина Л. К. Геоэкологическая оценка и картографирование состояния озелененных территорий специального назначения // Вестник СГУГиТ. 2018. - T. 23, № 4. - С. 262-274.

7. Стратегия инвестиционного развития муниципального образования город-курорт Сочи до 2020 года [Электронный ресурс]. - Режим доступа : https://sochi.ru/gorodskaya-vlast/normativnopravovyye-akty/?ELEMENT_ID=3043 (дата обращения: 10.05.2020).

8. Архивы погоды по городам России / ред. Гавришев А. Н. [Электронный ресурс]. - Режим доступа: https://climate-energy.ru/weather/archive weather_276120.php (дата обращения: 10.05.2020).

9. Мартынов Г. П., Могильникова А. В. Анализ статистики данных погоды города Сочи за 50 лет // Интерэкспо ГЕО-Сибирь. XV Междунар. науч. конгр. : Междунар. науч. конф. «Ди- 
станционные методы зондирования Земли и фотограмметрия, мониторинг окружающей среды, геоэкология〉 : сб. материалов в 4 т. (Новосибирск, 24-26 апреля 2019 г.). - Новосибирск : СГУГиТ, 2019. - Т. 4, № 2. - С. 89-97.

10. Мартынов Г. П., Могильникова А. В. Статистический анализ изменений метеорологических данных Московской области за 30 лет // Интерэкспо ГЕО-Сибирь-2018. XIV Междунар. науч. конгр. : Междунар. науч. конф. «Дистанционные методы зондирования Земли и фотограмметрия, мониторинг окружающей среды, геоэкология»: сб. материалов в 2 т. (Новосибирск, 23-27 апреля 2018 г.). - Новосибирск : СГУГиТ, 2018. T. 2. - C. 188-195.

11. Могильникова А. В., Мартынов Г. П. Применение современного программного STATISTICA для анализа больших массивов данных по содержанию кислорода в воздухе Москвы за период с 1983 по 2012 годы // Интерэкспо ГЕОСибирь-2018. XIV Междунар. науч. конгр. : Междунар. науч. конф. «Дистанционные методы зондирования Земли и фотограмметрия, мониторинг окружающей среды, геоэкология»: сб. материалов в 2 т. (Новосибирск, 23-27 апреля 2018 г.). - Новосибирск : СГУГиТ, 2018. Т. 2. C. 297-306.

12. Распределение содержания кислорода в воздухе по территории России [Электронный pecypc]. - Режим доступа : https://climateenergy.ru/weather/oxyg/karta_oxyg_inter.html (дата обращения: 10.05.2020)

13. Редикарцева Е. М., Карпик П. А. Математическое моделирование зависимости уровня воды в реке Оби в городе Новосибирске от сброса воды на Новосибирской ГЭС // Вестник СГУГиТ. - 2017. - Том 22, № 4. - С. 237-242.

14. Казазаев В. В., Шагалин Д. А. Фотосинтез С3-растений: основные факторы и математические модели // Математика и ее приложения: фундаментальные проблемы науки и техники : сборник трудов всероссийской конференции. Барнаул : Алтайский государственный университет, 2015. - С. 273-278.

15. О состоянии зеленых зон на территории отдельных муниципальных образований Краснодарского края : постановление Законодательного собрания Краснодарского края от 21.10.2015 № 1938-П [Электронный ресурс]. - Режим доступа: http://docs.cntd.ru/document/430655853 (дата обращения: 10.05.2020).

16. ЭтоМесто [Электронный ресурс]. - Режим доступа: http://www.etomesto.ru/ (дата обращения: 10.05.2020).

17. Retromap [Электронный ресурс]. - Режим доступа: http://www.retromap.ru/ (дата обращения: 10.05.2020).

18. Топографические карты. К-37 - Сочи [Электронный ресурс]. - Режим доступа: http://mapk37.narod.ru (дата обращения: 10.05.2020).

19. Публичная кадастровая карта Сочи на 26.05.2020 [Электронный ресурс]. - Режим доступа: https://egrp365.ru/map/?id=g3XAnH (дата обращения: 26.05.2020).

20. GoogleMaps [Электронный ресурс]. - Режим доступа: https://www.google.ru/maps (дата обращения: 12.05.2020).

\section{THE CARTOGRAPHIC TECHNIQUE FOR THE STUDY OF CHEMICAL COMPOSITION OF THE URBAN AIR ENVIRONMENT}

\section{Olga N. Nikolaeva}

Siberian State University of Geosystems and Technologies, 10, Plakhotnogo St., Novosibirsk, 630108, Russia, Dr. Sc., Professor, Department of Ecology and Environmental Management, phone: (383)361-06-86, e-mail: onixx76@mail.ru

\section{Gennadiy P. Martynov}

Siberian State University of Geosystems and Technologies, 10, Plakhotnogo St., Novosibirsk, 630108, Russia, Associate Professor, Department of Higher Mathematics, phone: (383)343-25-77, e-mail: martynov@ssga.ru

\section{Anastasia V. Mogil'nikova}

Siberian State University of Geosystems and Technologies, 10, Plakhotnogo St., Novosibirsk, 630108, Russia, Student, phone: (951)384-48-51, e-mail: mogilnikova_nastya@mail.ru 
The article deels witn the problem of reducing of oxygen concentration in the urban air environmental. A hypothesis was put forward on the relationship between a decrease in oxygen levels and a reduction of urban green spaces. It was decided to use the cartographic technique to gather more complete information about reducing of urban gardening over a long period of time. The results of a statistical analysis of oxygen concentration in the atmospheric air of Sochi for 50 years are presented. The fact of a steady long-term trend of a decrease in the concentration of oxygen in the atmospheric air of Sochi in comparison with the values in Moscow and on average in Russia is confirmed. The sequence of collection and processing of freeware multi-temporal cartographic data for 50 years is presented. The stages of GIS-analysis of gathered materials are described. Preliminary conclusions are made about the validity of the hypothesis. The lack of modern accurate cartographic data of Sochi is noted. Prospects for further research are outlined.

Key words: statistical analysis, cartographic technique, oxygen concentration, settlements, urban landscaping, digital maps, topographic maps, GIS, GIS technologies.

\section{REFERENCES}

1. Prokopova A. Yu. (2015). Zagryaznenie vozduha - odin iz osnovnyh faktorov riska dlya zdorov'ya naseleniya [Air pollution is one of the main risk factors for public health]. Smolenskij medicinskij al'manah [Smolensk medical almanac], 3, 115-117. [in Russian].

2. Burima L. Ya. (2019). Okruzhayushchaya sreda I zdorov'e naseleniya [Environment and public health]. Vestnik Prikamskogo social'nogo instituta [Bulletin of the Prikamsky social institute], 1 (82), 91-99. [in Russian].

3. Revich B. A. (2018). Prioritetnye factory gorodskoj sredy, vliyayushchie na kachestvo zhizni naseleniya megapolisov [Priority factors of the urban environment affecting the quality of life of the population of megacities]. Problemy prognozirovaniya [Problems of forecasting.], 3 (168), 58-66. [in Russian].

4. Litvickij P. F. (2016). Gipoksiya [Hypoxia]. Voprosy sovremennoj pediatrii [Questions of modern pediatrics], 15, 1, 45-58. [in Russian].

5. Trubina, L. K., Nikolaeva, O. N., Mullayarova P. I. (2017). Inventarizaciya gorodskih zelenyh nasazhdenij sredstvami GIS [GIS-based inventory of urban green spaces]. Vestnik SGUGiT [Vestnik SSUGT], 22(3), 107-117. [in Russian].

6. Mullayarova P. I., Nikolaeva, O. N., Trubina, L. K. (2018). Geoekologicheskaya ocenka i kartografirovanie sostoyaniya ozelenennyh territorij special'nogo naznacheniya [Geoecological assessment and mapping of urban road verges]. Vestnik SGUGiT [Vestnik SSUGT], 23 (4), 262-274. [in Russian].

7. Strategiya investicionnogo razvitiya municipal'nogo obrazovaniya gorod-kurort Sochi do 2020 goda [Strategy for the investment development of the municipal formation of the resort city of Sochi until 2020]. [Electronic resource] - Mode of access:https://sochi.ru/gorodskaya-vlast/normativnopravovyye-akty/?ELEMENT_ID=3043.
8. Weather statistics for years; Gavrishev A. N. (Ed.) [Electronic resource] - Mode of access: https://climate-energy.ru/weather/archive_weather_ 276120.php.

9. Mogil'nikova, A.V., Martynov, G. P. (2019). Statistical analysis of weather data of the city of Sochi for 50 years // In Sbornik materialov Mezhdunarodnogo nauchnogo kongressa: Interekspo GEOSibir'-2019. XV Mezhdunarodnojnauchnyj congress. Vol. 4. "Distancionnye metody zondirovaniya Zemli iI fotogrammetriya, monitoring okruzhayushchej sredy, geoekologiya» [Proceedings of International Scientific Conference: Inter-Expo GEO-Siberia2019. XV international scientific Congress: International scientific conference: Remote sensing methods and photogrammetry, environmental monitoring, Geoecology] (pp. 89-97). Novosibirsk: SGUGiT Publ. [in Russian].

10. Martynov, G. P., Mogil'nikova, A.V. (2018). Statistical analysis of changes in meteorological data of Moscow region for 30 years. In Sbornik materialov Mezhdunarodnogo nauchnogo kongressa: Interekspo GEO-Sibir'-2018. XIV Mezhdunarodnoj nauchnyj kongress. Vol. 2. "Distancionnye metody zondirovaniya Zemli i fotogrammetriya, monitoring okruzhayushchej sredy, geoekologiya» [Proceedings of International Scientific Conference: Inter-Expo GEO-Siberia-2018. XIV international scientific Congress: International scientific conference: Remote sensing methods and photogrammetry, environmental monitoring, Geoecology] (pp. 188-195). Novosibirsk: SGUGiT Publ. [in Russian]

11. Mogil'nikova, A.V., Martynov, G. P. (2018). Application of modern software STATISTICA for the analysis of large amounts of data on the oxygen content in the air of Moscow for the period from 1983 to 2012. In Sbornik materialov Mezhdunarodnogo nauchnogo kongressa: Interekspo GEO-Sibir'2018. XIV Mezhdunarodnoj nauchnyj kongress. 
Vol. 2. «Distancionnye metody zondirovaniya Zemli $i$ fotogrammetriya, monitoring okruzhayushchej sredy, geoekologiya» [Proceedings of International Scientific Conference: Inter-Expo GEO-Siberia2018. XIV international scientific Congress: International scientific conference: Remote sensing methods and photogrammetry, environmental monitoring, Geoecology] (pp. 297-306). Novosibirsk: SGUGiT Publ. [in Russian].

12. Raspredeleniye soderzhaniya kisloroda $\mathrm{v}$ vozdukhe po territorii Rossii [Distribution of oxygen in the air throughout Russia] [Electronic resource]. Mode of access: https://climate-energy.ru/weather/ oxyg/karta_oxyg_inter.html

13. Redikartseva Ye. M., Karpik P. A. (2017). Matematicheskoye modelirovaniye zavisimosti urovnya vody $\mathrm{v}$ reke Obi $\mathrm{v}$ gorode Novosibirske ot sbrosa vody na Novosibirskoy GES [Mathematical modeling of the dependence of the water level in the $\mathrm{Ob}$ River in the city of Novosibirsk on the discharge of water at the Novosibirsk hydroelectric station], Vestnik SGUGiT [Vestnik SSUGT], 22, 4, 237-242. [in Russian].

14. Kazazayev V. V., Shagalin D. A. (2015). Fotosintez S3-rasteniy: osnovnyye factory i matematicheskiye modeli [Photosynthesis of C3 plants: main factors and mathematical models] Matematika $i$ yeye prilozheniya: fundamental'nyye problemy nauki i tekhniki. - Sbornik trudov vserossiyskoy kon- ferentsii. Izdatel'stvo: Altayskiy gosuda-stvennyy universitet (Barnaul) [Mathematics and its applications: fundamental problems of science and technology. - Proceedings of the All-Russian Conference. Publisher: Altai State University (Barnaul)], 273-278.

15. O sostoyanii zelenykh zon na territorii otdel'nykh munitsipal'nykh obrazovaniy Krasnodarskogo kraya. Postanovleniye Zakonodatel'nogo sobraniya Krasnodarskogo kraya ot 21 oktyabrya 2015 goda [On the state of green areas in the territory of individual municipalities of the Krasnodar Territory. Resolution of the Legislative Assembly of the Krasnodar Territory, October 21, 2015 [Electronic resource]. - Mode of access: http://docs.cntd.ru/document/430655853.

16. EtoMesto [This place]. [Electronic resource]. - Mode of access: http://www.etomesto.ru/.

17. Retromap [Electronic resource]. - Mode of access: http://www.retromap.ru/.

18. Topograficheskiye karty. K-37 - Sochi [Topographic maps. K-37 - Sochi] [Electronic resource]. - Mode of access: http://mapk37.narod.ru.

19. Publichnaya kadastrovaya karta Sochi na 26.05.2020 [The public cadastral map of Sochi on 05/26/2020]. [Electronic resource] - Mode of access: https://egrp365.ru/map/?id=g3XAnH.

20. Google Maps [Electronic resource] - Mode of access: https://www.google.ru/maps. 
УДК 528.91:630

DOI: $10.33764 / 2411-1759-2020-25-3-201-213$

\section{СОВРЕМЕННЫЕ МЕТОДЫ ОПЕРАТИВНОГО КАРТОГРАФИРОВАНИЯ НАРУШЕНИЙ ЛЕСНОГО ПОКРОВА}

\section{Андрей Владимирович Тарасов}

Пермский государственный национально-исследовательский университет, 614990, Россия, г. Пермь, ул. Букирева, 15, аспирант кафедры картографии и геоинформатики, e-mail: andrew.tarasov1993.study@gmail.com

Своевременное и оперативное выявление нарушений в лесном фонде - важная задача при ведении лесохозяйственной деятельности в РФ. Раннее выявление участков насаждений, поврежденных в результате воздействия природных или антропогенных факторов, позволяет оперативно принимать управленческие решения. Для реализации такой стратегии управления необходимо использовать методы оперативного картографирования. С появлением данных дистанционного зондирования Земли (ДД33), которые обладают высоким пространственным и временным разрешением (Planet, Sentinel-2), становится возможным использовать современные методы оперативного картографирования для решения задач лесного хозяйства (в частности, выявление нарушений лесного покрова). По мере увеличения площади мониторинга и роста количества снимков возрастает необходимость в автоматизации этого процесса. В данной статье представлено описание «традиционных» методов выявления нарушений лесного покрова (вегетационные индексы, преобразование Tasseled Cap, многоканальное и одноканальное обнаружение изменений и др.), их основные принципы, ограничения, опыт применения в России и в мире. В качестве альтернативны представлены алгоритмы, основанные на методах машинного обучения, представлена их классификация. Отмечены преимущества и недостатки двух групп методов выявления нарушений лесного покрова. Обозначено, что опыт применения методов машинного обучения для обработки ДД33 небольшой, а подобные исследования обладают высоким уровнем новизны.

Ключевые слова: оперативное картографирование, методы обработки данных дистанционного зондирования земли, PlanetScope, Sentinel-2, машинное обучение.

\section{Введение}

Понятие «оперативное картографирование» подразумевает под собой создание и использование карт в реальном или близком к реальному масштабу времени с целью своевременного информирования пользователей для возможного воздействия на ход процесса. При этом реальный масштаб времени понимается как характеристика скорости создания и использования карт, т. е. темпа, обеспечивающего немедленную обработку поступающей информации, ее картографическую визуализацию для оценки, мониторинга, управления, контроля каких-либо процессов и явлений, изменяющихся в том же темпе [1].

В России теория оперативного картографирования разрабатывается с 90-х гг. XX в. Оперативно-хозяйственные карты впервые выделены в классификации карт, предложенной в работе [2]. А. М. Берлянт предло- жил классификацию карт по оперативности, он выделяет два типа карт: оперативные и базовые [1]. Реализация методов оперативного картографирования на практике стала возможна по мере развития ГИС-технологий и регулярно обновляемых источников пространственных данных, в том числе данных дистанционного зондирования Земли. В настоящее время оперативное картографирование стало одним из направлений геоинформационного картографирования. В современных условиях с появлением новых спутников, которые обладают высоким пространственным и временным разрешением (PlanetScope, Sentinel-2) возможна реализация оперативного картографирования в новых областях, в которых до недавнего времени это было невозможно по причине отсутствия необходимых данных. К таким областям относится лесное хозяйство и, в частности, мониторинг нарушений лесного покрова. 
В Российской Федерации ежегодные потери леса в результате действия антропогенных и природных факторов составляют в среднем несколько миллионов гектаров, а в отдельные годы свыше 10 млн га [3, 4]. В связи с этим является актуальным вопрос своевременного и эффективного способа выявления нарушений лесного покрова. Нарушения лесного покрова традиционно классифицируют на природные (в англоязычной терминологии - natural forest disturbances) и антропогенные (human-induced disturbances). В свою очередь, природные нарушения могут быть вызваны абиотическими и биотическими факторами. Среди первых наиболее значимыми являются лесные пожары, засухи и ветровалы, а среди вторых - повреждения, вызванные насекомыми-вредителями, а также болезни леса [5]. Приведенная классификация с некоторыми изменениями используется в большинстве исследований по оценке различных факторов, вызывающих нарушения лесного покрова.

Также широко используется классификация нарушений лесного покрова по характеру повреждения лесов. Выделяются сплошные нарушения (резкая гибель насаждений на значительной площади), а также несплошные (мозаичные) нарушения с разной степенью повреждения древостоя. В англоязычной литературе им соответствуют понятия stand-replacing disturbances и non-stand replacing disturbances [3]. Характер повреждения древостоя имеет решающее влияние на выбор ДД33, используемых для организации мониторинга, а также на возможность автоматизации распознавания нарушений по снимкам [6].

Вклад различных типов нарушений в общую площадь потерь лесного покрова существенно различается для разных регионов России и мира. Так, по данным [3], в целом по России за 2002-2011 гг. 65,5 \% площади потерь лесного покрова были вызваны пожарами, а около $30 \%$ связаны с лесозаготовкой. При этом средняя площадь лесозаготовок оценивалась в 0,8 млн га/год. На другие нарушения приходится всего 4,5 \% площади потерь лесов. В Восточной Европе, включая также Европейскую территорию России, вклад естественных нарушений составляет меньше $10 \%$ от общей площади потерь лесов [7]. Лишь в отдельные годы он может достигать 30-50 \%, главным образом за счет крупных лесных пожаров.

\section{«Традиционные» методы выявления нарушений лесного покрова по спутниковым данным}

Нарушения лесного покрова имеют свой набор дешифровочных признаков, который позволяет выделять их на космических снимках. К ним относятся спектральный образ, форма, площадь, внутренняя структура и текстура. По мере роста площади мониторинга и количества снимков возникает необходимость автоматизировать этот процесс. Методы автоматизации выявления нарушений на основе этих признаков разрабатываются на протяжении нескольких десятилетий, практически с момента запуска первых спутников серии Landsat и появления первых цифровых снимков Земли из космоса. Так, еще в работе [8] было предложено использовать мультивременные синтезы из различных каналов съемочной системы MSS/Landsat для идентификации участков гибели (дефолиации) лесов в результате вспышек насекомых-вредителей. В исследовании [9] впервые применены снимки Landsat для определения площади гибели лесов, вызванной пожарами и ветровалами.

С запуском в 1984 г. спутника Landsat-4 с сенсором ТМ (6 спектральных каналов с пространственным разрешением 30 м) возможности космического мониторинга лесов по разновременным снимкам значительно расширились. При повреждении растений и снижении фотосинтеза отражение в красной области спектра увеличивается, а в ближней - инфракрасной (ИК) падает, а также значительно возрастает отражательная способность в среднем ИК-канале, что связано с падением содержания влаги в поврежденных деревьях. На этих свойствах основаны разнообразные вегетационные индексы, используемые для выявления нарушений лесного покрова. Наиболее известными из них являются нормализованный разностный ве- 
гетационный индекс NDVI, нормализованный индекс инфракрасной разности NDII (в русскоязычной литературе он же - коротковолновой вегетационный индекс SWVI) и нормализованный разностный индекс гарей NBR. Идентификация нарушений лесного покрова производится по разности этих индексов, вычисленной по разновременным снимкам.

В дальнейшем была показана высокая эффективность индекса NDII для выявления вырубок, ветровалов и участков повреждения лесов вредителями [10-12]. В этих же работах подтверждено, что индекс NDII более эффективен для выявления нарушений лесного покрова, чем широко известный NDVI. В свою очередь разностный индекс NBR весьма эффективен для выявления выгоревших территорий и имеет высокую корреляцию со степенью повреждения лесов пожарами [13].

Для обнаружения нарушений лесного покрова в ряде работ рассматривалось применение более сложных индексов, чем простые нормализованные разности. К ним относятся как индексы, основанные на видимом и ближнем ИК-диапазонах спектра (SAVI и др.), так и с использованием среднего ИК-диапазона, а также результаты преобразования Tasseled Cap [14]. Преобразование Tasseled Cap частный случай анализа главных компонент. В исследовании [15] провели сравнительный анализ эффективности различных вегетационных индексов и ряда других методов обнаружения изменений по снимкам Landsat на примере ущерба от урагана Катрина в США и установили, что наибольшую точность обеспечивает именно это преобразование (Tasseled Cup). В этом преобразовании используются 6 каналов съемочной системы TM/Landsat c разными весами, причем максимальный вес имеет средний ИК-канал.

Помимо вегетационных индексов, для картографирования нарушений лесного покрова по снимкам оптического диапазона успешно применяется ряд других методов: одномерное и многомерное обнаружение изменений, анализ векторов изменений, сравнение результатов классификации, деревья решений.

Метод многомерного обнаружения изменений (Multivariate alteration detection, MAD) основан на построении многомерной корреляции между снимками (каноническом корреляционном анализе). Его преимуществом является сниженная чувствительность к настройкам сенсора, а также схемам радиометрической и атмосферной коррекции [16]. Метод MAD реализован в программном пакете Scanex Image Processor, разработанном ИТЦ СканЭкс, а в Руководстве пользователя [17] приведено его описание.

Выборочный анализ главных компонент (selective PCA) основан на использовании двух входных переменных - по одному каналу снимков, полученных до и после события, или их производных (NDVI или результатов преобразования Tasseled Cap) [18].

Метод анализа векторов изменений (change vector analysis, CVA), предложенный в работе [19], позволяет определить две компоненты изменений - магнитуду и направление. Он обеспечивает, во-первых, разделение реально произошедших изменений на местности и фоновых (связанных, например, с появлением атмосферной дымки), а также в ряде случаев определение характера изменений (положительные/отрицательные изменения и их возможная причина), что не позволяет определить метод MAD.

Сравнение результатов классификации разновременных снимков (post-classification comparison, PCC) также может использоваться для выявления нарушений лесного покрова с высокой точностью [15]. Недостатком данного метода является низкая степень автоматизации и сложность настройки параметров классификатора для множества снимков.

Современным и эффективным методом обнаружения изменений лесного покрова является построение «деревьев решений» (decision tree). Именно построение дерева решений на основе многолетнего ряда снимков Landsat, полученных за вегетационный период, было использовано в проекте Global Forest Change для создания ежегодно обновляемых данных о нарушениях лесного покрова Земли. Для лесов умеренной зоны данные о площади потерь имеют точность свыше 90 \% [20].

В России разработку методов обнаружения нарушений лесного покрова длительное 
время ведут Институт космических исследований (ИКИ) РАН и Российский центр защиты леса. В ИКИ РАН до недавнего времени основное внимание уделялось оценке повреждения лесов пожарами, для чего также успешно применяются разностные и относительные индексы, основанные на среднем ИК-диапазоне спектра [21]. Обзор российского опыта мониторинга нарушений лесного покрова и существующих проблем в данной области приведен в работе [11]. Также в данной работе предложены методические рекомендации и представлены результаты мониторинга ветровалов в лесах Европейской части России [22] и оценки повреждения лесов вследствие вспышек размножения вредителей [11]. Большой интерес представляет работа [23], в которой были оценены предельные возможности съемочной системы Landsat для выявления нарушений лесного покрова. Аналогичная методика может быть применена, например, для оценки точности автоматизированного выделения вырубок (в том числе незаконных) по снимкам среднего и высокого разрешения.

Основным ограничением всех перечисленных методов, основанных на спектральных признаках, является невозможность автоматизированного распознавания типов нарушений лесного покрова (вырубки, гари, ветровалы, повреждения вредителями и болезнями). Для решения этой задачи требуется дополнительный анализ геометрических и текстурных признаков, без которого точность разделения будет невысока. Так, в работе [24] была предпринята попытка разделения по спектральным признакам вырубок и ветровалов (на основе преобразования Tasseled Cap и последующей классификации методом опорных векторов). Точность разделения составила 76-77 \%, что недостаточно для практического применения. Еще один подобный эксперимент выполнен для разделения всех типов нарушений лесного покрова на территории США с применением современного и эффективного классификатора Random Forest [25]. Однако точность также оказалась невысокой (ошибки до 32 \%). Для более точного выделения нарушений необходимо рассматривать не только спектральные характеристики отдельно, а совместно с текстурой, и, главное, геометрией объекта.

В последние годы возникло еще одно существенное ограничение - новые группировки спутников, обеспечивающие оперативный мониторинг с высокой повторяемостью и детальностью, либо ведут съемку в среднем ИК-канале с более низким пространственным разрешением (Sentinel-2), либо не имеют его вовсе (PlanetScope). Таким образом, алгоритмы обнаружения изменений, разработанные для данных Landsat, часто оказываются неприменимы для данных Sentinel-2 и PlanetScope. Следовательно, требуется разработка новых алгоритмов, использующих данные только видимого и ближнего ИК-диапазона спектра, а также текстурные и геометрические признаки (значимость которых растет с повышением пространственного разрешения данных). Лучше всего для этого подходят методы машинного обучения.

\section{Современные методы выявления нарушений лесного покрова по спутниковым данным}

Исследования по разработке алгоритмов машинного обучения проводятся уже с середины прошлого века [26]. В 1940-1960-х гг. данное научное направление называлась кибернетикой, затем в 1980-1990-х - коннекционизмом. В современном понимании термин развивается с 2006 г. Именно тогда сформировался термин «Deep learning» (глубокое машинное обучение), который подразумевает использование все более сложных и «глубоких» моделей. [27]. Под «глубиной» в данном случае можно понимать количество слоев, их типы во внутренней структуре и степень связи между ними. Такие модели также отличают высокая производительность и возможность оценки сложных взаимосвязанных факторов. Сам термин «машинное обучение» был определен еще в 1959 г. «как научная дисциплина, которая наделяет компьютеры способностью учиться, не будучи явно запрограммированными» [28], а в 1997 г. было сформулировано более «техническое» определение: «говорят, что 
компьютерная программа обучается на основе опыта Е по отношению к некоторой задаче Т и некоторой оценке производительности Р, если ее производительность на Т, измеренная посредством Р, улучшается с опытом Е» [29].
За более чем 50 лет разработки создано множество алгоритмов машинного обучения, но единой общепринятой классификации не существует. Наиболее общая представлена на рис. 1, а более детальный вариант представлен на рис. 2.

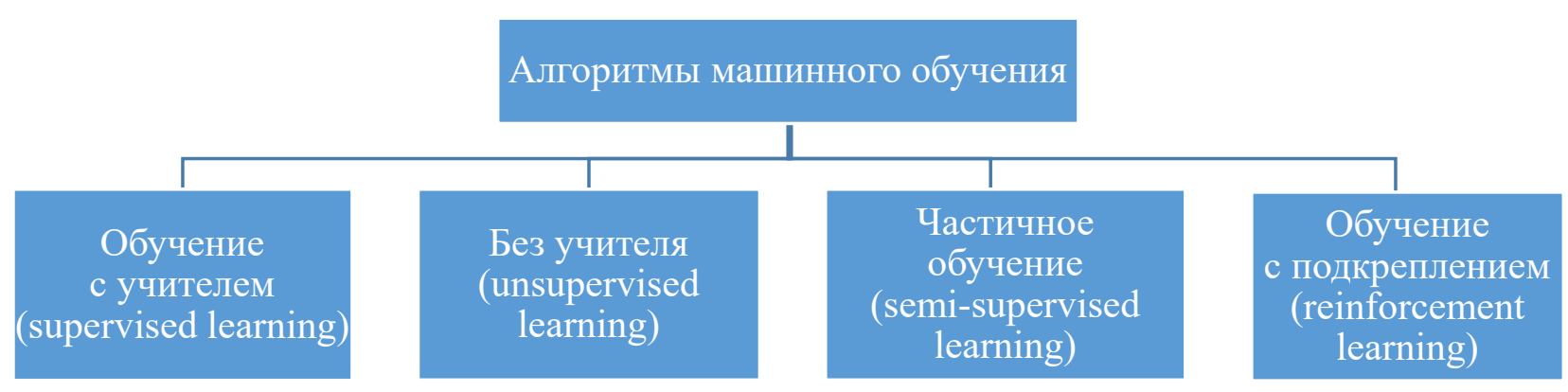

Рис. 1. Базовая классификация алгоритмов машинного обучения

В последние десятилетия наблюдается появление все более сложных архитектур для применения в различных областях, что связано с ростом возможностей вычислительных ресурсов и доступностью наборов для обучения алгоритмов. Методы машинного обучения позволили по-новому подойти к решению классических задач компьютерного зрения: классификации и сегментации изображений. С того момента, как в 2012 г. на соревновании исследователей по разработке алгоритма для распознавания изображений ImageNet Large Scale Visual Recognition Competition (ILSVRC) [30] лучший результат показали исследователи, которые использовали сверточные сети, именно такой тип архитектуры чаще всего используется для обработки изображений.

Обработка ДДЗ3 представляет собой частный случай задачи обработки изображений. Поэтому для их обработки также применяются сверточные нейронные сети. Главное их отличие от традиционных сетей это наличие сверточных слоев. Принцип работы сверточной сети похож на работу множества последовательных фокальных или скользящих фильтров. Слой нейронной сети, полученный после обработки входного, называется сверточным (convolution layers). На первых слоях выделяются самые простые свойства объекта. С каждым но- вым уровнем, на основе ранее выделенных признаков, получаются признаки объекта более высокого уровня. Наряду со сверточными слоями в сверточных сетях есть полносвязные слои (fully connected layers), слои пуллинга (pooling layers). Первый тип позволяет непосредственно получить результат. Второй тип позволяет сжать входное изображение для сокращения вычислительной нагрузки, расхода памяти и количества параметров, тем самым ограничивая риск переобучения. Можно получить множество различных архитектур, комбинируя различным способом эти слои, меняя порядок, количество слоев и т. п. Существует множество модификаций представленных архитектур (например ResNet50), где исследователи добавляют больше слоев или используют разные параметры при обучении и т. д.

Другой часто используемый для анализа ДД33 алгоритм машинного обучения - RandomForest. Этот алгоритм основан на усреднении значений множества деревьев решений. Деревья решений - простой, но мощный алгоритм машинного обучения. С помощью алгоритмов (например, CART) данные делятся на максимально «чистые» классы. Однородность классов определяется разными метриками (Gini impurity (неоднородность Джини), энтропия). 


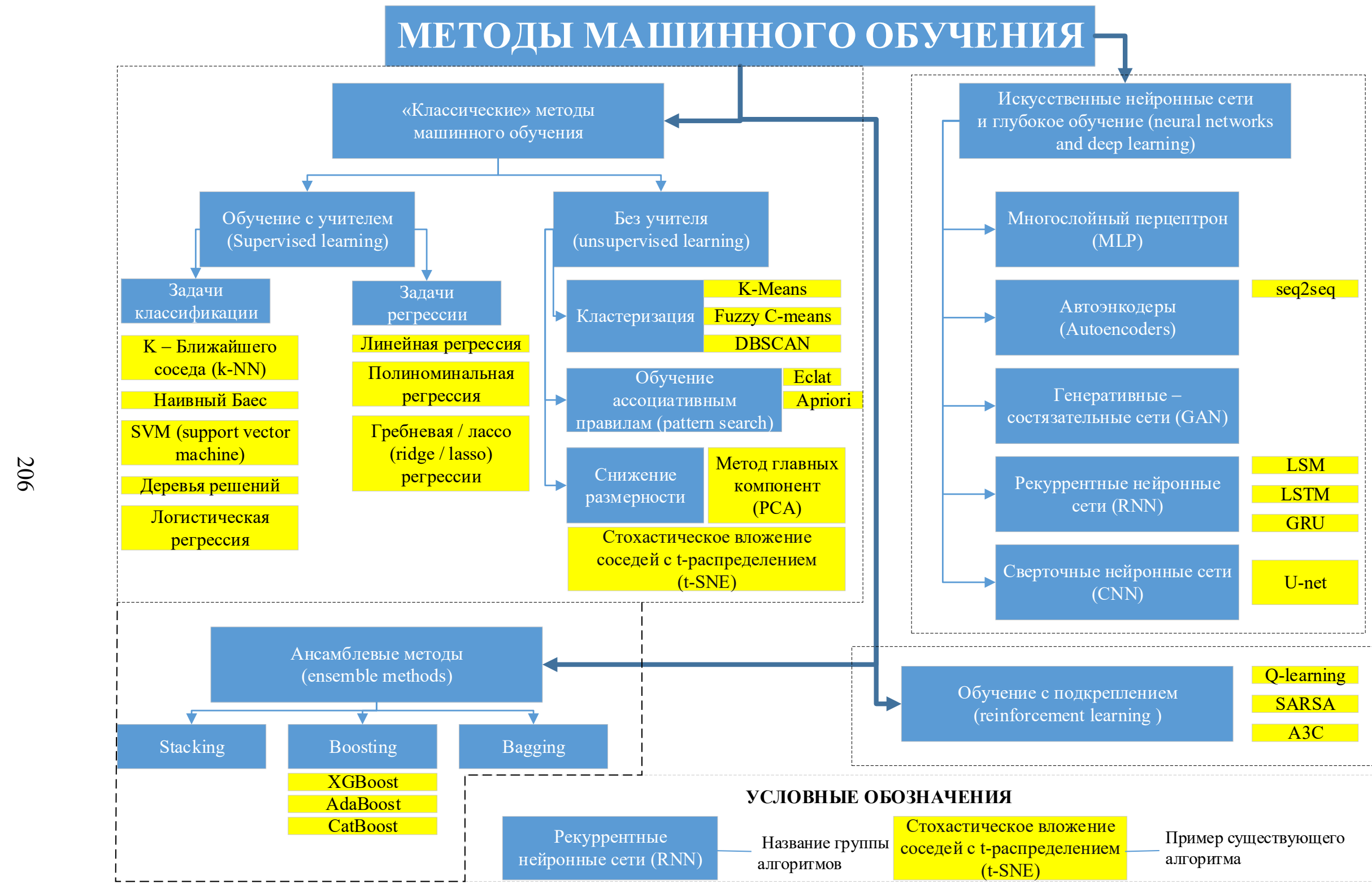

Рис. 2. Расширенная схема классификации методов машинного обучения 
Для классификации в каждом конкретном узле используется один признак, а для обучения случайно выбирается поднабор из всего обучающего набора. Именно предсказания множества таких деревьев использует алгоритм Random Forest. Для получения итогового решения учитываются прогнозы всех индивидуальных деревьев и предсказывается класс, который стал обладателем «большинства» голосов [27].

Совместное использование нескольких методов машинного обучения для решения одной задачи называется ансамблевыми методами (ensemble method). К такому типу относятся Random Forest, а также методы бустинга (boosting), стэкинга (stacking), бэггинга (bagging) [27]. Эти методы способны комбинировать нескольких «слабых» учеников в одного «сильного» ученика.

Основная идея большинства методов бустинга предусматривает последовательное обучение нескольких моделей, причем каждая из них старается «исправить» или улучшить своего предшественника. Так повторяется до того момента, пока не получится «идеальная модель» либо закончится число итераций. Результатом в данном случае будет взвешенное значение между прогнозом каждой отдельной модели и ее веса (под весом понимается правильность предсказания в обучающей выборки) (такой алгоритм называется AdaBoosting). Другой вид бустинга - градиентный. Он похож на алгоритм AdaBoosting, только каждая новая модель подгоняется к остаточным ошибкам предыдущего. Прогнозы делаются аналогично предыдущему методу. При бээгинге объединяются несколько моделей, которые обучены на разных поднаборах одной обучающей выборки. Причем одна модель может несколько раз обучаться на разных поднаборах. Итоговый прогноз обычно вырабатывается как статистическая мода (т. е. самый частый прогноз от всех моделей). Метод стэкинга использует еще одну модель (blender, смеситель) для агрегации результатов. Для этого специально выделяется удерживающий (hold-out) набор из обучающей выборки, который не использует ни одна из моделей. Используя результаты отдельных моделей, смеситель предсказывает значения из удерживающего набора [27].

\section{Опыт применения методов машинного обучения для мониторинга нарущений лесного покрова}

К настоящему времени опубликовано сравнительно немного работ, где рассматривается применимость алгоритмов обработки изображений, основанных на машинном обучении, для обнаружения нарушений лесного покрова по спутниковым данным. В большинстве случаев алгоритмы сегментации спутниковых снимков средствами глубокого обучения направлены на решение таких задач, как маскирование облачности [31] или классификация типов землепользования [32]. Следовательно, задача обнаружения нарушений лесного покрова с применением этих алгоритмов обладает высоким уровнем новизны.

Из других алгоритмов, основанных на машинном обучении, имеется опыт применения классификатора Random Forest для распознавания выборочных рубок по снимкам Landsat [33]. Точность обнаружения составила около $90 \%$ при этом пропуск объектов - около $8 \%$, доля ложных срабатываний - $20 \%$, что можно считать успешным результатом.

В работе [34] рассматриваются возможности картографического сервиса Silvisense [35] для комплексного мониторинга лесов Европы, в том числе обнаружения вырубок, гарей, ветровалов. Отмечается, что для этой задачи используются модели «глубокого обучения» (deep learning), однако оценки точности не приведены.

Еще меньше публикаций посвящено использованию спутниковых данных PlanetScope для решения этих задач. Вероятно, это объясняется тем, что данные появились только в 2017 г. и с 2018 г. распространяются на коммерческой основе. Можно отметить описание технологии мониторинга тропических лесов с высокой периодичностью [36]. Данная технология предполагает выявление нарушений лесного покрова в два этапа: на первом этапе производится семантическая сегментация снимков на несколько классов (лес, водная поверхность, открытая почва, облака и их тени) на основе архитектуры U-net [37] (рис. 3). 


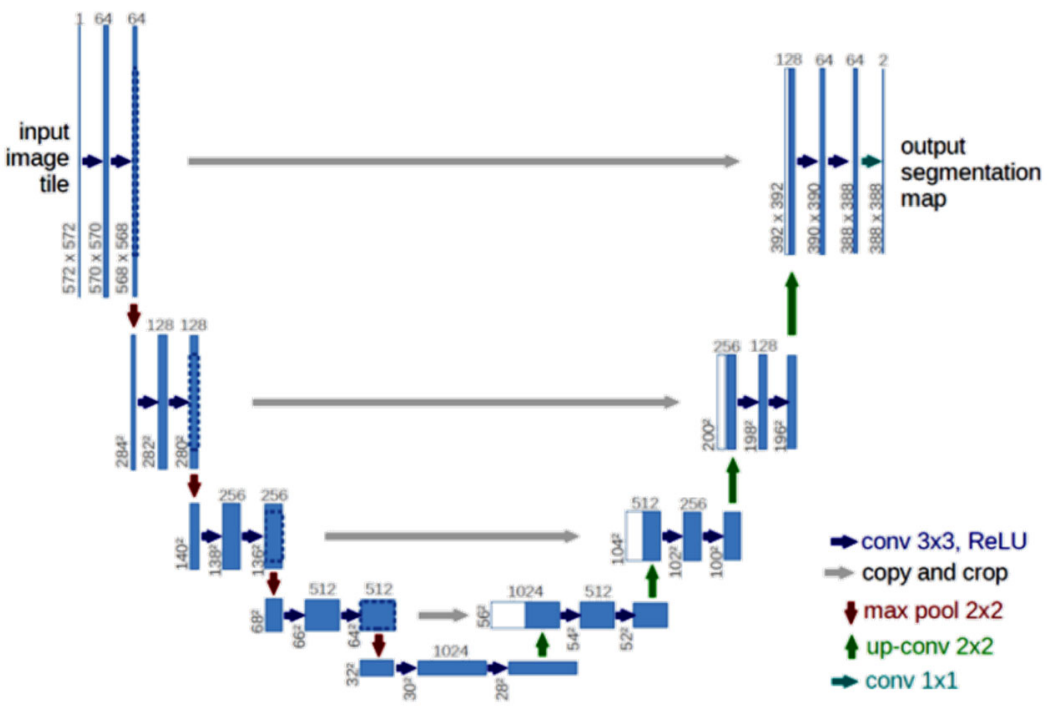

Рис. 3. Общая архитектура U-net

На втором этапе анализируется изменение вероятности каждого класса по серии разновременных снимков, в результате чего выявляются участки вырубок и других нарушений лесного покрова.

Решение задачи обработки ДДЗ3 с помощью задач машинного обучения имеет и ограничения. Прежде всего, для создания хорошей модели необходима большая обучающая выборка (dataset, датасет). С увеличением количества образцов все методы машинного обучения будут показывать схожие результаты [38]. Существующие обучающие выборки не всегда подходят для решения новых задач, а создавать новые очень трудозатратно.

Операции обучения модели и дальнейшие предсказания отличаются высокой вычислительной сложностью и требуют наличия соответствующего технического обеспечения. Лучше всего с этими задачами справляются графические процессоры. Обработка ДДЗ3 еще более увеличивает требования к техническим средствам, так как обрабатываемые данные имеют большой объем.

В работе [39] отмечается, что проблемой при обработке спутниковых изображений с помощью нейронных сетей является пространственный экстент объектов, т. е. их размер. В одном из крупнейших датасетов изображений ImageNet размеченные обучающие объекты имеют большой размер. Та- ким образом, даже крупные объекты (например, автомобиль) будут занимать только несколько пикселей (в зависимости от пространственного разрешения снимков).

Это ограничения, которые можно преодолеть (например, используя методы бустинга для сокращения размера обучающей выборки). Нейронные сети могут находить структуру в существующих данных и при правильном обучении делать предположения о данных, которые не были использованы в обучении. Нейронные сети - первый алгоритм, который превзошел человека по распознаванию образов [40], поэтому они имеют большой потенциал применения в обработке данных дистанционного зондирования Земли.

Сравнительный анализ описанных методов представлен в таблице.

\section{Buводbl}

В настоящее время с появлением новых ДД33, обладающих высоким пространственным и временным разрешением, появляется возможность использовать методы оперативного картографирования в новых областях (в лесном хозяйстве эта потребность особенно высока). Внедрение систем мониторинга за нарушениями растительного покрова является важной задачей лесопользования. 
Сравнение традиционных и современных методов выявления нарушений лесного покрова

\begin{tabular}{|c|c|c|}
\hline Группа методов & Преимущества & Ограничения \\
\hline $\begin{array}{l}\text { «Традиционные» методы } \\
\text { выявления нарушений лес- } \\
\text { ного покрова }\end{array}$ & $\begin{array}{l}\text { 1. Простота расчета } \\
\text { 2. Большой опыт применения }\end{array}$ & $\begin{array}{l}\text { 1. Сложность применения для } \\
\text { снимков высокого разрешения } \\
\text { (детальнее } 10 \text { м). } \\
\text { 2. Учет только спектральных } \\
\text { признаков нарушений }\end{array}$ \\
\hline $\begin{array}{l}\text { «Новые» методы выявления } \\
\text { нарушений лесного покрова } \\
\text { с помощью алгоритмов ма- } \\
\text { шинного обучения }\end{array}$ & $\begin{array}{l}\text { 1. Возможность обучения алго- } \\
\text { ритма, т. е. выявление новых слу- } \\
\text { чаев, отсутствующих в выборке. } \\
\text { 2. Выявление структуры во вход- } \\
\text { ных данных. } \\
\text { 3. Одновременная интерпретация } \\
\text { разных групп признаков (тек- } \\
\text { стурных, геометрических и др.) }\end{array}$ & $\begin{array}{l}\text { 1. Необходимость большой } \\
\text { обучающей выборки. } \\
\text { 2. Высокие требования к вы- } \\
\text { числительным мощностям } \\
\text { (особенно при обработке Д33). } \\
\text { 3. Небольшой опыт примене- } \\
\text { ния }\end{array}$ \\
\hline
\end{tabular}

Для непосредственной реализации мониторинга необходимо использовать автоматические методы обработки ДДЗ3. Их разработка ведется уже несколько десятилетий. В их числе одноканальное и многоканальное обнаружение изменений, разностные вегетационные индексы, сравнение классификаций разновременных снимков и др., однако эти методы имеют ряд ограничений.

В то же время, появляются методы машинного обучения, имеющие ряд преимуществ по сравнению с традиционными методами. Они увеличивают точность выявления нарушений лесного покров, прежде всего за счет совместного анализа разных групп дешифровочных признаков (как спектральных, так и геометрических). Это позволяет выявлять выборочные и проходные рубки, что является главной проблемой при использовании «традиционных» методов выявления нарушений лесного покрова. Однако в настоящее время опубликовано немного исследований, посвященных использованию этих алгоритмов для выявления нарушений лесного покрова.

Методы машинного обучения требуют значительных вычислительных ресурсов, а также объемной обучающей выборки для успешного применения. Доступность программно-аппаратных средств сейчас высока, появляются сервисы, которые предоставляют свои ресурсы для вычислений (облачные платформы Amazon, GoogleEarthEngine и др.), а в открытом доступе находится большое число обучающих выборок, в том числе с данными PlanetScope, Sentinel-2 (BigEarth dataset, PlanetLabs Competition), которые возможно использовать для построения собственных моделей. С другой стороны, для снижения объема необходимой обучающей выборки можно использовать ансамблевые методы.

В целом применение методов машинного обучения обладает большим потенциалом. Нейросетевые технологии являются де-факто стандартом в компьютерном зрении, так как они обеспечивают решение задач с очень высокой точностью. По сути обработка ДДЗ3 является частным случаем обработки изображений, поэтому применение методов машинного обучения для ведения оперативного картографирования обладает высокой степенью актуальности.

Исследование проведено при финансовой поддержке гранта РФФИ № 19-35-90005.

\section{БИБЛИОГРАФИЧЕСКИЙ СПИСОК}

1. Берлянт А. М. Теория геоизображений. М. : ГЕОС, 2006.

2. Салищев К. А. Картоведение. - М. : МГУ, 1990.
3. Remote sensing estimates of standreplacement fires in Russia 2002-2011 / A. Krylov, J. L. McCarty, P. Potapov, T. Loboda, A. Tyukavina, S. Turubanova, M. C. Hansen // Envi- 
ronmental Research Letters. - 2014. - Vol. 9 (10). Art. No. 105007.

4. Лесные пожары на территории России: особенности пожароопасного сезона 2019 г. / Е. А. Лупян, И. В. Балашов, С. А. Барталев, М. А. Бурцев, В. В. Дмитриев, К. С. Сенько, Ю. С. Крашенинникова // Современные проблемы дистанционного зондирования Земли из космоса. 2019. - T. 16, № 5. - C. 356-363.

5. Modelling natural disturbances in forest ecosystems: A review / R. Seidl, P. M. Fernandes, T. F. Fonseca, F. Gillet, A. M. Jönsson, K. Merganičová, S. Netherer, A. Arpaci, J.-D. Bontemps, H. Bugmann, J. R. González-Olabarria, P. Lasch, C. Meredieu, F. Moreira, M.-J. Schelhaas, F. Mohren // Ecological Modelling. - 2011. - Vol. 222 (4). P. 903-924.

6. Крылов А. М., Соболев А. А., Владимирова Н. А. Выявление очагов короеда-типографа в Московской области с использованием снимков Landsat // Лесной вестник. - 2011. - № 4. - C. 54-60.

7. Eastern Europe's forest cover dynamics from 1985 to 2012 quantified from the full Landsat archive / P. V. Potapov, S. A. Turubanova, A. Tyukavina, A. M. Krylov, J. L. McCarty, V. C. Radeloff, M. C. Hansen // Remote Sensing of Environment. - 2015. - Vol. 159. - P. 28-43.

8. Williams D. L., Stauffer M. L. Monitoring gypsy moth defoliation by applying change detection techniques to Landsat imagery // Proceedings of symposium on Remote Sensing for Vegetation Damage Assessment. - Seattle, United States, 1978. - P. 221-229.

9. Sayn-Wittgenstein L., Wightman J. M. Landsat application in Canadian forestry // Proceeding of the 10th International Symposium on Remote Sensing of Environment. - Michigan, United States, 1975. - Vol. 2. - P. 1209-1218.

10. Hardisky M. A., Klemas V., Smart R. M. The influence of soil salinity, growth form and leaf moisture on the spectral radiance of Spartina alterniflora canopies // Photogrammetric engineering and remote sensing. - 1983. - Vol. 49, № 1. - P. 77-83.

11. Крылов А. М., Владимирова Н. А. Дистанционный мониторинг состояния лесов по данным космической съемки [Электронный ресурс] // Геоматика. - 2011. - № 3. C. 53-58. - Режим доступа: http:/geomatica.ru/ clauses $/ 282 /$.

12. Post-hurricane forest damage assessment using satellite remote sensing / W. Wang, J. J. Qu, X. Hao, Y. Liu, J. A. Stanturf // Agricultural and Forest Meteorology. - 2010. - Vol. 150. - P. 122-132.

13. Cocke A. E., Fulé P. Z., Crouse J. E. Comparison of burn severity assessments using Differ- enced Normalized Burn Ratio and ground data // International Journal of Wildland Fire. - 2005. Vol. 14 (2). - P. 189-198.

14. Crist E. P., Laurin R., Cicone R. C. Vegetation and soils information contained in transformed Thematic Mapper data // Proceedings of International Geosciences and Remote Sensing Symposium (IGARSS) - Paris, France. 1986. - P. 1465-1470.

15. Wang F., Xu Y. J. Comparison of remote sensing change detection techniques for assessing hurricane damage to forests // Environmental Monitoring and Assessment. - 2010. - Vol. 162. P. 311-326.

16. Nielsen A. A., Conradsen K., Simpson J. J. Multivariate alteration detection (MAD) and MAF postprocessing in multispectral, bitemporal image data: New approaches to change detection studies // Remote Sensing of Environment. - 1998. Vol. 64 (1). - P. 1-9.

17. ScanEx Image Processor v.5.1. Программа обработки данных дистанционного зондирования Земли. Руководство пользователя. - М., 2018. $379 \mathrm{c}$.

18. Coppin P. R., Bauer M. E. Processing of multi-temporal Landsat TM imagery to optimize extraction of forest cover change features // IEEE Transactions on Geoscience and Remote Sensing. 1994. - Vol. 32. - P. 918-927.

19. Allen T. R., Kupfer J. A. Spectral response and spatial pattern of Fraser fir mortality and regeneration, Great Smoky Mountains, USA // Plant Ecology. - 2001. - Vol. 156. - P. 59-74.

20. High-Resolution Global Maps of 21st-Century Forest Cover Change / M. C. Hansen, P. V. Potapov, R. Moore, M. Hancher, S. A. Turubanova, A. Tyukavina, D. Thau, S. V. Stehman, S. J. Goetz, T. R. Loveland, A. Kommareddy, A. Egorov, L. Chini, C. O. Justice, J. R. G. Townshend // Science. - 2013. - Vol. 342. - P. 850-853.

21. Исследование возможностей оценки состояния поврежденных пожарами лесов по данным многоспектральных спутниковых измерений / С. А. Барталев, В. А. Егоров, А. М. Крылов, Ф. В. Стыценко, Т. С. Ховратович // Современные проблемы дистанционного зондирования Земли из космоса. - 2010. - Т. 7, № 3. - С. 215-225.

22. Крылов А. М., Малахова Е. Г., Владимирова Н. А. Выявление и оценка площадей катастрофических ветровалов 2009-2010 гг. по данным космической съемки // Изв. СанктПетербургской лесотехнической академии. 2012. - № 200. - C. 197-207.

23. Королева Н. В., Ершов Д. В. Оценка погрешности определения площадей ветровалов по космическим изображениям высокого простран- 
ственного разрешения LANDSAT-TM // Современные проблемы дистанционного зондирования Земли из космоса. - 2012. - Т. 9, № 1. C. $80-86$.

24. Landsat remote sensing of forest windfall disturbance / M. Baumann, M. Ozdogan, P. T. Wolter, A. M. Krylov, N. A. Vladimirova, V. C. Radelo // Remote Sensing of Environment. - 2014. - Vol. 143. P. 171-179.

25. Huo L.-Z., Boschetti L., Sparks A. M. Object-based classification of forest disturbance types in the conterminous United States // Remote Sensing. - 2019. - Vol. 11 (5). - Art. No. 477.

26. Rosenblatt F. The perceptron: A probabilistic model for information storage and organization in the brain // Psychol. Rev. - 1958. - Vol. 65. P. 386-408.

27. Goodfellow I., Bengio Y., Courville A. Deep learning. - MIT Press, 2016.

28. Samuel A. L. Some Studies in Machine Learning Using the Game of Checkers // IBM JOURNAL. - 1959. - Vol. 3, Issue 3. - P. 210-229.

29. Mitchell T. M. Machine learning. - New York: McGraw-Hill, 1997.

30. Krizhevsky A., Sutskever I., Hinton E. G. ImageNet Classification with Deep Convolutional Neural Networks // Proceedings of the 25th International Conference on Neural Information Processing Systems (issue 25). - New York, United States, 2012. - P. 1097-1105.

31. Deep learning based cloud detection for medium and high resolution remote sensing images of different sensors / Z. Li, H. Shen, Q. Cheng, Y. Liu, S. You, Z. He // ISPRS Journal of Photogrammetry and Remote Sensing. - 2019. Vol. 150. - P. 197- 212.

32. Evaluation of the potential of convolutional neural networks and random forests for multi-class segmentation of Sentinel-2 imagery / V. Syrris, P. Hasenohr, B. Delipetrev, A. Kotsev, P. Kempe- neers, P. Soille // Remote Sensing, - 2019. Vol. 11(8). - Art. No. 907.

33. A machine learning approach to map tropical selective logging / M. G. Hethcoat, D. P. Edwards, J. M. B. Carreiras, R. G. Bryant, F. M. França, S. Quegan // Remote Sensing of Environment. 2019. - Vol. 221. - P. 569-582.

34. Maximizing forest value through using Sentinel-2 in combination with hyperspectral UAVs / C. Aas, A. Jochemsen, V. Mantas, N. Lewyckyj, M. Jozefiak, M. Buchhorn // Proceedings of the 69th International Astronautical Congress. - Bremen, Germany, 2018. - P. 4492-4498.

35. Silvisense [Electronic resource]. - Mode of access: https://silvisense.com/.

36. Sub weekly detection of deforestation with planet data [Electronic resource] // Medium. - Mode of access: https://medium.com/planet-stories/subweekly-detection-of-deforestation-with-planet-data$7699553 b 3926$.

37. Ronneberger O., Fischer P., Brox T. U-Net: Convolutional Networks for Biomedical Image Segmentation // International Conference on Medical Image Computing and Computer-Assisted Intervention / Navab N., Hornegger J., Wells W., Frangi A. (Eds). - MICCAI, 2015.

38. Banko M., Brill E. Scaling to Very Very Large Corpora for Natural Language Disambiguation // Proceedings of the 39th Annual Meeting of the Association for Computational Linguistics. Toulouse, France. 2001. - P. 26-33.

39. Comparison of different convolutional neural network architectures for satellite image segmentation / V. Khryashchev, L. Ivanovisky, V. Pavlov, A. Rubtsov, A. Ostrovskay // Proceeding of the 23rd conference of fruct association. - Jyvaskyla, Finland, 2018. - P. 172-180.

40. Russakovsky O., Deng J., Su H. ImageNet large-scale visual recognition challenge, 2010-2015. 2015.

Получено 11.03.2020

(C) A. B. Тарасов, 2020

\section{TRADITIONAL AND MODERN METHODS OF SATELLITE IMAGES PROCESSING FOR OPERATIONAL MAPPING OF FOREST COVER DISTUBANCES}

\section{Andrey V. Tarasov}

Perm State University, 15, Bukireva St., Perm, 614990, Russia, Ph. D. Student, Department of Cartography and Geoinformatics, e-mail: andrew.tarasov1993.study@gmail.com

Real-time mapping of forest disturbances is important for forest management. Detection of forest stands damaged by natural or human-induced factors allows making immediate necessary management decisions. To implement such a management strategy, it is necessary to use the methods of operational mapping. With the advent of the Earth remote sensing data (RSD), which have high spatial and temporal resolution (Planet 
Scope and Sentinel-2), it becomes possible to implement modern operational mapping methods for forest management operations (particularly, forest disturbance detection). Since the monitoring area and the number of images sharply increases, the need for automated image processing methods also rises. This paper provides an overview of "traditional methods" for identifying forest cover disturbances (vegetation indexes, Tasseled Cap, multiband and single band change detection etc), their basis, limitations, and experience of their application in Russia and in the world. Instead, algorithm based on machine learning methods and their classification are presented. Benefits and limitations of both groups of forest disturbances detection algorithms are noted. In addition, it was found out that there is limited experience of application of machine learning algorithms for RSD processing and such kind of research is relevant.

Key words: real-time mapping, processing methods of remote sensing data, Planet Scope, Sentinel-2, machine learning.

\section{REFERENCES}

1. Berlyant, A. M. (2006). Teoriya geoizobrazheniy [Geoimages theory]. Moscow: GEOS Publ. [in Russian].

2. Salishev, K. A. (1990). Kartovedenie [Cartography]. Moscow: MSU Publ. [in Russian].

3. Krylov, A., McCarty, J. L., Potapov, P., Loboda, T., Tyukavina, A., Turubanova, S. \& Hansen, M. C. (2014). Remote sensing estimates of standreplacement fires in Russia 2002-2011. Environmental Research Letters, 9(10), Art. No. 105007.

4. Loupian, E. A., Balashov, I. V., Bartalev, S. A., Byrtsev, M. A., Dmitriev, V. V., Senko, K. S. \& Krasheninnikova Y. S. (2019). Forest fires in Russia: features of the 2019 fire season. Sovremennye problemy distantsionnogo zondirovaniya Zemli iz kosmosa [Modern Problems of Remote Sensing of the Earth from Space], 16(5), 356-363 [in Russian].

5. Seidl, R, Fernandes, P. M., Fonseca, T. F., Gillet, F, Jönsson, A. M, Merganičová, K, Netherer, S., Arpaci, A., Bontemps, J.-D., Bugmann, H., González-Olabarria, J. R., Lasch, P., Meredieu, C., Moreira, F., Schelhaas, M.-J. \& Mohren, F. (2011). Modelling natural disturbances in forest ecosystems: A review. Ecological Modelling, 222(4), 903-924.

6. Krylov, A. M., Sobolev, A. A., \& Vladimirova, N. A. (2011). Identification seat of a bark beetle typograph in the Moscow region using Landsat images. Lesnoy vestnik [Forest Bulletin], 4, 54-60 [in Russian].

7. Potapov, P. V., Turubanova, S. A., Tyukavina, A., Krylov, A. M., McCarty, J. L., Radeloff, V. C., \& Hansen, M. C. (2015). Eastern Europe's forest cover dynamics from 1985 to 2012 quantified from the full Landsat archive. Remote Sensing of Environment, 159, 28-43.

8. Williams, D. L., \& Stauffer, M. L. (1978) Monitoring gypsy moth defoliation by applying change detection techniques to Landsat imagery. In Proceedings of symposium on Remote Sensing for Vegetation Damage Assessment (pp. 221-229). Seattle, United States.

9. Sayn-Wittgenstein, L., \& Wightman, J. M. (1975). Landsat application in Canadian forestry. In
Proceeding of the 10th International Symposium on Remote Sensing of Environment (pp. 1209-1218). Michigan, United States.

10. Hardisky, M. A., Klemas, V., \& Smart R. M. (1983). The influence of soil salinity, growth form and leaf moisture on the spectral radiance of Spartina alterniflora canopies. Photogrammetric Engineering and Remote Sensing, 49(1), 77-83.

11. Krylov, A. M., \& Vladimirova, N. A. (2011). Space based monitoring of forest health. Geomatika [Geomatics], 3, 53-58.

12. Wang, W., Qu, J. J., Hao, X., Liu, Y., \& Stanturf, J. A. (2010) Post-hurricane forest damage assessment using satellite remote sensing. Agricultural and Forest Meteorology, 150, 122-132.

13. Cocke, A. E., Fulé, P. Z., \& Crouse, J. E. (2005). Comparison of burn severity assessments using Differenced Normalized Burn Ratio and ground data. International Journal of Wildland Fire, 14(2), 189-198.

14. Crist, E. P., Laurin, R., \& Cicone, R. C. (1986). Vegetation and soils information contained in transformed Thematic Mapper data. In Proceedings of International Geosciences and Remote Sensing Symposium (IGARSS) (pp. 1465-1470). Paris, France.

15. Wang, F., \& Xu, Y. J. (2010). Comparison of remote sensing change detection techniques for assessing hurricane damage to forests. Environmental Monitoring and Assessment, 162, 311-326.

16. Nielsen, A. A., Conradsen, K., \& Simpson, J. J. (1998). Multivariate alteration detection (MAD) and MAF postprocessing in multispectral, bitemporal image data: New approaches to change detection studies. Remote Sensing of Environment, 64(1), 1-9.

17. ScanEx Image Processor v.5.1. (2018). Software for remote sensing data processing. Manual. Moscow, 379 p.

18. Coppin, P. R., \& Bauer, M. E. (1994). Processing of multi-temporal Landsat TM imagery to optimize extraction of forest cover change features. IEEE Transactions on Geoscience and Remote Sensing, 32, 918-927. 
19. Allen, T. R., \& Kupfer, J. A. (2001). Spectral response and spatial pattern of Fraser fir mortality and regeneration, Great Smoky Mountains, USA. Plant Ecology, 156, 59-74.

20. Hansen, M. C., Potapov, P. V., Moore, R., Hancher, M., Turubanova, S. A., Tyukavina, A., Thau, D., Stehman, S. V., Goetz, S. J., Loveland, T. R., Kommareddy, A., Egorov, A., Chini, L., Justice, C. O., \& Townshend, J. R. G. (2013). HighResolution Global Maps of 21st-Century Forest Cover Change. Science, 342, 850-853.

21. Bartalev, S. A., Egorov, V. A., Krylov, A. M., Stycenko, F. V., \& Chovratovich T. S. (2010). Research of possibility to estimate post-fired forest condition according to multispectral satellite images. Sovremennye problemy distantsionnogo zondirovaniya Zemli iz kosmosa [Modern Problems of Remote Sensing of the Earth from Space], 7(3), 215225 [in Russian]

22. Krylov, A. M., Malahova, E. G., \& Vladimirova, N. A. (2012). Detection and estimation of areas of catastrophic windthrows 2009-2010 according to space imagery data. Izvestiya Sankt-Peterburgskoi lesotechnicheskoi akademii [Bulletin of the St. Petersburg Forestry Academy], 200, 197-207 [in Russian].

23. Koroleva, N. V., \& Ershov, D. V. (2012). Estimation of error of windthrow area detection according to space images with high spatial resolution LANDSAT-TM. Sovremennye problemy distantsionnogo zondirovaniya Zemli iz kosmosa [Modern Problems of Remote Sensing of the Earth from Space], 9(1), 80-86 [in Russian].

24. Baumann, M., Ozdogan, M., Wolter, P. T., Krylov, A. M., Vladimirova, N. A., \& Radeloff, V. C. (2014). Landsat remote sensing of forest windfall disturbance. Remote Sensing of Environment, 143, 171-179.

25. Huo, L.-Z., Boschetti, L. \& Sparks, A. M. (2019). Object-based classification of forest disturbance types in the conterminous United States. Remote Sensing, 11(5), Art. No. 477.

26. Rosenblatt ,F. (1958). The perceptron: A probabilistic model for information storage and organization in the brain. Psychol. Rev., 65, 386-408.

27. Goodfellow I., Bengio Y., \& Courville A. (2016). Deep learning. MIT Press.

28. Samuel, A. L. (1959). Some Studies in Machine Learning Using the Game of Checkers. IBM JOURNAL, 3(3), 210-229.

29. Mitchell, T. M. (1997). Machine learning.

New York: McGraw-Hill.

30. Krizhevsky, A., Sutskever, I. \& Hinton, E. G. (2012). ImageNet Classification with Deep Con- volutional Neural Networks. In Proceedings of the 25th International Conference on Neural Information Processing Systems (pp. 1097-1105). New York, United States.

31. Li, Z., Shen, H., Cheng, Q., Liu, Y., You, S., \& He, Z. (2019). Deep learning based cloud detection for medium and high resolution remote sensing images of different sensors. ISPRS Journal of Photogrammetry and Remote Sensing, 150, 197- 212.

32. Syrris, V., Hasenohr, P., Delipetrev, B., Kotsev, A., Kempeneers, P., \& Soille, P. (2019). Evaluation of the potential of convolutional neural networks and random forests for multi-class segmentation of Sentinel-2 imagery. Remote Sensing, 11(8), Art. No. 907.

33. Hethcoat, M. G., Edwards, D. P., Carreiras, J. M. B., Bryant, R. G., França, F. M., \& Quegan, S. (2019). A machine learning approach to map tropical selective logging. Remote Sensing of Environment, 221, 569-582.

34. Aas, C., Jochemsen, A., Mantas, V., Lewyckyj, N., Jozefiak, M., \& Buchhorn, M. (2018). Maximizing forest value through using Sentinel-2 in combination with hyperspectral UAVs. In Proceedings of the 69th International Astronautical Congress (pp. 4492-4498). Bremen, Germany.

35. Silvisense. (n. d.). Retrieved from https://silvisense.com/.

36. Sub weekly detection of deforestation with planet data. Retrieved from https://medium.com/ planet-stories/sub-weekly-detection-of-

deforestation-with-planet-data-7699553b3926.

37. Ronneberger, O., Fischer, P., \& Brox, T. (2015) U-Net: Convolutional Networks for Biomedical Image Segmentation. In Medical Image Computing and Computer-Assisted Intervention - MICCAI 2015. MICCAI 2015. Lecture Notes in Computer Science: Vol 9351. N. Navab, J. Hornegger, W. Wells, \& A. Frangi (Eds.). Springer, Cham.

38. Banko, M., \& Brill, E. (2001). Scaling to Very Very Large Corpora for Natural Language Disambiguation. In Proceedings of the 39th Annual Meeting of the Association for Computational Linguistics (pp. 26-33). Toulouse, France.

39. Khryashchev, V., Ivanovisky, L., Pavlov, V., Rubtsov, A., \& Ostrovskay, A. (2018). Comparison of different convolutional neural network architectures for satellite image segmentation. In Proceeding of the 23rd Conference of Fruct Association (pp. 172-180). Jyvaskyla, Finland.

40. Russakovsky, O., Deng J., \& Su, H. (2015). ImageNet large-scale visual recognition challenge, 2010-2015. 


\title{
ЗЕМЛЕУСТРОЙСТВО, КАДАСТР И МОНИТОРИНГ ЗЕМЕЛЬ
}

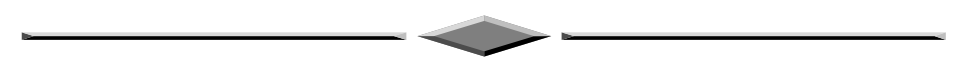

УДК 630(597)

DOI: $10.33764 / 2411-1759-2020-25-3-214-228$

\section{ПРОГНОЗ СОСТОЯНИЯ РАСТИТЕЛЬНОГО ПОКРОВА ЛЕСНЫХ УГОДИЙ ЗАПОВЕДНИКА ДОНГ НАЙ ВЬЕТНАМА}

\author{
Василий Федорович Ковязин \\ Санкт-Петербургский горный университет, 199106, Россия, г. Санкт-Петербург, Васильевский \\ остров, 21 линия, 2, доктор биологических наук, профессор кафедры инженерной геодезии, \\ тел. (911)954-26-89, e-mail: vfkedr@mail.ru
}

\section{Данг Тхи Лан Ань}

Санкт-Петербургский горный университет, 199106, Россия, г. Санкт-Петербург, Васильевский остров, 21 линия, 2, аспирант кафедры инженерной геодезии, тел. (961)807-21-49, e-mail: lananhvfu2@mail.com

\section{Данг Виет Хунг}

Вьетнамский государственный лесохозяйственный университет - Донг Най кампус, 810000, Вьетнам, район Транг Бом, ул. Чан Фу, 54, аспирант кафедры ботаники, тел. (962)708-27-30, e-mail: viethungvfu@gmail.com

Исследование проводилось на лесных угодьях заповедника Донг Най, который является особо охраняемой природной территорией (ООПТ) Вьетнама. Работа направлена на анализ изменений и прогноза состояния покрова лесных угодий в заповеднике. Для этих целей исследованы снимки Landsat-5, Landsat-7 и Landsat-8, полученные в 2003, 2011 и 2019 гг. Для выделения растительного покрова на лесных угодьях использован метод нормализованного индекса растений (NDVI). Выделенные по снимкам угодья классифицированы по категориям методом максимального правдоподобия. Для прогноза состояния выделенных угодий в районе исследований использовалась модель цепей Маркова и клеточных автоматов. Результаты исследования свидетельствуют, что в заповеднике Донг Най происходит трансформация угодий. По нашей оценке, с 2003 по 2019 г. площадь покрытых древесной растительностью угодий увеличилась на 7,0 \%. К 2035 г. площадь широколиственных лесов увеличится на 1,6 \%, за счет уменьшения площади лугов и кустарников. Динамика увеличения лесных угодий ООПТ объясняется принятыми Правительством Вьетнама мерами по расширению площади лесов.

Ключевые слова: заповедник Донг Най, лесные угодья, растительный покров, космоснимки, цепи Маркова.

\section{Введение}

Объект исследования является правопреемником природно-культурного объекта ВиньКыу Вьетнама. Объект был создан Постановлением Правительства страны 02.12.2003 г. [1]. Позже данный земельный участок объединили с заповедником внутренних водно-болотных угодий ЧиАн. Объединенный земельный участок получил новый статус «Природнокультурный заповедник Донг Най» [2], на котором проводились наши исследования. Площадь лесных угодий заповедника составляет 68 003,30 га, он расположен между $11^{\circ} 31^{\prime} 00^{\prime \prime}$ $11^{\circ} 06^{\prime} 00^{\prime \prime}$ северной широты и $106^{\circ} 54^{\prime} 30^{\prime \prime}$ $107^{\circ} 13 ' 30^{\prime \prime}$ восточной долготы (рис. 1). 


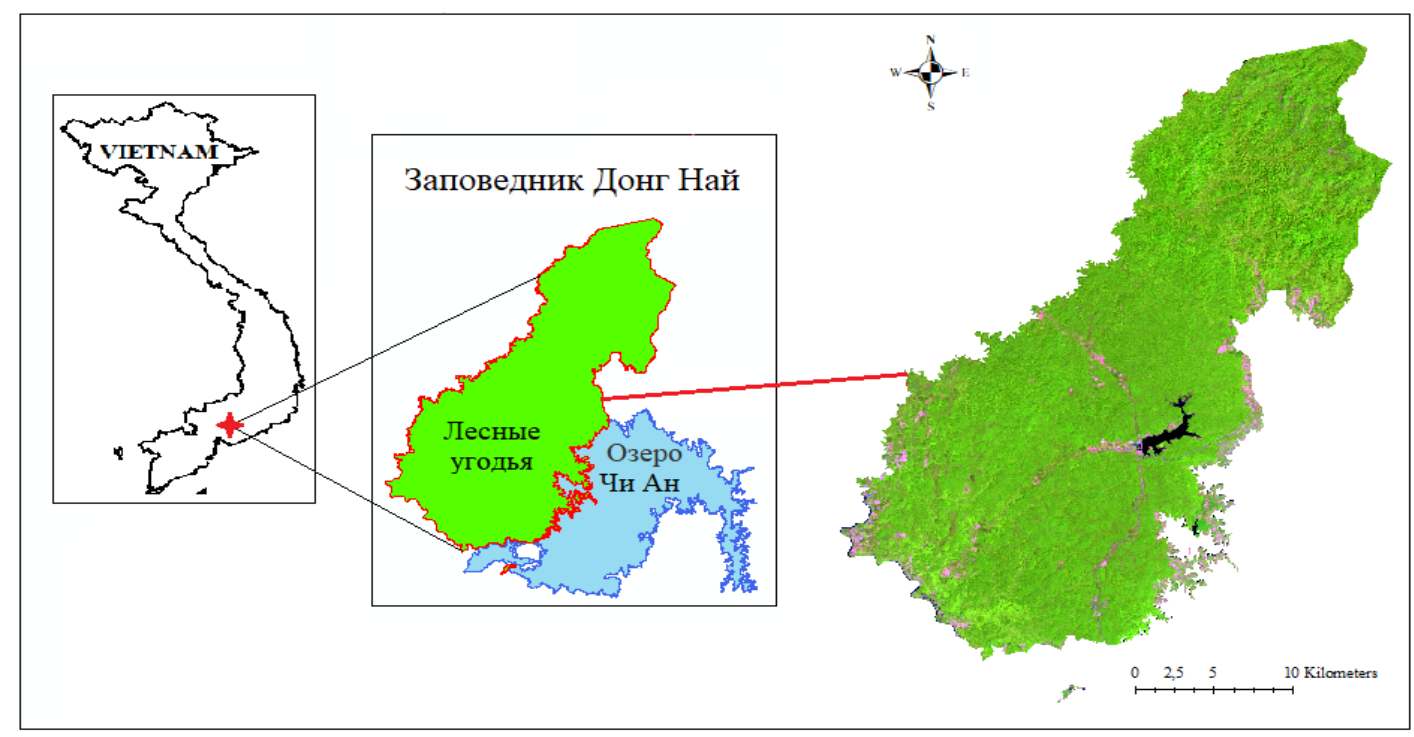

Рис. 1. Схема местонахождения и границы объекта исследований

Объект исследования является природной экосистемой в горах Чыонгшон [3], которая нуждается в срочном восстановлении лесов. Согласно данным Всемирного фонда дикой природы «Глобальные экологические проблемы - 200» [4], лесная экосистема в горах Чыонгшон включена в список регионов мира, нуждающихся в срочном восстановлении лесов после сплошной рубки. По решению международного координационного комитета ЮНЕСКО и программы «Человек и биосфера» от 29.06.2011 г. [2], заповедник Донг Най окружает национальный парк Каттьен, буферные и переходные зоны вокруг него также признаны биосферным заповедником Донг Най. Ранее, во время военных действий США во Вьетнаме, часть территории объекта исследования опрыскивалась токсичными химическими вещества- ми, что привело к серьезным изменениям в структуре угодий заповедника. В настоящее время осуществляются программы Правительства Вьетнама и международных организаций [5] по преодолению последствий войны и увеличению разнообразия видов растений и животных в заповеднике. Мониторинг состояния земель в заповеднике Донг Най позволит выявить причины изменений в структуре угодий и предложить мероприятия по совершенствованию правления и сохранению одной из самых богатых биоразнообразием экосистем мира.

\section{Материаль и методика}

Исходным материалом для исследований являлись космические снимки, краткая характеристика которых приведена в табл. 1 [6].

Таблица 1

Характеристики использованных космоснимков при исследованиях

\begin{tabular}{|c|l|c|l|}
\hline Название источника & \multicolumn{1}{|c|}{ Краткое описание снимков } & Дата создания & Источник данных \\
\hline LE71240522003024EDC00 & $\begin{array}{l}\text { Landsat-7, среднее спутниковое } \\
\text { разрешение 30 м }\end{array}$ & 24.01 .2003 & $\begin{array}{l}\text { Геологическая } \\
\text { служба США }\end{array}$ \\
\hline LT51240522011038BKT00 & $\begin{array}{l}\text { Landsat-5, среднее спутниковое } \\
\text { разрешение 30 м }\end{array}$ & 07.02 .2011 & $\begin{array}{l}\text { Геологическая } \\
\text { служба США }\end{array}$ \\
\hline LC81250522019051LGN00 & $\begin{array}{l}\text { Landsat-8, среднее спутниковое } \\
\text { разрешение 30 м }\end{array}$ & 20.02 .2019 & $\begin{array}{l}\text { Геологическая } \\
\text { служба США }\end{array}$ \\
\hline
\end{tabular}


Все космоснимки получены в сухой сезон 2003, 2011 и 2019 гг. при облачности менее $10 \%$. Они бесплатно загружены с сайта департамента США.

Методика исследований включала несколько этапов.

Предварительная обработка снимков это коррекция и улучшение спутниковых изображений. Радиометрическая калибровка данных Landsat-5, Landsat-7 и Landsat-8 выполнялась в программе ArcGis 10.5 [7].

Изменение растительного покрова оценивалось по нормализованному относительному индексу растительности NDVI (Normalized Difference Vegetation Index). Он определялся по интенсивности развития растений [8] и вычислялся по следующей формуле:

$$
\mathrm{NDVI}=\frac{\mathrm{NIR}-\mathrm{RED}}{\mathrm{NIR}+\mathrm{RED}}
$$

где NIR - коэффициент отражения в ближней инфракрасной зоне;

RED - коэффициент отражения в красной спектральной зоне.

Индекс может принимать значения от -1 до 1. Для растительности характерны положительные значения NDVI, и чем больше ее фитомасса, тем они выше [9]. Классификация растительности проведена в период 2003-2019 гг., при этом район исследований разделен на три категории: низкая плотность растительности $(0 \leq \mathrm{NDVI}<0,2)$, средняя плотность растительности $(0,2 \leq \mathrm{NDVI}<0,5)$ и высокая плотность растительности (NDVI $\geq 0,5$ ).

Классификация состояния лесных угодий проводилась методом контролируемого алгоритма максимального правдоподобия (Supervised Maximum likelihood classifier), который предполагает нормальное распределение значений отражения растительности для каждого вида и вычисляет вероятность принадлежности отдельного пикселя к определенному классу растительного покрова на угодьях. Классификация лесных угодий проводилась в программе ENVI 5.3.

Оценка точности классификации проводилась по космоснимкам. Классифицированные изображения сравнивались с другими источниками: снимками Google Earth и картами состояния лесов заповедника Донг Най
2010 и 2015 гг. Сравнение итоговой карты с эталонными значениями осуществлялось путем построения матрицы ошибок. На основе матрицы ошибок устанавливались четыре результата расчета: точность пользователя, точность производителя, общая точность и индекс Каппа.

Точность пользователя - это общее количество правильных пикселей в категории, деленное на их число, которое классифицировалось в этой категории (общее количество строк). Точность производителя - это показатель того, насколько хорошо можно классифицировать определенную область растительности. Индекс Каппа измеряет согласованность между классификацией $X$ и истинным значением $Y$ [10]. Индекс Каппа (Каппа Коэна) рассчитывался по формуле (2):

$$
\text { Kappa }=\frac{P_{o}-P_{e}}{1-P_{e}},
$$

где $P_{o}$ - доля случаев, когда измерения совпадали; $P_{e}$ - ожидаемая доля случаев случайного совпадения.

Значение индекса Каппа, равное 1, представляет собой высокую согласованность, а значение 0 - отсутствие результатов классификации со справочными данными.

Для оценки изменений площадей лесных угодий после классификации проведена их инвентаризация за период с 2003 по 2019 г. Для оценки динамики растительности использована программа Arcgis 10.5 [11], a ocновой явились наши ранее разработанные карты состояния лесных угодий за 16 лет.

Прогноз состояния лесных угодий в заповеднике проводился с использованием модели цепей Маркова и клеточных автоматов. Модель КА-Марков объединяет клеточные автоматы, цепь Маркова - многокритериальные и многоцелевые распределения земли для прогнозирования изменения земной поверхности с течением времени [12]. Модель КА-Марков эффективно сочетает в себе преимущества двух моделей: а) способность моделировать пространственные изменения в сложных системах модели КА; б) долгосрочные прогнозы модели Маркова [13]. В этом исследовании модель КА-Марков ис- 
пользуется для двух целей: во-первых, для моделирования состояния лесных угодий в 2019 г. для проверки точности модели КА-Марков, и во-вторых, для прогноза состояния покрова лесных угодий в 2035 г. Процесс прогноза покрова состояния лесных угодий с использованием модели КА-Марков позволил: 1) разработать карты пригодности лесных угодий для каждой категории на основе многочисленных критериев; 2) определить матрицы вероятности перехода состояния лесных угодий; 3) определить базовые карты, количество итераций и фильтров клеточных автоматов.

Многокритериальная оценка - это процесс, в котором несколько слоев объединяются для получения одной выходной карты. Это карта, показывающая пригодность земли для определенной деятельности. Карты пригодности разработаны путем установления правил перехода из одного состояния землепользования в другое. Ограничения являются критериями, которые ограждают расширение категорий угодий. Ограничения выражались в форме булевых карт (Booleanmaps), где для неподходящих областей устанавливалось значение 0, а для подходящих областей - значение 1. Факторы являлись критериями, которые давали степень пригодности лесных угодий для изменения состояния категории. Значения индекса пригодности на картах варьировали от 0 до 255, 0 - неподходящие и 255 - весьма подходящие угодья [14]. Считается, что близость к существующему индексу пригодности является движущей силой превращения землепользования в конкретный класс в будущем [15]. В этом исследовании природные факторы являлись движущей силой, под их действием происходило превращение лесных площадей в водноболотные угодья или дороги. Также при составлении карт пригодности к использованию каждой категории лесных угодий они принимались во внимание. Веса факторов рассчитывались по методу анализа иерархий (МАИ), разработанному американским математиком Томасом Л. Саати в 1991 г. Метод МАИ является признанным многокритериальным методом, который включен в основанные на ГИС-технологиях процедуры опреде- ления пригодности угодий [16]. Веса факторов определялись с помощью модуля «WEIGHT» [17]. Карты пригодности определенных категорий лесных угодий обрабатывались в модуле «МСЕ» [18] с учетом ограничений, факторов и весов.

Определение матриц вероятности перехода состояния лесных угодий проводилось с использованием цепи Маркова. Цепь Маркова впервые введена русским ученым А. А. Марковым в 1906 г. Цепь Маркова представляет собой статистический инструмент, который описывает вероятность изменений состояний угодий от одного периода $(t)$ к другому $(t+1)$ путем разработки матрицы вероятности перехода между двумя периодами $[19,20]$. В этом исследовании модель цепи Маркова описана как набор состояний лесных угодий в заповеднике: $\mathrm{S}=\{\mathrm{S} 1, \mathrm{~S} 2, \mathrm{~S} 3, \mathrm{~S} 4, \mathrm{~S} 5\}$, где 1, 2, $3,4,5$ - категория лесных угодий (1 - широколиственные леса, 2 - луга и кустарники, 3 - непокрытые растительностью земли, 4 - водно-болотные угодья и 5 - дороги). Состояние лесных угодий в момент времени $t+1$ рассчитывалось по формуле [21]:

$$
S_{t+1}=P \cdot S_{t},
$$

где $S_{t}, S_{t+1}$ - состояние лесных угодий в момент времени $t$ и $t+1 ; P$ - матрица вероятности перехода состояния лесных угодий с элементами, которые являются вероятностями перехода $\left(p_{i j}\right)$. Матрица $P$ обладает следующими свойствами:

$$
\begin{gathered}
P=\left[\begin{array}{ccc}
p_{11} & \cdots & p_{15} \\
\vdots & \ddots & \vdots \\
p_{51} & \cdots & p_{55}
\end{array}\right] \\
\left(0 \leq p_{i j}<1 \text { и } \sum_{\mathrm{j}=1}^{\mathrm{n}} p_{i j}=1,(i, j=1,2, \ldots, 5)\right) .
\end{gathered}
$$

Для моделирования прогноза состояния лесных угодий в заповеднике к 2035 г. по цепи Маркова использовался инструмент «MARKOV», с помощью которого получены матрицы вероятности перехода угодий.

Выбор базовой карты, количества итераций и фильтров клеточных автоматов проводился 
с использованием модели клеточных автоматов, предложенных в работе Неймана [22]. Клеточный автомат - дискретная динамическая система, представляющая собой совокупность клеток, одинаково соединенных между собой. Все клетки образуют так называемую решетку клеточного автомата [23]. В этом исследовании клетками являются сетки изображений, размер блока составляет $30 \times 30$ м. Модель клеточных автоматов может быть выражена следующим образом [24]:

$$
S_{(t, t+1)}=f\left(S_{(t)}, N\right),
$$

где $S$ - множество ограниченных и дискретных клеточных состояний; $N$ - клеточное поле; $t$ и $t+1$ - разные времена исследований; $f$ - правило переходов клеточных состояний в локальном пространстве.

Определение базовой карты, количества итераций и фильтров являются неотъемлемой частью действия компонента клеточных автоматов. В качестве базовой выбрана карта состояния лесных угодий 2011 г., количество итераций клеточных автоматов равно 8 для моделирования состояния лесных угодий в 2019 г. Карта состояния лесных угодий 2019 г. выбрана в качестве базовой карты, количество итераций клеточных автоматов равно 16 для прогноза состояния земель в 2035 г. В данном исследовании использован фильтр по умолчанию $5 \times 5$. Итак, моделирование и прогнозирование состояния лесных угодий в заповеднике Донг Най проведено по методу КА-Марков с помощью модуля «CA_MARKOV» в программе IDRISI.

Оценка точности модели прогноза проводилась путем сравнения результатов моделирования с истинными данными по целям исследований: 1 - согласованность по количеству угодий; 2 - согласованность по расположению ячеек в каждой категории угодий, между картами «сравнения» и «эталонной» [25]. Результаты измерения согласия являются статистическими показателями: несогласие из-за количества (Quantity disagreement), несогласие из-за расположения на уровне ячейки сетки (Allocation disagreement), Каппа без всякой информации или общая точность модели прогноза (Kno) и традиционный индекс Каппа или Каппа Коэна (Kstandard). Когда значения несогласия равны 1, моделирование считается несовершенным, а если оно равно 0, то моделирование считается совершенным. Значения индексов Каппа 0,61-0,80 означают существенные, в то время как 0,81-1,00 означают почти идеальные [26]. Все индексы вычислены с использованием модуля «VALIDATE» в программе IDRISI [15].

Процедура анализа данных Д3З приведена на рис. 2.

\section{Результать}

Индекса NDVI, полученные за 2003, 2011 и 2019 гг., показывают динамику площадей растительного покрова угодий в течение всего периода исследований (рис. 3).

Анализ приведенных на рис. 3 данных свидетельствует, что за последние 16 лет наблюдается тенденция к восстановлению растительности в целом по всему заповеднику, но в то же время некоторые лесные районы, находящиеся вблизи населенных пунктов, подвержены процессу деградации. Эти зоны характеризуются низким значением индекса NDVI, что связано с антропогенным воздействием на эти природные экосистемы. В частности, южная часть заповедника (лесной массив Хиеу Лием и Ма Да) имеет низкий уровень индекса NDVI.

Этот лесной массив последовательно увеличивает значения этого индекса с 2003 по 2019 г. На всех территории заповедника Донг Най в текушем году зарегистрировано повышение индекса NDVI до 0,82 и отмечено увеличение площади угодий с высокой плотностью растительности. Настоящее комплексное исследование позволило оценить степень распределения растительности по всей площади заповедника. Это первый опыт оценить степень покрытия земельных угодий заказника влажной тропической вечнозеленой широколиственной растительностью. Значительные изменения растительного покрова земельных угодий заповедника Донг Най также отмечены в восточном, западном и южном секторах. 


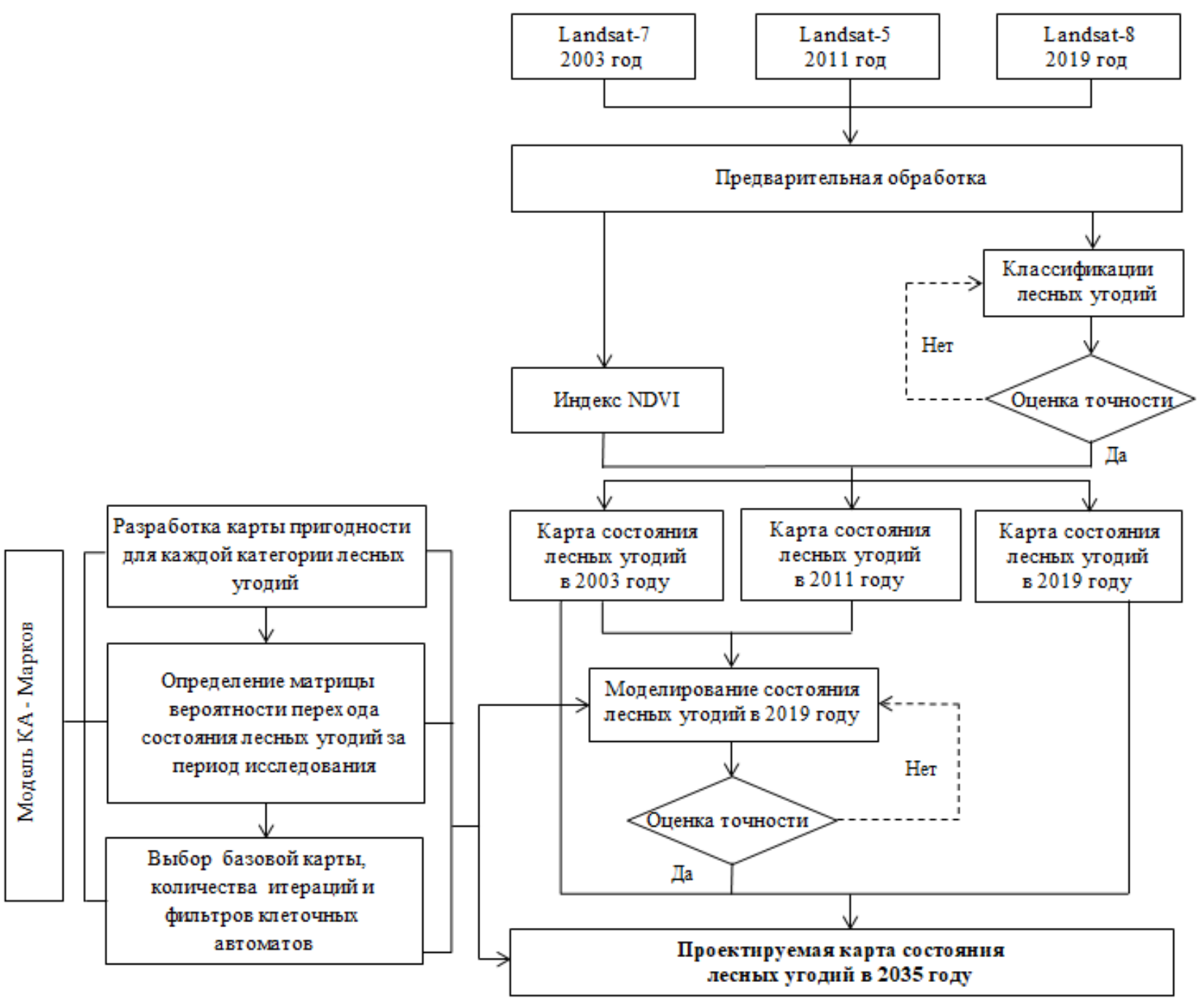

Рис. 2. Блок-схема методики исследований

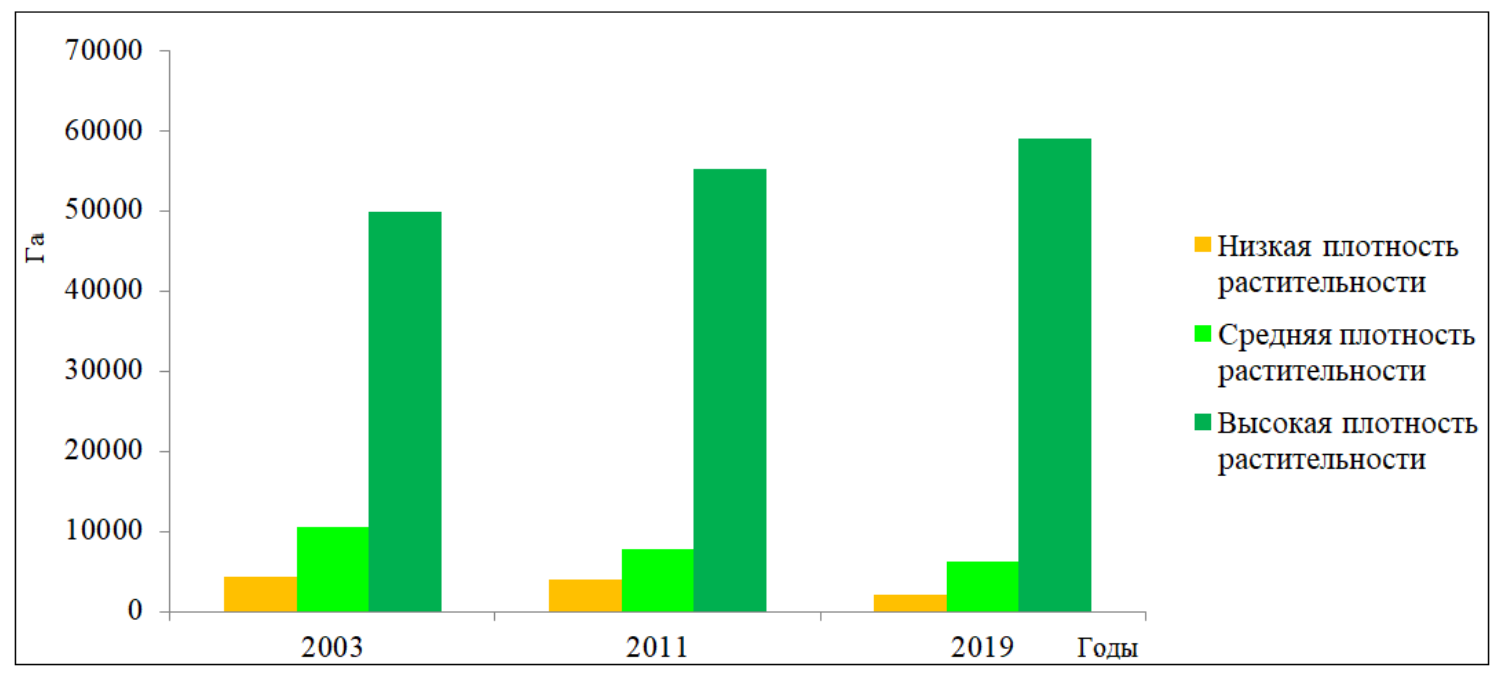

Рис. 3. Динамика площадей лесных угодий по категориям плотности растительности 
По результатам классификации космоснимков разработаны карты покрова лесных угодий заповедника Донг Най в 2003, 2011 и 2019 гг. (рис. 4). Оценка точности классификации снимков в период с 2003 по 2019 г. приведена в табл. 2. Из данных табл. 2 видно, что точность пользователя и производителя исследований достаточно высокие. Общая точность карт растительного покрова для 2003, 2011 и 2019 гг. исследований больше 87 \%, а индекс
Каппа равен 0,85, что указывает на то, что нами достигнута значительная согласованность между результатами классификации и справочными данными. Таким образом, результаты изначально считались приемлемыми для сравнения после классификации.

Данные инвентаризации растительного покрова угодий по категориям в заповеднике Донг Найв период с 2003 по 2019 г. приведена в табл. 3.

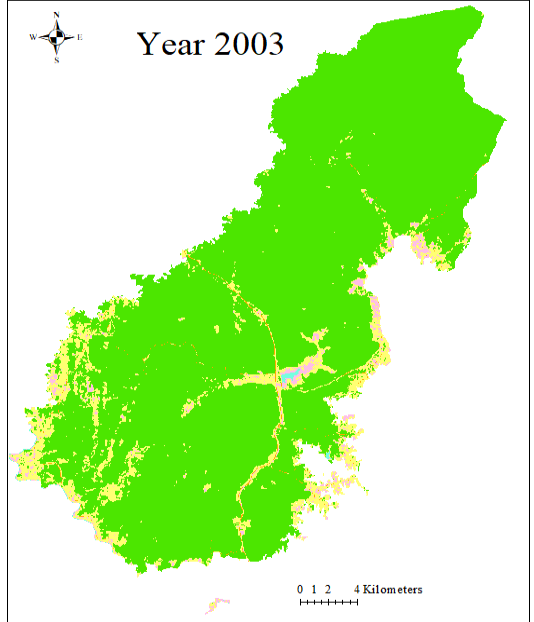

a)

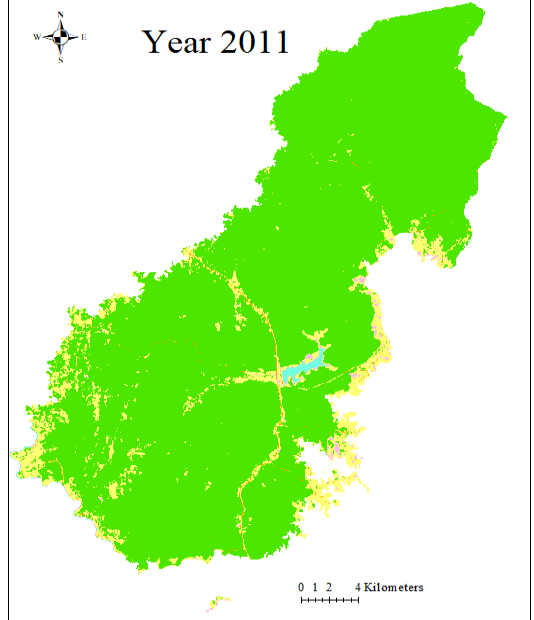

б)

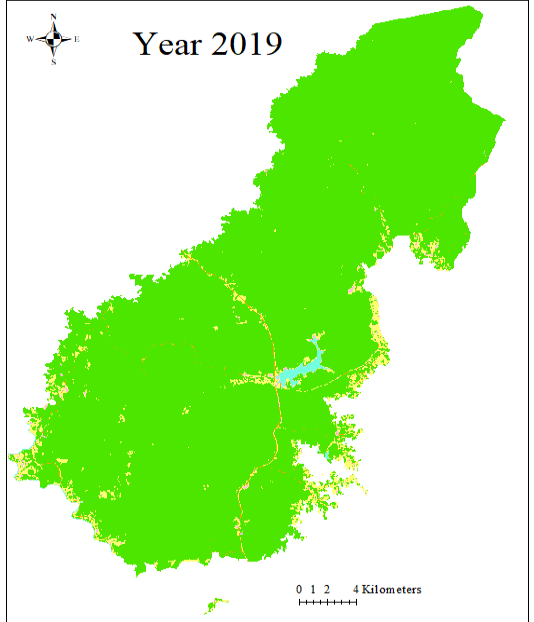

в)

УСЛОВНЫЕ ОБОЗНАЧЕНИЯ
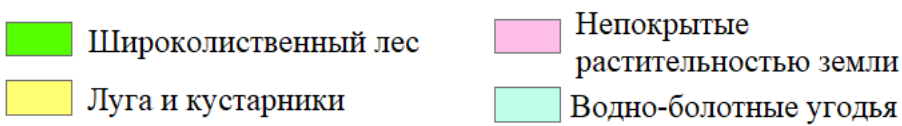

Дороги

Рис.4. Состояние лесных угодий заповедника Донг Най в разные годы исследований:

a) карта в 2003 г.; б) карта в 2011 г.; в) карта в 2019 г.

Таблица 2

Результаты оценка точности классификации снимков по годам исследований

\begin{tabular}{|l|c|c|c|c|c|c|}
\hline \multirow{2}{*}{ Категории лесных угодий } & \multicolumn{6}{|c|}{ Точность по годам исследований, \% } \\
\cline { 2 - 8 } & \multicolumn{2}{|c|}{2003 г. } & \multicolumn{2}{c|}{2011 г. } \\
\cline { 2 - 8 } & $\begin{array}{c}\text { пользова- } \\
\text { теля }\end{array}$ & $\begin{array}{c}\text { произво- } \\
\text { дителя }\end{array}$ & $\begin{array}{c}\text { пользова- } \\
\text { теля }\end{array}$ & $\begin{array}{c}\text { произво- } \\
\text { дителя }\end{array}$ & $\begin{array}{c}\text { пользова- } \\
\text { теля }\end{array}$ & $\begin{array}{c}\text { произво- } \\
\text { дителя }\end{array}$ \\
\hline Широколиственный лес & 91,8 & 90,0 & 95,7 & 91,8 & 97,6 & 96,4 \\
\hline Луга и кустарники & 78,9 & 86,5 & 81,8 & 90,0 & 89,7 & 92,9 \\
\hline $\begin{array}{l}\text { Не покрытые раститель- } \\
\text { ностью земли }\end{array}$ & 82,7 & 81,1 & 87,0 & 85,5 & 93,9 & 91,8 \\
\hline Водно-болотные угодья & 91,8 & 90,0 & 93,8 & 91,8 & 92,9 & 94,6 \\
\hline Дороги & 94,3 & 90,9 & 98,0 & 96,2 & 94,1 & 92,3 \\
\hline Общая точность, \% & \multicolumn{2}{|c|}{87,9} & \multicolumn{2}{c|}{91,3} & \multicolumn{3}{c|}{93,7} \\
\hline Индекс Каппа & \multicolumn{2}{|c|}{0,85} & \multicolumn{3}{c|}{0,89} \\
\hline
\end{tabular}


Динамика площадей лесных угодий по категориям в заповеднике Донг Най

\begin{tabular}{|l|c|c|c|c|c|c|}
\hline \multirow{2}{*}{$\begin{array}{c}\text { Категории растительного } \\
\text { покрова угодий }\end{array}$} & \multicolumn{2}{|c|}{2003 г. } & \multicolumn{2}{c|}{2011 г. } & \multicolumn{2}{c|}{2019 г. } \\
\cline { 2 - 7 } & га & $\%$ & га & $\%$ & га & $\%$ \\
\hline Широколиственные леса & 60601,0 & 88,7 & 62199,3 & 91,1 & 63693,0 & 93,3 \\
\hline Луга и кустарники & 6708,0 & 9,8 & 5333,6 & 7,8 & 3792,3 & 5,6 \\
\hline $\begin{array}{l}\text { Не покрытые растительно- } \\
\text { стью земли }\end{array}$ & 550,1 & 0,8 & 218,0 & 0,3 & 185,8 & 0,3 \\
\hline Водно-болотные угодья & 185,9 & 0,3 & 294,2 & 0,4 & 374,0 & 0,5 \\
\hline Дороги & 258,2 & 0,4 & 258,2 & 0,4 & 258,2 & 0,4 \\
\hline Итого & 68303,3 & 100 & 68303,3 & 100 & 68303,3 & 100 \\
\hline
\end{tabular}

Как видно из табл. 3, доминирующей категорией растительного покрова на лесных угодьях заповедника являются широколиственные леса, доля которых возрастает и составляет соответственно 88,7, 91,1, 93,3 \% для 2003, 2011 и 2019 г. С 1997 г. провинция Донг Най явилась первым регионом Вьетнама, усилившим работы по охране, защите и восстановлению естественных лесов. В результате этих действий провинция Донг Най до сих пор имеет наибольшую лесопокрытую площадь на юго-востоке Вьетнама, включая лесные угодия заповедника Донг Най. При формировании заповедника у местных жителей, проживающих в его границах, сохранены сельскохозяйственные угодья для собственных целей. С 2003 г. хозяйства местного населения, живущего и использующего землю заповедника, стали переводить в другие места страны, чтобы использовать земли только для целей заповедника. Кроме того, в заповеднике постоянно ведется посадка саженцев на непокрытых лесной растительностью и сельскохозяйственных землях коммун. В результате таких мер за последние 16 лет лесная экосистема заповедника была восстановлена за счет широколиственных лесов, площадь которых увеличилась на 3 092,0 га (4,5\%). В первоначальный период наблюдений в заповеднике преобладали луга, кустарники и не покрытые растительностью земли. Большая часть этих угодий находится на юге заповедника, почвы которых малоплодородны, загрязнены химическими веществами и обломками снарядов, которые сбрасывались на вьетнамское население во время военных действий США. В этих условиях может про- израстать только травянистая растительность и кустарники, корневые системы которых располагаются у поверхности земли, в верхнем слое почвенного горизонта. С целью восстановления лесных экосистем площадь лугов, кустарников и непокрытых растительностью земель соответственно сократилась на 3 792,3 га и 185,8 га. Водно-болотные угодья, включающие озеро Ба Хао и многие небольшие ручьи и реки, впадающие в озеро Чи Ан, равномерно распределены по всей территории заповедника. В заповеднике Донг Най сухой сезон длится почти 6 месяцев, за этот период мелкие реки и ручьи практически пересыхают, поэтому площадь водно-болотных угодий довольно сильно колеблется в течение года. Но в целом, с 2003 по 2019 г. площадь водно-болотных угодий увеличилась на 188,1 га (0,3 \%), благодаря мерам, принятым Правительством Вьетнама, по пополнению водохранилища Чи Ан водой. Вырубка лесов для строительства дорог приведет к увеличению количества отдыхающих в лесных угодьях, что станет проблемой сохранения окружающей среды и биоразнообразия в заповеднике Донг Най. Поэтому в последние 16 лет политика Правительства Вьетнама направлена на планирование землепользования, поддерживая лишь состояние дорог путем их текущего ремонта (258,2 га).

Для проверки точности модели КА-Марков и прогноза состояния лесных угодий в 2035 г. нами составлены карты пригодности и матрицы вероятностей переходов. Карты пригодности к использованию каждой категории лесных угодий в заповеднике приведены на рис. 5. 


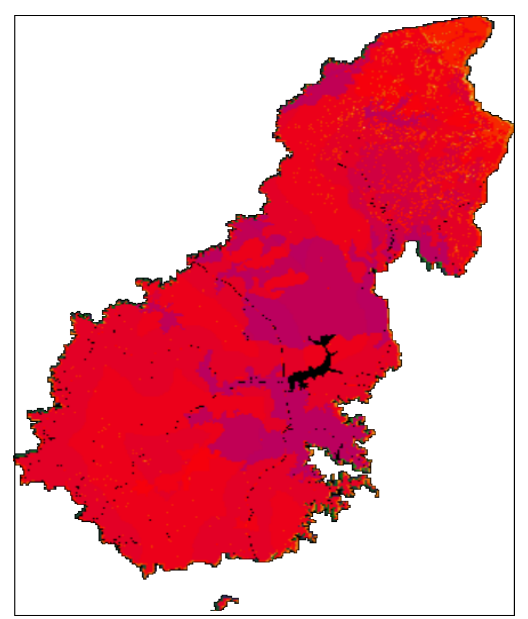

a)

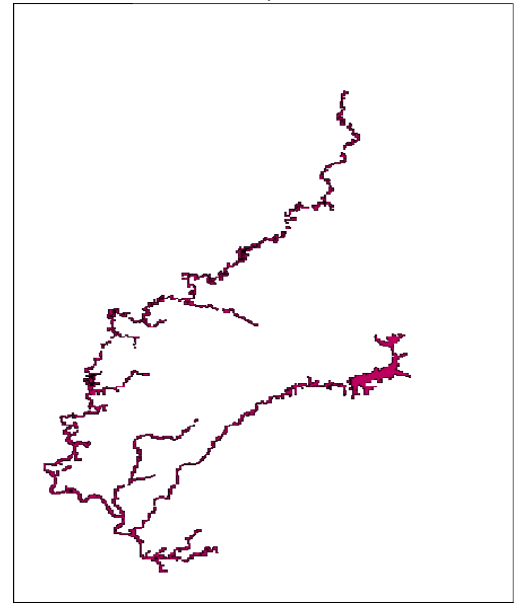

2)

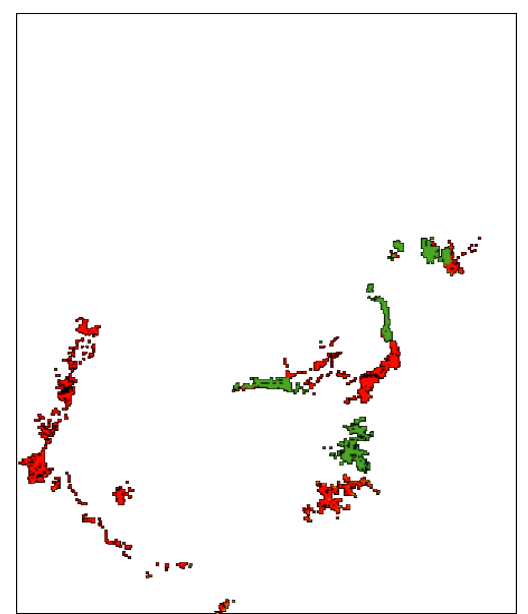

б)

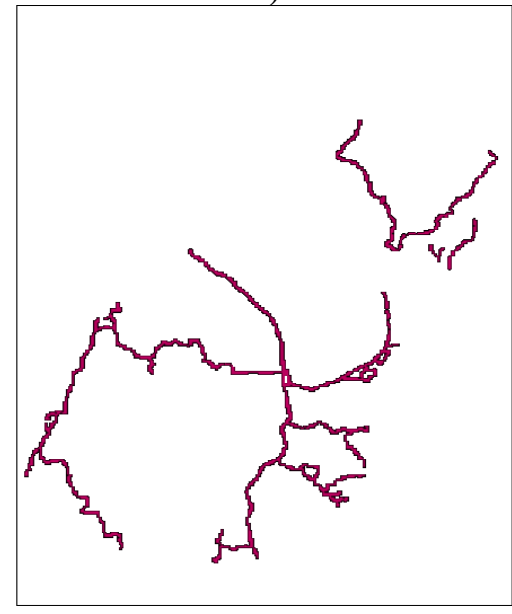

$\partial)$

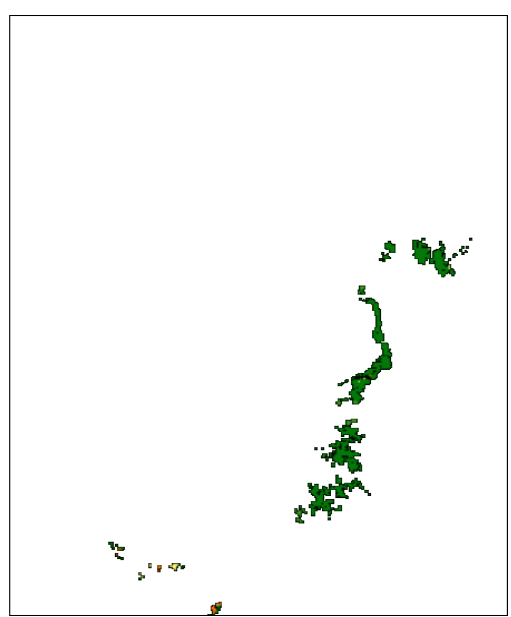

в)

УСЛОВНЫЕ ОБОЗНАЧЕНИЯ

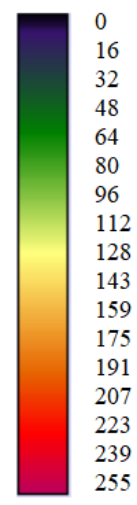

Индекс пригодности

Рис. 5. Карты пригодности к использованию земельных угодий:

a) широколиственные леса; б) луга и кустарники; в) не покрытые растительностью земли;

г) водно-болотные угодья; $\partial$ ) дороги

Матрица вероятностей переходов угодий в заповеднике за 2003-2011 гг. приведена в табл. 4, за 2011-2019 гг. - в табл. 5.

Таблий 4

Матрица вероятности перехода угодий за 2003-2011 гг.

\begin{tabular}{|c|c|c|c|c|c|c|}
\hline \multirow{2}{*}{\multicolumn{2}{|c|}{$\begin{array}{c}\text { Категории } \\
\text { земельных } \\
\text { угодий }\end{array}$}} & \multicolumn{5}{|c|}{2011 г. } \\
\hline & & 1 & 2 & 3 & 4 & 5 \\
\hline \multirow{5}{*}{ 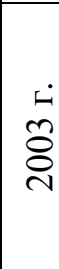 } & 1 & 0,99 & 0,01 & 0,00 & 0,00 & 0,00 \\
\hline & 2 & 0,35 & 0,61 & 0,02 & 0,01 & 0,00 \\
\hline & 3 & 0,14 & 0,68 & 0,07 & 0,12 & 0,00 \\
\hline & 4 & 0,01 & 0,21 & 0,07 & 0,71 & 0,00 \\
\hline & 5 & 0,00 & 0,00 & 0,00 & 0,00 & 1,00 \\
\hline
\end{tabular}

Таблица 5

Матрица вероятности перехода угодий за 2003-2019 гг.

\begin{tabular}{|c|c|c|c|c|c|c|}
\hline \multirow{2}{*}{\multicolumn{2}{|c|}{$\begin{array}{c}\text { Категории } \\
\text { земельных } \\
\text { угодий }\end{array}$}} & \multicolumn{5}{|c|}{2019 г. } \\
\hline & & 1 & 2 & 3 & 4 & 5 \\
\hline \multirow{5}{*}{ 宛 } & 1 & 0,99 & 0,01 & 0,00 & 0,00 & 0,00 \\
\hline & 2 & 0,51 & 0,45 & 0,02 & 0,02 & 0,00 \\
\hline & 3 & 0,29 & 0,52 & 0,05 & 0,13 & 0,00 \\
\hline & 4 & 0,04 & 0,12 & 0,07 & 0,78 & 0,00 \\
\hline & 5 & 0,00 & 0,00 & 0,00 & 0,00 & 1,00 \\
\hline
\end{tabular}

Примечание: 1 - широколиственные леса; 2 луга и кустарники; 3 - не покрытые растительностью земли; 4 - водно-болотные угодья; 5 - дороги. 
Проверка модели прогноза землепользования проводилась путем математического моделирование прошедшего периода исследований [27]. Результаты моделирования со- стояния лесных угодий заповедника Донг Най в 2019 г. приведены на рис. 6, а оценка точности прогнозной модели представлена в табл. 6.

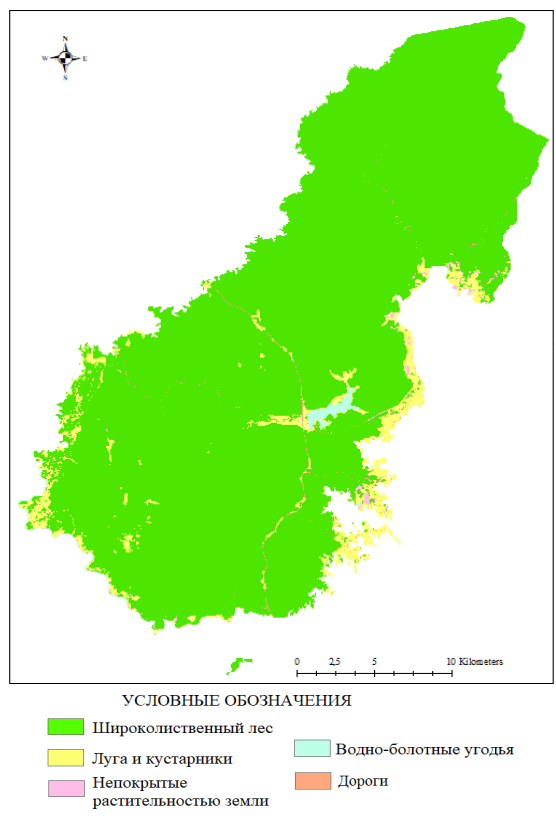

a)

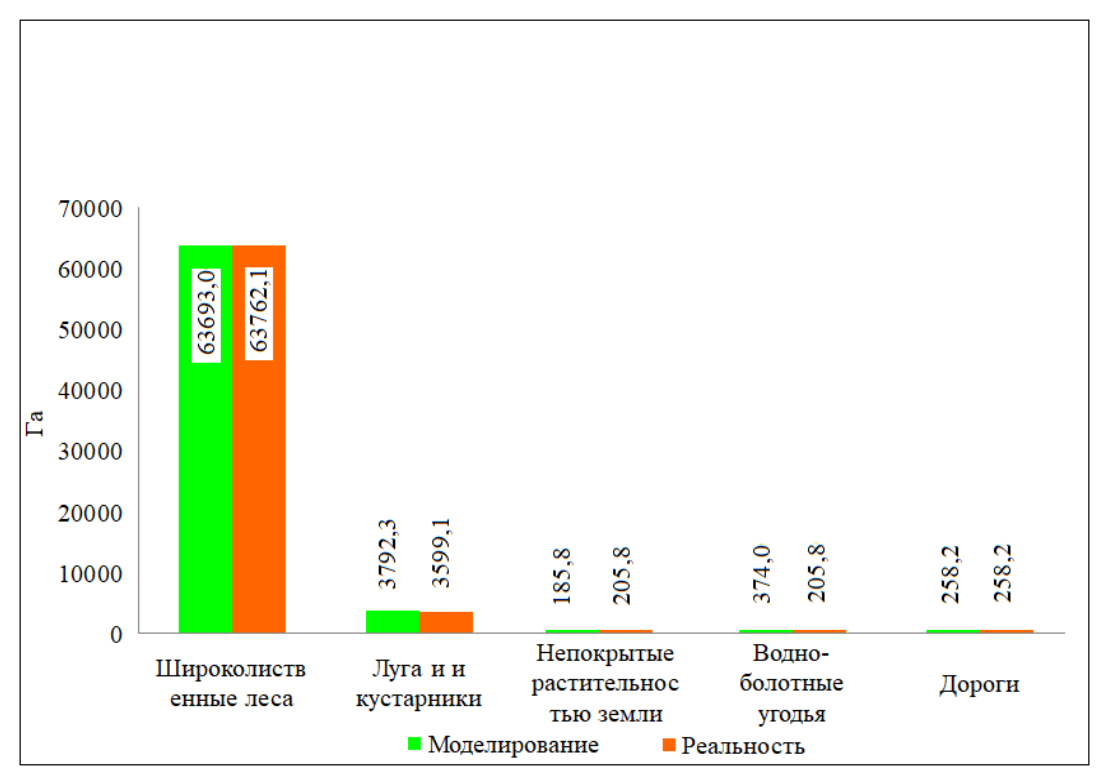

б)

Рис. 6. Результаты моделирования состояния лесных угодий в заповеднике Донг Най в 2019 г.:

a) карта моделирования; б) сравнение данных карт моделирования и реальной по категориям

Таблиия 6 Проверка соглашения между картами моделирования и реальной при оценке состояния лесных угодий в заповеднике Донг Най в 2019 г.

\begin{tabular}{|l|c|c|}
\hline Индекс соглашения & Обозначение & Значение \\
\hline $\begin{array}{l}\text { Несогласие } \\
\text { из-за количества }\end{array}$ & $\begin{array}{c}\text { Quantity } \\
\text { disagreement }\end{array}$ & 0,0085 \\
\hline $\begin{array}{l}\text { Несогласие из-за } \\
\text { местоположения }\end{array}$ & $\begin{array}{c}\text { Allocation } \\
\text { disagreement }\end{array}$ & 0,0202 \\
\hline Общая точность & Kno & 0,9656 \\
\hline Индекс Каппа & Kstandard & 0,9448 \\
\hline
\end{tabular}

Из данных табл. 6 видно, что значений индексов «несогласие» довольно мало: несогласий по количеству $-0,0085$, а несогласии из-за местоположения - 0,020 2. Значение индекса общей точности составляет 0,965 6, а индекса Каппа - 0,944 8. Эти индексы показывают хорошее согласие между картой моделирования и реальными данными. Это доказывает, что модель прогноза состояния лесных угодий заповедника достоверна и достигнута значительная точность прогнозирования.

Карты прогноза растительного покрова лесных угодий исследуемого района созданы путем комбинации модели клеточных автоматов и цепей Маркова (рис. 7). Результаты прогноза состояния растительного покрова лесных угодий по категориям в заповеднике Донг Най в 2035 г. приведена в табл. 7.

Тенденция изменения состояния лесных угодий по категориям в заповеднике Донг Най с 2003 по 2035 г. приведена на рис. 8. 


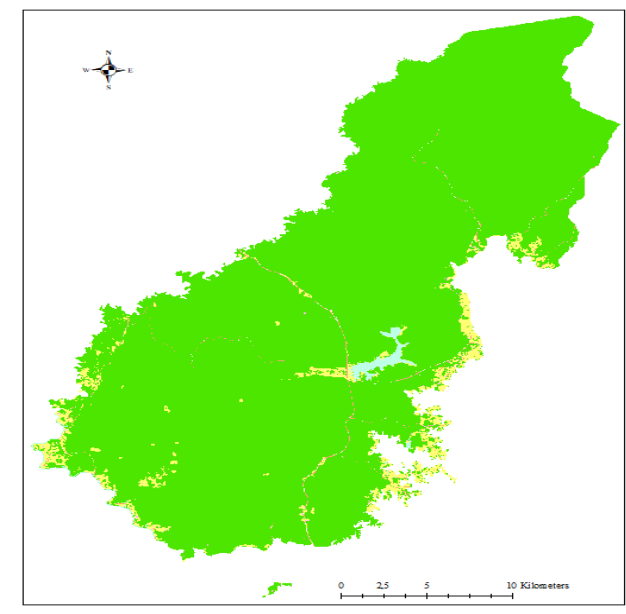

УСЛОВНЫЕ ОБОЗНАЧЕНИЯ

Широколиственный лес

$\square$ Луга и кустарники

$\square$ Непокрытые

растительностьо земли

Водно-болотные угодья

$\square$ Дороги

Рис. 7. Карта прогноза состояния лесных угодий по категориям в заповеднике Донг Най к 2035 г.

Таблица 7 поведника продолжается. Площадь широко-

Прогноз площадей категорий растительного покрова лесных угодий в заповеднике Донг Най к 2035 г.

\begin{tabular}{|l|c|c|}
\hline \multicolumn{1}{|c|}{$\begin{array}{c}\text { Категории покрова } \\
\text { лесных угодий }\end{array}$} & га & \% \\
\hline Широколиственные леса & 64783,7 & 94,8 \\
\hline Луга и кустарники & 2634,6 & 3,9 \\
\hline $\begin{array}{l}\text { Не покрытые раститель- } \\
\text { ностью земли }\end{array}$ & 116,6 & 0,2 \\
\hline Водно-болотные угодья & 510,1 & 0,7 \\
\hline Дороги & 258,2 & 0,4 \\
\hline Итого & 68303,3 & 100,0 \\
\hline
\end{tabular}

Результаты прогнозирования показывают, что тенденция увеличения площади лесов за- лиственных лесов к 2035 году увеличится на 4 182,7 га (6,1\%), водно-болотных угодий - на 324,2 га (0,5 \%). Площади лесных угодий: луга и кустарник, не покрытые растительностью земли уменьшатся на 4 506,90 га (6,6 \%). Площади лесных угодий к концу периода прогнозирования составят следующие соотношения: широколиственных лесов достигнут 64 783,7 га $(94,8 \%)$, лугов и кустарников - 2 634,6 га $(3,9 \%)$, не покрытых растительностью земель 116,6 га $(0,2 \%)$, водно-болотных угодий 510,1 га (0,7 \%), дорог - 258,2 (0,4 \%). Полученные при прогнозировании площади лесных угодий свидетельствуют об увеличении в заповеднике Донг Най широколиственных высокополнотных древостоев.

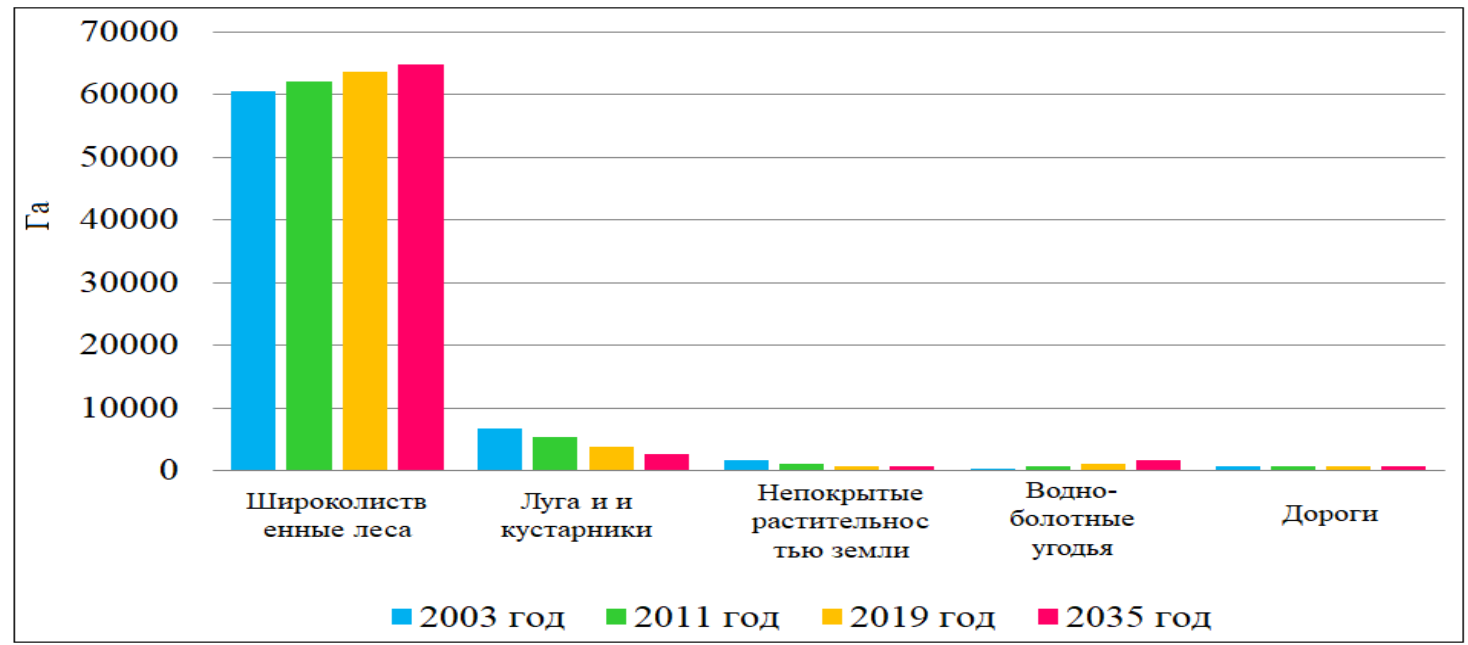

Рис. 8. Динамика площадей категорий растительного покрова лесных угодий в заповеднике Донг Най по категориям в 2003, 2011, 2019 гг. и прогноз к 2035 г. 


\section{Заключение}

Многолетние исследования с 2003 по 2019 г. земельных угодий заповедника Донг Най Вьетнама показали, что на них преобладает естественный широколиственный лес, но отмечена тенденция изменения состояния всех других категорий растительности. Динамика площадей широколиственных лесов, лугов и кустарников, не покрытых растительностью земель, водно-болотных угодий и дорог составляет соответственно 4,5, 4,3, $0,5,0,3$ и $0 \%$. За 16 лет наблюдений площадь широколиственных лесов заповедника увеличилась на 3092,0 га $(4,5 \%)$, водноболотных угодий - 188,1 га $(0,3 \%)$, соответ- ственно сократились площади других категорий лесных угодий. Согласно прогнозной модели, разработанной нами, если политика Правительства Вьетнама относительно ООПТ в отношении заповедника Донг Най, будет направлена на охрану окружающей среды и совершенствование управления земельными ресурсами, то площади лесных экосистем к 2035 г. будут возрастать. Это будет способствовать сохранению и даже увеличению биоразнообразия лесных экосистем заповедника Донг Най, в частности, и сохранению окружающей среды в юговосточном регионе Вьетнама, в целом.

\section{БИБЛИОГРАФИЧЕСКИЙ СПИСОК}

1. Нгуен Ван Тхинь. Биоразнообразие и свойства почв биосферного заповедника Донгнай : дис. ... канд. биол. наук. - Ростов-н/Д. : РГУ, 2015. - $170 \mathrm{c}$.

2. Dang Viet Hung, Potokin A. F. Diversity of plant species composition and forest vegetation cover of Dong Nai Culture and Nature Reseve, Vietnam // Earth and Environmental Science. 2019. - I. 316. - P. 1-9.

3. Hunting and Collecting Practices in the Central Truong Son Landscape / Le Trong Trai, Dang Thang Long, Phan Thanh Ha, Le Ngoc Tuan // Central Truong Son Initiative Report. - 2003. - No. 7. - 32 p.

4. Groombridge B., Jenkins M. D. Global biodiversity: earth's living resources in the 21st century. Cambridge, World Conservation Press, 2000. - 254 p.

5. Отчет по земельной статистике за 2013 год в заповеднике Донгнай. - Департамент природных ресурсов и окружающей среды провинции Донгнай, 2013. - 12 с.

6. Хлебникова Е. П., Арбузов С. А. Использование геопространственных данных для решения задач мониторинга особо охраняемых природных территорий // Вестник СГУГиТ. - 2020. T. 25, № 1. - С. 96-105.

7. Ковязин В. Ф., Данг Т. Л. А. Мониторинг лесных земель заповедника «Ким Хи» Вьетнама с использованием ГИС-технологий // Астраханский вестник экологического образования. 2019. - № 3. - C. 95-102.

8. Monitoring vegetation systems in the Great Plains with ERTS / J. W. Rouse, R. H. Haas, J. A. Schell, D. W. Deering // Third Earth Resources Technology Satellite-1 Syposium, NASA SP-351, NASA. - 1974. - Vol. 1 - P. 309-317.
9. Жолобов Д. А., Баев А. В. Уточнение значений нормализованного вегетативного индекса (NDVI) методом наложения транспирационной маски // Инновации в науке : сб. статей по матер. XLV междунар. науч.-практ. конф. - Новосибирск : СибАК, 2015. - № 5 (42). - С. 164-185.

10. Congalton R. G., Oderwald R. G., Mead R. A. Assessing landsat classification accuracy using descrete multivariate analysis statistical techniques // Photogrammetry Engineering and Remote Sensing. - 1983. - Vol. 49, No. 12. - P. 1671-1678.

11. Ковязин В. Ф., Нгуен Т. С. Разработка прогнозной модели трансформации земельных угодий Вьетнама // Изв. Томского политехнического университета. Инжиниринг георесурсов. 2019. - T. 330, № 9. - C. 221-229.

12. Simulation of land use spatial pattern of towns and villages based on CA-Markov model / L. Sang, C. Zhang, J. Yang, D. Zhu, W. Yun // Mathematical and Computer Modelling. - 2011.- Vol. 54. P. 938-943.

13. Liping C., Yujun S., Saeed S. Monitoring and predicting land use and land cover changes using remote sensing and GIS techniques - A case study of a hilly area, Jiangle, China // PLOS ONE. 2018. - Vol. 13 (7). - P. 1-23.

14. Toward a sustainable city of tomorrow: a hybrid Markov-Cellular Automata modeling for urban landscape evolution in the Hanoi city (Vietnam) during 1990-2030 / T. A. Nguyen, P. M. T. Le, T. M. Pham et. al. // Environ Dev Sustain - 2019. - Vol. 21. - P. 429-446.

15. Praveen Subedi, Kabiraj Subedi, Bina Thapa. Application of a Hybrid Cellular Automaton - Markov (CA-Markov) Model in Land-Use Change Pre- 
diction: A Case Study of Saddle Creek Drainage Basin, Florida // Applied Ecology and Environmental Sciences. - 2013. - Vol. 1(6). - P. 126-132.

16. GIS based land suitability assessment for tobacco production using AHP and fuzzy set in Shandong province of China / J. Zhang, Y. Su, J. Wu, H. Liang // Comput. Electron. Agric. - 2015. - Vol. 114. - P. 202-211.

17. Marcel Török-Oance, Dorel Micle. Digital terrain analysis as a tool for the identification of possible areas with rural post - Roman archaeological sites in the S-W Dacia // Annales d'Universite 'Valahia' Targoviste, Section d'Archeologie et d'Histoire. 2010. - Vol. 2. - P. 139-147.

18. Modelling of Land Use Land Cover Change using Earth Observation Datasets of Tons River Basin, Madhya Pradesh, India / Sudhir Kumar Singh, Prosper Basommi Laari, Sk. Mustak, Prashant K. Srivastavad, Szilárd Szabó // Geocarto International 2017. - P. 1-21.

19. Wang S., Zhang Z., Wang X. Land use change and prediction in the Baimahe Basin using GIS and CA-Markov model // IOP Conf. Ser. Earth Environ. Sci. - 2014. - 17 p.

20. Ozturk D. Urban Growth Simulation of Atakum (Samsun, Turkey) Using Cellular AutomataMarkov Chain and Multi-Layer Perceptron-Markov Chain Models // RemoteSens. - 2015. - Vol. 7 (5). P. 5918-5950.

Получено 22.04.2020
21. Dynamic simulation of land use change in Jihe watershed based on CA-Markov model / W. Yousheng, Y. Xinxiao, H. Kangning, L. Qingyun, Z. Yousong, S. Siming // Transactions of the Chinese Society of Agricultural Engineering. 2011. - Vol. 27 (12). - P. 330-336.

22. Фон Нейман Дж. Теория самовоспроизводящихся автоматов. - М. : Мир, 1971. - 326 с.

23. Наумов Л., Шалыто А. Клеточные автоматы. Реализация и эксперименты. - 2003. $15 \mathrm{c}$.

24. Hou X. Y., Chang B., Yu. X. F. Land use change in Hexi corridor based on CA-Markov methods // Transactions of the CSAE. - 2004. - Vol. 20 (5). - P. 286-291.

25. Pontius R. G. Jr. Statistical methods to partition effects of quantity and location during comparison of categorical maps at multiple resolutions // Photogramm Eng Remote Sens. - 2002. Vol. 68(10). - P. 1041-1050.

26. Feinstein A. R., Cicchetti D. V. High agreement but low kappa: I. The problems of two paradoxes // J Clin Epidemiol. - 1990. - Vol. 43 (6). P. 543-549.

27. Azizi A., Malakmohamadi B., Jafari H. R. Land use and land cover spatiotemporal dynamic pattern and predicting changes using integrated CA-Markov model // Global J. Environ. Sci. Manage. - 2016. - Vol. 2 (3). - P. 223-234.

(C) В. Ф. Ковязин, Данг Тхи Лан Ань, Данг Вьет Хунг, 2020

\section{PREDICTING FOREST LAND COVER CHANGES OF DONG NAI RESERVE, VIETNAM}

\section{Vasiliy F. Kovyazin}

Saint-Petersburg Mining University, 2, Vasilyevsky Island, 21 line, St. Petersburg, 199106, Russia, D. Sc., Professor, Department of Engineering Geodesy, phone: (911)954-26-89, e-mail: vfkedr@mail.ru

\section{Dang Thi Lan Anh}

Saint-Petersburg Mining University, 2, Vasilyevsky Island, 21 line, St. Petersburg, 199106, Russia, Ph. D. Student, Department of Engineering Geodesy, phone: (961)807-21-49, e-mail: lananhvfu2@mail.com

\section{Dang Viet Hung}

Vietnam National University of Forestry-Dong Nai Campus, 54, Tran Phu St., Trang Bom, Dong Nai, 810000, Vietnam, Ph. D. Student, Department of Forest Plant, phone: (962)708-27-30, e-mail: viethungvfu@gmail.com

The study was conducted in Dong Nai Reserve, specially protected natural area (SPNA), Vietnam. It aims to analyze and forecast forest land cover in the Reserve. For these purposes were studied satellite images (Landsat 5, Landsat 7 and Landsat 8) taken in 2003, 2011 and 2019. The Normalized Difference Vegetation Index (NDVI) was used to identify vegetation quality. Forest land cover was divided into 5 categories using maximum likelihood classifier algorithm. In order to detect and evaluate forest land cover changes, supervised classification and image differencing method are applied. Then, Cellular Automata and Markov 
Chain model was employed for making forecast of forest land cover in this area. The results of the study indicate that forest land cover change is being transformed in Dong Nai Reserve. According to our estimation, from 2003 to 2019, the area covered by woody vegetation increased by $7.0 \%$. By 2035, the area of broadleaved forests will increase by $1.6 \%$, due to a decrease in areas of meadows and shrubs. The dynamics of increasing forest land is explained by the measures taken by the Vietnamese government to expand the area of forests in SPNA.

Key words: Dong Nai nature reserve, forest land, vegetation cover, satellite images, Markov chains.

\section{REFERENCES}

1. Nguyen Van Thinh. (2015). Biodiversity and soil properties Dong Naibiosphere reserve. Candidate's thesis. Rostov-on-don [in Russian].

2. Dang Viet Hung, \& Potokin, A. F. (2019). Diversity of plant species composition and forest vegetation cover of Dong Nai Culture and Nature Reseve, Vietnam. Earth and Environmental Science, 316, 1-9.

3. Le Trong Trai, Dang Thang Long, Phan Thanh Ha, \& Le Ngoc Tuan. (2003). Hunting and Collecting Practices in the Central Truong Son Landscape. Central Truong Son Initiative Report, 7 , $32 \mathrm{p}$.

4. Groombridge, B., \& Jenkins, M. D. (2000). Global biodiversity: earth's living resources in the 21 st century. Cambridge, World Conservation Press, $254 \mathrm{p}$.

5. Report on land statistics for 2013 in the Dongnai nature reserve. (2013). Dong Nai Province Department of Natural Resources and Environment, $12 \mathrm{p}$.

6. Hlebnikova E. P., \& Arbuzov S. A. (2020). Using of geospatial data for solution of tasks of monitoring the specially protected natural territories. Vestnik SGUGiT [Vestnik SSUGT], 25(1), 96-105 [in Russian].

7. Kovyazin, V. F., \& Dang, T. L. A. (2019). Monitoring of forest lands of Kim Hy reserve of Vietnam using GIS Technologies. Astrahanskij vestnik ekologicheskogo obrazovaniya [Astrakhan Bulletin of Environmental Education], 3, 95-102 [in Russian].

8. Rouse, J. W., Haas, R. H., Schell, J. A., \& Deering, D. W. (1974). Monitoring vegetation systems in the Great Plains with ERTS. Third Earth Resources Technology Satellite-1 Symposium. Greenbelt, NASA SP-351, 1, 309-317.

9. Zholobov, D. A., \& Baev, A. V. (2015). Refining the values of the normalized vegetative index (NDVI) by applying a transpiration mask. In Sbornik statey XLV mezhdunarodnoy nauchno-prakticheskoy konferentsii: No. 5 (42). Innovatsii v nauke [Proceedings of XLV International Scientific and Practical Conferences: No. 5 (42). Innovations in Science] (pp. 164-185). Novosibirsk: SibAK Publ. [in Russian].

10. Congalton, R. G., Oderwald, R. G., \& Mead, R. A. (1983). Assessing landsat classification accuracy using descrete multivariate analysis statistical techniques. Photogrammetry Engineering and Remote Sensing, 49(12), 1671-1678.

11. Kovyazin, V. F., \& Nguyen, T. X. (2019). Development of a forecast model for the transformation of land in Vietnam. Izvestiya Tomskogo politekhnicheskogo universiteta. Inzhiniring georesursov [News of Tomsk Polytechnic University. Engineering of Georesources], 330(9), 221-229 [in Russian].

12. Sang, L., Zhang, C., Yang, J., Zhu, D., \& Yun, W. (2011). Simulation of land use spatial pattern of towns and villages based on CA-Markov model. Mathematical and Computer Modelling, 54, 938-943.

13. Liping, C., Yujun, S., \& Saeed, S. (2018). Monitoring and predicting land use and land cover changes using remote sensing and GIS techniques A case study of a hilly area, Jiangle, China. PLOS ONE, 13(7), 1-23.

14. Nguyen, T. A., Le, P. M. T., Pham, T. M., $\&$ et al. (2019). Toward a sustainable city of tomorrow: a hybrid Markov-Cellular Automata modeling for urban landscape evolution in the Hanoi city (Vietnam) during 1990 - 2030. Environ Dev Sustain, 21, 429-446.

15. Praveen Subedi, Kabiraj Subedi, \& Bina Thapa (2013). Application of a Hybrid Cellular Automaton - Markov (CA-Markov) Model in LandUse Change Prediction: A Case Study of Saddle Creek Drainage Basin, Florida. Applied Ecology and Environmental Sciences, 1(6), 126-132.

16. Zhang, J., Su, Y., Wu, J., \& Liang, $\mathrm{H}$. (2015). GIS based land suitability assessment for tobacco production using AHP and fuzzy set in Shandong province of China. Comput. Electron. Agric, 114, 202-211.

17. Marcel Török-Oance, \& Dorel Micle. (2010). Digital terrain analysis as a tool for the identification of possible areas with rural post - Roman archaeological sites in the S-W Dacia. Annales $d^{\prime} U$ - 
niversite 'Valahia' Targoviste, Section d'Archeologie et d'Histoire, 2, 139-147.

18. Sudhir Kumar Singh, Prosper Basommi Laari, Sk. Mustak, Prashant K. Srivastavad, \& Szilárd Szabó. (2017). Modelling of Land Use Land Cover Change using Earth Observation Datasets of Tons River Basin, Madhya Pradesh, India. Geocarto International, 1-21.

19. Wang, S., Zhang, Z., \& Wang, X. (2014). Land use change and prediction in the Baimahe Basin using GIS and CA-Markov model. IOP Conf. Ser. Earth Environ. Sci., 17 p.

20. Ozturk, D. (2015). Urban Growth Simulation of Atakum (Samsun, Turkey) Using Cellular Automata-Markov Chain and Multi-Layer PerceptronMarkov Chain Models. Remote Sens., 7, 5918-5950.

21. Yousheng, W., Xinxiao, Y., Kangning, H., Qingyun, L., Yousong, Z., \& Siming, S. (2011). Dynamic simulation of land use change in Jihe watershed based on CA-Markov model. Transactions of the Chinese Society of Agricultural Engineering, 27(12), 330-336.

22. J. von Neumann. (1971). Teoriya samovosproizvodyashchihsya avtomatov [Theory of self- replicating automata]. Moscow: Mir Publ., 326 p. [in Russian].

23. Naumov, L., \& Shalyto, A. (2003). Kletochnye avtomaty. Realizatsiya $i$ eksperimenty [Cellular automata. Implementation and experiments], 15 p. [in Russian].

24. Hou, X. Y., Chang, B., \& Yu, X. F. (2004). Land use change in Hexi corridor based on CAMarkov methods. Transactions of the CSAE, 20(5), 286-291.

25. Pontius, R. G. Jr. (2002). Statistical methods to partition effects of quantity and location during comparison of categorical maps at multiple resolutions. Photogramm. Eng. Remote Sens., 68(10), 1041-1050.

26. Feinstein, A. R., \& Cicchetti, D. V. (1990). High agreement but low kappa: I. The problems of two paradoxes. J Clin Epidemiol, 43(6), 543-549.

27. Azizi, A., Malakmohamadi, B., \& Jafari, H. R. (2016). Land use and land cover spatiotemporal dynamic pattern and predicting changes using integrated CA-Markov model. Global J. Environ. Sci. Manage, 2(3), 223-234.

Received 22.04.2020

(C) V. F. Kovyazin, Dang Thi Lan Anh, Dang Viet Hung, 2020 
УДК 528.91:332.3

DOI: $10.33764 / 2411-1759-2020-25-3-229-240$

\section{ИНФОРМАЦИОННОЕ ОБЕСПЕЧЕНИЕ МЕРОПРИЯТИЙ ПО ВОСПРОИЗВОДСТВУ И ПОВЫШЕНИЮ ЭФФЕКТИВНОСТИ ИСПОЛЬЗОВАНИЯ АГРОЛАНДШАФТОВ}

\section{Елена Вильевна Коцур}

Омский государственный аграрный университет им. П. А. Столыпина (ОмГАУ), 644008, Россия, г. Омск, Институтская площадь, 1, ст. преподаватель, тел. (950)790-14-00, e-mail: ev.kotsur@omgau.org

\section{Алексей Викторович Дубровский}

Сибирский государственный университет геосистем и технологий, 630108, Россия, г. Новосибирск, ул. Плахотного, 10, кандидат технических наук, доцент, тел. (383)344-31-73, e-mail: avd5@ssga.ru

В статье проанализированы причины, сдерживающие увеличение производительности сельского хозяйства. Отмечено, что для стабилизации ситуации необходимо учитывать экологическое состояние агроландшафтов. Проблемой является отсутствие актуальной информации о процессах, протекающих в агроландшафтах. Решением может стать формирование единой ландшафтно-экологической информационной базы, привязанной к цифровым картам с помощью ГИС-технологий. Предложено в проект «Цифровое сельское хозяйство» в качестве модуля подсистемы «Комплексные цифровые решения для АПК» системы обеспечения операционной деятельности и внедрения комплексных цифровых решений внедрить земельную информационную систему (ЗИС) «Устойчивый агроландшафт». Результаты апробации данного модуля показали эффективность его применения и необходимость внедрения в проект, так как это способствует обеспечению графической и атрибутивной БД муниципального уровня управления для целей учета и мониторинга агроландшафтов, информационного обеспечения мероприятий по воспроизводству и повышению эффективности их использования.

Ключевые слова: цифровизация, сельское хозяйство, эффективность использования агроландшафтов, информационное обеспечение, ГИС-технологии.

\section{Введение}

В период проведения цифровизации перед Россией стоит задача увеличения производительности сельского хозяйства в ускоренные сроки. Основными причинами, сдерживающими данный процесс, являются: ослабление экологической устойчивости агроландшафтов; загрязнение и деградация почвенного покрова; понижение урожайности сельскохозяйственных угодий; большие площади невостребованных и неиспользуемых сельскохозяйственных угодий; низкий уровень обоснованного планирования производства сельскохозяйственной продукции с учетом качества земли; отсутствие оптимального распределения капитальных вложений для повышения эффективности использования земли; пониженный уровень внимания со стороны административных органов власти и работников сельскохозяйственного сектора к состоянию почвенного плодородия и т. д. [1-3].
Первопричиной возникновения вышеперечисленных проблем является ослабление экологической устойчивости агроландшафтов, которое влечет за собой загрязнение и деградацию почвенного покрова, следствием чего является понижение урожайности сельскохозяйственных угодий. Пониженный уровень внимания со стороны административных органов власти и работников сельскохозяйственного сектора к состоянию почвенного плодородия и обоснованному планированию производства сельскохозяйственной продукции с учетом качества земли приводит к отсутствию оптимального распределения капитальных вложений для повышения эффективности использования земли. Результатом является увеличение площадей невостребованных и неиспользуемых сельскохозяйственных угодий.

Отсюда следует, что для предотвращения негативных последствий хозяйственной деятельности необходимо учитывать экологическое состояние агроландшафтов, периодиче- 
ски проводить учет и мониторинг, а также мероприятия по воспроизводству и повышению эффективности их использования.

Зачастую отсутствие актуальной информации о количественных, качественных и пространственных характеристиках процессов, протекающих в агроландшафтах, приводит к невозможности избежать данной проблемы [4, 5]. Способствовать этому может ландшафтно-экологическая информационная база, привязанная к цифровым картам. Связать информационную и картографическую базу можно с помощью ГИС-технологий [6, 7], возможности которых представлены на рис. 1.

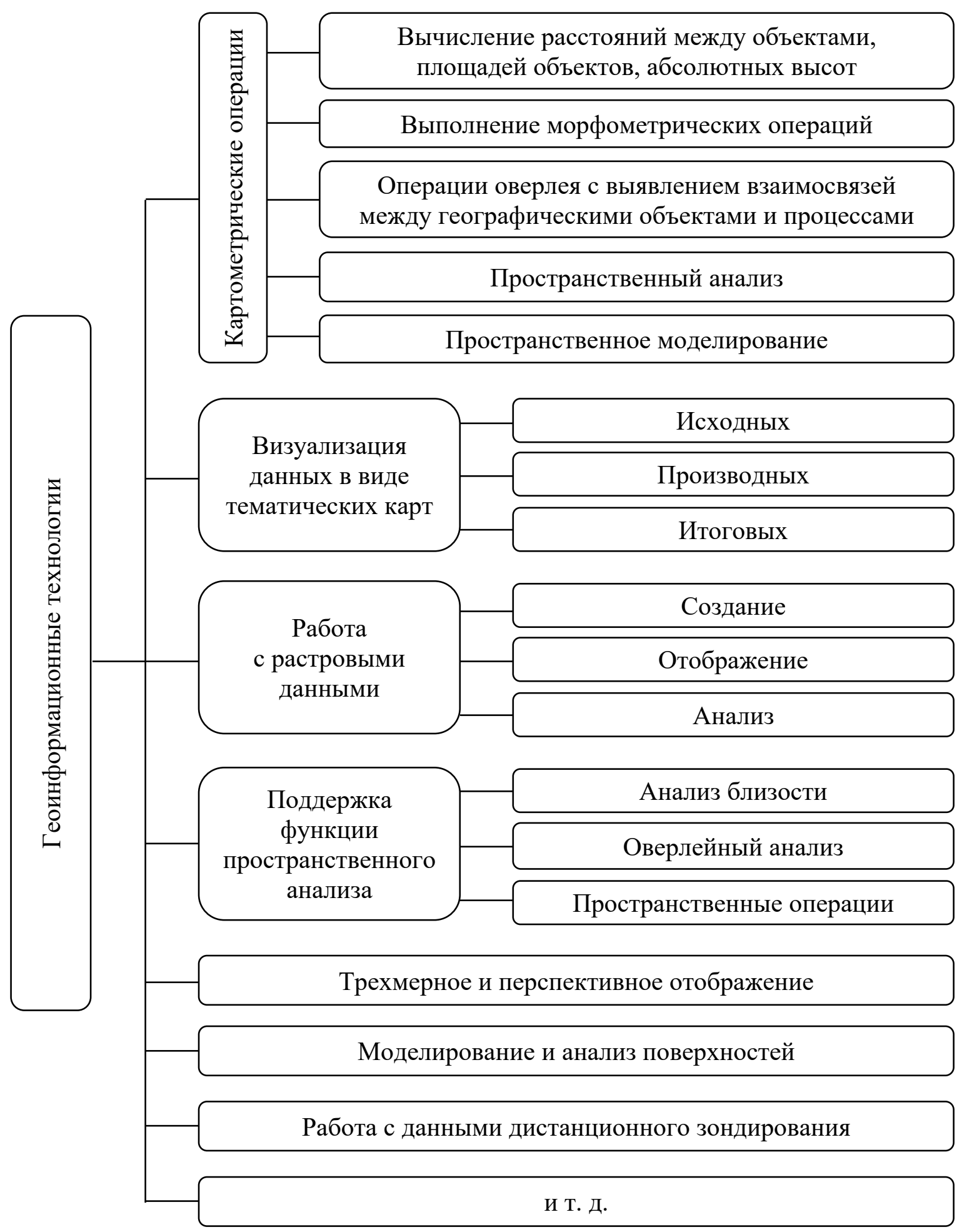

Рис. 1. Возможности ГИС-технологий 
При формировании ландшафтно-экологической информационной базы применение ГИС-технологий значительно ускорит процесс обработки больших объемов информации. В ГИС осуществляется комплексная обработка информации - от ее сбора до хранения, обновления и представления $[8,9]$.

Сбор информации является важным моментом создания картографического материала, но и его визуализация является не менее значимым этапом. Сущность визуализации заключается в том, чтобы сделать невидимые данные видимыми для человека, например, построить геоизображение по цифровой модели местности, хранящейся в цифровом виде на электронном носителе [10]. Форма представления пространственных данных предполагает создание диаграмм, вывод статистических данных, создание картографической продукции и совмещение этих результатов в отчетном проекте. Иногда информацию, созданную в ГИС, достаточно вывести на дисплей монитора в виде цифровой карты «цифровой модели карты» [11].

Так же можно цифровую карту распечатать и представлять в виде графической карты на бумажной, пластиковой или иной основе. Преобразовав цифровое картографическое изображение в растровый формат (растеризация), можно получить электронную карту. Необходимо различать цифровые, графические и электронные карты потому, что в научной, нормативной и производственной литературе часто смешивают эти понятия [11, 12].

Картографическая информация, в том числе ландшафтно-экологическая, очень динамична, варианты ее отображения всегда связаны с перераспределением земель, следовательно, с изменением границ уже сложившихся землепользований. Широкий диапазон и специфика применения земельноресурсной информации определяют основные требования к планово-картографическим материалам. К таким требованиям относятся: целостность и полнота информации; максимальная унификация; компактность и наглядность (хорошая читаемость); точность (детализация) и достоверность; непрерывность обновления и согласованность [13, 14].

ГИС-технологии помогут создать ландшафтно-экологическую информационную базу, необходимую для формирования геоинформационной модели местности (ГММ). ГММ является фундаментом для создания набора различных специализированных карт, которые помогут собственникам земель формировать высокопродуктивные и экономически устойчивые агроландшафты и разрабатывать мероприятия по улучшению плодородия земель. В основе ГММ заложена система показателей, позволяющих наиболее объективно оценить качество земель. К основным относятся почвенные показатели, агроклиматические и орографические условия. ГММ содержит координированную информацию о расположении, форме, размерах и заданных характеристиках географических объектов местности, природных явлений, природных и техногенных процессов и событий, происходящих на рассматриваемой территории.

Она подлежит накоплению, хранению и обновлению в территориальных банках данных [15]. Совокупность информационных координированных компьютерных моделей территории образует геоинформационное пространство [16].

\section{Основная часть}

Аналитическим центром Министерства сельского хозяйства разработана и реализуется Единая федеральная информационная система о землях сельскохозяйственного назначения и землях, используемых или предоставленных для ведения сельского хозяйства в составе земель иных категорий (ЕФИС ЗСН) [17]. В систему вносится информация о возделываемых культурах для каждого поля, указываются наименование и ИНН землепользователя, информация об объектах и сооружениях мелиорации. Система систематизирует результаты агрохимических обследова- 
ний, проводимых учреждениями агрохимической службы Минсельхоза России, обеспечивает автоматическое построение графиков, отображающих структуру севооборота и хода вегетационных индексов, позволяет определять поля с низким уровнем плодородия. В планах расширить функции модуля с применением данных дистанционного зондирования Земли: определения выращиваемых культур, выявления неиспользуемых угодий, оценки степени зарастания угодий древеснокустарниковой растительностью.

Bce вышеперечисленные данные будут отображены в электронном атласе земель сельскохозяйственного назначения (ФГИС ФП АЗСН), что обеспечит свободный доступ сельхозтоваропроизводителям и инвесторам [18]. Недостатком данных систем является то, что они функционируют на обособленных интернет-платформах, которые не имеют функции объединения данных, что приводит к разрозненности данных, получаемых от федеральных агентств и ведомств, отсутствию единого подхода по сбору, накоплению и отображению данных в цифровой среде $[17,19]$.

В настоящее время одним из приоритетных проектов развития сельского хозяйства является ведомственный проект «Цифровое сельское хозяйство», цель которого - цифровая трансформация сельского хозяйства посредством внедрения цифровых технологий и платформенных решений для обеспечения технологического прорыва в АПК и достижения роста производительности труда (рис. 2) [20, 21]. В рамках выполнения проекта предполагается создание единой информационной системы учета сельскохозяйственных земель [22].

В проект «Цифровое сельское хозяйство» в качестве модуля подсистемы «Комплексные цифровые решения для АПК» системы обеспечения операционной деятельности и внедрения комплексных цифровых решений предлагается внедрить ЗИС «Устойчивый агроландшафт» $[17,23]$, инфологическая модель которой представлена на рис. 3.
ЗИС «Устойчивый агроландшафт» предназначена для обеспечения информационной (графической и атрибутивной) базой данных (БД) муниципального уровня управления для целей учета и мониторинга агроландшафтов воспроизводства и повышения эффективности их использования. Характеристика модуля представлена на рис. 4.

Ключевым звеном модуля является схема эколого-хозяйственного зонирования территорий муниципальных районов, формируемая на базе данных карты видов агроландшафтов [24]. Данный картографический материал является результатом проведения эколого-хозяйственного зонирования территорий муниципальных районов по методике авторов статьи [25-27]. Алгоритм создания СЭХЗ с применением информационных технологий представлен на рис. 5.

Создание СЭХЗ начинается с формирования ЦММ с графическими и атрибутивными данными показателей, необходимых для проведения ЭХЗ: населенные пункты, дороги, сельские поселения, геоморфологические зоны, сельхозпроизводители, почвенные разности, несельскохозяйственные угодья, пашня, кормовые угодья. Необходимые для формирования ЦММ исходные материалы представлены на рис. 6.

На основе данной ЦММ формируются две цифровые карты: КВАгр и СЭХЗ. Для формирования КВАгр к уже существующим слоям ЦММ создаются слои необходимые для проведения ЭХЗ. Данная карта служит основой для формирования СЭХЗ. По сути, процесс ее создания является продолжением формирования БД исследуемой территории. Эколого-хозяйственные зоны, как итог всей проделанной работы, представлены на СЭХЗ.

Программным обеспечением ЗИС «Устойчивый агроландшафт» являются ГИС-программы позволяющие создавать полномасштабный картографический материал (MapInfo Professional, ArcGIS и т. д.). В ГИСпрограммах формируются ЦММ, КВАгр и СЭХЗ, БД которых подгружаются в ЗИС «Устойчивый агроландшафт». 


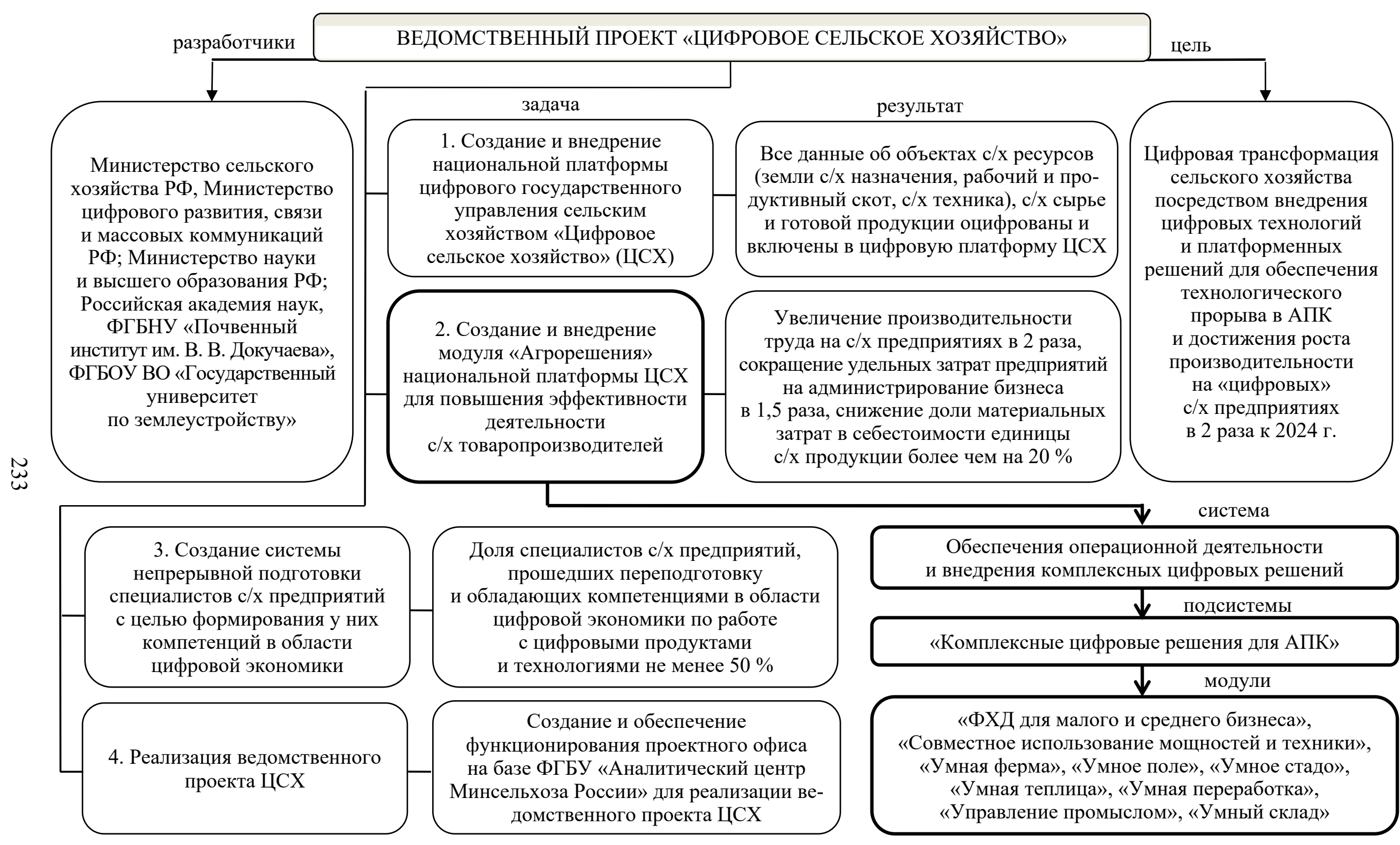

Рис. 2. Проект «Цифровое сельское хозяйство» 
Описание предметной области

\section{ОБЪЕКТЫ содержат:}

ЦММ - графическую и атрибутивную БД по МО, угодьям, сельхозпроизводителям, почвенным разностям, геоморфологическим зонам.

КВАгр - графическую и атрибутивную БД по подклассам и видам агроландшафтов, выделенным в процессе проведения ЭХЗ.

СЭХЗ - графическую и атрибутивную БД

по группам пригодности к использованию под пашню или кормовые угодья, типам агроландшафтов и эколого-хозяйственным зонам, выделенным в процессе проведения ЭХЗ

\section{СВЯЗЬ МЕЖДУ ОБЪЕКТАМИ}

БД ЦММ является основой для КВАгр БД КВАгр является основой для СЭХЗ СЭХЗ содержит всю БД ЭХЗ

\section{ИСХОДНЫЕ ДАННЫЕ}

ЦММ - картографическая основа местности, актуализированная почвенная карта, почвенный очерк, карта эрозии почв, геоморфологическая карта.

КВАгр - ЦММ, результаты классификации агроландшафтов проведенной в рамках ЭХЗ. СЭХЗ - КВАгр, результаты проведения ЭХЗ
Технология формирования объектов

\section{ПРОГРАММНОЕ ОБЕСПЕЧЕНИЕ}

ГИС-программы, позволяющие создавать полномасштабный картографический материал (MapInfo Professional, ArcGIS и т. д.).

В данных программах формируются ЦММ, КВАгр, СЭХЗ, база данных которых подгружается в ЗИС «Устойчивый агроландшафт»

\section{ТЕХНОЛОГИЯ ФОРМИРОВАНИЯ ЦММ}

1.Преобразование графических карт в растровые.

2.Преобразование растровой формы в векторную.

3.Формирование атрибутивной БД

ТЕХНОЛОГИЯ ФОРМИРОВАНИЯ КВАгр

\section{1. БД ЦММ.}

2. Выделение подклассов в границах

геоморфологических зон.

3. Выделение видов агроландшафтов.

4. Формирование атрибутивной БД

\section{ТЕХНОЛОГИЯ ФОРМИРОВАНИЯ СЭХЗ}

\section{1. БД ЦММ и КВАгр.}

2. Объединение видов агроландшафтов

в группы пригодности к использованию.

3. Объединение групп в типы агроландшафтов.

4. Выделение эколого-хозяйственных зон.

5. Формирование атрибутивной БД $\sqrt{4}$

Описание информационных потребностей пользователя

\section{ЦЕЛЬ}

обеспечение графической и атрибутивной БД муниципального уровня управления для целей учета и мониторинга агроландшафтов, воспроизводства и повышения эффективности их использования

ВИД ВЫХОДНЫХ ДАННЫХ

СЭХЗ, КВАгр, ЦММ представлены графической и атрибутивной БД в электронном виде

ФОРМА ПРЕДСТАВЛЕНИЯ

Пользователи имеют ограниченный (визуализированный) доступ к СЭХЗ, КВАгр, ЦММ

\section{СПОСОБ ПРЕДСТАВЛЕНИЯ}

Пользователи просматривают БД ЗИС с помощью информационных элементов (полей данных) и элементов управления данными (набор кнопок на панели инструментов, строки меню, пиктограммы, древовидные списки, переключатели)

Рис. 3. Инфологическая модель ЗИС «Устойчивый агроландшафт»

ЦММ - цифровая модель местности; МО - муниципальный округ; КВАгр - карта видов агроландшафтов; СЭХЗ - схема экологохозяйственного зонирования; ЭХЗ - эколого-хозяйственное зонирование 


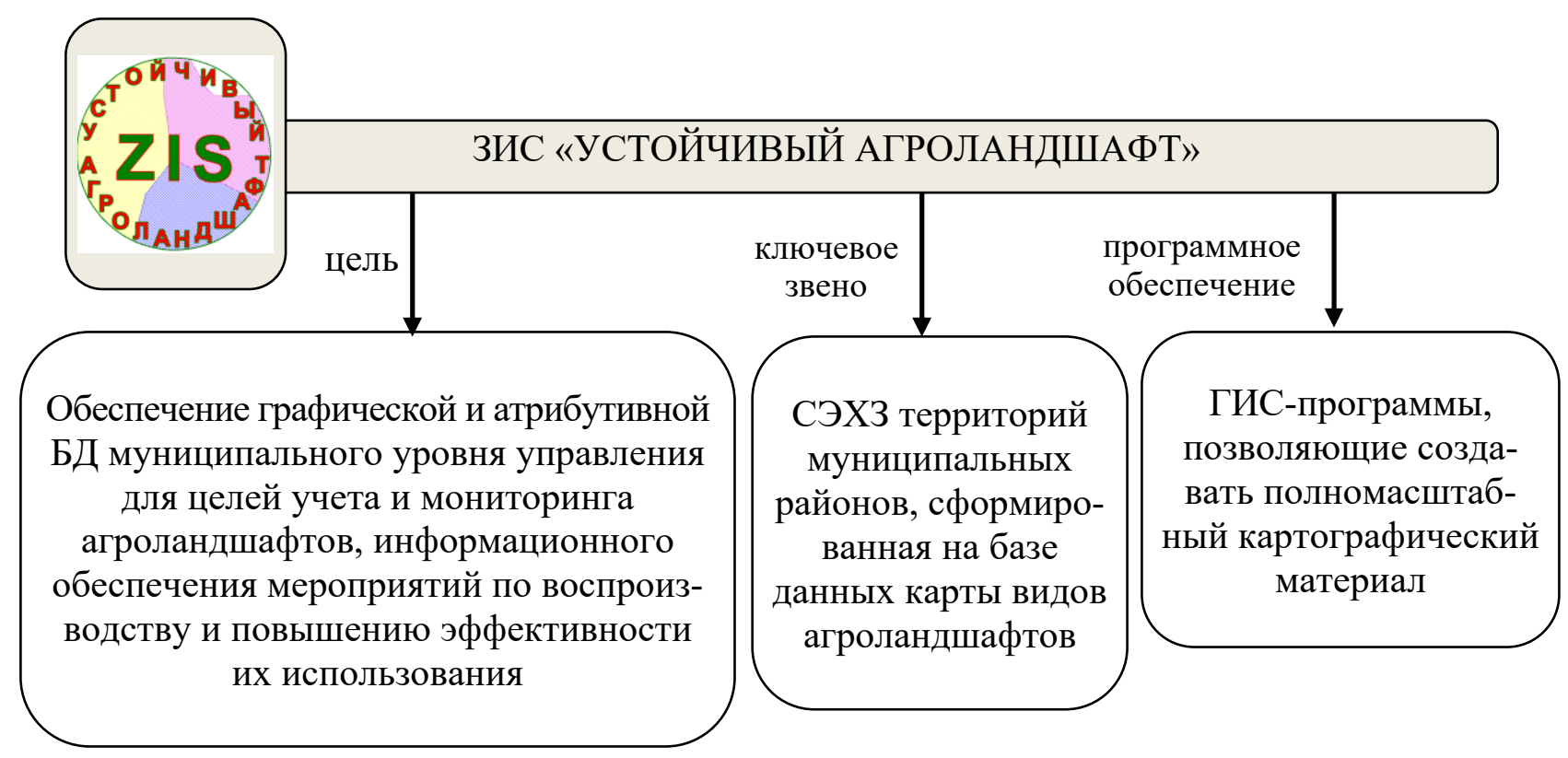

Рис. 4. Характеристика ЗИС «Устойчивый агроландшафт»

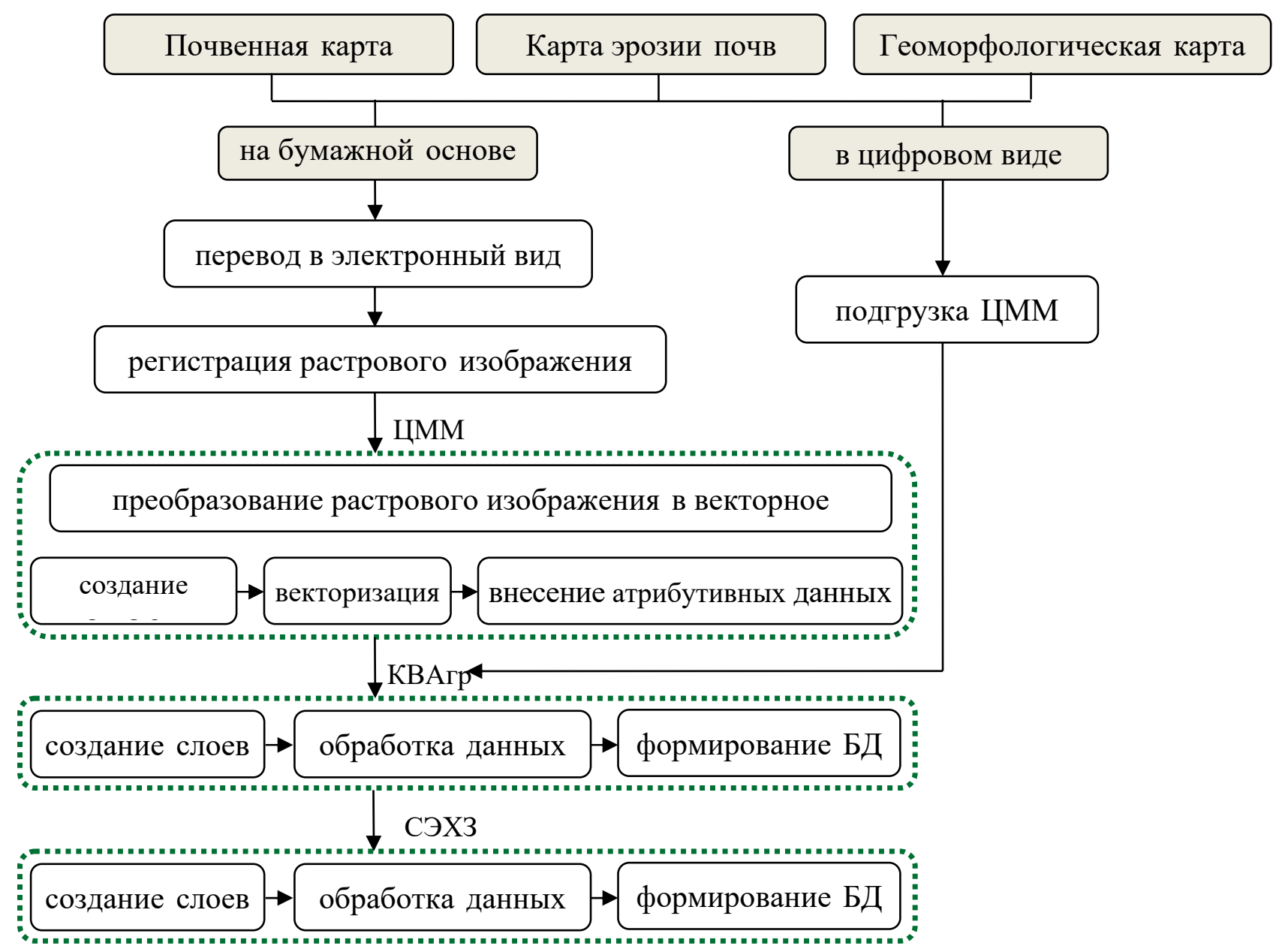

Рис. 5. Алгоритм создания СЭХЗ с применением информационных технологий 


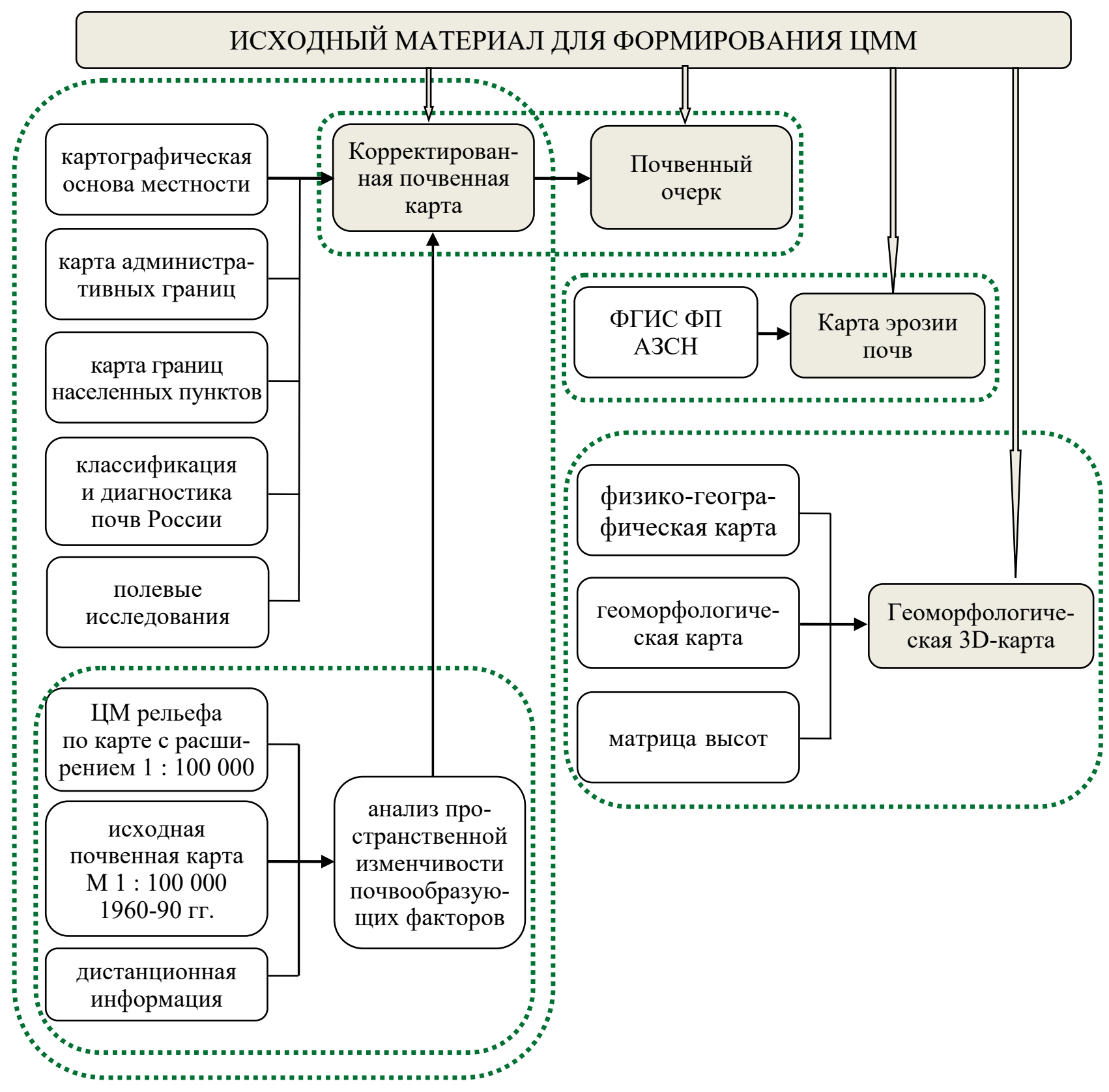

Рис. 6. Исходный материал для формирования ЦММ муниципального района

\section{Заключение}

Результаты апробации ЗИС «Устойчивый агроландшафт», проведенной на территории Павлоградского муниципального района, показали возможность ее применения проектными организациями при разработке плановых и проектных документов по использованию земель для административнотерриториальных образований и хозяйствующих субъектов, а также органами управле- ния в области сельскохозяйственного землепользования [17, 23].

Внедрение модуля ЗИС «Устойчивый агроландшафт» в ведомственный проект «Цифровое сельское хозяйство» позволит обеспечить графической и атрибутивной БД муниципальный уровень управления для целей учета и мониторинга агроландшафтов, информационного обеспечения мероприятий по воспроизводству и повышению эффективности их использования. 


\section{БИБЛИОГРАФИЧЕСКИЙ СПИСОК}

1. Желясков А. Л., Сетуридзе Д. Э. Актуальные проблемы использования сельскохозяйственных угодий и пути их решения // Вестник Курской государственной сельскохозяйственной академии. - 2017. - № 8. - С. 59-64.

2. Рейнгард Я. Р., Махт В. А., Осинцева Н. В. Состояние, использование и охрана почв Омской области : монография. - Омск : М-во сел. хоз-ва Рос. Федерации, ФГОУ ВПО ОмГАУ, 2011. $110 \mathrm{c}$.

3. Рогатнев Ю. М., Долматова О. Н. Эффективное использование земельных ресурсов как основа устойчивого развития сельского хозяйства региона (на материалах Омской области) : монография. - Омск : ОмГАУ, 2017. - 188 с.

4. Долматова О. Н., Рогатнев Ю. М., Щерба В. Н. Электронное картирование полей - основа для принятия управленческих решений сельскохозяйственных товаропроизводителей // Сборник материалов международной научнопрактической конференции, посвященной 70летию экономического факультета. - Омск : ОмГАУ, 2019. - С. 279-287.

5. Environmental and economic problems related to rationalizing the use of agricultural lands in the Irtysh land / I. Khorechko, Y. Rogatnev, M. Veselova, T. Filippova, E. Kotsur // International Journal of GEOMATE. - 2019. - Vol. 17 (61). P. 248-256.

6. Дубровский А. В., Троценко Е. С. Опыт использования геоинформационных технологий при проектировании систем адаптивноландшафтного земледелия на территорию $\mathrm{HCO} / /$ Интерэкспо ГЕО-Сибирь-2012. VIII Междунар. науч. конгр. : Междунар. науч. конф. «Экономическое развитие Сибири и Дальнего Востока. Экономика природопользования, землеустройство, лесоустройство, управление недвижимостью» : сб. материалов в 4 т. (Новосибирск, 10-20 апреля 2012 г.). - Новосибирск : СГГА, 2012. Т. 3. C. 64-68.

7. Дубровский А. В., Ершов А. В., Малыгина О. И. Элементы современного геоинформационно-картографического обеспечения для управления муниципальными образованиями // Актуальные вопросы образования. Ведущая роль современного университета в технологической и кадровой модернизации российской экономики : сб. материалов Междунар. науч.-метод. конф. в 3 ч. (Новосибирск, 16-20 февраля 2015 г.). - Новосибирск : СГУГиТ, 2015. Ч. 2. - С. 22-27.

8. Долматова О. Н., Гилева Л. Н., Коцур Е. В. Географические и земельно-информационные системы : учеб. пособие. - Омск : ОмГАУ, 2013. - $148 \mathrm{c}$.

9. Дубровский А. В. Геоинформационные системы: управление и навигация : учеб.- метод. пособие. - Новосибирск : СГГА, 2013. - 96 с.

10. Лисицкий Д. В., Бугаков П. Ю. Картографическая визуализация трехмерных моделей местности // Вестник СГГА. - 2011. - Вып. 3 (16). C. $81-87$.

11. Карпик А. П. Методологические и технологические основы геоинформационного обеспечения территорий : монография. - Новосибирск : СГГА, 2004. - 260 c.

12. Лисицкий Д. В. Общность и различие понятий «цифровая модель местности», «цифровая карта» и «электронная карта» // Современные проблемы геодезии и оптики. LI научно-техн. конф., 16-19 апр. 2001 г. : тез. докл. - Новосибирск : СГГА, 2001. - С. 143-144.

13. Лебедев П. П., Сизов А. П., Донцов А. В. Карты в системе мониторинга земель (СМЗ) // Московский экономический журнал. - 2018. № 5 (1). - С. 66-75.

14. Кочергина 3. Ф. Ландшафтноэкологические основы рационализации землепользования (на материалах лесостепной зоны Омской области) : монография. - Омск : ОмГАУ, 2007. - 224 c.

15. Лисицкий Д. В., Кацко С. Ю. Назначение и особенности цифрового картографического изображения в геоинформационном картографировании // ГЕО-Сибирь-2005. Науч. конгр. : сб. материалов в 7 т. (Новосибирск, 25-29 апреля 2005 г.). - Новосибирск : СГГА, 2005. Т. 4. C. $23-28$.

16. Лисицкий Д. В., Кацко С. Ю. Концепция создания и функционирования геоинформационного пространства // Интерэкспо ГЕО-Сибирь2013. IX Междунар. науч. конгр. : Пленарное заседание : сб. материалов в 2 т. (Новосибирск, 15-26 апреля 2013 г.). - Новосибирск: СГГА, 2013. T. 2. - C. $72-75$.

17. GIS as a tool for creating a global geographic information platform for digital transformation of agriculture / E. V. Kotsur, M. N. Veselova, A. V. Dubrovskiy, V. N. Moskvin, Yu. S. Yusov // Conference on Applied Physics, Information Technologies and Engineering. Journal of Physics: Conference Series. - 2019. - Vol. 1399. Doi: 10.1088/1742-6596/1399/3/033009.

18. Мониторинг земель сельскохозяйственного назначения: состояние и проблемы [Элек- 
тронный pecypc]. - Режим доступа: https://cutt.ly/HrQswKP.

19. Геоинформационные проекты землеустройства сельскохозяйственных предприятий как основа цифровизации сельского хозяйства / В. В. Вершинин, Т. Н. Ковалева, М. М. Демидова, П. П. Лебедев // Московский экономический журнал. - 2018. - № 5 (1). - С. 16-27.

20. Ведомственный проект «Цифровое сельское хозяйство» [Электронный ресурс]. - Режим доступа: https://wdco.ru/TAMlo.

21. Ведомственный проект «Цифровое сельское хозяйство» Минсельхоза России [Электронный pecypc]. - Режим доступа: https://clck.ru/M4S97.

22. Долматова О. Н., Щерба В. Н. ГИСтехнологии в области управления землями сельскохозяйственного назначения // Сборник материалов международной научно-практической конференции, посвященной 70-летию экономического факультета. - Омск : ОмГАУ, 2019. C. $288-293$.

23. Kotsur E., Kapitulina N., Yusova Y. Creation and use of the module "Sustainable agrolandscape» in the framework of the digital transformation of agriculture // International Scientific and Practical Conference «Digitization of Agriculture Development Strategy» (ISPC 2019) / Advances in Intelligent Systems Research. - Atlantis Press, 2019. Vol. 167. - P. 93-97.

24. Коцур Е. В., Веселова М. Н. Применение ГИС Mapinfo Professional при создании карты агроландшафтов (на примере Павлоградского района Омской области) // Вестник Омского государственного аграрного университета. - 2016. № 2 (22). - C. 121-127.

25. Коцур Е. В., Веселова М. Н. Экологохозяйственное зонирование агроландшафтов Павлоградского муниципального района Омской области // Ом. науч. вестн. - 2015. - С. 186-190.

26. Коцур Е. В., Кочергина 3. Ф. Применение эколого-хозяйственного зонирования и типизации земель для детального учета природных особенностей агроландшафтов // Реализация государственной программы развития сельского хозяйства и регулирование рынков сельскохозяйственной продукции, сырья и продовольствия: инновации, проблемы, перспективы : материалы второго Междунар. науч.-техн. форума (27-29 марта 2013 г.). - Омск : ОмГАУ, 2013. - C. 291-294.

27. Коцур Е. В., Веселова М. Н. Конструирование высокопродуктивных и экологически устойчивых агроландшафтов юга Омской области (на примере Павлоградского муниципального района Омской области) // Сборник докладов III Международного конкурса научно-исследовательских работ (29 апреля 2016 года). Том III (Естественные и технические науки) / Научный ред. д.э.н., проф. А. В. Гумеров. - Казань : ООО «Рокета Союз», 2016.

Получено 03.06.2020

(C) E. В. Кочур, А. В. Дубровский, 2020

\section{INFORMATION SUPPORT FOR MEASURES FOR RECREATION AND IMPROVEMENT OF AGRICULTURAL LANDSCAPES USAGE}

\section{Elena $V$. Kotsur}

Omsk State Agrarian University named after P. A. Stolypin (OmGAU), 1, Institutskaya Square, Omsk, 644008, Russia, Senior Lecturer, Department of Land Management, phone: (950)790-14-00, e-mail: ev.kotsur@omgau.org

\section{Alexey V. Dubrovsky}

Siberian State University of Geosystems and Technologies, 10, Plakhotnogo St., Novosibirsk, 630108, Russia, Ph. D., Head of the Department of Cadastre and Territorial Planning, phone: (383)361-01-09, e-mail: avd5@ssga.ru

The article analyzes the reasons constraining productivity increase of agriculture. It is noted that to stabilize the situation it is necessary to take into account ecological condition of the landscapes. The main problem is the absence of actual information about processes taking place in landscapes. The solution of this problem can be the formation of unified landscape - ecological information base linked to digital maps with the help of GIS - technologies. It is suggested to apply LIS "Stable landscape" in project "Digital agricul- 
ture" as a subsystem module of "Complex digital solutions for agroindustrial complex" support system of operating activities and implementation of complex digital solutions. Testing results of this module showed the effectiveness of its usage and the need for implementation in the project as it helps providing graphic and attributive BD municipal level of management for the record and monitoring of landscapes, information support of reproduction measures and increasing the productivity usage.

Key words: digitalization, agriculture, efficiency of landscapes usage, information support, GIStechnologies.

\section{REFERENCES}

1. Zhelyaskov, A. L., \& Seturidze, D. E. (2017). Actual problems of agricultural lands usage and solutions. Vestnik Kurskoy gosudarstvennoy sel'skokhozyaystvennoy akademii [Vestnik of Kursk State Agricultural Academy], 8, 59-64 [in Russian].

2. Reinhard, Ya. R., Makht, V. A., \& Osintseva, N. V. (2011). Sostoyanie, ispol'zovanie i okhrana pochv Omskoy oblasti [State, use and protection of soils of the Omsk region]. Omsk: Ministry of Agriculture of the Russian Federation, Omsk State Agrarian University Publ., 110 p. [in Russian].

3. Rogatnev, Yu. M., \& Dolmatova, O. N. (2017). Effektivnoe ispol'zovanie zemel'nykh resursov kak osnova ustoychivogo razvitiya sel'skogo khozyaystva regiona (na materialakh Omskoy oblasti) [Efficient use of land resources as the basis for sustainable development of agriculture in the region (based on materials from the Omsk region)]. Omsk: Omsk State Agrarian University Publ., 188 p. [in Russian].

4. Dolmatova, O. N., Rogatnev, Yu. M., \& Sherba, V. N. (2019). Electronic mapping of the fields - the basis of making management decisions of agricultural commodity producers. In Sbornik materialov mezhdunarodnoy nauchno-prakticheskoy konferentsii, posvyashchennoy 70-letiyu ekonomicheskogo fakul'teta [Proceedings of International Scientific and Practical Conference, devoted to the $70^{\text {th }}$ Anniversary of Economy Faculty] (pp. 279-287). Omsk: Omsk State Agrarian University Publ. [in Russian].

5. Khorechko, I. V., Rogatnev, Y. M., Veselova, M. N., Filippova, T. A., \& Kotsur, E. V. (2019). Environmental and economic problems related to rationalizing the use of agricultural lands in the Irtysh land. International Journal of GEOMATE, 17(61), 248-256.

6. Dubrovsky, A. V., \& Trotsenko, E. S. (2012). The experience of geoinformation technologies usage for projecting of adaptive landscape arable farming use on the territory of NSO. In Sbornik materialov Interekspo GEO-Sibir'-2012: Mezhdunarodnoy nauchnoy konferentsii: T. 3. Ekonomicheskoe razvitie Sibiri i Dal'nego Vostoka. Ekonomika prirodopol'zovaniia, zemleustroistvo, lesoustroistvo, upravlenii e nedvizhimost'iu [Proceedings of Interexpo GEO-Siberia-2012: International Scientific Conference: Vol. 3. Economic Development of Siberia and the Far East. Enviromental Economics, Land Management, Forestry Management and Property Management] (pp. 64-68). Novosibirsk: SSGA Publ. [in Russian].

7. Dubrovsky, A. V., Ershov, A. V., \& Malygina, O. I. (2015). The elements of modern geoinformation cartographic support for management of municipality. In Sbornik materialov Mezhdunarodnoy nauchno-metodicheskoy konferentsii: ch. 2. Aktual'nye voprosy obrazovaniya. Vedushchaya rol' sovremennogo universiteta $v$ tekhnologicheskoy $i$ kadrovoy modernizatsii rossiyskoy ekonomiki [Proceedings of International Scientific and Practical Conference: Part 2. Actual Education Problems. The Main Role of Modern University in Technological and Personnel Modernization of the Russian Economy] (pp. 22-27). Novosibirsk: SSUGT Publ. [in Russian].

8. Dolmatova, O. N., Gileva, L. N., \& Kotsur, E. V. (2013). Geograficheskie $i$ zemel'noinformatsionnye sistemy [Geographic and land information system]. Omsk: Omsk State Agrarian University named after P. A. Stolypin, 148 p. [in Russian].

9. Dubrovsky, A. V. (2013). Geoinformatsionnye sistemy: upravlenie $i$ navigatsiya [Geoinformation systems: management and navigation]. Novosibirsk: SSGA Publ., 96 p. [in Russian]

10. Lisitsky, D. V., \& Bugakov, P. Yu. (2011). Cartographic visualization of three-dimensional terrain models. Vestnik SGGA [Vestnik SSGA], 3(16), 81-87 [in Russian].

11. Karpik, A. P. (2004). Metodologicheskie $i$ tekhnologicheskie osnovy geoinformatsionnogo obespecheniya territoriy [Methodological and technological basis of geoinformation support of the territories]. Novosibirsk: SSGA Publ., 260 p. [in Russian].

12. Lisitsky, D. V. (2001). Commonality and difference of the meanings "digital model of the territory", "digital card" and "electronic card". In Tezisy dokladov LI nauchno-tekhnicheskoy konferentsii: 
Sovremennye problemy geodezii i optiki [Abstracts of II Scientific Technical Conference: Modern Problems of Geodesy and Optics] (pp. 143-144). Novosibirsk: SSGA Publ. [in Russian].

13. Lebedev, P. P., Sizov, A. P., \& Dontsov, A. V. (2018). Maps in monitoring land system (SML). Moskovskiy ekonomicheskiy zhurnal [Moscow Economic Journal], 5(1), 66-75 [in Russian].

14. Kochergina, Z. F. (2007). Landshaftnoekologicheskie osnovy ratsionalizatsii zemlepol'zovaniya (na materialakh lesostepnoy zony Omskoy oblasti) [Landscape ecological basis of rational land use (on the material of forest-steppe zone of Omsk region)]. Omsk: Omsk State Agrarian University named after P. A. Stolypin, 224 p. [in Russian].

15. Lisitsky, D. V., \& Katsko, S. Yu. (2005). Purpose and features of digital cartographic picture in geoinformation cartography. In Sbornik materialov GEO-Sibir'-2005: T. 4 [Proceedings of GEOSiberia-2005: Vol. 4] (pp. 23-28). Novosibirsk: SSGA Publ. [in Russian].

16. Lisitsky, D. V., \& Katsko, S. Yu. (2013). The concept of creation and functioning of geoinformation space. In Sbornik materialov Interekspo GEO-Sibir'-2013: T. 2. Plenarnoe zasedanie [Proceedings of Interexpo GEO-Siberia-2013: Vol. 2. Plenary Session] (pp. 72-75). Novosibirsk: SSGA Publ. [in Russian].

17. Kotsur, E. V., Veselova, M. N., Dubrovsky, A. V., Moskvin, V. N., \& Yusova, Yu. S. (2019). GIS as a tool for creating a global geographic information platform for digital transformation of agriculture. Conference on Applied Physics, Information Technologies and Engineerin. Journal of Physics: Conference Series, 1399. doi:10.1088/17426596/1399/3/033009.

18. Monitoring of agricultural lands: condition and problems. (n. d.). Retrieved from https://cutt.ly/HrQswKP [in Russian].

19. Vershinin, V. V., Kovaleva, T. N., Demidova, M. M., \& Lebedev, P. P. (2018). Geoinformation projects of land use planning of agricultural enterprises as a basis of digitalization of agriculture. Moskovskiy ekonomicheskiy zhurnal [Moscow Economic Journal], 5(1), 16-27 [in Russian].

20. Departmental project "Digital agriculture". Retrieved from https://wdco.ru/TAMlo [in Russian].

21. Departmental project "Digital agriculture" Ministry of Agriculture of Russia. Retrieved from https://clck.ru/M4S97 [in Russian].

22. Dolmatova, O. N., \& Sherba, V. N. GIS technologies in management of agricultural lands. In
Sbornik materialov mezhdunarodnoy nauchnoprakticheskoy konferentsii, posvyashchennoy 70letiyu ekonomicheskogo fakul'teta [Proceedings of International Scientific and Practical Conference, Devoted to the $70^{\text {th }}$ Anniversary of Economy Faculty] (pp. 288-293). Omsk: Omsk State Agrarian University named after P. A. Stolypin [in Russian].

23. Kotsur, E. V., Kapitulina, N. A., \& Yusova, Yu. S. (2019). Creation and use of the module "Sustainable agrolandscape" in the framework of the digital transformation of agriculture. In International Scientific and Practical Conference "Digitization of Agriculture - Development Strategy" (ISPC 2019): Vol. 167. Advances in Intelligent Systems Research (pp. 93-97). Atlantis Press.

24. Kotsur, E. V., \& Veselova, M. N. (2016). Use of GIS MapinfoProfessional in creation of landscapes card (for example of Pavlogradsky district of Omsk region). Vestnik Omskogo gosudarstvennogo agrarnogo universiteta [Vestnik of Omsk State Agrarian University], 2(22), 121-127 [in Russian].

25. Kotsur, E. V., \& Veselova, M. N. (2015). Ecological and economic landscapes zoning of Pavlogradsky municipal district of Omsk region. Omskiy nauchnyy vestnik [Omsk Scientific Bulletin], pp. 186-190 [in Russian].

26. Kotsur, E. V., \& Kochergina, Z. F. (2013). Use of ecological and economic zoning and typing of lands for the detailed accounting of landscapes natural features. In Sbornik materialov vtorogo Mezhdunarodnogo nauchno-tekhnicheskogo Foruma: Realizatsiya gosudarstvennoy programmy razvitiya sel'skogo khozyaystva i regulirovanie rynkov sel'skokhozyaystvennoy produktsii, syr'ya i prodovol'stviya: innovatsii, problemy, perspektivy [Proceedings of the II International Scientific and Technical Forum: Realization of the State Program of Agricultural Development and Regulation of Agricultural Production Markets, Raw Material and Food: Innovation, Problems, Perspectives] (pp. 291-294). Omsk: Omsk State Agrarian University Publ. [in Russian].

27. Kotsur, E. V., \& Veselova, M. N. (2016). Construction of high productive and ecologically stable agrolandscapes of the south of Omsk region (for example of Pavlogradsky district of Omsk region). In Sbornik dokladov III Mezhdunarodnogo konkursa nauchno-issledovatel'skikh rabot: T. III: Estestvennye i tekhnicheskie nauki [Collection of Reports of III International Competition of Scientific Research Works: Vol. III: Natural and Technical Sciences] (294 p.). A. V. Gumerov (Scientific editor). Kazan: OOO "Raketa Soyuz" Publ. [in Russian]. 
УДК 332.3631 .4

DOI: $10.33764 / 2411-1759-2020-25-3-241-250$

\title{
ФОРМИРОВАНИЕ СИСТЕМЫ
}

\section{РАЦИОНАЛЬНОГО СЕЛЬСКОХОЗЯЙСТВЕННОГО ЗЕМЛЕПОЛЬЗОВАНИЯ} НА ОСНОВЕ ТЕОРИИ ВОСПРОИЗВОДСТВА ПОЧВЕННОГО ПЛОДОРОДИЯ

\author{
Юрий Степанович Ларионов \\ Сибирский государственный университет геосистем и технологий, 630108, Россия, г. Новосибирск, \\ ул. Плахотного, 10, доктор сельскохозяйственных наук, профессор кафедры экологии и природополь- \\ зования, тел. (383)361-08-86, e-mail: larionov42@mail.ru
}

\section{Валерий Борисович Жарников}

Сибирский государственный университет геосистем и технологий, 630108, Россия, г. Новосибирск, ул. Плахотного, 10, кандидат технических наук, профессор, директор регионального информационного центра, тел. (383)361-05-66, e-mail: v.b.jarnikov@ssga.ru

\section{Андрей Александрович Стуканов}

Сибирский государственный университет геосистем и технологий, 630108, Россия, г. Новосибирск, ул. Плахотного, 10, аспирант, тел. (383)361-08-86

В статье представлен научно-методический подход к проблеме формирования системы рационального сельскохозяйственного землепользования (РСХ3) с позиций теории воспроизводства почвенного плодородия. Основные методы исследования: системный подход к анализу предметной области, метод теоретического обобщения состояния проблемы. В основу подхода к формированию системы РСХЗ положен алгоритм оценки плодородия почвы, представленный совокупностью признаков, отражающих плодородие почв, используемых в технологических системах земледелия и землепользования, определяемых основными региональными эволюционно- и эколого-генетическими условиями формирования и воспроизводства уровня плодородия данного вида и типа почв. Итоговая оценка уровня плодородия сельскохозяйственных угодий, составляющих основу системы РСХЗ хозяйства, муниципального образования, осуществляется на основе расчета продуктивности - получения среднего значения фактической биомассы на единицу площади по 8-10 наиболее распространенным возделываемым сельскохозяйственным культурам и их смесям (пшеницы, ячменя, овса, ржи, гороха, гречихи, рапса, костреца, люцерны, донника и др.) в конкретной почвенно-климатической зоне. В результате проведенного исследования сформулировано основания и содержание научно-методического подхода к оценке уровня плодородия (прјдуктивности) сельскохозяйственных угодий, а также даны рекомендации по формированию РСХЗ зонального характера на примере Новосибирской области, использование которых дает возможность более надежно использовать (по данным 3-5 лет) растениеводческий потенциал земельного фонда хозяйства, района, региона.

Ключевые слова: почвы, плодородие, урожайность, рациональное землепользование, оценка, результат, биомасса, мониторинг.

\section{Введение}

Важнейшим фактором формирования системы рационального землепользования (РЗП) в сельском хозяйстве является неразрывная связь процесса производства продукции с естественными процессами развития живых организмов в природной среде [1-5]. Погодные риски, обусловленные неблагоприятными явлениями (сильные морозы, ма- лый снежный покров на полях, засухи, пыльные бури, град, наводнения и др.), способны существенно повлиять на урожайность сельскохозяйственных культур, объемы реализации сырья и готовой продукции, серьезно корректировать издержки производства, его прибыль и рентабельность. Поэтому колебания урожайности в регионах России нередко превышают 30-50 \% среднегодовых уровней, а 2-3 года из десяти быва- 
ют неурожайными [6-8]. В этой связи учет факторов влияния внешней среды, глобальный погодный прогноз, особенно в части стихийных явлений, способных нанести колоссальный ущерб растениеводству и другим отраслям сельскохозяйственного производства (СХП), является важнейшим элементом современных систем земледелия, адаптированных к конкретным природноклиматическим условиям ведения хозяйственной деятельности [3, 6, 9-11]. Особую роль в реализации современных задач СХП играют технологии растениеводства, основанные на биоземледелии, минимизирующие техногенные риски современного, ориентированного на масштабные программы применения минеральных удобрений и химических средств защиты культивируемых растений, определившего новый этап производства «зеленой» продукции в системе экологически безопасного природопользования [6, $4,10]$. Исследованию одного из актуальных аспектов стабилизации почвенного плодородия, до настоящего времени все еще малоизученного, в системе биологического (органического) земледелия, посвящена настоящая статья.

\section{Методология исследования}

Современные технологии биоземледелия [4-6] позволяют с большей степенью безопасности реализовать биологическую природу используемых производственных ресурсов в получаемой продукции. Именно здесь оптимизируются сроки и содержание технологических процессов, определяемых природными условиями и биологическими требованиями культур, минимизируются нарушения, усиливающие риск потерь конечной продукции и потенциальных доходов. Биоземледелие на основе биологических требований возделываемой культуры определяет поздний или ранний сев культуры, сорта, глубину заделки семян, за счет сортовой агротехники включаются эволюционные механизмы противодействия болезням и вредителям растений, предусматриваются реальные мероприятия по уборке урожая, условия хранения продукции, учет других прямых и косвенных рисков потери продукции, повышения затрат, снижения прибыли. Следует подчеркнуть, что инновационные методы СХП не исключают, а наоборот, подчеркивают роль человеческого капитала [4, 6, 11-15], особенно ярко проявляющегося в малом и среднем предпринимательстве (МСП), позволяющем в большей степени учесть основные риски СХП, творческие подходы к агротехнике возделывания культуры, включая сезонность работ, сложный подготовительный период, профессиональные требования к субъектам МСП, не всегда достаточную техническую оснащенность хозяйств, территориальную и временную протяженность производства, требуемый технологический контроль, обеспечивающий «зеленые» и экспортные качества продукции.

При этом СХП, особенно растениеводство, обладает сильными компенсационными возможностями, обеспечивающими его эффективность в нормальных условиях и позволяющими снизить его потери в кризисных ситуациях. Залогом этого являются природное, усиленное человеком свойство плодородия почв сельскохозяйственных угодий, обусловливающее их использование в качестве главного средства СХП. В отличие от иных средств производства, подверженных физическому и моральному износу, почвы при правильном их использовании не только не снижают своих продуктивных возможностей, но даже увеличивают их, равно как и стоимость земельных участков, соответствующий рентный доход и постоянный рыночный спрос [6, 13-16]. Сельскохозяйственные угодья в результате получают новые возможности своей трансформации, обеспечивающие систему их регулирования в отношении структуры посевов и их возможных комбинаций, размеров обрабатываемых площадей, обеспечивающих формирование и рациональное использование современных систем землепользования разного уровня в условиях постоянно возрастающей рыночной конъюнктуры [5-7, 17-20].

При этом различные источники рисков (их совокупное воздействие на СХП) могут быть весьма чувствительным при неблаго- 
приятном стечении различных обстоятельств. Частью таких рисков можно управлять непосредственно в хозяйстве, другую часть, находящуюся вне зоны управления, как правило, покрывают программой страхования посевов, актуальным механизмом современной системы сельскохозяйственного производства $[7,8,19,21,22]$. Одновременно указанные риски являются предметом исследований, поскольку именно они способны составить содержание новых технологических решений, особенно в сложно реализуемых сферах деятельности, каковым, в частности, является СХП.

Подобную систему представляют земли сельскохозяйственного назначения Новосибирской области (HCO), на примере которых рассмотрим решение поставленной задачи формирование предпосылок системы РСХЗ в виде научно-методического подхода к оценке плодородия почв на основе ряда их признаков, выделяемых в системе биоземледелия с учетом принципов и закономерностей формирования и воспроизводства почвенного плодородия $[5,8]$.

\section{Результаты и их обсуюждение}

Наиболее существенным фактором повышения адаптационных возможностей сельского хозяйства является применение научнообоснованных биотехнологий возделывания культур $[5,6,8]$, что позволяет существенно снизить последствия неблагоприятных по погодным условиям лет и уменьшить риски резкого падения урожайности. Учитывая результаты научных исследований и практический опыт освоения подобных технологий в хозяйствах, сформулируем основные положения и рекомендации научнометодического характера к формированию зональной системы РСХ3 на примере Новосибирской области [21-24].

Географическое положение и природные условия НСО изначально предполагают особое внимание как к системе биоземледелия в целом, так и к реальным возможностям повышения плодородия почв в частности. Это вызвано существенными затруднениями в развитии СХП, связанными, в том числе, с почвенно-ландшафтными особенностями региона. Так, нередкие здесь эрозия и дефляция почв, их засоленность создают весьма пеструю мозаичность, существенно затрудняющую использование угодий в СХП.

Новосибирская область представляет собой один из наиболее крупных в Западной Сибири сельскохозяйственных регионов. Территория области отличается высокой сельскохозяйственной освоенностью: из общей ее площади 17,776 млн. га на долю сельскохозяйственных угодий приходится почти 7,6 млн. га, из них пашня - около 3 млн. га, а сенокосы и пастбища - более 4 млн. га. Общая сельскохозяйственная освоенность земель достигает 48 \%, по Западной Сибири $33 \%$. Распаханность территории колеблется от 3-10 \% в южнотаежно-лесной подзоне, до $28-56 \%$ - в лесостепи и степи. При этом все почвы, вовлеченные в сельскохозяйственное землепользование, за последние 100 и более лет снизили свое плодородие [4-6, 18]. Это еще раз показывает актуальность наук о Земле, лежащих в основе современного пространственного развития, необходимых технологических решений, в том числе в СХП, разработке и совершенствовании систем земледелия и землепользования. Именно в СХП особенную роль играют принципы, закономерности и условия обеспечения воспроизводства плодородия почв, в том числе их эволюционно- и эколого-генетические принципы формирования и развития $[5,8,10,11]$. Для подтверждения указанного положения используем данные о состояния сельскохозяйственных угодий на разных этапах СХП (табл. 1, 2), представленные Е. Ю. Матвеевой в автореферате кандидатской диссертации «Характеристика пахотного, залежного и целинного чернозема выщелоченного Челябинской области» [25].

Исследования показывают, что накопленный объем общей биофитомассы (органического вещества) в наземных и подземных органах растений (см. табл. 1) зависит от активности использования ее в почве биотой, поэтому ее полный объем частично используется почвенной флорой и фауной. Это следует из данных табл. 1 для анализируемых вариантов: целина, многолетние травы, 
залежь. Тот же результат наблюдается при балансе биогенных элементов (см. табл. 2), причем не только в структуре посевов, но и на целине. Таким образом, для восстановления баланса органического вещества в целом и биогенных элементов в пашне при возделывании зерновых культур необходимо интенсифицировать этот процесс целенаправленным использованием сидератов, пожнивных и поукосных культур, а также органических удобрений. Одновременно, при условии запуска эколого-генетического механизма биоземледелия - дополнительного накопления органического вещества в почве, будет решена важнейшая задача интенсификации процессов минерализации и гумификации (в первую очередь через эдафитные процессы) органического вещества почвы в процессе ее сельскохозяйственного использования. Это серьезный этап и большая работа по совершенствованию (трансформации) современных систем земледелия на основе принципов биоземледелия и закона плодородия почв [4-6,8].

Таблица 1

Накопление и ежегодное поступление фитомассы в почву с учетом ее производственного отчуждения (по данным за 2006-2007 гг.)

\begin{tabular}{|l|c|c|c|c|c|c|c|}
\hline \multirow{2}{*}{$\begin{array}{c}\text { зельстскохон- } \\
\text { угодья }\end{array}$} & \multicolumn{4}{|c|}{ Накопление фитомассы } & \multicolumn{3}{|c|}{ Поступление фитомассы } \\
\cline { 2 - 8 } & $\begin{array}{c}\text { в полях, } \\
\text { влое 0-20 см, } \\
\text { т/га }\end{array}$ & $\begin{array}{c}\text { в наземной } \\
\text { массе, } \\
\text { т/га }\end{array}$ & $\begin{array}{c}\text { в общей } \\
\text { массе, } \\
\text { т/га }\end{array}$ & $\begin{array}{c}\text { в корнях, } \\
\text { \% к общей } \\
\text { массе }\end{array}$ & $\begin{array}{c}\text { в наземной } \\
\text { массе, } \\
\text { т/га }\end{array}$ & $\begin{array}{c}\text { в корнях, } \\
\text { т/га }\end{array}$ & $\begin{array}{c}\text { от общей } \\
\text { массы, } \\
\text { т/га }\end{array}$ \\
\hline Пашня (зерно) & 0,67 & 7,97 & 8,64 & 7,8 & 2,40 & 0,20 & 2,60 \\
\hline Залежь, 1 год & 0,37 & 2,90 & 3,27 & 11,3 & 2,90 & 0,11 & 3,01 \\
\hline Залежь, 6 лет & 2,42 & 6,52 & 8,94 & 27,1 & 5,63 & 0,70 & 6,33 \\
\hline Залежь, 12 лет & 4,80 & 6,22 & 11,02 & 43,6 & 5,12 & 1,40 & 6,52 \\
\hline $\begin{array}{l}\text { Многолетние } \\
\text { труды, 3 года }\end{array}$ & 4,12 & 7,78 & 11,90 & 34,6 & 5,40 & 1,24 & 6,64 \\
\hline $\begin{array}{l}\text { Многолетние } \\
\text { труды, 15 лет }\end{array}$ & 5,64 & 7,43 & 13,07 & 43,2 & 6,12 & 1,70 & 7,82 \\
\hline Целина & 7,73 & 5,67 & 13,10 & 56,7 & 4,36 & 2,20 & 6,56 \\
\hline
\end{tabular}

Таблица 2

Баланс биогенных элементов в фитомассе (лесостепная зона, по данным 2009 г.)

\begin{tabular}{|l|c|c|c|c|c|c|c|}
\hline \multicolumn{1}{|c|}{ Элементы } & $\begin{array}{c}\text { Пашня } \\
\text { (ерновые) }\end{array}$ & $\begin{array}{c}\text { Залежь, } \\
1 \text { год }\end{array}$ & $\begin{array}{c}\text { Залежь, } \\
6 \text { лет }\end{array}$ & $\begin{array}{c}\text { Залежь, } \\
12 \text { лет }\end{array}$ & $\begin{array}{c}\text { Многолетние } \\
\text { травы, 3 года }\end{array}$ & $\begin{array}{c}\text { Многолетние } \\
\text { травы, 15 лет }\end{array}$ & Целина \\
\hline \multicolumn{7}{|c|}{ Синтезировано в фитомассе, кг/га } \\
\hline Азот - N & 111,0 & 21,1 & 86,1 & 169,5 & 303,6 & 282,7 & 245,4 \\
Фосфор - $\mathrm{P}_{2} \mathrm{O}_{5}$ & 11,7 & 2,1 & 8,1 & 11,7 & 28,6 & 15,5 & 20,5 \\
Калий - К20 & 37,8 & 5,1 & 19,1 & 27,3 & 25,9 & 29,9 & 37,2 \\
\hline \multicolumn{7}{|c|}{ В процентах (\%) к синтезированному в фитомассе } \\
\hline Азот - N & 33,4 & 19,5 & 57,1 & 86,4 & 164,2 & 169,8 & 108,6 \\
Фосфор - $\mathrm{P}_{2} \mathrm{O}_{5}$ & 3,5 & 1,8 & 5,3 & 6,1 & 11,1 & 7,8 & 9,8 \\
Калий - К20 & 11,4 & 4,6 & 13,1 & 14,5 & 13,9 & 18,7 & 17,7 \\
\hline \multicolumn{7}{|c|}{ Возврат в почву, кг/га } \\
\hline Азот - N & 30 & 92 & 66 & 51 & 60 & 44 & \\
Фосфор - $\mathrm{P}_{2} \mathrm{O}_{5}$ & 30 & 86 & 65 & 52 & 50 & 48 & \\
Калий - К20 & 30 & 90 & 69 & 53 & 63 & 48 & \\
\hline
\end{tabular}


На рисунке представлены результаты проведенного нами исследования по оценке влияния основных, наиболее часто используемых для анализа урожайности зерновых и зернобобовых культур факторов и показателей почв [3, 9, 10, 19, 22]. В результате установленные коэффициенты корреляции К (рисунок) между урожайностью зерновых культур и типами почв, различающимися по агрохимической оценке плодородия, показывают весьма различную степень влияния последних в условиях НСО.

Полученный вывод может быть обусловлен несколькими причинами, например тем, что урожайность определена рядом других, не рассматриваемых нами агроэкологических факторов: запасами продуктивной влаги, наличием нитратных и аммиачных форм азота, биологической активностью почвы, водно-физическими свойствами, суммой активных температур, технологическими приемами возделывания культур, включая нормы и сроки посева, внесение удобрений и некоторыми другими.

В этой связи возможно указать иную, более принципиальную причину: значимость используемых агрохимических и агроэколо- гических показателей в принятой системе государственной оценки плодородия и бонитета почв оказывается не определенной и требует совершенствования. Тем не менее, система работает, подтверждая существенную связь между общей надземной биомассой (сидеральная масса, пожнивные остатки) и урожайностью зерновых культур $(r=0,78)$, а также информативность данных о содержании подвижных форм фосфора и калия, кислотности солевой, сумме активных температур.

Отметим также, что в условиях развивающейся био- и экологизации современных технологий растениеводства, практического снижения вносимых в почвы доз химических препаратов и используемых химических средств защиты растений, для оценки потенциального плодородия почвы существен учет показателя синтеза биомассы. С помощью мониторинга $[10,11,20,21]$ синтезируемой биомассы можно определить потребность растений в элементах питания, составить прогноз и разработать оперативные меры предотвращения негативных почвенных процессов, более рационально использовать методы и средства мелиорации.

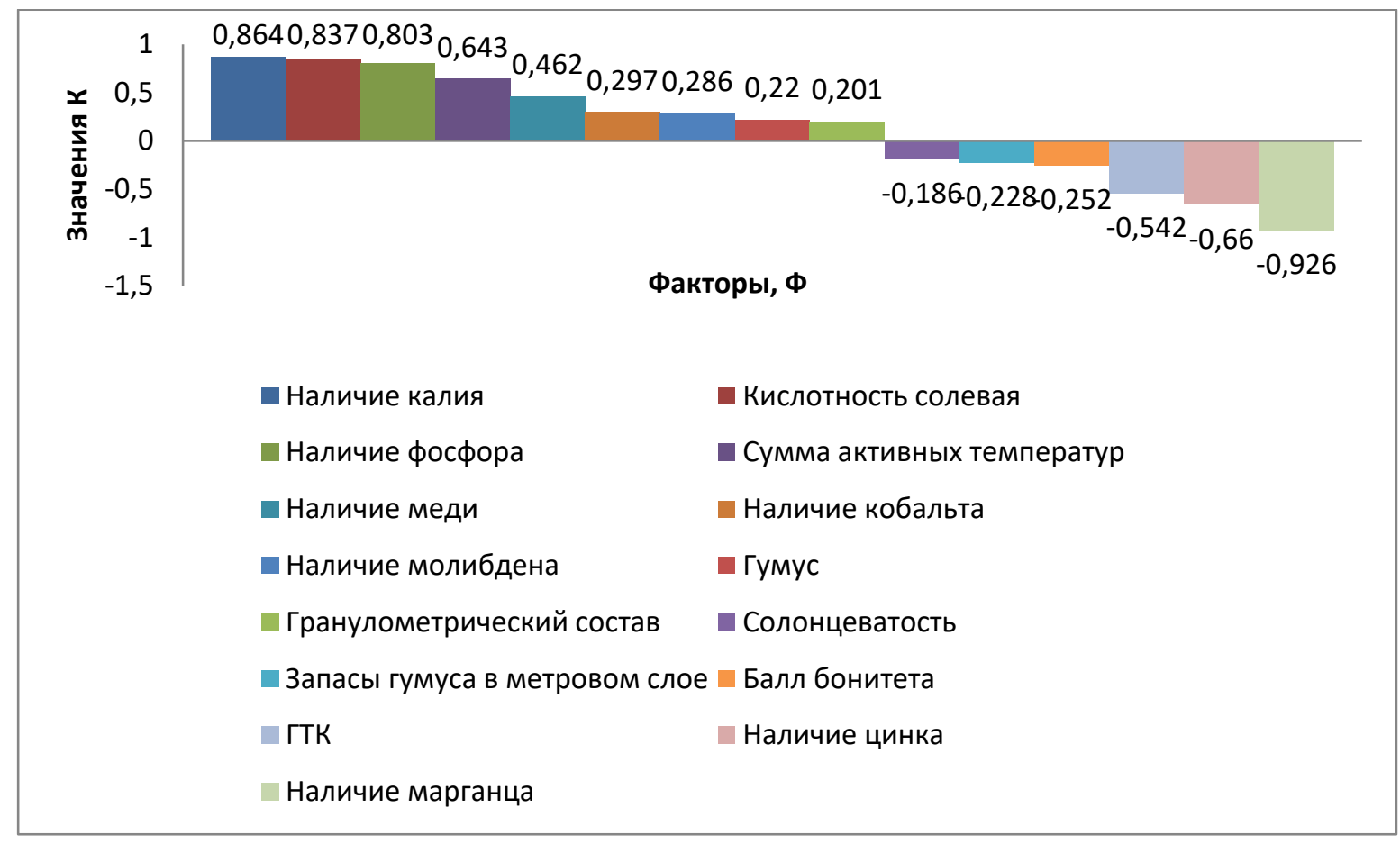

Корреляционная зависимость между урожайностью зерновых культур и показателями плодородия почвы, агроэкологическими условиями (2014-2017 гг.) 
Подобный мониторинг позволит также получить детальную информацию о плодородии земельных участков, занятых сельскохозяйственными культурами, в частности: вычислять индекс влажности и вегетации, индекс листовой поверхности, синтез биомассы возделываемых сельскохозяйственных культур и сортов, химический состав и содержание микроэлементов в почве; оперативно улавливать начало деградации почв и намечать агротехнические приемы по их восстановлению, оценивать перспективность иных мер по повышению плодородия сельскохозяйственных угодий.

\section{Выводы и предложения}

В результате проведенного исследования и обобщения наших ранних работ можно сделать вывод о том, что решение принципиальной задачи сохранения и воспроизводства плодородия почв связано с разработкой и внедрением новых систем земледелия и адекватных им систем землепользования. При этом системными признаками систем земледелия являются: накопление органического вещества в почве на основе корнеоборота возделываемых культур и применения микробиологических консорциумов, регулирующих минерализацию и гумификацию указанного органического вещества.

Основное содержание новых систем землепользования с учетом существующих зональных систем земледелия и выявленных недостатков используемых агрохимических показателей оценки плодородия почв под зерновые культуры представим на примере Новосибирской области следующим образом.

1. Система землепользования - северовосточные, северо-западные районы НСО. Отметим, что зональные технологии возделывания сельскохозяйственных культур должны компенсировать отсутствующие или недостающие факторы, обеспечивающие оптимизацию продукционного процесса конкретной культуры на всех этапах ее органогенеза в конкретных зональных условиях. Система землепользования выглядит ориентировочно так: обработка почвы - мини- мальная, почвозащитная; культуры севооборота - мягкая озимая, яровая пшеница, озимая рожь, горох, ячмень, овес, лен, картофель и др.; смешанные посевы, пожнивные, поукосные, сидеральные культуры в корнеобороте - рапс, сурепица, вика, горох пелюшка, донник и другие корнестержневые культуры; многолетние травы - люцерна, козлятник и других с корнестержневой системой; система минеральных и органических удобрений - при посеве используется стартовая доза NPK и микроудобрения, органические удобрения на прифермских севооборотах; защита растений - протравливание семян, борьба с сорной растительностью агротехническими методами, эдафитными и эпифитными консорциумами.

2. Система землепользования - центральные и юго-восточные районы (лесостепные районы) НCO. Ее основное содержание: обработка почвы - минимальная, почвозащитная; культуры севооборота - мягкая озимая, яровая пшеница, озимая рожь, скороспелые сорта твердой пшеницы, горох, ячмень, овес, герчиха, кукуруза на силос, рапс, фасоль, картофель и др.; смешанные посевы, пожнивные, поукосные, сидеральные культуры в корнеобороте - рапс, сурепица, вика, горох пелюшка, донник, люпин и другие корнестержневые культуры; многолетние травы - люцерна, козлятник и другие с корнестержневой системой; система минеральных и органических удобрений - при посеве стартовая доза NPK и микроудобрения, органические удобрения на прифермских севооборотах; защита растений - протравливание семян, борьба с сорной растительностью агротехническими методами, эдафитными и эпифитными консорциумами.

3. Система землепользования: южные степные районы НСО. Ее основное содержание: обработка почвы - минимальная, почвозащитная; культуры севооборота - мягкая яровая пшеница, озимая рожь + рапс или кулисы, скороспелые сорта твердой пшеницы, кукуруза на силос, горох, ячмень, и др.; смешанные посевы, пожнивные, поукосные, сидеральные культуры в корнеобороте рапс, сурепица, вика, горох пелюшка, донник, люпин и другие корнестержневые куль- 
туры; многолетние травы - люцерна, люцерно-кострецовый посев, козлятник и другие с корнестержневой системой; система минеральных и органических удобрений при посеве стартовая доза NPK и микроудобрения, органические удобрения на прифермских севооборотах; защита растений - протравливание семян, борьба с сорной растительностью агротехническими методами и эдафитными и эпифитными консорциумами. Неотъемлемой частью любой системы земледелия является система семеноводства, обеспечивающая высокоурожайным семенным материалом возделываемые культуры.

Управление эдафитными и эпифитными процессами в земледелии пока слабо разра- ботано, но уже сегодня можно рекомендовать для повышения адаптивности посевов пшеницы и других культур смесовые комплексы гербицидов с гуматами: Гранстар и Гуми, Пума-супер и Гуми, а также Фитоспорин или Интеграл - живая споровая культура Bacillus subtilis 24D [5].

В заключение подчеркнем, что обсуждаемые варианты систем землепользования являются рекомендуемыми. Широкий спектр возможностей современного биоземледелия открывает новые пути совершенствовании сельскохозяйственного землепользования, производства требуемой для страны экологически чистой продукции, решения задач продуктового экспорта и продовольственной безопасности.

\section{БИБЛИОГРАФИЧЕСКИЙ СПИСОК}

1. Березин Л. В., Кленов Б. М., Леонова В. В. Экология и биология почв. - Омск : ОмГАУ, 2008. - $122 \mathrm{c}$.

2. Каштанов А. Н. Сохраним и преумножим плодородие земли // Земледелие. - 1999. - № 3. C. $7-8$.

3. Татаринцев Л. М., Татаринцев В. Л., Кирякина Ю. Ю. Организация современного землепользования на эколого-ландшафтной основе : монография. - Барнаул : Изд-во АГАУ, 2011. - 106 с.

4. Конев А. А. Система биологизации земледелия. - Новосибирск : НГАУ, 2004. - 51 с.

5. Ларионов Ю. С. Биоземледелие и закон плодородия почв. - Омск : СГГА, ОмГАУ, 2012. $207 \mathrm{c}$.

6. Яшутин Н. В., Дробышев А. П., Хоменко А. И. Биоземледелие (научные основы, инновационные технологии и машины). - Барнаул : АГАУ, 2008. - $191 \mathrm{c.}$

7. Киреев А. К. Концепция развития систем земледелия Казахстана // Глобальные из- менения климата и биоразнообразия : материалы II Международного конгресса. - Алматы : КазНИИЗиР, 2015. - С. 108-112.

8. Ларионов Ю. С. Альтернативные подходы к современному земледелию и наращиванию плодородия почв (новая парадигма) // Вестник СГГА. - 2013. - Вып 1 (21). - С. 49-60.

9. Рунов Б. А., Пильникова Н. Основы технологии точного земледелия: зарубежный и отечественный опыт. - М. : Росинформагротех, 2010. $120 \mathrm{c}$.

10. Захарова Н. И. Мониторинг почв земель сельскохозяйственного назначения : сущность, цели и задачи // Вестник ПАГС. - 2012. - № 312. С. $117-121$.

11. Жарников В. Б., Ларионов Ю. С. Мониторинг плодородия земель сельскохозяйственного назначения как механизм их рационального использования // Вестник СГУГиТ. - 2017. T. 22, № 1. - C. 203-210.

12. Методология системного проведения научных исследований в растениеводстве, земледелии и защите растений : метод. положения / П. А. Гончаров, Г. П. Гамзиков, В. К. Каличкин, А. Ф. Ашмарина, Ю. А. Христоф. - Новосибирск : СО РАСХН, 2014. - 77 c.

13. Шагайда Н. И., Узун В. Я. Тенденции развития и основные вызовы аграрного сектора России: аналитический доклад. - М. : РАНХиГС, 2016. - 82 c.

14. Аграрная реформа в постсоветской России. - М. : Депо, 2015. - 352 с.

15. Ковалев Н. Г., Зинковская Т. С. Биологические и агрохимические показатели осу- шаемых почв в различные по увлажненности годы // Материалы Всероссийской научной конференции (с международным участием) «Методы оценки сельскохозяйственных рисков и технологии смягчения последствий изменения климата в земледелии» (Санкт-Петербург, 13-14 октября 2011 г.). - СПб. : АФИ, 2011. - С. 67-70.

16. Ларионов Ю. С., Стуканов А. А., Конева А. В. Инновационные подходы к развитию АПК на основе биоземледелия и закона плодородия почв // Информационные технологии, системы и приборы в АПК: материалы 7-й Международной научно-практической конференции 
«АГРОИНФО-2018» (Новосибирская обл., р.п. Краснообск, 24-25 октября 2018 г.). - Новосибирск : Академиздат, 2018. - С. 542-547.

17. Комарова Н. А. Влияние различных паров на показатели почвенного плодородия // Инновационные технологии в АПК Евро-СевероВостока РФ : сборник научных трудов к 75-летию Нижегородского научно-исследовательского института сельского хозяйства Российской академии сельскохозяйственных наук. - Нижний Новгород : Дятловы горы, 2011. - С. 127-132.

18. Красницкий В. М., Шмидт А. Г. Динамика плодородия пахотных почв Омской области и эффективность использования средств его повышения в современных условиях // Достижения науки и техники АПК. - 2016. - № 7.- С. 34-37.

19. Садикова Г. С., Бурханова Д. У. Изменение показателей плодородия орошаемых луговых почв под влиянием биоудобрений // Аграрная наука - сельскому хозяйству: IX Международная научно-практическая конференция: сборник статей в 3 кн. - Барнаул : АГАУ, 2014. Кн. 2. C. 237-239.

20. Система показателей оценки экологической емкости агроландшафтов для формирования экологически устойчивых агроландшафтов / Н. П. Масютенко, Н. А. Чуян, Г. И. Бахирев и др.; Рос. акад. с.-х. наук, Всерос. науч.-исслед. ин-т земледелия и защиты почв от эрозии. Курск : ВНИИЗиЗПЭ РАСХН, 2011. - 42 с.

21. Оценка почвенного плодородия по данным дистанционного зондирования / А. А. Савельев, Б. Р. Григорьян, Д. В. Добрынин, С. С. Мухарамина, В. И. Кулагина, И. А. Сахабиев // Ученые записки Казанского университета. - 2012. Т. 154, кн. 3. - С. 158-172.

22. Об утверждении Порядка осуществления государственного мониторинга земель сельскохозяйственного назначения [Электронный ресурс]: приказ Министерства сельского хозяйства РФ от 24.12.2015 № 664. - Доступ из справ.правовой системы «Консультант Плюс».

23. Методика расчета почвенного плодородия [Электронный ресурс]: приказ Министерства сельского хозяйства РФ от 06.07.2017 № 32. Доступ из справ.-правовой системы «Консультант Плюс».

24. Министерство сельского хозяйства НСО [Электронный pecypc]. - Режим доступа: https://mcx.nso.ru/.

25. Матвеева Е. Ю. Характеристика пахотного, залежного и целинного чернозема выщелоченного Челябинской области : автореф. дисс. ... канд. биол. наук. - Тюмень, 2009. - 18 с.

\section{FORMATION OF RATIONAL AGRICULTURAL LAND USE SYSTEM ON THE BASIS OF SOIL FERTILITY RECREATION THEORY}

\section{Yuriy S. Larionov}

Siberian State University of Geosystems and Technologies, 10, Plakhotnogo St., Novosibirsk, 630108, Russia, Dr. Sc., Professor, Department of Ecology and Environmental Management, phone: (383)361-08-86, e-mail: larionov42@mail.ru

\section{Valeriy B. Zharnikov}

Siberian State University of Geosystems and Technologies, 10, Plakhotnogo St., Novosibirsk, 630108, Russia, Ph. D., Professor, Director of the Regional Information Center, phone: (383)361-05-66, e-mail: v.b.jarnikov@ssga.ru

\section{Andrey A. Stukanov}

Siberian State University of Geosystems and Technologies, 10, Plakhotnogo St., Novosibirsk, 630108, Russia, Ph. D. Student, phone: (383)361-08-86

The article represents scientific and methodological approach to the problem of rational agricultural land use system formation (RALUS) based on soil fertility recreation theory. The main methods of research: system approach to the analysis of subject matter, theoretical generalization of the problem condition. The basis of approach to RALUS formation is the algorithm of soil fertility estimation, represented by a number of parameters, determining soil fertility, used in technological land use systems, determined by the main regional evolutional and ecological and genetic conditions for formation and recreation of the fertility level of the 
given soil types. The final estimation of agricultural land fertility level - the backbone of the RALUS economy of the municipality, is based on the calculation of productivity - getting the average values of biomass per unit area at the 8-10 most common cultivated crops and their mixtures (wheat, barley, oats, rye, peas, buckwheat, canola, rump, alfalfa, clover, etc.) in specific soil-climatic zone. As a result of the research, there were formulated the basis and content of the scientific and methodological approach to the estimation of the agricultural land fertility (productivity) level, as well as recommendations for the formation of zonal RALUS on the example of the Novosibirsk region, the use of which makes it possible to more reliably use (according to 3-5 years) the crop potential of the land fund of the economy, district, region.

Key words: soils, fertility, crop potential, rational land use, estimation, result, biomass, monitoring.

\section{REFERENCES}

1. Berezin, L. V., Klenov, B. M., \& Leonova, V. V. (2008). Ehkologiya i biologiya pochv [Ecology and soil biology]. Omsk: OmGAU Publ., 122 p. [in Russian].

2. Kashtanov, A. N. (1999). Keep and multiply the fertility of the earth. Zemledelie [Agriculture], 3, $7-8$ [in Russian].

3. Tatarincev, L. M., Tatarincev, V. L., \& Kiryakina, Yu. Yu. (2011). Organizaciya sovremennogo zemlepol'zovaniya na ehkologo-landshaftnoj osnove [The organization of modern land use on the ecological-landscape basis]. Barnaul: AGAU Publ., 106 p. [in Russian].

4. Konev, A. A. (2004). Sistema biologizatsii zemledeliya [The system of biologization of agriculture]. Novosibirsk: Novosibirsk GAU Publ., 51 p. [in Russian].

5. Larionov, Yu. S. (2012). Biozemledeliye i zakon plodorodiya pochv [Biozemusleie and the law of soil fertility]. Omsk: SSGA Publ., OmGAU Publ., 207 p. [in Russian].

6. Yashutin, N. V., Drobyshev, A. P., \& Khomenko, A. I. (2008). Biozemledeliye (nauchnyye osnovy, innovatsionnyye tekhnologii $i$ mashiny) [Bio-farming (scientific foundations, innovative technologies and machines)]. Barnaul: AGAU Publ., 191 p. [in Russian].

7. Kireyev, A. K. (2015). The concept of development of agriculture systems in Kazakhstan In Sbornik materialov II Mezhdunarodnogo kongressa: Global'nyye izmeneniya klimata i bioraznoobraziya [Proceedings of the II International Congress: Global Climate Change and Biodiversity] (pp. 108-112). Almaty: KazNIIZiR Publ. [in Russian].

8. Larionov, Yu. S. (2013). Alternative approaches to the modern soil cultivation and improvement of soil fertility (new paradigm). Vestnik SGUGiT [Vestnik SSUGT], 1(21), 49-60 [in Russian].

9. Runov, B. A., \& Pil'nikova, N. (2010). Osnovy tekhnologii tochnogo zemledeliya: zarubezhnyy $i$ otechestvennyy opyt [Basics of precision farming technology: foreign and domestic experience]. Moscow: Rosinformagrotekh Publ., 120 p. [in Russian].

10. Zakharova, N. I. (2012). Monitoring of Agricultural Land Soils: the Subject Matter, Targets, and Tasks. Vestnik PAGS [The Bulletin of the Volga Region Institute of Administration], 31, 227-121 [in Russian].

11. Larionov, Ju. S., \& Zharnikov, V. B. (2017). Soil fertility monitoring of agricultural purpose lands as a mechanism of their rational use. Vestnik SGUGiT [Vestnik SSUGT], 22(1), 203-210 [in Russian].

12. Goncharov, P. A., Gamzikov, G. P., Kalichkin, V. K., Ashmarina, A. F., \& Khristof, Yu. A. (2014). Metodologiya sistemnogo provedeniya nauchnykh issledovaniy $v$ rasteniyevodstve, zemledelii $i$ zashchite rasteniy [Methodology of systematic research in crop production, agriculture and plant protection: methodological provisions]. Novosibirsk: Siberian Branch of Russian Academy of the Agricultural Sciences Publ., 77 p. [in Russian].

13. Shagayda, N. I., \& Uzun, V. Ya. (2016). Tendentsii razvitiya $i$ osnovnyye vyzovy agrarnogo sektora Rossii [Tendencies of development and main challenges of the agricultural sector of Russia]. Moscow: RANEPA Publ., 82 p. [in Russian].

14. Agrarnaya reforma $v$ postsovetskoy Rossii [Agrarian reform in post-Soviet Russia]. (2015). Moscow: Depo Publ., 352 p. [in Russian].

15. Kovalev, N. G., \& Zinkovskaya, T. S. (2011). Biological and agrochemical indicators of drained soils in different wet years. In Sbornik materialov Vserossiyskoy nauchnoy konferentsii $s$ mezhdunarodnym uchastiyem: Metody otsenki sel'skokhozshchyaystvennykh riskov $i$ tekhnologii smyagcheniya posledstviy izemenniya klimata $v$ zemledelii [Proccedings of the All-Russian Scientific Conference with International Participation: Methods for Assessing Agricultural Risks and Technologies for Mitigating the Effects of Climate Change in Agriculture] (pp. 67-70). St. Petersburg: API Publ. [in Russian]. 
16. Zharnikov, V. B., Larionov, Yu. S., Stukanov, A. A., \& Koneva, A. V. (2018). Innovative approaches to the development of the agro-industrial complex based on bio-farming and the law of soil fertility. In Sbornik materialov 7-y Mezhdunarodnoy nauchno-prakticheskoy konferentsii "AGROINFO2018": Innovatsionnyye podkhody $k$ razvitiyu APK na osnove biozemledeliya $i$ zakona plodorodiya pochv [Proccedings of the 7th International Scientific and Practical Conference "AGROINFO-2018": Information Technologies, Systems and Devices in the Agro-Industrial Complex] (pp. 542-547). Novosibirsk region, Krasnoobsk: Academic Publ. [in Russian].

17. Komarova, N. A. (2011). Influence of various vapors on indicators of soil fertility. In Sbornik nauchnykh trudov $k$ 75-letiyu Nizhegorodskogo nauchno-issledovatel'skogo instituta sel'skogo khozyaystva Rossiyskoy akademii sel'skokhozyaystvennykh nauk: Innovatsionnyye tekhnologii $v$ APK Yevro-Severo-Vostoka RF [Collection of Scientific Papers to the 75th Anniversary of the Nizhny Novgorod Research Institute of Agriculture of the Russian Academy of Agricultural Sciences: Innovative Technologies in the Agroindustrial Complex of Euro-North-East of the Russian Federation] (pp. 127132). Nizhny Novgorod: Dyatlov Mountains Publ. [in Russian].

18. Krasnitsky, V. M., \& Schmidt, A. G. (2016). Dynamics of Fertility of Arable Soils in Omsk Region and Efficiency of Use of Means for Its Increase under Modern Conditions Dostizheniya nauki $i$ tekhniki APK [Achievements of Science and Technology of AICis], 7, 34-37 [in Russian].

19. Sadikova, G. S., \& Burkhanova, D. U. (2014). The change in the fertility indicators of irrigated meadow soils under the influence of biofertilizers. In Sbornik statey IX Mezhdunarodnoy nauchno-prakticheskoy konferentsii: Kniga 2. Agrarnaya nauka - sel'skomu khozyaystvu [Proceedings of the IX International Scientific and Practical Conference: Book 2. Agrarian Science to Agriculture] (pp. 237-239). Barnaul: AGAU Publ. [in Russian].

20. Masyutenko, N. P., Chuyan, N. A., Bakhirev G. I. \& etc. (2011). Sistema pokazateley otsenki ekologicheskoy yemkosti agrolandshaftov dlya formirovaniya ekologicheski ustoychivykh agrolandshaftov [The system of indicators for assessing the ecological capacity of agricultural landscapes for the formation of environmentally sustainable agricultural landscapes]. Kursk: AllRussian Research Institute of Agriculture and Soil Protection Against Erosion Russian Academy of the Agricultural Sciences Publ., 42 p. [in Russian].

21. Saveliev, A. A., Grigorian, B. R., Dobrynin, D. V., Mukharamina, S. S., Kulagina, V. I., \& Sakhabiev, I. A. (2012). Earth remote sensing for soil fertility monitoring. Uchenyye zapiski $\mathrm{Ka}$ zanskogo universiteta [Scientific Notes of the Kazan University], 154(3), 158-172 [in Russian].

22. Order of the Ministry of Agriculture of the Russian Federation of December 24, 2015 No. 664. On approval of the Procedure for the implementation of state monitoring of agricultural lands Retrieved from ConsultantPlus online database [in Russian].

23. Order of the Ministry of Agriculture of the Russian Federation dated July 6, 2017 No. 32. Method of calculating soil fertility. Retrieved from ConsultantPlus online database [in Russian].

24. Ministry of Agriculture of the Novosibirsk Region. (n. d.). Retrieved from https://mcx.nso.ru/.

25. Matveeva, E. Yu. (2009). Characteristics of arable, fallow and virgin leached chernozem of the Chelyabinsk region. Extended abstract of candidate's thesis. Tyumen, 18 p. [in Russian].

Received 25.04.2020

(C) Yu. S. Larionov, V. B. Zharnikov, A. A. Stukanov, 2020 